\title{
Abstracts
}

\section{1st Annual International Conference of the American Society for Horticultural Science Austin, Texas}

Presenting authors are denoted by an astrisk $\left({ }^{*}\right)$

Number preceeding title corresponds to the location of the poster in the Rio Grande Exhibit Hall

Poster Session 1-Weed Control and Pest Management July 17, 2004, 12:30-1:30 PM Rio Grande Exhibit Hall

1 GIS Analysis of Sweetpotato Weevil Trap Data in Louisiana

Arthur Villordon*1, Craig Roussel ${ }^{2}$, Tad Hardy ${ }^{3}$

${ }^{1}$ LSU AgCenter, Sweetpotato Research Station, Chase, LA 71324; ${ }^{2}$ Louisiana Dept. of Agriculture and Forestry, Agriculture and Environmental Sciences, Baton Rouge, LA $70821 ;{ }^{3}$ Louisiana Dept. of Agriculture and Forestry, Agriculture and Environmental Sciences, Baton Rouge, LA 70821

The Louisiana Dept. of Agriculture and Forestry (LDAF) conducts sweetpotato weevil [SPW, Cylas formicarius (Fabricius)] monitoring in support of the statewide SPW quarantine program. The monitoring activity primarily involves a statewide pheromone-based trapping process that generates trap data for sweetpotato beds and production fields. We conducted GIS analysis of SPW trap data, collected over three years, to assess the potential use of GIS tools in managing and interpreting the data. The LDAF has already generated shapefiles for all beds and fields in each of three years, facilitating GIS analysis. However, trap data was manually collected and statewide data was compiled and stored in spreadsheet files. Trap data was mapped to specific beds and fields in each of three years, generating layers that clearly showed fields and parishes that reported high trap counts. GIS analysis showed potential SPW "hotspots" in each year, indicating that certain beds or fields are more prone to SPW infestation than others. This information can be useful in planning SPW management strategies by growers and other stakeholders. The GIS database also provides the foundation for the development of descriptive and predictive models of SPW occurence in Louisiana. Compiling the SPW trap data into a GIS database allows the data to be distributed over the Internet, facilitating real-time access by stakeholders.

\section{Poster withdrawn.}

3 Biofumigation Potential of Field Pennycress (Thlaspi arvense) Seedmeal

Steven Vaughn*1, Terry Isbell ${ }^{2}$, David Weisleder ${ }^{3}$, Mark Berhow ${ }^{4}$

${ }^{1}$ USDA-ARS, National Center for Agricultural Utilization Research, New Crops and Processing Technology Research, Peoria, IL 61604; ${ }^{2}$ USDA-ARS, National Center for Agricultural Utilization Research, New Crops and Processing Technology Research, Peoria, IL 61604; ${ }^{3}$ USDA-ARS, National Center for Agricultural Utilization Research, New Crops and Processing Technology Research, Peoria, IL 61604; ${ }^{4}$ USDA-ARS, National Center for Agricultural Utilization Research, New Crops and Processing Technology Research, Peoria, IL 61604

Field pennycress (Thlaspi arvense L.) seedmeal was found to suppress seedling germination/emergence and biomass accumulation when added to a sandy loam soil containing wheat (Triticum aestivum L.), arugula [Eruca vesicaria (L.) Cav. subsp. sativa (Mill.) Thell.] and sicklepod (Senna obtusifolia (L.) H.S. Irwin \& Barneby) seeds. Covering the pots with petri dishes containing the soil-seedmeal mixture increased phytotoxicity at the lowest application rate, suggesting that the some of the phytotoxins were volatile. Dichloromethane, methanol and water extracts of the wetted seedmeal were bioassayed against wheat and sicklepod radicle elongation. Only the dichloromethane extract was found to be strongly inhibitory to both species. Fractionation of the dichloromethane extract identified two major phytotoxins, identified by GC-MS and NMR analyses as 2-propen-1-yl (allyl) isothiocyanate (AITC) and allyl thiocyanate (ATC), which constituted 80.9 and $18.8 \%$, respectively, of the active fraction. When seeds of wheat, arugula and sicklepod were exposed to volatilized AITC and ATC, the germination of all three species were completely inhibited by both compounds at concentrations of 5 ppm or less.

\section{Phytotoxicity and Weed Control Efficacy of Three Non-labeled} Herbicides for Field-grown Hemerocallis spp.

Patricia R. Knight*1, Christine E. Coker ${ }^{2}$, Benedict Posadas ${ }^{3}$, John M. Anderson ${ }^{4}$

${ }^{1}$ Mississippi State Univ., Coastal Research and Extension Center, Poplarville, MS 39470; ${ }^{2}$ Mississippi State Univ., Coastal Research and Extension Center, Biloxi, MS 39531; ${ }^{3}$ Mississippi State Univ., Coastal Research and Extension Center, Biloxi, MS 39531; ${ }^{4}$ Mississippi State Univ., Coastal Research and Extension Center, Poplarville, MS 39470

The IR-4 program works to identify potential minor-use horticultural chemicals and evaluate them for phytotoxicity and efficacy. The objective of this experiment was to evaluate phytotoxicity and weed control of three unlabeled herbicides on field production of Hemerocallis spp. 'Ming Toy'. Ten-cm pots of 'Ming Toy' were planted into the field 16 July 2001. Each plot consisted of 3 plants per treatment with 6 replications in a completely random design. Each herbicide was analyzed as a separate experiment. Herbicide treatments consisted of clopyralid $\left(0.14,0.28,0.56\right.$, or $1.1 \mathrm{~kg} \cdot \mathrm{ha}^{-1}$ a.i. $)$, clethodim $\left(125,250\right.$, or $500 \mathrm{~mL} \cdot \mathrm{L}^{-1}$ a.i.), or bentazon $\left(1.1,2.2\right.$, or $4.4 \mathrm{~kg} \cdot \mathrm{ha}^{-1}$ a.i.). Data collected included weed number, percentage of weed coverage ( $\%$ weed coverage), and phytotoxicity and foliar color ratings for 'Ming Toy'. Clopyralid reduced total weed number 90 DAT although \% weed coverage was similar or worse compared to the control treatment. Phytotoxicity 90 DAT was not significant for plants treated with clopyralid, but foliar color ratings were reduced. Application of clethodim to 'Ming Toy' plots, regardless of rate, resulted in similar weed numbers compared to the control 49 DAT. Clethodim application, regardless of rate, reduced $\%$ weed coverage compared to the control treatment. Phytotoxicity 90 DAT was not significant, regardless of herbicide treatment, but foliar color ratings were lower for herbicide treated plants compared to the control. Bentazon, regardless of rate, reduced weed number and \% weed coverage 49 DAT compared to the control. Phytotoxicity was similar to the control for plants treated with $1.1 \mathrm{~kg} \cdot \mathrm{ha}^{-1}$ a.i.

\section{Preemergence Weed Control in Container-grown Herbaceous} Perennials

James Klett*1, Dave Staats ${ }^{2}$, Matt Rogoyski ${ }^{3}$

${ }^{1}$ Colorado State Univ., Horticulture and Landscape Architecuture, Fort Collins, CO 80523; ${ }^{2}$ Colorado State Univ., Horticulture and Landscape Architecture; ${ }^{3}$ Colorado State Univ. Horticulture and Landscape Architecture

During the 2003 season, preemergence herbicide was applied to twelve container grown herbaceous perennials and woody plants and evaluated for weed control, phytotoxicity, and effect on plant growth. The herbicide and rates were: Flumioxazin (Broadstar) $113.5 \mathrm{~g}$ (label rate), $227 \mathrm{~g}$ and $454 \mathrm{~g}$ a.i./A. Herbicides were applied to Buxus microphylla 
'Winter Gem', Cytisus purgans ‘Spanish Gold', Festuca ovina glauca 'Elijah Blue', Hakonechloa macra 'Aureola', Lonicera tatarica 'Arnold Red', Pachysandraterminalis 'Green Sheen', Hydrangea arborescens 'Annabelle', Mahonia aquifolium, Phalaris arundinacea 'Picta', Carex buchananii,Cerastium tomentosum, and Achillea millefolium 'Red Beauty'. Weed control was excellent at all rates and controlled at least $99 \%$ of all weeds. No phytotoxicity symptoms were apparent on Mahonia,Buxus, Cytisus, Festuca, Hakonechloa, Pachysandra or Phlaris. Phytotoxicity resulted on some of the other plants. Carex had smaller plants (dry weights) at all rates. Cerastium had severe phytotoxicty at the $227 \mathrm{~g}$ and $454 \mathrm{~g}$ rates and moderate stunting at the recommended label rate, $113.5 \mathrm{~g}$. Hydrangea became chlorotic and stunted at the $113.5 \mathrm{~g}$ rate and some fatal toxicity ocurred at the $227 \mathrm{~g}$ and $454 \mathrm{~g}$ rates. Phytotoxicity resulted on Lonicera at all rates and ranged from mild chlorosis in leaf veins (113.5 g rate) to plant death (454 g rate). Achillea at the $113.5 \mathrm{~g}$ rate only resulted in stunted plant growth while the $227 \mathrm{~g}$ and $454 \mathrm{~g}$ rates resulted in severe phytotoxcity and plant death.

\section{Mugwort (Artemisia vulgaris) Rhizome Regeneration in Pine Bark, Soil and Sand Substrates}

William E. Klingeman*1, Darren K. Robinson², Gary L. McDaniel ${ }^{3}$ ${ }^{1}$ Univ. of Tennessee, Plant Sciences, Knoxville, TN 37996-4561; ${ }^{2}$ Univ. of Tennessee, Plant Sciences; ${ }^{3}$ Univ. of Tennessee, Plant Sciences

Mugwort, or false chrysanthemum (Artemisia vulgaris L) is a welladapted invasive plant that presents increasing management challenges to agricultural producers, Green Industry professionals and homeowners across portions of the eastern U.S. The ability of mugwort to regenerate from cut rhizome sections has not been adequately quantified for substrates that are typical of landscapes and nursery fields, container nurseries, and propagation beds. Cut rhizome sections were analyzed by rhizome color, length, and the presence or absence of a leaf scale. Media substrates included pine bark, sand, and soil. Rhizomes darken with time and color did not account for differences in growth among treatments. When grown in pine bark, sand, and soil substrates during 45 -d trials, $85 \%, 78 \%$, and $69 \%$ of $2 \mathrm{~cm}$-long rhizome sections produced both roots and shoots. These results contrast with previous research. When rhizome fragments $0.5 \mathrm{~cm}$ long did not include a leaf scale, slightly fewer than $31 \%$ produced both roots and shoots in soil. Fewer rhizomes survived in soil, but root and shoot fresh masses of soil-grown rhizomes were greater than rhizomes that were regenerated in pine bark and sand. When rhizome sections had a leaf scale, survival, fresh masses of roots and shoots, shoot height, leaf number and root lengths were greater, regardless of substrate type. Root initials emerged in the internode between leaf scales and also adjacent to leaf scales. Shoot emergence preceded root emergence from rhizome sections. Growers, landscape managers and homeowners should scout regularly and initiate aggressive controls when mugwort populations are found.

\section{Investigating the Use of Living Mulches in Edamame (Glycine max) Field Production for Weed Management}

Dru Bernthal*1, Elsa Sánchez², Kathleen Kelley ${ }^{3}$

${ }^{1}$ The Pennsylvania State Univ., Dept. of Horticulture, Univ. Park, PA 16802; ${ }^{2}$ The Pennsylvania State Univ., Dept. of Horticulture, Univ. Park, PA 16802; ${ }^{3}$ The Pennsylvania State Univ., Dept. of Horticulture, Univ. Park, PA 16802

A field trial investigating the use of living mulches for weed management in edamame (Glycine max), also known as vegetable soybean, was conducted in 2003 at the Russell E. Larson Agricultural Research Center, Rock Springs, Pa. Edamame was direct seeded on 24-25 June 2003. Seven weeks later, the living mulch treatments were broadcast seeded. The living mulch species were white clover (Trifolium repens), buckwheat (Fagopyrum esculentum) and a control with no living mulch (bare ground). Each living mulch plot was divided into a weeded and non-weeded subplot. Weed pressure was evaluated every 2 weeks from the time living mulches were sown. Data collected included the total number of weeds present, number of different species present, number of broadleaf and grass species and number of annual and perennial species. The total number of weeds in weeded and non-weeded subplots was lowest in the buckwheat and highest in the clover. Species diversity in weeded subplots was lowest for the control and highest in clover while species diversity in non-weeded subplots was lowest in buckwheat and highest in the control. Overall, most weeds present were broadleaf annuals including pigweeds (Amaranthus spp.), shepard's purse (Capsella bursa-pastoris), common lambsquarters (Chenopodium album) and common purslane (Portulaca oleracea). Based on this 1-year study, which will be repeated in 2004, the buckwheat treatment is likely the most effective in managing weeds in edamame field production for consideration by Pennsylvania growers.

\section{Pre and Early Postemergence Herbicide Phytotoxicity and Yield Effects in Transplanted Peppers}

Russell W. Wallace*1

${ }^{1}$ Texas A\&M Univ., Horticultural Sciences, Lubbock, TX 79403

Field research was conducted to evaluate pre-transplant (PRE) applications of sulfentrazone $\left(0.20\right.$ or $0.41 \mathrm{~kg} \cdot \mathrm{ha}^{-1}$ a.i. $)$ and flufenacet $(0.045$ $\mathrm{kg} \cdot \mathrm{ha}^{-1}$ a.i.), or early postemergence (EPOST) halosulfuron $(0.027$, 0.036 or $0.054 \mathrm{~kg} \cdot \mathrm{ha}^{-1}$ a.i.) on phytotoxicity and yield of field-grown chili (var. Sonora), jalapeño (var. Grande) and bell (var. Giant Belle) peppers (Capiscum annuum) in Texas. Crop injury recorded 15 days after sulfentrazone treatments (DAT) showed minor stunting at the low rate, but moderate stunting and temporary leaf malformation when applied at $0.41 \mathrm{~kg} \cdot \mathrm{ha}^{-1}$ a.i. Increased stunting occurred 37 DAT at both rates; however, new leaf growth was not affected. Flufenacet did not result in crop injury to any of the three types grown. Phytotoxicity from halosulfuron recorded 7 DAT gave significantly higher ratings for stunting/chlorosis for broadcast EPOST treatments when compared to EPOST-directed applications. Injury from halosulfuron was temporary and considered minor with all EPOST treatments by 22 DAT. Pepper yield data showed that EPOST halosulfuron treatments were statistically equivalent to the untreated controls for each of the three types, but there was a trend for lower yields with rates higher than $0.027 \mathrm{~kg} \cdot \mathrm{ha}^{-1}$ a.i. All peppers treated with flufenacet gave excellent yields. Sulfentrazone applied at the high rate gave the greatest yield losses in all three types, and this was significant in the jalapeños. The results indicate that all three herbicides have potential for use in commercial pepper production in Texas. However, more research is needed to evaluate these and other herbicides for improved crop safety in peppers.

\section{Weed Control in No-tillage Cucumber Production}

\section{S. Alan Walters*1, Scott A. Nolte ${ }^{2}$, Joseph L. Matthews ${ }^{3}$, Bryan G.} Young 4

${ }^{1}$ Southern Illinois Univ., Plant, Soil, and Agricultural Systems, Carbondale, IL 629014415; ${ }^{2}$ Southern Illinois Univ., Dept. Plant, Soil, and Agricultural Systems, Carbondale, IL 62901-4415; ${ }^{3}$ Southern Illinois Univ., Plant, Soil, and Agricultural Systems, Carbondale, IL 62901-4415; ${ }^{4}$ Southern Illinois Univ., Plant, Soil, and Agricultural Systems, Carbondale, IL 62901-4415

A field study was conducted in 2002 and 2003 to evaluate various herbicides (ethafluralin \& clomazone, halosulfuron, and ethafluralin $\&$ clomazone + halosulfuron) with or without a winter rye (Secale cereale L.) cover crop in no-tillage 'Daytona' cucumber (Cucumis sativus L.) production. All herbicides were applied preplant prior to cucumber transplanting, and no injury or stunting to cucumber was observed with any of the treatments evaluated at any time during the two growing seasons. Winter rye provided a significant advantage for weed control compared to the no cover crop production system. The combination of ethafluralin \& clomazone + halosulfuron provided the greatest control of smooth crabgrass [Digitaria ischaemum (Schreb. Ex Schweig) Schreb. Ex Muhl.] and redroot pigweed (Amaranthus retroflexus L.). Ethafluralin \& clomazone provided little redroot pigweed control, while halosulfuron alone provided no control of smooth crabgrass. Winter rye enhanced cucumber yields in 2002 (drought conditions), while in 2003 (sufficient moisture and cooler soil tempera- 
tures), winter rye tended to suppress yields. During drought conditions (2002), treatments with ethafluralin \& clomazone and ethafluralin \& clomazone + halosulfuron produced similar yields. However, in 2003 , treatments with ethafluralin \& clomazone + halosulfuron produced greater yields than treatments with ethafluralin \& clomazone. Overall, the handweed treatment provided the greatest yields, while the nontreated and halosulfuron only treatment provided the lowest yields. Winter rye will provide some additional weed control in a no-tillage vegetable production system, but may also provide negative effects by suppressing crop yield depending on seasonal growing conditions.

10 Seasonal Influence on Infection Rates of Malus sylvestris var. domestica Roots by Phymatotrichopsis omnivora

Wesley T. Watson*1, David N. Appel², Michael A. Arnold ${ }^{3}$, Charles M. Kenerley ${ }^{4}$, James L. Starr ${ }^{5}$

${ }^{1}$ Texas A\&M Univ., Forest Science, College Station, TX 77843-2135; ${ }^{2}$ Texas A\&M Univ., Plant Pathology and Microbiology, College Station, TX 77843-2132; ${ }^{3}$ Texas A\&M Univ., Horticultural Sciences, College Station, TX 77843-2133; ${ }^{4}$ Texas A\&M Univ., Plant Pathology and Microbiology, College Station, TX 77843-2132; ${ }^{5}$ Texas A\&M Univ., Plant Pathology and Microbiology, College Station, TX 77843-2132

Phymatotrichopsis omnivora (Duggar) Hennebert (syn. Phymatotrichum omnivorum Duggar) is a recalcitrant soilborne pathogen that causes serious root rot problems on numerous plant species in the southwestern United States and northern Mexico. Apple trees [Malus sylvestris (L.) Mill. var. domestica (Borkh.) Mansf. (syn. M. domestica Borkh. non Poir.)] are highly susceptible to P. omnivora with most tree death occurring in the summer months. Studies were conducted from 1996 to 1999 to examine when and at what rate infection and colonization of roots of apple trees by P. omnivora actually occurs. In three-year-old trees growing in orchard soils in 45-gallon containers $\left(171,457 \mathrm{~cm}^{3}\right)$ and inoculated with sclerotia in August 1997, infection occurred in the nursery after 12 weeks. For trees inoculated with sclerotia in February 1998, infection occurred within 15 weeks. After 18 weeks, $100 \%$ of trees were infected after inoculation in August and $80 \%$ of trees were infected after the February inoculation. This information is vital to understanding the epidemiology of Phymatotrichum root rot in apple orchards.

\section{Nematode Genera Associated with Selected Vegetable Crops in a Tropical Region}

Cesar A. Martinez-Mateo ${ }^{1}$, A. Jimenez ${ }^{2}$, Miguel Martinez ${ }^{3}$, J. Pablo Morales-Payan*4

${ }^{1}$ Instituto Politecnico Loyola, Plant Sciences, San Cristobal, Dominican Republic; ${ }^{2}$ Instituto Politecnico Loyola, Plant Sciences, San Cristobal, Dominican Republic; ${ }^{3}$ Instituto Politecnico Loyola, Plant Sciences, San Cristobal, Dominican Republic; ${ }^{4}$ SODIAF, Horticultural Sciences, Santo Domingo, Dominican Republic

A survey was conducted in a tropical region under continuous crop production for more than a century in the Dominican Republic, to determine the incidence of nematode genera in the soil and in tomato, eggplant, okra, carrot, cabbage, onion, Sweetpotato, squash, and cucumber roots. Typical crop sequences in the region were tomato, eggplant, or beans, followed by either corn, sorghum, cassava, squash or Sweetpotato, followed by either onion, carrot or cabbage, all the crops being grown with medium to high agrichemical input levels. The genera Meloidogyne, Rotylenchulus, Pratylenchus, Aphelenchus, Helicotylenchus, Tylenchus, and Criconemoides were found in soil and/or crop root samples. Meloidogyne was the most prevalent genus in the soil ( $41 \%$ of the samples) and in roots of squash, cucumber, tomato, Sweetpotato, and carrot (50\% of the samples). Rotylenchulus was found in $27 \%$ of the soil samples, and in $33 \%$ of the tomato, okra, and carrot root samples. Aphelenchus was isolated from $2.5 \%$ of the eggplant, onion, and cabbage root samples, and from $11 \%$ of the soil samples. Pratylenchus was found only in cucumber roots $(13 \%$ of the samples) and soil samples (10\%). Helicotylenchus, Tylenchus, and Criconemoides were isolated from soil $(5 \%, 4 \%$, and $1 \%$ of the samples, respectively), but were not found in crop roots. The incidence of Meloidogyne, Rotylenchulus, Pratylenchus, and Aphelenchus tended to be higher in plots where cucurbits and/or solanaceaous crops were grown more frequently, whereas the presence of Criconemoides seemed to be associated with plots where cassava, corn or sorghum had been grown recently.

\section{Insecticides from Five Chemical Classes Differentially Affect the Plant Growth and Development of Chrysanthemum (Dendranthema grandiflora Tzvelev var. Charm)}

James D. Spiers*1, Fred T. Davies², Chuanjiu $\mathrm{He}^{3}$, Amanda Chau ${ }^{4}$, Kevin M. Heinz ${ }^{5}$, Terri W. Starman ${ }^{6}$

${ }^{1}$ Texas A\&M Univ., Horticulture, College Station, TX 77843-2133; ${ }^{2}$ Texas A\&M Univ., Horticulture; ${ }^{3}$ Texas A\&M Univ., Horticulture; ${ }^{4}$ Texas A\&M Univ., Entomology; ${ }^{5}$ Texas A\&M Univ., Entomology; ${ }^{6}$ Texas A\&M Univ., Horticulture

This research focused on the influence of insecticides on plant growth, gas exchange, rate of flowering, and chlorophyll content of chrysanthemum (Dendranthema grandiflora Tzvelev cv. Charm) grown according to recommended procedures for pot plant production . Five insecticides were applied at recommended concentrations at three different frequencies: weekly (7 days), bi-weekly (14 days), or monthly (28 days). A separate treatment was applied weekly at $4 \times$ the recommended concentration. Insecticides used were: acephate (Orthene $\left.{ }^{\circledR}\right)$ Turf, Tree \& Ornamental Spray 97), bifenthrin (Talstar $\left.{ }^{\circledR}\right)$ Flowable), endosulfan $\left(\right.$ Thiodan $^{\circledR}$ ) 50 WP), imidacloprid (Marathon ${ }^{\circledR}$ ) II), and spinosad (Conserve ${ }^{\circledR}$ ) SC). Phytotoxicity occurred in the form of leaf burn on all acephate treatments, with the greatest damage occurring at the $4 \times$ concentration. Photosynthesis and stomatal conductance were influenced primarily by the degree of aphid and/or spider mite infestation-except for acephate and endosulfan treatments (weekly and $4 x$ ), which had reduced photosynthesis with minimal insect infestations. Plants receiving imadacloprid monthly had the greatest leaf dry mass (DM). Plants treated with acephate had lower leaf and stem DM with bi-weekly and $4 \times$ treatments. Spinosad treatments at recommended concentrations had reduced stem DM, in part due to aphid infestations. The flower DM was not significantly different among treatments. There were treatment differences in chlorophyll content as measured with a SPAD-502 portable chlorophyll meter.

\section{Feeding and Oviposition Behavior of Diaprepes abbreviatus (L.) on Peach Prunus persica L. in Puerto Rico}

Alexandra Delgado ${ }^{1}$, Angel L. Gonzalez*2, Maria Del C. Libran ${ }^{3}$

${ }^{1}$ Univ. of P. R.- Mayaguez, Crop Protection, Mayaguez, PR 00681; ${ }^{2}$ Univ. of P. R. -Mayaguez, Crop Protection, Mayaguez, PR 00681; ${ }^{3}$ Univ. of P. R.- Mayaguez, Horticulture Mayaguez, PR 00681

Peach cultivars are being evaluated for their adaptation to the conditions of the central region of Puerto Rico. The root weevil, Diaprepes abbreviatus (L.), a common insect pest in the area, is being previously reported on peach trees. With the purpose of evaluating the potential feeding damage that this insect might represent for future peach production, choice and no-choice tests were made with leaf discs (feeding) and leaf strips (oviposition) to determine adult feeding and oviposition behavior in comparison with 'Navel' orange. Larval feeding behavior on the roots was studied on a peach rootstock and 'Cleopatra' mandarin planted in 18.9-Lcontainers. In the no-choice test, adults fed significantly more on 'Navel' orange foliage than on peach foliage. In the choice test, adults preferred to feed on 'Navel' orange leaf discs. Oviposition occurred on both peach cultivars tested, but more egg masses were laid on Navel orange leaf strips in the no-choice test. However, given the choice, adults preferred to oviposit on peach leaf strips while fed on 'Navel' orange leaf strips. In some replications this behavior was reversed. At 90 days after infestation, larval feeding damage on the roots was severe on 'Cleopatra' mandarin where most of the cortex tissue on the primary root was removed and growth of roots and foliage was reduced. Larvae bore also on peach trees, but there was no sign of growth reduction on foliage or the roots compared to the control These preliminary results indicate that $D$. abbreviatus will not be a primary pest on peach. 


\section{Poster Session 2-Vegetable Crop Management 1}

\section{July 17, 2004, 12:30-1:30 PM Rio Grande Exhibit Hall}

14 Productivity and Quality of Green Snap Beans Varieties Under Desertic Conditions in Northwestern Mexico

Raul Leonel Grijalva-Contreras*1, Eduardo Liñeiro-Celaya ${ }^{2}$, Gerardo Araiza-Celaya ${ }^{3}$, Victor Salvador-Rivas ${ }^{4}$, Francisco LopezVilchez ${ }^{5}$

${ }^{1}$ INIFAP-Caborca, Horticulture, Caborca, Sonora, 83600, Mexico; ${ }^{2}$ Growers Club, Horticulture, Caborca, Sonora, 83600 , Mexico $;^{3}$ Growers Club, Horticulture, Caborca, Sonora, 83600 , Mexico, ${ }^{4}$ Growers Club, Horticulture, Caborca, Sonora, 83600, Mexico; ${ }^{5}$ Growers Club, Horticulture, Caborca, Sonora, 83600, Mexico

The agricultural activity in Caborca, Sonora, depends on fruit trees and vegetable production, and the main crops are grapes, olive, and asparagus. However, is necessary to evaluate other vegetables. An alternative is the green snap beans production. This vegetable can be harvested during the last week of November,when, good prices aare available in the market. The objective of this experiment was to evaluate seven green snap beans varieties with round pod. The experiment was on 24 Aug. The density used was 20 seeds per meter (about $60 \mathrm{~kg} \cdot \mathrm{ha}^{-1}$ ). The experiment was carried out during 2001 with commercial growers. The date of sow was distance between beds was $2.0 \mathrm{~m}$ and we used two rows with $36 \mathrm{~cm}$ of separation. In our experiment, we used a drip irrigation system. The first harvest was 67 days after the date sowing and it was for 28 days with seven cuttings. The varieties with more yield were Festina, Mercury, and Castaño with 771,632 and 558 boxes/ha, (30 pounds/box), respectively. The control variety (Savannah) yielded only 345 boxes/ha. The pod quality distribution was $26 \%, 32 \%, 50 \%$, and $15 \%$ for classification $1,2,3$, and no commercial value respectively. The Savannah variety was the best pod color (dark green) and more yield during the last cutting. None of the varieties evaluated had problems of pest and diseases.

\section{Irrigation Levels Affect Plant Growth and Fruit Yield of Drip-Irrigated Bell Pepper}

Juan C. Diaz-Perez*1, Darbie Granberry², Kenneth Seebold ${ }^{3}$, David Giddings $^{4}$, Denne Bertrand ${ }^{5}$

${ }^{1}$ Univ. of Georgia, Horticulture, Tifton, GA 31793-0748; ${ }^{2}$ Univ. of Georgia, Horticulture; ${ }^{3}$ Univ. of Georgia, Plant Pathology; ${ }^{4}$ Univ. of Georgia, Horticulture; ${ }^{5}$ Univ. of Georgia, Horticulture

Bell pepper (Capsicum annum L.)plants have a high demand for water and nutrients and are sensitive to water stress during the establishment period and fruit setting. High levels of irrigation are often applied in order to maximize yields. However, field observations suggest that excessive irrigations may negatively affect bell pepper plants. The objective was to evaluate the effects of irrigation rate on plant growth and fruit yield. The trial was conducted in Spring 2003 at the Coastal Plain Experiment Station, Tifton, Ga. Drip-irrigated bell pepper ('Stiletto') plants were grown on black plastic mulch in 1-m wide beds (1.8-m centers). Plants were irrigated with an amount of water that ranged from $33 \%$ to $167 \%$ the rate of evapotranspiration (ET), adjusted by crop stage of development. Soil moisture content (\% by volume) over the season was continuously monitored with time domain reflectometry sensors connected to a datalogger. The results showed that the average soil moisture content for the season increased with increasing rates of irrigation. Vegetative top fresh wt. and marketable fruit yield were reduced at both, low (33\% ET) and high $(166 \%$ ET) rates of water application. However, irrigation rate had a stronger effect on fruit yield than on top fresh wt. Plants supplied with high irrigation rates appeared to be more chlorotic compared to plants irrigated at medium rates $(100 \%$ ET). There was a tendency for higher incidences of soil borne diseases (Pythium sp., Phytophtora capsici) in plants receiving higher rates of irrigation. The conclusion is high irrigation rates $(>166 \%$ ET) are not recommended since they waste water and may result in both, higher incidences of soil-borne diseases and reduced bell pepper yields.
16 A Survey of Sweetpotato Growers - Practices and Conditions Associated with Good Root Appearance

Luz Reyes*1, Sylvia M. Blankenship*2, Jonathan R. Schultheis*3, Michael D. Boyette ${ }^{4}$

${ }^{1}$ North Carolina State Univ., Horticultural Science, Raleigh, NC 27695-7609; ${ }^{2}$ North Carolina State Univ., Horticultural Science, Raleigh, North Carolina, 27695-7609; ${ }^{3}$ North Carolina State Univ., Horticultural Science, Raleigh, NC 27695-7609; ${ }^{4}$ North Carolina State Univ., Biological \& Agricultural Engineering, Raleigh, NC 27695-7625

Sweetpotato roots, especially the cultivar Beauregard, tend to experience epidermal loss during harvest and postharvest handling which results in a less attractive product in the market. A survey study was conducted among North Carolina (N.C.) sweetpotato growers in Fall 2001 and 2002. The purpose of the survey was to gather information and try to correlate cultural practices, growing conditions and site characteristics with the occurrence of attractive roots and to define new scientific approaches to reducing epidermal loss. Samples were obtained from 42 N.C. farms. Survey field information and laboratory results were correlated to identify possible factors affecting the appearance of the roots. 1300 roots were used to measure skin adhesion, peeling susceptibility, skin moisture, skin anthocyanin and lignin content. From survey questions, 50 characteristics were defined for each sample, according to field characteristics, cultivar information, cultural practices and harvest and postharvest practices. Statistical analyses were performed to determine the relationship between the skin characteristics analyzed at the laboratory, and the survey descriptors information. Analysis of variance was used for laboratory data analysis. Person correlations were made between survey variables and laboratory characteristics. Several possible relationships between root appearance and other characteristics/practices were identified. Root skin adhesion may improve in later generations from elite propagation material. Early application of phosphate and potash fertilizers were correlated to improved root skin adhesion. There appeared to be a relationship between soil moisture at harvest time, increased lignin content in the skin and peeling susceptibility. Future areas of study were identified.

\section{Environmental Stressors That May Influence Internal Heat Necrosis in Potato Production in Northeast Florida}

Christine M. Worthington*1, Chad M. Hutchinson ${ }^{2}$

${ }^{1}$ Univ. of Florida, Horticultural Sciences, Hastings, FL 32145; ${ }^{2}$ Univ. of Florida, Horticultural Sciences, Hastings, FlL, 32145

'Atlantic' potatoes (Solanum tuberosum L.) are grown on approximately 8100 hectares with seepage irrigation in Northeast Florida's Tri-County Agricultural Area (St. Johns, Putnam, and Flagler counties). 'Atlantic' is preferred for its chipping quality, high specific gravity and yield, but is susceptible to internal heat necrosis (IHN), a physiologic disorder that affects potato tuber quality. The relationships of environmental stressors (growing degree days, GDD and rainfall) to IHN were evaluated on two fields (fields 3 and 4) on a local producer's farm. IHN reduced marketable tuber yield by $100 \%$ in the 1995 and 2003 seasons, but not in 2001 and 2002 seasons. From 3 to 6 weeks after planting (WAP), GDD for 1995, 2001, 2002, and 2003 were 470, 325 , 386 , and $628\left(45^{\circ} \mathrm{F}\right.$ base), respectively. This is the only 4 week period during the 14 week season that GDD accumulation by week was different among treatments. Average rainfalls $(\mathrm{cm})$ for the same periods were $1.60,1.12,2.23$ and 7.91, respectively. Both warmer/dryer and warmer/wetter early season conditions occurred during seasons with higher rates of IHN. Although circumstantial, higher accumulated heat units and water stress within the first 6 weeks of the growing season resulted in higher percentages of tubers with IHN. These relationships should be evaluated further with other growers.

18 Weather Affects Seedless Watermelon Yield, But Not Fruit Size or Quality

Timothy E. Elkner*1, David H. Johnson²

${ }^{1}$ Penn State Univ., Lancaster County Cooperative Extension, Lancaster, PA $17601 ;{ }^{2}$ Penn State Univ., Penn State Southeast Research and Extension Center, Manheim, PA 17545

Medium-sized triploid watermelons were evaluated in southeast Penn- 
sylvania in 2002 and 2003 to determine the best adapted cultivars for this region. The 2002 season was unusually hot and dry, while 2003 was unusually cool and wet. Yields and fruit quality were compared for the eight cultivars that were grown both seasons to determine the effect of weather on seedless watermelon. Cooler temperatures reduced total fruit number and total yield but not average fruit weight or soluble solids. Researchers evaluating triploid watermelons over several seasons can compare size and ${ }^{\circ}$ Brix among cultivars, but will need to be cautious when predicting total yields.

\section{Comparison of Cover Crops Alone or in Mixture with Inorganic Nitrogen for Above Ground Biomass Production and Fruit Yields in Bell Pepper}

Wayne F. Whitehead*1, Bharat P. Singh ${ }^{2}$

${ }^{1}$ ARS, Fort Valley State Univ., Agricultural Research Station, Fort Valley, GA 31030-4313; ${ }^{2}$ ARS, Fort Valley State Univ., Agricultural Research Station, Fort Valley, GA 31030-4313

The goal of this study was to compare the effect of leguminous and non-leguminous cover crops alone or in mixture with fertilizer nitrogen rates on above ground biomass, fruit number, and bell pepper yield. The following fall-spring fertility treatments were applied using randomized complete-block design with three replications: 1) fall-0 N, fallow, spring-0 N; 2) fall- $0 \mathrm{~N}$, abruzzi rye, spring-0 N; 3) fall- $0 \mathrm{~N}$, hairy vetch, spring-0 N;4) fall-0 N, abruzzi rye+hairy vetch, spring-0 N; 5) fall- $0 \mathrm{~N}$, fallow, spring-84 kg $\cdot \mathrm{ha}^{-1} \mathrm{~N}$; 6) fall-0 $\mathrm{N}$, abruzzi rye; spring- $84 \mathrm{~kg} \cdot \mathrm{ha}^{-1}$ $\mathrm{N}$; 7) fall-0 $\mathrm{N}$, hairy vetch, spring-84 $\mathrm{kg} \cdot \mathrm{ha}^{-1} \mathrm{~N} ; 8$ ) fall-0 $\mathrm{N}$, abruzzi rye+hairy vetch; spring- $84 \mathrm{~kg} \cdot \mathrm{ha}^{-1} \mathrm{~N}$; 9) fall-0 $\mathrm{N}$, fallow, spring-168 $\mathrm{kg} \cdot \mathrm{ha}^{-1} \mathrm{~N}$; 10) fall-0 N, abruzzi rye, spring-168 kg $\cdot \mathrm{ha}^{-1} \mathrm{~N}$; 11) fall-0 N, hairy vetch, spring-168 $\mathrm{kg} \cdot \mathrm{ha}^{-1} \mathrm{~N}$; and 12 ) fall- $0 \mathrm{~N}$, abruzzi rye+hairy vetch, spring-168 kg·ha- ${ }^{-1}$ N. In Spring 2003, 'Camelott' bell pepper were transplanted. Total yield and fruit number were compiled over 8 weeks, while total vegetative dry matter was measured at final harvest.

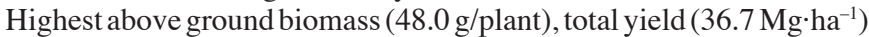
and fruit number (11/plant) were produced by fall- $0 \mathrm{~N}$, hairy vetch; spring-0 N. Lowest above ground biomass (19.0 g/plant), total yield $\left(11.5 \mathrm{Mg} \cdot \mathrm{ha}^{-1}\right)$ and fruit number (4/plant) were produced by fall- $0 \mathrm{~N}$, abruzzi rye; spring- $0 \mathrm{~N}$. Hairy vetch without any additional $\mathrm{N}$ produced plant biomass, fruit number and yield better than all other treatments. Results indicate the legume cover crop can be an effective $\mathrm{N}$ source in supporting plant biomass, fruit number and yield of bell pepper.

\section{Cover Crops their Mixture and Inorganic Nitrogen Effect on Bell Pepper Gas Exchange at Three Stages of Fruiting}

\section{Wayne F. Whitehead*1, Bharat P. Singh ${ }^{2}$}

${ }^{1}$ Fort Valley State Univ., Agricultural Research Station, Fort Valley, GA 31030-4313; ${ }^{2}$ Fort Valley State Univ., Agricultural Research Station, Fort Valley, GA 31020-4313

A study was conducted in 2002-2003 to determine effect of leguminous and nonleguminous cover crops alone or in mixture with fertilizer $\mathrm{N}$ rates on gas exchange (GE) at different fruiting stages of bell pepper. Transpiration $(\mathrm{E})$, photosynthesis $\left(\mathrm{P}_{\mathrm{n}}\right)$ and internal leaf $\mathrm{CO}_{2}$ concentration $\left(\mathrm{C}_{\mathrm{i}}\right)$ are reported. Fall-spring fertility treatments were applied with 3 replications in a randomized complete-block design: 1) fall-0 N, fallow, spring-0 N; 2) fall-0 N, abruzzi rye, spring-0 N;3) fall- $0 \mathrm{~N}$, hairy vetch, spring- $0 \mathrm{~N} ; 4$ ) fall- $0 \mathrm{~N}$, abruzzi rye+hairy vetch, spring-0 N; 5) fall-0 N, fallow, spring- $84 \mathrm{~kg} \cdot \mathrm{ha}^{-1} \mathrm{~N}$; 6) fall- $0 \mathrm{~N}$, abruzzi rye, spring-84 $\mathrm{kg} \cdot \mathrm{ha}^{-1} \mathrm{~N}$; 7) fall-0 $\mathrm{N}$, hairy vetch; spring-84 $\mathrm{kg} \cdot \mathrm{ha}^{-1}$ $\mathrm{N}$; 8) fall-0 N, abruzzi rye+hairy vetch, spring- $84 \mathrm{~kg} \cdot \mathrm{ha}^{-1} \mathrm{~N}$; 9) fall-0 $\mathrm{N}$, fallow, spring-168 $\mathrm{kg} \cdot \mathrm{ha}^{-1} \mathrm{~N}$; 10) fall-0 $\mathrm{N}$, abruzzi rye, spring-168 $\mathrm{kg} \cdot \mathrm{ha}^{-1} \mathrm{~N}$; 11) fall-0 N, hairy vetch, spring-168 $\mathrm{kg} \cdot \mathrm{ha}^{-1} \mathrm{~N}$; and 12) fall$0 \mathrm{~N}$, abruzzi rye+hairy vetch, spring-168 kg·ha- N. In Spring 2003, 'Camelott' bell pepper were transplanted in all plots. Maximum E (15.1 $\left.\mathrm{mmol} \cdot \mathrm{m}^{-2} \cdot \mathrm{s}^{-1}\right)$ and $\mathrm{P}\left(16.2 \mu \mathrm{mol} \cdot \mathrm{m}^{-2} \cdot \mathrm{s}^{-1} \mathrm{CO}_{2}\right.$ occurred at mid-fruiting, and maximum $\mathrm{C}_{\mathrm{i}}\left(445.5 \mu \mathrm{L} \cdot \mathrm{L}^{-1}\right)$ occurred at final-fruiting. Fall-0 $\mathrm{N}$, hairy vetch; spring-168 kg $\cdot \mathrm{ha}^{-1} \mathrm{~N}$ influenced $\mathrm{E}$ and $\mathrm{P}_{\mathrm{n}}$ the most while $\mathrm{C}_{\mathrm{i}}$ was affected the most by fall- $0 \mathrm{~N}$, abruzzi rye; spring- $168 \mathrm{~kg} \cdot \mathrm{ha}^{-1}$ $\mathrm{N}$. Results indicate that organic $\mathrm{N}$ from this legume can enhance GE of bell pepper similar to the inorganic $\mathrm{N}$ rates.
21 Strip Tillage Pumpkin Production Using Rye, and Rye/Hairy Vetch Cover Crop

Maurice Ogutu*1

${ }^{1}$ Univ. of Illinois at Urbana-Champaign, Univ. of Illinois Extension, Countryside, IL 60525

Pumpkin is usually grown on bare ground. Weeds are controlled by pre-emergence herbicides and cultivation early in the season before pumpkin vines cover the ground. The pumpkin fruit lie on bare ground and covered with soil. In pick-your-own pumpkin operation it is impossible to walk on muddy fields to pick pumpkin fruits. Experiment was carried out using three treatments (Control- bare ground, Rye only mulch, and rye/hairy vetch mulch) replicated four times in complete randomized block design with plot sizes of $30 \mathrm{ft}(9 \mathrm{~m})$ by $30 \mathrm{ft}(9$ $\mathrm{m})$. In each plot, two pumpkin rows were planted $8 \mathrm{ft}(2.4 \mathrm{~m})$ a part and $2 \mathrm{ft}(0.6 \mathrm{~m})$ a part within rows. In rye only, and rye/hairy vetch plots, two 2-ft wide strips 8 -ft a part were mowed and rototilled in each plot. Cover crop in between the rows were rolled using a multiculchler roller, and emergence of eastern black night shade (Solanum phytanthum Dun.), red root pig weed (Amaranthus retroflexus L.), and common lambsquarters (Chenopodium album L.) on cover crop plots between the rows were evaluated 4-10 weeks after transplanting. The effect of cover mulches on pumpkin fruit number, yield, fruit size, and fruit rots were assessed as well. Emergence of red root pigweed, black nightshade, and common lambsquarters was less than 2,1 , and $1 / 2$ seedlings per $12-\mathrm{ft}^{-2}\left(1-\mathrm{m}^{-2}\right)$ area respectively. There was no significant difference in marketable fruit number between control and strip tilled plots. Control plots had higher pumpkin fruit weight than rye/hairy vetch plots, and no significant difference between rye only and rye/hairy vetch plots. Control plots had significantly larger fruits and higher fruit rot incidence than strip tilled plots.

\section{Assessing How Cultural Practices Influence Long-term Productivity in Asparagus}

\section{R. Seth Peterson*1, Daniel Drost ${ }^{2}$}

${ }^{1}$ Utah State Univ., Plants, Soils, and Biometeorology, Logan, UT 84322-4820; ${ }^{2}$ Utah State Univ., Plants, Soils, and Biometeorology, Logan, UT 84322-4820

Asparagus producers have reported a decrease in plant longevity and plant productivity in asparagus fields. Eleven commercial sites (6 in California and 5 in Washington) were monitored starting in Spring 2003. The purpose in monitoring was to evaluate how long-term growth dynamics are affected by harvest pressure. Sites were planted as crowns in Spring 2002 and farm irrigation methods included furrow, sprinkler, and drip. Most sites were harvested starting in Spring 2003 at varying pressures. Harvest yields ranged from 0 to $1300 \mathrm{~kg} \cdot \mathrm{ha}^{-1}$. Carbohydrate (CHO) levels in the roots were sampled over the entire growing season and assessed with AspireUS (www.aspireus.com). At the last sampling in Oct. and Nov. 2003, CHO levels ranged from $438 \mathrm{mg} \cdot \mathrm{g}^{-1}$ to $712 \mathrm{mg} \cdot \mathrm{g}^{-1}$ ( $97 \%$ to $158 \%$ of the ideal). This resulted in a root $\mathrm{CHO}$ load of 2.6 to 6.3 megagrams/hectare. Root mass and distribution was sampled in Spring 2003 and again at the end of the growing season. Root biomass increased by $18 \%$ to $487 \%$ of the previous year's growth. Fern number, fern mass and plant population were also sampled. Fern number ranged from 3.2 to 6.4 stems per plant and total fern weight ranged from 8.9 to 36.2 megagrams/hectare. Plant populations were reduced by $3 \%$ to $19 \%$ when compared to the initial planted population. Findings suggest that excessive harvest pressure in the year after planting adversely affects storage $\mathrm{CHO}$ accumulation and root growth. Additional site monitoring will occur through 2005 .

\section{Reduced Tillage Tomato/Wheat Rotations in California's Central Valley}

Jeffrey P. Mitchell*1, Gene M. Miyao², Jim J. Jackson³, Lee F. Jackson $^{4}$, Tom Lanini ${ }^{5}$, Charlie G. Summers ${ }^{6}$, Jim J. Stapleton ${ }^{7}$

${ }^{1}$ Univ. of California, Davis, Vegetable Crops and Weed Science, Davis, CA 95616; ${ }^{2}$ Yolo/ Solano/Sacramento Counties, Cooperative Extension, Woodland, CA95695; ${ }^{3}$ Univ. of California, Davis, Vegetable Crops and Weed Science, Davis, CA 95616; ${ }^{4}$ Univ. of California, Davis, Agronomy and Range Science, Davis, CA95616; ${ }^{5}$ Univ. of California, Davis, Vegetable Crops and Weed Science, Davis, CA 95616; ${ }^{6}$ Univ. of California, Davis, Entomology, Davis, 
Two field comparisons of conservation tillage tomato production alternatives following wheat were conducted in California's Central Valley. Both studies compared: 1) standard tillage; 2) bed disk or permanent bed minimum tillage; and 3) strip-tillage following winter wheat crops that were harvested the previous June. Processing tomatoes were produced at the site in Davis, Calif., and fresh market tomatoes were grown in Parlier, Calif. At both sites, establishing tomatoes using a commercial transplanter or a modified conservation tillage transplanter achieved adequate stands even in the minimally-tilled strip-till system. Timing of the strip till operation, however, is critical so that large chuncks of dry soil are not brought up and so that these do not create very rough bed surfaces that may cause harvest problems, particularly for processing tomatoes. Machine harvesting the crop at the Davis site did not seem to create any mechanical difficulties or generate additional trash going into the harvest trailer. This may have been due to the fact that by harvest time, the majority of the surface residue from the previous wheat crop had already been broken down or at least sufficiently worked into the soil to pose minimal mechanical harvester impedance or contamination. Tomato yields for the reduced till systems equalled yields of the standard till systems at both sites.

\section{Evaluation of Plastic Reflective and Wheat Straw Mulches for Pest and Disease Control in Cucurbit Production Systems}

Charlie G. Summers ${ }^{1}$, Jeffrey P. Mitchell ${ }^{2}$, James J. Stapleton ${ }^{3}$

${ }^{1}$ Univ. of California, Davis, Entomology, Parlier, CA 93648; ${ }^{2}$ Univ. of California, Davis, Vegetable Crops and Weed Science, Parlier, CA 93648; ${ }^{3}$ Univ. of California, Davis, Integrated Pest Management, Parlier, CA 93648

Trials were conducted in 2002 and 2003 in California's San Joaquin Valley to determine the efficiency of reflective plastic and wheat straw in managing silverleaf whitefly and aphid-borne virus diseases in late planted cantaloupes. In 2002, the incidence of aphid-borne viruses was lowest in plants growing over reflective plastic followed by those growing over wheat straw and then those growing over bare soil. Wheat straw mulch was as effective as reflective plastic during the early part of the growing season in reducing the incidence of virus disease, but by mid-season, the reflective plastic was superior. The incidence of virus diseases in plants growing over wheat straw was significantly $(P<0.05)$ lower than that in plants growing over bare soil throughout the season. Whitefly numbers (nymphs per $\mathrm{cm}^{2}$ ) and aphid numbers were significantly reduced on plants growing over both reflective mulch and wheat straw mulch compared to those growing over bare soil. Yields of all sizes of melons were significantly higher in the reflective mulch plots and yield for the straw mulched and bare soil plots were not significantly different. Results in 2003 were similar to those of 2002. Both whitefly numbers and aphid numbers were significantly lower in plants growing over both mulches than in those growing over bare soil. Virus incidence was initially low but following an aphid flight in late August, the number of infected plants increased rapidly. Both the reflective plastic and straw provided equal protection form aphid-borne viruses throughout the growing season. Yields were highest in the reflective plastic plots, followed by the straw mulch and finally the bare soil. Differences were significant $(P<0.05)$ among all three treatments.

\section{The Central Great Plains High Tunnel Horticulture Project}

Lewis Jett*1, Edward Carey ${ }^{2}$, Laurie Hodges ${ }^{3}$

${ }^{1}$ Univ. of Missouri, Horticulture, Columbia, MO 65211; ${ }^{2}$ Kansas State Univ., Horticulture; ${ }^{3}$ Univ. of Nebraska, Horticulture

There is great interest by horticulture producers in the Central Great Plains in methods to extend the traditional growing season, increase value of crops and provide more locally grown produce. High tunnels are low-cost, unheated greenhouses that can accomplish these goals. In 2002, the Central Great Plains High Tunnel Project was initiated through funding support by the Initiative for Future Agriculture and Food Systems (IFAFS). The Univ. of Missouri, Kansas State Univ., and the Univ. of Nebraska have constructed 24 high tunnels to conduct research on vegetables, small fruits and cut flowers. Each year, a multi-state workshop is conducted along with several on-farm and research center tours. Growers are collaborating with extension personnel on projects ranging from high tunnel temperature management to pest management. A web site for high tunnel information has been constructed (www. hightunnels.org). Production guides on specific high tunnel crops have been printed. From 2002-03, a significant number of high tunnels have been constructed in the Central Great Plains.

\section{Poster Session 3-Waste Utilization in Horticulture July 17, 2004, 12:30-1:30 PM Rio Grande Exhibit Hall}

\section{Effects of Compost Amended Container Media on Ornamental} Plant Growth

Mark T.F. Highland*1, Daniel C. Sclar², Elaine R. Ingham³ ${ }^{3}$ Karen L. Gartley $^{4}$, James E. Swasey ${ }^{5}$

${ }^{1}$ Univ. of Delaware, Dept. of Plant and Soil Science, Newark, DE 19717; ${ }^{2}$ Univ. of Delaware, Dept. of Plant and Soil Science, Newark, DE 19717; ${ }^{3}$ Soil Foodweb, Inc., President, Corvallis, OR 97330; ${ }^{4}$ Univ. of Delaware, Dept. of Plant and Soil Science, Newark, DE 19717; ${ }^{5}$ Univ. of Delaware, Dept. of Plant and Soil Science, Newark, DE 19717

Compost has great potential for use in horticulture; however, the relationship between compost feedstock materials and resultant compost characteristics must be well understood. Research examining plant growth response from the addition of compost to container growing media is limited. This research had two parts: the first part examined the relationship between compost feedstock materials and resultant mature compost characteristics. The second part investigated plant growth responses when compost replaced the peat component of container growing media. Two feedstock treatments were aerobically composted in turned windrows. Compost characteristics examined include $\mathrm{pH}, \mathrm{EC}, \mathrm{C}: \mathrm{N}$ Ratio, Solvita Maturity, and several biological characteristics (total and active bacteria, total and active fungi, protozoa, spore forming bacteria, E. coli $\mathrm{O} 157: \mathrm{H} 7$, and total coliformic bacteria). To examine plant growth response, compost was substituted for peat (from $0 \%-40 \%$ by total volume) in container growing media. Crops tested were Antirrhinum majus 'Rocket White', Viola $\times$ wittrockiana 'Crown Azure', Oriental Hybrid Lilium 'Siberia', and Chrysanthemum $\times$ grandiflorum 'Yellow Kodiak'. Quantitative plant growth response measurements (shoot fresh and dry weight, percent root necrosis, flower number, and flower size) were recorded and compared by treatment. Despite initial feedstock differences between the two compost treatments, both resulted in similar compost biology and species richness. Coliformic bacteria and E. coli O157:H7 levels were below detection limits in final compost. Choice of compost feedstock materials had a significant effect on the chemical characteristics of the finished product. Compost replacement for peat resulted in plant growth greater than or equal to those of the control treatment.

\section{Production of Environmentally Safe and Sustainable Compost- based Fertilizer Products from Horticultural and Farm Wastes}

Juluri Rao*1, John Moore ${ }^{2}$, Andrew Stewart ${ }^{3}$

${ }^{1}$ Dept. of Agriculture and Rural Development, Applied Plant Science Division, Belfast, Northern Ireland, BT9 5 PX, United Kingdom; ${ }^{2}$ Belfast City Hospital, Public Health Laboratory, Belfast, Northern Ireland, BT9 7AD, United Kingdom; ${ }^{3}$ Private Ltd, ApT Solutions, County Antrim, Northern Ireland, BT39 0EA, United Kingdom

The EU Regional Draft Waste Management Plan (1999-2004) identified pig slurry (501,590 tonnes), poultry manure (217,110 tonnes) and spent mushroom compost (221,665 tonnes) as the main contributors to the 3.5 million tonnes of waste generated annually in Ireland. Current legislative restrictions prevent pig wastes from intensive pig units and horticultural wastes mainly spent compost produced in mushroom farms being disposed via landspreading due to pollution threat from nutrient run-off and the health hazards due to animal and human risk pathogen contents in wastes. Composting is a world-wide popular option for environmentally sustainable means of recycling farm wastes. In Ireland, profitable conversion of farm wastes such as pig slurry solids and spent mushroom compost has not yet been fully explored for their 
economic viability as 'green' fertilizers. In this study, we produced pelleted formulations of the composted pig waste solids, $(20 \%)$ blended with spent mushroom compost $(26 \%)$, turkey litter (26\%) cocoa husks $(18 \%)$ and shredded paper (10\%) to an environmentally safe, organicbased fertiliser resulting in $\mathrm{N}: \mathrm{P}: \mathrm{K}=3: 5: 10$, ideally suitable for use on amenity grassland such as golf course fairways and greens in Ireland, wherein spring and summer fertilizers with slow release of nutrients would aid an even growth of grass. We describe the composting methods used, processing technology developed and additional amendments such as dried blood or feather meal that were used during the pelletisation operation yielding specific $\mathrm{N}: \mathrm{P}: \mathrm{K}$ target ratios from the pig manure and spent compost wastes. We also report on the rigorous microbiological tests carried out throughout the composting phase and ascertained the pathogen-free status of the final pelletised fertilser products.

105 Electroremediation Methods for Removal of Excessive Salts Juluri Rao*1

${ }^{1}$ 1Dept. of Agriculture and Rural Development, Applied Plant Science Division, Belfast, Northern Ireland, BT9 5 PX, U.K.

There is world-wide interest in disposal technologies suitable for handling farm wastes. The Northern Ireland mushroom industry generates 200,000 tonnes/year of "spent" mushroom compost waste containing excess salts (P, K, Ca) and heavy metals. Its disposal by landspreading is restricted by EU, U.K. legislation. Farmers in Europe and the United States use this waste as a soil nutrient improver, but such operations are deleterious to the environment owing to microbial loading of soil and the release of human and animal pathogens. An ideal option is to reduce salt levels and pathogen content before granulating the waste into fertilizers. Electroremediation is a novel, in situ environmental technology which utilises low voltage electrical fields to remove salts or metals in contaminated soil sites. We developed electroremediation methods for the removal of excessive salts from 'spent' mushroom compost or from soils contaminated with this waste. Electroremediation of excess salts / heavy metals from the horticultural waste was carried out in an anti-corrosive electrolysis tank with a built-in central holding bay for the waste material. A thin layer of charged fluid (rain water, $\mathrm{pH} 5.5$; adjusted with $0.005 \mathrm{~N} \mathrm{HCl}$ ) maintained over the mushroom compost waste achieved the removal of salts when electrical fields ranged from 20 to $200 \mathrm{~V}$ were applied across electrodes (spacing 1.5 $\mathrm{m}$ apart) in our investigations. Electrode saturation by $\mathrm{H}+$ or $\mathrm{OH}-$ and thermal/alkaline front build up were minimised by flushing with cooled $\left(15^{\circ} \mathrm{C}\right)$ fresh rainwater circulated via peristaltic pumps. The above prototype is useful for nutrient tailoring of spent compost waste in bagged compost prior to producing commercially viable granulated fertilizers from wastes.

106 Land Application of Saline Industrial Wastewater on a Chihuahuan Desert Upland

A. Ruiz*1, D.S. Rodriguez², G.A. Picchioni ${ }^{3}$, J.G. Mexal', T.W. Sammis $^{5}$

${ }^{1}$ New Mexico State Univ., Dept. of Agronomy and Horticulture, Las Cruces, NM 88003; ${ }^{2}$ New Mexico State Univ., Dept. of Agronomy and Horticulture, Las Cruces, NM 88003; ${ }^{3}$ New Mexico State Univ., Dept. of Agronomy and Horticulture, Las Cruces, NM 88003 ${ }^{4}$ New Mexico State Univ., Dept. of Agronomy and Horticulture, Las Cruces, NM 88003; ${ }^{5}$ New Mexico State Univ., Dept. of Agronomy and Horticulture, Las Cruces, NM 88003

Low-cost, sustainable wastewater treatment systems are needed for rapidly-growing communities of the southwestern United States. The objective of this study is to develop a practical management plan for land application of industrial wastewater on native Chihuahuan Desert vegetation. To assess environmental impact and create the management plan, wastewater effluent characteristics, soil physicochemical changes, and mineral uptake of the vegetation were monitored. The effluent was saline, ranging from 2500 to $6000 \mathrm{mg} \cdot \mathrm{L}^{-1}$ of TDS and dominated by $\mathrm{Na}$ and $\mathrm{Cl}$. Total $\mathrm{N}$ ranged from 10 to $40 \mathrm{mg} \cdot \mathrm{L}^{-1}$. Soils sampled in Dec. 2002 (after 11 months and $64 \mathrm{~cm}$ of effluent irrigation) increased in salinity in the top $60 \mathrm{~cm}$ from 1.85 to $3.5 \mathrm{dS} \cdot \mathrm{m}^{-1}$, and SAR in the top $30 \mathrm{~cm}$ was close to 15 , but diminished with depth.
Branch samples of the co-dominant perennial shrub vegetation members (Larrea tridentata and Prosopis glandulosa) harvested in July 2002 had elevated $\mathrm{Na}$ and $\mathrm{Cl}$ concentrations $(0.4 \%$ to $2.1 \%$ of dry weight, respectively). By Oct. 2002, L. tridentata leaves contained comparable $\mathrm{Na}$ and $\mathrm{Cl}$ concentrations as those of $P$. glandulosa, yet removed 2 to three times more $\mathrm{Na}, \mathrm{Cl}$, and total $\mathrm{N}$ per branch, while maintaining their dry mass per branch. This raises the possibility of interspecific variation among the shrub species in salinity stress tolerance and capacity to remove wastewater contaminants. These data will aid in determining total vegetation removal of effluent components, preventing adverse environmental impact to the site, and developing a practical management plan suitable for small communities seeking cost-effective wastewater handling protocols.

\section{Poster Session 4-Citrus Crops/Tropical Horticulture}

\section{July 17, 2004, 12:30-1:30 PM Rio Grande Exhibit Hall}

\section{8 'Satsuma' Mandarin Cultivar Trial on the Central Coast of California}

Robert J. McNeil*1, Colleen M. Dettling ${ }^{2}$

${ }^{1}$ California Polytechnic State Univ., Horticulture and Crop Science, San Luis Obispo, California, 93407; ${ }^{2}$ California Polytechnic State Univ., Horticulture and Crop Science, San Luis Obispo, California, 93407

A 4-year 'Satsuma' mandarin cultivar trial was conducted on the California Central Coast in San Luis Obispo. Cultivars compared were Owari, Dobashi Beni, and Okitsu Wase, all on Carizzo citrange rootstock. Trees were from 3 to 6 years of age and in their first 4 years of production during the four seasons that data was taken. Data taken each year was fruit maturity, color, size, and yield. Tree size was measured in the fourth year. 'Okitsu Wase' fruit were harvestable 2 to 4 weeks earlier than 'Owari' and 'Dobashi Beni' considering meeting both minimum soluble solids to acid ratio (6.5/1) and minimum color $(75 \%)$. 'Okitsu Wase' was more consistent as to time of maturity. Maturity time of all cultivars varied each season based on weather. 'Okitsu Wase' first minimum internal maturity varied from 15 Oct. to 1 Nov. Minimum color varied from 1 Nov. to 1 Dec. Dobashi Beni first internal maturity varied from 15 Oct. to 31 Dec. Minimum color varied from 15 Nov. to $31 \mathrm{Dec}$. Owari first minimum internal maturity varied from 15 Nov. to 31 Dec. Minimum color varied from 15 Nov. to 31 Dec. 'Owari' had the highest total yield for the 4 years, followed by 'Dobashi Beni'. 'Okitsu Wase' had a significantly lower total yield than the other two cultivars for the 4 years. 'Okitsu Wase' had higher percentages of smaller fruit and lower percentages of larger fruit than the other two cultivars in the first and fourth crop year, but had comparable percentages of larger fruit in the second and third year. The 'Okitsu Wase' was a smaller tree than both the 'Owari' and 'Dobashi Beni' in height, width, and canopy volume.

\section{Control of Citrus Nematode with Ditera WDG, a Biological Nematicide, Applied through Minisprinkler Irrigation}

\section{Daniel E. Ray*1, Robert J. McNeil ${ }^{2}$}

${ }^{1}$ California Polytechnic State Univ., Horticulture and Crop Science, Morro Bay, CA 93442; ${ }^{2}$ California Polytechnic State Univ., Horticulture and Crop Science, San Luis Obispo, CA 93407

The objectives of the study were to measure the effectiveness of Ditera WDG, a biological nematicide derived from the fermentation of a nematode-parasitic isolate of the Myrothecium species, in controlling citrus nematode numbers and the effects on tree growth, fruit yield, and fruit size as applied through minisprinkler irrigation. Nematodeinfested trees utilized for the study included three different blocks of sweet oranges: 1) 20-year-old 'Valencia' orange trees on Troyer citrange rootstock; 2) 15-year-old Washington navel orange trees on Troyer citrange rootstock; and 3) 8-year-old Washington navel orange trees on three citrange rootstocks (Troyer, Carizzo, and C-35). Three treatments were utilized within each orchard block: 1) $28.01 \mathrm{~kg}$ of active ingredient per hectare (25 lb per acre); 2) $56.02 \mathrm{~kg}$ of active ingredient 
per hectare (50 lb per acre); and 3) an untreated control. Treatments 1 and 2 were split into early spring and early fall applications for three seasons. Chemical was injected through minisprinkler irrigation in a $3.41 \mathrm{~m}$ (11.2 ft.) diameter under each tree. There was a positive trend toward reduction of nematode numbers for the high rate of Ditera in all three treatment blocks and for the low rate in one block. Effects on tree growth, fruit yield, and fruit size will also be presented.

\section{Agroforestry as It Pertains to Vegetable Production in Ban- gladesh \\ Lutfor Rahman*1, Farid Mir² \\ ${ }^{1}$ Texas A\&M Univ., Horticulture, Dallas, Texas, 75252-6599; ${ }^{2}$ BSMRAU, Dept. of Agroforestry and Environment, Bear, DE 19701-2528}

This study identified the diversity and distribution of tree species and which vegetable crops are grown beneath them, uses of different plants, to identify the problem faced by the farmer, and to recommend a suitable small scale mixed production system. The study was conducted in three sub districts of the Gazipur district in Bangladesh. Respondents for the survey were selected based on five different farm categories, i.e., tenant, marginal, small, medium, and large farm. The most common species in the study area was jackfruit (Artocarpus heterophyllus, 26.3) and mango (Mangifera indica, 22.5) followed by mahogany (Swietenia mahagoni, 10.3), coconut (Cocos nucifera, 10.0), while low prevalence species was gora neem (Melia azadirch, 0.18 ) and tamarind (Tamarindus indica, 0.19). A total number of 43 plant species were identified in the homestead of the study area of which 28 were horticultural, and 15 were timber and fuelwood producing species. Total income was found to increase with increase of farm size. A large number of vegetables ( 32 species) are cultivated in the study area, largely for local consumption. The study showed that stem amaranthus, indian spinach, aroids, sweet gourd, chili, turmeric, eggplant, and radish were grown under shade of jackfruit, mango, date palm, litchi, mahogany, and drumstick trees. Country bean, bitter gourd, sponge gourd, and cowpea were found to grow as creeper on jackfruit, mango, litchi, mahogany, and drumstick trees. Farmers earned cash income by selling trees and vegetables produced in the homestead. Among different tree species, jackfruit was identified as an important cash generating crop in the study area. Scopes for improvement of tree management practices were prevalent in the study area.

\section{Agroforestry on Small Landholdings in Bangladesh}

\section{Lutfor S. Rahman*1, Farid A. Mir ${ }^{2}$}

${ }^{1}$ Texas A\&M Univ., Horticulture, Dallas, TX 75252-6599; ${ }^{2}$ BSMRAU, Bangladesh, Dept. of Agroforestry and Environment, Bear, DE 19701-2528

The study was conducted in three sub-districts of Gazipur district in Bangladesh. It identified the diversity and distribution of tree species and which vegetable crops are grown beneath them, uses of different plants, to identify the problem faced by the farmers. Total of 43 tree plant species are used for fruit and timber were identified in the study area. Based on diversified uses, the major fruit species were jackfruit, mango and coconut. The major timber species were koroi (Albizia procera), raintree (Samanea saman), neem (Azadirachta indica), teak (Tectona grandis) and eucalyptus (Eucalyptus sp.). Total income was found to increase with increase of farm size. A large number of vegetables (32 species) are cultivated in the study area, largely for local consumption. The study showed that stem amaranthus, indian spinach, aroids, sweet gourd, chili pepper, turmeric, eggplant, and radish were grown under shade of jackfruit, mango, date palm, litchi, mahogany, and drumstick trees. The total income from trees in the last five years was higher in the large farm category than that in the tenant category. The major problems faced by the farmers in tree establishment were damage caused by animals which was reported by $68 \%$ of the respondents.
112 Yield and Fruit Quality of Carambola Cultivars Grown at Three Locations in Puerto Rico

Ricardo Goenaga*1, Edmundo Rivera ${ }^{2}$

${ }^{1}$ Tropical Agriculture Research Station, USDA, ARS, Mayaguez, PR 00680-5470; ${ }^{2}$ Tropical Agriculture Research Station, USDA, ARS, Mayaguez, PR 00680-5470

Nine carambola (Averrhoa carambola) cultivars grown on an Oxisol, Ultisol, and Mollisol were evaluated for 2 years under intensive management at Isabela, Corozal and Juana Diaz, Puerto Rico, respectively. There were no significant differences in number and weight of marketable fruits per hectare between Corozal and Isabela; average values for both locations were 249,824 fruits/ha and 29,864 kg/ha. At Juana Diaz these values were 196,254 fruits/ha and $24,339 \mathrm{~kg} / \mathrm{ha}$, respectively. There were no significant differences in weight of marketable fruit per hectare among cultivars B-17, Thai Knight, B-10, Sri Kembangan, and Kajang between locations. The average marketable fruit weight for these higher yielding cultivars was $31,457 \mathrm{~kg} / \mathrm{ha}$. Cultivar Kari produced significantly longer fruits at all locations, whereas cultivar B-16 produced the shortest fruits. Significantly higher brix values were obtained from fruits of cultivar B-17 at all locations whereas lower values were obtained from those of Arkin.

\section{Chromatographic Techniques to Purify Individual Limonoids} from Seeds and Molasses of Citrus Fruits

Shibu M. Poulose ${ }^{* 1}$,Jennifer S. Brodbelt ${ }^{2}$, Leonard M. Pike ${ }^{3}$, Bhimanagouda S. Patil ${ }^{4}$,

${ }^{1}$ Texas A\&M Univ., Kingsville Citrus Center, Weslaco, TX 78596; ${ }^{2}$ Univ. of Texas, Dept of Chemistry and Biochemistry, Austin, TX 78712; ${ }^{3}$ Texas A\&M Univ., vegetable and Fruit Improvement Center, College Station, TCX 78712; ${ }^{4}$ Texas A\&M Univ., Kingsville Citrus Center, Weslaco, TX 7859

Limonoids, chemically related triterpinoids predominantly found in citrus and neem relatives, are known to play a pivotal role in the prevention of different types of cancer and cardiovascular diseases. Since the concentrations of these compounds are low in the plant tissues, the isolation of pure compounds is the limiting factor for the individual activity studies in animal models. In this study, combinations of chromatographic techniques were used to isolate limonoid aglycones and limonoid glucosides from citrus byproducts such as seeds and molasses. The compounds were initially extracted with different polar solvents and the concentrated extracts were passed through a series of adsorbent resin (SP-70) and ion-exchange resins (WA-30, Dowex-50, Q-sepharose) to remove further impurities. The use of increasing ionic strength of $\mathrm{NaCl}$ from 0 to $800 \mathrm{~mm}$ to release the exchanged compounds from the ion exchange columns further separated the limonoids from flavonoids, which was confirmed through TLC, UV, and analytical HPLC methods. Individual compounds were further purified using flash chromatography and preparative HPLC methods and identified by using LC-MS analysis. Direct crystallization of limonin resulted in a $17 \%$ increase in the yield as compared to the previously reported methods. The results suggest that application of these purification methods are useful for the bulk purification of compounds in order to further investigate their biological activity.

\section{Poster Session 5-Genetics and Germplasm 1}

\section{July 17, 2004, 12:30-1:30 PM Rio Grande Exhibit Hall}

172 Cryopreservation of Apple: Results with Non-desiccated Winter Scions

Leigh E. Towill*1

${ }^{1}$ National Center for Genetic Resources Preservation, USDA-ARS, Fort Collins, CO 80521

Apple cryopreservation at USDA-ARS NCGRP uses a winter vegetative bud method that incorporates desiccation prior to cooling. Although this method is valuable, desiccation is time consuming, requiring cutting nodal sections to exact lengths, moisture content estimates, and 1-4 weeks of desiccation. Processing sections without desiccation is being examined to improve the efficiency of handling Malus accessions. Vi- 
ability was estimated using an oxidative browning assay or a sprouting test. Sections from mid-winter collected scions were cooled at different rates to $-30^{\circ} \mathrm{C}$ or $-35^{\circ} \mathrm{C}$ and transferred to the vapor phase over liquid nitrogen. Sections were warmed at $+4{ }^{\circ} \mathrm{C}$ and held for $24 \mathrm{~h}$ before testing viability. Some lines were processed after several months of storage at $-3.5^{\circ} \mathrm{C}$. Although viability after cryopreservation occurred with a cooling rate of $1{ }^{\circ} \mathrm{C} / \mathrm{h}$, slower cooling $\left(5^{\circ} \mathrm{C} /\right.$ day $)$ was beneficial for many accessions. In tests with a limited number of lines, cooling rates $\geq 10{ }^{\circ} \mathrm{C} / \mathrm{h}$ to $-30{ }^{\circ} \mathrm{C}$ caused injury to buds and cambium. Scions stored for up to 8 months could survive cryoexposure. Scions from three lines tested survived three cycles of cooling from $+4{ }^{\circ} \mathrm{C}$ to $\mathrm{LN}$. Extent of acclimation affected results. With non-desiccated sections cryogenic survival of 'Golden Delicious' differed over years, but this has also occurred with the procedure that uses a desiccation step. It is not expected that this method is generally applicable to more tender species of Malus or other fruit genera, but the method has been successful with many lines of $M . \times$ domestica, a fairly cold hardy taxa, and with some other cold hardy Malus species. Grafting tests are needed to confirm the usefulness of the method

\section{Morphological and Phenological Variation in World Collections of Velvetleaf (Abutilon theophrasti)}

Lynn Marie Sosnoskie*1, John Cardina², Sajal Sthapit ${ }^{3}$,

David Francis ${ }^{4}$, A. Raymond Miller

${ }^{1}$ The Ohio State Univ., Dept. of Horticulture and Crop Science, Wooster, OH 44691; ${ }^{2}$ The Ohio State Univ., Dept. of Horticulture and Crop Science; ${ }^{3}$ College of Wooster, Dept. of Biology; ${ }^{4}$ The Ohio State Univ., Dept. of Horticulture and Crop Science, Wooster, OH 44691; ${ }^{5}$ The Ohio State Univ., Dept. of Horticulture and Crop Science

Our lab characterized the growth and development of 83 velvetleaf accessions, collected from locations in Asia, India, Europe, Eastern Africa and North America, to test the hypothesis that two biotypes ("crop" and "weedy") exist and are easily differentiated. Measurements taken to gauge morphological and phenological variability include: initial seed weight, stem height at 3, 7, and 11 weeks, leaf size at 3, 7, and 11 weeks, stem and petiole color, time to flowering, time to first capsule maturity, stem height at flowering, height to first mature capsule, basal stem diameter, number of capsules, and capsule size and color. Analyses indicate that accessions producing yellow-colored seed capsules were taller, produced fewer nodes, and were longer-lived than their brown-colored counterparts. This finding supports previous assertions that the yellow-colored varieties were originally selected for use as a fiber crop: i.e., increased stem yield resulted in longer lengths of lignified tissue. The accessions producing brown-colored capsules exhibited greater reproductive output, as measured by the number of capsules and the number of seed-containing valves per capsule, a desirable trait for weedy species. Using capsule color as an independent variable, Discriminant Analysis was able to correctly classify $96 \%$ of the observations by the remaining characters, further affirming that the yellow- and brown-capsuled accessions varied, significantly, with respect to their morphology and phenology. Velvetleaf is believed to have originated in China, where it was eventually domesticated. Early records suggest that velvetleaf, a noxious weed in modern agricultural production, was introduced to colonial America to serve as a fiber source for the burgeoning rope-making industry.

\section{Seed Technology in Plant Germplasm Conservation}

\section{David Tay*1}

${ }^{1}$ The Ohio State Univ., Ornamental Plant Germplasm Center, Columbus, OH 43210-1086

In plant germplasm conservation, "orthodox" seed (i.e. seed that survives drying down to low moisture content) is the most suitable propagule for long-term storage. In general, high quality seeds of around 5\% seed moisture content can be stored for $5-15$ years at $2^{\circ} \mathrm{C}$ and $15-50$ years at $-18^{\circ} \mathrm{C}$. Globally, there are some 1,300 genebanks and 6.1 million accessions of food and industrial crops in conservation. When collecting and conserving plant germplasm, seed science and technology have to be applied during germplasm collection; seed regeneration -germination, seedling establishment, flower synchronization, pollination, harvesting, drying, processing and packaging; seed storage and conservation; characterization and evaluation; and finally, distribution. Some of the seed science knowledge and technology skills encompass seed sampling strategy, sample size, seed health, germination and vigor testing, dormancy breaking, scarification, stratification, vernalization, photoperiod treatment, isolation and pollination techniques, harvesting, threshing, drying, hermetic packaging, storage facility design, etc. The goal is to produce seed lots that fulfill the required genetic, physical, physiological and health quality. A summary was presented to relate germplasm conservation activities to seed science and technology. Some of the seed production, processing and testing equipment used were highlighted. Seed research in germplasm conservation is therefore crucial to streamline the operation and management of a genebank to make it more cost effective and attractive for funding.

\section{Introducing Cereus into an Arid Region as a New Fruit Crop Ahmed ElObeidy*1}

${ }^{1}$ Faculty of Agriculture, Cairo Univ., Horticulture, Giza, Egypt

One of the major steps in responding to imminent water shortages in the Middle East is improving water use efficiency. Drought-resistant crops would be an effective technology to curb rising demands of water. Columnar Cactus species characteristics fit with most of the requirements of a drought tolerant crop with very high water-use efficiency. Cereus cacti have physiological and morphological methods of exploiting environments that would soon desiccate other plants. Four Cereus species were introduced into UAE deserts and could be ideal for establishing crop plantations in the arid environment. The introduced fruiting cacti are Cereus hexagonus, C.pachanoi, C.peruvianus, and C. validus. Plants were propagated by cuttings in the greenhouse. Cuttings developed roots within $2 * \& 8211 ; 4$ weeks of planting. The propagated plants were acclimatized and transplanted into the field in the desert. $C$. peruvianus was the most promising in the new environment in terms of its high adaptability and healthy growth in the new environment. $C$. pachanoi grew very fast, averaging up to a fifteen centimeter a month of new growth. C. pachanoi was recommended as a rootstock for other species. $C$. validus could not survive the new environment.

\section{In Vitro Multiplication of Brazilian Ginseng (Pfaffia spp.) for in Vitro Conservation Purposes}

Gerson Renan de Luces Fortes*1, Ana Carolina Pereira e Silva ${ }^{2}$

${ }^{1}$ Embrapa Recursos Genéticos e Biotecnologia, P.O. Box 02372, Brasilia, DF 70820-008, Brazil; ${ }^{2}$ Faculdade da Terra, $3^{\mathrm{a}}$ Avenida, Núcleo Bandeirante, Brasilia, DF 71720-008, Brazil

Brazilian ginseng (Pfaffia sp.) is largely known as having anabolic, analgesic, anticancerous, anti-inflammatory, antileukemic properties, and more. Embrapa Genetic Resources and Biotechnology is the major Conservation Center in Brazil. This species could only be stored under in vitro conditions. There are more than two hundred native acessions collected from different locations in the country. So far very few works are found in the literature and there is no specific protocol for in vitro conservation. The aim of this study was to test five different acessions from in vitro collection under one specific nutrient medium. The acessions were catalogued as 2205-12; 2202-04; 2209-11;2209-10 and 2205-21. One-bud microcutting was inoculated on a MS nutrient medium without growth regulators and added with vitamins, myoinositol $\left(100 \mathrm{mg} \cdot \mathrm{L}^{-1}\right)$, sucrose $\left(30 \mathrm{mg} \cdot \mathrm{L}^{-1}\right)$ and agar $\left(6 \mathrm{mg} \cdot \mathrm{L}^{-1}\right)$. The $\mathrm{pH}$ was adjusted to 5.7 before the agar addition. Each treatment was replicated 7 (seven) times and each plot consisted of six test tubes with 5 -mL solution. The trial was replicated twice. The evaluations were performed once weekly where the shoot growth was taken along with the number of buds and roots formed. The highest shoot growth were obtained for the acessions 2205-12 and 2209-10. Acession 2209-11 had an intermediate shoot growth and number of buds, but had the highest number of roots per shoot (4.27) compared to 2.14 and 3.75 for acessions 2205-21 and 2209-10, respectively. The highest rate of multiplication was achieved for acessions 2205-12 (4.49) and 2202-04 (4.46) as compared to 3.60 for acession $2205-21$. It was clearly shown that acession 2205-21 is a recalcitrant one as in vitro multiplication is concerned. All the acessions rooted in this medium. 


\section{Poster Session 6-Plant Biotechnology 1}

\section{July 17, 2004, 12:30-1:30 PM Rio Grande Exhibit Hall}

\section{Genetic Sequence Variation in the ITS Region of Nine Rubus Genotypes}

Eric Stafne*1, John Clark ${ }^{2}$, Allen Szalanski ${ }^{3}$

${ }^{1}$ Univ. of Arkansas, Horticulture, Fayetteville, AR 72701; ${ }^{2}$ Univ. of Arkansas, Horticulture; ${ }^{3}$ Univ. of Arkansas, Entomology

In this study, the nuclear ribosomal DNA internal transcribed spacer region (ITS) of six Rubus cultivars were sequenced, then compared with sequences of three Rubus species in Genbank. DNA sequencing revealed little genetic variation among blackberry cultivars, but ably revealed distinctions between blackberry and red raspberry genotypes. Analysis by maximum-parsimony and pairwise genetic distances confirmed the small variation among blackberry cultivars. The resulting sequences were analyzed for useful restriction sites and polymerase chain reaction- restriction fragment length polymorphism(PCR-RFLP) analysis was conducted on a total of six cultivars to establish genetic variation. Digests were difficult to interpret due to heterogeneity at restriction sites.

\section{Expression of Anthocyanin Genes in Potato Periderm}

Daniel Keifenheim ${ }^{1}$, Cindy Tong*2

${ }^{1}$ Univ. of Minnesota, Horticultural Science, St. Paul, MN 55108; ${ }^{2}$ Univ. of Minnesota, Horticultural Science, St. Paul, MN 55108

Anthocyanins are a class of flavonoids that are responsible for pigments in flowers, fruit, and potato periderm. Developing 'Norland' potatoes synthesize anthocyanins in periderm tissue when the tubers are mere swollen stolon tips. As the tubers enlarge, anthocyanin accumulation seems to stop, and anthocyanins synthesized early in development seem to be diluted as the tubers enlarge. Expression of dihydroflavonol reductase $(D F R)$ limits anthocyanin synthesis in grape and maize fruit, and in petunia and snapdragon flowers. However, DFR expression in periderm tissue occurred throughout tuber development (Hung et al., 1999). To determine if expression of late anthocyanin pathway genes limit anthocyanin synthesis in developing potato tubers, we performed RNAgel blot analyses. Expression of leucoanthocyanidin dioxygenase and UDP glucose: flavonoid 3-O-glucosyl transferase was observed in swollen stolon tips but not in periderm of later tuber development stages. Surprisingly, expression was also observed in cortex tissue, although that tissue remained white throughout tuber growth.

\section{Detecting Genes Expressed at Different Stages of Reproductive Arrest in Brassica oleracea}

Denise V. Duclos*1, Thomas Björkman ${ }^{2}$

${ }^{1}$ Cornell Univ., Horticultural Sciences, Geneva, NY $14456 ;{ }^{2}$ Cornell Univ., Horticultural Sciences, Geneva, NY 14456,

Cauliflower (Brassica oleracea var. italica) and Broccoli (Brassica oleracea var. botrytis) differ mainly in the stage of reproductive arrest. Cauliflower curd is an inflorescence meristem, while broccoli arrests just before anthesis. Arabidopsis studies led to the hypothesis that a mutant BoCAL allele arrested cauliflower earlier. Later, a mutant in BoAP1 was found to have similar effects. These partially redundant genes, and several identified since, are present in multiple copies in B. oleracea. Understanding their role in the arrest requires quantification of transcript abundance analysis by real-time PCR. Designing selective PCR primers is a critical first step in the process. Designs were based on alignment among the genes of interest (MADS-box genes BoCAL, BoAP1, FUL, and the non MADS-box genes LFY and TFL1) and their paralogs. The high sequence similarity (some over 95\%) makes the target transcripts difficult to distinguish. Therefore, primers were designed mostly for targets in the 3'UTR region in order to gain specificity. Short amplicons, $68 \mathrm{bp}$ to $200 \mathrm{bp}$, were required for the high PCR efficiency required to quantify these low-abundance transcripts. Primers were evaluated by conventional RT-PCR and real-time PCR. By altering temperature, Total RNA was isolated from plants that were arrested at three developmental stages, inflorescence meristem (cauliflower), floral meristem (intermediate), and floral bud (broccoli) by varying temperature. RT-PCR products were single bands of the expected size, despite the high homology between genes under study. Real-time melting curve analysis (fluorescence derivative vs. melting temperature) corroborated the presence of a single amplicon. The identity of products was confirmed by sequencing and restriction enzyme digestion.

\section{In Vitro Response of Strawberry Cultivars and Somaclones to Colletotrichum acutatum}

Freddi A. Hammerschlag*1, Sandra Garces², Margery Koch-Dean ${ }^{3}$, Stephanie Ray ${ }^{4}$, Kim S. Lewers ${ }^{5}$, John L. Maas ${ }^{6}$, Barbara J. Smith

${ }^{1}$ USDA/ARS, Fruit Laboratory, Beltsville, MD 20705; ${ }^{2}$ USDA/ARS, Fruit Laboratory, Beltsville, MD 20705; ${ }^{3}$ USDA/ARS, Fruit Lab, Beltsville, MD 20705; ${ }^{4}$ USDA/ARS, Fruit Lab, Beltsville, MD 20705; ${ }^{5}$ USDA/ARS, Fruit Lab, Beltsville, MD $20705 ;{ }^{6}$ USDA/ARS, Fruit Lab, Beltsville, MD 20705; ${ }^{7}$ USDA/ARS, Small Fruit Research Station, Poplarville, MS 39470

Diseases affecting strawberries have been of major concern in recent years because of their widespread occurrence and potential for yield loss. Anthracnose caused by the fungus Colletotrichum acutatum is one of the most serious disases of strawberry worldwide. Although chemical controls are being used to treat anthracnose, generating disease resistant plants is a more attractive solution to the problem because chemicals can pose a health hazard, have a negative impact on the environment and may only be moderately effective. Tissue culture-induced (somaclonal) variation provides us with one strategy for generating disease-resistant genotypes. An in vitro screening system was used to evaluate several commercially important cultivars, Chandler, Delmarvel, Honeoye, Latestar, Pelican and Sweet Charlie, and shoots regenerated from leaf explants of these cultivars for resistance to $C$. acutatum isolate Goff (highly virulent). Somaclones with increased levels of anthracnose resistance were identified for all the cultivars. The greatest increases in disease resistance were observed for somaclones of cultivars Chandler, Pelican and Sweet Charlie that exhibited 6.8-, 12-, and 4.2-fold increases in resistance, respectively. These studies provide evidence that: 1 ) in vitro screening can be used to evaluate strawberry germplasm for anthracnose resistance, 2) somaclonal variation is influenced by stawberry genotype, and 3) generating somaclonal variants may be a feasible approach to obtaining strawberry plants with increased levels of anthracnose resistance.

\section{Factors Affecting Transient Gene Expression in Mango Tissue Using Particle Bombardment}

\section{Vaughan Agrez*1, Zora Singh², Mis Gill ${ }^{3}$}

${ }^{1}$ Curtin Univ. of Technology, Horticulture / Viticulture, Perth, Western Australia, 6845, Australia; ${ }^{2}$ Curtin Univ. of Technology, Horticulutre / Viticulture, Perth, Western Australia, 6845, Australia; ${ }^{3}$ Punjab Agricultural Univ., Horticulture, Ludhina, Punjab, 141 004, India

Particle bombardment seems to be a promising method for genetic transformation of mango and the information on various factors affecting transient gene expression is inconclusive. Pro-embryonic masses (PEMs) of mango (Mangifera indica L. cv. Kensington Pride) used for particle bombardment were established and maintained in vitro using various liquid and semisolid media containing 2,4-D. Various factors affecting the biolistic transformation efficiency in mango and subsequent transient gene expression were optimized using $\beta$-glucuronidase (GUS) as a reporter gene driven by CaMV 35 S promoter. Our results show that bombardment pressure significantly affects transient gene expression with the best results obtained from PEMs bombarded at 1200 $\mathrm{kPa}$ of helium pressure under vacuum. The application of osmoticum pre and post-bombardment also significantly increased the transient gene expression in the PEMs as compared to the controls. Mannitol $(0.2 \mathrm{M})$ proved to be the best osmoticum in improving transient GUS expression as compared to sorbitol. The duration of exposure of PEMs to mannitol $(0.2 \mathrm{M})$ both pre and post-bombardment also played a 
significant role in improving transient gene expression. The transient GUS expression was significantly highest with a pre-treatment of $0.2 \mathrm{~m}$ mannitol for 4 hours as compared to 0,8 and 12 hours. The post-bombardment treatment of $0.2 \mathrm{M}$ mannitol for 16 hours resulted in significantly highest transient gene expression as compared to 0 , 4, 8, 12, 20 and 24 hours. In conclusion, PEMs of 'Kensington Pride' mango bombarded at $1200 \mathrm{kPa}$, which were exposed to mannitol $(0.2$ M) for 4 and 16 hours pre and post bombardment respectively, resulted in the highest transient GUS expression (25.1 GUS foci/mg PEMs).

\section{Effects of Genotype, Benzylaminopurine and Sucrose Concen- tration on Microtuberization of Layered Shoots of Potato (Solanum tuberosum L.) through Meristem Culture}

Leila Farhadi*1, Cyrus Abdmishani², Shahram Ahmadian³ Majid Foolad ${ }^{4}$

${ }^{1}$ Univ. of Tehran, Agricultural Biotechnology, Karaj, Iran; ${ }^{2}$ Univ. of Tehran, Agricultural Biotechnology, Karaj, Iran; ${ }^{3}$ Univ. of Tehran, Agricultural Biotechnology, Karaj, Iran; ${ }^{4}$ The Pennsylvania State Univ., Horticulture, State College, PA 16802

The aim of this study was to assess the suitable hormonal balance on potato microtuberization from the plantlets which had been in heat therapy condition before culturing the meristem. The effects of different levels of BAP and sucrose concentration were studied 16 weeks after the last culture in two genotypes. Explants from meristem were propagated in vitro in several stages and then subcultured with MS medium containing the combination of BAP (three levels) and sucrose (three levels). Then they were transferred to a completely dark incubation room at $22{ }^{\circ} \mathrm{C}$. In vitro tuber formation was analyzed 16 weeks later. Traits which studied were: length, diameter, fresh weight and number of micro tubers. There was no significant difference among the genotypes for all the traits. The micro tuber number was significantly different among the levels of BAP concentration and the BAP and sucrose interaction was significant for the diameter. The micro tuber fresh weight and diameter were highly significant for the sucrose levels. The sucrose and genotype interaction for micro tuber length; sucrose and BAP interaction for micro tuber length and diameter were significant. Also the genotype, BAP and sucrose interaction was significant for the micro tuber fresh weight.

\section{Agrobacterium-mediated Transformation of Chokecherry (Prunus virginiana L.)}

Wenhao Dai ${ }^{* 1}$, Christopher P. Johnson², Victoria A. Jacques ${ }^{3}$, James A. Walla ${ }^{4}$

${ }^{1}$ North Dakota State Univ., Plant Sciences, Fargo, ND 58105; ${ }^{2}$ North Dakota State Univ., Plant Sciences; ${ }^{3}$ North Dakota State Univ., Plant Sciences; ${ }^{4}$ North Dakota State Univ., Plant Pathology

An Agrobacterium-mediated transformation system was developed for chokecherry (Prunus virginiana L.), one of the most popular native small tree or large shrub species for resource conservation and wildlife habitat in North America. Leaf tissues from in vitro plants previously maintained in MS medium with $2.5 \mu \mathrm{M}$ BA were co-cultivated on woody plant medium (WPM) containing $10 \mu \mathrm{M}$ BA and 200 $\mu \mathrm{M}$ acetosyringone with Agrobacterium tumefaciens strain EHA105 harboring the binary Ti plasmid pBI121 carrying the uidA gene encoding for $\beta$-glucuronidase (GUS) and the $n p t I I$ gene encoding neomycin phosphotransferase II. Infected leaf explants were disinfected in sterile water and antibiotics and then transferred to WPM containing 10 $\mu \mathrm{M}$ BA and the antibiotics cefotaxime, carbenicillin, and kanamycin (CCK) for shoot regeneration at $25^{\circ} \mathrm{C}$ with a 16-hour photoperiod. Agrobacterium concentration, pre-conditioning of explants, application of acetosyringone, infection time, and kanamycin tolerance of leaf tissues were evaluated for effects on transformation efficiency. Regeneration of chokecherry shoots on kanamycin-containing medium and screening by GUS histochemical assays showed that both the nptII and the uidA genes were successfully transferred into chokecherry. The transformation will be further confirmed by polymerase chain reaction (PCR) and Southern blot analyses.
86 Development of Agrobacterium-mediated Transformation System in Pear Cultivars with Low-regeneration Frequency

Narumi Matsuda*1, Kanji Isuzugawa ${ }^{2}, \mathrm{Mei} \mathrm{Gao}^{3}$, Tadashi Takashina $^{4}$, Koichi Nishimura ${ }^{5}$

${ }^{1}$ Yamagata Prefectural Horticultural Experiment Station, Biotechnology and Plant Breeding Division, 991-0043, Japan; ${ }^{2}$ Yamagata Prefectural Horticultural Experiment Station, Biotechnology and Plant Breeding Division, 991-0043, Japan; JST, Regional Joint Research Project of Yamagata Prefecture, Research \& Development Dept., 991-0043, Japan; ${ }^{4}$ Yamagata Prefectural Horticultural Experiment Station, Biotechnology and Plant Breeding Division, 991-0043, Japan; ${ }^{5}$ Yamagata Prefectural Horticultural Experiment Station, Biotechnology and Plant Breeding Division, 991-0043, Japan

The transformation of pears such as 'Conference', 'Doyenne du Comice' and 'Passe-Crassane' has been attributed to the high regeneration frequency from leaf discs (71\% to $97 \%$; Leblay et al. 1991). However, it has been difficult to transfer desirable genes into cultivars with lowregeneration frequency such as 'Silver bell' (35.4\%) and 'La France' $(10.7 \%)$, which are the two major pear cultivars in Japan. In this study, we developed an Agrobacterium-mediated transformation system for 'Silver bell' and 'La France'. For 'Silver bell', leaf discs derived from in vitro shoots were used as explants. The antibiotics for selection of transformants and elimination of Agrobacteria were investigated. In the most optimum condition, which is $30 \mathrm{mg} \cdot \mathrm{L}^{-1} \mathrm{Kanamycin}$ and $500 \mathrm{mg} \cdot \mathrm{L}^{-1}$ Sulbenicillin, a $3.2 \%$ transformation efficiency was obtained. However, no success was recorded in an effort to transform 'La France' using leaf disc explants because of very poor regeneration frequency. Therefore, axillary shoot meristems were used as explants for transformation of 'La France'. The conditions for antibiotic selection and elimination of Agrobacteria were also investigated. In $5 \mathrm{mg} \cdot \mathrm{L}^{-1}$ Kanamycin and $375 \mathrm{mg} \cdot \mathrm{L}^{-1}$ Carbenicillin, transformed shoots were produced at $4.8 \%$ efficiency. No chimera was observed in the transgenic shoots during a 2-year subculture period. Since the inoculated explants developed into multiple shoots during selection, it was thought that the problem of chimera might have been overcome. Therefore, this transformation method using axillary shoot meristem may be applicable to pear cultivars recalcitrant to regeneration from leaf disc. To the best of our knowledge, this is the first report of a transformation system in pear cultivars with low regeneration efficiency.

\section{Enhanced Axillary Branching and Pigment Development of Double-Node Explants of Bigtooth Maple}

Clare A. Bowen-O'Connor*1, Rolston St. Hilaire ${ }^{2}$, John Hubstenberger $^{3}$, Dawn VanLeeuwen ${ }^{4}$

${ }^{1}$ New Mexico State Univ., Agronomy and Horticulture, Las Cruces, NM 88003; ${ }^{2} \mathrm{New}$ Mexico State Univ., Agronomy and Horticulture; ${ }^{3}$ New Mexico State Univ., Agronomy and Horticulture; ${ }^{4}$ New Mexico State Univ., Agricultural and Extension Education

Bigtooth maple ( Acer grandidentatum Nutt.) is indigenous to the southwestern United States. This species is not widely used in managed landscapes but the plant holds promise as a useful ornamental tree. Micropropagation might provide additional sources of selected genotypes for the nursery industry, but tissue culture has not been used successfully to propagate this species. We cultured double-node explants from greenhouse-grown, 2-year old seedlings of bigtooth maples that originated from Utah, Texas and New Mexico. Seedling height ranged from $15-90 \mathrm{~cm}$. The shoot region was divided into three equal zones designated as terminal, intermediate and basal. Explants were selected from each of those zones. Explants were established on MurashigeSkoog (MS), Linsmaier-Skoog (LS), Woody Plant Medium (WPM) and Driver-Kuniyuki (DKW) tissue culture media. Shoot proliferation, area of the plate covered by callus and foliar pigment development (hue as determined by Royal Horticultural Society Color charts) were monitored for 17 weeks. Media affected shoot proliferation $(P=0.0042)$ but the zone of origin $(P=0.6664)$ of the explant did not. Callus area showed no significant difference among the four media and three zones $(P=0.2091)$ and averaged 3.60 centimeters $^{2}$. After four subcultures, each lasting 30 days, explants on DKW media produced 10 shoots per explant. This media might hold promise for the micropropagation of bigtooth maple. Twenty-nine percent of all explants expressed foliar pigmentation, which ranged from red-purple to orange-red. Whether foliar pigment development in tissue culture correlates with expressed pigmentation in nature warrants further investigation. 
88 Functional Characterization of S-adenosylmethionine Decarboxylase and Spermine Synthase Genes from Apple

Hiroyasu Kitashiba*1, Yu-Jin $\mathrm{Hao}^{2}$, Chikako Honda ${ }^{3}$, Masayuki

\section{$\mathrm{Kita}^{4}$, Takaya Moriguchi ${ }^{5}$}

${ }^{1}$ National Institute of Fruit Tree Science, Plant, Cell and Environment, Tsukuba, Ibaraki, 305-8605, Japan; ${ }^{2}$ National Institute of Fruit Tree Science, Plant, Cell and Environment; ${ }^{3}$ National Institute of Fruit Tree Science, Plant, Cell and Environment, Japan; ${ }^{4}$ National Institute of Fruit Tree Science, Plant, Cell and Environment, Japan; ${ }^{5}$ National Institute of Fruit Tree Science, Plant, Cell and Environment, Japan

Polyamines [putrescine(put), spermidine (spd), and spermine (spm)] are aliphatic amines that are implicated in the regulation of many basic physiological processes such as cell growth, proliferation and stress responses in organisms including plants (Walden et al. 1997). Put is metabolized to spd and spm through the successive enzymatic reactions of spd synthase (SPDS) and spm synthase (SPMS) with the use of decarboxylated S-adenosylmethionine (dcSAM) as an aminopropyl donor, which is generated by SAM decarboxylase (SAMDC). So far, two MdSAMDC (MdSAMDC1 and MdSAMDC2) homologous to SAMDC and two MdACL5 (MdACL5-1 and MdACL5-2) homologous to ACL5 encoding SPMS in Arabidopsis (Hanzawa et al. 2000) were isolated from 'Orin' apple. To investigate the function of these genes, complementation analyses were carried out using yeast mutants. Each of the MdSAMDCs consists of three ORFs; tiny- and small-ORFs in the 5' regions, and main ORF like other plant SAMDC genes. Both constructs for MdSAMDC containing all ORFs (SAMDCall) or containing only main ORF (SAMDCorf) were capable of recovering the growth of yeast SAMDC-deficient mutants (delta spe2) without supplement of spd, although the SAMDCall constructs always showed the lower growth speed than the SAMDCorf constructs. On the other hand, yeast SPMS-deficient mutant (delta spe4) introduced by MdACL5 cDNA produced significantly higher amount of spm than the delta spe 4 with control vector by HPLC. Collectively, these results suggest that both MdSAMDCs are functional as a SAMDC and the tiny- and small-ORFs are negative-regulatory factor for the translation efficiency of SAMDC, and also that MdACL5 encodes a functional SPMS like as ACL5 in Arabidopsis. The first and second authors contributed equally to this work.

\section{Phloem Loading of Sorbitol in Apple (Malus domestica Borkh.): Cloning and Sequence Analysis of Potential H+/Sorbitol Symport- ers from a Mature Leaf cDNA Library}

Edwin J. Reidel ${ }^{* 1}$, Brian G. Ayre ${ }^{2}$, E. Robert Turgeon ${ }^{3}$, Lailiang Cheng ${ }^{4}$

${ }^{1}$ Cornell Univ., Horticulture, Ithaca, NY 14853-5904; ${ }^{2}$ Univ. of North Texas, Biological Sciences, Denton, TX 76203-5220; ${ }^{3}$ Cornell Univ., Plant Biology, Ithaca, NY 14853-5904; ${ }^{4}$ Cornell Univ., Horticulture, Ithaca, NY 14853-5904

Sorbitol (D-glucitol) is the major end product of photosynthesis in apple (Malus domestica Borkh.), as well as the predominant phloemtranslocated carbohydrate. The mechanism by which sorbitol is phloem-loaded for transport to heterotrophic sink tissues is unknown. We hypothesized that a plasma membrane-bound H+/sorbitol symporter mediates apoplastic phloem-loading of sorbitol. To discover genes potentially encoding sorbitol transporters, a cDNA library was constructed from mature 'Gala' apple leaves. A homologous probe was synthesized via PCR with primers were designed against the cherry fruit sorbitol transporter, PcSot1, and using library lysate as template. From an initial plating of approximately $5 \times 10^{5}$ clones, twelve positives were identified after three rounds of hybridization screening. Following single-pass, 5 ' end sequencing, the clones were sorted into four contiguous sequences. One clone was chosen from each contig for complete sequencing. The four clones, provisionally named MdSOT1-4 (Malus domesitca Sorbitol Transporter), potentially encode full-length cDNAs for sorbitol transporters: Translated-BLAST searching (blastx) revealed that the open reading frames encode the complete Pfam sugar transporter domain, and the most significant alignments are with sequences encoding known- and putative polyol and sugar transporters.
90 Differential Expression of rolC Results in Unique Plant Phenotypes

Alan G. Smith*1, Nicole Gardner ${ }^{2}$, Tracy A. Melberg ${ }^{3}$

${ }^{1}$ Univ. of Minnesota, Horticultural Science, St. Paul, MN 55108; ${ }^{2}$ Univ. of Minnesota, Horticultural Science; ${ }^{3}$ Univ. of Minnesota, Horticultural Science

As residential lot sizes decrease, there is an increased demand for new, small-statured landscape plants to fit into the smaller lots. One promising method to create smaller plants is by introducing a dwarfing gene into a plant of interest. A dwarfing gene that has been identified is the rolC gene from Agrobacterium rhizogenes. Expression of rolC in plants has been shown to cause decreased height and internode length, increased branching, and modified leaf size in a several species. Although the effects of the rolC gene have been well characterized for many plant species, most research has concerned the native promoter or the CaMV $35 \mathrm{~S}$ promoter. Less research has been done with additional promoters or comparing the results from different promoters. In this study we examined the effects of three separate gene constructs, all containing rolC driven under either the $35 \mathrm{~S}$ promoter, the light inducible rbcs promoter, or the native rolC promoter in tobacco. Plants transformed with these constructs ranged widely for height and other phenotypic traits. Representative plants were crossed back to wild-type tobacco. Plants from this next generation, six with the $35 \mathrm{~S}$ promoter, six with the rbcs promoter and four with the native rolC promoter, were measured for traits such as height, days to flower, number of branches and internode length. RolC RNA expression levels were also measured in roots, stems, and leaves to determine correlations between rolC expression level in specific tissues and the observed phenotype. Information about these relationships can be used to provide insight into the use of rolC in ornamental plants and the potential to modify its phenotypic effects by controlling expression level.

\section{Preliminary Pathogenesis-relative Pathways Network Analysis and Relative Putative Genes Annotation In Vitis shuttleworthii Grape through EST Analysis}

Jiang Lu*1, Hong Huang ${ }^{2}$, Wayne Hunter ${ }^{3}$, Phat Dang ${ }^{4}$, Stephen Leong ${ }^{5}$ ${ }^{1}$ Florida A\&M Univ., Viticulture Center, Tallahassee, FL 32317; ${ }^{2}$ Florida A\&M Univ., Viticulture Center, Tallahassee, FL 32317; ${ }^{3}$ USDA, ARS, U.S. Horticultural Res. Lab., Fort Pierce, FL 34945; ${ }^{4}$ USDA, ARS, U.S. Horticultural Res. Lab., Fort Pierce, FL 34945; ${ }^{5}$ Florida A\&M Univ., Vticulture Center, Tallahassee, FL 32317

Vitis shuttleworthii is one of the most disease and pest resistant grape species originated and distributed in the southeast United States. It is highly resistant to Pierce's disease, anthracnose, black rot and downy mildew diseases, which are the limited factors to grow Vitis vinifera grapes in this region. A $V$. shuttleworthii cDNA library was constructed with mRNA isolated from leaves and flowers harvested during anthesis. 12,008 clean EST sequences were obtained and assembled. and generated 5776 unigenes 2106 contigs and 3670 singletons). ESTs distribution based on protein function using a modified MIPS MATDB Arabidopsis Scheme revealed that $7 \%$ of the $V$. shuttleworthii ESTs were related to disease/pest defense or stress tolerance genes. Over 300 contigs containing complete or $90 \%$ open coding region of known functional genes were obtained. The ESTs that were annotated as pathogenesisrelated proteins, enzymes in salicylic acid, jasmonic acid, and ethylene signaling, were selected for further study in order to elucidate the role and interaction of them in the signal transduction cascade that leads to grape defense gene activation upon treatment of bacterial pathogen. We report the identification of novel disease resistant genes based on preliminary pathogenesis-relative pathways network analysis.

\section{Poster Session 7-Ornamental/Landscape and Turf}

\section{July 17, 2004, 12:30-1:30 PM Rio Grande Exhibit Hall}

114 Evaluation of 48 Rose Cultivars for Low Maintenance Landscapes in Oklahoma

Louis B. Anella*1, Keith Reed ${ }^{2}$, P.I. Erickson ${ }^{3}$, Janet C. Cole ${ }^{4}$

${ }^{1}$ Oklahoma State Univ., Horticulture and Landscape Architecture, Stillwater, OK 74078; 
${ }^{2}$ Oklahoma State Univ., Horticulture and Landscape Architecture; ${ }^{3}$ Oklahoma State Univ., Horticulture and Landscape Architecture; ${ }^{4}$ Oklahoma State Univ., Horticulture and Landscape Architecture

Although roses have long been an important landscape plant, there is a growing interest in the use of low-maintenance roses that do not require heavy pruning or spraying. Poulsen Roser Pacific, Inc. of Central Point, Oregon, provided three plants of 48 cultivars for a trial in Stillwater, Oklahoma. The plants were produced in Oregon by grafting cultivars on seedling Rosa multiflora rootstock. Two-year-old plants were shipped bare-root to Stillwater, Oklahoma where they were planted in the field in early April, 2001. The plants were placed in three randomized complete blocks (rows) with $90 \mathrm{~cm}$ spacing between plants and $240 \mathrm{~cm}$ spacing between rows. The plants were drip irrigated as needed. During the 2002 growing season the roses were evaluated weekly for flower number, black spot, and overall quality. Four rose cultivars from Poulsen's Town and Country ${ }^{\circledR}$ series of landscape roses, Martha's Vineyard ${ }^{\mathrm{TM}}$ ('Poulans'), followed by Madison ${ }^{\mathrm{TM}}$ ('Poulrijk'), Kent ${ }^{\text {Ti }}$ ('Poulcov'), and Tumbling Waters ${ }^{\text {TM }}$ ('Poultumb'), had the highest average flower number. Martha's Vineyard ${ }^{\mathrm{TM}}$, Kent ${ }^{\mathrm{TM}}$, and Tumbling Waters ${ }^{\mathrm{TM}}$ also rated highest among the cultivars tested for overall plant quality and black spot resistance. Other roses in the top grouping (Waller-Duncan K-ratio $t$ test) for black spot resistance and overall quality were: Ragtime ${ }^{\mathrm{TM}}$ ('Poultieme', a climber from the Courtyard $\AA^{\circledR}$ series), Sophia Renaissance ${ }^{\circledR}$ ('Poulen002', Renaissance ${ }^{\circledR}$ series), Nashville ${ }^{\mathrm{TM}}$ ('Poulbico', Town and Country ${ }^{\circledR}$ series), Redwood ${ }^{\mathrm{TM}}$ ('Poultry', National Parks ${ }^{\circledR}$ series), Julia Renaissance ${ }^{\circledR}$ ('Poulheart', Renaissance ${ }^{\circledR}$ series), Santa Barbara ${ }^{\text {TM }}$ ('Pouloesy', Town and Country ${ }^{\circledR}$ series), and Everglades ${ }^{\text {TI }}$ ('Poulege', National Parks ${ }^{\circledR}$ series).

\section{Screening Ornamental Plants for Their Ability to Accumulate} Nitrogen and Phosphorus

Robert F. Polomski*1, Milton D. Taylor ${ }^{2}$, Stephen J. Klaine ${ }^{3}$, Ted Whitwell ${ }^{4}$

${ }^{1}$ Clemson Univ., Horticulture, Clemson, SC 29634-0375; ${ }^{2}$ Clemson Univ., Clemson Institute of Environmental Toxicology, Pendleton, SC 29670; ${ }^{3}$ Clemson Univ., Clemson Institute of Environmental Toxicolo, Pendleton, SC 29670; ${ }^{4}$ Clemson Univ., Horticulture, Clemson, SC 29634-0375

Commercial nurseries utilize large amounts of water and nutrients during the production cycle of container-grown plants. Excess water contaminated with $\mathrm{N}$ and $\mathrm{P}$ can impact the quality of surface water and groundwater. Earlier work by the authors found that constructed wetlands are highly efficient for removing $\mathrm{N}$ at water temperatures above $15^{\circ} \mathrm{C}$. However, $\mathrm{PO}_{4}$ removal was highly variable with uptake coinciding with periods of active plant growth and net export occurring during all other periods. Ornamental plants that remediate nutrients, especially phosphorus, would be very useful in designing constructed wetlands for commercial nurseries and greenhouses, rain gardens, and homeowner buffer strips. A greenhouse study was initiated in 2003 at Clemson Univ.'s Biosystems Research Complex to screen commercially available ornamental plants for their phytoremediation potential. Among others, these included the woody ornamental plants Cornus amomum, Myrica cerifera 'Emperor', and Salix integra 'Hakura Nishiki' and the semiaquatic herbaceous ornamental plants Canna 'Bengal Tiger' and 'King Humbert', Colocasia esculenta 'Illustris', Rhynchospora colorata , Iris virginica 'Full Eclipse, Pontederia cordata 'Singapore Pink', and Thalia geniculata 'Red Stem'. Plants were grown in pea gravel media kept saturated with one of five concentrations of Hoagland's Solution. Herbaceous and woody ornamental plants were harvested after 8 and 13 weeks, respectively. Water usage and biomass production were measured and nitrogen and phosphorus uptake was assessed. Experiments were replicated twice for each cultivar. Results indicate several species have the potential to be used in phytoremediation systems.

\section{Genotypic Variation in Flower Bud Development in Hydrangea macrophylla}

Warner Orozco-Obando*1, Hazel Y. Wetzstein ${ }^{2}$

${ }^{1}$ Univ. of Georgia., Dept. of Horticulture., Athens, GA., 30602; ${ }^{2}$ Univ. of Georgia., Dept. of Horticulture., Athens,, GA., 30602-7273

The general doctrine of flowering in Hydrangea is that floral induction occurs during the previous season on last year's growth and usually at the stem's terminal bud. However, Hydrangea cultivars widely differ in their relative abundance and duration of flower production. The objective of this study was to determine how developmental flowering patterns compare among different genotypes. Flowering was characterized in $18 \mathrm{H}$. macrophylla cultivars by assessing the extent of flower initiation and development in terminal and lateral buds of dormant shoots (i.e., after they have received floral inductive conditions.) Plants were managed under outdoor conditions. Dormant, 1-year-old stems were collected and characterized for caliper and length. All buds $>2 \mathrm{~mm}$ were dissected and the vegetative or floral bud stage of development was categorized for each bud microscopically. Flower development occurred in $100 \%$ of the terminal buds for all the cultivars with the exception of 'Ayesha' (33\%). In contrast, lateral buds showed a wide variation in flower development. For example: 'All Summer Beauty', 'David Ramsey', 'Kardinal', 'Masja', and 'Nightingale' showed high levels of floral induction ( $>92 \%$ of lateral buds induced.) In contrast, 'Ayesha', 'Blushing Pink', 'Freudenstein', and 'Nigra' had 10\% or fewer lateral buds with floral initials. Thus, the degree of floral induction in lateral buds varied tremendously among different cultivars. In addition, flower initiation and development were not related to the size (length and caliper) of individual buds. Thus, bud size does not appear to be a good indicator of flowering potential.

\section{DNA Analyses of the Genus Dirca L. (Leatherwoods)}

James A. Schrader ${ }^{1}$, William R. Graves*2

${ }^{1}$ Iowa State Univ., Dept. of Horticulture, Ames, IA 50011-1100; ${ }^{2}$ Iowa State Univ., Dept. of Horticulture, Ames, IA 50011-1100

Long regarded as a genus of two species, Dirca L. was expanded to include a third North American shrub discovered in 1994 as one population in the Sierra Madre Oriental of Tamaulipas in northeastern Mexico. The designation of Dirca mexicana Nesom \& Mayfield as a third species in the genus was based in part on geographical separation from Dirca palustris L. and Dirca occidentalis Gray, which occur farther north in eastern North America and in a small region of California, respectively. Morphologically, D. mexicana was regarded as more similar to D. occidentalis than to D. palustris. Our objectives were to obtain fruits of all species, germinate seeds, and compare the three species genetically through analyses of seedling DNA. Drupes of D. mexicana, D. palustris (from populations in Iowa), and D. occidentalis were collected as they abscised naturally from plants in native habitats in mid-May, late May to early June, and mid-June, respectively. Embryo extraction, gibberellin, and cold stratification were used to promote germination, and DNA was extracted from leaves of seedlings by using the fully automated Autogen Autogenprep 740 DNA extraction system. Genomic DNA templates were used to compare sequences of the internal transcribed spacers (ITS) and the $5.8 \mathrm{~S}$ coding region of the nuclear ribosomal DNA repeat and to examine polymorphisms in inter-simple sequence repeats (ISSRs). These analyses reinforce the present morphologically based classification of the three Dirca species by confirming species-level divergence at the molecular level. ITS sequences and ISSR banding patterns also enabled us to reconstruct the phylogenetic relationship among the three extant species of Dirca.

\section{Poster Session 8-Vegetable Crops Management/Seed}

\section{\& Stand Establishment}

July 17, 5:30-6:30 PM Rio Grande Exhibit Hall

\section{Early Growth Control of Plants by Seed Soaking in Growth Regulator Solutions}

Stanislav Magnitskiy*1, Claudio Pasian², Mark Bennett ${ }^{3}$

${ }^{1}$ The Ohio State Univ., Horticulture and Crop Science, Columbus, OH 43210; ${ }^{2}$ The Ohio State Univ., Horticulture and Crop Science, Columbus, OH 43210; ${ }^{3}$ The Ohio State Univ., Horticulture and Crop Science, Columbus, OH 43210

Regulation of excessive vegetative growth is of importance in both field 
and bedding plant production. The goal of the study was to evaluate the effect of preplant seed soaking in growth regulators on the growth control of floricultural (verbena, salvia, pansy, marigold, celosia) and agronomic (cucumber, dill) crops. Seeds were soaked in water solutions of growth regulators of different concentrations ranging according to the crop from 50 to $1000 \mathrm{mg} \cdot \mathrm{L}^{-1}$ for paclobutrazol, 1 to $10 \mathrm{mg} \cdot \mathrm{L}^{-1}$ for uniconazole, 10 to $200 \mathrm{mg} \cdot \mathrm{L}^{-1}$ for ancymidol, 100 to $5000 \mathrm{mg} \cdot \mathrm{L}^{-1}$ for chlormequate chloride and dried at $20^{\circ} \mathrm{C}$ for $24 \mathrm{~h}$ prior to sowing into plugs. In the first experiment, seeds of verbena, salvia, pansy, and dill soaked for 5 minutes in $50 \mathrm{mg} \cdot \mathrm{L}^{-1}$ paclobutrazol solutions produced seedlings that were up to $43,18,30$, and $22 \%$ shorter than the controls, respectively. Increased paclobutrazol concentrations and soaking time generally corresponded to a greater reduction of plant height, as well as delays and reduction in seedling emergence of all crops, except cucumber. In the second experiment, growth of marigold plugs from seeds soaked in $5 \mathrm{mg} \cdot \mathrm{L}^{-1}$ uniconazole or $60 \mathrm{mg} \cdot \mathrm{L}^{-1}$ ancymidol solutions during 45 min was associated with $23 \%$ or $6 \%$ plant height reduction, respectively. Soaking of marigold seeds in the solutions of chlormequate chloride did not significantly affect seedling growth. Increasing time of seed soaking in growth regulator solutions did not influence emergence of marigold seedlings. The height of celosia seedlings was only slightly reduced by soaking seeds in the solutions of all studied growth regulators. Results indicate that seed treatments with growth regulators might be useful in growth control of selected bedding plants.

\section{Fungicidal Seed Treatments and Formonetin Affect Arbuscular-Mycorrhizal Fungi Colonization of Muskmelon}

\section{Rhoda L. Burrows*1, Ismail Ahmed ${ }^{2}$}

${ }^{1}$ South Dakota State Univ., Horticulture, Forestry, Landscape and Parks, Brookings, SD 57007; ${ }^{2}$ South Dakota State Univ., Horticulture, Forestry, Landscape and Parks, Brookings, SD 57007

Fungicides applied as soil drenches affect arbuscular-mycorrhizal (AM) fungal colonization of plant roots to different degrees, depending on the chemical used. However, the effect of fungicides applied as seed treatments has been less studied, and is of particular interest to growers who want to encourage beneficial mutualisms while protecting seedlings against pathogens. We tested the effects of four common seed treatments, Apron (mefenoxam), Thiram, Raxil (tebuconzaole), and Captan on colonization of 'Superstar' muskmelon roots by the AM fungus Glomus intraradices in the greenhouse. By 30 days after planting, colonization was very high ( $>90 \%$ root length) for all treatments, with relatively minor $(<10 \%)$ differences in percent length root with AM hyphae. The Apron seed treatment had the highest percent root length with hyphae, but the lowest amount of vesicles, while roots from Raxil and Captantreated seeds had the lowest hyphal colonization and highest vesicle formation. Myconate ${ }^{\circledR}$, a commercial formulation of formononetin, an isoflavone previously shown to increase AM colonization, significantly increased the percent colonization of roots from the Raxil treatment, but not other treatments. Myconate also increased vesicle numbers in all but the Captan treatments, but not significantly.

\section{Out Season Onion Production Using 'Sterling' Variety in Northwestern Mexico}

Ruben Macias-Duarte ${ }^{1}$, Raul Leonel Grijalva-Contreras*2, Manuel de Jesus Valenzuela-Ruiz ${ }^{3}$, Fabian Robles-Contreras ${ }^{4}$

${ }^{1}$ INIFAP-Caborca, Soil \& Horticultural, Caborca, Sonora, 83600, Mexico; ${ }^{2}$ INIFAP-Caborca, Protected Horticulture, Caborca, Sonora, 83600, Mexico; ${ }^{3}$ INIFAP-Caborca, Viticulture, Caborca, Sonora, 83600, Mexico; ${ }^{4}$ INIFAP-Caborca, Agroclimatology, Caborca, Sonora, 83600 , Mexico

In Northwestern Mexico, the sowing, transplant and vegetative development of onion bulb coincide with the winter and the harvest with the end of the spring. During the summer, this vegetable can't be produced because there were no varieties that develop appropriately under the high temperature and constant humidity characteristic of this time of the year. For this reason, in autumn and winter. there exists a shortage of onion in the market being increased the value of the same one. The objective of the present investigation was to evaluate and to develop a methodology to produce onion bulb in autumn. This experiment was car- ried out at INIFAP-CIRNO Experimental Station on. The white variety used was 'Sterling' of long photoperiod. The plant establishment was on 27 Apr. 2002 ( 82 days after sow date) in this trial we used furrows to double row, with 1.00-m separation among them. Fertilization with nitrogen and phosphorus (180 and $80 \mathrm{~kg} \cdot \mathrm{ha}^{-1}$ respectively), during the growing season using drip irrigation system. Two application were applied against the fungous disease (Metalaxil + Clorotalonil). Our results indicate that the bulb obtained had a globe form with good quality and firmness. The harvest time was from 7 to 10 Sept., with means bulb weight of 214 grams and a yield of $36.5 \mathrm{t} \cdot \mathrm{ha}^{-1}$.

\section{Producing Double-stemmed Tomato Seedlings by Cutting Propa- gation, Pinching, and Plant Bioregulators Application}

Ki-Yun Jung*1, Bong-Hwa Kang², Yu-Jin Park³, Jung-Myung Lee ${ }^{4}$

${ }^{1}$ Kyung Hee Univ., Horticulture, Yongin, Gyeonggi-do, 449-701, Republic of Korea; ${ }^{2}$ Kyung Hee Univ., Horticulture, Yongin, Gyeonggi-do, 449-701, Republic of Korea; ${ }^{3}$ Kyung Hee Univ., Horticulture, Yongin, Gyeonggi-do, 449-701, Republic of Korea; ${ }^{4} \mathrm{Kyung}$ Hee Univ., Horticulture, Yongin, Gyeonggi-do, 449-701, Republic of Korea

Double-stemmed seedlings(DSS) will be favored by the growers because they can save the expense needed to purchase commercial seedlings. This is also true with grafted tomatoes since the price of grafted tomato seedlings is about 2 times higher than non-grafted ones. The plug seedling growers will also benefit from the increased demand for DSS if the production cost for DSS can be maintained at appropriate level. Two stem cuttings having two expanded leaves were taken from a seedling when the seedling had four expanded leaves and rooted in 32-cell trays filled with commercial soil mix. Lower stem cuttings having first and second leaves produced well-balanced DSS even without any plant bioregulator treatment whereas up upper stem cuttings having third and fourth leaves resulted in single-stem seedlings with very limited outgrowth of axillary shoot from the third node. DSS can be obtained from the decapitated seedling stump by outgrowth of axillary shoots from the cotyledonary nodes, but the quality and uniformity were inferior to other seedlings. Pinching off the tips of seedlings thus leaving three expanded leaves per seedling and application of plant bioregulators to the decapitated seedlings were also effective for producing DDS. Application of thidiazuron (TDZ) in lanolin paste to the second node was most effective even though whole plant spray with TDZ or BA was also partially effective. Subsequent growth characteristics of these seedlings will be further discussed.

\section{Moisture Contents in Bottle Gourd Seeds during Dry Heat Treatment and Subsequent Germination}

Seung-Hee Lee*1, Jin-Seok Kim², Jung-Myung Lee ${ }^{3}$

${ }^{1}$ Kyung Hee Univ., Horticulture, Yongin, Gyeonggi-do, 449-701, Korea; ${ }^{2}$ Kyung Hee Univ., Horticulture, Yongin, Gyeonggi-do, 449-701, Korea; ${ }^{3}$ Kyung Hee Univ., Horticulture, Yongin, Gyeonggi-do, 449-701, Korea

Dry heat treatment (DHT), a powerful and agrochemical-free means of inactivating seed-borne virus and other pathogens, has been extensively used for value-added vegetable seeds in Korea, Japan, and some other countries. Since seeds are treated with extremely high heat $\left(75^{\circ} \mathrm{C}\right.$ or higher) for a long time (72 $\mathrm{h}$ or longer), heat-induced phytotoxicity symptoms are frequently observed. Even though various internal and external factors, such as seed maturity and vigor, maximum temperature and duration of DHT, are known to influence the severity of phytotoxicity, precise control of seed moisture contents during DHT is regarded as one of the most important factors for successful DHT. In an ideal condition using a specifically designed DTH machine, seed moisture content of bottle gourd, initially around $6.20 \%$ to $0.64 \%$ when stored in a storage room with $50 \% \mathrm{RH}$, decreased by $1 \%$ after $24 \mathrm{~h}$ at $35^{\circ} \mathrm{C}$ $(5.20 \%$ to $0.23 \%)$, and further decreased below $4 \%$ after $24 \mathrm{~h}$ pretreatment at $50{ }^{\circ} \mathrm{C}(3.64 \%$ to $0.37 \%)$. The seed moisture content was further reduced down to about $2 \%$ after $72 \mathrm{~h} \mathrm{DHT}$ at $75^{\circ} \mathrm{C}(2.16 \%$ to $0.28 \%)$. During the post-treatment conditioning at $50{ }^{\circ} \mathrm{C}$ and $70 \% \mathrm{RH}$ for 24 $\mathrm{h}$, the moisture contents were raised to about $6 \%(5.94 \%$ to $0.45 \%)$, thus approaching the initial moisture content of $6 \%$ to $7 \%$. During the germination period, treated seeds showed slower absorption of water as compared to the intact seeds, thus suggesting that this slow absorption of initial moisture absorption may be responsible for the slow initial 
germination frequently observed in treated seeds. Final germination and seedling vigor were not affected by DHT.

\section{Effect of Shade on Quality of Greenhouse Tomato}

Martin P.N. Gent*1

${ }^{1}$ Connecticut Agricultural Experiment Station, Forestry and Horticulture, New Haven, Conn.

Shading a greenhouse increased the fraction of tomatoes that were marketable, and the marketable yield, in a comparison of greenhouse tomato yields across years, in some of which the greenhouses were shaded. In 2003, the yield and quality of greenhouse tomatoes were compared directly when grown in spring and summer in Connecticut in identical greenhouses that differed only in the degree of shade. Each half of four greenhouses was either unshaded or shaded using reflective aluminized shade cloth rated to reduced light transmission by $15 \%, 30 \%$, or $50 \%$. Each shade treatment was repeated in two houses. Tomatoes were germinated in February and transplanted in March The houses were shaded when fruit began to ripen in early June. Picking continued through August. The effect of shade on total yield developed gradually. Yields in June were unaffected by shade, but in August yield under no shade was about $30 \%$ higher than under $50 \%$ shade. In contrast, there was an immediate effect of shade on fruit size. Fruit picked in June from plants under $50 \%$ shade was $16 \%$ smaller than from plants grown under no shade. This difference declined later in the season, to 6 and $9 \%$, in July and August respectively. The highest yield of marketable fruit in 2003 was picked from houses under no shade, but this was only $10 \%$ more than picked from the houses under $50 \%$ shade. Shade increased the fraction of marketable fruit, from $54 \%$ under no shade to $63 \%$ under $50 \%$ shade. Certain defects were decreased by shade. For instance the fraction of fruit with cracked skin was decreased from $33 \%$ to $25 \%$. In general, effects on fruit quality varied linearly with the degree of applied shade.

\section{Phytochemical Profile Changes of Tomatoes in Response to Altered Light Environments}

Katherine A. Ellingson*1, Nihal C. Rajapakse ${ }^{2}$, Melissa B. Riley ${ }^{3}$

${ }^{1}$ Clemson Univ., Horticulture, Clemson, SC 29634 ; ${ }^{2}$ Clemson Univ., Horticulture; ${ }^{3}$ Entomology, Soils, and Plant Sciences

Recent medical interest in plant antioxidants in human health has stimulated the interest in functional phytochemicals of fruits and vegetables. Numerous reports link antioxidant capacity of phytochemicals to the reduction of degenerative diseases. As a result, sales of herbal antioxidant supplements have increased tremendously although negative (or no) effects have been documented with certain supplements. There are many interactive reactions among phytochemicals. At this point, our understanding of interactions among phytochemicals is limited. Therefore, medical professionals are reluctant to prescribe supplements as a mean to boost antioxidants, but they agree that consumption of fresh fruits and vegetables is essential for a healthy life and provides a better alternative than supplements to boost antioxidant uptake. Carotenoids are receiving attention because of their pro-vitamin A activity and antioxidant properties. Two of the widely investigated carotenoids for improvement are lycopene and $\beta$-carotene. Genetic composition, cultural practices, environmental conditions, and processing can all affect carotenoid profiles. Light has been shown to affect carotenoids and we are investigating if changing the spectral composition in the growing environment can alter carotenoid levels. Preliminary results show that tomatoes grown under a high red light environment have increased lycopene and overall carotenoid contents. Nutritionally enhanced produce will benefit both growers and consumers.

\section{Position of Source Leaf Affects Translocation and Distribution of $\mathrm{C}^{14}$ Photo-Assimilates in Tomato}

Sang Gyu Lee*1, Chiwon W. Lee ${ }^{2}$

${ }^{1}$ National Horticultural Research Institute, Dept. of Vegetable Culture, Suwon, 440-310, South Korea; ${ }^{2}$ North Dakota State Univ., Dept. of Plant Sciences, Fargo, ND 58105 translocation and distribution was characterized for tomato (Lycopersicon esculentum Mill.) grown in the greenhouse. Three different positions of source leaf on the stem (first node above or below the first fruit cluster and fifth node above the first fruit cluster) were tested for their influence on ${ }^{14} \mathrm{CO}_{2}$ assimilation and transfer to different parts of the plant. The leaves at the fifth node above the first fruit cluster transferred the highest $(57 \%)$ proportion of $\mathrm{C}^{14}$ to other plant parts, followed by leaves borne on the first node below the first fruit cluster (50\%), and the first node above the first fruit cluster (39\%). In all treatments, fruits served as the strongest sink for $\mathrm{C}^{14}$, followed by stem, leaf, and root tissues. The leaf borne on the fifth node above the first fruit cluster transferred the largest amount of $\mathrm{C}^{14}$ to the second fruit cluster.

\section{Genotypic Variability in Staminate Flower and Pollen Grain Production of Diploid Watermelons [Citrullus lanatus (Thunb.) Matsum. \& Nakai]}

Mike Stanghellini ${ }^{1}$, Jonathan R. Schultheis ${ }^{2}$

${ }^{1}$ Rutgers Univ., Extension Specialists, Chatsworth, NJ 08019; ${ }^{2}$ North Carolina State Univ., Horticultural Science, Raleigh, NC 27695

In 1999 and 2000, a total of 28 diploid watermelon cultigens (released cultivars and advanced breeding lines) were evaluated for staminate flower and pollen grain production to assess their potential to serve as pollenizers (pollen source plants) in triploid watermelon production systems. Male reproductive output (staminate flower and pollen production) was quantified during the peak flowering and fruit setting phase of the cultigens under field conditions. The number of staminate flowers produced per plant per day, number of pollen grains produced per flower, and total number of pollen grains produced per plant per day (staminate flowers per plant $\mathrm{x}$ pollen grains produced per flower) differed greatly between cultigens (for all tests, $P<0.01$ ). Staminate flower production by cultigens differed by year $(P<0.0003)$ and days-within-years $(P=0.0094)$, but pollen production between years by cultigens was stable $(P=0.3845)$. Total male reproductive output ranged from 134,206 pollen grains per plant per day for 'Jamboree' to 321,905 pollen grains per plant per day for 'Summer Flavor 500'. These studies demonstrate the genotypic variability in watermelon male reproductive output potential, and may assist growers in selecting an optimal diploid pollenizer for triploid watermelon production.

\section{Planting Date Influences on Yield and Fruit Size of Jack-o- lantern Pumpkins}

Elizabeth T. Maynard*1

${ }^{1}$ Purdue Univ., Horticulture and Landscape Architecture, Westville, IN 46391

In northern Indiana, jack-o-lantern pumpkins (Cucurbita pepo) can be planted from late May through June to produce mature fruit for sales associated with Halloween. Field trials were conducted to evaluate the influence of planting date on pumpkin yield and yield components. 'Gold Medal' and 'Magic Lantern' pumpkins were each seeded on three planting dates (PD) in 2002 (31 May, 10 and 20 June 10) and 2003 (5, 16 , and 25 June). Each planting date was harvested between 100 and 110 days after planting. The weight per plant of pumpkins that were completely mature (orange) was greatest for the June 10 planting in 2002 (14.9 kg vs. $12.5 \mathrm{~kg}$ for $1 \mathrm{st}$ and $12.2 \mathrm{~kg}$ for $3 \mathrm{rd} \mathrm{PD),} \mathrm{but} \mathrm{did} \mathrm{not} \mathrm{differ}$ among dates in 2003 (PD1: $10.9 \mathrm{~kg}$, PD2: $10.4 \mathrm{~kg}$, PD3: $9.0 \mathrm{~kg}$ ). The number of orange pumpkins per plant was lowest for the 20 June 2002 planting (1.63 vs. 1.88 for 1 st and 1.91 for 2 nd PD) but did not differ among dates in 2003 (PD1: 1.08, PD2: 1.20, PD3: 1.19). The average weight of an orange pumpkin was lowest for the 31 May 200 planting date ( $7.17 \mathrm{~kg}$ vs. $8.35 \mathrm{~kg}$ for $2 \mathrm{nd}$ and $7.89 \mathrm{~kg}$ for $3 \mathrm{rd}$ PD) and highest for the 5 June 2003 planting date ( $10.6 \mathrm{~kg}$ vs. $9.07 \mathrm{~kg}$ for 2 nd and 8.16 $\mathrm{kg}$ for $3 \mathrm{rd} \mathrm{PD)}$. In both years the last planting date produced the least weight per plant, and in 2002 the fewest number, of pumpkins that had begun to turn orange plus fully orange pumpkins. The two cultivars produced similar weight per plant and responded similarly to planting date, but 'Gold Medal' produced fewer and larger fruit. No planting date consistently produced the greatest yield or largest fruit. 
37 Translocation and Distribution of $\mathrm{C}^{14}$ Photosynthates in Watermelon and Tomato

Sang Gyu Lee*1, Chiwon W. Lee ${ }^{2}$

${ }^{1}$ National Horticultural Research Institute, Dept. of Vegetable Culture, Suwon, 440-310, South Korea; ${ }^{2}$ North Dakota State Univ., Dept. of Plant Sciences, Fargo, ND 58105

The pattern of translocation and distribution of $\mathrm{C}^{14}$ labeled photo-assimilates in watermelon and tomato grown in the greenhouse and field was characterized. Each of the mature leaves of the plant at active fruit development stage was exposed to ${ }^{14} \mathrm{CO}_{2}(20 \mu \mathrm{Ci}$ radio activity) for $40 \mathrm{~min}$ and the leaves, stems, fruit, and roots were harvested 3, 6, 9, or 12 hours after treatment. One half of the plants were grown under natural light and the other half in the dark during the experimental period. The activity of $\mathrm{C}^{14}$ in the dry tissues of the leaves, stems, fruits, and roots was determined, using a liquid scintillation analyzer. Both watermelon and tomato plants grown in the greenhouse and field contained $\mathrm{C}^{14}$ in all tissue types $3 \mathrm{hr}$ after treatment, regardless of exposure to light or dark during the experimental period. Watermelon and tomato, respectively, transferred $22 \%$ to $61 \%$ and $9 \%$ to $26 \% \mathrm{C}^{14}$ from the source leaf in 3 hours. Fruit tissues served as the strongest sink, with the highest percentages of $\mathrm{C}^{14}$ transfer in watermelon $(99 \%)$ and tomato (90\%) in plants grown in the field. The rate of $\mathrm{C}^{14}$ translocation was highest when plants were kept in the dark after ${ }^{14} \mathrm{CO}_{2}$ feeding. In general, total translocation of $\mathrm{C}^{14}$ compounds from the source leaf was higher in watermelon than in tomato plants. For both watermelon and tomato, most field-grown plants showed a higher rate of $\mathrm{C}^{14}$ translocation as compared to greenhouse grown plants for a given period of time.

\section{Poster Session 9-Crop Physiology \\ July 17, 2004, 5:30-6:30 PM Rio Grande Exhibit Hall}

360 Effects of Ultrasonic Wave on Water Conditions, Antioxidases, and Free Radical in Cut Nymphaea tetragona During Cold Wet Storage

Wenting $\mathrm{He}^{1}$, Weiming $\mathrm{Guo}^{2}$, Zhongchun Jiang*3

${ }^{1}$ Nanjing Agricultural Univ., Dept. of Ornamental Horticulture; ${ }^{2}$ Nanjing Agricultural Univ., Dept. of Ornamental Horticulture; ${ }^{3}$ State Univ. of New York at Cobleskill, Dept. of Plant Science

Effects of two pretreatments, i.e., ultrasonic wave (UW) and ultrasonic wave plus preservative solution (UW+PS), on water conditions of flower stem and membrane stability of petals in Nymphaea tetragona during 6-d cold wet storage. Compared with no pretreatment control, the two pretreatments prolonged the vase life and improved water conditions of the cut flower during cold storage to different degrees. Fresh weight of flower stems and relative water content of petals increased during cold storage. The water utilization efficiency of flower stem and water potential in different parts of flower stem were improved significantly as a result of the pretreatments. Although both pretreatments helped the cut flowers maintain favorable water relations, the effects of UW + PS combined pretreatment were better than UW pretreatment alone. In addition, UW and UW+PS inhibited the increase in the contents of lipid peroxidation product malondialdehyde (MDA) and superoxide anion in petals. UW + PS promoted superoxide dismutase (SOD) and catalase (CAT) activities in petals during cold storage to a greater degree than did UW.

\section{Effect of Rootstock on Shoot Preformation and Neoformation} in Pistachio cv. Kerman

Timothy M. Spann*1, Robert H. Beede ${ }^{2}$, Steven A. Weinbaum² ${ }^{3}$, Theodore M. DeJong ${ }^{4}$

${ }^{1}$ Univ. of California Davis, Pomology, Davis, CA 95616; ${ }^{2}$ Univ. of California Cooperative Extension, Farm Advisor, Kings County, Hanford, CA 93230; ${ }^{3}$ Univ. of California Davis, Pomology, Davis, CA 95616; ${ }^{4}$ Univ. of California Davis, Pomology, Davis, CA 95616

Rootstock significantly alters the pattern of shoot growth of pistachio (Pistacia vera) cv. Kerman. Trees on P. atlantica typically produce a single flush of spring growth whereas trees on $P$. integerrima selection PGI and $P$. atlantica $\times$ P. integerrima selection UCB-1 can produce multiple flushes during the season. Terminal buds of shoots on all three rootstocks were dissected during the dormant season to determine the number of preformed nodes. Data indicate that there are 8-9 nodes preformed in the dormant terminal bud of shoots from Kerman trees and that this number is independent of rootstock, canopy location, crop load, and shoot carbohydrate concentration, suggesting genetic control. This number corresponds with the number of nodes typically found on a shoot at the end of the spring growth flush. Unlike the spring flush which is preformed in the dormant bud, later flushes are neoformed, that is, nodes are initiated and extended during the same season. Neoformed growth depends on current season photosynthates and may compete with fruit growth for available resources. Neoformed growth is sensitive to water stress and trees on all three rootstocks grown under two levels of regulated deficit irrigation showed a reduction in both the number and length of neoformed shoots. Preformed shoot growth did not appear to be reduced under water stress conditions, supporting the hypothesis that preformed shoots are more dependent on environmental conditions during the season they are initiated than during the season they are extended. Additionally, preformed shoots on well irrigated trees were similar in length for all rootstocks, further supporting the idea that preformed shoots are under genetic control and are not easily manipulated.

\section{Plant Population Modulate Occurrence of Green Shoulders (GS) and Internal Greening (IG) in Carrots (Daucus carota var. sativus)}

Ravishankar Palanisamy*1, Rajasekaran Lada ${ }^{2}$, Steve Kyei-Boahen $^{3}$, Asture Stiles ${ }^{4}$, Claude Caldwell ${ }^{5}$, Sam Asiedu ${ }^{6}$

${ }^{1}$ Nova Scotia Agricultural College, Plant and Animal Sciences, Truro, Nova Scotia, B2N5E3, Canada; ${ }^{2}$ Nova Scotia Agricultural College, Dept of Plant \& Animal Sciences, Truro, Nova Scotia, B2N5E3, Canada; ${ }^{3}$ Mississippi State Univ., Delta Research and Extension Center, Stoneville, MS 38776; ${ }^{4}$ Nova Scotia Agricultural College, Plant and Animal Sciences, Truro, Nova Scotia, B2N5E3, Canada ${ }^{5}$ Nova Scotia Agricultural College, Plant and Animal Sciences, Truro, Nova Scotia, B2N5E3, Canada; ${ }^{\circ}$ Nova Scotia Agricultural College, Plant and Animal Sciences, Truro, Nova Scotia, B2N5E3, Canada

Green shoulder (GS) and Internal Greening (IG) are the physiological disorders in carrots due to chlorophyll accumulates either at the crown or internal tissues or both. GS and IG affect root quality and makes carrot roots unfit for consumption and cause a great lose to the processing industry. One of the hypothesis in our study was that plant population modulate GS and IG due to its variation in light interception. The objectives of this study were to identify the effect of plant population on the occurrence of GS and IG and establish a relationship between them. Dicer (Red core chantenay) and Slicer (Caro choice) varieties were seeded at various seeding rates. The experiment used a Randomized Block design. Each treatment was replicated four times. GS and IG were measured using a Chlorophyll meter and the output was read as Chlorophyll Index (CI). Leaf area index (LAI) was determined using a LAI-2000 Plant canopy analyzer. Carrot roots were also collected per meter for each plot. Plant population showed a significant negative correlation with GS. Correlation also existed between GS and LAI. However, plant population and LAI had poor correlation with IG in both the Dicer as well as in the Slicer varieties. It is possible that the IG may perhaps be induced prior to canopy development. Also, a poor correlation existed between IG and GS in both the Slicers and Dicers implying that one does not control other event.

\section{Effect of Colored Plastic Mulch on Soil Temperature and Yield of Eastern Muskmelon in Indiana}

\section{Christopher Gunter*1 ${ }^{\text {, Frankie Lam }}{ }^{2}$}

${ }^{1}$ Purdue Univ., Horticulture and Landscape Architecture, Vincennes, IN 47591; ${ }^{2}$ Purdue Univ., Entomology, Vincennes, IN 47591

Indiana ranks seventh in the nation for watermelon production and fifth in the nation in muskmelon production. Both of these crops are intensively managed and cultivation using plastic mulches is the industry standard in the area. The purpose of this study was to determine the effect of plastic mulches of various colors and breakdown properties 
on the yield and earliness of eastern muskmelons in southwestern Indiana in 2002 and 2003. In 2002, eight colors were used, black, clear, brown, green, olive, grey, blue, and red. In 2003, five colors were used, grey, black, blue, clear, and olive. A bare ground treatment was also included in 2003. Temperature information was also collected both above and below these plastics in attempt to relate that back to performance of the crop. In 2002, green and clear mulches produced more melon numbers and higher melon weights compared to other mulch colors, however this was not significantly different than the black control mulch. In 2003, olive mulch produced significantly higher melon number and weight than clear mulches. In 2003, early-breakdown clear mulches, designed to last only until canopy fill, produced significantly lower yields than early-breakdown black mulch. This appears to be due primarily to weed production initiated early under the clear mulch and subsequent weed growth after mulch was broken down. The effect of plastic mulch type and earliness to crop maturity is also explored.

364 Source-Sink Relationships in Cranberry: Effects on Carbo-

Justine E. Vanden Heuvel*1

${ }^{1}$ Univ. of Massachusetts - Amherst, Cranberry Experiment Station, E. Wareham, MA02538

Fruiting and vegetative greenhouse-grown cranberry uprights (Vaccinium macrocarpon Ait.) were subjected to four defoliation levels $(0 \%, 25 \%, 50 \%, 75 \%)$ on one of three dates during the growing season. Seven days following defoliation, vines were destructively harvested and carbohydrate concentration was quantified using HPLC. Prior to new growth, defoliation did not affect the concentration of total nonstructural carbohydrates (TNSC) in the uprights, or the partitioning of water-soluble (i.e., sucrose, glucose, fructose) to ethanol-insoluble (i.e., starch) carbohydrates, even though uprights with lower leaf areas had higher net $\mathrm{CO}_{2}$ assimilation rates (A). At 2 weeks post-bloom, TNSC concentration was reduced in defoliated vines, although A was not affected by defoliation. Prior to harvest, TNSC concentration was reduced in vines subjected to defoliation while A was unaffected, although the positive relationship between soluble carbohydrate concentration and leaf area per upright reached an asymptote, while the direct relationship between starch concentration and leaf area remained linear. Carbohydrate production and partitioning of an upright was unaffected by the presence of a single fruit throughout the experiment. These results suggest that carbohydrate production in cranberry uprights may be sink-limited prior to fruiting, and then becomes source-limited as the growing season progresses.

\section{Leaf Carbohydrate Concentration Affects Development of Phenolic Compounds in Grape Berries}

Justine E. Vanden Heuvel*1, Jessica L. Robidoux ${ }^{2}$, Catherine C. Neto ${ }^{3}$ ${ }^{1}$ Univ. of Massachusetts-Amherst, Cranberry Experiment Station, E. Wareham, MA 02538; ${ }^{2}$ Univ. of Massachusetts-Dartmouth, Chemistry and Biochemistry, N. Dartmouth MA 02747; ${ }^{3}$ Univ. of Massachusetts-Dartmouth, Chemistry and Biochemistry, N. Dartmouth, MA 02747

Carbon supply reduction was used to investigate the relationship between total non-structural carbohydrate (TNSC) concentration in the vegetative tissue and the production of phenolic compounds in the fruit of grapevines. Potted, greenhouse-grown DeChaunac vines were partially defoliated on one of three dates (berry set, veraison, or 7 days pre-harvest) during the growing season. Light environment of the fruit clusters was not affected by defoliation. Seven days following defoliation, half of the vines were destructively harvested for carbohydrate analysis, while the remaining vines were kept for fruit analysis at maturity. Defoliation of vines at berry set and veraison significantly reduced TNSC concentration in the leaf tissue. Partial defoliation of vines at berry set reduced total flavonols by $24 \%$, total anthocyanins by $33 \%$, and total phenolics by $13 \%$ in the fruit compared to the control vines. At veraison, partial defoliation of vines reduced total flavonols by $8 \%$, anthocyanins by $43 \%$, and did not affect total phenolics. While flavonol and total phenolic content was not affected by defoliation 7 days prior to harvest, total anthocyanins were increased by $39 \%$, although leaf TNSC concentration was not affected. Concentration of total flavonols and anthocyanins were positively correlated with TNSC in the leaves $(r=0.53$ and $r=0.73$, respectively) while total phenolic content was not correlated with TNSC. These results indicate that development of anthocyanins and flavonols in fruit is linked to carbohydrate availability from vegetative tissues during berry set and veraison.

\section{Regulatory Properties of Apple Leaf Cytosolic Fructose-1,6- bisphosphatase}

Rui Zhou*1, Lailiang Cheng ${ }^{2}$

${ }^{1}$ Cornell Univ., Hort., Ithaca, NY 14853; ${ }^{2}$ Cornell Univ., Hort., Ithaca, NY 14853

Cytosolic fructose-1,6-bisphosphatase (cytoFBPase) (EC 3.1.3.11) occupies a strategic site in sucrose synthesis and has been demonstrated to play a key role in carbon partitioning between sucrose and starch in non-sorbitol forming plants. In addition to sucrose and starch, Sorbitol is the primary photosynthetic end product in the leaves of many tree fruit species in the Rosaceae family. To understand the biochemical regulation of photosynthetic carbon partitioning between sorbitol, sucrose and starch in sorbitol synthesizing species, we purified cytoFBPase to apparent homogeneity from apple leaves. The enzyme was a homotetramer with a subunit mass of $37 \mathrm{kDa}$. It was highly specific for fructose-1,6-bisphosphate with a $\mathrm{Km}$ of $3.1 \mu \mathrm{M}$ and a Vmax of 48 units/mg protein. Either $\mathrm{Mg}^{2+}$ or $\mathrm{Mn}^{2+}$ was required for its activity with a $\mathrm{Km}$ of $0.59 \mathrm{~mm}$ and $62 \mu \mathrm{M}$, respectively. $\mathrm{Li}^{+}, \mathrm{Ca}^{2+}, \mathrm{Zn}^{2+}$, $\mathrm{Cu}^{2+}$ and $\mathrm{Hg}^{2+}$ inhibited whereas $\mathrm{Mn}^{2+}$ enhanced the $\mathrm{Mg}^{2+}$-activated enzyme activity. Fructose-6-phosphate was found to be a mixed type inhibitor with a $\mathrm{Ki}$ of $0.47 \mathrm{~mm}$. Fructose 2,6-bisphosphate (F2,6BP) competitively inhibited the enzyme activity and changed the substrate saturation curve from hyperbolic to sigmoidal. Adenosine monophosphate (AMP) was a non-competitive inhibitor for the enzyme. F2,6BP interacted with AMP to inhibit the enzyme in a synergistic way. Dihydroxyacetone phosphate did not have inhibitory effect on apple leaf cytosolic FBPase activity. Sorbitol increased the susceptibility of the enzyme to the inhibition by F1,6BP. The presence of sorbitol in the reaction mixture led to a reduction in the enzyme activity.

\section{Stone Cells in Fruit of Pears Influenced by Water Stress and Calcium}

\section{Wol-Soo Kim*1, Jin-Ho Choi ${ }^{2}$}

${ }^{1}$ Chonnam National Univ., Dept. of Horticulture, Gwangju, 500-757, South Korea; ${ }^{2}$ Chonnam National Univ., Dept. of Horticulture, Gwangju 500-757, 500-757, South Korea

To find out the formation time of stone cell, drought stress, isolated from water by plastic house, was inflicted on pear trees at 30 days before full bloom, full bloom stage, 30 days after full bloom and 60 days after full bloom during 30 days, respectively. Adhesiveness, gumminess, cohesiveness and chewiness increased suddenly in fruits contained stone cell more then $28.0 \mathrm{mg} / \mathrm{g}$ in flesh and hardness was higher in pear fruit with higher stone cells, but the changes of the springiness as contents of the stone cells showed no difference. By optical microscope, stone cell observed first from 14 days after full bloom. The adjacent cells to stone cell was first showed spherical type on initial forming stage but showed radial form at 90 days after full bloom. The shape of stone cell inspected by SEM was like a cluster and its size was various. By using TEM, components of stone cell, such as nucleus and vacuole, and secondary cell wall thickening were observed, so it could consider that the stone cell is living thing. The largest amount of stone cell clusters existed beneath fruit skin. The stone cell in flesh enlarged by drought stress compared to control, and then stone cell per areas was the largest at 30 days after full bloom. Therefore, it seems that the drought stress became a cause of inducing stone cell. The stone cell was decreased by the application of calcium chloride $0.5 \%$, on 30 days after full bloom. Also, fruit firmness was increased compared to control on harvest time. Calcium chloride application showed a possibility for the inhibition of stone cell formation 
368 Pollen Germination Potential Influences by Carbohydrates and Proteins in Pollen Grains of Asian Pear

Wol-Soo Kim*1, Sang-Hyun Lee ${ }^{2}$

${ }^{1}$ Chonnam National Univ., Dept. of Horticulture, Gwangju, 500-757, South Korea; ${ }^{2}$ Chonnam National Univ., Dept. of Horticulture, 500-757, South Korea

In order to investigate the cause of differences of mature pollen in Asian pear (Pyrus phyfolia) that are collected from various sources for the artificial pollination, various factors were measured as below: the composition of nonstructural carbohydrate in bud at 30 days after full bloom, the contents of crude protein in skin, cytosol and membrane, and the affinity for lectin (CON-A: Concanavalin, type III A) of glycoprotein in cytosol of pollen were measured. Contents of sucrose and glucose in buds influenced pollen germination rate and pollen tube growth, respectively. Therefore, soluble types of carbohydrates stored in bud were regarded as influencing on pollen germination rate and pollen tube growth. Pollen, which showed low activity, had low affinity on CON-A, lectin of glycoprotein, because it had fragile membrane, proteins in cells were denatured to pollen surface and certain enzymes concerned in pollen germination lost stability and activity. Pollens that showed high activity contained $92 \mathrm{kDa}$ protein while others not. This was assumed as influencing on control of pollen viability.

\section{Effects of Osmotic Agents on Apple Pollen Grain Germination} Vikramjit S. Bajwa*1, Curt Rom²

${ }^{1}$ Univ. of Arkansas, Horticulture, Fayetteville, AR 72701; ${ }^{2}$ Univ. of Arkansas, Horticulture, Fayetteville, AR 72701

Osmotic agents used to prevent apple pollen grain germination were studied in vitro by applying $10 \mu \mathrm{L}$ of solutions to germinating apple pollen on germinating and growth media. Seven concentrations $(0 \%$, $0.25 \%, 0.5 \%, 1 \%, 2 \%, 5 \%$ and $10 \%$ ) of the solution were prepared for each chemical and the characteristics of $\mathrm{pH}, \mathrm{EC}$, and osmotic potential were measured. Apple pollen was dispersed onto the media in petri dishes. Micro drops of solution were then applied to marked areas. Dishes were then placed in germination cabinets at $25^{\circ} \mathrm{C}$. Cumulative percentage pollen germination was calculated $4,8,12$, and $24 \mathrm{~h}$ after treatment by microscopic observation. Generally, the cumulative percentage pollen germination decreased asymptotically with increasing chemical concentration. The most effective chemicals for restricting pollen germination and growth were $\mathrm{CuSO}_{4}(0.25 \%), \mathrm{CH}_{3} \mathrm{COOH}$ $(0.25 \%), \mathrm{CaCl}_{2}(10 \%), \mathrm{K}_{2} \mathrm{~S}_{2} \mathrm{O}_{5}(0.25 \%)$, Methyl Jasmonate (2\%). The effect of these chemicals has also been tested on pistil viability both in vitro and on excised limbs.

370 Ethylene Biosynthesis and Fruit Color Development in 'Pink Lady' Apples during Growth and Maturation

Suparna Whale ${ }^{* 1}$, Zora Singh ${ }^{2}$, John Janes ${ }^{3}$

${ }^{1}$ Curtin Univ. of Technology, Horticulture/Viticulture, Muresk Institute, Perth, Western Australia, 6845, Australia; ${ }^{2}$ Curtin Univ. of Technology, Horticulture/Viticulture, Muresk Institute, Perth, Western Australia, 6845, Australia; ${ }^{3}$ Curtin Univ. of Technology, Horticulture/Viticulture, Muresk Institute, Perth, Western Australia, 6845, Australia

Growth and maturation of 'Pink Lady'(Malus domestica Borkh.) apples with special emphasis on ethylene biosynthesis and color development were monitored in Western Australia during 2002-2003. Changes in fruit growth, respiration rate, ethylene production, anthocyanin accumulation and development of red blush were evaluated between 60 days after full bloom (DAFB) and commercial harvest (191DAFB). Fruit diameter, length and fresh weight showed the typical single sigmoid growth curve, with linear increases until 158 DAFB. High respiration rate and ethylene production were recorded 60 DAFB followed by rapid decrease until 144 DAFB and then a steady increase, which peaked between 172 and 179 DAFB. Red blush on the fruit surface showed steady increase from 167 DAFB and corresponded to concomitant decrease in hue angle. Total anthocyanin increased from 167 DAFB till harvest and synchronized with increasing ethylene and maturity of apples. There were $\operatorname{significant}(P \leq 0.001)$, direct linear relationships between ethylene production and total anthocyanin $(r$ $=0.63, \mathrm{y}=7.6032 \mathrm{x}+2.4756)$, total anthocyanin and red blush $(r=$
$0.74, \mathrm{y}=0.5082 \mathrm{x}-1.54)$. Significant $(P \leq 0.001)$ negative direct linear relationships between total anthocyanin and hue angle $(r=-0.89$, y $=-0.5973 \mathrm{x}+110.14)$, and ethylene and hue angle $(r=-0.69, \mathrm{y}=$ $-5.37 x+109.60)$ were recorded. Increasing anthocyanin content and red blush also coincided with decreasing daily temperatures in the orchard. Reduction in fruit firmness and acidity and increase in TSS from 167DAFB were good indicators of advancing maturity of apples. Our experimental results indicate that red blush in 'Pink Lady' apples develops a few weeks before harvest and is regulated by ethylene biosynthesis and temperature.

\section{Examining the Vascular Transport System in Grafted Prunus avium L. on Dwarfing Rootstocks}

Mercy A. Olmstead ${ }^{1}$, N. Suzanne Lang*2, Frank W. Ewers ${ }^{3}$, Shirley A. Owens ${ }^{4}$

${ }^{1}$ Michigan State Univ., Horticulture, East Lansing, MI 48824-1325; ${ }^{2}$ Michigan State Univ., Horticulture, East Lansing, MI 48824-1325; ${ }^{3}$ Michigan State Univ., Plant Biology, East Lansing, MI 48824-1312; ${ }^{4}$ Michigan State Univ., Center for Advanced Microscopy, East Lansing, MI 48824-1311

Dwarfing rootstocks in sweet cherry (Prunus avium L.) have been planted worldwide. No single theory has emerged to answer why scion dwarfing occurs in fruit trees. This research examines the vascular pathway in a dwarfing cherry system to determine if physical limitations alter water transport as a possible dwarfing mechanism. Second-leaf 'Lapins' trees grafted onto Gisela 5 (Gi5; dwarfing) and Colt (vigorous) rootstocks were field-grown in East Lansing, Mich. During maximum shoot elongation, trees were dug, placed into containers with safranin dye solution $(0.1 \% \mathrm{w} / \mathrm{v})$ for 6 hours and then removed for division (3-5 cm in length) based on location in scion, graft union, and rootstock tissue. Tissues were sectioned using a sliding microtome $(120 \mu \mathrm{m})$ for examination with a laser confocal microscope (Zeiss LSM Pascal). Mean stem area and vessel diameter were measured; and mean hydraulic diameter was calculated for vessels in the area of dye translocation. Overall, Lapins/Gi5 stem area in the graft union was larger compared to Lapins/Colt; however dye translocation in Lapins/Gi5 was reduced compared to other tissues in the tree. Confocal microscopy indicated dye uptake through the grafted region was more uniformly distributed in Lapins/Colt than in Lapins/Gi5, with dye accumulation in areas of maximum translocation. Vessel diameter did not differ in these areas of translocation. However, in both combinations there was a reduction in mean hydraulic diameter of graft union sections, suggesting a reduction in vessel efficiency to translocate water in this region. Vascular system anomalies were more frequent in Lapins/Gi5, disrupting acropetal dye translocation. This suggests the greatest reduction in vascular transport is in Lapins/Gi5.

372 Correlation Among the Nitrogen, Chlorophyll (SPAD Value) and Photosynthetic Reactions on the Leaves of One-year-old Shoots by Training Angles in 'Fuji' Apple Trees

Hyun-Hee Han*1, Yong-Koo Kim² ${ }^{2}$ Jae-Young Lee ${ }^{3}$

${ }^{1}$ KyungHee Univ., Horticulture, Yongin, Gyeonggi-do, 449-701, Republic of Korea; ${ }^{2}$ Kyung Hee Univ., Horticulture; ${ }^{3}$ Kyung Hee Univ., Horticulture

The nitrogen contents of leaves were the same on the first measurement of 9 May 2003 and the date was immediately prior date to application of different training angles to the one-year-old shoots grown during the previous year. However, the nitrogen content began to be different according to training angles as early as 8 days after the training of one-year-old branches. The $90^{\circ}$ branch showed higher nitrogen content on the eighth date from the training application against $120^{\circ}$ or nontrained slanting branch. The $90^{\circ}$ branch continuously demonstrated larger nitrogen contents on 23 May and 2 June against non-trained branch. While, the $120^{\circ}$ branch began to show the tendency of larger nitrogen content compared with slanting branches from 23rd May which was 2 weeks from training, and this difference continued up to 2 June 2003. The chlorophyll (SPAD value) of the leaves trained to $120^{\circ}$ and $90^{\circ}$ were the same at the time of initial training was applied on $9 \mathrm{t}$ May 2003, but a significant reduction of the chlorophyll (SPAD value) was found as early as eighth date from the first training date and this 
difference was reduced to be the same on the date of 2 weeks after the initial training date, but the chlorophyll (SPAD value) became different again on 2 June 2003. Correlations between chlorophyll contents (SPAD value) and photosynthetic rates influenced by training angles were highly positive in $90^{\circ}$ training and in 120-degree training than non-training. Additionally, the correlations between the specific leaf weight and chlorophyll contents (SPAD value) were highly positive in $120^{\circ}$ training than in $90^{\circ}$ training or non-training.

\section{Poster Session 10-Waste Utilization and Management}

\section{July 17, 2004, 5:30-6:30 PM Rio Grande Exhibit Hall}

\section{Two New Moisture Sensors for Soilless Growing Media}

Krishna Nemali*1, Marc van Iersel ${ }^{2}$

${ }^{1}$ Univ. of Georgia, Horticulture, Athens, GA 30602; ${ }^{2}$ Univ. of Georgia, Horticulture, Athens, GA 30602

Monitoring moisture status of the growing medium is essential as growth and quality of greenhouse crops largely depend on the amount of available water. Recently, two new types of moisture sensors have been developed ( $\mathrm{ECH}_{2} \mathrm{O}$, Decagon devices, Inc., Pullman, Wash.; Theta probe ML2X, Delta -T devices Ltd., Burwell, Cambridge, U.K.). We studied the performance of these sensors for measuring the volumetric water content (VWC) of a soilless growing medium. We also tested the sensitivity of these sensors to temperature and electrical conductivity (EC) of the growing medium. Our results indicate that these sensors can be calibrated and used effectively for measuring a wide range of moisture contents in the growing medium; however media specific calibration may be required. Regression analysis indicated that the output of $\mathrm{ECH}_{2} \mathrm{O}$ probes was affected by changes in the $\mathrm{EC}$ and temperature of the growing medium. Effects of EC were too small to be of practical significance, while the measured VWC increased by $0.003 \mathrm{~m}^{3} / \mathrm{m}^{3}$ for each ${ }^{\circ} \mathrm{C}$ increase in temperature. The output from the Theta Probe was not affected by changes in the EC or temperature of the growing medium. In a comparison study, both probes were found to give similar estimates of the VWC of the growing medium within the common range seen under greenhouse production.

\section{Increased Water Use Efficiency with a Surfactant}

John Sloan*1, Wayne Mackay²

${ }^{1}$ Texas A\&M Univ. - Dallas, Soil \& Crop Sciences, Dallas, TX 75252; ${ }^{2}$ Texas A\&M Univ. Dallas, Horticultural Sciences, Dallas, TX 75252

Soils exhibit a degree of hydrophobicity and can repel water rather than absorb it. Surfactants lower the surface tension of water which may increase its infiltration into the soil and adsorption to soil solids. The objective of this study was to determine if water treated with a surfactant would increase conserve soil moisture and decrease the amount of water needed to sustain healthy plant growth. Clay and sandy loam soils were placed in $15-\mathrm{cm}$ greenhouse pots. Impatiens seedlings were transplanted into each pot. All pots were fertilized equally and the Impatiens flowers were allowed to grow for 8 weeks. Then the pots were treated with tap water or tap water mixed with a commercial surfactant at one times $(1 \times)$ or two times $(2 x)$ the recommended rate. After applying the water treatments, pots received no additional water. Each pot was weighed twice per day and the plants were observed for signs of wilting. Upon initial signs of wilting, each plant was rated on a scale of 1 to 3 with $1=$ no wilting, 2 = leaves starting to droop, and 3 $=$ wilting leaves and stems. Addition of the surfactant at the $1 \times$ and $2 \times$ rates slowed the loss of water from both the sandy loam and the clay soils. The effects of the surfactant were apparent within 3 to 5 days in the sandy loam soil and 6 to 10 days in the clay soil. The benefits of reduced water loss from soil were manifested by reduced wilting in Impatiens plants in soils treated with $1 \times$ and $2 \times$ the recommended rate of surfactant. In the clay soil, use of the surfactant increased the amount of time before Impatiens plants began to wilt. It appears that adding a surfactant to irrigation water can conserve soil moisture and extend the time between water applications.

\section{Irrigation Cutback a Reliable Tool for Soluble Solids Improve- ment in Processing Tomato}

T.K. Hartz ${ }^{* 1}$, P.R. Johnstone ${ }^{2}$, M. LeStrange ${ }^{3}$, J.J. Nunez ${ }^{4}$, E.M. Miyao 5

${ }^{1}$ Univ. of California, Dept. of Vegetable Crops, Davis, CA 95616; ${ }^{2}$ Univ. of California, Dept. of Vegetable Crops; ${ }^{3}$ Univ. of California, Cooperative Extension; ${ }^{4}$ Univ. of California, Cooperative Extension; ${ }^{5}$ Univ. of California, Cooperative Extension

Soluble solids concentration (SSC) is a major quality factor for tomatoes (Lycopersicon esculentum Mill.) grown for processing. The effects of early irrigation cutback were investigated in a series of drip-irrigated field trials in California from 2000-03. Irrigation cutback was initiated from 4-7 weeks preharvest, with irrigation volume reduced to $30 \%$ to $70 \%$ of reference evapotranspiration. Early irrigation cutback was compared to full irrigation until cutoff $2-3$ weeks preharvest. SSC was monitored from the initiation of deficit irrigation until harvest, with breaker-stage fruit sampled at approximately 10-day intervals; additionally, early-maturing fruits were tagged on the plant at breaker stage and retrieved at harvest for SSC analysis. Fruit yield, overall SSC, and brix yield $\left(\mathrm{Mg} \cdot \mathrm{ha}^{-1}\right.$ fruit solids ) were evaluated at commercial maturity. Fruit SSC increased in response to soil moisture stress, with late-maturing fruit as much as $2.0^{\circ}$ Brix higher than fruit maturing before significant moisture stress. However, once a fruit reached the breaker stage of maturity, its SSC did not increase regardless of subsequent soil moisture stress. Across field trials, yield decline resulting from early irrigation cutback was matched by a corresponding increase in overall SSC, resulting in equivalent brix yield in all test fields. We conclude that the early irrigation cutback provides a flexible tool for SSC management and that ${ }^{\circ}$ Brix monitoring of breaker-stage fruit can augment soil moisture monitoring to tune irrigation management to field-specific conditions.

\section{Irrigation Timing Effects on Cabbage (Brassica oleracea, L. Capitata Group) Head Traits and Sugar Concentrations}

\section{T.J.K. Radovich*1, M.D. Kleinhenz ${ }^{2}$, J.G. Streeter ${ }^{3}$, M.A. Bennett ${ }^{4}$}

${ }^{1}$ The Ohio State Univ., Horticulture and Crop Science; ${ }^{2}$ The Ohio State Univ., Horticulture and Crop Science, Wooster, OH 44691; ${ }^{3}$ The Ohio State Univ., OARDC, Horticulture and Crop Science; ${ }^{4}$ The Ohio State Univ., Horticulture and Crop Science

Cabbage (cv. Bravo) was grown in 2002 and 2003 at The Ohio State Univ., Ohio Agricultural Research and development Center in Wooster, Ohio. The four irrigation treatments, arranged in a RCB design, were: 1) irrigation throughout development [no stress (NS)], 2) irrigation only during head development [frame stress (FS)], 3) irrigation only during frame development [head stress (HS)], and 4) no irrigation [frame and head stress (FHS)]. Irrigation timing relative to crop stage significantly affected all head characteristics except density, with the greatest differences between cabbage receiving irrigation during head development (NS, FS) and cabbage not irrigated during head development (FHS, HS). On average, heads from NS and FS plots were heavier $(38 \%)$, larger $(15 \%)$, less pointed and had less volume occupied by the core than heads from HS and FHS plots. Combined head fructose and glucose concentrations were significantly greater in cabbage receiving irrigation during head development than in cabbage not irrigated during head development ( $47 \%$ vs. $41 \%$ dwt, respectively). Sucrose concentrations were significantly greater in cabbage not irrigated during head development than cabbage receiving irrigation during head development ( $8 \%$ vs. $6 \%$ dwt, respectively). The higher ratio of sucrose : fructose+glucose observed in HS and FHS relative to NS and FS treatments was interpreted as an osmo-regulatory response with potential implications for cabbage flavor. Overall, it was concluded that physiological responses elicited in cabbage by differential irrigation can affect important head traits, and that targeted applications of water during specific stages of crop development may be utilized to maximize water use efficiency and crop quality. 
74 Nitrogen and Phosphorus Discharge during Spring Regeneration of Constructed Wetlands at a Commercial Nursery

Milton D. Taylor*1, Stephen J. Klaine ${ }^{2}$, Ted Whitwell ${ }^{3}$

${ }^{1}$ Clemson Univ., Environmental Toxicology, Pendleton, SC 29670; ${ }^{2}$ Clemson Univ., Environmental Toxicology, Pendleton, SC 29670; ${ }^{3} \mathrm{Clemson}$ Univ., Dept. of Horticulture, Clemson, SC 29634-0375

Mitigation of offsite movement of nutrients in nursery runoff is a serious concern for commercial nurseries with container-grown plants. Wight Nurseries, Cairo, Ga. has operated 3.77 ha of planted constructed wetlands since 1996 to remediate nutrients from runoff. The wetlands receive drainage from a 48.6 ha nursery production area. Monitoring by nursery staff had suggested net export of nitrogen and phosphorus may occur during spring regeneration. Intensive monitoring was conducted between early March and mid-May 2003. There was no net export of nitrogen during the study. Nitrite nitrogen removal remained at $100 \%$ in the $1^{\text {st }}$ stage wetland throughout March but declined in April to 89.6\% as loading increased 5-fold. However, the $2^{\text {nd }}$ stage wetland removed $100 \%$ of the remaining nitrite. Nitrate removal in the $1^{\text {st }}$ stage wetland was high through early April $(97.6 \%)$ but low in $2^{\text {nd }}$ stage wetlands (16\%) until loading increased 10 -fold when efficiency rose to $94.9 \%$. Nitrate removal by the $1^{\text {st }}$ stage declined during mid-April but $2^{\text {nd }}$ stage efficiency remained above $95 \%$. For phosphorus, there was net export during March from both stages. However, during April, the wetlands removed phosphorus although loading tripled during the month. In May, net export of phosphorus from the wetlands recommenced with peak $1^{\text {st }}$ stage export of $130 \%$ and $2^{\text {nd }}$ stage uptake declining until midMay when export began again. Neither water temperature nor rainfall appeared correlated with wetland efficiency. While phosphorus was exported by the wetlands during parts of the study, neither nitrate nor nitrite was exported as spring progressed and decomposition of last year's growth accelerated.

75 Growth and Flower Quality of Single-node Cutting Rose 'Versillia' Under Irrigation Control by Integrated Solar Radiation in Aeroponics

Joo Hyun Lee*1, Yong-Beom Lee², Kang Pal Kwon³

${ }^{1}$ The Univ. of Seoul, Environmental Horticulture, Seoul, Korea; ${ }^{2}$ The Univ. of Seoul, Environmental Horticulture, Seoul, Korea; ${ }^{3}$ The Univ. of Seoul, Environmental Horticulture, Seoul, Korea

This study was conducted to determine the growth and flower quality of single-node cutting rose 'Versillia' under two different irrigation control methods (time clock and integrated solar radiation). The frequency of irrigation was controlled by time clock and integrated solar radiation of 1.25 and 2.09 and $3.35 \mathrm{MJ} \cdot \mathrm{m}^{-2}$ in aeroponics. Photosynthesis was the highest in the integrated solar radiation of $2.09 \mathrm{MJ} \cdot \mathrm{m}^{-2}$ and 1.25 $\mathrm{MJ} \cdot \mathrm{m}^{-2}$ the lowest in the integrated solar radiation of $3.35 \mathrm{MJ} \cdot \mathrm{m}^{-2}$. The growth of single-node cutting rose 'Versillia' at $1.25 \mathrm{MJ} \cdot \mathrm{m}^{-2}$ and 2.09 $\mathrm{MJ} \cdot \mathrm{m}^{-2}$ was better than $3.35 \mathrm{MJ} \cdot \mathrm{m}^{-2}$ for stem length and fresh weight. Root activities of single-node cutting rose were significantly higher at $2.09 \mathrm{MJ} \cdot \mathrm{m}^{-2}$ and $1.25 \mathrm{MJ} \cdot \mathrm{m}^{-2}$ than those at $3.35 \mathrm{MJ} \cdot \mathrm{m}^{-2}$. The irrigation control method using integrated solar radiation of $1.25-2.09 \mathrm{MJ} \cdot \mathrm{m}^{-2}$ showed a improvement of plant growth and flower quality.

\section{Water Use and Stomatal Behavior of Sweetgum (Liquidambar styraciflua) Relative to Reference Evapotranspiration in Three Contrasting Regions}

Roger Kjelgren*1, Thayne Montague ${ }^{2}$, Richard Beeson ${ }^{3}$

${ }^{1}$ Utah State Univ., Plants and Soils; ${ }^{2}$ Texas Tech, Plants and Soils; ${ }^{3}$ Univ. of Florida, IFAS

We investigated water use and a water needs index multiplier relative to reference evapotranspiration for a sweetgum cultivar (Liquidambar styraciflua 'Moraine') in Logan, Utah, Lubbock, Texas, and Orlando Fla. Three individual trees with $\approx 80$-mm trunk diameter, were potted in to large containers with organic media at each location. Sweetgum water use (Tsw) was measured over the season at each location with load cells and dataloggers, concurrent with measurement of reference evapotranspiration (ETo) from adjacent weather stations. Dawn-to-dusk stomatal conductance (Gs) was measured several times during the season at all locations. Trees were watered daily. At the end of the season, total tree leaf area was collected and used to normalize volumetric water use data to depth units. Tsw was highest in Florida, up to $4 \mathrm{~mm} /$ day, as was maximum daily Gs. Tsw only reached $2.5 \mathrm{~mm} /$ day in Texas and Utah due in part to stomatal sensitivity to high vapor pressure deficits that moderated transpiration. There was no relationship between Tsw and ETo at ETo levels above $4 \mathrm{~mm} /$ day in Texas and Utah, resulting in substantial scatter in the water needs index multiplier relative to ETo that centered on 0.3 in Texas and 0.4 in Utah. Tsw in Florida showed an upper boundary relationship with ETo, under which it varied considerably, resulting in a values relative to ETo centered on 0.6. During a partial dry down in Utah, morning Gs was unaffected while afternoon Gs declined progressively under mild water stress, resulting multiplier values of $0.15-2$. The study shows that regional climate affects tree water use independent of effects measured in ETo, increasing the uncertainty of sweetgum water use estimated as a function of ETo.

\section{Establishment of Seeded Bermudagrass Using Subsurface Drip Irrigation}

Michael Maurer*1, Justin Weeaks ${ }^{2}$

${ }^{1}$ Texas Tech Univ., Plant \& Soil Science Dept., Lubbock, TX 79409; ${ }^{2}$ Louisiana State Univ., Dept. of Horticulture, Baton Rouge, LA 70803

Throughout much of the Southwestern United States, poor quality water and limited water resources require innovative methods to conserve water. No research to date has indicated whether seeded bermudagrass Cynodon dactylon can be established by using subsurface drip irrigation (SDI). In 2001 (Expt. I) and 2002 (Expt. II), seeded bermudagrass was evaluated for establishment using SDI. Treatments consisted of emitters and tubing spaced at 30,46 , and $61 \mathrm{~cm}$. The control treatment consisted of pop-up sprinklers. Salinity accumulation is a concern when irrigating turfgrass in areas of poor water quality and low annual rainfall. Salinity accumulation was visible at the soil surface during establishment in 2001, but turfgrass showed no visible signs of stress due to salinity. In 2002, substantial rainfall reduced salinity accumulation during establishment as salinity was not present on the soil surface. Salinity accumulation was greater in most months at the 0-15 cm depth in both years compared to the $15-30 \mathrm{~cm}$ depth. Full turfgrass coverage ( $\geq 90 \%)$ for the control plots in 2001 was about 8.5 weeks and the SDI treatments had complete coverage in 10 weeks. Turfgrass coverage for all treatments in 2002 was 9 weeks. Expt. II had a slightly faster establishment rate due to greater rainfall and different soil characteristics than that of Expt. I. Root count and depth of roots for both years showed roots to $61 \mathrm{~cm}$ depth in all treatments. A general trend of higher salinity accumulation at the midpoint between tubing was seen in Expts. I and II. However, after significant rainfall salinity levels returned to concentrations comparable to initial soil salinity concentrations in both years. This research documents the ability to successfully establish seeded bermudagrass using SDI.

\section{Poster Session 11-Marketing and Economics}

July 17, 2004, 5:30-6:30 PM Rio Grande Exhibit Hall

193 Investigating Professional Chefs' Demand for Edamame (Glycine max)

Dru Bernthal*1, Kathleen Kelley², Elsa Sánchez ${ }^{3}$

${ }^{1}$ The Pennsylvania State Univ., Dept. of Horticulture, Univ. Park, PA 16802; ${ }^{2}$ The Pennsylvania State Univ., Dept. of Horticulture, Univ. Park, PA 16802; ${ }^{3}$ The Pennsylvania State Univ., Dept. of Horticulture, Univ. Park, PA 16802

A consumer-research study was conducted in Fall 2003 to determine professional chefs' preferences for edamame or vegetable soybean (Glycine max) cultivars, their estimated demand for edamame and their interest in acquiring edamame from local Pennsylvania growers. Twenty chefs in the Metro-Philadelphia area were provided with shelled (beans removed from the pod) and unshelled edamame of three cultivars, 'Early Hakucho,' 'Green Legend', and 'Kenko,' and asked to create a recipe using edamame as an ingredient. Chefs were 
also asked to rate the edamame cultivars based on overall appeal and firmness and complete a follow-up survey on their preferences for the edamame provided, prior use and interest in locally grown edamame. Chefs preferred shelled 'Green Legend' edamame, but many indicated that all cultivars were acceptable. The majority of chefs also noted that they were "very likely" to use edamame as an ingredient in a recipe again and $70 \%$ noted that they were interested in obtaining contact information for small-acreage growers in Pennsylvania who produce edamame. Results indicate that there is likely a demand for edamame amongst chefs in the Metro-Philadelphia area. Results from this study will be used to develop a marketing strategy for small-acreage growers.

\section{Poinsettia Consumer Survey Reveals Preferred Cultivars}

Christopher Catanzaro*1, Haval Kamake ${ }^{2}$, Sarabjit Bhatti ${ }^{3}$

${ }^{1}$ Tennessee State Univ., Institute of Agricultural and Environmental Research, Nashville, TN 37209-1561; ${ }^{2}$ Tennessee State Univ., Institute of Agricultural and Environmenta Research, Nashville, TN 37209-1561; ${ }^{3}$ Tennessee State Univ., Institute of Agricultural and Environmental Research, Nashville, TN 37209-1561

A poinsettia (Euphorbia pulcherrima Willd. ex Klotzsch) open house was held at the TSU main campus farm in Dec. 2003, during which a high quality finished plant of each of 21 cultivars was on display (supplied by Dummen USA and Ecke in August as rooted cuttings). The cultivars varied in inflorescence color and pattern, plant size and plant growth habit. Members of the campus community, the Tennessee Flower Growers Association, extension personnel, and the general public attended. Most attendees completed a written survey $(n=173)$, in which they rated how strongly they liked or disliked each cultivar. Cultivars were rated on a Likert-type scale $(1=$ strongly dislike, $7=$ strongly like). Highly rated cultivars (mean $>6)$ included 'Premium Red', 'Infinity Red', 'Spotlight Dark Red', 'Coco 2000 Red', 'Merlot', 'Prestige', 'Freedom', and 'Premium Hot Pink'. Less preferred (mean <4.4) were 'Premium Marble', 'Mirage', and 'Limelight'. Although no cultivars were strongly disliked, the large, traditional red cultivars were preferred. Attendees also provided information on demographics and plant purchases. The typical attendee was a 40- to 59-year-old female with a college education and 2 to 3 people in the household with a total income of $\$ 25,000-50,000$. Eighty percent bought poinsettias in 2002, with an average of 3.7 plants purchased. Eighty percent of plants purchased were red, and color was the most important selection feature. Results suggest that although most consumers prefer traditional red cultivars, a niche market exists for plants with novel inflorescence colors and unique bract and leaf coloration patterns and shapes.

\section{Economic Assessment of Marketing U.S. Sweetpotatoes in the United Kingdom}

David Picha*1, Roger Hinson ${ }^{2}$

${ }^{1}$ Louisiana State Univ., Horticulture, Baton Rouge, LA 70803; ${ }^{2}$ Louisiana State Univ., Agricultural Economics and Agribusiness, Baton Rouge, LA 70803

Opportunities for marketing United States (U.S.) sweetpotatoes in the United Kingdom (U.K.) are expanding, particularly within the retail sector. The U.K. import volume has steadily increased in recent years. Trade statistics indicate the U.K. imported nearly 12 thousand metric tons of sweetpotatoes in 2002, with the U.S. providing slightly over half of the total import volume. Considerable competition exists among suppliers and countries of origin in their attempts to penetrate the U.K. market. Currently, over a dozen countries supply sweetpotatoes to the U.K., and additional countries are planning on sending product in the near future. An economic assessment of production and transport costs was made among the principal supplying nations to estimate their comparative market advantages. Price histories for sweetpotatoes in various U.K. market destinations were compiled to determine seasonality patterns. Comparisons of net profit (or loss) between U.S. and U.K. market destinations were made to determine appropriate marketing strategies for U.S. sweetpotato growers/shippers. Results indicated the U.K. to be a profitable and increasingly important potential market for U.S. sweetpotatoes.

\section{Poster Session 12-Vegetable Breeding \\ July 17, 2004, 5:30-6:30 PM \\ Rio Grande Exhibit Hall}

\section{Genetically Modified Herbicide-tolerant Chile Pepper Does Not Differ From Non-GM Chile Pepper (Capsicum annuum L. cv. 'Subicho') For Horticultural Characteristics.}

Myeong Cheoul Cho*1, Taek-Ryoun Kwon*2, Tae-Hun Ryu*3, Young Chae*4, Seung-Ryong Cheong*5, Il-Gin Mok*6

${ }^{1}$ National Horticultural Research Institute, Horticultural Biotechnology Division; ${ }^{2}$ National Horticultural Research Institute, Genetic Response Lab.; ${ }^{3}$ National Institute of Agricultural Biotechnology, GMO Risk Assessment Lab.; ${ }^{4}$ National Horticultural Research Institute, Horticultural Biotechnology Division; ${ }^{5}$ National Institute of Agricultural Biotechnology, Horticultural Biotechnology Division; ${ }^{6}$ National Institute of Agricultural Biotechnology, Horticultural Biotechnology Division, Korea

Genetically modified herbicide-tolerant (GMHT) and non-GM chile pepper plants (Capsicum annuum L. cv. 'Subicho') were grown in an isolated GMO field to evaluate horticultural characteristics. Phosphinotricin acetyltransferase (bar gene), which has a function of herbicide-resistance in plant, was introduced into chile pepper plants using the protocol of Agrobacterium-mediated transformation. Thirty nine characteristics were evaluated, consisting of 14 qualitative, 18 quantitative and 7 other characters. The evaluations were achieved by visual assessment for qualitative characteristics and numerical measurement for quantitative ones. The GMHT and non-GM plants did not differ in the 39 characteristics tested. Pollen viability and germination rate were not significant different between the GMHT plants and the non-GM plants. These results indicated that genetic transformation of bar gene into the chile pepper did not affect those horticultural characteristics and pollen viability.

\section{Host Plant Resistance in Valmaine Cos Lettuce to the Banded Cucumber Beetle}

\section{Russell Nagata*1, Gregg Nuessly ${ }^{2}$, Heather McAuslane ${ }^{3}$}

${ }^{1}$ Univ. of Florida, Everglades Research and Education Center, Belle Glade, FL 33430; ${ }^{2}$ Univ. of Florida, Everglades Research and Education Center, Belle Glade, FL 33430; ${ }^{3}$ Univ. of Florida, Dept. of Emtomology and Nematology, Gainesville, FL 32611

Host plant resistance is a key element in a viable integrated pest management plan. Resistance to plant feeding was observed on Valmaine cos lettuce, Lactuca sativa L. to the banded cucumber beetle (BCB), Diabotica balteata (LeConte). In no-choice feeding evaluations, adult BCB contained on three week old Valmaine plants gained less weight, died and fed less than individuals contained on susceptible Tall Guzmaine cos lettuce. Individual female BCB held on Valmaine plants also did not have egg development as in those individual held on Tall Guzmaine. Based on weight gain and feeding damage $\mathrm{F}_{1}, \mathrm{~F}_{2}$, and $\mathrm{F}_{3}$ segregation data indicates that the resistance factor is recessive in inheritance and controlled by more that one gene.

\section{TAM Mild Habanero: A Low-pungency Habanero Variety for South Texas}

Kevin Crosby*1, Daniel Leskovar², Kil Sun $\mathrm{Yoo}^{3}$

${ }^{1}$ Texas A\&M Univ., Horticultural Sciences, Weslaco, TX 78596; ${ }^{2}$ Texas A\&M Univ., Horticultural Sciences, Uvalde, TX 78801; ${ }^{3}$ Texas A\&M Univ., Horticultural Sciences, College Station, TX 77845

The Habanero pepper, a distinct cultigen of Capsicum chinense, has become increasingly popular in American markets due to its unique flavor and aroma. It is extremely pungent compared to other commonly cultivated hot peppers. This attribute restricts its culinary uses. The objective of the Habanero pepper improvement project was to breed for important flavor compounds in the absence of genes involved in capsaicin synthesis. Intensive selection in large breeding populations was carried out to identify individual plants producing fruit with good aroma and flavor and low capsaicin concentrations. An initial cross was made between a non-pungent selection of $C$. chinense out of PI 543188 and a highly pungent, typical Habanero pepper from Yucatan. A series 
of sib-selections following a single backcross of a non-pungent $\mathrm{F}_{2}$ individual to the Habanero line were carried out in field and greenhouse plantings at Weslaco. Six subsequent generations of inbreeding resulted in a highly uniform, novel variety- TAM Mild Habanero (TMH). The fruit of TMH is very similar in size and shape to the recurrent parent. Color is yellow-orange as opposed to the deep orange of the Yucatan Habanero (YH), but aroma and flavor are extremely similar. In contrast, total capsaicin concentration of TMH fruit at Weslaco averaged $154 \mu \mathrm{g} \cdot \mathrm{g}^{-1}$, compared to $12,704 \mu \mathrm{g} \cdot \mathrm{g}^{-1}$ for the YH. Field trials conducted in south Texas showed that TMH consistently matured about 10 days earlier, had significantly higher levels of beta-carotene $\left(7.6 \mu \mathrm{g} \cdot \mathrm{g}^{-1}\right.$ compared to $<0.5 \mu \mathrm{g} \cdot \mathrm{g}^{-1}$ in $\mathrm{YH}$ ) and out-yielded $\mathrm{YH}$ by $25 \%$. These traits make $\mathrm{TMH}$ an ideal cultivar for Fall production in south Texas.

\section{Antioxidant Capacity of Selected Spinach Genotypes}

\section{Teddy Morelock*1, Luke Howard², J. Brad Murphy ${ }^{3}$}

${ }^{1}$ Univ. of Arkansas, Horticulture, Fayetteville, AR 72701; ${ }^{2}$ Univ. of Arkansas, Food Science, Fayetteville, AR 72701; ${ }^{3}$ Univ. of Arkansas, Horticulture, Fayetteville, AR 72701

Spinach (Spinacia oleracea L.) is a highly nutritious leafy green vegetable that contains high levels of vitamins A, C, E and folate as well as minerals such as iron and calcium. Spinach is high in carotenoids, specifically lutein and $\beta$-carotene. Spinach has also been shown to have high ORAC (oxygen radical absorbency capacity) values and to have a high total flavonoids content $\left(100 \mathrm{mg} \cdot \mathrm{kg}^{-1}\right)$. Leaves were collected from 11 commercial cultivars and 15 advanced breeding lines which were grown at the Univ. of Arkansas vegetable substation near Kibler, Arkansas. Samples were placed in polyethylene bags in ice chests and transported to the Univ. of Arkansas within 2 hours and samples were stored at $-20^{\circ} \mathrm{C}$ until analysis were performed. Both growing season and genotype had an effect on both ORAC and total phenolics. Over-winter spinach, which is planted in the fall and harvested in the spring, had higher total phenolics as well as higher ORAC than fall-planted fallharvested spinach. Univ. of Arkansas breeding lines had higher average levels of total phenolics and ORAC than commercial cultivars. These data indicate that it should be possible to breed for higher antioxidant capacity in spinach. In a separate study involving the same cultivars wide variation in lutein content was observed with the cultivars F380 and Fallgreen having the highest levels. Data indicate wide variation in lutein and that breeding for increased lutein content is possible.

\section{Root-knot Nematode Resistance in Capsicum chinense: Develop- ment of Resistant Habanero-type Cultivars}

Richard L. Fery*1, Judy A. Thies ${ }^{2}$

${ }^{1}$ U.S. Dept. of Agriculture-Agricultural Research Service, U.S. Vegetable Laboratory, Charleston, SC 29414-5334; ${ }^{2}$ U.S. Dept. of Agriculture-Agricultural Research Service, U.S. Vegetable Laboratory, Charleston, SC 29414-5334

Root-knot nematodes (Meloidogyne spp.) are major pests of pepper (Capsicum spp.) in the United States, and parasitism of susceptible plants can result in severe yield losses. Although cultivars belonging to the species $C$. annuum account for most of the peppers grown in the United States. Habanero-type cultivars belonging to the species $C$. chinense are becoming increasingly popular. Unfortunately, all commercial Habanero-type cultivars are susceptible to root-knot nematodes. In 1997, the USDA released three $C$. chinense germplasm lines that exhibit high levels of resistance to root-knot nematodes. The resistance in these lines is conditioned by a single dominant gene, and this gene conditions resistance to the southern root-knot nematode ( $M$. incognita), the peanut root-knot nematode $(M$. arenaria race 1$)$, and the tropical root-knot nematode (M. javanica). A recurrent backcross breeding procedure has been used to transfer the $C$. chinense root-knot nematode resistance gene in Habanero-type germplasm. Several root-knot nematode resistant, Habanero-type candidate cultivars have been developed. Each of these Habanero-type candidate cultivars has a compact plant habit and produces a high yield of orange-colored, lantern-shaped fruit.

\section{Resistance to Leafminers in Lettuce}

Beiquan Mou*1, Yong-Biao Liu ${ }^{2}$
${ }^{1}$ USDA, ARS, Salinas, CA 93905; ${ }^{2}$ USDA, ARS, Salinas, CA 93905

Leafminer (Liriomyza spp.) is a major insect pest of many important agricultural crops including lettuce (Lactuca sativa L.). The goals of this study were to evaluate lettuce genotypes for resistance to leafminers and to estimate the heritabilities of leafminer-resistant traits in the field, to examine the association among different resistant traits, and to study the mechanism of leafminer resistance in lettuce. Seventyeight lettuce accessions and $232 \mathrm{~F}_{2}$ plants of crosses were evaluated for leafminer stings and the production of pupae and flies in the field in 2001 and 2002, and resistant genotypes were subjected to no-choice test. Wild species (Lactuca serriola L., L. saligna L., and L. virosa L.) had significantly fewer stings than cultivated lettuces. Among cultivated lettuces, sting densities were lowest on leaf lettuce and highest on romaine types. The sting results from the field were highly correlated with the results from insect cages $(r=0.770$ and 0.756 for 2001 and 2002 tests, respectively), suggesting that a cage test can be used to screen for resistance in the field. Broad-sense heritability estimates for stings per unit leaf area in the field were $81.6 \%$ and $67.4 \%$ for 2001 and 2002 tests, respectively. The number of pupae produced per plant or per leaf was moderately correlated with sting density but was not correlated with leaf weight. Results suggest that both antixenosis and antibiosis exist in lettuce germplasm and resistant genotypes from choice tests remain resistant under no-choice conditions. These findings suggest that genetic improvement of cultivated lettuce for leafminer resistance is feasible.

\section{Hybridizing Collard and Cabbage to Make Collard Cultivars}

Mark Farnham*1, Glen Ruttencutter ${ }^{2}$, Powell Smith ${ }^{3}$, Anthony Keinath $^{4}$

${ }^{1}$ USDA-ARS, U.S. Vegetable Laboratory, Charleston, SC 29414; ${ }^{2}$ Sunseeds, Lodi, Calif.; ${ }^{3}$ Clemson Univ., Edisto Research and Education Center, Blackville, S,C.; ${ }^{4}$ Clemson Univ., Coastal Research and Education Center, Charleston, S.C.

Collard (Brassica oleracea L., Acephala Group) is a uniquely American cole crop adapted to the southeastern United States, and several lines of evidence indicate its closest relative is heading cabbage (B. olera$c e a$, Capitata Group). These two cole crops have been grown in close proximity in the Southeast from colonial times. Today, the number of commercially available collard cultivars is limited, and the most popular ones are susceptible to diseases like fusarium yellows, something that numerous cultivars of cabbage are highly resistant to. We postulated that hybrids between cabbage and collard would look more like collard because heading of cabbage is recessive to the nonheading nature of collard, and that such hybrids might be directly used as collard cultivars that express disease resistance from cabbage. Cytoplasmic male-sterile (cms) cabbage inbreds were crossed with different male-fertile collard inbreds using bees in cages to produce hybrid seed. Resulting cabbagecollard hybrids were compared to conventional collard and cabbage cultivars in three replicated field trials in South Carolina. In all trials, collard-cabbage hybrids exhibited similar size and stature as conventional collard, and throughout most of the growing season the hybrids remained nonheading. In addition, the collard-cabbage hybrids were much more uniform than open-pollinated collard cultivars. Among the cabbage-collard hybrids there was significant variation with some more collard-like than others. Results indicate that select collard-cabbage hybrids could out perform certain conventional collards and serve as potential new collard cultivars

\section{Poster Session 13-Floriculture 1}

\section{July 17, 2004, 12:30-1:30 PM Rio Grande Exhibit Hall}

\section{Response of Zonal and Ivy Geraniums to Root Medium pH}

Pauline H. Kaufmann*1, P. Allen Hammer ${ }^{2}$

${ }^{1}$ Purdue Univ., Dept. of Horticulture and Landscape Architecture, West Lafayette, IN 47909-2010; ${ }^{2}$ Purdue Univ., Dept. of Horticulture and Landscape Architecture, West Lafayette, IN 47909-2010 
In 2002 the USDA reported potted geraniums accounted for \$150 million in wholesale value, more than any other bedding or garden plant surveyed. Despite the importance of the geranium in floriculture production, little published research data is available pertaining to the media $\mathrm{pH}$ requirements of zonal and ivy geraniums. Current recommendations suggest zonal geraniums be grown at $\mathrm{pH}$ 5.7-6.6 and ivy geraniums at $\mathrm{pH}$ 5.0-6.2. The wide range in root medium $\mathrm{pH}$ recommendations for both zonal and ivy geraniums and the lack of research data prompted this research. Also, the basis for recommending a lower medium $\mathrm{pH}$ for ivy geraniums could not be found in published literature. The research objectives were to investigate the effect of medium $\mathrm{pH}$ on plant growth and to determine more precise recommendations for both species. The growth of 3 cultivars each of zonal and ivy geraniums growing in 8 medium $\mathrm{pH}$ treatments were evaluated. Limestone and hydrated lime were incorporated at increasing rates into a 1:1:1 peat, perlite and bark mix to achieve a medium $\mathrm{pH}$ ranging from $\mathrm{pH}$ 4.0-7.5. Plants were harvested at weeks 3,6 , and 11 and plant dry weight and media $\mathrm{pH}$ were determined. Leaf luminance, chroma and hue were evaluated at week 10. Plant dry weight was greatest at $\mathrm{pH} 6.55$ or higher for both zonal and ivy geraniums at week 11. Leaves of plants grown at pH 6.55 or higher had significantly lower luminance and chroma and greater hue in all cultivars, corresponding to leaves that were darker, less vivid, and deeper green in color. This study shows a root medium $\mathrm{pH}$ greater than $\mathrm{pH} 6.5$ results in greatest plant dry weight accumulation and quality of leaf color for both zonal and ivy geraniums. This study also shows ivy geraniums can be grown at the same media $\mathrm{pH}$ as zonal geraniums.

\section{Effects of ZeoPro ${ }^{\mathrm{TM}}$ Incorporation in the Growing Medium on the Growth of Pansy}

Harold N. Fonda*1

${ }^{1}$ Premier Horticulture, Grower Services Dept., Ferndale, WA 98248

Many strategies have been utilized by commercial growers to reduce leaching of nutrients from the growing medium during bedding plant production. Incorporation of controlled release fertilizers into the growing medium reduces the reliance on water-soluble fertilizers but nutrient release is usually temperature-dependent. One material that shows potential for this application is ZeoPro which combines a nutient-loaded zeolite with a synthetic apatite to supply the necessary nutrients for plant growth. Pansy (Viola xwittrockiana 'Majestic Giant Yellow') seedlings were transplanted into 6-packs using a peat-perlite growing medium containing dolomitic lime but without a starter fertilizer charge. Two types of ZeoPro that differ in their nutrient-loading rates, regular ZeoPro $(\mathrm{Hr})$ and ZeoPro Plus $(\mathrm{H}+)$, were added to the growing medium at rates of $0,2.5,5,10$, and $20 \%$ by volume. One half of the plants in each treatment received clear water only while the other half were irrigated with a 20-10-20 fertilizer solution at the rate of $100 \mathrm{mg} . \mathrm{L}^{-1} \mathrm{~N}$. Shoot dry weights were higher at all ZeoPro rates in $\mathrm{H}+$ media compared to their respective $\mathrm{Hr}$ media for both fertilized and unfertilized treatments. The highest shoot dry weights were measured for fertilized plants in media with $\mathrm{H}+$ at 5,10 , and $20 \%$. Tissue analysis showed that leaf $\% \mathrm{~N}, \mathrm{P}$, and $\mathrm{K}$ increased with the rate of $\mathrm{Hr}$ and $\mathrm{H}+$ for unfertilized treatments. However, for fertilized treatments, while leaf $\% \mathrm{~N}$ increased, $\% \mathrm{~K}$ decreased with increasing rate of $\mathrm{H}+$.

\section{Productivity of Two Limonium Species Irrigated with Saline} Wastewaters

Catherine M. Grieve ${ }^{1}$, Christy T. Carter*2, James A. Poss ${ }^{3}$

${ }^{1}$ George E. Brown, Jr., (USDA) Salinity Laboratory, Plant unit, Riverside, CA $92507 ;{ }^{2}$ George E. Brown, Jr., (USDA) Salinity Laboratory, Plant unit, Riverside, CA 92507; ${ }^{3}$ George E. Brown, Jr., (USDA) Salinity Laboratory, Plant unit, Riverside, CA 92507

Saline wastewaters may provide a valuable water source for the irrigation of selected floriculture crops as demand for quality water increases. A completely randomized design with 3 replications was used to test the effects of salinity on productivity and mineral accumulation on each of two Limonium species grown in greenhouse sand tanks. Threeweek-old seedlings $(\mathrm{n}=15)$ of Limonium perezii 'Blue Seas' and $L$. sinuatum 'American Beauty' were exposed to 7 salinity treatments
(2.5 (control), 7, 11, 15, 20, 25, and $30 \mathrm{dS} \cdot \mathrm{m}^{-1}$ ) prepared to simulate saline drainage waters of the San Joaquin Valley (SJV) in California. After 10 weeks, vegetative material from five plants from each tank was harvested to assess mineral composition (total-S, total-P, $\mathrm{Ca}^{2+}$, $\mathrm{Mg}^{2+}, \mathrm{Na}^{+}, \mathrm{K}^{+}$, and $\mathrm{Cl}^{-}$), for each variety. Ion selectivity coefficients were calculated by dividing the ratio of specific ions in the plant by those found in the medium. Stem length and weight, and flower stem numbers were determined at harvest. Salt tolerance thresholds based on stem length for L. perezii and L. sinuatum were 2.5 and $7.0 \mathrm{dS} \cdot \mathrm{m}^{-1}$, respectively. Maximum growth of both species declined as salinity increased, but both species were able to complete their life cycles at 30 $\mathrm{dS} \mathrm{m}{ }^{-1}$. L. sinuatum had higher leaf concentrations of $\mathrm{Na}^{+}, \mathrm{K}^{+}, \mathrm{Mg}^{2+}$, $\mathrm{Cl}^{-}$, and total-P than L. perezii. $\mathrm{K}^{+}$was preferentially accumulated with regard to $\mathrm{Na}^{+}$by both species, but was significantly higher in $L$. sinuatum. Limonium perezii and L. sinuatum can be rated as sensitive and moderately salt tolerant plants, respectively.

\section{Mycorrhiza-induced Changes in Partitioning and Composition} Alters Flower and Vegetative Production of Floral Geophytes

\section{Carolyn Scagel*1}

${ }^{1}$ Horticultural Crops Research Laboratory, USDA-ARS, Corvallis, OR 97330

Resource partitioning and plant storage components are important factors that influence the productivity and profitability of geophyte species produced as floral crops. We determined that inoculation with arbuscular mycorrhizal fungi (AMF) can alter different plant characteristics affecting productivity and quality of bulb and cut flower production of several floral geophytes including Brodiaea laxa, Zephyranthes sp., Sparaxis tricolor, Freesia $\times$ hybrida, Zantedeschia sp., and Canna sp. Plant growth, flower production, bulb/corm/tuber (bulb) production and composition were measured for two growth cycles after inoculation with Glomus intraradices. In general, shoots and flowers on plants inoculated with AMF emerged earlier than shoots and flowers on non-inoculated plants for species that produced most of their leaf area prior to flower emergence. However for species that produced leaves throughout the growth cycle or large flowers early in the growth cycle, AMF inoculation delayed shoot emergence and flower emergence. Many species that exhibited an earlier flower emergence or produced more flowers in response to AMF inoculation also produced smaller daughter bulbs and more offsets than non-inoculated plants. Across all species, the concentrations and contents of several storage components ( $\mathrm{Zn}$, $\mathrm{S}$, and $\mathrm{N}$, amino acids, and carbohydrates) that influence bulb quality were increased by AMF inoculation. Changes in partitioning between bulb and flower production resulting from AMF inoculation altered important aspects of commercial geophyte production for flowers or bulbs. AMF-induced increases in mineral uptake and resource storage are also related to aspects of quality important in the production of vegetative propagates.

325 Effect of Tank Mixing Pesticides in Controlling Western Flower Thrips, Frankliniella occidentalis (Pergande) (Thysanoptera: Thripidae)

\section{Daniel Warnock*1, Raymond Cloyd ${ }^{2}$}

${ }^{1}$ Univ. of Illinois, Natural Resources and Environmental Sciences, Urbana, IL 61801; ${ }^{2}$ Univ. of Illinois, Natural Resources and Environmental Sciences

Greenhouse managers tank mix pesticides to broaden the spectrum of pest control, and reduce pesticide and labor costs. However, the effect of tank mixing an assortment of pesticides on efficacy to control pests has not been documented. This study assessed how tank mixing commercially available insecticides and miticides in two-, three-, and four-way combinations impacts the control of western flower thrips (WFT), Frankliniella occidentalis in greenhouse experiments and a laboratory bioassay. The pesticides screened were spinosad, abamectin, bifenazate, azadirachtin, and imidacloprid. Each pesticide was applied at the label-recommended rate. In the greenhouse experiments, transvaal daisy (Gerbera jamesonii) and lisianthus (Eustoma grandiflorum) flowers were inoculated with 25 adult WFT, and then flowers were sprayed with the designated treatments. After 72 hours, flowers were emasculated to assess the numbers of live and dead WFT. In the 
laboratory bioassay, chrysanthemum (Dendranthema grandiflora) leaf disks, treated with each pesticide and all tank mixes, were exposed to 15 adult WFT. The numbers of live and dead WFT were assessed after 48 hours. For all three experiments, no antagonistic tank mixes were identified. All treatments with spinosad, including the individual application and tank mixes, resulted in high mortality of WFT based on the numbers of live and dead WFT recovered. Our data suggest that tank mixes of spinosad with the other pesticides tested do not affect the efficacy of spinosad in controlling WFT. This information is important to greenhouse managers who want to tank mix pesticides and still control WFT in addition to the other plant-feeding arthropods found in greenhouses.

\section{Growth and Fertilizer Consumption of Single-node Cutting Rose 'Versillia' by Mineral Nutrient Control in a Closed Hydro- ponic System}

Eun Young Yang ${ }^{* 1}$, Keum Soon Park ${ }^{2}$, Dong Soo Lee ${ }^{3}$, Yong-Beom Lee ${ }^{4}$ ${ }^{1}$ The Univ. of Seoul, Environmental Horticulture, Seoul, Korea; ${ }^{2}$ The Univ. of Seoul, Environmental Horticulture, Seoul, Korea; ${ }^{3}$ The Univ. of Seoul, Environmental Horticulture, Seoul, Korea; ${ }^{4}$ The Univ. of Seoul, Environmental Horticulture, Seoul, Korea

This study was conducted to understand the effect of different nutrient control method on the growth, cut-flower quality, root activity and fertilizer consumption. Single-node cutting rose 'Versillia' was grown in aeroponics and DFT system and was irrigated with the nutrient solution of the Univ. of Seoul $\left(\mathrm{NO}_{3}-\mathrm{N} 8.8, \mathrm{NH}_{4}-\mathrm{N}\right.$ 0.67, P 2.0, K 4.8, $\left.\mathrm{Ca} 4.0, \mathrm{Mg} 2.0 \mathrm{me} \cdot \mathrm{L}^{-1}\right)$. Recirculated nutrient solution was managed by five different control method: macro- and micro-element control in aeroponic system (M\&M); macroelement control in aeroponic system (M); nutrient solution supplement in aeroponic system (S); electrical conductivity (EC) control in aeroponic system (EC-A); EC control in deep flow technique system (EC-D). The mineral nutrient control method had significantly effected on the cut-flower quality. In the M\&M and $\mathrm{M}$, flower length, fresh weight and root activity were higher than those with other mineral nutrients control method. Although EC-A and EC-D could save total amount of fertilizer compared to M\&M and M, the growth and quality of the rose with EC control system were lower than those with mineral nutrient control system. Therefore, these result suggest that EC control system is not economic method in a closed hydroponic system.

327 Absorption of Nutrient Elements on Single-node Cutting Rose 'Versillia' as Affected by Mineral Nutrient Control in a Closed Hydroponic System

Eun Young Yang ${ }^{* 1}$, Hye Jin Lee ${ }^{2}$, Yong-Beom Lee ${ }^{3}$

${ }^{1}$ The Univ. of Seoul, Environmental Horticulture, Seoul, Korea; ${ }^{2}$ The Univ. of Seoul, Environmental Horticulture, Seoul, Korea; ${ }^{3}$ The Univ. of Seoul, Environmental Horticulture, Seoul, Korea

The application of a closed hydroponic system for rose poses some horticultural problems. The nutrient uptake by the plants changes constantly depending upon environmental conditions and growing stages, which results in the imbalanced composition of the drained solution and aggravates root environmental conditions. This research was aimed to observe the effect of mineral nutrient control method on the nutrient solution management in a closed hydroponic system. Single-node cutting rose 'Versillia' was grown in aeroponics and DFT system and was irrigated with the nutrient solution of the Univ. of Seoul $\left(\mathrm{NO}_{3}-\mathrm{N} 8.8, \mathrm{NH}_{4}-\mathrm{N}\right.$ 0.67, P 2.0, K 4.8, Ca 4.0, and $\mathrm{Mg} 2.0$ $\left.\mathrm{me} \cdot \mathrm{L}^{-1}\right)$. Recirculated nutrient solution was managed by five different control method: macro- and micro-element control in aeroponic system (M\&M); macroelement control in aeroponic system (M); nutrient solution supplement in aeroponic system (S); electrical conductivity (EC) control in aeroponic system (EC-A); EC control in deep flow technique system (EC-D). In the EC control method, the concentration of $\mathrm{NO}_{3}-\mathrm{N}$ exceeds optimal range whereas $\mathrm{P}$ and $\mathrm{Mg}$ decreased at the later stage of plant growth. The overall mineral nutrient content increased with S. On the other hand, the nutrient content of root environment was maintained optimally with M\&M and $\mathrm{M}$.
328 Photosynthetic Characteristics of Single-node Cutting Rose 'Versillia' by Mineral Nutrient Control in a Closed Hydroponic System

Eun Young Yang*1, Jung-Sim $\mathrm{Oh}^{2}$, Yong-Beom Lee ${ }^{3}$

${ }^{1}$ The Univ. of Seoul, Environmental Horticulture, Seoul, Korea; ${ }^{2}$ The Univ. of Seoul, Environmental Horticulture, Seoul, Korea; ${ }^{3}$ The Univ. of Seoul, Environmental Horticulture, Seoul, Korea

This experiment was carried out to observe the effect of mineral nutrient control in photosynthetic capacity of single-node cutting rose grown in a closed hydroponic system. Single-node cutting rose 'Versillia' was grown in aeroponics and DFT system and was irrigated with the nutrient solution of the Univ. of Seoul $\left(\mathrm{NO}_{3}-\mathrm{N} 8.8, \mathrm{NH}_{4}-\mathrm{N}\right.$ 0.67, P 2.0, K 4.8, $\left.\mathrm{Ca} 4.0, \mathrm{Mg} 2.0 \mathrm{me} \cdot \mathrm{L}^{-1}\right)$. Recirculated nutrient solution was managed by five different control method: macro- and micro-element control in aeroponic system (M\&M); macro-element control in aeroponic system (M); nutrient solution supplement in aeroponic system (S); electrical conductivity (EC) control in aeroponic system (EC-A); EC control in deep flow technique system (EC-D). The photosynthetic rate, stomatal conductance and transpiration rate at 35 days after transplant with $M \& M$ and $\mathrm{M}$ were higher compared to those with S, EC-A and EC-D. The maximal efficiency of photochemistry (Fv/Fm) was higher for M\&M, $\mathrm{M}$ and $\mathrm{S}$ than that with EC-A and EC-D. Therefore, it is possible to increase photosynthetic capacity of rose with mineral nutrient control in recirculated nutrient solution.

329 The Assessment of Ozone Treatment for Control of Fungal Diseases of Floriculture Crops in Greenhouses and Cold Storages

Lisa J. Skog*1, Theo Blom², Wayne Brown ${ }^{3}$, Dennis Murr ${ }^{4}$, George Chu ${ }^{5}$

${ }^{1}$ Univ. of Guelph, Plant Agriculture, Guelph, ON N1G2W1, Canada; ${ }^{2}$ Univ. of Guelph, Plant Agriculture; ${ }^{3}$ Ontario Ministry of Agriculture and Food, Floriculture, Vineland Station, ON LOR 2E0; ${ }^{4}$ Univ. of Guelph, Plant Agriculture; ${ }^{5}$ Univ. of Guelph, Plant Agriculture

Ozone treatment has many advantages for control of fungal diseases. There are no residue concerns, no registration is required, and it is non-specific, therefore potentially effective against a broad spectrum of pathogens. However, ozone is known to cause plant damage. There is little information available on either the ozone tolerance of floriculture crops or the levels required to kill plant pathogens under commercial conditions. Nine floriculture crops (begonia, petunia, Impatiens, Kalanchoe, pot roses, pot chrysanthemums, lilies, snapdragons and Alstroemeria) were subjected to increasing levels of ozone. Trials were conducted at 5 and $20{ }^{\circ} \mathrm{C}(90 \%$ to $95 \% \mathrm{RH})$ and ozone exposure was for 4 days for either 10 hours per day (simulating night treatment) or for 10 minutes every hour. Damage was assessed immediately after treatment and after an additional 3 days at room temperature in ozonefree air. Trials were terminated for the crop when an unacceptable level of damage was observed. Trials to determine the lethal dose for actively growing pathogens (Alternaria alternata, Alternaria zinniae and Botrytis cinerea) and fungal spores were conducted under identical conditions. Ozone tolerance varied with plant type and ranged between $<0.2$ and $3 \mathrm{ppm}$. Generally, the crops surveyed were more susceptible to ozone damage at the low temperature. As a group, the bedding plants were the least tolerant. Fungal spores were killed at treatment levels between 0.8 and 2 ppm ozone. The actively growing fungal mycelium was still viable at $3 \mathrm{ppm}$ ozone when the trial had to be terminated due to ozone-induced structural damage in the treatment chambers. Under the trial conditions, only the Kalanchoe would be able to tolerate the high levels of ozone required to kill the fungal spores.

330 Fertility Affects Susceptibility of Chrysanthemum to Western Flower Thrips: Influence on Plant Growth, Photosynthesis, and Ethylene Evolution

Fred Davies*1, Chuanjiu He ${ }^{2}$, Amanda Chau ${ }^{3}$, Kevin Heinz $^{4}$, Jay Spiers ${ }^{5}$ ${ }^{1}$ Texas A\&M Univ., Horticultural Sciences, College Station; ${ }^{2}$ Texas A\&M Univ., Horticultural Sciences, College Station; ${ }^{3}$ Texas A\&M Univ., Entomology, College Station; ${ }^{4}$ Texas A\&M Univ., Entomology, College Station; ${ }^{5}$ Texas A\&M Univ., Horticultural Sciences, College Station

This research details the influence of fertility on plant growth, photosynthesis and ethylene evolution of chrysanthemum (Dendranthema 
grandiflora Tzvelev var. Charm) inoculated with western flower thrips (Frankliniella occidentalis (Pergande). We tested the hypothesis that moderate levels of nitrogen would better control western flower thrips on chrysanthemum. While thrips are known to reduce plant quality, there have been few comprehensive studies on plant response to thrips population dynamics - analyzing changes in plant growth and development, plant gas exchange and ethylene evolution. Plants were exposed to four fertility levels that consisted of $0 \%, 10 \%, 20 \%$ and $100 \%$ (375 $\mathrm{ppm} \mathrm{N}$ ) of recommended nitrogen levels. Thrips abundance was greatest at high fertility. Thrips depressed plant vegetative and reproductive growth and altered carbohydrate partitioning. Thrips-inoculated (TI) plants also had reduced leaf area and lower leaf mass than thrips-free (NonTI) plants, but did not differ in specific leaf area [(SLA) leaf area $\left(\mathrm{cm}^{2}\right) /$ leaf DM $\left.(\mathrm{g})\right]$. However, high fertility plants had greater biomass and higher SLA, i.e., thinner leaves than low fertility treatments. Thrips reduced photosynthesis $(P n)$ and stomatal conductance $\left(\mathrm{g}_{\mathrm{s}}\right)$ in young, mature and older basal leaves, with $g_{s}$ showing greater sensitivity than $P n$. Ethylene and chlorophyll levels in thrips damaged leaves did not differ from Non-TI plants.

\section{Nutrient Uptake of Single-node Cutting Rose 'Red Velvet' and 'Vital' by Nutritional Control in a Plant Factory}

Kyung-Hwan Yeo*1, Jung-Min Son ${ }^{2}$, Yong-Beom Lee ${ }^{3}$

${ }^{1}$ The Univ. of Seoul, Environmental Horticulture, Seoul, Korea; ${ }^{2}$ The Univ. of Seoul, Environmental Horticulture; ${ }^{3}$ The Univ. of Seoul, Environmental Horticulture

The plant factory to control growing system automatically is necessary to cultivate single-node cutting rose, which produce large numbers of uniform shoots per unit area in short cultivation. However, the recirculation of the nutrient solution in closed system leads to several problems. One of them is connected with the quality of nutrient solution and the supply of minerals. The uptake of specific nutrients depends on growth and development, or plant stage, which results in a shift in ionic ratio in the drainage water compared to the nutrient solution supplied. Consequently, the nutrient supply should be controlled to be equal to the demand of the plant to avoid disorder of nutrient solution, such as depletion or accumulation. Therefore this study was conducted to examine the effect of mineral nutritional control on nutrient uptake of single-node cutting rose 'Red velvet' and 'Vital' in a plant factory. The nutritional control of nutrient solution was conducted by five methods: the control of electrical conductivity (EC), N, P, and K elements (NPK), macro elements (M), macro and micro elements (MM) to target ranges in root zone, and the supplement of nutrient solution (S). In NPK, M, and MM control system, the input of nutrients was calculated as amounts of absorption by the plants compared to target values in root environment. The fertilizer supplement of $\mathrm{N}, \mathrm{P}$, and $\mathrm{K}$ was lower in EC control system than other control systems. In EC and S control system, the concentration of $\mathrm{NO}_{3}^{-}-\mathrm{N}$ and $\mathrm{K}$ in root zone exceed optimal range whereas $\mathrm{P}, \mathrm{Ca}$, and $\mathrm{Mg}$ decreased at the later stage of growth. The concentrations of each nutrient in root environment were kept at the target ranges in M and MM control system, which showed optimum yield and product quality.

332 Automatic Irrigation of Container Plants in Outdoor Sales Area Kyle P. Lewis*1, Jack W. Buxton ${ }^{2}$

${ }^{1}$ Univ. of Kentucky, Dept. of Horticulture, Lexington, KY 40546; ${ }^{2}$ Univ. of Kentucky, Dept. of Horticulture, Lexington, KY 40546

Maintaining adequate water for container plants in outdoor sales areas is difficult during the late spring and summer. In mass marketing areas employees are uninformed about the water requirements of plants under various environmental conditions. Plants often are severely stressed and over all quality reduced. A system was developed to automatically irrigate container plants in an outdoor sales area. The system is a modification of the Controlled Water Table (CWT) irrigation system developed at the Univ. of Kentucky (U.K.). The sales area consisted of 2 shelves each $2.44 \mathrm{~m}$ long and $0.28 \mathrm{~m}$ wide. A trough was constructed from a $5-\mathrm{cm}$ diameter pipe with a $1 / 4 \mathrm{slot}$; it was attached to the back side of the shelf. One side of a capillary mat, placed on the shelves, was suspended in the trough containing water. Two systems were used to maintain the level of water in the trough. One was a small float valve installed in a $10-\mathrm{cm}$ PVC pipe which was attached to the $5-\mathrm{cm}$ PVC pipe. The float was adjusted to maintain the water in the trough $2 \mathrm{~cm}$ below the top of the shelf. The water reservoir consisted of a 20 -cm diameter PVC pipe, $1.22 \mathrm{~m}$ long that held $70 \mathrm{~L}$ of water. A second system maintained a constant water level in the trough using Torricellian tube principle. The water reservoir was the same as above except it was tightly sealed so no air could leak from the system. The water table was maintained $2 \mathrm{~cm}$ below the bench surface by rotating a hole in small cap. A variety of plants in containers, ranging from 10 $\mathrm{cm}$ to $5 \mathrm{~L}$ pots were maintained without water stress, in a greenhouse environment as well in an outdoor environment for several weeks.

\section{Evaluation of Growth Parameters of Anthurium andreanum Plants Grown in Mixes with Municipal Solid Waste Compost}

\section{Maria Del Carmen Libran*1, Dania Rivera², Lizzette Gonzalez ${ }^{3}$}

${ }^{1}$ Univ. of PuertoRico, Horticulture, Mayaguez, PR 00681; ${ }^{2}$ Univ. of Puerto Rico, Horticulture, Mayaguez, PR 00681; ${ }^{3}$ Univ. of Puerto Rico, Horticulture, Mayaguez, PR 00681

In Puerto Rico, the ornamental crop production is one of the most important agricultural enterprises. The growing media most used to grow ornamentals contains peat moss which is very expensive and everyday results less available. There is a need to conduct studies to evaluate alternate organic components. In Puerto Rico, the Municipal solid waste compost (MSW) has been considered as a possible component for a growing mix to grow plants. Results from chemical properties studies of the MSW compost shows that it is a source of nutrients for plants. A raw MSW is a contaminat to the environment, but once is composted does not represent a hazard to humans or environment. The objective of this research was to evaluate the growth responses of Anthurium plants grown in mixes containing different proportions of MSW with a commercial type of mix containing peat moss. Plant of Rosa cultivar Anthura Co. were grown under six treatments containing proportions of MSW : Peatlite mix (0:100,15:85,25:75,50:50,75:25, and 100:0). Data of growth parameters such as number of leaves, leaf area index, clorophyll content, number of flowers, adn fresh and dry weight was gathered and analyzed. Results did show not significant differences in all treatments on number of leaves and leaves area. Clorophyll content was similar on treatment $0: 100,15: 85$ and 25:75 of MSW : Peatlite mix. Fresh and dry weight $(\mathrm{g})$ were lower in all treatments except on 0:100, which got the highest weight.These results shown that MSW could be considered to be a component of a soiless mix to grow ornamentals in order to reduce cost production and environmental impact.

\section{Fluctuating Controlled Water Table Irrigation}

\section{Jack W. Buxton*1, Janet Pfeiffer ${ }^{2}$, Darrell Slone ${ }^{3}$}

${ }^{1}$ Univ. of Kentucky, Dept. of Horticulture, Lexington, KY 40546; ${ }^{2}$ Univ. of Kentucky, Dept. of Horticulture; ${ }^{3}$ Univ. of Kentucky, Dept. of Horticulture, Lexington, KY 40546

Acontrolled water table irrigation system(CWT) automatically provides water to plants. One edge of a capillary mat, on the bench surface, draws water from a trough (water table) below the bench. Each treatment trough was $30 \mathrm{~cm}$ long. As the distance between the water surface and the bench surface increases, the water in the growing medium decreases, the air increases; and the water potential decreases. In previous studies a constant CWT of $2 \mathrm{~cm}$ below the bench surface was the optimum placement for producing $15-\mathrm{cm}$ pots of geranium. In this study the water table fluctuated between two distances below the bench surface. The fluctuating treatments were $2 \mathrm{~cm}$ to $3 \mathrm{~cm}, 2 \mathrm{~cm}$ to $4 \mathrm{~cm}$, and $1 \mathrm{~cm}$ to $4 \mathrm{~cm}$. The control treatment remained at a constant $2 \mathrm{~cm}$ below the bench surface. The fluctuating treatments were established by using two liquid level controllers connected to a switching mechanism that allowed the water table to fluctuate between the treatment settings. The rate of movement from the higher level to the lower level was determined by the rate of transpiration and evaporation occurring in individual treatments. The amount of water used for each treatment was determined by counting the number of times the solenoid turned on and multiplying this by the amount of water added to the trough. The 
leaf area and dry weight were the same for plants grown in $2 \mathrm{~cm}, 2$ to $3 \mathrm{~cm}$, and 2 to $4 \mathrm{~cm}$ treatments and these treatments were significantly greater than plants in the 1 to $4 \mathrm{~cm}$ treatment. The amount of water used by all treatments was nearly the same.

335 Influence of Water-soluble and Slow-release Fertilizers on Growth of Pot Carnation in C-Channel Mat Irrigation System

Chun Ho Pak*1, Seung Won Kang ${ }^{2}$, Chiwon W. Lee ${ }^{3}$

${ }^{1}$ Korea Univ., Dept. of Horticultural Science, Seoul, 136-701, South Korea; ${ }^{2}$ Korea Univ., Dept. of Horticultural Science, Seoul, 136-701, Soouth Korea; ${ }^{3}$ North Dakota State Univ., Dept. of Plant Sciences, Fargo, ND 58105

The influence of water-soluble fertilizer (WSF, 3 different formulations) and slow-release fertilizer (SRF, Osmocote, 14N-6.2P-11.6K) on the growth and quality of potted carnation (Dianthus caryophyllus cv. Invitation) in a C-channel mat irrigation system was investigated. When fertilized with $0.4,0.8$, or $2.0 \mathrm{~g} \cdot \mathrm{L}^{-1}$ of WSF $(20 \mathrm{~N}-7.9 \mathrm{P}-16.6 \mathrm{~K}$ for weeks $1-4,13 \mathrm{~K}-0.1 \mathrm{P}-18.8 \mathrm{~K}$ for weeks $5-11$, and $15 \mathrm{~N}-0 \mathrm{P}-12.5 \mathrm{~K}$ for weeks $12-15$ ), the $0.8 \mathrm{~g} \cdot \mathrm{L}^{-1}$ solution produced the highest quality plants as determined by total shoot fresh and dry weights, leaf area and number, plant height, and number of branches per pot. The quality of plants grown with $0.4 \mathrm{~g} \cdot \mathrm{L}^{-1}$ or $2.0 \mathrm{~g} \cdot \mathrm{L}^{-1} \mathrm{WSF}$ solution was also commercially acceptable. The growth rate of all plants began to accelerate at around 60 days after treatment started, with some variation with the fertilizer treatments. Plants began to show a reduced growth rate at around 90 days from the treatment when they underwent a phase change from vegetative growth to reproductive growth. Plants grown with SRF alone were less vigorous than those grown with WSF, especially when temperature was lower. Results of this study indicate that high quality pot carnations can be produced, using a reduced amount of fertilizer applied to the $\mathrm{C}$-channel mat irrigation system.

\section{Poster Session 14-Environmental Stress Physiology}

\section{July 18, 2004, 12:30-1:30 PM Rio Grande Exhibit Hall}

211 Off-season Strawberry Production under High Tunnel Compared to Open Field in Kansas

Sorkel Kadir*1, Edward Carey ${ }^{2}$

${ }^{1}$ Kansas State Univ., Horticulture, Manhattan, KS 66506; ${ }^{2}$ Kansas State Univ., Horticulture, Olathe, KS 66061

High tunnel strawberry $($ Fragaria $\times$ ananassa $)$ production experiment was conducted in south central Kansas, which consisted of two cultivars and four tunnels. The same experimental design was conducted under field conditions. The objectives of this study were to compare strawberry production and quality under high tunnels to those grown in the field and to assess the potential for high tunnels for early-season strawberry production. Plug plants of 'Sweet Charlie' and 'Chandler' were planted October 18. Plants were spaced at 12 " $\times 12$ " in double rows on raised beds covered with black plastic mulch. Protected plants under high tunnels had $100 \%$ winter survival rate compared to $60 \%$ of the field plants. Yield and berry quality of the high tunnel plants were by far better than those of field grown plants. Plant growth under high tunnels was about three to four fold higher than the unprotected field plants. 'Sweet Charlie' flowered in early February and produced berries one week earlier than 'Chandler'. Both cultivars were harvest from early April through late May at weekly interval. 'Sweet Charlie' in early April produced an average berry weight of $14 \mathrm{~g}$, soluble solids of $8^{\circ} \mathrm{Brix}$, and the largest average berry weight was $15 \mathrm{~g}$. 'Chandler' harvested late April produced larger berries than 'Sweet Charlie' with the largest average berry weight of $35 \mathrm{~g}$ compared to $31 \mathrm{~g}$ for 'Sweet Charlie'. In mid May, 'Chandler' produced $72 \%$ higher yield than 'Sweet Charlie'. High tunnel not only produced higher yield and better quality berries than field strawberries but it has a potential to produce early crop and extend the season production of strawberry in Kansas.
213 Photosynthesis and Rubber Production in Transgenic Guayule (Parthenium argentatum, Gray) in Response to Cold Night Temperatures

Maren E. Veatch*1, Dennis T. Ray ${ }^{2}$

${ }^{1}$ Univ. of Arizona, Plant Science, Tucson, AZ 85721; ${ }^{2}$ Univ. of Arizona, Plant Science, Tucson, AZ 85721

Rubber production in guayule (Parthenium argentatum, Gray) is highest in the winter months. It has been suggested that lower nighttime temperatures stimulate rubber production. Higher rubber production could be the result of up regulation of the enzymes involved in rubber synthesis, or acclimation of the photosynthetic apparatus to cold temperatures, making photosynthates available for rubber production when the plants are not actively growing, or a combination of the two factors. The effect of low night temperatures on photosynthesis and rubber production was examined in greenhouse grown plants. The experiment was set up as a split plot with different sub plots enclosed in heated or non-heated containers during the night. Those placed in non-heated containers were exposed to the ambient night temperatures of the greenhouse. During the growing season, growth was measured as change in height, and midday and diurnal photosynthetic measurements were collected. At harvest fresh and dry weight of both roots and shoots were taken. Resin and rubber were then extracted with acetone and cyclohexane respectively. Midday photosynthesis was as high or higher in cold night plants than in the warm night plants. In addition, the cold night treatment had lower growth than the warm night treatment. Percent resin and rubber were significantly higher in both shoots and roots of cold night plants, as was the overall yield of rubber. An increase in photosynthetic rate in the cold night treatment, without the concomitant increase in growth seen in the warm night treatment, could account for the increase in rubber production during the winter months.

214 Glomus intraradices Enhances Growth and Gas Exchange of Lolium perenne Seedlings in Petroleum-contaminated Soil

Alejandro Alarcon*1, Frederick T. Davies ${ }^{2}$, David Wm. Reed ${ }^{3}$, Robin L. Autenrieth ${ }^{4}$, David A. Zuberer ${ }^{5}$

${ }^{1}$ Texas A\&M Univ., Horticultural Sciences, College Station, TX 77843-2133; ${ }^{2}$ Texas A\&M Univ., Horticultural Sciences, College Station, TX 77843-2133; ${ }^{3}$ Texas A\&M Univ., Horticultural Sciences, College Station, TX 77843-2133; ${ }^{4}$ Texas A\&M Univ., Civil Engineering, College Station, TX 77843-3136; ${ }^{5}$ Texas A\&M Univ., Soil \& Crop Sciences, College Station, TX 77843- 2474

Arbuscular mycorhizal fungi (AMF) have been used in phytoremediation and can increase tolerance and growth of plants in contaminated environments. However, little is known about the influence AMF on plant growth to organic contaminants in soils. A greenhouse experiment was conducted to study the response of seedlings of annual ryegrass (Lolium perenne L.) var. Passerel Plus inoculated with Glomus intraradices Schenck \& Smith in soil contaminated with sweet Arabian median crude oil. Inoculated (AMF) and non-inoculated (Non-AMF) plants were established in an pasteurized and artificially contaminated sandy loam soil with $0 ; 3000 ; 15,000$; or $45,000 \mathrm{mg}$ of petroleum $\mathrm{kg}^{-1}$ soil $(\mathrm{n}=20)$. Plants were inoculated with 500 spores of $G$. intraradices (Mycorise ${ }^{\circledR}$ ASP, PremierTech Biotechnologies, Canada). After 90 days, plant growth of AMF or Non-AMF plants, was drastically affected at all petroleum concentrations. However, G. intraradices enhanced plant growth, chlorophyll content, and gas exchange of plants grown at $3,000 \mathrm{mg} \mathrm{kg}^{-1}$ compared to Non-AMF plants. Total leaf area, chlorophyll, and net photosynthesis were also higher $(+380 \%,+63 \%$, and $+81 \%$, respectively) at this concentration. Water use efficiency (net photosynthesis/stomatal conductance) of AMF-plants was three times greater than Non-AMF at $3,000 \mathrm{mg} \cdot \mathrm{kg}^{-1}$. At concentrations of 15,000 and 45,000 $\mathrm{mg} \mathrm{kg}^{-1} \mathrm{AMF}$ did not have effect, but colonization was observed (11.8\% and $18.6 \%$, respectively). These values of colonization were significantly lower than those observed in AMF-plants at $0(42.5 \%)$ and $3,000 \mathrm{mg} \cdot \mathrm{kg}^{-1}(55.6 \%)$. Studies are currently being conducted to understand the physiological role of AMF on plants exposed to organic contaminants. 
215 Growth and Gas Exchange Responses of Olive Tree Cuttings to Elevated $\mathrm{CO}_{2}$ Concentration under Saline Conditions

J.C. Melgar ${ }^{1}$, J. Dunlop ${ }^{2}$, J.P. Syvertsen*3 ${ }^{*}$ F. García-Sánchez ${ }^{4}$

${ }^{1}$ Univ. of Córdoba, Agronomy; ${ }^{2} \mathrm{UF} / \mathrm{CREC}, \mathrm{CREC} ;{ }^{3} \mathrm{UF} / \mathrm{IFAS}, \mathrm{CREC} ;{ }^{4} \mathrm{UF} / \mathrm{IFAS}, \mathrm{CREC}$

Physiological responses of olive cuttings of 'Koroneiki' and 'Picual' (Olea europaea $\mathrm{L}$.) to zero or high salinity $\left(\mathrm{NaCl} 100 \mathrm{mmol} \cdot \mathrm{L}^{-1}\right.$ ) and to ambient $\mathrm{CO}_{2}(380 \mathrm{ppm})$ or elevated $(700 \mathrm{ppm}) \mathrm{CO}_{2}$ concentration were studied in sand culture in greenhouses. Growth parameters, net gas exchange of leaves and leaf chloride concentration were measured after two months of treatment. 'Koroneiki' had significantly greater shoot growth and net assimilation of $\mathrm{CO}_{2}(\mathrm{Ac})$ at elevated $\mathrm{CO}_{2}$ than at ambient $\mathrm{CO}$ but this difference disappeared under salt stress. Growth and Ac of 'Picual' did not respond to elevated $\mathrm{CO}_{2}$ regardless of salinity treatment. Stomatal conductance and leaf transpiration were lower at elevated $\mathrm{CO}_{2}$ such that leaf water use efficiency increased at elevated $\mathrm{CO}_{2}$ in both cultivars regardless of saline treatment. The saline treatment increased leaf chloride $(\mathrm{Cl})$ concentration and reduced growth and net gas exchange responses in both cultivars. There was no difference in leaf $\mathrm{Cl}$ accumulation between the two varieties. At high salinity, elevated $\mathrm{CO}_{2}$ had little effect on leaf $\mathrm{Cl}$ implying that at least in 'Koroneiki', $\mathrm{Cl}$ accumulation was not closely linked to water uptake.

\section{Petunia Growth and Maintenance in the Landscape as Influ- enced by Alternative Irrigation Strategies}

Sloane M. Scheiber*1, Richard C. Beeson, Jr. ${ }^{2}$

${ }^{1}$ Univ. of Florida, Environmental Horticulture, Apopka, FL 32703; ${ }^{2}$ Univ. of Florida, Environmental Horticulture

Petunia 'Midnight' were grown in drainage lysimeters in an open-sided clear polyethylene covered shelter to evaluate growth responses in response to alternative irrigation strategies. Three irrigation methods were evaluated: tensiometer-controlled automatic irrigation system, regularly scheduled irrigation utilizing an automated controller, and human perception of plant irrigation need. Drainage lysimeters (250 L) were backfilled with native sand field soil to simulate landscape conditions and managed with Best Management Practices. Following establishment, lysimeters irrigated by an automated controller were irrigated 1.3 $\mathrm{cm}$ daily. Tensiometer-controlled lysimeters were irrigated when plant available water $(2.5 \mathrm{kPa}$ to $1.5 \mathrm{MPa}$ ) had declined to $70 \%$ or less, and were irrigated back to field capacity. Canopy growth indices and leaf gas exchange measurements were evaluated relative to irrigation strategies. Actual evapotranspiration was calculated for each replication. Daily irrigation resulted in significantly higher assimilation rates, transpiration rates, and final shoot dry weights than the other treatments tested. Assimilation rates and transpiration rates were significantly higher for tensiometer-controlled irrigation than the human judged treatment, but no differences were found in final shoot dry mass.

217 Anthocyanins From the Flowers of Prunus mume Sieb. et Zucc. Changling Zhao ${ }^{1}$, Weiming Guo ${ }^{2}$, Junyu Chen ${ }^{3}$, Zhongchun Jiang*4

${ }^{1}$ Yunnan Agricultural Univ., College of Agricultural Sciences and Biotechnology; ${ }^{2} \mathrm{Nanjing}$ Agricultural Univ., Dept. of Ornamental Horticulture; ${ }^{3}$ Beijing Forestry Univ., College of Landscape Architecture; ${ }^{4}$ State Univ. of New York at Cobleskill, Dept. of Plant Science

Mei (Prunus mume Sieb. et Zucc.) flower is one of the candidates for the national flower of the People's Republic of China. Several major anthocyanins from the flowers of P. mume Sieb. et Zucc. were isolated with $\mathrm{MeOH}-\mathrm{HOAc}$-water $(10: 1: 9, \mathrm{v} / \mathrm{v})$, and purified by paper chromatography and subsequent column chromatography. Specific chemical reactions, chromatographic and spectroscopic analyses indicated that the anthocyanins in 'Nanjing Hongxu' (Nanjing red-bearded) were cyanidin 3-O-(6'-O- $\alpha$-rhamnopyranosyl- $\beta$-glucopyranoside) and cyanidin 3-O-(6'-O-galloyl-3'-O- $\beta$-glucopyranosyl- $\beta$-glucopyranoside). Anthocyanins in 'Nanjing Hong' (Nanjing red) were cyanidin 3-O-(6'-O- $\alpha$-rhamnopyranosyl- $\beta$-glucopyranoside), cyanidin 3-O-(6'O-galloyl- $\beta$-glucopyranoside) and cyanidin 3-O-(6'-O-E-feruloyl- $\beta$ glucopyranoside). In addition to contributing to the blue flower color, the anthocyanins may improve the ability of the two cultivars to survive at low temperatures.
218 Preliminary Observations on the Effect of Light Intensity and Time of Day on Mustard Greens Leaf Ascorbic Acid and Greenness at Harvest

Donald J. Makus*1, Gene E. Lester ${ }^{2}$

${ }^{1}$ USDA, ARS, IF\&NR, Weslaco, TX 78596; ${ }^{2}$ USDA, ARS, Fruit and Crop Quality, Weslaco, TX 78596

Field-grown mustard greens, Brassica juncea, were used to validate several observations of a greenhouse study which reported nutrient changes in mustard greens grown, in part, under ambient and reduced light. The cultivar Florida Broadleaf was transplanted into a Hildago sandy clay soil near Weslaco, Texas (26 08' Lat.) on 6 Nov 2003. Greens were fertigated with $30 \mathrm{~kg} \cdot \mathrm{ha}^{-1}$ of $\mathrm{N}$ on $1 \mathrm{Dec}$. Plants 14 days before harvest were grown under the following four light regimes: (1) continuous ambient light; (2) 7 days of $50 \%$ shade then 7 days of ambient light; (3) 7 days of ambient light then 7 days of $50 \%$ shade; and (4) 14 days of $50 \%$ shade. Cumulative solar light was 28.9 and $19.4 \mathrm{~kW} / \mathrm{m}^{2}$ during the first and second 7 days, respectively. Measured cumulative light, as PPFD, for treatments $1-4$ were $108,67,78$, and $44 \mathrm{mM} \cdot \mathrm{m}^{-2} \cdot \mathrm{s}^{-1}$, respectively. Plants were harvested at 0800,1100 , and $1400 \mathrm{~h}$ on 2 Jan. 2004. Shade during the last 7 days generally evoked the greatest responses. Increased shade duration did not significantly effect the agronomic performance, but did increase leaf total carotenoids, chlorophylls, water content, and reduced total ascorbate levels. As time of daylight progressed, sample plant weight and average leaf weight decreased in shaded plants only. Free ascorbic acid, chlorophyll a:b ratio, and the chlorophyll to carotenoid ratio decreased with time of day. Cumulative sunlight, as PPFD, was significantly correlated with total ascorbate (fresh weight basis), chlorophyll a:b ratio, and plant weight $(P<0.06)$ and negatively correlated with chlorophylls and total carotenoids (dry weight basis). Thus, cloudy weather prior to harvest can reduce leaf Vitamin $\mathrm{C}$ and alter leaf greenness

\section{Response of Sweetpotato Nodal Cultures to Low Temperature Stress}

Tianna W. Weathington*1, DeviPrasad V. Potluri ${ }^{2}$

${ }^{1}$ Chicago State Univ., Biological Sciences, Chicago, IL 60628; ${ }^{2}$ Chicago State Univ., Biol. Sciences, Chicago, IL 60628

Axillary bud cultures of sweetpotato Ipomoea batatus L. [cultivars comensal and salyboro] were propagated in vitro. Nodal cultures of these were grown at different temperatures ranging from $10^{\circ} \mathrm{C}$ to $30^{\circ} \mathrm{C}$ at $5{ }^{\circ} \mathrm{C}$ intervals from the time of axillary bud transfer to 10 weeks of growth in a controlled growth chamber. After 10 weeks of growth, morphological and physiological parameters were measured including shoot height, number of nodes and branches, levels of proline, soluble carbohydrate and protein. There was not much difference in the cultures grown at 25 and $30^{\circ} \mathrm{C}$ but temperatures lower than $25^{\circ} \mathrm{C}$ were inhibitory to both cultivars, though the effects were more pronounced in salyboro than comensal. Salyboro grew slower and exhibited leaf discoloration, weak stems, and poor root growth. Proline levels increased in both cultivars and the increase was higher in shoot than root due to low temperature stress. Soluble carbohydrates and proteins increased in comensal, maintaining the carbohydrate protein ratio, but decreased in salyboro. The results suggest that the cultivar comensal may tolerate cooler temperatures and the cultivar salyboro is susceptible to them.

220 Water Relations, Growth, and Carbon Isotope Discrimination of Drought-stressed Bigtooth Maples Indigenous to New Mexico, Texas, and Utah

Emad Bsoul*1, Rolston St. Hilaire ${ }^{2}$

${ }^{1}$ New Mexico State Univ., Dept. of Agronomy and Horticulture, Las Cruces, NM 88003; ${ }^{2}$ New Mexico State Univ., Dept. of Agronomy and Horticulture, Las Cruces, NM 88003

Although valued for its fall foliage color, bigtooth maple (Acer grandidentatum Nutt.) is not widely used in managed landscapes. Furthermore, information on the tolerance of bigtooth maples to drought is scant. We studied water relations, plant development, and carbon isotope composition of bigtooth maples indigenous to New Mexico, Texas, 
and Utah. Plants were field grown in New Mexico using a pot-in-pot nursery production system. Plants were maintained as well-irrigated controls or irrigated after the weight of pots decreased by $35 \%$ due to evapotranspiration. Drought treatment lasted 71 days. Among the drought-stressed plants, plants native to Logan Canyon in Utah (designated UW2), had the greatest root : shoot dry weight ratio (3.0), while plants with the lowest root: shoot dry weight ratio(0.9) were half siblings from a tree native to the Lost Maples State Park in Texas (designated LMP5). Among the five sources we tested, LMP5 had the greatest $\left(1242 \mathrm{~cm}^{2}\right)$ leaf area, while UW2 plants had the smallest $\left(216 \mathrm{~cm}^{2}\right)$. Regardless of the treatment, plants from LMP5 had the highest shoot dry weight $(25.7 \mathrm{~g})$. Plants showed no differences neither among sources nor between treatments in relative water content, specific leaf weight, xylem diameter, root dry weight, plant dry weight, relative growth rate, and carbon isotope discrimination, which averaged ${ }^{-} 26.53 \%$. The lack of differences in these parameters might be due to selection of these sources from provenances we deemed to be the most drought tolerant. Our selection was based on the results of a previous greenhouse study of 15 bigtooth maple sources. We conclude that these sources, and in particular, plants from LMP5 in Texas, might hold promise for use in areas prone to drought.

221 Physiological Effects of Drought Stress on Two Commercial Cultivars of the American Cranberry (Vaccinium macrocarpon)

\section{Ricardo Cesped-Ruiz*1, Bingru Huang ${ }^{2}$}

${ }^{1}$ Rutgers Univ., Plant Biology and Plant Pathology, New Brunswick, NJ08901; ${ }^{2}$ Rutgers Univ., Plant Biology and Plant Pathology, New Brunswick, NJ 08901

The American cranberry often undergoes drought stress during the summer. However, the physiological response of this species to drought is not well understood. This study was designed to determine the effects of drought on two commercial cranberry cultivars of high potential yield, 'Ben Lear' and 'Stevens', during a vegetative stage. The plants were subjected to drought for 15 days in a greenhouse. Soil water content, leaf water content, leaf photosynthetic rate, stomatal conductance, transpiration, differential leaf-air temperature, photochemical efficiency (Fv'/Fm') and the actual PSII efficiency (deltaF/Fm') decreased in those plants subjected to drought. Drought reduced differential leaf-air temperature at day 6 of treatment and stomatal conductance and transpiration starting at day 9 and photosynthetic rate at day 13 . Drought decreased leaf water content at day 14 and Fv'/Fm' and PSII efficiency at day 15 . Our results indicated that cranberry plants in vegetative stage were sensitive to drought for both cultivars and stomatal conductance was the most sensitive parameter among those examined for both cultivars.

222 Application of Reflectance Spectroscopy in 'Fuji' Apple Sunburn Early Detection

Pinghai Ding*1, Leslie H. Fuchigami ${ }^{2}$

${ }^{1}$ Oregon State Univ., Dept. of Horticulture, Corvallis, OR 97331; ${ }^{2}$ Oregon State Univ., Dept. of Horticulture, Corvallis, OR 97331

Sunburn can be caused either by heat stress or by UV-B radiation. Under natural conditions fruit sunburn is usually caused by the combination of both heat stress and UV-B radiation. To evaluate the use of reflectance spectroscopy in early detection of fruit sunburn, 5-year-old 'Fuji' apple bearing trees growing in pot-in-pot system at the Lewis-Brown Horticulture Farm of Oregon State Univ. were used in the experiment. Fruit sunburn was monitored either under natural conditions or treated with UV-B, heat or both under controlled conditions after detached from the tree. Under natural conditions, the sun-exposed side of Fuji fruit has much higher anthocyanins than the shaded side. The increase in anthocyanins at the sun-exposed side is to protect the fruit from sunburn. When the temperature higher than $40{ }^{\circ} \mathrm{C}$ the sunburn symptom initiated first by change the color of the sun-exposed side from red to tan, then to yellow patches, and finally turn to brown and dark brown patches. The peel pigments analysis results indicated that anthocyanins decreased earlier than chlorophyll in the symptom development. The results of detached fruit exposure to $30,000 \mu \mathrm{W} / \mathrm{cm}^{2} \mathrm{UV}-\mathrm{B}$ lights or to $40{ }^{\circ} \mathrm{C}$ at control conditions for $2,4,6,8,10$, and 12 hours indicated that high intensity UV-B lights or high temperature alone can cause sunburn respectively. The UV-B and temperature combination treatment enhanced the sunburn processes. The apples with sunburn caused under natural conditions or under UV-B and temperature controlled conditions were scanned by using reflectance spectroscopy of FOSS NIR system at different stage of the sunburn. The results indicted that Fuji apple sunburn can be efficiently detected at the early stage of sunburn in both natural and controlled conditions.

\section{Poster Session 15-Ornamental Plant Breeding 1 \\ July 18, 2004, 12:30-1:30 PM Rio Grande Exhibit Hall}

\section{The Identity of the African Firebush (Hamelia) in the Orna- mental Nursery Trade}

\section{Margaret R. Pooler*1, Thomas S. Elias²}

${ }^{1}$ U.S. National Arboretum, Floral and Nursery Plants Research Unit, Washington, DC, 20002; ${ }^{2}$ U.S. National Arboretum, Director's Office, Washington, DC, 20002

The neotropical shrub Hamelia patens Jacq. has been cultivated as an ornamental in the United States, Great Britain, and South Africa for many years, although only in limited numbers and as a minor element in the trade. In recent years, other taxa of Hamelia have been grown and evaluated as new flowering shrubs. The relatively recent introduction of a superior ornamental species of Hamelia called the "African firebush" has propelled this genus to greater prominence as an excellent small flowering shrub or container plant, especially throughout the southeastern United States and in other countries such as South Africa. Initially, this firebush was sold as an African plant. Data from field studies, herbarium specimens, and from DNA analysis of several taxa and populations of Hamelia show that the African firebush in southern Florida may have originated from populations of Hamelia patens var. glabra native to southern Mexico. The original plants were taken to Europe, southern Africa, and southeastern Asia probably in the mid to late 1800 s and then recently re-introduced to New World markets as a new African ornamental plant.

\section{Latest Developments in Crapemyrtle Breeding at the U.S. National Arboretum}

Margaret R. Pooler*1

${ }^{1}$ U.S. National Arboretum, Floral and Nursery Plants Research Unit, Washington, DC, 20002

The crapemyrtle (Lagerstroemia) is one of the most widely planted and beloved woody ornamental landscape plant in the Southern United States. With hundreds of named cultivars that offer the grower and gardener diverse combinations of flower color, growth habit, and bark characteristics, crapemyrtles are planted primarily for their spectacular bloom in mid to late summer. The crapemyrtle breeding program at the U.S. National Arboretum was started in the early 1960s, and has resulted in the release of 31 improved cultivars of L. indica, L. indica $x$ L. fauriei, and most recently, hybrids between L. indica, L. fauriei, and $L$. limii . The development of these cultivars, with a focus on the newly released red-flowering cultivars 'Arapaho' and 'Cheyenne', will be the focus of this poster. Information on Lagerstroemia germplasm, historical perspective, and breeding methodology and goals will be presented.

\section{Evaluation of Caladium Cultivars for Resistance to Pythium Root Rot}

Zhanao Deng*1, Brent K. Harbaugh ${ }^{2}$, Rick Kelly ${ }^{3}$, Teresa Seijo ${ }^{4}$, Robert J. McGovern ${ }^{5}$

${ }^{1}$ Univ. of Florida /IFAS, Gulf Coast Research and Education Center, Bradenton, FL 34203; ${ }^{2}$ Univ. of Florida /IFAS, Gulf Coast Research and Education Center, Bradenton, FL 34203; ${ }^{3}$ Univ. of Florida /IFAS, Gulf Coast Research and Education Center, Bradenton, FL 34203; ${ }^{4}$ Univ. of Florida /IFAS, Gulf Coast Research and Education Center, Bradenton, FL 34203; ${ }^{5}$ Univ. of Florida, Doctor of Plant Medicine Degree Program, Gainesville, FL 32611

Caladiums (Caladium $\times$ hortulanum) are widely grown for their bright colorful leaves. Pythium root rot, caused primarily by P. myriotylum, 
is one of the most important diseases in caladiums. This disease can dramatically reduce plant growth, impact plant aesthetical value, and lower tuber yield. Pythium infection in the roots may also lead to subsequent entry of Fusarium into tubers resulting in tuber rot. There has been a strong interest in the tuber production and greenhouse plant production industries to identify cultivars that are resistant or tolerant to Pythium. However, few studies have been conducted since the pathogen was identified, and little information is available regarding the existence of any possible resistance in commercial cultivars. Pythium isolates were made from diseased plants collected from different sites; their pathogenicity was confirmed using tissue culture-derived plants. Procedures were developed for oogonia spore production, inoculation, and disease severity assessment. Nineteen major commercial cultivars were inoculated at two spore densities and then maintained in greenhouses under growing conditions favorable for root rotting. Plant appearance, leaf characteristics and severity of root rotting were evaluated 2-3 times after inoculation. Observations indicated that the isolates were highly virulent. They induced visible root rot within 3-5 days, and caused a complete loss of the root system and plant death for some cultivars within 2-3 weeks after inoculation. Several cultivars, including 'Candidum' and 'Frieda Hemple' which are widely grown cultivars, had much less root rot, higher plant survival, and seemed to have moderate levels of resistance.

\section{Susceptibility of Deciduous Azalea Cultivars to Powdery Mildew Disease}

\section{Michael C. Long*1, Stephen L. Krebs², Stan C. Hokanson ${ }^{3}$}

'Univ. of Minnesota, Horticultural Science, St. Paul, MN 55108; ${ }^{2}$ Holden Arboretum, The David G. Leach Research Station, Madison, OH 44057; ${ }^{3}$ Univ. of Minnesota, Horticultural Science, St. Paul, MN 55108

Forty deciduous azalea (Rhododendron $s p$.) cultivars from commercial sources were evaluated for powdery mildew (Microsphaera sp.) resistance. Plants were established in two duplicate field plantings in Ohio and Minnesota and evaluated in 2002 and 2003. Plants were scored using a disease symptom rating based on the percent of leaf area infected, evaluating both ab- and adaxial leaf surfaces. Highly significant differences were found for cultivar, location, year, cultivar $\times$ location and cultivar $\times$ year for disease severity. Calendulaceum $\times$ speciosum, 'Fragrant Star', 'Garden Party', 'Late Lady', 'Millennium', 'Parade', and 'Popsicle' showed no powdery mildew symptoms in both locations. Another group of plants with only minimal symptoms $(<25 \%$ leaf area affected) included 'Jane Abbott', 'Magic', 'Northern Hi-Lights' and 'Snowbird'. The symptom-free cultivars exhibited glaucous foliage, suggesting a potential, common resistance mechanism. The mean scores for the abaxial and adaxial leaf surfaces were 2.34 and 1.64 , respectively, although four cultivars had more disease symptoms on the adaxial surface. 'Arneson Gem' showed nearly a two-point difference between abaxial and adaxial scores. Evaluations of azalea powdery mildew susceptibility should consider both leaf surfaces and use the highest score as the best estimate of host resistance.

\section{Variation in Ploidy Levels and Reproductive Pathways Among Flowering Crabapples}

Thomas Ranney*1, Thomas Eaker ${ }^{2}$

${ }^{1}$ North Carolina State Univ., Horticultural Science, Fletcher, NC 28732; ${ }^{2}$ North Carolina State Univ., Horticultural Science, Fletcher, NC 28732

Information on ploidy levels is extremely valuable for use in plant breeding programs. Fertility, crossability, and heritability of traits are all influenced by ploidy levels. Knowledge of reproductive pathways, including occurrence of apomixes, pseudogamy, and formation of unreduced gametes can also be important information for developing breeding strategies. Although ploidy level can be determined by counting chromosomes, flow cytometry provides a reliable and much faster means for determination of nuclear DNA content and associated ploidy level. Measurement of ploidy levels of seeds (embryo and endosperm) can also provide useful insights into reproductive pathways. The objective of this study was to determine the approximate genome size, estimated ploidy level, and range of reproductive pathways of a diverse collection of flowering crapbapples (Malus spp.). Genome sizes were calculated as nuclear DNA content for unreduced tissue (2C). Results from the taxa included in our survey showed DNA contents ranging from 1.52 to 1.82 for diploids, 2.40 to 2.62 for triploids, and 3.36 to $3.74 \mathrm{pg} / 2 \mathrm{C}$ for tetraploids. Based on these ranges, we identified 43 diploid, 10 triploid, and 4 tetraploid crabapple taxa in this collection. Results from open pollinated seeds and seedlings demonstrated a variety of reproductive pathways including apomixes and unreduced gametes. This research provides information on ploidy levels and reproductive pathways of flowering crabapples and will allow for more systematic and efficient progress in the development of improved cultivars.

\section{Poster Session 16-Genetics and Germplasm 2

July 18, 2004, 12:30-1:30 PM Rio Grande Exhibit Hall

\section{Utility of BoCAL-a and BoAP1-a Genotypes in Identifying} Broccoli and Cauliflower Accessions

Joanne A. Labate ${ }^{1}$, Larry D. Robertson ${ }^{2}$, Thomas Bjorkman*3

${ }^{1}$ Cornell Univ., USDA-ARS-PGRU, Geneva, NY 14456; ${ }^{2}$ Cornell Univ., USDA-ARSPGRU, Geneva, NY 14456; '3Cornell Univ., Horticultrual Sciences, Geneva, NY 14456

Broccoli and cauliflower are different botanical varieties of Brassica oleracea. Mutant alleles at the loci BoCAL and BoAP1 can cause arrest at curding that is characteristic of cauliflower. These genes control early floral differentiation, necessary for the progression from a cauliflowerlike inflorescence to the flower buds of broccoli. To what extent is the cauliflower-to-broccoli variation within the USDA-PGRU collection determined by mutant alleles of these genes? We surveyed the broccoli collection to examine the correlation between genotype and phenotype. Earlier work showed that BoCAL alone was not an effective predictor of cauliflower phenotype in this collection. The redundant function of BoCAL and BoAP1 in determining inflorescence arrest raises the possibilty that the combined genotype can explain the phenotypic variation. We found that not to be the case. Two accessions varied in phenotype and segregated at both loci, but the combined genotypes were not associated with the expected phenotypes. Two additional accesssion varied in phenotype and segregated at one locus, but with no association between genotype and phenotype. One line varying widely in phenotype was fixed for both loci. One line that was a stable intermediate phenotype segregated for BoCAL. Acommercial broccoli cultivar had the cauliflower allele at both loci. The genetic basis of the cauliflower phenotype in the USDA B. oleracea collection is due more to alleles of genes affecting the expression of BoAP1 adn BoCAL than to variation in these alleles of the genes themselves.

178 Comparison of Morphological and Genetic Characteristics of 15 Sweetpotato [Ipomoea batatas (L.) Lam] Accessions Grown on Guam

Rozalyn Pama*1, Jay Doronila ${ }^{2}$, Mari Marutani ${ }^{3}$

${ }^{1}$ Univ. of Guam, College of Natural and Applied Sciences / AES, Mangilao, GU 96923 ; ${ }^{2}$ Univ. of Guam, College of Natural and Applied Sciences / AES, Mangilao, GU 96923 ${ }^{3}$ Univ. of Guam, College of Natural and Applied Sciences / AES, Mangilao, GU 96923

Fifteen sweetpotato [Ipomoea batatas (L.) Lam] accessions grown on Guam were studied for morphological and genetic characteristics. Accessions, obtained from AVRDC (Asian Vegetable Research and Development Center) in Taiwan, Saipan, Rota, and Guam, were investigated for marketable yield, growth habit and characteristics of tuberous roots (color, shape, sugar content and moisture content). Results of this study were used to determine the morphological relationship of the accessions of sweetpotato. Phenetic analysis revealed four major clusters according to tuberous root characteristics. The genetic relationship of these sweetpotato accessions was also evaluated for genetic differences among accessions. DNA was extracted and went through polymerase chain reaction (PCR). PCR products were analyzed by random amplified polymorphic DNA(RAPD) fingerprinting. Result of the genetic relationship among the sweetpotatoes was compared 
with the morphology of accessions using UPGMA cluster analysis and principal compounds analysis.

\section{Inheritance and Characteristics of a New Dwarf and Seedless Mutant in Watermelon [Citrullus lanatus (Thunb.) Matsum. \& Nakai]}

Yun-Chan Huh ${ }^{1}$, Seung-Ryong Cheong ${ }^{2}$, Jung-Myung Lee*3

${ }^{1}$ National Horticultural Research Institute, Division of Horticultural Biotechnology, Suwon, Gyeonggi-do, 441-440, Republic of Korea; ${ }^{2}$ National Horticultural Research Institute, Division of Horticultural Biotechnology, Suwon, Gyeonggi-do, 441-440, Republic of Korea ${ }^{3}$ Kyung Hee Univ., Dept. of Horticulture, Yongin, Gyeonggi-do, 449-701, Republic of Korea

Common watermelons have an indeterminate growth habit with normal internode length, thus allowing the vine to grow indefinitely under the normal conditions. Watermelon breeders have identified four dwarf genes $\left(d w-1, d w-1^{\mathrm{s}}, d w-2, d w-3\right)$ and used these for developing dwarf watermelon cultivars. We discovered a naturally occurring new dwarf and seedless mutant (NDSM) from a landrace cv. Mudungsan that had been cultivated in the Mountain Mudung area nearby Gwangju City in Korea. The progenies of this mutant segregated in a ratio of 3 vine to $1 \mathrm{dwarf}$ indicating a single recessive gene nature. Morphological characteristics of the NDSM were markedly different from those of the four known dwarf genotypes. NDSM plants grow shorter than 1 $m$ in length with fan-shaped leaves and have fewer leaf lobes than normal plants, which could be clearly distinguished at 2 or 3 true leaf stage. Male and female flowers have just one petal and failed to open completely even at the anthesis. Even though there were some fertile pollen grains, the fruits of NDSM had no seed after fertilization. The $\mathrm{F}_{2}$ progenies, obtained from crossing '920533' (normal vine type) and NDSM, segregated in a ratio of 3 vine to 1 dwarf. All $\mathrm{F}_{1}$ plants from crosses between 2 dwarf types, 'Sugar Bush' $(d w-1 d w-1)$ and 'NH 9' $(d w-2 d w-2)$, and NDSM were normal, while $\mathrm{F}_{2}$ showed 9 vines, $3 d w$ 1 or $d w-2$ types, 3 NDSM types, and 1 double dwarf. The backcross generation segregated in a ratio of 1 vine to 1 dwarf. These results indicate that the genes for the NDSM and 2 dwarf types are non-allelic. We named this new dwarf genotype (NDSM) as $d w-4$ in addition to four dwarf genes previously identified.

180 Determining the Contribution of Tomato Carotenoids to Plasma Antioxidant Status: A Study of Potential Applications for Breeding Tomatoes with Increased Health Benefits

Peter J. Mes*1, James R. Myers², Balz Frei ${ }^{3}$

${ }^{1}$ Oregon State Univ., Horticulture, Corvallis, OR 97331; ${ }^{2}$ Oregon State Univ., Horticulture, Corvallis, OR 97331-7304; ${ }^{3}$ Oregon State Univ., Linus Pauling Institute, Corvallis, OR 97331-6512

A nutritional study was initiated to determine which carotenoids found in tomato result in decreased lipid oxidation ex vivo. To compare the carotenoids in a human diet without the use of purified supplements, tomatoes expressing nonfunctional enzymes in the carotenoid pathway were used. Tomato lines carrying the genes t, B, ogc, Del, or $r$ were grown to produce fruit containing with high levels of prolycopene, beta-carotene, lycopene, or delta-carotene respectively, or low total carotenoids in r. Juices were processed from these lines and used in a dietary intervention study. Plasma samples were drawn before and after consumption of each juice. These samples were subjected to a battery of tests to analyze the contribution of carotenoids to the total lipid antioxidant status. Results of these tests are discussed.

\section{Development of Genomic Tools for Cucumber, Cucumis sativus $\mathbf{L}$.}

Rebecca Grumet*1, Xiaofeng Wang ${ }^{2}$, MohamedTawfik ${ }^{3}$, Mitch McGrath ${ }^{4}$

${ }^{1}$ Michigan State Univ., Horticulture, East Lansing, MI 48824; ${ }^{2}$ Michigan State Univ., Horticulture, East Lansing, MI 48824; ${ }^{3}$ Michigan State Univ., Horticulture, East Lansing, MI 48824; ${ }^{4}$ Michigan State Univ., Crop and Soil Sciences, East Lansing, MI 48824

Genomics tools have become increasingly varied and valuable for crop improvement. While several species have been targeted for concerted genomic efforts, the majority of horticultural species have received limited attention. Despite the wide variety of important cucurbit crop species, the Cucurbitaceae family has had minimal effort. We have initiated projects to develop genomic tools for cucumber, Cucumis sativus L. Efforts include production of cDNA, yeast two-hybrid, and genomic libraries, and development of an EST database and website for cucumber genomics. Sequences of cucumber leaf ESTs so far indicate that the cDNA library is of high quality and has modest redundancy. Distribution of sequences, as nominally predicted from GeneBank BLAST analysis, indicates that expressed genes fall in the following general categories: photosynthesis (21\%), DNA/RNA/protein synthesis (20\%), metabolism (15\%), signaling (5\%), other (16\%), and unknown proteins $(23 \%)$. Cucumber sequence data have been deposited into GenBank and are available on the Michigan State Univ. website (http://genomics.msu.edu/cucumberdb). The yeast two-hybrid library has been successfully used to identify and characterize several genes based on interaction with key proteins of interest, including genes interacting with viral replicases and poly(A) binding protein. The genomic library has been verified to be of high quality and has been used to identify clones of interest.

\section{Identification of QTL Affecting Sugars in Ananas Melon}

Soon O. Park*1, Kevin M. Crosby ${ }^{2}$, Jonathan W. Sinclair ${ }^{3}$, Kilsun $\mathrm{Yoo}^{4}$, Leonard M. Pike

${ }^{1}$ Texas A\&M Univ., Dept. of Horticultural Sciences, Weslaco, TX 78596; ${ }^{2}$ Texas A\&M Univ., Dept. of Horticultural Sciences, Weslaco, TX 78596; ${ }^{3}$ Texas A\&M Univ., Dept. of Horticultural Sciences, Weslaco, TX 78596; ${ }^{4}$ Texas A\&M Univ., Dept. of Horticultural Sciences, College Station, TX 77843; ${ }^{5}$ Texas A\&M Univ., Dept. of Horticultural Sciences, College Station, TX 77843

Sucrose, fructose, total sugars and soluble solids are major factors in determining mature melon fruit sweetness. Bulked segregant analysis was utilized to detect RAPD markers associated with QTL for sucrose, total sugars and soluble solids in an $\mathrm{F}_{2}$ population from the ananas melon cross of Deltex (high sugars) x TGR1551 (low sugars). Sucrose, glucose, fructose and total sugar data were obtained from $108 \mathrm{~F}_{2}$ plants by means of HPLC. Clear separations for sucrose, total sugars and soluble solids between Deltex and TGR1551 were observed, whereas slight differences for glucose and fructose were found. Continuous distributions for sucrose, total sugars and soluble solids were observed in the $\mathrm{F}_{2}$ population indicating quantitative inheritance for the sweetness traits. A significant negative correlation was observed between sucrose and glucose $(r=-25)$ or fructose $(r=-0.31)$. A significant positive correlation was noted between sucrose and total sugars $(r=0.80)$ or soluble solids $(r=0.64)$. Three low and high DNA bulk pairs for sucrose, total sugars and soluble solids were developed. A total of 360 primers were used to simultaneously screen between the low and high bulks, and between Deltex and TGR1551. Sixty-eight RAPD markers were polymorphic for the low and high bulks. Of the 68 markers, 24 were found to be significantly associated with sucrose, total sugars or soluble solids on the basis of single-factor ANOVA. Marker OM15.550 was consistently associated with QTL affecting sucrose, glucose, fructose, total sugars and soluble solids, and accounted for $7 \%$ to $25 \%$ of the phenotypic variation for the traits. These markers associated with the sugar synthesis QTL could be useful to transfer these genes into a low sugar cultivar to enhance the fruit sweetness.

\section{Detection of QTL Controlling Fruit Size and Shape in Cucumis melo $\mathbf{L}$.}

Soon O. Park ${ }^{* 1}$, Kevin M. Crosby ${ }^{2}$

${ }^{1}$ Texas A\&M Univ., Dept. of Horticultural Sciences, Weslaco, TX 78596; ${ }^{2}$ Texas A\&M Univ., Dept. of Horticultural Sciences, Weslaco, TX 78596

Mature fruit size and shape are important traits of most melon types. Our objective was to identify RAPD markers associated with major QTL affecting fruit weight, length, diameter and shape by means of bulked segregant analysis in an $\mathrm{F}_{2}$ population from the ananas melon cross of Deltex (larger fruit size) x TGR1551 (smaller fruit size). Clear separations for fruit weight, length, diameter, and shape between Deltex and TGR1551 were observed. Continuous distributions for fruit weight, length, diameter and shape were found in the $\mathrm{F}_{2}$ population indicating quantitative inheritance for the fruit traits. Significant positive correlations 
were detected between fruit weight and shape traits ( $r=0.73$ to 0.80$)$. A significant positive correlation was observed between fruit weight and glucose $(r=0.35)$ or fructose $(r=0.25)$, whereas no correlation was noted between fruit weight and sucrose or total soluble solids. Two small and large bulks for fruit weight and shape were developed from $\mathrm{F}_{2}$ plants. A total of 240 primers were used to simultaneously screen between the small and large bulks, and between Deltex and TGR1551. Twenty-six RAPD markers were polymorphic for the small and large bulks. Ten markers were found to be significantly and consistently associated with fruit size and shape traits on the basis of simple linear regression. Of the 10 markers associated, four displayed an amplified DNA fragment in the small bulk, while six showed an amplified DNA fragment in the large bulk. The associated marker OJ07.350 explained 15\% to $27 \%$ of the phenotypic variation for the fruit traits. These markers associated with QTL for melon fruit size and shape are expected to be useful in melon breeding programs for modifying fruit size.

\section{Genetic Linkage Map of Garlic (Allium sativum)}

YayehZewdie $^{1}$, Michael J. Havey ${ }^{2}$, James P. Prince ${ }^{3}$, Maria M. Jenderek*4 ${ }^{1}$ California State Univ., Dept. of Biology, Fresno, CA 93740; ${ }^{2}$ Dept. of Horticulture, Univ. of Wisconsin, Vegetable Crops Unit, USDA, ARS, Madison, WI 53706; ${ }^{3}$ California State Univ., Dept. of Biology, Fresno, CA 93740; ${ }^{4}$ USDA, ARS, National Arid Land Plant Genetic Resource Unit, Parlier, CA 93648

Garlic has been propagated exclusively by asexual means since time immemorial. The recent discovery of male fertile garlic accessions allowed studies on genetics and garlic improvement. Single nucleotide polymorphism (SNP) and random amplified polymorphic DNA(RAPD) based genetic linkage map was developed for garlic using a segregating population derived from one plant of PI 540316. Progenies segregated for male fertility and other morphological characters. Distortion of segregation was observed for most of the markers. This was expected due to the segregation of recessive deleterious alleles present in the garlic genome. The map contained 23 loci distributed on five linkage groups. It covered $319 \mathrm{cM}$ with the average of $18 \mathrm{cM}$ between loci. Linkage with the male fertility (Mf) locus was established with SNP marker AOB155 (26.7 cM).

185 The Potential for Green Fluorescent Protein as a Screening Tool in the Production of Haploid Potato

Rose E. Palumbo ${ }^{1}$, Richard E. Veilleux ${ }^{2}$

${ }^{1}$ Virginia Tech, Horticulture Blacksburg, Va.; ${ }^{2}$ Virginia Tech, Horticulture, Blacksburg, Va.

A hybrid between a highly regenerative diploid clone (BARD 1-3) of Solanum phureja and haploid inducer IVP 101 was transformed with Agrobacterium tumefaciens strain 4404 containing plasmid pHB2892 with genes for green florescent protein (GFP) and kanamycin resistance. Hemizygous primary transformants $\left(\mathrm{T}_{\mathrm{o}}\right)$ were produced from three leaf discs: 17 diploid plants from one leaf disc, three and nine tetraploids from the other two leaf discs. GFP expression was observed qualitatively under fluorescence microscopes and quantitatively with a GFP meter. Segregation ratios for tetraploid $T_{1}$ seedlings fit models for single duplex insertions (35 transgenic: 1 non) or double simplex insertions (15 transgenic: 1 non). Diploid $\mathrm{T}_{1}$ seedlings segregated for deleterious traits: dwarfed size and curled leaves, as well as the GFP transgene. Similar segregation patterns in diploid families implied that all diploids may have been from the same transformation event. The cumulative segregation showed the dwarfed and curled plants fit a single recessive gene ratio (3 normal: 1 mutant), and GFP fit a double-copy insertion ratio (15 transgenic: 1 non). Six $\mathrm{T}_{1}$ selections were free of deleterious traits, consistently high expressers of GFP, and produced fertile pollen.

\section{Tolerance to Rust (Puccinia allii) in Seed Derived Garlic Progenies}

Maria M. Jenderek*1, Richard Hannan ${ }^{2}$

${ }^{1}$ NALPGRU, USDA, ARS, Parlier, CA 93648; ${ }^{2}$ WRPIS, USDA, ARS, Pullman, WA 99164-6402

In California, rust (Puccinia allii) on garlic (Allium sativum) was not considered an economic problem until 1998, when a severe infection of the disease caused an average $51 \%$ reduction in yield throughout the state. The weight of harvested bulbs was $25 \%$ to $60 \%$ smaller than the average weight in the previous year, and soluble solids were reduced by an average of $15 \%$. Until recently, garlic varieties that are resistant or highly tolerant to rust have not been grown in garlic production fields in California. Open pollinated progenies derived from 3 Plant Introduction accessions of the U.S. Dept. of Agriculture-Agricultural Research Service germplasm collection (PI 493099, PI 540315 and W6 12820) were inoculated with a suspension of urediniospores (1, $2 \times 10^{5} / \mathrm{mL}$ ) isolated from rust infected garlic leaves obtained from production fields in Kings, Fresno and Yolo counties. Inoculations were carried out in a replicated experiment in the field under plastic covers, where 12 hours of misting was applied. The disease symptoms were scored on all leaves of the inoculated plants. The size of observed lesions varied from $<1$ to $280 \mathrm{~mm}^{2}$. Of the 118 plants evaluated, $9.3 \%$ had an average leaf area with rust symptoms of less than $1 \%$. The majority of the plants $(83.1 \%)$ had 1 to $5 \%$ of leaf area infected, and over $6 \%$ of plants had symptoms on 5 to $25 \%$ of their leaf surface. The highest number of plants with a low percent of rust symptoms on leaves was observed on progenies produced from PI 493099. While all maternal plants used to produce the seeds showed rust symptoms, the presence of progenies with $\leq 0.5 \%$ of leaf area infected indicated that a tolerance source to $P$. allii may exist in the A. sativum NPGS, germplasm collection.

\section{Poster Session 17-Mineral Nutrition}

\section{July 18, 2004, 12:30-1:30 PM Rio Grande Exhibit Hall}

\section{Current Fertilizer Input for Pot Gerbera Production Can Be} Reduced by More than 50\%

Youbin Zheng*1, Thomas Graham², Stefan Richard ${ }^{3}$, Mike Dixon ${ }^{4}$

${ }^{1}$ Univ. of Guelph, Environmental Biology, Guelph, Ontario, N1G 2W1, Canada; ${ }^{2}$ Univ. of Guelph, Environmental Biology, Guelph, Ontario, N1G 2W1, Canada; ${ }^{3}$ Univ. of Guelph, Environmental Biology, Guelph, Ontario, N1G 2W1, Canada; ${ }^{4}$ Univ. of Guelph, Environmental Biology, Guelph, Ontario, N1G 2W1, Canada

Pot gerbera (Gerbera jamesonii Var. 'Shogun') plants were subirrigated with one of four nutrient solutions $(10,25,50$, and $100 \%$ of full strength) in order to determine whether currently used commercial nutrient solution concentrations can be reduced without negative impact on crop production. Nutrient concentration levels did not affect leaf area, flower number and appearance, and plant total dry weight. There were no significant differences in leaf chlorophyll content between the plants that received the 50 and $100 \%$ strength nutrient solutions. It is concluded that nutrient solution concentrations typically used in commercial greenhouse, for pot gerbera production, can be safely reduced by at least $50 \%$ without adversely affecting crop production. Nutrients accumulated in the top section of the growth substrate under all treatment levels; however, no phytotoxic effect was observed. Fertilizer inputs were reduced in the $50 \%, 25 \%$, and $10 \%$ treatments by $54 \%$, $75 \%$, and $90 \%$ respectively. After 4 weeks recirculating, the quality of the nutrient solutions was still within acceptable limits.

\section{Effects of Fertigation with Nitrogen on Growth and Cropping of 'Elstar' Apple Trees}

\section{Zlatko Cmelik*1, Stanislav Tojnko}

${ }^{1}$ Faculty of Agriculture, Dept. of Pomology, Zagreb, 10000 , Croatia; ${ }^{2}$ Faculty of Agriculture, Fruit growing, Maribor, 2000, Slovenia

The trial was conducted in a 'Elstar'/M9 orchard (2500 trees/ha) and the experiment was designed as a split-block comprising five treatments (fertigation with $45 \mathrm{~kg} \cdot \mathrm{ha}^{-1} \mathrm{~N}, 60 \mathrm{~kg} \cdot \mathrm{ha}^{-1} \mathrm{~N}, 120 \mathrm{~kg} \cdot \mathrm{ha}^{-1}$ $\mathrm{N}$, irrigation without fertilizers, and control - without irrigation and without fertilizers), and two timing variants (treatments during vegetation period from 1 May to 20 June - variant A, and treatments from 1 May to 1 Aug. - variant B). The treatments were imposed beginning in the second year after planting and lasted five years. Fertigation 
with different amounts of nitrogen had no consistent effect on tree growth, cumulative yield and yield efficiency, however, treatments had a significant influence on regularity of bearing. The index of alternate bearing varied with treatment, but in both variant was significantly higher in control and in treatment with irrigation without application of fertilizer. These results demonstrated that the natural tendency of 'Elstar' to alternate bearing could be broken by the different rates of nitrogen applied by fertigation.

\section{Evaluating Silica Uptake in Bedding Plants}

Jonathan M. Frantz*1, Dharmalingam S. Pitchay², James C. Locke ${ }^{3}$, Charles Krause ${ }^{4}$

${ }^{1}$ ARS, USDA, Toledo, OH 43606; ${ }^{2}$ Univ. of Toledo, Plant Science Research Center, Toledo, $\mathrm{OH} 43606 ;{ }^{3} \mathrm{ARS}$, USDA, Toledo, OH 43606; ${ }^{4}$ ARS, USDA, Wooster, OH 44691

Silica ( $\mathrm{Si}$ ) is not considered to be an essential plant nutrient because without it, most plants can be grown from seed to seed without its presence. However, many investigations have shown a positive growth effect if $\mathrm{Si}$ is present, including increased dry weight, increased yield, enhanced pollination, and most commonly, increased disease resistance, which leads to its official designation as a beneficial nutrient. Surprisingly, some effects, such as reduced incidence of micronutrient toxicity, appear to occur even if $\mathrm{Si}$ is not taken up in appreciable amounts. The literature results must be interpreted with care, however, because many of the benefits can be obtained with the counterion of the Si supplied to the plant. Determining a potential benefit from $\mathrm{Si}$ could be a large benefit to greenhouse plant producers because more production is using soilless media that are devoid of $\mathrm{Si}$. Therefore, $\mathrm{Si}$ must be supplied either as a foliar spray or nutrient solution amendment. We investigated adding Si to New Guinea Impatiens (Impatiens hawkeri Bull), marigold (Tagetes erecta), pansy (Viola wittrockiana), spreading petunia (Petunia hybridia), geranium (Pelargonium spp.), and orchid (Phalaenopsis spp.). Using SEM, energy dispersive X-ray analysis, and ICP analysis, Si content and location was determined. This information and other growth characteristics will be used as a first step in determining the likelihood of using $\mathrm{Si}$ as a beneficial element in greenhouse fertilizer solutions for higher quality bedding plants with fewer agrochemical inputs.

\section{Determination of Optimal Nitrogen Requirements for Ratibida} columnifera Biomass Production and Flowering

\section{Rebecca Kincaid*1, Tracy Dougher ${ }^{2}$}

${ }^{1}$ Montana State Univ., Plant Sciences and Plant Pathology, Bozeman, MT 59717-3140; ${ }^{2}$ Montana State Univ., Plant Sciences and Plant Pathology, Bozeman, MT 59717-3140

There has been an increasing interest in drought tolerant native flower species for Montana residential landscapes and roadsides. Ratibida columnifera is a drought tolerant, perennial wildflower that can be used in home gardens as well as on roadsides. However, there is no knowledge of how $R$. columnifera will respond to typical nitrogen fertilization in residential landscapes. Our objective was to determine the correct nitrogen application required for $R$. columnifera to acquire optimal growth and development. After germinating and transplanting $R$. columnifera seedlings, nitrogen treatments began with five groups containing six pots in each group. Pots were fertilized with $100 \mathrm{ml}$ of ammonium nitrate at $0 \mathrm{ppm} \mathrm{N}, 25 \mathrm{ppm} \mathrm{N}, 50 \mathrm{ppm} \mathrm{N}, 75 \mathrm{ppm} \mathrm{N}$, or $100 \mathrm{ppm} \mathrm{N}$ at weekly intervals. All pots were fertilized with $100 \mathrm{~mL}$ of $50 \mathrm{ppm}$ potassium phosphate. Three plants from each treatment were harvested 30 days after the start of fertilization treatments and underwent biomass evaluations of their fresh and dry weights. The remaining three pots from each treatment were evaluated at blooming for time to flowering, flower number, and flower quality. R. columnifera biomass at 30 days benefited from $25-50$ ppm nitrogen, but did not increase biomass above $50 \mathrm{ppm}$. Flowering was affected at different levels than biomass and was delayed by high nitrogen.
377 Influence of Root Zone Calcium on Maintenance of Potato Shoot Tip

James S. Busse ${ }^{1}$, Senay Ozgen², Jiwan P. Palta*3

${ }^{1}$ Univ. of Wisconsin-Madison, Horticulture, Madison, WI 53706; ${ }^{2}$ Univ. of WisconsinMadison, Horticulture; ${ }^{3}$ Univ. of Wisconsin-Madison, Horticulture

Calcium deficiency in the potato shoot results in sub-apical necrosis. This is a physiological condition whereby necrotic lesions form a few millimeters below the shoot apex ultimately causing shoot tip senescence, loss of apical dominance, and the release of axillary buds. Using a Dark Red Norland tissue culture system, we studied the relationship of root zone calcium levels to shoot tip maintenance. Root zone calcium levels lower than $50 \mathrm{ppm}$ resulted in shoot tip death and prolific branching from axillary buds. Chelator studies with EGTA and tracer studies with $45 \mathrm{Ca}$, indicated a direct involvement of calcium at the shoot tip for shoot tip maintenance. Interestingly, low root zone calcium deficiency syptoms could be mitigated with 0.001 to $0.01 \mu \mathrm{M}$ of the auxin analog NAA. Developmental studies of calcium deficiency symptoms indicate no anatomical relationship with shoot tip necrosis as xylem conducting elements were found near the shoot apex regardless of the root zone calcium level. These results have important implications for potato shoot development especially during the early development stage from the seed piece.

\section{Nitrogen Source and Concentration Affect Growth and Per- formance of Bedding-plant Impatiens}

\section{Fredy R. Romero*1, Richard J. Gladon ${ }^{2}$, Henry G. Taber ${ }^{3}$}

${ }^{1}$ Iowa State Univ., Horticulture, Ames, Iowa; ${ }^{2}$ Iowa State Univ., Horticulture, Ames, Iowa; ${ }^{3}$ Iowa State Univ., Horticulture, Ames, Iowa

Impatiens (Impatiens wallerana Hook. f.) is the most important annual bedding plant in the US, based on wholesale dollar volume. Production of high-quality plants requires optimization of the nutrition regimen during growth, especially the total nitrogen $(\mathrm{N})$ concentration and the ratio of $\mathrm{N}$ sources. Our objective was to determine the $\mathrm{N}$ concentration and ratio of $\mathrm{N}$ sources that optimize bedding-plant impatiens growth and development. We used four $\mathrm{N}$ concentrations $(3.5,7,10.5$, and 14 $\mathrm{mmol} \cdot \mathrm{L}^{-1}$ of $\mathrm{N}$ ) in factorial combination with four ratios of nitrate- $\mathrm{N}$ $\left(\mathrm{NO}_{3}{ }^{-} \mathrm{N}\right)$ to ammonium-N $\left(\mathrm{NH}_{4}{ }^{+} \mathrm{N}\right)(4: 0,3: 1,1: 1$, and 1:3). Application of treatments began at day 30 , and every-other-day applications were conducted until day 60 . From day 60 to day 70 only deionized water was applied. $\mathrm{N}$ concentration and source displayed interation for most growth parameters. When $\mathrm{N}$ was supplied at a concentration $\leq 7 \mathrm{mmol} \cdot \mathrm{L}^{-1}$, the $\mathrm{NO}_{3}-\mathrm{N}$ to $\mathrm{NH}_{4}{ }^{+} \mathrm{N}$ ratio did not affect growth. When $\mathrm{N}$ was supplied at a concentration $\geq 10.5 \mathrm{mmol} \cdot \mathrm{L}^{-1}$, a $1: 3 \mathrm{NO}_{3}^{-}-\mathrm{N}$ to $\mathrm{NH}_{4}{ }^{+}-\mathrm{N}$ ratio yielded the greatest shoot dry weight, shoot fresh weight, plant diameter, and number of flower buds per plant. With a $\mathrm{NO}_{3}^{-}-\mathrm{N}$ to $\mathrm{NH}_{4}^{+}-\mathrm{N}$ ratio of 4:0, these growth parameters decreased. To produce high-quality, bedding-plant impatiens, $\mathrm{N}$ should be applied at $\mathrm{NO}_{3}^{-}-\mathrm{N}$ to $\mathrm{NH}_{4}^{+}-\mathrm{N}$ ratios between $1: 1$ and $1: 3$ in combination with an $\mathrm{N}$ concentration of $10.5 \mathrm{mmol} \cdot \mathrm{L}^{-1}$ at each fertigation from day 30 to day 60 of the production cycle.

\section{Anion Species in Fertilizers Affect Growth and Development in Bedding Plants}

Dharmalingam S. Pitchay*1, Jonathan M. Frantz ${ }^{2}$, James C. Locke

${ }^{1}$ Univ. of Toledo, Plant Science Research Center, Toledo, OH 43606; ${ }^{2}$ ARS, USDA, Toledo, OH $43606 ;{ }^{3}$ ARS, USDA, Toledo, OH 43606

Currently, formulation of inorganic fertilizers is based on cation amounts such as $\mathrm{NH}_{4}, \mathrm{~K}, \mathrm{Mg}, \mathrm{Ca}, \mathrm{Fe}, \mathrm{MN} \mathrm{Cu}$, and $\mathrm{Zn}$, whereas anion species and amounts are viewed, with few exceptions, as necessary fillers. The delivery of cations in the nutrient solution is associated with an anion such as $\mathrm{Cl}, \mathrm{SO}_{4}, \mathrm{NO}_{3}, \mathrm{PO}_{4}$ or $\mathrm{CO}_{3}$. These anions at higher concentrations can result in different growth responses by altering the rhizosphere $\mathrm{pH}$, soluble salts, and influencing the uptake of both cations and anions. The impact of these anions has not been extensively studied in the formulation of inorganic fertilizers. Several experiments assessed the effect of $\mathrm{SO}_{4}$ and $\mathrm{Cl}$ on root and shoot growth and development of bedding 
plants represented by petunia, impatiens, and vinca. In all treatments, plant height, shoot and root dry weight, and flower number decreased with an increase in $\mathrm{Cl}$ concentration. Root morphology was marked by fewer total roots and shorter primary and secondary roots when grown with $\mathrm{Cl}$ anions compared to the plants grown with $\mathrm{SO}_{4}$ anions. This indicates that anions have a larger role in determining optimum fertilizer formulation than previously believed. This information provides an additional tool in formulating fertilizers for greenhouse bedding plant production.

\section{Nitrogen and Phosphorous Absorption and Leaching from Anthurium Plants Grown in Municipal Solid Waste Compost}

\section{Lizzette Gonzalez*1, Juan C. Vazquez², Maria del C. Libran ${ }^{3}$}

${ }^{1}$ Univ. of Puerto Rico, Horticulture, Mayaguez, PR 00680-9030, Puerto Rico; ${ }^{2}$ Univ. of Puerto Rico, Horticulure, Mayaguez, PR 00680-9030; ${ }^{3}$ Univ. of Puerto Rico, Horticulture, Mayaguez, PR 00680-9030

Municipal solid waste compost (MSW) can be used as an effective substrate for ornamental plant production as an alternative to peat. In a previous study a mix with peat, perlite, and vermiculite $(1: 1: 1$ per volume) was used along MSW compost at 1:1 per volume ratio as a growing substrate for Catharanthus roseus, providing nitrogen (N) for adequate plant growth. This study will focus in determining if MSW provides adequate amounts of $\mathrm{N}$ and Phosphorous $(\mathrm{P})$ for Anthurium pot plant production, reducing the use of fertilizers and nutrient loss to the environment. Plants were fertilized at $0,100,150$, and $200 \mathrm{ppm}$ $\mathrm{N}$ using a 20-10-20 soluble fertilizer. Chemical characterization of leachates collected from plants grown in substrates with or without MSW, to determine possible nutrient run off. Tissue analysis for $\mathrm{N}$ and $\mathrm{P}$ content was conducted to determine absorption. Our results shows an increase in $\mathrm{NH}_{4}-\mathrm{N}, \mathrm{NO}_{3}-\mathrm{N}$ and soluble $\mathrm{P}$ in leachates as the fertilizer level increased. Higher $\mathrm{NO}_{3}-\mathrm{N}$ content in leachates was observed in treatments with MSW. Higher P concentrations were observed in leachates from substrate without MSW. Weeks after, $62 \%$ of the plants grown in MSW were dead; the surviving plants had less biomass, but similar $\mathrm{N}$ content in leaf and root tissues than plants grown without MSW. Higher P content in tissues was observed in fertilized plants grown without MSW. The MSW was a nutrient source for the plants, but further studies should be conducted for optimum use of MSW as a component of growing substrate.

\section{Managing Nitrogen, Potassium, and Boron in New Guinea Impatiens: Is More Better?}

Dharmalingam S. Pitchay*1, Jonathan M. Frantz ${ }^{2}$, Jonathan M. Locke $^{3}$, Charles Krause ${ }^{4}$

${ }^{1}$ Univ. of Toledo, Plant Science Research Center, Toledo, OH 43606; ${ }^{2}$ ARS, USDA, Toledo, $\mathrm{OH} ;{ }^{3}$ ARS, USDA, Toledo, OH 43606; ${ }^{4}$ ARS, USDA, Toledo, OH 44691

Growers tend to over fertilize their plants as a way to minimize the likelihood of encountering nutrient deficiencies that would reduce the quality of their plants. Much of the nutrition literature focuses on the nutritional extremes namely of toxicity and deficiency. Once plants get to this stage, little can be done to correct the problem. Characteristics of plant performance in super-optimal conditions, yet below toxic levels, is less well known, and needs to be developed to help growers identify problems in their production practices before they impact sales. New Guinea Impatiens were grown over a wide range of N, K, and B levels, from $15 \%$ to $400 \%$ full strength Hoagland's solution for each nutrient after establishing transplanted rooted cuttings in a peat : perlite soilless media. Plants were grown for four weeks during treatment, during which time the flowers were pinched. After only 2 weeks of treatment, plants with $200 \%$ and $400 \%$ N were significantly shorter than control plants and plants with $15 \%$ N. Reflectance measurements and photographs were made twice a week. At the end of the four weeks, plant tissue was analyzed for form of $\mathrm{N}$, root development and structure, and leaf area. Tissue samples were also analyzed with SEM and energy dispersive $\mathrm{X}$-ray analysis to determine changes in nutrient location and tissue structure. This data provides insight into the nutrition economy of plants in general, tests the use of reflectance spectrometry as a method of detecting super-optimal fertilizer concentrations, and will help growers optimize their fertilization requirements to reduce production costs yet maintain high plant quality.

\section{Effect of Neutralizing Irrigation Water Alkalinity with Acid} on Nutritional Status and Growth of Thryallis (Galphimia glauca Cav.)

Joseph P. Albano*1, P. Chris Wilson ${ }^{2}$, Sandra B. Wilson ${ }^{3}$

${ }^{1}$ USDA, ARS, U.S. Horticultural Research Laboratory, Ft. Pierce, FL 34945; ${ }^{2}$ Univ. of Florida, Indian River Research and Education Center, Ft Pierce, FL 34945; ${ }^{3}$ Univ. of Florida, Indian River Research and Education Center, Ft Pierce, FL 34945

Sources of irrigation water in South Florida typically contain high levels of dissolved carbonates and bicarbonates. Repeated application of high alkalinity water can cause substrate-solution $\mathrm{pH}$ to rise, thereby altering nutrient availability, and possibly leading to the development of nutrient disorders and a reduction in plant growth. The objectives of the current study were to determine the effects of neutralizing alkalinity of irrigation water on the nutritional status and growth of Thryallis (Galphimia glauca Cav.). Plants were grown in 11.4-L containers in a 5 peat : 4 pine bark : 1 sand (v:v:v) mix. Treatments were prepared with water collected from a commercial nursery with inherent calcium carbonate levels in excess of $260 \mathrm{mg} \cdot \mathrm{L}^{-1}$ and $\mathrm{pH}$ above 7.3. Treatments consisted of $0 \%$ (control), $40 \%$, or $80 \%$ alkalinity neutralized with sulfuric acid. At harvest, 51 weeks after initiating treatments, foliar levels of Fe were $28 \%$ greater, Mn 55\% greater, and $\mathrm{Zn} 27 \%$ greater in the $80 \%$ than $0 \%$ neutralized alkalinity treatment. Growth indices and leaf greenness averaged over the course of the study were significantly greater in the $40 \%$ than in the $0 \%$ or $80 \%$ alkalinity neutralized treatments. Over the course of the study, leachate $\mathrm{pH}$ averaged 7.5, 6.8, and 5.3; and electrical conductivity (EC) averaged $1.4,1.9$, and $2.2 \mathrm{dS} \cdot \mathrm{m}^{-1}$ in the $0 \%, 40 \%$, and $80 \%$ alkalinity neutralized treatments, respectively.

\section{Developing Value-added Practices and Branding for High- Sugar Tomatoes}

Christopher D. Harlow ${ }^{1}$, Elizabeth S. Larrea², Mary M. Peet*3

${ }^{1}$ N.C. State Univ., Horticultural Science, Raleigh, NC 27695-7609; ${ }^{2}$ N.C. State Univ., Horticultural Science, Raleigh, NC 27695-7609; ${ }^{3}$ N.C. State Univ., Horticultural Science, Raleigh, NC 27695-7609

Research was initiated at the N.C. State Univ. Horticultural Field Laboratory, Raleigh, to identify cultural practices and tomato cultivars giving superior taste under North Carolina greenhouse conditions. The specialty cultivars '67', 'Diana', 'Elegance', 'Momotaro', and 'S630' were grown and harvested, as well as 'Trust', which is grown on $85 \%$ of the North American greenhouse tomato acreage. Additionally, two fertilizer regimes were provided to the plants: standard greenhouse tomato fertilization $\left(\mathrm{EC} \approx 1.75 \mathrm{dS} \cdot \mathrm{m}^{-1}\right)$ or high fertilization $(\mathrm{EC} \approx 3.75$ $\left.\mathrm{dS} \cdot \mathrm{m}^{-1}\right)$. Fertilizers were the same in both treatments. Seeds were started in October 2002 and transplanted, 2 per pot, into 'Bato' buckets containing perlite in November. Standard cultural practices were followed, and plants were fertigated using the Harrow Fertigation Manager ${ }^{\mathrm{TM}}$ system. Taste tests conducted on three dates revealed differences among cultivars, with '67', 'Elegance' and 'Momotaro' consistently scoring well. Overall, all test varieties were scored higher than 'Trust'; however flavor was somewhat less sweet than anticipated, especially early in the season, averaging 2-3 on a scale of 5, where 5 was "best". No significant differences were seen between the standard and high fertilization treatments. Differences in total harvest weight were seen among cultivars. 'Elegance' and ' 67 ' produced fruit consistently well through the harvest season, while the remaining cultivars' yields were sporadic. Harvested fruit were homogenized, and Brix was measured as an indicator of fruit quality. Significant differences in Brix were seen among the cultivars, with ' 67 ' significantly higher than all other varieties and 'Elegance' and 'Momotaro' higher than the remaining cultivars. All specialty cultivars had higher 'Brix than 'Trust'. 


\section{Poster Session 18-Herbs, Spices and Medicinals}

\section{July 18, 2004, 12:30-1:30 PM Rio Grande Exhibit Hall}

299 Antimicrobial Effect of Guava Products against Foodborne Pathogens

Guochen Yang*1, Salam A. Ibrahim² ${ }^{2}$ Carl E. Niedziela, Jr. ${ }^{3}$

${ }^{1}$ North Carolina A\&T State Univ., Natural Resources and Environmental Design, Greensboro, NC 27411; ${ }^{2}$ North Carolina A\&T State Univ., Human Environment and Family Sciences, Greensboro, NC 27411; ${ }^{3}$ North Carolina A\&T State Univ., Natural Resources and Environmental Design, Greensboro, NC 27411

This study investigated antimicrobial effects of guava products on the survival and growth of Escherichia coli O157:H7 in liquid medium. Seven strains of E. coli O157:H7 (944, 380, E0019, F4546, H1730, Cider, 9727) were tested. These strains were maintained in BHI broth. Guava fruits were sliced into small pieces and blended using a blender. Guava juice and leaves were then extracted using three solvents: water, methanol and hexane. Fruit extracts were dissolved in $10 \mathrm{ml} \mathrm{BHI} \mathrm{broth}$ tubes to make a fruit solution of 5\% (w/v). E. coli O157:H7 was inoculated into fruit solutions at $2 \log \mathrm{cfu} / \mathrm{mL}$. After incubation at $37^{\circ} \mathrm{C}$ for $24 \mathrm{~h}$, samples were serially diluted 10 folds. The proper diluent was spread-plated on TSA in duplicate. After incubation at $35^{\circ} \mathrm{C}$ for $24 \mathrm{~h}$, viable cell counts were obtained. The experiment was replicated three times in a randomized complete-block design. Results demonstrated that guava products (fruit, juice, and leaf extracts) significantly reduced survival and growth of the tested foodborne pathogen strains. Water extract showed the highest antimicrobial activity, followed by methanol and hexane. These results indicate guava extracts are a potential antimicrobial agent to ensure food safety.

300 Growth iInhibition of Pathogenic Bacteria by Artificially grown Ipomoea batatas (L.) Leaf

MD. Shahidul Islam*1, M. Jalaluddin², M. Yoshimoto ${ }^{3}$, O. Yamakawa ${ }^{4}$

${ }^{1}$ Univ. of Arkansas at Pine Bluff, Dept. of Agriculture, Pine Bluff, AR 71601; ${ }^{2}$ Univ. of Arkansas, Agriculture, Pine Bluff, AR 71602; ${ }^{3}$ National Agril. Research Center, Upland Crop Research, Japan; ${ }^{4}$, NARCKO, Japan

The antibacterial activity of artificially grown sweetpotato [Ipomoea batatas (L.) Lam.] leaves was investigated against both gram positive and gram negative bacteria namely Escherichia coli (O157:H7), Bacillus and Ecolai using three different cultivars, which are developed to use as a leafy vegetables namely Simon-1, Kyushu-119 and Elegant Summer. The sweetpotato leaves were grown under different temperatures $\left(20^{\circ} \mathrm{C}, 25^{\circ} \mathrm{C}\right.$, and $\left.30^{\circ} \mathrm{C}\right)$ and artificial shading $(\mathrm{O} \%, 40 \%$ and $80 \%)$ conditions. There were some cultivar differences but the lyophilized leaf powder $(100 \mathrm{mg})$ from all the cultivars in the Trypto Soya Broth cultivation medium $(10 \mathrm{~mL})$ strongly suppressed the growth of all the bacteria studied and its effect was detectable even after autoclave treatment. But the antibacterial extract of the leaves had no effect on the growth of five types of bifidobacterium useful for human health. The water extracted antibacterial fractions from all the cultivars were viscous and the color was brown. Furthermore, the leaves grown under moderate low temperature $\left(20^{\circ} \mathrm{C}\right)$ with $0 \%$ shading treatments strongly suppressed the bacterial growth as comported to other treatments, which was accompanied by significantly high accumulation of sugar and polyphenol contents in the leaves. The results also suggest that there were a strong relationship among bacterial growth and antioxidatative compounds in the sweetpotato leaves. Therefore, the antibacterial action of sweetpotato leaves may depend on their antioxidative compounds or/and pectin like materials. Thus, the practical use of sweetpotato leaves is expected to prevent bacteria caused food poisoning.

\section{The Influence of Mulching with Straw on the Field Microcli-} mate and Ginger Growth

\section{Kun $\mathrm{Xu}^{* 1}$, Xiufeng Wang ${ }^{2}$, Fang Wang}

${ }^{1}$ Shandong Agricultural Univ., Horticultural College, Tai'an, Shandong, 271018, China; ${ }^{2}$ Shandong Agricultural Univ., Horticultural College, Tai' an, Shandong, 271018, China; ${ }^{3}$ Shandong Agricultural Dept., Shandong Agricultural Dept.

Mulching with straw increase soil water content, air relative humidity and air temperature, but decreased soil temperature. Though mulching with straw didn't change light intensity, ginger growth and yield were the same as shading. The growth and yield under shading and mulching with straw were both higher than that of naked soil.

\section{Bitter Melon (Momordica charantia L.) a Potential Vegetable} for Special Nutritional and Medicinal Values in America

\section{Jalaluddin ${ }^{1}$, Md. Shahidul Islam*2}

${ }^{1}$ Univ. of Arkansas at Pine Bluff, Dept. of Agriculture, Pine Bluff, AR 71601; ${ }^{2}$ Univ. of Arkansas at Pine Bluff, Dept. of Agriculture, Pine Bluff, AR 71601

Foods from plants can provide enough energy and essential nutrients for maintaining human health as well as for prevention of many serious diseases. Many exotic vegetables are known for their special nutritional and medicinal properties. Bitter Melon (Momordica charantia L.), an annual vegetable of Cucurbitaceae family, is found to be one of the important vegetables of special nutritional and medicinal qualities. Germplasm lines and land races of Bitter Melon were evaluated in 2000 and 2001 for their adaptability in Southeast Arkansas. Seven adaptable lines/varieties were tested in replicated field trials for productivity at the Univ. of Arkansas at Pine Bluff Agricultural Research Center in 2002 and 2003. Melons were harvested at their marketable stages beginning in June and ending in September for yield estimation. Nutritional qualities of Bitter Melons were examined by chemical analyses conducted at the Univ. of Arkansas, Fayetteville (UAF) Food Science Laboratory. Analyses for antioxidants and other compounds as well as cooking qualities are currently underway. Several recipes have been tasted for consumer acceptance. The popular belief of bitter melon to improve glucose tolerance in Type II diabetes and lower blood cholesterol are being investigated. It is still to be determined if the chemical constituents such as certain alkaloids and polypeptides found in bitter melons are effective individually or in combination.

\section{Perspective for the Sabila (Aloe vera barbadensis) Production in the Mexico Sonoran Desert}

Fabian Robles-Contreras ${ }^{1}$, Raul Leonel Grijalva-Contreras*2, Manuel de Jesus Valenzuela-Ruiz ${ }^{3}$, Ruben Macias-Duarte ${ }^{4}$

${ }^{1}$ INIFAP-Caborca, Agroclimatology, Caborca, Sonora, 83600, Mexico; ${ }^{2}$ INIFAP-Caborca, Protected Horticulture, Caborca, Sonora, 83600, Mexico; ${ }^{3}$ INIFAP-Caborca, Viticulture, Caborca, Sonora, 83600, Mexico; ${ }^{4}$ INIFAP-Caborca, Soil \& Horticultural, Caborca, Sonora, 83600, Mexico

Sabila is a plant that by his multiple applications in the medicine as in the naturist feeding and the cosmetics industry is taking a lot of importance at world-wide level. In addition, this is a crop that requires little amount of water to be developed satisfactorily, for this reason this crop is a good alternative to cultivate in the agricultural areas of the sonoran desert. The objective of this study was to determine the viability to produce sabila in the sonoran desert. During Summer 2002, two experiments of sabila was conducted, and distributed on two agricultural areas of the sonoran desert: The first experiment was carried out in two location of the agricultural region of Sonoyta, Sonora, Mexico, ("The Nariz" and "The Papago" farm). The second experiment was carried out in two lacation of the agricultural region of Caborca, Sonora, Mexico, ("The Bizani" and "The Coast" area) being the less cold area. During the first year we evaluated the surviving plants and the sprout emission. The result indicated that the plant in the Sonoyta region is more affected for the winter frosts, and it is reflected in a smaller average of surviving plants, being this of $78.6 \%$ and $97.8 \%$ in Sonoyta and Caborca respectively. Also we observed an effect in the percentage of plants that present sprout emission, being this of $11.25 \%$ and $23.65 \%$ in Sonoyta and Caborca respectively. Apparently the agricultural area of caborca has suitable condition for Sabila production.

304 Influence of Physical Parameters on the Growth, Morphogenesis and Volatile Monoterpene Production in Mentha spicata L. Cultures In Vitro

Brent Tisseret*1, Steven Vaughn ${ }^{2}$

${ }^{1}$ USDA, ARS, Fermentation Biochemistry Research Unit, Peoria, IL 61548; ${ }^{2}$ USDA, ARS 
The influence of altering the physical environment on the growth (fresh weight), morphogenesis (leaf, root, and shoot numbers) and secondary metabolism (i.e., volatile monoterpene, and carvone) of Mentha spicata L. (spearmint) shoots cultured on MS medium was studied. The type of physical support (e.g., agar, liquid, platforms, or glass supports) using Magenta vessels altered growth and morphogenesis. Mint shoots grown on liquid produced 4-x fold more fresh weight than on agar. Carvone levels were unaffected physical supports. Increasing the frequency of media replacement significantly increased growth without altering carvone. Vessel size influence was tested by culturing shoots on culture tubes, Magenta vessels and 1/2-gal. jars. Positive correlations occurred between vessel capacity and culture growth, morphogenesis and carvone levels. A comparative study testing several spearmint cultivars on either culture tubes or an automated plant culture system (APCS, a sterile hydroponics system) was conducted. The APCS produced more biomass (e.g., $\approx 15$-x fold increase in fresh weight), morphogenesis and carvone than employing culture tubes. Carvone was only produced from shoots and was absent in either roots or callus. Carvone levels decreased proportionally in shoots as the distance from the shoot terminus increased. Altering the number of media culture immersions $(4,8,12$, or 16 immersions/day) with the APCS was tested. Twelve immersions of media/day was optimum. Higher culture growth rates resulted in lower carvone levels/culture; however, overall carvone levels/vessel increased due to greater biomass production.

\section{Morphological Variation in Black Cohosh-A Threatened Medicinal Plant}

Zoë E. Gardner ${ }^{1}$, Lorna Lueck², Lyle E. Craker*3

${ }^{1}$ Univ. of Massachusetts, Dept. of Plant \& Soil Sciences, Amherst, MA 01003; ${ }^{2}$ Univ. of Massachusetts, Dept. of Plant \& Soil Sciences, Amherst, MA 01003; ${ }^{3}$ Univ. of Massachusetts, Dept. of Plant \& Soil Sciences, Amherst, MA 01003

Black cohosh [Actaea racemosa L.; syn. Cimicifuga racemosa (L.) Nutt], a plant native to the eastern United States, is believed to have been used as a medicinal by Native Americans for thousands of years. Currently, the root of the species is popular as a herbal remedy for the relief of menopausal symptoms. Recent estimates suggest that over $90 \%$ of the black cohosh sold is collected from the wild, resulting in an unsustainable harvest of $\approx 9$ million individual plants per year. This study investigated the morphological variation of the plant at the population and species levels to assist plant breeders working on domestication and government agencies responsible for conservation of the species. Examination of leaves and flowers suggest morphological of the species is relatively low, but that several populations have unique morphological characteristics.

\section{Synthesis of n-Benzylhexadecanamide as a Standard for Quantifying Macamides in Maca}

\section{Megan McCollom*1, Stefan Gafner², Lyle E. Craker ${ }^{3}$}

${ }^{1}$ Univ. of Massachusetts, Dept. of Plant and Soil Sciences, Amherst,, MA 01003; ${ }^{2}$ Tom's of Maine, Chemistry, Kennebunk, ME 04043; ${ }^{3}$ Univ. of Massachusetts, Dept. of Plant \& Soil Sciences, Amherst, MA 01003

Maca (Lepidium meyenii Walp.), a root crop similar to radish, has been consumed in Peru for thousands of years as a food and medicine. Medicinally, the plant is used to increase human and livestock stamina and to ameliorate fertility problems associated with living at the high elevations in which the plant grows. The reputation of maca as a fertility and libido enhancer has increased the popularity of the plant in the United States and other Western countries. Constituents of interest in maca include fatty acids and macamides, but to evaluate the quality of maca products and raw material, fatty acid and macamide standards are required. While fatty acid standards are obtainable, macamide standards are not commercially available. In this study, one major macamide, $n$-benzylhexadecanamide, was synthesized with high yields using benzylamine and palmitoyl chloride as starting materials. The process, which was a relatively easy, one-step synthesis, could be used also to obtain other macamides without going through a time-consuming isolation. The major macamides in extracts of dried, ground maca sourced from vendors in the United States and Peru were identified and quantified by LC-UV/MS using $n$-benzylhexadecanamide as a standard compound.

\section{Growth and Yield of Six Medicinal Herbs in Response to Mulch Type}

Jeanine M. Davis*1, George B. Cox ${ }^{2}$

${ }^{1}$ N.C. State Univ., Horticultural Science, Fletcher, NC 28732; ${ }^{2}$ N.C. State Univ., Horticultural Science, Fletcher, NC 28732

Weeds are a major concern in the production of many medicinal herbs. Weeds can interfere with the growth of the herb, reducing yields of foliage, flowers, and roots. The presence of weeds in the harvested herb can lessen the value of the herb or render it unmarketable. Weed control on medicinal herbs is difficult because there are few herbicides cleared for use and many herbs are organically grown. In this study, we examined the use of white and black plastic mulches to control weeds in the production of six medicinal herbs in the northern piedmont region of North Carolina. The herbs were grown for 2 years on raised beds with drip-irrigation. The beds were left bare or covered with black plastic mulch or white plastic mulch. The herbs grown were Arnica chamissonis, Echinacea angustifolia, Echinacea purpurea, Leonurus cardiaca, Scutellaria lateriflora, and Spilanthes oleracea. Transplants were field set in May and June. Depending on the particular herb, foliage, and flowers were harvested during both growing seasons and roots were harvested at the end of the second season. Both plastic mulches provided excellent weed control compared to the bare ground treatment. A. chamissonis flower yields were reduced when plants were grown with either plastic mulch. Growth and yield of E. angustifolia, L. cardiaca, and S. lateriflora were unaffected by any mulch treatment In contrast, total season yields of E. purpurea tops (stems, leaves, and flowers) and roots were higher with both plastic mulches than with the bare ground treatment. Root yields of $S$. oleracea were higher with the bare ground treatment than with either mulch, but top yields were unaffected by treatment.

\section{Propagule Type and Planting Time Affect Subsequent Growth of American Mayapple}

Kent Cushman ${ }^{* 1}$, Muhammad Maqbool ${ }^{2}$

${ }^{1}$ Mississippi State Univ., North Mississippi Research \& Extension Center, Verona, MS 38879; ${ }^{2}$ Mississippi State Univ., North Mississippi Research \& Extension Center; Verona, MS 38879

The American mayapple (Podophyllum peltatum L.) is native to eastern North America and its leaves contain the pharmaceutical compound podophyllotoxin. Podophyllotoxin is used in the manufacture of several types of drugs used in the treatment of cancer, arthritis, and various skin conditions. With leaves being a renewable resource, the plant is a candidate for cultivation by growers of specialty crops. We are investigating strategies of establishing mayapple in field plantings. Rhizome segments were harvested from the wild and immediately transplanted to raised beds in northern Mississippi. There were three planting times, Fall 2000, Spring 2001, or Summer 2001, and three propagule types: (1) two-node rhizome segments with a terminal node and its adjacent one-year-old node, referred to as $\mathrm{Nt}+\mathrm{N} 1$, (2) one-node segments with a single node, other than $\mathrm{Nt}$, of unknown age, referred to as $\mathrm{Nx}$, or (3) one-node segments with a single terminal node, referred to as Nt. Each spring, shoots emerged from the ground in March, grew during April, and senesced throughout May. Shoot emergence, leaf area, leaf dry mass, and shoot height were recorded each spring. Plant growth and performance can be ranked as follows. EXCELLENT: Spring-planted $\mathrm{Nt}+\mathrm{N} 1$. GOOD: Fall- and summer-planted Nt+N1; fall-, spring-, and summer-planted Nx; and spring-planted Nt. FAIR: Fall-planted Nt. POOR: Summer-planted Nt. We can now recommend all three planting dates, but in the following order of preference: spring $>$ fall $>$ summer. We can also recommend two of the three propagule types, also in the following order of preference: $\mathrm{Nt}+\mathrm{N} 1>\mathrm{Nx}$. The Nt propagules performed adequately when planted during fall or spring, but they did not perform well when planted during summer. 
309 Crop Diversification in Ontario: Adaptation of Chives

Alan W. McKeown*1, Mary Ruth McDonald², Cathy J. Bakker³, Kevin Vander $\mathrm{Kooi}^{4}$

${ }^{1}$ Univ. of Guelph, Plant Agriculture, Simcoe, ON N3Y 4N5, Canada; ${ }^{2}$ Univ. of Guelph, Plant Agriculture, Kettleby, ON L0G 1J0, Canada; ${ }^{3}$ Univ. of Guelph, Plant Agriculture, Simcoe, ON N3Y 4N5, Canada; ${ }^{4}$ Univ. of Guelph, Plant Agriculture, Kettleby, ON L0G 1J0, Canada

Chives, (Allium schoenoprasum) consumption and production are increasing in Ontario. Rust (Puccinia allii F. Rudolphi) has been a problem with some chive cultivars for some growers, and in Ontario, basic information on production is nonexistent. The objectives were to identify cultivars with high yields, disease resistance and winter survivability. Plantings of six cultivars of chives were established in 2002 and 2003 in two contrasting environments, on organic (Kettleby) and mineral (Simcoe) soils; and one cultivar of garlic chives (A. tuberosum) at Kettleby. Leaves were harvested to a length of $30 \mathrm{~cm}$, weighed and assessed for visible signs of rust. In Spring 2003, the number of dead plants was recorded to determine the overwinter survivability of each cultivar. Performance varied among cultivars and between locations. In Simcoe, Staro produced the highest yield in 2002 while generic (unnamed) chives produced the highest yield in the second year. In Kettleby, yield was similar among cultivars in 2002 but in 2003 generic chives produced the highest yield. Overwinter survival also varied between locations and second season yields were much higher in Kettleby. Less snow cover and subsequent winter injury is a possible explanation for the lower yields and poorer winter survival in Simcoe. No symptoms of rust were found in either location. Chives are a viable crop in Ontario, and appear to have different adaptability to regional soils and climates.

\section{Poster Session 19-Pomology 1}

July 18, 2004, 12:30-1:30 PM

Rio Grande Exhibit Hall

134 Can Pawpaw Fruit be Cold-stored for Extended Periods?

Federica Galli*1, Douglas D. Archbold², Kirk W. Pomper ${ }^{3}$, Thomas R. Hamilton-Kemp ${ }^{4}$, Randall W. Collins ${ }^{5}$

${ }^{1}$ Univ. of Kentucky, Horticulture, Lexington, KY 40546-0091; ${ }^{2}$ Univ. of Kentucky, Horticulture, Lexington, KY 40546-0091; ${ }^{3}$ Kentucky State Univ., Community Research Service, Frankfort, KY 40601; ${ }^{4}$ Univ. of Kentucky, Horticulture, Lexington, KY 40546-0091; ${ }^{5}$ Univ. of Kentucky, Horticulture, Lexington, KY 40546-0091

Pawpaw [Asimina triloba (L.) Dunal] is a highly perishable climacteric fruit, softening rapidly once ripening commences which may limit its marketability. In studies to determine the optimum cold storage temperature and maximum storage life of the fruit, pawpaw fruit were stored at $-2,2$, and $6{ }^{\circ} \mathrm{C}$ for $1,2,4,8$, and 12 weeks, and then ripened upon removal to ambient temperature. Through 4 weeks, fruit exhibited adequate firmness upon removal from cold storage, but at 8 and 12 weeks fruit held at 2 and $6{ }^{\circ} \mathrm{C}$ were very soft. Irrespective of storage temperature, at 8 weeks fruit showed a delay in a climacteric-like respiratory increase, and by 12 weeks a respiratory climacteric was not apparent. An ethylene climacteric was evident after all temperature and storage periods except those held at $6^{\circ} \mathrm{C}$ for 12 weeks. Significant symptoms of cold injury were found by 8 weeks of $2{ }^{\circ} \mathrm{C}$ cold storage. In addition to a delayed respiratory climacteric, pawpaw fruit stored for 8 and 12 weeks exhibited flesh browning within $48 \mathrm{~h}$ of moving to ambient temperature. A change in fruit aroma volatile profile suggested injury might have been developing by 4 weeks of cold storage even though other symptoms were not evident. Immediately after harvest, methyl octanoate was the dominant volatile ester followed by methyl hexanoate. By 4 weeks of postharvest cold storage, ethyl hexanoate was the dominant ester followed by ethyl octanoate, but methyl octanoate production was still substantial. At 8 weeks, volatile ester production was generally lower with ethyl hexanoate the major volatile followed by ethyl octanoate. These symptoms indicate that pawpaw fruit can suffer cold injury during extended periods of cold storage.
135 Susceptibility of Five Apple Cultivars to Browning

Jafar Milani*1

${ }^{1}$ Tehran Univ., Food Science, Tehran, Iran

Phenolic compounds and polyphenol oxidase (ppo) activity in five apple cultivars were assessed in relation tobrowning susceptibility. The degree of browning was determined by measuring brown pigments in homogenised pulp.The analysis variance of the browning rate,polyphenol content and ppo activity showed that only the effect of cultivar was significant while the interaction of location and cultivar not significant.Comparison of means (Duncan) classified the cultivars in view of browning rate in three groups $(P<0.01)$ : Strong (Red Delicious), weak (Arangeh and Granny Smith), and mid (Golden Delicious). Arangeh was the superior variety due to its highest total soluble solids and lowest browning rate.

\section{The Effect of Calcium Sprays and Crop Load on Bitter Pit Incidence in 'Honeycrisp' Apple}

Adriana Telias*1, Emily Hoover ${ }^{2}$, Carl Rosen ${ }^{3}$, David Bedford ${ }^{4}$

${ }^{1}$ Univ. of Minnesota, Horticultural Science, St. Paul, MN 55108; ${ }^{2}$ Univ. of Minnesota, Horticultural Science, St. Paul, MN 55108; ${ }^{3}$ Univ. of Minnesota, Horticultural Science, St. Paul, MN 55108; ${ }^{4}$ Univ. of Minnesota, Horticultural Science, Excelsior, MN 55331

'Honeycrisp', a relatively new apple cultivar, is susceptible to bitter pit, a physiological disorder that develops mainly during storage. Although the cause of bitter pit is unknown, calcium $(\mathrm{Ca})$ content of the fruit is known to be involved. A field experiment was conducted in Chanhassen, Minn. to refine recommendations for use of Ca sprays for reduction of bitter pit in 'Honeycrisp' apple. Specific objectives were to determine: 1) Ca concentration and content throughout the fruit growing season; and 2) the association of bitter pit incidence with $\mathrm{Ca}$ concentration, crop load, vegetative growth and fruit size. Six treatments tested included: control; $\mathrm{Ca}\left(\mathrm{NO}_{3}\right)_{2}$ sprays all season; $\mathrm{Ca}\left(\mathrm{NO}_{3}\right)_{2}$ sprays early in the season; $\mathrm{Ca}\left(\mathrm{NO}_{3}\right)_{2}$ sprays late in the season; hand-thinning combined with $\mathrm{Ca}\left(\mathrm{NO}_{3}\right)_{2}$ sprays all season and hand-thinning. $\mathrm{Ca}$ concentration in fruits was measured bi-weekly using three different sampling methods: segments, cores and plugs. A randomized block design with four trees as experimental unit and five replications was used. Results suggest lower crop loads increase bitter pit incidence. While fruit from the thinned treatments was larger in size by the end of the experiment, no bitter pit was present at harvest. After 4 months of storage, the hand thinning treatment had $7.4 \%$ bitter pit, while thinning plus $\mathrm{Ca}$ reduced bitter pit to $2.4 \%$. The other treatments had less than $1 \%$ bitter pit. Fruit analyses at the end of the growing season indicate that early and full season sprays resulted in the highest Ca concentration in fruit segments and cores. The lowest values were found for the thinning treatment. No association was found between vegetative growth and bitter pit incidence.

\section{Contamination of Apple Fruit with Diphenylamine During Storage}

Charles F. Forney*1, Jun Song ${ }^{2}$, Michael A. Jordan ${ }^{3}$

${ }^{1}$ Agriculture and Agri-Food Canada, Atlantic Food and Horticulture Research Centre, Kentville, Nova Scotia, B4N 1J5, Canada; ${ }^{2}$ Agriculture and Agri-Food Canada, Atlantic Food and Horticulture Research Centre, Kentville, Nova Scotia, B4N 1J5, Canada; ${ }^{3}$ Agriculture and Agri-Food Canada, Atlantic Food and Horticulture Research Centre, Kentville, Nova Scotia, B4N 1J5, Canada

Apple fruit are treatmented with diphenylamine (DPA) in the form of a postharvest dip to prevent the development of storage scald. However, DPA residues have been detected on apples not treated with DPA, which is problematic in markets where DPA residues are not acceptable. The objective of this study was to identify sources of DPA contamination and evaluate the effectiveness of ozone to reduce contamination. Concentrations of DPA in the atmosphere of commercial storage rooms was monitored during the storage season and the adsorption of DPA onto wood and plastic bin material, plastic bin liners, foam insulation, and apple fruit was assessed. DPA was sampled from headspace with solid phase micro extraction using $65 \mu \mathrm{m}$ polyacrylate micro fibers and analyzed using GC-MS. The effectiveness of gaseous treatments of 300 and $800 \mathrm{ppb}$ ozone to reduce DPA contamination on apple fruit 
and bin material was also determined. DPA was found to volatilize from treated apples and bins into the storage room air, where it was adsorbed onto storage room walls, bins, bin liners and other fruit. DPA was found in the atmosphere of storage rooms containing apples that were not treated with DPA. Wood and plastic bin material, bin liners, and foam insulation all had a high affinity for DPA and were determined to be potential sources of contamination. Ozone reacted with DPA and following gaseous ozone treatments, off-gassing of DPA from wood and plastic bin material and bin liners was reduced. However, ozone was not effective in removing all DPA in contaminated materials and was ineffective in removing DPA from contaminated apples. Due to the pervasive and persistent nature of DPA, fruit should be handled and stored in facilities where DPA is not used to prevent contamination of fruit.

138 Improved Fruit Color, Quality, and Shelf Life of 'Pink Lady' Apples with Preharvest Application of Aminoethoxyvinylglycine (AVG) in Combination with Ethephon

\section{Suparna Whale ${ }^{* 1}$, Zora Singh ${ }^{2}$, John Janes ${ }^{3}$}

${ }^{1}$ Curtin Univ. of Technology, Horticulture/Viticulture, Muresk institute, Perth, Western Australia, 6845, Australia; ${ }^{2}$ Curtin Univ. of Technology, Horticulture/Viticulture, Perth, Western Australia, 6845, Australia; ${ }^{3}$ Curtin Univ. of Technology, Horticulture/Viticulture, Perth, Western Australia, 6845, Australia

The effects of preharvest application of AVG and ethephon alone, or in combinations, on color development, fruit quality and shelf life were tested in 'Pink Lady' apples (Malus domestica Borkh.) in Western Australia during 2002. The experiment aimed at improving color without adversely affecting fruit quality at harvest and after long term cold storage. Treatments included $124.5 \mathrm{~g} \cdot \mathrm{ha}^{-1}$ AVG only [148 Days after full bloom (DAFB)]; $280 \mathrm{~g} \cdot \mathrm{ha}^{-1}$ ethephon only (148 DAFB);AVG (148 DAFB) followed by ethephon (166 DAFB); and control. Fruit were evaluated for color development, internal ethylene concentration (IEC) and quality at commercial harvest(181DAFB) and 45,90, and135 days after cold storage $\left(1{ }^{\circ} \mathrm{C} \pm 0.5^{\circ} \mathrm{C}\right)$. At harvest, ethephon with or without AVG significantly $(P \leq 0.05)$ improved red blush and total anthocyanin in fruit skin. AVG+ethephon treated-fruit had higher total anthocyanin and TSS compared to AVG alone and control fruit. There were no significant differences among different AVG and ethephon treatments for fruit firmness and IEC. During different storage periods, fruit treated with AVG alone and AVG+ethephon had significantly lower IEC compared to fruit treated with ethephon only and the control, however the interactions between treatments and storage periods were not significant for fruit firmness. AVG + ethephon and ethephon alone did not significantly affect fruit color during different storage periods, which showed that the subsequent ethephon spray on AVG-treated fruit had overcome the inhibitory effect of AVG. Our experimental results showed that application of AVG followed by ethephon improved color in 'Pink Lady' apples without compromising fruit quality including firmness during extended cold storage.

\section{Identifying Flavor Metabolites Under Ethylene Regulation in Apples}

Bruno Defilippi*1, Abhaya Dandekar², Adel Kader ${ }^{3}$

${ }^{1}$ Univ. of California-Davis, Pomology Dept., Davis, CA 95616; ${ }^{2}$ Univ. of California, Pomology Dept.; ${ }^{3}$ Univ. of California, Pomology Dept.

To understand the role of ethylene in overall flavor of apple fruits, ethylene production, and action were reduced using apple trees lines transformed for suppressing activity of ACC-synthase or ACC-oxidase enzymes, and 1-methylcyclopropene (1-MCP), an ethylene action inhibitor. A major reduction in ethylene biosynthesis and respiration rates was measured in fruits from these treatments. As expected, we found differential levels of dependence of flavor components on ethylene biosynthesis and action. Regarding aroma production, an ethyleneassociated event, headspace analysis showed a reduction in ester production in the ethylene-suppressed lines and in the apples treated with $1.0 \mu \mathrm{L} \cdot \mathrm{L}^{-1} 1-\mathrm{MCP}$ for 20 hours at $20^{\circ} \mathrm{C}$. However, no major differences were observed in concentrations of alcohol and aldehyde volatiles. Other flavor metabolites that showed an ethylene-dependent pattern were organic acids and sugars. Malic acid degradation was significantly reduced under ethylene suppressed conditions, showing a recovery after exposing the fruit to ethylene. Sucrose and fructose concentrations were influenced by suppression or enhancement of ethylene. Total phenolics and individual phenolics showed an ethylene-dependent behavior only when ethylene biosynthesis was reduced, but not when ethylene action was affected. These results suggest that the regulatory mechanisms of aroma biosynthesis in apple are under partial ethylene regulation. Therefore, we are using the ethylene suppressed apple fruits study the channeling and regulation of other metabolic pathways that lead to the manifestation of a complex trait like fruit quality.

\section{Purification and Characterization of a Glutathione $S$-Trans- ferase from Pome Fruits}

\section{Dan D. MacLean*1, Dennis P. Murr², Jennifer R. DeEll ${ }^{3}$}

${ }^{1}$ Univ. of Guelph, Plant Agriculture, Guelph, Ontario, N1G 2W1, Canada; ${ }^{2}$ Univ. of Guelph, Plant Agriculture, Guelph, Ontario, N1G 2W1, Canada; ${ }^{3}$ Ontario Ministry of Agriculture and Food, Ontario Ministry of Agriculture and Food, Simcoe, Ontario, N3Y 4N5, Canada

Glutathione S-transferase (GST) is a ubiquitous and constitutive enzyme that is involved in numerous cellular activities including the amelioration of oxidative stresses caused by the presence of xenobiotics and reactive oxygen species. In the present study, a glutathione S-transferase was extracted, purified, and partially characterized from two types of pome fruits. Pear (Pyrus $\times$ communis L., cultivar D'Anjou) and apple (Malus $\times$ domestica Borkh., cultivar Delicious) fruit were tested. The glutathione $S$-transferase was extracted using traditional methods, and purified using a combination of ammonium sulfate precipitation, dialysis, and GST-specific affinity chromatography. The GST enzyme was subsequently eluted from the column and concentrated prior to characterization studies. A purified fraction from the column was loaded onto an SDS-PAGE gel, and resulted in a single band with an apparent molecular weight of $\approx 26 \mathrm{kDa}$. This band was excised and used for MALDI-TOF/MS peptide mass fingerprint studies, and also served to confirm the apparent mass of the protein (25969 Da). The ExPASy software was used for the peptide mass fingerprint study, where the digest of the GST using trypsin was compared to a theoretical digest of an Arabidopsis GST, and resulted in two peptides of significant mass homology. The purified GST was also tested for enzyme activity using the standard assay substrate of 1-chloro-2,4-dinitrobenzene and reduced glutathione. Total GST protein extracted from 'D'Anjou' pear was $0.532 \mathrm{mg} \cdot \mathrm{mL}^{-1}$, while 'Delicious' apple contained $0.127 \mathrm{mg} \cdot \mathrm{mL}^{-1}$. The activity of GST enzymes may play a role in minimizing oxidative stress injury in stored pear and apple tissues.

\section{Cultivar Variation in Response to AVG and Heat Treatments for Sustaining Apple Fruit Quality in Cold Storage}

Valeria Sigal Escalada*1, Douglas D. Archbold ${ }^{2}$

${ }^{1}$ Univ. of Kentucky, Horticulture, Lexington, KY 40546-0091; ${ }^{2}$ Univ. of Kentucky, Horticulture, Lexington, KY 40546-0091

To determine if apple cultivars vary in their response to aminoethoxyvinylglycine (AVG) and heat treatment, alone or combined, postharvest ripening traits and storability of treated Lodi, Senshu, Red Delicious and Fuji have been studied. An aqueous solution of AVG was applied 4 weeks before harvest of each cultivar at $124 \mathrm{~g} \cdot \mathrm{ha}^{-1}$ a.i. Control and AVG-treated fruit were heated at $38{ }^{\circ} \mathrm{C}$ for 4 days. Fruit were ripened at ambient temperature immediately harvest and treatment, or after storage at $4{ }^{\circ} \mathrm{C}$ for 30 days. AVG reduced firmness loss in all but Fuji apples immediately after harvest, and that effect was maintained in Senshu and Red Delicious apples after 30 days in cold storage. All AVG-treated fruit showed a reduction in respiration rate and ethylene production immediately after harvest as well as after removal from cold storage. Heat treatment alone prevented firmness loss in Senshu and Red Delicious cultivars, and slightly reduced respiration rate of Lodi and Senshu apples. Ethylene production was clearly lower in heated compared to non-heated fruit in Senshu, Red Delicious and Fuji. After cold storage, AVG and heat treatments combined decreased flesh firmness loss of Lodi apples, reduced respiration in Lodi and Fuji apples, and highly repressed ethylene production of Red Delicious and Fuj 
fruit. Overall, AVG seemed to have a stronger effect on the measured ripening traits, and its combination with heat treatment improved fruit quality of cold-stored Lodi apples and reduced ethylene production the most for all but Lodi.

142 The Relationship Between the Production of Volatile Aromas and the Induction of Ethylene in Apple Fruits

Zimian Niu*1, Dapeng Zhang ${ }^{2}$, Hongyu Zhao ${ }^{3}$, Curt Rom ${ }^{4}$

${ }^{1}$ Univ. of Arkansas, Horticulture; ${ }^{2}$ Agricultural Univ. of China, Horticulture, China; ${ }^{3}$ Agricultural Univ. of China, Horticulture, China; ${ }^{4}$ Univ. of Arkansas, Horticulture, Fayetteville, Ark.

The volatile aromas from the fruits of 'Naganofuji No.2' apple (Malus domestica Mill.) were determined by gas chromatography (GC) and combined GC- mass spectrometry (GC-MS) after different temperature conditions. The fruits from CA storage were sealed in glass and the volatiles in the headspace were determined. Eleven compounds of four chemical classes from active carbon absorbed samples were measured and three of them - tormic acid pentyl ester, butanoic acid-1-methyl ethylester and 4-hydroxy-3-methyl-2-butanone, were identified at $20{ }^{\circ} \mathrm{C}$, but not at ${ }^{\circ} \mathrm{C}$. Under $20{ }^{\circ} \mathrm{C}$ condition, the contents of three volatiles increased from 1 hour and reached to their peaks at the 4th to 7 th hour. The content of ethylene reached its peak at 4 hours and changed synchronically with the other volatiles during the experiment. The content of ethylene was significantly positively correlated with the contents of volatile aromas $(r=0.96-0.98, P \leq 0.01)$. Under ${ }^{\circ} \mathrm{C}$ condition, the content of ethylene was significant lower than that of at $20^{\circ} \mathrm{C}$ and there was no ethylene peak produced during experiment. When the fruits were treated with ethephon $\left(0.1 \mathrm{mg} \cdot \mathrm{L}^{-1}\right)$ at $5^{\circ} \mathrm{C}$, the content of ethylene increased greatly. The highest level of ethylene was found at 4 to 7 hours and the peaks of volatiles also appeared at 7 hours or 10 hours after the treatment. It was suggested that the production of ethylene in fruits could be thought as an indicator of some volatile aromas.

143 Expression of Alpha-farnesene Synthase Gene AFS1 in Relation to Levels of Farnesene and Conjugated Trienols in Peel Tissue of Scald-susceptible 'Law Rome' and Scald-resistant 'Idared' Apple fruit

Steven W. Pechous ${ }^{1}$, Bruce D. Whitaker*2 ${ }^{2}$, Christopher B. Watkins ${ }^{3}$

${ }^{1}$ USDA-ARS Beltsville Agricultural Research Center, Produce Quality \& Safety Laboratory, PSI, Beltsville, MD 20705; ${ }^{2}$ USDA-ARS Beltsville Agricultural Research Center, Produce Quality \& Safety Laboratory, PSI, Beltsville, MD 20705; ${ }^{3}$ Cornell Univ., Dept. of Horticulture, Ithaca, NY 14853

Fruit of different apple cultivars vary widely in susceptibility to superficial scald. The genetic and biochemical factors involved in this variation are unknown. Conjugated trienol (CTol) oxidation products of alpha-farnesene have been linked with scald induction, and a high rate of farnesene synthesis in peel tissue of scald-prone apples early in storage is often associated with development of the disorder. Pre-storage treatment of apple fruit with 1-methylcyclopropene (1-MCP) inhibits the early burst of farnesene production and prevents scald, suggesting that ethylene induces transcription of genes involved in farnesene synthesis. We recently cloned a gene from apple peel tissue, AFS1, which encodes alpha-farnesene synthase, the last enzyme in the farnesene biosynthetic pathway. In this study, expression of AFS1 was compared in scaldsusceptible Law Rome (LR) and scald-resistant Idared (IR) apples at harvest and over 20 weeks of storage at $0.5 \mathrm{C}$. AFS1 transcript levels were closely correlated with accumulation of farnesene and CTols. In fruit of both cultivars, a sharp increase in AFS1 mRNA during the first 4 to 8 weeks of storage preceded a proportional rise in farnesene and a subsequent increase in CTols. However, maximum levels of AFS1 transcript, farnesene, and CTols were, respectively, 2.5-, 4-, and 33fold greater in LR than in IR apples. Treatment of fruit with 1-MCP at harvest suppressed the increases in AFS1 transcript and farnesene early in storage, but AFS1 expression and farnesene synthesis recovered in LR fruit after 20 weeks. Scald incidence in LR apples after 20 weeks at $0.5^{\circ} \mathrm{C}$ plus 1 week at $20^{\circ} \mathrm{C}$ averaged $86 \%$, whereas IR fruit had no scald. 1-MCP treatment reduced scald incidence in LR to $<1 \%$.
144 Inducing Optimal Ripening Capacity of 1-MCP-treated 'Bartlett' Pears after Regular Air or Controlled Atmosphere Storage

Jinhe Bai*1, Paul Chen ${ }^{2}$, Elizabeth Baldwin ${ }^{3}$, James Mattheis ${ }^{4}$

${ }^{1}$ Oregon State Univ., Mid-Columbia Agricultural Research \& Extension Center, Hood River, OR 97031; ${ }^{2}$ Oregon State Univ., Mid-Columbia Agricultural Research \& Extension Center, Hood River, OR 97031; ${ }^{3}$ USDA/ARS, Citrus \&,Subtropical Products Laboratory, Winter Haven, FL 33881; ${ }^{4}$ USDA/ARS, Tree Fruit Research Laboratory, Wenatchee, WA 98801

'Bartlett' pears were treated with $300 \mathrm{~nL} \cdot \mathrm{L}^{-1} 1-\mathrm{MCP}$ at $20^{\circ} \mathrm{C}$ for $24 \mathrm{~h}$ shortly after harvest, and were stored at $-1{ }^{\circ} \mathrm{C}$ in either regular atmosphere (RA) or controlled atmosphere (CA: $1.5 \mathrm{kPa} \mathrm{O} / 0.5 \mathrm{kPa} \mathrm{CO}_{2}$ ). After 2 and 4 months of RA storage, or 4 months of CA storage, fruit were pre-conditioned at $10^{\circ} \mathrm{C}, 15^{\circ} \mathrm{C}$ or $20^{\circ} \mathrm{C}$ for 5,10 , or 20 days, respectively. Pre-conditioned fruit were then held at $20^{\circ} \mathrm{C}$ for 14 days to simulate marketing conditions. Flesh firmness (FF) and extractable juice $(\mathrm{EJ})$ were monitored during the marketing period. The optimal stage of ripeness for 'Bartlett' pears was defined to be when FF decreases to $27 \mathrm{~N}$ and EJ decreases to $55 \mathrm{~mL} / 100 \mathrm{~g}$. The proper pre-conditioning combinations of temperature and duration were $15^{\circ} \mathrm{C}$ or $20^{\circ} \mathrm{C}$ for $10 \mathrm{~d}$ or $10^{\circ} \mathrm{C}$ for $20 \mathrm{~d}$ if the fruit had been stored in RA for 2 months, $10^{\circ} \mathrm{C}$ or $15{ }^{\circ} \mathrm{C}$ for $5 \mathrm{~d}$ if the fruit had been in RA for 4 months, and $20{ }^{\circ} \mathrm{C}$ for $10 \mathrm{~d}$ or $10^{\circ} \mathrm{C}$ for $20 \mathrm{~d}$ if the fruit had been in CA for 4 months, for which combinations the fruit ripened within a week and maintained quality for 14 days at $20^{\circ} \mathrm{C}$. The treatment combinations of lower temperature and/or shorter duration times in pre-conditioning delayed the ripening response of the fruit, and combinations of higher temperature and/or longer duration times in pre-conditioning resulted in a shorter marketing life because of senescence breakdown, in comparison the optimal combinations mentioned above. These results indicate that pre-conditioning regimes for 1-MCP treated 'Bartlett' pears are storage atmosphere and time dependent. Generally, CA stored fruit needed more preconditioning (in terms of higher temperature and/or longer duration) than did RA stored fruit.

\section{Poster Session 20-Human Issues in Horticulture}

\section{July 18, 2004, 12:30-1:30 PM Rio Grande Exhibit Hall}

237 The Charleston Area Children's Garden Project: A Community Sponsored Initiative

Fred B. Phillips ${ }^{1}$, James W. Rushing ${ }^{* 2}$, Brenda J. Vander Mey ${ }^{3}$

${ }^{1}$ Clemson Univ., Coastal Research and Education Center, Charleston, SC 29414; ${ }^{2}$ Clemson Univ., Coastal Research and Education Center, Charleston, SC 29414; ${ }^{3}$ Clemson Univ., Sociology, Clemson, SC 29634

The Charleston Area Children's Garden Project is a community-sponsored initiative affiliated with the Clemson Univ. Coastal Research and Education Center and the Landscapes for Learning Program. The Project transforms vacant lots and other unused spaces into neighborhood outdoor learning centers. Garden activities are free and open to all. The children plan, plant, and tend the garden under the supervision and guidance of adult Garden Leaders. Whatever is grown, the children take home. A "sidewalk learning session" is held in the garden each week. At these sessions, the garden manager, parents, neighbors, or visitors teach the youngsters about garden-related topics from insects to siphons, from origami to pickling, and a multitude of other topics designed to stimulate learning and child participation. The Project is designed to give children a hands-on learning experience outside the classroom setting, to make neighborhoods more attractive, and to build a sense of community. The Project is totally funded by grant monies and has grown from one garden in 2000 to ten gardens in 2004. Gardens are planted with the involvement of neighborhood associations, the Boys and Girls Clubs, the Homeless Shelter, and in conjunction with after-school programs. The Project makes use of such resources as The Growing Classroom and the Junior Master Gardener Teaching Guide. An array of program materials has been developed that are designed for use in the coastal communities of South Carolina. 
238 Preliminary Examination of the Impact of a Gardening Program on Confidence, Physical Activity, Fruit and Vegetable Consumption, and Quality of Life

Mu-Chuan Lin ${ }^{1}$, Candice Shoemaker*2, Nancy Gyurcsik ${ }^{3}$

${ }^{1}$ Kansas State Univ., Horticulture, Forestry and Recreation Resources, Manhattan, KS 66506; ${ }^{2}$ Kansas State Univ., Horticulture, Forestry and Recreation Resources; ${ }^{3}$ Kansas State Univ., Kinesiology

Older adults are not sufficiently physically active and do not consume sufficient fruits and vegetables to achieve health benefits, such as an improved health-related quality of life (HRQL). As a result, an innovative gardening intervention, comprised of stretching exercises, the teaching of home garden knowledge and skills, and the preparation and taste testing of fruits and vegetables, was developed to target increased: (a) confidence to garden and to consume fruits and vegetables, (b) physical activity, (c) fruit and vegetable consumption, and (d) HRQL. Seven older adults, aged 60 years or older, participated in the gardening intervention and 10 older adults participated in the control group during the fall. Measures of confidence, physical activity (i.e., gardening), fruit and vegetable consumption, and HRQL were obtained at baseline and at the end of the 10-week program. Findings revealed that, at baseline, intervention participants had significantly higher confidence to garden compared to control participants but at end-program intervention and control participants did not significantly differ in any of the outcome variables. Bivariate findings also revealed that intervention participants who had higher confidence to garden or to consume fruits and vegetables at baseline also gardened more at end-program. Thus, interventions targeting confidence to garden and to consume fruits and vegetables may be effective in improving gardening (i.e., physical activity) behavior. Findings also suggest that seasonal change may be one influential moderator of the gardening program on confidence and gardening and fruit and vegetable consumption behavior change. Future research should examine the impact of the program in different seasons to clarify the effects.

239 A Case Study of the Mighty Morris Blooms: Quantitative and Qualitative Program Assessment of a Youth Gardening Program in a 3rd Grade Classroom

Amy Dirks ${ }^{1}$, Kathryn Orvis*2

${ }^{1}$ Purdue Univ., Dept. of Youth Development and Agricultural Education and Dept. of Hort and LA West Lafayette, IN 47907-2053; ${ }^{2}$ Purdue Univ., Dept. of Youth Development and Agricultural Education and Dept. of Hort and LA West Lafayette, IN 47907-2053

Research has shown that hands-on, experiential learning is very effective in the classroom and school gardening utilizes this method of learning. Gardening has been shown to have many positive effects on children including in academic areas. Of the youth gardening programs that exist, little research has been done with the Junior Master Gardener ${ }^{\circledR}$ program to evaluate it for its use in the classroom. $\mathrm{JMG}^{\circledR}$ is a youth gardening program designed to teach aspects of horticulture and environmental science through hands-on activities in both informal and formal learning environments. A case study of one particular classroom evolved from a larger evaluation study of the $\mathrm{JMG}^{\circledR}$ program in Indiana third grade classrooms. Research with this classroom utilized a mixed approach to acquire quantitative and qualitative data of knowledge and attitudes toward science, horticulture, and the environment. Quantitative measurements were made pre, post, and post-post (after summer break) the program. Qualitative methods included weekly classroom observations during the study, student post and post-post program evaluations, and post program teacher evaluations. Results indicated that students had significant levels of knowledge and positive attitude gain from pre to post tests. Observations and evaluations supported the quantitative results showing that the students and teacher found the $\mathrm{JMG}^{\circledR}$ program to be valuable in the classroom, as well as enjoyable which may lead to more student interest in science. Through this casestudy post-post program assessment showed that the students retained a significant amount of positive attitudes toward science, horticulture and the environment.

\section{Sensory Evaluation of Edible Daylilies (Hemerocallis sp.)}

\section{Ashley N. Pollard*1, Patti C. Coggins², Patricia R. Knight ${ }^{3}$}

${ }^{1}$ Mississippi State Univ., Food Science and Technology, Mississippi State, MS 39762; ${ }^{2}$ Mississippi State Univ., Food Science and Technology, Mississippi State, MS 39762; ${ }^{3}$ Mississippi State Univ., South MS Branch Experiment Station, Biloxi, MS 39531

Flowers are traditionally used to flavor and garnish dishes. There are many different varieties of edible flowers such as daylilies (Hemerocallis sp.). Daylilies come in many varieties and colors. Their blooms and buds are tasty and nutritious. The objective of this study was to indicate most preferred to least preferred among 15 daylily cultivars (Gentle Shepherd, Lavender Doll, Siloam Powder Pink, Aztec Gold, Rosie Meyers, Catherine Woodberry, Pink Charm, Virginia Henson, Lemon Yellow, Joan Senior, Along the Way, Border Baby, Bonanza, Pandora's Box, and Apricot Beauty). A consumer panel was conducted evaluating the taste preference of fifteen participants to an assortment of daylilies. Panelists were associated with Mississippi State Univ. Each panelist received 15 different daylily blooms. The ranking methods and analysis of variance were used to determine the preference. The questionnaire for ranking given to each panelist stated to "Please taste each numbered sample and rank in order of preference with the first being most preferred and last being least preferred and to provide comments." Among the 15 daylilies tested, Rosie Meyer was the most preferred, followed by a second group that consisted of Lavender Doll, Jones Senior, and Aztec Gold. The third most preferred group consisted of two, Gentle Shepherd and Along the Way. The preference for the remainder tapered off with the last two samples, Bonanza and Border Baby. These results suggest that of the 15 daylily varieties, Border Baby and Bonanza were statistically non-preferred with no daylily being statistically preferred.

\section{The Kentucky Master Gardener Program}

Richard E. Durham*1

${ }^{1}$ Univ. of Kentucky, Dept. of Horticulture, Lexington, KY 40546-0091

The Kentucy Master Gardener Program is administered through the Cooperative Extension Service of the Univ. of Kentucky with assistance from the Kentucky State Univ. Land Grant Program. Master Gardener Programs in Kentucky were originally established in urban areas of the state, but have more recently expanded to rural areas as well. Master Gardener Programs are currently active in over 25 Kentucky counties. Individual Master Gardener programs are under the direction of a county extension agent (or group of agents if the program involves multiple counties) who is assisted by two, part-time state co-coordinators (extension horticulture specialists). The county agents are responsible for Master Gardener recruitment, training, and volunteer management. A required "core content" for Master Gardener training includes a total of 24 hours of instruction in basic plant science and an orientation to Cooperative Extension. State extension specialists have compiled an extensive training manual that covers the required topics as well as additional subject areas. To become certified Master Gardeners, trainees must complete assigned homework, pass a comprehensive final exam, and complete at least one hour of volunteer service for each hour of formal instruction. The county agents determine requirements for continued certification and agents may also offer advanced Master Gardener training. This poster will provide details regarding Master Gardener recruitment, training, and retention in Kentucky.

\section{Revision Process of Master Gardener Training Curriculum into a More User-friendly Lesson Plan Format}

Lelia S. Kelly*1

Mississippi State Univ., Dept. of Plant and Soil Science, Verona, MS 38879

State specialists and agents developed a Master Gardener training curriculum that consisted of a collection of powerpoint presentations in the year 2000. After three years of use this curriculum was in need of revision and updating. The revision process that utilized volunteers, agents, subject matter specialists as well as curriculum specialists will be presented. Suggestions for improvement were gleaned from three 
years of class evaluations. In addition to obvious updating of material, formatting the curriculum into a lesson plan with complete step-by-step instructions for teachers was required to enable the curriculum to be more easily taught by non-extension personnel such as Master Gardener Educators. Removal of all questionable copyrighted pictures, graphs, drawings, etc. from the original curriculum was accomplished. This process will allow Mississippi State to share this curriculum with other universities if requested without fear of legal repercussions. Aligning the student's training notebook to more accurately reflect the material presented in class was done also. Resource material lists were added and standardized tests for the new material were included. The incorporation of hands-on activities or demonstrations to more actively engage the student in the learning process was included as well. The entire revised training curriculum was contained on a compact disc that was made available to instructors.

\section{The Idaho Master Gardener Program-Diverse, Different, and Meeting Local Needs}

\section{Jo Ann Robbins*1, Susan Bell ${ }^{2}$, Tim Davis ${ }^{3}$, Kevin Laughlin ${ }^{4}$}

${ }^{1}$ Univ. of Idaho, Jerome County Extension, Jerome, ID 83338; ${ }^{2}$ Univ. of Idaho, Ada County Extension, Boise, ID 83714; ${ }^{3}$ Univ. of Idaho, Payette County Extension, Payette, ID 83661; ${ }^{4}$ Univ. of Idaho, Ada County Extension, Boise, ID 83714

Master Gardener training was first offered in Idaho in 1976. Univ. of Idaho (U of I) Master Gardener trainings are held in various counties and organized by county extension faculty. The number of Master Gardeners in Idaho is estimated at 1800. In 1993, U of I published the first edition of the Idaho Master Gardener Handbook. This 23-chapter state-specific handbook is revised annually. The first chapter outlines the Idaho Master Gardener guidelines. These were the first statewide guidelines. The Idaho program requires a minimum of 30 hours of classes and 30 hours of practicum/hands-on training (the volunteer commitment). Certification is received after these requirements are met and is good for one year. Annual recertification is provided through participation in Advanced Master Gardener trainings and activities. These recertification programs differ; depending on wants and needs within Idaho. The U of I Horticulture Programming Topic Team loosely organizes all county efforts, but there is no statewide Master Gardener program in Idaho. Each region and county brings a unique framework to the title Master Gardener. Hands-on training in many counties includes problem solving services to phone and office visiting clients. Other horticultural community and extension projects are the balance of the hands on hours. Idaho Master Gardeners also serve as uniquely qualified educators in a state as geographically diverse as Idaho. In 2001, the Idaho Junior Master Gardener Program began in cooperation with Idaho Master Gardeners and Texas A\&M Univ.. Over 2000 youth and 200 adults have been involved in Idaho.

\section{Expanding Outreach via Colorado Master Gardener Clinics}

\section{Carol A. O’Meara*1, Kerrie B. Badertscher ${ }^{2}$}

${ }^{1}$ Colorado State Univ., Cooperative Extension, Longmont, CO 80501; ${ }^{2}$ Colorado State Univ., Cooperative Extension, Longmont, CO 80501

Data supports the success of Colorado Master Gardener sm (MG) of Boulder County outreach beyond the Cooperative Extension office at outlying clinic sites. Initially unique in Colorado, $\mathrm{MG}$ plant clinics at area nurseries and garden centers has gained acceptance in other counties of Colorado. Exploration of benefits and investments for programs interested in expanding outreach to the public are discussed to provide a blueprint for clinics start-up. MG clinics are set up to provide answers to questions from the public on Friday through Sundays from April through mid-July. This schedule, coupled with the Monday through Friday MG desk hours, provides seven day per week access to the public during the busiest part of the growing season. Clinics are conveniently located in all county communities at Green Industry locations. Participating businesses consider the clinics a benefit worth investing IN and justification of sites is uniform. Additional singleday clinics have spun off as an addition to fixed clinic schedule. High requirement of staff time, increased sample load and resource investment is offset by the benefits of increased visibility of program in the community leading to increased recruitment of volunteers. Knowledge gained by the public has brought about measurable positive changes in pesticide use and responsible cultural practices. Volunteer retention is favorably affected with increased flexibility of scheduling opportunities and communications. Information on setting up clinic sites, what the sites receive, staff time and services requirements, and refinements as a result of clinic survey will be given.

\section{Assessing Penn State Master Gardener Use of Teaching Tools}

Rebecca H. Wehry*1, Kathleen M. Kelley², Antoinette Bilik ${ }^{3}$

'Penn State Univ., Horticulture, Univ. Park, PA 16802; ${ }^{2}$ Penn State Univ., Horticulture, Univ. Park, PA 16802; ${ }^{3}$ Penn State Univ., Horticulture, Univ. Park, PA 16802

A direct-mail survey was administered to gain perspective of the audio/ visual tools Penn State Master Gardeners currently use to teach their clientele and their comfort level with using computers and accessing the Internet. Of the 700 surveys that were distributed to active MG during the month of November 2002, 386 completed surveys were returned. Male MG were more likely to use slides (44\%) and less likely to use posters $(15 \%)$ than female MG to teach consumer clientele (29\% and $26 \%$, respectively). Participants from single-adult households (20\%) were more likely to use PowerPoint than those from households with two or more adults (11\%). A greater percentage of participants, 54 years of age and younger reported having Internet access at their home $(90 \%)$ and at work $(42 \%)$ compared to MG age 55 years and older $(75 \%$ and $16 \%$, respectively). Over half of the younger MG $(53 \%)$ responded that they were "very comfortable" with using the Internet to search for information compared to $37 \%$ of their counterparts. Currently MG use computers as a teaching tool on a limited basis, with younger MG possessing a greater degree of comfort with both the computer and Internet. By teaching MG how to use this technology the ability to reach a large audience can increase, thus further extending the reach of this component of Cooperative Extension. Though use of high tech methods to deliver information is continually gaining momentum, the number of MG who use less technical teaching tools should also be considered and appropriate tools should remain available.

\section{Master Gardener-led Projects in Southern Nevada}

Angela O'Callaghan*1, Florence Brown ${ }^{2}$, Denise McConnell ${ }^{3}$, Robert Morris ${ }^{4}$

${ }^{1}$ Univ. of Nevada, Cooperative Extension, Las Vegas, NV 89146; ${ }^{2}$ Las Vegas Springs Preserve, Desert Demonstration Garden, Las Vegas, Nevada; ${ }^{3}$ Las Vegas Springs Preserve, Education, Las Vegas, NV 89153; ${ }^{4}$ Univ. of Nevada, Cooperative Extension, Las Vegas, NV 89146

Southern Nevada Master Gardeners (MGs) donate 50 hours annually to educational and service projects. These volunteers respond to community needs by developing and staffing horticultural projects under UNCE supervision. In Las Vegas, 20 such projects exist. Some are more energy and information intensive than others. Mojave Guides are docents at the Desert Demonstration Garden, a part of the Las Vegas Springs Preserve, not Extension. They commit to a shift at the garden, providing information to visitors. While they are directly supervised by garden staff, the hours they contribute are Master Gardener hours. These volunteers receive training in desert flora from gardens staff and participate in seminars on selected topics. The MG Orchard Team operates a teaching orchard at the Center for Urban Water Conservation in North Las Vegas. These volunteers maintain hundreds of fruit trees and grape vines. They receive training on topics related to fruit trees and orchard management. This project began in 1996. Since 2002, they have been formalizing their organization using the logic model and SWOT analysis. Many members work weekly at the orchard and take the produce to a local farmers market. This raises funds for the orchard and is an opportunity to teach the community about desert horticulture. Project PLANT volunteers work at the Red Rock National Recreation Area visitor center and grounds. They are docents who also learn about and maintain the native plants there, and prevent infestations of invasive weeds which threaten the area. Their monthly meetings include training on topics related to the project. These projects are successful because 
of the MGs themselves. They grew out of interest and continue because the volunteers have drawn commitment from others.

\section{Poster Session 21-Weed Control and Pest Management}

\section{July 18, 2004, 5:30-6:30 PM Rio Grande Exhibit Hall}

186 Simulation of Phenology, Growth and Yield of Cucumis melo S.M. Lutfor Rahman*1, Jeffrey T. Baker ${ }^{2}$, Raul I. Cabrera ${ }^{3}$, Dennis J. Timlin $^{4}$, Bruno Quebedeaux ${ }^{5}$

${ }^{1}$ Texas A\&M Univ., Res \& Extn Ctr, Horticulture, Dallas, TX 75252-6599; ${ }^{2}$ USDA-ARS Plant Science, Big Spring, Texas, 79720; ${ }^{3}$ Texas A\&M Univ., Res \& Extn Ctr, Horticulture, Dallas, TX 75252-6599; ${ }^{4}$ USDA-ARS, Beltsville, Alternate Crops \& Systems Lab, Beltsville, MD 20705-2350; ${ }^{5}$ Univ. of Maryland, Natural Resources Science and Landscape Architecture, College Park, MD 20742

We collected growth and yield data on eight cantaloupe cultivars and constructed a simple phenology model that uses local weather data to allow growers to quantify phenological growth and development to project harvest dates. Main vine plastochron interval (PI), time to harvest, and final yield were determined. PI was calculated for each cultivar $\times$ transplanting date combination as the reciprocal of the slope of main vine node number vs. growing degree days. Among the tested cultivars, 'Ovation' and 'Primo'produced significantly higher yields of marketable melons (51.3 Mg/ha, 49.5 Mg/ha, respectively), whereas 'Santa Fe' produced the lowest $(28.6 \mathrm{Mg} / \mathrm{ha})$. The rest of the tested cultivars produced on average $34.4 \mathrm{Mg} / \mathrm{ha}$. Fruit weight was significantly higher in 'Morning Ice' $(2.7 \mathrm{~kg} /$ fruit $)$ and lowest in 'Mission' ( $1.4 \mathrm{~kg} /$ fruit). There were also significant differences among cultivars in the number of marketable melons/ha, which ranged from 11500 melons/ha for 'Morning Ice' to 32300 melons/ha for 'Ovation'. Plant dry matter production was higher in 'Ovation' and 'Mission' than all the other cultivars. The relative days to maturity were significantly higher in 'Morning Ice' and 'Honey Brew' (115 days) and lower in 'Gold Rush' (72 days). There were no differences found in days to maturity for 'Mission', and 'Ovation'( 82 days). The average \% of soluble solids content ranged from 9.5 for 'Ovation' to 14.5 for 'Mission' and 'Honey Brew'. The variety cantaloupensis types are earlier in maturity than inodorus types. PI was significantly different for all cultivars. Main vine node number was a useful descriptor of vegetative development for cantaloupes. Procedures for calibrating and fitting the model for these cultivars will be discussed and outlined

\section{Transformation of HVA1 Gene Into Malus hupenensis var. 'Pingyitiancha'}

\section{Xian Shen*1, Ling $\mathrm{Guo}^{2}$, Zhenlin $\mathrm{Wei}^{3}$}

${ }^{1}$ Shandong Agriculture Univ., College of Hort., Tai An, Shandong, 271018, P.R. China; ${ }^{2}$ Shandong Agriculture Univ., College of Hort., Tai An, Shandong, 271018, P.R. China; ${ }^{3}$ Shandong Agriculture Univ., College of Hort., Tai An, Shandong, 271018, P.R. China

Malus hupenensis var. 'Pingyitiancha' is an important apple stock with many good characteristics, including waterloggig resistance, cold resistance, salt resistance and so on. The three group gene-HVA1 come from barley was transformed into 'Pingyitiancha' mediated by Agrobacterium tumefaciens and transformed regeneration plants were obtained in this research. The HAV1 gene cloned from plasmid containing it (offered by Dr. Guo Weidong) by PCR with high fidelity pfu Taq DNA polymerase. It was ligated between BamH 1 and Sac 1 site in PUC118 vector, and identified by electrophoresis after digested with BamH 1 and Sac 1. Through nuclear sequence detecting, it is confirmed that the HAV1 gene cloned in this research is 703bp.This fragment was ligated with $11 \mathrm{~kb}$ fragment from pB121 plasmid and constructed $\mathrm{pBHA}$ vetor. The pBHA vectorwas introduced in A.tum LBA4404 by triparental mating and the binary vector was obtained. It is cinfirmed that HVA1 gene had been insert in T-DNA by in situ hybirdization. Using 'Pingyitiancha' shoot apex, mediated by A. tum. System, the HAV 1 gene was transformed into the plant. Kam resistance regeneration plants were obtained, 6 of them were confirmed as transformation plants by PCR and dot blot.
188 Research on Transformation Conditions using Malus hupenensis var. 'Pingyitiancha'

Xiang Shen*1, Zhenlin $\mathrm{Wei}^{2}$, Ling Guo ${ }^{3}$

${ }^{1}$ Shandong Agriculture Univ., College of Hort., Tai An, Shandong, 271018, China; ${ }^{2}$ Shandong Agriculture Univ., College of Hort., Tai An, Shandong, 271018, China; ${ }^{3}$ Shandong Agriculture Univ., College of Hort., Tai An, Shandong, 271018, China

'Pingyitiancha' has good agricultural traits and is an important rootstock for apples. It was studied for Kam, Cef and Carb concentrations, precultural times, active medium of A.tum, $\mathrm{Ca}^{++}$concentration, mixed inoculation times of $\mathrm{AgNO}_{3}$, and PVP delay selection times for getting transgenic 'Pingyitiancha' stock with more resistance to drought and salt. It was demonstrated that the highest transformation frequency was obtained with $200 \mathrm{mg} \cdot \mathrm{L}^{-1}$ Cef as an A.tum restraining antibiotic, $8 \mathrm{mg} \cdot \mathrm{L}^{-1}$ Kam as a selection antibiotic, GCJ8 active medium, a precultural of 2 days, $5 \mathrm{Ca}^{++}$concentrations in preculture and coculture medium compared with standard MS medium, immersed in A. tum as OD600 for 0.5 to $1 \mathrm{~min}$., $4 \mathrm{mg} \cdot \mathrm{L}^{-1} \mathrm{AgNO}_{3}$ and $0.7 \% \mathrm{PVP}$ as an anti-oxidation compound to reduce hydroxybenzene oxidation and delay selection for 5 days by using 'Pingyitiancha' apex shoots as explants. Using mediate of A. tum strain LBA4404 under conditions mentioned above and same explants, the HVA1 gene were transformed into 'Pingyitiancha' under the control of CaMV35S promoter and obtained Kam resistance regeneration plants. Six transgenic plants were confirmed by PCR and subsequent dot blot methods.

\section{Simple Sequence Repeat (SSR) Markers for Raspberry and Blackberry}

Kim S. Lewers*1, Eric T. Stafne ${ }^{2}$, John R. Clark ${ }^{3}$, Courtney A. Weber $^{4}$, Julie Graham ${ }^{5}$

${ }^{1}$ USDA-ARS, BARC Fruit Lab, Beltsville, MD 21046; ${ }^{2}$ Univ. of Arkansas, Dept. of Horticulture, Fayettville, AR 72701; ${ }^{3}$ Univ. of Arkansas, Dept. of Horticulture, Fayetteville, AR $72701 ;{ }^{4}$ Cornell Univ.-NYSAES, Dept. of Horticultural Sciences, Geneva, NY $14456 ;{ }^{5}$ Scottish Crop Research Institute, Rubus, Invergowrie, Dundee, Scotland, DD2 5DA, UK

Some raspberry and blackberry breeders are interested in using molecular markers to assist with selection. Simple Sequence Repeat markers (SSRs) have many advantages, and SSRs developed from one species can sometimes be used with related species. Six SSRs derived from the weed $R$. alceifolius, and 74 SSRs from $R$. idaeus red raspberry 'Glen Moy' were tested on $R$. idaeus red raspberry selection NY322 from Cornell Univ., $R$. occidentalis 'Jewel' black raspberry, Rubus spp. blackberry 'Arapaho', and blackberry selection APF-12 from the Univ. of Arkansas. The two raspberry genotypes are parents of an interspecific mapping population segregating for primocane fruiting and other traits. The two blackberry genotypes are parents of a population segregating for primocane fruiting and thornlessness. Of the six $R$. alceifolius SSRs, two amplified a product from all genotypes. Of the 74 red raspberry SSRs, $56(74 \%)$ amplified a product from NY322, $39(53 \%)$ amplified a product from 'Jewel', and $24(32 \%)$ amplified a product from blackberry. Of the $56 \mathrm{SSR}$ that amplified a product from NY322, 17 failed to amplify a product from 'Jewel' and, therefore, detected polymorphisms between the parents of this mapping population. Twice as many detected polymorphisms of this type between blackberry and red raspberry, since 33 SSRs amplified a product from NY322, but neither of the blackberry genotypes. Differences in PCR product sizes from these genotypes reveal additional polymorphisms. Rubus is among the most diverse genera in the plant kingdom, so it is not surprising that only 19 of the 74 raspberry-derived SSRs amplified a product from all four of the genotypes tested. These SSRs will be useful in interspecific mapping and cultivar development.

\section{Improved Regeneration of Wild Strawberry (Fragaria vesca) Using TDZ and 2,4-D}

Phillip A. Wadl ${ }^{* 1}$, Richard E. Veilleux ${ }^{2}$

${ }^{1}$ Virginia Polytechnic Institute and State Univ., Horticulture Blacksburg, Va.; ${ }^{2}$ Virginia Polytechnic Institute and State Univ., Horticulture, Blacksburg, Va.

In order to facilitate the high throughput transformation required to use Fragaria vesca (wild strawberry) as a tool in genomic research, functional genomics, and gene discovery not only for strawberry but 
for fruit crops in general, we need to increase its regeneration frequency and transformation efficiency using Agrobacterium. Ten accessions of $F$. vesca representing a range of germplasm with worldwide distribution were obtained from the USDA National Germplasm Repository, Corvallis, Ore. for use in shoot regeneration experiments. Seed germination with or without vernalization ranged from $0 \%$ to $90 \%$. In vitro growth varied for the accessions with five accessions eliminated from further experiments due to poor growth. In preliminary experiments with 125 leaf explants and 40 petiole explants combined representing PI 551573, PI 602923, and F. vesca 'Alpine'; 100\% of the uncontaminated explants regenerated at least one shoot after 8 weeks on medium supplemented with $1 \mathrm{mg} \cdot \mathrm{L}^{-1}$ 1-phenyl-3- (1,2,3-thiadiazol-5-yl) urea (thidiazuron or TDZ) and $0.2 \mathrm{mg} \cdot \mathrm{L}^{-1}$ 2,4-dichlorophenoxyacetic acid (2,4-D). In a replicated study of 'Alpine' comparing regeneration on the above TDZ/2,4-D medium with control medium $\left[0.25 \mathrm{mg} \cdot \mathrm{L}^{-1}\right.$ indole-3-butyric acid (IBA) $/ 3 \mathrm{mg} \cdot \mathrm{L}^{-1}$ benzyladenine $\left.(\mathrm{BA})\right]$, regeneration frequency at 6 weeks for leaf or petiole explants on control medium was $8 \%(\mathrm{n}=$ 180) compared to $27 \%(\mathrm{n}=210)$ on the TDZ/2,4-D medium. This optimized shoot regeneration protocol for $F$. vesca 'Alpine' is currently under investigation in transformation experiments with several other accessions and Agrobacterium constructs.

\section{Assessment of the Utility of ISSR Markers for Evaluating Genetic Relationships Among Members of Asimina and Annona}

Danielle Rascoe ${ }^{1}$, Kirk W. Pomper*2, Jeremiah Lowe ${ }^{3}$, Sheri B.

Crabtree $^{4}$, Har Mahdeem ${ }^{5}$, Tejender S. Kochhar ${ }^{6}$

${ }^{1}$ Kentucky State Univ., Land Grant Program, Frankfort, KY 40601; ${ }^{2}$ Kentucky State Univ., Land Grant Program, Frankfort, KY 40601; ${ }^{3}$ Kentucky State Univ., Land Grant Program, Frankfort, KY 40601; ${ }^{4}$ Kentucky State Univ., Land Grant Program, Frankfort, KY 40601; ${ }^{5}$ Dharma Properties, Dharma Properties, Boynton Beach, FL 33435; ${ }^{6}$ Kentucky State Univ., Math and Sciences Dept., Frankfort, KY 40601

The genus Asimina has the only temperate representatives of the tropical Annonaceae, or Custard Apple family, and includes eight species that are indigenous to North America. The North American pawpaw Asimina triloba (L.) Dunal has the largest edible fruit native to the United States and is the best-known of these species. The USDA National Clonal Germplasm Repository for Asimina species is located at Kentucky State Univ. (KSU); therefore, assessment of genetic diversity is an important research priority for KSU. The inter-simple sequence repeat PCR (ISSR-PCR) methodology has been used successfully to characterize genetic diversity within and among populations of many plant species. The objective of this study was to assess the utility of ISSR markers in evaluating genetic relationships in members of the Asimina genus, as well as closely related tropical relatives in the Annona genus. Leaf samples were collected from three plants each of Asimina longifolia, A. obovata, A. parviflora, A. reticulata, A. tetramera and A. triloba. Leaf samples were also collected from three plants each of Annona cherimola, A. squamosa, A. reticulata, A. muricata, A. glabra, A. diversifolia, and A. montana. DNA was extracted from leaf samples and subjected to ISSR-PCR using the REDExtract-N-Amp ${ }^{\text {TM }}$ Plant PCR Kit. DNA samples were screened with ISSR primers using the Univ. of British Columbia microsatellite primer set \#9. Three primers, UBC812, UBC841, and UBC873 were found to produce 84 scorable ISSR markers and allowed the determination of genetic relationships among Asimina and Annona members examined.

\section{Mapping QTL for Day-neutrality in Strawberry}

\section{Cholani K. Weebadde*1, James F. Hancock ${ }^{2}$}

${ }^{1}$ Michigan State Univ., Horticulture, East Lansing, MI 48824; ${ }^{2}$ Michigan State Univ., Horticulture, East Lansing, MI 48824

While it is important for strawberry breeders to know the genetics of day-neutrality, evidence for inheritance of the trait is still contradictory. It is not known how many genes govern the trait, to what extent each gene affects phenotype and how the environment influences gene expression. Several recent studies point toward a polygenic threshold model and a rejection of the single gene model. A linkage mapping approach is being used to determine if day neutrality can be mapped to several different quantitative trait loci(QTL) that may represent different genes.
To confirm that a linkage mapping approach is the method of choice for QTL detection, a small population of the cross 'Honeoye' $\mathrm{x}$ 'Tribute' consisting of 57 progeny segregating for the trait was genotyped with single dose restriction fragment (SDRF) markers and a preliminary genetic map was created using Join Map 3.0. Results separated the molecular markers into at least 24 linkage groups and several putative QTL for day neutrality were identified indicating that the technique will be successful. However, due to the complexity of the octoploid genome of strawberry, over 200 progeny need to be genotyped to build a complete map that includes the 56 linkage groups of the genome. Furthermore, for determining QTL, an accurate phenotypic evaluation is critical. Individuals of the population above were phenotyped under field conditions (East Lansing, Mich.) in 2002 and 2003, and are now being analyzed under controlled temperature and photoperiod conditions for confirmation of the QTL detected for the trait. A larger population of the same cross with over 200 progeny has also been generated and will be mapped using molecular markers after determining their phenotype under the same environmental conditions.

\section{Poster Session 22-Propagation}

July 18, 2004, 6:30-5:30 PM Rio Grande Exhibit Hall

\section{Utilizing Tobacco Greenhouses for Producing Plants for En-} vironmental Restoration

Andrew C. Bell ${ }^{1}$, Mary M. Peet*2

${ }^{1}$ NC State Univ., Horticultural Science, Raleigh, NC 27695-7609; ${ }^{2}$ NC State Univ., Horticultural Science, Raleigh, NC 27695-7609

Environmental restoration of streams and wetlands in North Carolina is creating a growing demand for commercially available native plant material. Recent changes in the tobacco industry have resulted in decreased production leaving some tobacco greenhouses, once utilized for a few months, empty year-round. Identifying alternative crops that can be grown in tobacco greenhouses will provide valuable income to economically distressed tobacco growers. The floatation system (sub-irrigation) employed in the production of tobacco transplants in greenhouses is similar to that utilized by some native plant nurseries to produce wetland and riparian species. Local production of this plant material can enhance restoration project goals by increasing utilization of regional germplasm in this industry and reducing the risk of importing exotic pests with material shipped from out-of-state. To research these possibilities, we constructed a demonstration tobacco greenhouse with multiple float beds. Three commercially available media, including a tobacco seedling mixture, were tested. No differences were observed among the plants grown in different media. After one growing season, we have identified close to 20 species, woody and herbaceous, that can be successfully grown in a traditional tobacco greenhouse with minimal input or alternation to the structure or normal production practices. Additional research is needed, however, to address optimal production criteria.

\section{Storage of Flowering Dogwood (C. florida) Seed}

Sandra Reed*1

${ }^{1}$ USDA-ARS, Floral \& Nursery Plants Res. Unit, McMinnville, TN 37110

Flowering dogwood (Cornus florida) is a popular flowering tree that is a mainstay of the southeastern U.S. nursery industry. Because cultivars of this species are primarily propagated through budding onto seedpropagated rootstock, a reliable source of seeds is needed. Diseaseand weather-related problems may sometimes result in a shortage of dogwood seed. The objective of this study was to develop a method of storing dogwood seed that would allow growers to save seed during years in which good flowering and seed set occur for use when insufficient seed is available. Open-pollinated seeds were collected in Fall 1999, dried to $6 \%, 10 \%$, and $14 \%$ moisture, and stored at $-20,5$, and $22{ }^{\circ} \mathrm{C}$. After 1,2 and 3 years of storage, seed was stratified for 3 months and then planted in the greenhouse. Percent germination was 
compared to that of a subsample of the seed lot that had been stratified and planted following collection in Fall 1999. After 1 year in storage, seed dried to $10 \%$ and $14 \%$ moisture and stored at $22{ }^{\circ} \mathrm{C}$ failed to germinate; germination of the other samples ranged from 55\% to $97 \%$ of that of the control sample. After 2 or 3 years in storage, all seed stored at $22{ }^{\circ} \mathrm{C}$ and the seed dried to $14 \%$ moisture and stored at $5{ }^{\circ} \mathrm{C}$ failed to germinate. Germination of the remaining samples ranged from $76 \%$ to $97 \%$ of the control in year 2, and from $72 \%$ to $109 \%$ in year 3 . After 3 years in storage, seed dried to $6 \%$ moisture and stored at $5{ }^{\circ} \mathrm{C}$ and seed dried to $10 \%$ moisture and stored at $-20{ }^{\circ} \mathrm{C}$ had the highest germination percentage and best seedling vigor. Development of a seed storage method for dogwood will benefit both dogwood producers and germplasm preservation efforts.

\section{Stem Anatomy Influences Rooting of Cuttings from Bur Oak, Quercus macrocarpa}

\section{Cheryl L. Moore*1, Tracy A.O. Dougher ${ }^{2}$}

${ }^{1}$ Montana State Univ., Plant Sciences and Plant Pathology, Bozeman, MT 59717; ${ }^{2}$ Montana State Univ., Plant Sciences and Plant Pathology, Bozeman, MT 59717

Bur oak, Quercus macrocarpa Michaux, does not root readily from cuttings, and is considered a recalcitrant species. A method producing industry-acceptable levels of rooted cuttings has not been determined. In this study, we explored the possibility of a physical barrier to root initiation. Bur oak stems exhibit a pentarch vascular cylinder, with roots and leaf traces only initiating at the five "points" of the vascular system. External to this vascular system is a series of sclerified tissue, both fibers and sclerenchyma. Both light microscopy and electron microscopy were utilized to determine whether a combination hedging and etiolation treatment of parent plants would inhibit formation of sclerified tissues.

\section{Rooting of Elaeocarpus yoga, an Ornamental Tree Indigenous to Guam}

\section{Jean-Marc G. Guedon*1, James McConnel1²}

${ }^{1}$ Univ. of Guam, College of Natural and Applied Sciences/AES, Mangilao, GU 96923; ${ }^{2}$ Univ. of Guam, College of Natural and Applied Sciences/AES, Mangilao, GU 96923

Elaeocarpus yoga Merr. (Tiliaceae) is an attractive tree indigenous to the Mariana Islands and Palau. Recently its population has declined due to deforestation, typhoon damage, and pest problems. Stem cuttings of E. yoga were taken from hardwood, semihardwood, or softwood and treated with acid or salt forms of indole-3-butyric acid (IBA) or napthaleneacetic acid (NAA) at several concentrations. The cuttings were treated with on of the following: acid form at $0.5 \mathrm{~mL} \cdot \mathrm{L}^{-1} \mathrm{IBA}+$ $0.25 \mathrm{~mL} \cdot \mathrm{L}^{-1} \mathrm{NAA} ; 1 \mathrm{~mL} \cdot \mathrm{L}^{-1} \mathrm{IBA}+0.5 \mathrm{~mL} \cdot \mathrm{L}^{-1} \mathrm{NAA}, 2 \mathrm{~mL} \cdot \mathrm{L}^{-1} \mathrm{IBA}$ $+1 \mathrm{~mL} \cdot \mathrm{L}^{-1} \mathrm{NAA}$; salt form at 1,3 , and $8 \mathrm{~g} \cdot \mathrm{kg}^{-1} \mathrm{IBA} /$. Rooting after 8 weeks was compared among treatments. The salt form of the IBA treatment at $3 \mathrm{~g} \cdot \mathrm{kg}^{-1}$ produced the greatest rooting percentage, root number and length. The acid form containing both IBA and NAA produced the smallest average rooting percentage.

\section{Grafting Compatibility of Three Varieties of Ficus (Ficus benjamina L.) Grafted on the Rootstock Variety Profit}

Juan Manuel González-González*1, Marcelino Bazán-Tene², Francisco Radillo-Juárez ${ }^{3}$, Jaime Molina-Ochoa ${ }^{4}$

${ }^{1}$ Universidad de Colima, Facultad de Ciencias Biológicas y Agropecuarias, Tecomán, Colima 28100, México; ${ }^{2}$ Universidad de Colima, Facultad de Ciencias Biológicas y Agropecuarias, Tecomán, Colima, 28100, México; ${ }^{3}$ Universidad de Colima, Facultad de Ciencias Biológicas y Agropecuarias, Tecomán, Colima, 28100, México; ${ }^{4}$ Universidad de Colima, Facultad de Ciencias Biológicas y Agropecuarias, Tecomán, Colima, 28100, México

Plants in the genus Ficus are one of the most used in the ornamentals. it is also used for plant handcrafting such as braid, cylinders, and wall rockets, using a single plant or braiding some plants. The ficus are commonly asexually propagated by slip or shoots. There is the possibility to graft and to obtain plants with two levels of foliage, combining the color and texture. The objective of this research was to evaluate the grafting compatibility of varieties of Ficus benjamina, such as: Vivian, Winter green, and Antillean (green color) grafted on the variety Profit (white color) used as rootstock. The study was carried out under environmental conditions of the Mexican Dry Tropic in Tecomán, Colima, Mexico. The grafting method was by whip or tongue approximation. Bud sticks of the four varieties $\approx 70-\mathrm{cm}$ long were used as scions. They were previously rooted in polyethylene bags containing $1.5 \mathrm{~kg}$ of coconut fiber used as rooting substrate. The rootstocks were grown long in soil until $1.5 \mathrm{~m}$ and when they reach similar diameter to the scions. The grafting height and diameter was $\approx 50-60 \mathrm{~cm}$, and $2-2.6 \mathrm{~cm}$, respectively. Five grafted plants were used as experimental unit, and the treatments were distributed in a completely randomized design with four replications. The variables estimated were: number of leaves after 28 and 35 days post-grafting, and percentage of grafting at 28 and 35 days post-grafting. The tree varieties were compatible with the rootstock, and no differences were obtained between the treatments (Tukey test $P<0.05$ ); both three varieties exhibited $75 \%$ of grafting success, and 'Antillean' had higher number of leaves, but the three varieties were statistically similar.

\section{Seed Recalcitrance of Carolina Buckthorn: Implications for Ecology and Horticulture}

J. Ryan Stewart*1, William R. Graves ${ }^{2}$

${ }^{1}$ Iowa State Univ., Horticulture Dept., Ames, IA 50011-1100; ${ }^{2}$ Iowa State Univ., Horticulture Dept., Ames, IA 50011-1100

Carolina buckthorn (Rhamnus caroliniana Walt.) is ornamental and could be promoted as a stress-resistant shrub for horticultural landscapes. Its status as a relative of invasive species, including common buckthorn (Rhamnus cathartica L.), raises concerns regarding the environmental consequences of planting Carolina buckthorn outside of its natural habitat. To assess the ease of propagating Carolina buckthorn from seed, and to gather data relevant to assessments of invasiveness, we compared seed-germination characteristics between the two species. Seeds of Carolina buckthorn were collected from native populations in Missouri, Oklahoma, and Texas. Seeds of common buckthorn were collected from populations in Iowa. We stratified seeds of both species for up to 112 days at $4{ }^{\circ} \mathrm{C}$. Germination at $20{ }^{\circ} \mathrm{C}$ then was evaluated for 56 days. Over stratification durations, $40 \%$ and $71 \%$ of seeds of Carolina buckthorn and common buckthorn germinated, respectively. Stratification for 112 days optimized germination value for Carolina buckthorn, but stratification for 42,56,84, and 112 days evoked similar germination percentages. Seeds of Carolina buckthorn from Oklahoma germinated at a higher percentage $(56 \%)$ than did seeds from Missouri $(25 \%)$. Neither germination value nor germination percentage of common buckthorn was influenced by stratification. We conclude that seeds of Carolina buckthorn are more recalcitrant than are seeds of common buckthorn. This suggests that Carolina buckthorn, particularly those from Missouri with low reproductive success, may be less invasive than their Eurasian kin. Horticulturists can optimize germination percentage of Carolina buckthorn by cold-stratifying seeds for as little as 42 days, but 112 days optimizes germination value.

\section{Effects of Seed Coat Treatment and Stratification on the Germination Rate of Montezuma Cypress}

\section{Geoffrey C. Denny*1, Michael A. Arnold ${ }^{2}$}

'Texas A\&M Univ., Dept. of Horticultural Sciences, College Station, TX 77843-2133; ${ }^{2}$ Texas A\&M Univ., Dept. of Horticultural Sciences, College Station, TX 77843-2133

An experiment was initiated to evaluate the effects of previously recommended seed treatments for baldcypress [Taxodium distichum (L.) Rich.] or pondcypress [Taxodium distichum (L.) Rich. var. imbricarium (Nutt.) Croom] on Montezuma cypress [Taxodium distichum (L.) Rich. var. mexicanum Gordon], and to determine which, if any, provided optimum germination. Factorial combinations of seed treatments and stratification $\left(2{ }^{\circ} \mathrm{C}\right.$ for 0,45 , or $\left.90 \mathrm{~d}\right)$ were applied to seeds of Montezuma cypress. Treatments included: 1) $90 \%$ ethanol 5 min soak, 2) ethyl ether $5 \mathrm{~min}$ soak, 3) $100 \mathrm{mg} \cdot \mathrm{L}^{-1}$ citric acid $48 \mathrm{~h}$ soak, 4) mechanical scarification, 5) five hot water baths $\left(42^{\circ} \mathrm{C}\right)$ allowing the water to cool to room temperature between baths, and 6) a non-treated control. Three more seed treatments consisted of water soaks at room temperature $\left(25^{\circ} \mathrm{C}\right)$ for 0,45 , or $90 \mathrm{~d}$. Seeds were germinated on moist 
filter paper in a growth chamber with a 12-h day/night photoperiod at a constant $25^{\circ} \mathrm{C}$. Data was collected daily for $14 \mathrm{~d}$ and then weekly for the following $4 \mathrm{wks}$. Radicle elongation of $1 \mathrm{~cm}$ was considered germination. Without stratification, $100 \mathrm{mg} \cdot \mathrm{L}^{-1}$ citric acid and the hot water bath treatments were significantly different from other treatments by $7 \mathrm{~d}$, though not from each other, with a mean cumulative germination of $15.6 \%$ and $12.2 \%$, respectively. By $14 \mathrm{~d}$, the $100 \mathrm{mg} \cdot \mathrm{L}^{-1}$ citric acid treatment differed only from the ethyl ether wash attaining $28.9 \%$ and $14.4 \%$ germination, respectively. There were no other statistically significant differences observed among any other treatments without stratification. Germination percentages were low, $<30 \%$, without stratification. Effects of additional stratification will also be discussed.

\section{Relationships Between Seed Biomass, Germination Time, and Seedling Growth in Olea europaea}

Rinaldi Laura*1

${ }^{1}$ CNR, IVALSA, Sesto Fiorentino, Florence, 50019, Italy

Olive plants for commercial production are vegetatively propagated by cutting and grafting. While genetic identity can be maintained by "own root"; plants by cutting, the grafted plants may show different growth characteristics due to the influence of the rootstock. The selection of mother plants, able to produce seeds with desirable characteristics and rootstocks that may control seedling growth in grafted stock, can be an objective of study to facilitate the development of olive breeding programmes. The relationship between seed biomass, mineral nutrient reserves, time to germination and seedling growth was analysed for six cultivars of Olea europaea. The cultivars, exhibiting initial differences in seed biomass, differed significantly with respect to germination capacity, germination time and mineral content. Significant variation among cultivars was also evident in the linear growth of seedlings, evaluated at different intervals from 2 to 30 weeks. The seeds from all six cultivars exhibited low germination. There is a significant effect of cultivar on the levels of single mineral nutrient content of seeds, high concentrations of $\mathrm{N}$ and significant concentrations of $\mathrm{K}, \mathrm{P}, \mathrm{Mg}$, and $\mathrm{Ca}$ were detected. Seed biomass was not related to time to germination and the levels of single nutrients of the seeds themselves. For seed tissue, significantly positive correlations existed only between $\mathrm{K}$, and $\mathrm{Mg}$ concentrations. Seed biomass was positively and significantly related to root biomass. The seedlings obtained from larger seeds showed a substantially greater proportion of biomass to roots. Some root traits may be important for survival and the establishment of the seedlings, not least under conditions of limited water availability.

\section{Rooting Woody Stem Cuttings in Grape Pomace Media Amended with Composted Bark, Perlite or Peat}

\section{Calvin Chong*1 ${ }^{*}$ Adam Dale ${ }^{2}$}

${ }^{1}$ Univ. of Guelph, Dept. of Plant Agriculture, Guelph, Ontario, N1G 2W1, Canada; ${ }^{2}$ Univ. of Guelph, Dept. of Plant Agriculture, Simcoe, Ontario, N3Y 4N5, Canada

Terminal stem cuttings of seven woody nursery species [boxwood (Buxus sempervirens L. 'Green Mountain'), coralberry (Symphoricarpus $\times$ chenaultii Rehd. 'Hancock'), lilac (Syringa velutina Kom.), Peegee hydrangea (Hydrangea paniculata Siebold. 'Grandiflora'), purple-leaf sandcherry (Prunus $\times$ cistena N.E. Hansen), Rose-of-Sharon (Hibiscus syriacus L. 'Lucy'), and winged spindle-tree (Euonymus alata Thunb.) Siebold. 'Compacta')] were rooted under outdoor lath (50\% shade) and mist in leached rooting media consisting of $0,20,40,60$ and $80 \%$ by volume of 2 -year-old grape pomace amended in binary mixtures with sphagnum peat, perlite or composted bark. Rooting performance, expressed in terms of percent rooting, mean root number per rooted cutting, and length of the longest root per cutting, was regressed on level of pomace. When there were differences due to amendments, most species rooted better with perlite than with bark and peat, to a lesser degree, due in part to more favourable air-filled porosities with perlite (33\% to $42 \%)$ than with bark $(29 \%$ to $37 \%)$ or peat $(24 \%$ to $35 \%)$. With boxwood, increasing level of pomace up to $\approx 60 \%$, especially when mixed with perlite or peat, resulted in substantial increases in rooting percentage, root number and length. All three rooting parameters of winged spindle-tree decreased linearly with increasing level of pomace with perlite or bark. The effect of pomace level on other species varied between these extremes with little or no negative effect on rooting.

\section{Rooting Medium Composition and In Vitro Rooting and Greenhouse Survival of Five Raspberry Cultivars}

Becky R. Hughes*1, Wanda J. Cook ${ }^{2}$, Candy N.F. Keith ${ }^{3}$

${ }^{1}$ Univ. of Guelph, New Liskeard Agricultural Research Station, New Liskeard, ON P0J 1P0, Canada; ${ }^{2}$ Univ. of Guelph, New Liskeard Agricultual Research Station; ${ }^{3}$ Univ. of Guelph, New Liskeard Agricultural Research Station

In vitro rooting and subsequent greenhouse survival of 'Autumn Britten', 'Boyne', 'Comet', 'Nova' and 'Qualicum' raspberry (Rubus idaeus L.) plantlets were compared following four weeks on a rooting medium with and without activated charcoal, and with $0.1,0.5,1.0,2.0$ or 3.0 milligrams per litre IBA. The addition of charcoal significantly increased the percentage of plantlets that produced roots in vitro for the hard-to-root cultivars. Percent rooting in vitro was highest with the three lower levels of IBA. Root number was influenced only by the cultivar, while root diameter and length were affected by all the factors investigated. Greenhouse survival was affected by the cultivar, the presence or absence of charcoal and the IBA level in the in vitro rooting medium, with significant interactions. Provided charcoal was present in the rooting medium, the level of IBA didn't alter survival. The addition of charcoal to the rooting medium improved greenhouse survival of the three hardest-to-root cultivars. Plug plant stem length; internode length and dry weight were increased by the presence of charcoal in the in vitro rooting medium for all but the easiest to establish cultivar. Chemical names used: 3 -indolebutyric acid (IBA).

\section{In Vitro Response of Micropropagated Chestnut Shoot to Dif-} ferent Growth Regulators

Theophilus Asante*1, Guochen Yang ${ }^{2}$

${ }^{1}$ North Carolina A\&T State Univ., Natural Resources and Environmental Design, Greensboro, NC 27411; ${ }^{2}$ North Carolina A\&T State Univ., Natural Resources and Environmental Design, Greensboro, NC 27411

The role of plant growth regulators in enhancing axillary shoot proliferation, callus production and root initiation of the American chestnut (Castanea dentata) was investigated. Micropropagated shoots were used as explant materials. Different concentrations of indoleburytic acid (IBA), kinetin, N-(2-chloro-4-pyridyl)-N'-pheylurea (CPPU), naphtha-leneacetic acid (NAA), thidiazuron (TDZ), zeatin, 2,4-dichlorophenoxyacetic acid (2,4-D), and 2,4,5-trichlorophenoxyacetic acid (2,4,5-T) were added to McCown woody plant medium (WPM) to evaluate their effects on in vitro shoot proliferation, callus production, and root initiation. Differences in the number of shoots (primordia), morphology of micropropagated shoots, and amount of callus were observed between the plant growth regulator treatments and concentrations. Explants cultured in media containing CPPU or TDZ produced more shoots (primordia). Callus production increased from NAA to IBA to $2,4-\mathrm{D}$ to $2,4,5-\mathrm{T}$.

\section{Promotion of Embryogenic Callus Induction of Pimpinella brachicarpa by Environmental Control}

\section{Hae Young Na*1, Dong Jin Shin ${ }^{2}$, Changhoo Chun ${ }^{3}$}

${ }^{1}$ Seoul National Univ., Dept. of Horticultural Science, Seoul, 151-742, Korea; ${ }^{2}$ Seoul National Univ., Dept. of Horticultural Science, Seoul, 151-742, Korea; ${ }^{3}$ Seoul National Univ., Dept. of Horticultural Science, Seoul, 151-742, Korea

Pimpinella brachicarpa (Chamnamul in Korean) is an indigenous plant that grows in Korean mountain areas. It has not been cultivated yet but is gathered to use as a vegetable. Its difficulty of propagation by seeds is one of the major reasons not to be cultivated as a horticultural crop despite its demand. As a promising propagation method for the Chamnamul, we have developed a micropropagation system using somatic embryogenesis. In the present study, induction of embryogenic callus of the Chamnamul affected by part of explants (leaf and stem) and concentration $\left(0,0.1,0.5,1.0,1.5\right.$, and $\left.2.0 \mathrm{mg} \cdot \mathrm{L}^{-1}\right)$ of growth regulators (2.4-D, IAA, IBA, and NAA) was investigated to find the 
best conditions for embryogenic callus induction. A full strength of MS medium was used for a 50-day culture for all the treatments. The embryogenic callus was firm and light yellow in color and was distinct from the non-embryogenic callus that was friable and semitransparent. More embryogenic callus was induced in the treatments that the stem was used as an explant comparing with the treatments that the leaf was used. The 2.4-D treatments resulted in the better induction of embryogenic callus than other growth regulator treatments, and $1.5 \mathrm{mg} \cdot \mathrm{L}^{-1}$ was the most effective among all the $2,4-\mathrm{D}$ concentration treatments. Addition of $0.1 \mathrm{mg} \cdot \mathrm{L}^{-1} \mathrm{BA}$ to $2.4-\mathrm{D}$ treatments retarded the induction of embryogenic callus of the Chamnamul, while the promotion of induction and multiplication of embryogenic callus was reported in many plant species by adding BA with low concentration to an auxin-base medium. The better induction was found in the treatments of darkness and dim lighting $\left(10 \mu \mathrm{mol} \cdot \mathrm{m}^{-2} \cdot \mathrm{s}^{-1}\right.$ of PPF $)$ than in treatments of the higher PPF.

431 Influence of Basal Medium and Hormones on Callus Induction and its Organogenesis from In Vitro Culture of Rose Leaf Segments

Rajendra Maurya*1, Nathu Ram Godara*2, Ram C. Yadav*3

${ }^{1}$ Central Arid Zone Research Institute, Jodhpur-342 003 India, Division of Soil Water Plant Relationship, Jodhpur, Rajasthan, 342003 India; ${ }^{2}$ Chaudhary Charan singh Haryana Agricultural Univ., Hisar-125 004 India, Dept. of Horticulture, Hisar, Haryana, 125 004, India; ${ }^{3}$ CCs Haryana Agricultural Univ., Hisar-125 004, Dept. of Biotechnology and Molecular Biology, Hisar, Haryana, 125 004, India

Influence of culture media and hormone concentrations on plant regeneration from rose (Rosa hybrida L. cv. Raktagandha) leaf segments were investigated. Leaves were excised from healthy, well-grown and mature plants. Leaf segments (4-5 $\mathrm{mm}$ long) were sectioned and cultured on Murashige and Skoog (1962) medium containing different concentration of growth hormones. Callus formation was most prolific (97.09\%) on MS medium containing MS basal salts $+0.5 \mathrm{mg} \cdot \mathrm{L}^{-1} \mathrm{BAP}$ $+2.0 \mathrm{mg} \cdot \mathrm{L}^{-1} 2,4$-D. maximum $(56.67 \%)$ organogenesis or shoot differentiation was achieved on MS modified medium supplemented with $1.0 \mathrm{mg} \mathrm{L}-1 \mathrm{BAP}+0.1 \mathrm{mg} \cdot \mathrm{L}^{-1} \mathrm{NAA}+10.0 \mathrm{mg} \cdot \mathrm{L}^{-1}$ Adenine Sulphate. The highest percentage $(93.73 \%)$ of in-vitro rooting was observed in half-strength MS basal medium containing $0.5 \mathrm{mg} \cdot \mathrm{L}^{-1}$ IBA. Rooted plants were transferred in to sterilized potting mixture and grown in a greenhouse.

\section{Poster Session 23-Ornamentals/Landscape and Turf}

July 18, 2004, 5:30-6:30 PM Rio Grande Exhibit Hall

\section{Influence of Fertilizer Application Timing and Rate on Azalea} Bloom

Julie Fulenwider*1, David Creech ${ }^{2}$

${ }^{1}$ Stephen F. Austin State Univ., Agriculture, Nacogdoches, TX 75962-3000; ${ }^{2}$ Stephen F. Austin State Univ., Agriculture, Nacogdoches, TX 75962-3000

General guidelines for the fertilization of azaleas in Southern landscapes often suggest applications be made after bloom. Early fertilizations are thought to encourage earlier blooms which are more likely to be damaged by spring freezes. Three years of data will be presented. Treatments include four fertilization rates, and various times of application from early (December-January) to late (March-April). Four to six varieties were evaluated (depending on the year of the study) in the SFA Ruby M. Mize Azalea Garden and in plantings on the Stephen F. Austin State Univ. campus. A randomized complete block design was utilized with three plants per replication. Influence of timing and rate of fertilizer application on bloom date and persistence. Influence of fertilizer treatments on leaf nutrient concentrations will be presented.
120 The Impact of Composted, Municipal Biosolid Amendments to Soil on the Growth and Nutrient Content of Rhododendron $x$ 'PJM'

Jae H. Han ${ }^{1}$, George L. Good*2, Harold M. Van Es ${ }^{3}$

${ }^{1}$ Cornell Univ., Horticulture, Ithaca, NY 14853; ${ }^{2}$ Cornell Univ., Horticulture, Ithaca, NY 14853; ${ }^{3}$ Cornell Univ., Crop and Soil Science, Ithaca, NY 14853

Field experiments were conducted in 1998 and 1999 to determine the effect of soil-incorporated, composted municipal biosolids on the growth and nutrient content of $30.8 \mathrm{~cm}-38.5 \mathrm{~cm}$ Rhododendron $\mathrm{x}$ 'PJM' grown as containerized plants. Biosolid compost produced in Endicott, N.Y., was incorporated in May 1998 and 1999 at rates of 0, $9.8 \mathrm{Mg} / \mathrm{ha}$ and $19.7 \mathrm{megag} / \mathrm{ha}$ to a depth of $23 \mathrm{~cm}$. Each treatment was replicated six times in a randomized block design. Plants were planted 10 June 1998 and 8 June 1999. Plants were harvested 10 June, 19 Aug., and 22 Oct. 1998 and 8 June and 22 Sept.1999 after which they were dried, weighed, and analyzed. During 1998, there was little difference in dry weight or nutrient content in plants harvested at the August harvest date, however, dry weight and most nutrient levels increased with increasing rates of compost application in plants harvested at the October harvest date. In 1999, no statistical differences were noted at the September harvest date in plant dry weight or nutrient content. In 1999, measured soil physical properties (water retention, bulk density, water content, and soil strength) did not differ significantly between treatments. Excellent soil structure and drainage, relatively low rates of compost application and a severe drought may have contributed to the lack of any conclusive results noted in 1999 though some positive plant responses to the treatments were evident in 1998

\section{Effect of Compost Type on Bermudagrass Invasion}

Kristen L. McDowell*1, Kevin Ong ${ }^{2}$, Derald A. Harp ${ }^{3}$

${ }^{1}$ Texas A\&M-Commerce, Agricultural Sciences, Commerce, TX 75482; ${ }^{2}$ Texas A\&M, Texas Cooperative Extension, Dallas, TX 75252; ${ }^{3}$ Texas A\&M-Commerce, Agricultura Sciences, Commerce, TX 75482

A study was conducted on the Texas A\&M Univ.-Commerce campus to evaluate the effect of compost type on the spread of bermudagrass into rose garden beds. Roses were planted in an randomized complete-block design in beds amended with composts derived from yard waste, manure, poultry litter, or dairy manure, or an unamended control. The study site was free of vegetation prior to planting. No pre- or post- emergent herbicides were applied after planting. Each bed was assessed visually monthly and scored on a scale of 0 to 10 , with each point equivalent to $10 \%$ coverage. A bed received a score of 10 upon full coverage. Beds amended with poultry litter and yard waste had significantly higher bermudagrass invasion and reached $100 \%$ coverage more quickly than other treatments. Some of the poultry litter beds reached $100 \%$ coverage within 40 days of planting. The control planting had significantly lower coverage than all compost treatments throughout the study.

\section{Effects of Aquatic Extract from Chrysanthemum's Rhizospheric Soil on the Seed Germination and Root Enzymes}

\section{Kai Zhou ${ }^{1}$, Weiming $\mathrm{Guo}^{2}$, Zhongchun Jiang*3}

${ }^{1}$ Nanjing Agricultural Univ., Dept. of Ornamental Horticulture, Nanjing, Jiangsu, 210095 P.R. China; ${ }^{2}$ Nanjing Agricultural Univ., Dept. of Ornamental Horticulture, Nanjing, Jiangsu, 210095, P.R. China; ${ }^{3}$ State Univ. of New York at Cobleskill, Dept. of Plant Science, Cobleskill, NY 12043

The autointoxication of chrysanthemum was studied using water extract of Dendranthema morifolium's rhizospheric soil. Results of bioassays showed that the water extract inhibited chrysanthemum seed germination and the activities of some important root enzymes. The seedling nitrate reductase activity was decreased linearly with increasing concentration of the extract. The activity of root dehydrogenase was inhibited only at the highest concentration tested $\left[3.2 \mathrm{~g} \cdot \mathrm{mL}^{-1}\right.$, dry weight (DW)], but was stimulated at a lower concentration tested $\left(1.6 \mathrm{~g} \cdot \mathrm{mL}^{-1}, \mathrm{DW}\right)$. Malondialdehyde content increased at higher than $1.6 \mathrm{~g} \cdot \mathrm{mL}^{-1}$, DW concentrations of the extract. The autointoxication phenomenon might be related to the difficulties in continuous plantings of chrysanthemum at the same location. 
123 Biostimulants Improve Post-winter Performance of Residential St. Augustinegrass

\section{J. Pablo Morales-Payan*1, William M. Stall ${ }^{2}$}

${ }^{1}$ Univ. of Florida, Horticultural Sciences, Gainesville, FL 32611-0690; ${ }^{2}$ Univ. of Florida, Horticultural Sciences, Gainesville, FL 32611-0690

Aglycine-rich mixture of amino acids and short-chain peptides (Siapton) (3 g a.i. per L), two citokinin-rich seaweed (Ascophyllum nodosum) extracts (Stimplex and Triggrr) [50 $\mathrm{mg} \cdot \mathrm{L}^{-1}$, active ingredient (a.i.)], a mixture of cysteine and folic acid (Ergostim) $\left(300 \mathrm{mg} \cdot \mathrm{L}^{-1}\right.$ a.i.), and a terpenic acid-rich Siberian fir (Abies sibirica) extract (Silk) $\left(50 \mathrm{mg} \cdot \mathrm{L}^{-1}\right.$ a.i.) were sprayed on St. Augustinegrass residential turf at the beginning of the post-winter regrowth in Gainesville, North-Central Florida, to determine their effect on the growth and aesthetics of the lawn. Aboveand belowground biomass, leaf color, and density in St. Augustinegrass were enhanced by all the biostimulants, as compared to untreated St. Augustinegrass plots. The best results were obtained, in descending order, with the cytokinin-rich seaweed extracts, the glycine-rich mixture of amino acids and short-chain peptides, the mixture of cysteine and folic acid, and the terpenic acid-rich Siberian fir extract.

\section{Effect of Soil Amendments on Growth of Pentas in a Simulated Landscape}

Sudeep Vyapari*1, S.M. Scheiber ${ }^{2}$, Richard C. Beeson, Jr. ${ }^{3}$

${ }^{1}$ Univ. of Florida, Environmetal Horticulture, Apopka, FL 32703; ${ }^{2}$ Univ. of Florida, Environmental Horticulture, Apopka, FL 32703; ${ }^{3}$ Univ. of Florida, Environmental Horticulture, Apopka, FL 32703

During Fall 2003, a study was conducted to determine the effect of soil amendments on growth and response of Pentas lanceolata 'New Look Red' in the landscape. Pentas were grown in 250L drainage lysimeters in an open-sided clear polyethylene covered shelter filled with local top soil (Apopka fine sand). The treatments used were non-amended top soil (control) and soil amended with either compost ( $5 \%$ by volume) or clay ( $5 \%$ by volume) in the top $15 \mathrm{~cm}$. Best Management Practices were followed. Irrigation frequency and rate were regulated using a tensiometer-controlled automatic irrigation system. When plant available water in each soil type had declined to $70 \%$ or less, the plants were irrigated back to field capacity. Data were recorded on initial and final growth indices, shoot dry weight, and root dry weight. Final growth indices between control and soil amended with compost were not different; however, growth in the clay-based soil was significantly less than the compost-based soil type. The mean shoot dry weight $(77.2 \mathrm{~g})$ produced from plants in compost amended soil type was significantly higher than either control (57.45 g) or clay amended (54.92 g) soil types. No significant differences were found for either initial growth indices or root dry weight among the three treatments.

\section{Induction of Flowering in Saltgrass (Distichlis spicata)}

\section{Hrvoje Rukavina*1, Harrison Hughes ${ }^{2}$}

${ }^{1}$ Colorado State Univ., Horticultural \& Landscape Architecture, Fort Collins, CO 80523 1173; ${ }^{2}$ Colorado State Univ., Horticulture \& Landscape Architecture, Fort Collins, CO 80523-1173

Efforts are ongoing at Colorado State Univ. to develop cultivars of saltgrass for turf use. Crossing among genotypes have been limited because of the species' short flowering period that generally occurs in late May or early June. Therefore, this study was made to establish a floral induction procedure for saltgrass to facilitate winter crosses in the greenhouse. The effects of vernalization/photoperiod, nitrogen and burning on the flowering induction of three saltgrass genotypes were investigated in the Colorado State Univ. greenhouse. Genotypes 49 and C66 from South Dakota and Nevada, respectively did not respond to flowering induction treatments. Only genotype A54 from the Colorado Front Range gave adequate response to flowering induction treatments. Saltgrass genotype (origin of clone) is a major factor relative to floral induction with the treatments used. All three treatment factors significantly influenced the number of spikes or flowering in saltgrass clone A54. There was a highly significant effect of vernalization/photoperiod $(P<0.01)$ and burning treatment $(P<0.01)$, with a smaller but significant interaction $(P<0.05)$ among these two factors. There was also a significant effect of nitrogen $(P<0.05)$. Burning had a significant influence on flowering only in treatments without vernalization/photoperiod effect. Vernalization/photoperiod levels significantly influenced flowering regardless of the burning treatment. Since flowering induction requirements differ among saltgrass genotypes originating in different areas, further studies will evaluate more Colorado genotypes as well as different lengths of vernalization/photoperiod on efficiency of flower induction.

\section{Paclobutrazol and Ancymidol Spray Applications Affect Production Responses and Subsequent Landscape Performance of Ornamental Cabbage, Calendula, and Pansy}

\section{Garry V. McDonald*1, Michael A. Arnold ${ }^{2}$}

${ }^{1}$ Texas A\&M Univ., Dept. of Horticultural Sciences, College Station, TX 77843-2133; ${ }^{2}$ Texas A\&M Univ., Dept. of Horticultural Sciences, College Station, TX 77843-2133

Previous experiments indicated that plant growth regulators applied during greenhouse production can have a negative effect on subsequent landscape performance of pansy (Viola $\times$ wittrockiana $\mathrm{H}$. Gams 'Crown Yellow'). Three experiments were initiated in September 2003 to determine the affects of paclobutrazol and ancymidol on production and landscape performance of ornamental cabbage (Brassica oleracea $\mathrm{L}$. var. acephala A.P. deCandolle 'Dynasty Pink'), calendula (Calendula officinalis L. 'Bon Bon Orange'), and pansy. Seeds were germinated in plug trays $\left(1.5 \mathrm{~cm}^{3}\right.$ inverted cone-shaped pockets $)$ in a growth chamber with a $12 \mathrm{~h}$ photoperiod at $25 / 21{ }^{\circ} \mathrm{C}$ day/night. Plants were sprayed with paclobutrazol (formaulated as Bonzi) or ancymidol (formulated as Arest) at plug stage (cabbage, pansy, and calendula on 25 Sept., 2 Oct., 11 Nov., respectively), at 14 days after transplant into $0.73 \mathrm{~L}$ containers, or at both stages. Paclobutrazol was applied at $0,5,10$ or $15 \mathrm{mg} \cdot \mathrm{L}^{-1}$ and ancymidol at $0,2,4$, or $8 \mathrm{mg} \cdot \mathrm{L}^{-1}$. Cabbage (30 Oct. ), pansy (6 Nov.), and calendula (4 Dec.) were transplanted to landscape beds to assess residual effects on growth and flowering. Cabbage and calendula, showed minor differences in growth during greenhouse production due to varying rates of either paclobutrazol or ancymidol, but exhibited a greater response to application time. Only minor differences in growth occurred with pansy during greenhouse production due to rate or time of application using ancymidol, but exhibited major differences in response to both rate and time of application using paclobutrazol. Residual effects on growth and flowering during landscape performance phase will be discussed.

\section{Water Loss Estimates of Three Containerized Landscape Tree Species Using Thermal Dissipation Probes and Load Cells}

Thayne Montague*1

${ }^{1}$ Texas Tech Univ., Plant and Soil Science, Lubbock, TX 79409-2122

Granier style thermal dissipation probes (TDP) have been used to estimate whole plant water loss on a variety of tree and vine species. However, studies using TDPs to investigate water loss of landscape tree species is rare. This research compared containerized tree water loss estimates of three landscape tree species using TDPs with containerized tree water loss estimates as measured by load cells. Over a three-year period, established, $5.0 \mathrm{~cm}$ caliper Bradford pear (Pyrus calleryana 'Bradford'), English oak (Quercus robar), and sweetgum (Liquidambar styraciflua 'Rotundiloba') trees in 75 L containers were placed on load cells, and water loss was measured for a 60 -d period. One $3.0 \mathrm{~cm}$ TDP was placed into the north side of each trunk $30 \mathrm{~cm}$ above soil level. To reduce evaporation, container growing media was covered with plastic. Each night, plants were irrigated to soil field capacity and allowed to drain. To provide thermal insulation TDPs and tree trunks (up to $30 \mathrm{~cm}$ ) were covered with aluminum foil coated bubble wrap. Hourly TDP water loss estimates for each species over a three-day period indicate TDP estimated water loss followed a similar trend as load cell estimated water loss. However, TDP estimates were generally less, especially during peak transpiration periods. In addition, mean, total daily water loss estimates for each species was less for TDP estimated water loss when compared to load cell estimated 
water loss. Although TDP estimated water loss has been verified for several plant species, these data suggest potential errors can arise when using TDPs to estimate water loss of select landscape tree species. Additional work is likely needed to confirm estimated sap flow using TDPs for many tree species.

\section{The Response of Four Anthurium (Anthurium andraeanum) Cultivars to Five Sequential Applications of Four Preemergence Herbicides}

Joe DeFrank*1, James J.K. Leary ${ }^{2}$

${ }^{1}$ Univ. of Hawaii at Manoa, Tropicla Plant and Soil Science, Honolulu, HI 96822; ${ }^{2}$ Univ. of Hawaii at Manoa, Tropical Plant and Soil Science, Honolulu, HI 96822

An experiment to determine the response of four potted anthurium cultivars to sequential preemergence herbicide applications was conducted at a commercial nursery located in Mt. View on the Island of Hawaii. The four cultivars tested were: Lady Ann, Sundial, Tropic Fire, and Nicoya. Herbicides were applied at two rates, the anticipated labeled use rate $(1 \mathrm{X})$ and two times the anticipated labeled use rate $(2 \mathrm{X})$. The herbicides evaluated in this experiment were diuron, isoxaben, sulfentrazone and oryzalin. Herbicide applications were directed to the base of plants to avoid direct contact with leaves and flowers. Applications were made at 64-, 69-, 70-, and 98-day intervals for a total of 5 sprays. At 71 days after the last spray application, each plant was collected to determine the number of flowers and dry weight accumulation of leaves, shoots and roots. There was a significant interaction between the chemical treatments and the cultivar for leaf dry weight accumulation. Sulfentrazone $1 \mathrm{X}$ and $2 \mathrm{X}$ significantly reduced the dry weight in all four cultivars compared to the untreated controls. Leaf weights for the isoxaben $(1 \mathrm{X})$ treatments were not significantly reduced for all cultivars. However, 'Lady Anne' was significantly reduced at the $2 \mathrm{X}$ rate of isoxaben. Leaf weights for diuron and oryzalin at both $1 \mathrm{X}$ and $2 \mathrm{X}$ treatments were not significantly different from the untreated control. Only sulfentrazone reduced shoot dry weight and flower number. Diuron was the only herbicide that did not reduced root dry weight.

\section{Landscape Leaf-waste Pellets as an Herbicide Carrier for Container-grown Landscape Plants}

Jayesh Samtani ${ }^{1}$, Gary Kling*2, David Williams ${ }^{3}$

${ }^{1}$ Univ. of Illinois, Natural Resources and Environmental Sciences, Urbana, IL 61801; ${ }^{2}$ Univ. of Illinois, Natural Resources and Environmental Sciences, Urbana, IL 61801; ${ }^{3}$ Univ. of Illinois, Natural Resources and Environmental Sciences, Urbana, IL 61801

Conventional herbicide applications to container-grown landscape plants, often requires multiple spray applications of herbicides in a growing season and presents problems such as non-uniform application, leaching, run-off, environmental pollution, worker exposure and phytotoxicity to the landscape plants. The use of an organic herbicide carrier could help reduce some of the problems associated with spray applications. Landscape-leaf waste pellets were evaluated as a preemergent herbicide carrier for container-grown landscape plants. Isoxaben, prodiamine and pendimethalin were applied to Chrysanthemum $\times$ grandiflorum 'Lisa', Euonymus fortunei 'Coloratus' and Spiraea japonica 'Neon Flash', at rates of 1.12, 2.25, and $2.25 \mathrm{~kg} \cdot \mathrm{ha}^{-1}$ active ingredient,respectively, with either water or landscape leaf waste pellets as a carrier. Portulaca oleracea, Senecio vulgaris, and Setaria faberi were seeded following treatment application. Visual ratings on efficacy and photoxicity to landscape plants, and shoot fresh and dry biomass were determined for both weeds and crop plants. Landscape leaf pellets served as an effective carrier for application of prodiamine and pendimethalin and combinations of these herbicides with isoxaben in controlling weeds. Leaf waste pellets as a carrier produced equivalent weed control and phytotoxicity ratings to conventional spray application of these herbicides, on both Chrysanthemum and Euonymus. The pellets did not make a consistently effective carrier for the application of isoxaben alone. Application of herbicides on leaf pellets could result in more uniform herbicide applications, minimize loss of herbicides to the environment and reduce the risk of herbicide contact with nursery workers.
130 Evaluation of Dichlobenil and Flumioxazin Preemergent Formulations for Ornamental Weed Control

Michele M. Bigger*1, Hannah M. Mathers ${ }^{2}$, Jennifer A. Pope ${ }^{3}$, Luke T. Case ${ }^{4}$

${ }^{1}$ Ohio State Univ., Horticulture and Crop Science, Columbus, OH 43210-1096; ${ }^{2}$ Ohio State Univ., Horticulture and Crop Science, Columbus, OH 43210-1096; ${ }^{3}$ Ohio State Univ., Horticulture and Crop Science, Columbus, OH 43210-1096; ${ }^{4}$ Ohio State Univ., Horticulture and Crop Science, Columbus, OH 43210-1096

The objective of this study was to evaluate the extent and duration of efficacy and phytotoxicity of two new formulations of dichlobenil (Casoron 50WP and Casoron CS), applied alone or onto two bark mulches, pine nuggets or shredded hardwood. The herbicide treated bark was compared to a control (weedy check), direct sprays of the herbicides and mulch alone. Three granular preemergent herbicides, dichlobenil (Casoron 4G) and two formulation of flumioxazin (Broadstar 0.17G, VC1351, and VC1453) were also evaluated for a total of 12 treatments. The trial started on May 23, 2003. Visual ratings and dry weights were evaluated for efficacy at 4, 8 and 16 weeks after treatment (WAT) and phytotoxicity 2, 4, 8, and 16 WAT. Ratings of efficacy were based on a 1-10 scale where, 0 represents no control, 10 represents complete control. Visual rating scores of 1 (no injury) to 10 (complete kill) were used for phytotoxicity on Salvia May Night. The two most efficacious treatments are Casoron CS as a directed spray (7.9) and treated on pine nuggets (9.0). The hardwood bark with Casoron CS also was providing an efficacy rating of 7.75 in the analyses of combined dates 4 and 8 WAT. The weed control provided by the untreated hardwood bark and pine nuggets was not significantly different from the control. Four treatments - Casoron CS and 4G, Casoron CS on pine, and CS on hardwood-provided ratings of 3 and above for phytotoxicity, in the analyses of combined dates $2,4,8$, and 16 WAT. Although the Casoron CS was the second most efficacious treatment it had a phytotoxicity rating of 9.25 over combined dates. The CS on pine, however, had a significantly reduced phytotoxicity rating (3.5) and superior efficacy.

\section{The Fate of Bifenthrin and Fipronil in Pine Bark Nursery Media}

\section{Russell S. Harris*1, Edward W. Bush*2, Ronald J. Ward ${ }^{3}$}

${ }^{1}$ Louisiana State Univ., Horticulture, Baton Rouge, LA 70803; ${ }^{2}$ Louisiana State Univ., Horticulture, Baton Rouge, LA 70803; ${ }^{3}$ Louisiana State Univ., Ag Chemistry, Baton Rouge, LA 70803

Bifenthrin and fipronil are important pesticides used in the nursery industry for the control of imported fire ants. Our research measured the influence of irrigation frequency and time on the degradation of bifenthrin and fipronil in pine bark nursery medium. Pine bark media leachates were collected over a 180-d period. Levels of bifenthrin, fipronil, and metabolites of fipronil (MB 46513, MB 45950, MB 46136) were measured using gas chromatography and mass spectrophotometery. Bifenthrin leachate concentrations decreased from $60 \mathrm{ppb}$ on day 1 to $\approx 1 \mathrm{ppb}$ after $120 \mathrm{~d}$. Fipronil leachate concentrations decreased from 40 $\mathrm{ppb}$ on day one to a low of $15 \mathrm{ppb}$ after $120 \mathrm{~d}$. In contrast, metabolites MB 45950 and MB 46136 gradually increased over the 180-d period. Metabolite MB 46513 was not detected during the experiment. Pine bark medium leachate concentrations of bifenthrin and fipronil were greater than previously reported levels in pure water. We theorize that organic compounds present in pine bark may have increased the solubility of these chemicals.

\section{Effectiveness of Copper Sulfate Pentahydrate and Mancozeb in Controlling Anthracnose on Euonymus fortunei}

\section{Cheryl R. Boyer*1, Janet C. Cole ${ }^{2}$, Kenneth E. Conway ${ }^{3}$}

'Oklahoma State Univ., Horticulture and Landscape Architecture, Stillwater, OK 74078 6027; ${ }^{2}$ Oklahoma State Univ., Horticulture and Landscape Architecture, Stillwater, OK 74078-6027; ${ }^{3}$ Oklahoma State Univ., Entomology and Plant Pathology, Stillwater, OK $74078-3033$

Plants of Euonymus fortunei 'Emerald Gaiety', 'Emerald 'n Gold' and 'Canadale Gold' were sprayed to runoff weekly at two sites with one of three fungicide treatments or water (control) to determine fungicide effectiveness in controlling anthracnose caused by Colletotrichum 
gloeosporioides. Copper sulfate pentahydrate was applied at 0.4 or 0.6 $\mathrm{g} \cdot \mathrm{L}^{-1}$ a.i. or mancozeb was applied at $1.8 \mathrm{~g} \cdot \mathrm{L}^{-1}$ a.i.. Plants were rated for disease incidence approximately monthly. No interaction occurred between fungicide and cultivar. Differences among fungicide treatments were not apparent until weeks 18 or 20 depending on the site, when plants treated with mancozeb had lower disease ratings than plants receiving any other treatment. Cultivars differed at almost every rating date at both sites. Poison agar experiments were conducted to determine mycelial inhibition by copper sulfate pentahydrate or mancozeb.

\section{Evaluation of Soybean Oil Formulations for Effects on Powdery Mildew and Net Photosynthetic Rates of Dogwoods}

Adriane Cannon*1, Dennis Deyton ${ }^{2}$, Carl Sams ${ }^{3}$, William Klingeman ${ }^{4}$

${ }^{1}$ Univ. of Tennessee, Dept. of Plant Sciences, Knoxville, TN 37923; ${ }^{2}$ Univ. of Tennessee, Dept. of Plant Sciences, Knoxville, TN 37923; ${ }^{3}$ Univ. of Tennessee, Dept. of Plant Sciences, Knoxville, TN 37923; ${ }^{4}$ Univ. of Tennessee, Dept. of Plant Sciences, Knoxville, TN 37923

Two experiments were conducted in a greenhouse to evaluate soybean oil (SO) formulations for effects on powdery mildew (PM) and photosynthesis of dogwood trees. In the first experiment, one-year-old potted trees were sprayed with different formulations of $2 \%$ SO one day before exposure to PM. The formulations were emulsified with: teric/termul, lauriciden, lecithin, lecithin/MD 1, lecithin/MD 2, or Latron B-1956. A commercial formulation of Golden Natur'1 was also used. The trees were arranged in a completely randomized design with six replications and eight treatments. In the second experiment, trees were sprayed 4 days after initial exposure to PM with the same treatments and arranged in a similar experimental design. The severity of PM infection was rated using the scale: $1=0 \%, 2=1 \%$ to $3 \%, 3$ $=4 \%$ to $6 \%, 4=7 \%$ to $12 \%, 5=13 \%$ to $25 \%, 6=26 \%$ to $50 \%, 7=$ $51 \%$ to $87 \%$, and $8=88 \%$ to $100 \%$ of leaves visually displaying PM. The net photosynthetic $(\mathrm{Pn})$ rates were measured using an infrared gas analyzer. In the first experiment, trees sprayed pre-inoculation with Golden Natur'l, lecithin, lecithin/MD 1, or Latron B-1956 formulation had less PM than control trees at 19 and 24 days after spraying (DAS). Pn of leaves sprayed with lecithin or Latron B-1956 formulations had $68 \%$ and $40 \%$ lower Pn rates, respectively, of the control leaves at one DAS. However, by 11 DAS, none of the SO formulations significantly affected Pn rates. Leaves of plants (expt. 2) sprayed with teric/termul, lauriciden, lecithin, and lecithin/ MD 2 formulations had less PM than control trees at 28 DAS. All formulations reduced Pn rates at 6 DAS, with only Golden Natur'l treated leaves recovering to rates similar to control leaves by 15 DAS.

\section{Miscanthus: Ornamental and Invasive Grass}

Mary Hockenberry Meyer*1

${ }^{1}$ Univ. of Minnesota, Horticultural Science, Chaska, MN 55318

Miscanthus sinensis was investigated where it has naturalized and invaded native plant communities in southeastern Pennsylvania, the Washington, D.C. area, western North Carolina, and Iowa. Plants were identified; inflorescences were collected; seed was cleaned and tested for viability; and soil was collected for seed bank analysis. Many individuals were interviewed at each location. Locations were mapped to show miscanthus. The species or "wild type" Miscanthus sinensis that has naturalized at the above locations is rarely sold in the nursery trade. The numerous, popular, ornamental cultivars derived from this species are vegetatively propagated clones that are common in the nursery trade. Miscanthus is self-incompatible and sets seed only when two or more genotypes are grown together. Individual isolated plants set little seed. Plants of the wild type which have naturalized each represent a unique individual or genotype and thus set heavy seed, quite different from ornamental cultivars. Further complicating this is the high variability of seed set due to environmental conditions. Management guidelines were developed along with recommendations which include: Do not plant the species Miscanthus sinensis. Cultivars of the species, especially when two are more are grown together, represent a high risk for self-seeding in the Mid Atlantic states. Cultivars should only be planted in areas where they can be watched and managed for self-seeding. No miscanthus should be planted where it can seed into native areas, such as highways, fields, meadows, or wooded areas. A comprehensive website with identification, pictures, management guidelines, and recommendations was developed: http://horticulture. coafes.umn.edu/miscanthus.

\section{Poster Session 24-Growth Regulators in Fruit and Nut \\ Production}

\section{July 18, 2004, 5:30-6:30 PM Rio Grande Exhibit Hall}

\section{Flower Thinning of the Pear Cultivar 'Abbé Fetel' with Lime} Sulphur

Patricia I. Garriz*1, Hugo L. Alvarez², Graciela M. Colavita ${ }^{3}$, María S. Gajdos ${ }^{4}$

${ }^{1}$ Universidad Nacional del Comahue, Departamento de Biología Aplicada, Cinco Saltos, Río Negro, 8303, Argentina; ${ }^{2}$ Universidad Nacional del Comahue, Departamento de Biología Aplicada, Cinco Saltos, Río Negro, 8303, Argentina; ${ }^{3}$ Universidad Nacional del Comahue, Departamento de Biología Aplicada, Cinco Saltos, Río Negro, 8303, Argentina; ${ }^{4}$ Universidad Nacional del Comahue, Departamento de Biología Aplicada, Cinco Saltos, Río Negro, 8303, Argentina

Flower thinning of pears has advantages over fruit thinning in that the earlier it is performed the greater the potential effect on fruit size. At the Comahue National Univ. in Argentina (lat. 38 $56^{\prime}$ 6759' W), lime sulphur was evaluated as flower thinner on 10-year-old 'AbbAbbé Fetel' (Pyrus communis L.) pear trees trained to palmette leader. Cultural practices were similar to those of commercial orchards in the High Valley. Treatments were 1) control, and 2) 7\% lime sulphur, applied on 16 Sept. 2002 (30\% bloom) using an orchard sprayer. Fruit diameter (FD) was recorded two weekly $(n=20$ per date and treatment). At 144 days after full bloom (DAFB), or initial commercial harvest, crop load, fruit weight and the maturity indices were determined. Fruits were then graded into size categories. Growth equations were developed with SYSTAT procedure and mean separations were computed with Student's $t$-test. Mean FD was significantly increased by the lime sulphur sprays, starting from 115 DAFB. Logistic models best fitted the fruit growth vs. time curves. The equation was: FD = $77.87 / 1+\mathrm{e}^{2.26-0.03 \mathrm{DAFB}}\left(R^{2}=0.97\right)$, for the non-thinned trees. Treatment 2 increased the percentage of fruits $\geq 70 \mathrm{~mm}$ by $42.16 \%$. At 144 DAFB, thinned trees showed firmer fruits than the controls (64.4 vs. $61.7 \mathrm{~N})$ and there were no statistical differences among treatments in soluble solids concentration and starch index; the values were $11.5^{\circ} \mathrm{Brix}$ and 3.55 , respectively, for the control fruits. Consequently, our data indicate that lime sulphur applied at $30 \%$ bloom was an effective practice to thin 'Abbé Fetel' pears and to enhance fruit quality at ripening.

\section{Thinning York Imperial Apple with Chemical Combinations} Richard Marini*1

${ }^{1}$ Virginia Tech, Horticulture, Blacksburg, VA 24061

Six-year-old York/M.9 trees were used to evaluate combinations of chemicals for fruit thinning. In one experiment a factorial combination of 2 levels of carbaryl $\left(0 \mathrm{or} 600 \mathrm{mg} \cdot \mathrm{L}^{-1}\right)$ and 5 levels of 6-BA $(0$, $40,80,120$, and $\left.160 \mathrm{mg} \cdot \mathrm{L}^{-1}\right)$ were sprayed when fruit diam. averaged $10.5 \mathrm{~mm}$. Carbaryl significantly reduced fruit set, number of fruit/tree, yield efficiency, and crop density, and increased fruit weight. The main effect of 6-BA did not significantly influence any response variable. Two variables were significantly influenced by the carbaryl $\times 6$-BA interaction. In the absence of carbaryl, fruit set was reduced and fruit weight was increased by $6-\mathrm{BA}$ at concentrations less than $160 \mathrm{mg} \cdot \mathrm{L}^{-1}$, but the addition of 6-BA to carbaryl was no more effective than carbaryl alone. In a second experiment, a factorial combination of 2 levels of carbaryl ( 0 vs. $\left.600 \mathrm{mg} \cdot \mathrm{L}^{-1}\right), 2$ levels of NAA $\left(0 \mathrm{vs} .5 \mathrm{mg} \cdot \mathrm{L}^{-1}\right)$, and 2 levels of ethephon ( $\left.0 \mathrm{vs} .450 \mathrm{mg} \cdot \mathrm{L}^{-1}\right)$ were sprayed when fruit when fruit diam. averaged $10.5 \mathrm{~mm}$. Carbaryl and NAA reduced fruit set by about $30 \%$, but ethephon overthinned and reduced set by $65 \%$. When 
the other materials were combined with ethephon, thinning was similar to ethephon alone. The combination of carbaryl and NAA was no more effective than either material alone. The lowest values for yield, yield efficiency, and numbers of fruit per tree were associated with the combination of ethephon plus NAA. Ethephon was the only material that increased fruit weight.

206 Effects of CPPU on Fruit Size, Set, and Yield of Southern Highbush Blueberry in Florida

Jeffrey G. Williamson*1, E. Paul Miller ${ }^{2}$

${ }^{1}$ Univ. of Florida, Horticultural Sciences Dept., Gainesville, FL 32611-0690; ${ }^{2}$ Univ. of Florida, Horticultural Sciences Dept., Gainesville, FL 32611-0690

Poor fruit set and sub-optimum berry size are potential yield- and profit-limiting factors for southern highbush (Vaccinium corymbosum) blueberry production in Florida. The cytokinin N-(2-chloro-4-pyridyl)N'-phenylurea (CPPU) has increased fruit size and fruit set of a number of fruit crops including rabbiteye blueberry. The purpose of this study was to determine the effects of CPPU applied at different rates and phenological stages of bloom and/or fruit development on fruit size, set, and yield of southern highbush blueberry. 'Millennia' and 'Star' southern highbush blueberry plants located on a commercial blueberry farm in Alachua County, Fla., were treated with 5 or $10 \mathrm{ppm}$ CPPU at various stages of development ranging from full bloom to 20 days after full bloom. In contrast to findings with rabbiteye blueberry, fruit set in this study of southern highbush blueberry was not affected by any of the CPPU treatments when compared to the controls. Nor was total fruit yield affected by CPPU treatments. The most noticeable potentia benefit found in this study was an increase in mean fruit fresh weight from CPPU treatments. However, cultivars responded differently to CPPU with respect to mean fruit fresh weight. For 'Millennia', only one CPPU treatment increased mean fruit weight compared to controls. However, for 'Star', all but one CPPU treatment increased mean fruit fresh weight. Several CPPU treatments resulted in delayed fruit ripening for 'Star' but not for 'Millennia'. For 'Star', the treatments that most consistently delayed fruit ripening tended to have greater fruit fresh weights.

207 Effects of Grape Berry Developmental Stages on Ammonium Nitrate-enhanced Penetration of Gibberellin A

Hitoshi Ohara*1, Marom Ungsa ${ }^{2}$, Katsuya Ohkawa ${ }^{3}$, Hiroyuki Matsui ${ }^{4}$, Martin J. Bukovac ${ }^{5}$

${ }^{1}$ Chiba Univ., Faculty of Horticulture, Matsudo, Chiba, 271-8510, Japan; ${ }^{2}$ Chiba Univ. Faculty of Horticulture, Matsudo, Chiba, 271-8510, Japan; ${ }^{3}$ Chiba Univ., Faculty of Horticulture, Matsudo, Chiba, 271-8510, , Japan; ${ }^{4}$ Chiba Univ., Faculty of Horticulture, Matsudo, Chiba, 271-8510, Japan; ${ }^{5}$ Michigan State Univ., Dept. of Horticulture, East Lansing, MI 48824

The effects of ammonium nitrate (AMN) on the penetration of Gibberellin $\mathrm{A}_{3}\left(\mathrm{GA}_{3}\right)$ into berries of 'Kyoho' (Vitis labruscana Bailey) grape during berry development were studied. Treatment solutions of $\mathrm{GA}_{3}\left(100 \mathrm{ng} \cdot \mu \mathrm{L}^{-1}\right)$ and $\mathrm{GA}_{3}+\mathrm{AMN}$ (20 millimolar concentration) were applied to the surface of grape berries under field conditions. The amount of $\mathrm{GA}_{3}$ penetrated was assayed using dwarf rice (Oryza sativa L., cv. Tan-ginbozu). At full bloom, the addition of AMN significantly enhanced $\mathrm{GA}_{3}$ penetration 24,48 ad 72 hours after application by $13 \%$, $16 \%$ and $21 \%$ of the applied $\mathrm{GA}_{3}$, respectively, representing a 1.7- to 2.4-fold increase over $\mathrm{GA}_{3}$ alone. At 4 weeks after full bloom (WAFB) at 24 hours after application, $20 \%$ of the applied $\mathrm{GA}_{3}$ penetrated in the presence of AMN compared to $15 \%$ in the absence of AMN. From varaison (7 WAFB) to maturity (10 WAFB), GA penetration decreased from $6 \%$ to $2 \%$, respectively, in the presence of $A M N$, and from $3 \%$ to $1 \%$ in the absence of AMN. The addition of AMN to the GA solution increased $\mathrm{GA}_{3}$ penetration relative to $\mathrm{GA}_{3}$ alone at all berry developmental stages. On the other hand, Cuticular wax density on the berry surface at 4 WAFB was $1.10 \mu \mathrm{g} \cdot \mathrm{mm}^{-2}, 5.8$-fold greater than at full bloom $\left(0.19 \mu \mathrm{g} \cdot \mathrm{mm}^{-2}\right)$. The thickness of the epidermal tissue doubled during the first 2 WAFB, but was maintained almost constant over the next 6 weeks. $\mathrm{GA}_{3}$ penetration was more closely related to the cuticular wax levels than the epidermal tissue thickness.
208 Development and Testing of a Model to Rapidly Predict Apple Thinner Response

D.W. Greene ${ }^{* 1}$, A.N. Lakso², T.L. Robinson ${ }^{3}$

${ }^{1}$ Univ. of Massachusetts, Plant and Soil Sciences, Amherst, MA 01003; ${ }^{2}$ Cornell Univ., Horticultural Scinece, Geneva, NY $14456 ;{ }^{3}$ Cornell Univ., Dept. of Hortilcutural Science, Geneva, NY 14456

Several thinning experiments were initiated in 2003 to test the hypothesis that monitoring fruit growth is an appropriate and accurate method to predict final fruit set early enough to apply supplemental thinners if appropriate. A total of eight thinning treatments were applied in Massachusetts and New York. On the day of thinner application 70 to 100 spurs were tagged on 4-8 trees (replications). All fruit within a spur were individually identified and fruit were measured. At 2 to 3 day intervals fruit diameter was measured at a designated point on the fruit. Growth rate of the fastest growing 20 fruit on the untreated trees was used as the criteria to determine growth rate of fruit that would persist to harvest. A fruit on a treated tree was predicted to abscise if growth rate slowed to $50 \%$ or less of the growth rate of the 20 fastest growing fruit on untreated trees. Cold weather in 2003 following thinner application slowed the response time to thinners. Thinning treatments were applied to Delicious, Golden Delicious, McIntosh, and Gala at 7-9-mm stage. BA, carbaryl, and combinations of NAA and carbaryl were used. In Massachusetts accuracy of prediction of final fruit set at 7-11 days after application ranged from $87 \%$ to $100 \%$ with and average of $95 \%$ accuracy compared to final observed drop at the end of June drop in July. In Geneva, N.Y., the temperature was so unseasonably cold following application that prediction of final set at 7 to 11 days after application was between $68 \%$ and $79 \%$ with an average of $74 \%$ accuracy. We conclude that prediction of final fruit set following growth rate of individual fruit shows promise as an accurate predictor of final fruit set early enough to apply supplemental thinners if appropriate.

\section{Poster Session 25-Growth Chambers and Controlled Environments \\ July 18, 2004, 5:30-6:30 PM Rio Grande Exhibit Hall}

209 Compatibility of Radish, Lettuce, and Bunching Onions Grown Hydroponically in a Mixed-crop System

Neil C. Yorio ${ }^{1}$, Jeff T. Richards ${ }^{2}$, Sharon L. Edney ${ }^{3}$, Joel O. Wilkinson $^{4}$, Gary W. Stutte ${ }^{* 5}$, Raymond M. Wheeler ${ }^{6}$

${ }^{1}$ Dynamac Corporation, Advanced Life Support, Kennedy Space Center, FL 32899; ${ }^{2} \mathrm{Dy}-$ namac Corporation, Advanced Life Support, Kennedy Space Center, FL 32899; ${ }^{3}$ Dynamac Corporation, Advanced Life Support, Kennedy Space Center, FL 32899; ${ }^{4}$ Texas A\&M Univ., College of Agriculture and Life Sciences, College Station, TX 77843; ${ }^{5}$ Dynamac Corporation, Advanced Life Support, Kennedy Space Center,FL32899; ${ }^{6}$ Biological Sciences Office, NASA, Kennedy Space Center, FL 32899

The effects of using mixed cropping strategies for reducing overall mass and increasing system efficiency was examined as part of NASA's mission to study minimally-processed or "salad" crops as dietary supplements on long-duration space missions. To test interspecific compatibility, radish (Raphanus sativus L. cv. Cherry Bomb II), lettuce (Lactuca sativa L.cv. Flandria), and bunching onion (Allium fistulosum L.cv. Kinka) were grown hydroponically as either monoculture (control) or mixed-crop within a walk-in growth chamber maintained at $25^{\circ} \mathrm{C}$, $50 \%$ relative humidity, $300 \mu \mathrm{mol} \cdot \mathrm{m}^{-2} \cdot \mathrm{s}^{-1} \mathrm{PPF}$, and a 16 -h light $/ 8$-h dark photoperiod under cool-white fluorescent lamps. Weekly time-course harvests were taken over 28 days of growth. Results showed that none of the species showed any negative growth effects when grown together under mixed-crop compared to monoculture growth conditions. However, radish showed significant increases in edible mass when grown under mixed-crop compared to monoculture conditions. The observed increases in growth are likely attributable to increased light interception due to a decreased guard row effect as well as a faster canopy development for radish. 
210 Hypobaria Affects Gas Exchange, Ethylene Evolution and Growth of Lettuce in NASAAdvanced Life Support Systems (ALS) Chuanjiu $\mathrm{He}^{1}$, Fred Davies*2, Ronald $\mathrm{Lacey}^{3}$, Que $\mathrm{Ngo}^{4}$

${ }^{1}$ Teaxs A\&M Univ., Horticultural Sciences, College Station, Texas; ${ }^{2}$ Teaxs A\&M Univ., Horticultural Sciences, College Station, Texas; ${ }^{3}$ Teaxs A\&M Univ., Biological \& Agricultural Engineering, College Station, Texas; ${ }^{4}$ Teaxs A\&M Univ., Horticultural Sciences, College Station, Texas

Elevated levels of ethylene occur in enclosed crop production systems and in space-flight environments-leading to adverse plant growth and sterility. There are engineering advantages in growing plants at hypobaric (reduced atmospheric pressure) conditions in biomass production for extraterrestrial base or spaceflight environments. Objectives of this research were to characterize the influence of hypobaria on gas exchange and ethylene evolution of lettuce (Lactuca sativa $\mathrm{L}$. cv. Buttercrunch). Lettuce was grown under variable total gas pressures [50 and $101 \mathrm{kPa}$ (ambient)]. The six chambered, modular low plant growth (LPPG) system has a Rosemount industrial process gas chromatograph (GC) for determining gas concentrations of oxygen $\left(\mathrm{O}_{2}\right)$, carbon dioxide $\left(\mathrm{CO}_{2}\right)$ and nitrogen $(\mathrm{N})$. With the LPPG system, changes in $\mathrm{CO}_{2}$ can be tracked during the light and dark periods on a whole canopy basis, and transpirate collected as a measurement of transpiration. During short growth periods of up to seven days, growth was comparable between low and ambient pressure. However, there was a tendency for leaf tip burn under ambient pressure, in part because of higher ethylene levels. Tip burn increased under high light (600 vs. $\left.300 \mu \mathrm{mol} \cdot \mathrm{m}^{-1} \cdot \mathrm{s}^{-1}\right)$ and high $\mathrm{CO}_{2}(600 \mathrm{vs}$. $100 \mathrm{~Pa})$. The $\mathrm{CO}_{2}$ assimilation rate and dark respiration tended to be higher under ambient conditions. High humidity ( $100 \%$ ) reduced $\mathrm{CO}_{2}$ assimilation rate compared to $70 \%$ RH. Ethylene was increased by high light (600 vs. $\left.300 \mu \mathrm{mol} \cdot \mathrm{m}^{-1} \cdot \mathrm{s}^{-1}\right)$ and high $\mathrm{CO}_{2}$ (600 vs. $100 \mathrm{~Pa}$ ). Ethylene was higher under ambient than low pressure. Enhanced plant growth under low pressure may be attributed to reduced ethylene production and decreased dark respiration (lower night consumption of metabolites).

\section{Poster Session 26-Mineral Nutrition}

\section{July 18, 2004, 5:30-6:30 PM Rio Grande Exhibit Hall}

\section{Development of a Controlled Release Fertilizer Program for Chipping Potatoes}

\section{Chad Hutchinson*1, Eric Simonne ${ }^{2}$}

${ }^{1}$ Univ. of Florida, Horticultural Sciences Dept., Gainesville, FL 32611; ${ }^{2}$ Univ. of Florida, Horticultural Sciences Dept., Gainesville, FL 32611

Potato (Solanum tuberosum L.) production best management practices (BMPs) are under development for the Tri-County Agricultural Area (TCAA; St. Johns, Putnam, and Flagler counties) near Hastings, Fla. BMPs are designed to reduce nitrate non-point pollution in the St. Johns River from the $\$ 8000$ ha in potato production in the TCAA. Research to develop a controlled release fertilizer (CRF) program to help growers meet the current nitrogen rate BMPs was conducted during the 2003 season. A randomized complete block experiment with four replications was conducted at the Plant Science Research and Education Unit in Hastings, Fla. The treatments were no nitrogen control, ammonium nitrate (168 and $212 \mathrm{~kg} \mathrm{~N} / \mathrm{ha}$ ) and three CRF products blended at different ratios (168 kg N/ha). Total tuber yields for 'Atlantic' for the no nitrogen, and 168 and $212 \mathrm{~kg} \mathrm{~N} / \mathrm{ha}$ ammonium nitrate treatments were $11.5,23.4$, and $36.4 \mathrm{MT} / \mathrm{ha}$. The best combination of the three CRF products were a ratio of 33:33:33 with a 40 day, 75 day, 120 day release period, respectively. Total yield for this blend was $42.2 \mathrm{MT} / \mathrm{ha}$. Specific gravities for tubers in all four treatments were 1.060, 1.072, 1.078 , and 1.082, respectively. Percent of tubers with hollow heart four all four treatment were $8.1,18.2,20.0$, and $6.4 \%$ respectively. Percent of tubers with internal heat necrosis four all four treatments were $20.6,8.1,20.6$, and $6.3 \%$, respectively. The CRF treatment produced significantly more tubers than the ammonium nitrate treatment at the same nitrogen rate. Quality of the tubers in the CRF treatment was higher than tubers from the no nitrogen control and ammonium nitrate treatments. Research will continue to optimize the CRF program for potato production in Florida.

385 Evaluation of Different Fertilization Formulas on the 'Jalapeño' Hot Pepper (Capsicum annuum L.) Production in Colima, México

Francisco Radillo-Juárez*1, Marcelino Bazán-Tene², Jaime MolinaOchoa $^{3}$, Edgar Damián Rolón-Vejar ${ }^{4}$

${ }^{1}$ Universidad de Colima, Facultad de Ciencias Biológicas y Agropecuarias, Tecomán, Colima, 28100, México; ${ }^{2}$ Universidad de Colima, Facultad de Ciencias Biológicas y Agropecuarias, Tecomán,, Colima, 28100, México; ${ }^{3}$ Facultad de Ciencias Biológicas y Agropecuarias, Universidad de Colima, Tecomán,, Colima, 28100, México; ${ }^{4}$ Universidad de Colima, Facultad de Ciencias Biológicas y Agropecuarias, Tecomán, Colima, 28100, México

The production of 'Jalapeño' hot pepper has been increased in the last 10 years in about $6.21 \%$ during the period between 1992-2003, with a growing rate of $72 \%$. In Mexico, is an important produce, because it is considered part of the traditional Mexican diet as well as its high productive level. One of the most frequent problems in this crop is the low production of fresh fruits caused by an inadequate fertilization. The objective of this research was to evaluate the effect of four fertilization formulas on the yield of fresh fruit of hot pepper variety Jalapeño cultivar Grande under irrigation conditions The evaluated formulas were (N-P-K-S): 1) 58-51-35-12 (control); 2) 78-68-46-16; 3 ) 97-85-58-20; and 4) 117-102-69-24. Treatments were distributed under a completely randomized block design with four replications. The formula 117-102-69-24 showed the highest values in the plant height and number of fruits with $62.5 \mathrm{~cm}$, and 48 fruits, respectively. This formula also showed the highest values on equatorial and longitudinal diameters, and fruit weight with $3.36 \mathrm{~cm}, 11.26 \mathrm{~cm}$, and $33.66 \mathrm{~g}$, respectively. The total yields per plant and per hectare was $1.54 \mathrm{~kg}$; and $38.22 \mathrm{t}$ was obtained with the formula 117-102-69-24. The formula with the higher units of each element showed the best performance and exhibited the highest yield of fresh hot pepper, it was more productive than the control treatment commonly used by the hot pepper growers in Colima.

386 Intercellular Distribution of Phosphorus and Cations within Arbuscular Mycorrhizal Cucumber Root using X-Ray Microanalysis

Yun-Jeong Lee*1, Sang-Min Lee ${ }^{2}$, Seung-Hwan Kim ${ }^{3}$

${ }^{1}$ National Institute of Agricultural Science and Technology, Crop Life Safety, Suwon, 441-707, Republic of Korea; ${ }^{2}$ National Institute of Agricultural Science and Technology, Crop Life Safety; ${ }^{3}$ National Institute of Agricultural Science and Technology, Crop Life Safety

The elemental distribution ( $\mathrm{P}, \mathrm{Ca}, \mathrm{K}, \mathrm{Mg}$ ) within inter- and intracellular structure of arbuscular mycorrhizal (AM) cucumber root was determined using energy dispersive X-ray spectroscopy (EDAX). Cucumber (Cucumis sativus cv. Chinesische Schlange) was grown as a test plant using compartmentalized pots with separate zones for hyphal growth and was inoculated or not with the AM fungus, Glomus mosseae (BEG 107). EDAX studies revealed that $P$ in intercellular structures including fungal cells in cucumber root colonized with AM was mainly localized in both polyphosphate granules in arbuscular vacuole and arbuscular cytoplasm. Ca in AM root was mostly localized in cortex cell wall, interfacial apoplast between root and fungus, arbuscular cytoplasm and poly phosphate granules. $\mathrm{Mg}$ was distributed homogenously in most cell compartments within AM root while $\mathrm{K}$ was localized mainly in cell wall of stele. Higher contents of $\mathrm{Ca}$ and $\mathrm{Mg}$ were detected in polyphosphate granules whereas lower content of $\mathrm{K}$ was detectable. These results indicate that polyphosphate granules could play a role as a complex forming site with metal cations especially with divalent cations like $\mathrm{Ca}$ and $\mathrm{Mg}$. In addition, it could give a possibility of regulation function of polyphosphate granules on element transfer from fungus to host plant root. Furthermore, the distribution of element within cortex cytoplasm, interfacial apoplast between plant root and fungus and arbuscular cytoplasm might give a clue on the element transfer mechanism between symbionts. 
387 Survey of Compost Use by South Florida Vegetable Growers Monica Ozores-Hampton*1

${ }^{1}$ IFAS/SWFREC, Univ. of Florida, Immokalee, FL 34142-9515

The success of long-term vegetable production and maintenance of environmental quality is dependent on soil quality. Indicators of soil quality include cation exchange capacity (CEC), organic matter (OM), carbon $(\mathrm{C}), \mathrm{pH}$, and the number and community structure of soil organisms. The use of appropriate compost has been shown to improve soil quality and enhance the response to fertilizer, therefore improving growth and yield of vegetable crops. The objective of this study was to evaluate changes in the chemical and biological properties of soil in response to compost use in conventional vegetables production systems. A survey was conducted on 5 farms (three in Immokalee, and one each in Delray Beach, and Clewiston) growing tomato, pepper, and specialty vegetables. Most of the farms were applying composted yard trimming waste alone or in combination with biosolids or horse manure at application rates of between 7 to $112 \mathrm{Mg} \cdot \mathrm{ha}^{-1}$ once a year. Soil samples were taken from composted and non-composted areas in each farm during Feb. and Mar. 2002. Soil pH, OM, C, K, Ca, Mg, Cu, $\mathrm{Fe}, \mathrm{MN}$ and $\mathrm{Zn}$ were higher in the composted areas compared with the non-composted areas for each farm. CEC values in composted areas were double those in non-composted areas. Most importantly, application of compost enhanced the overall soil microbial activity as determined by total microorganism number, SRD (species richness diversity), and TSRD (total species richness diversity) of six functional groups including heterotrophic aerobic bacteria, anaerobic bacteria, fungi, actinomycetes, pseudomonads, and nitrogen-fixing bacteria, in all the participating farms. The greatest soil quality improvement was seen in soils receiving the highest rates of compost for the longest time.

\section{Effect of Nitrogen Rate and Residual Soil Nitrogen on Yield and Quality of Carrots}

Sean M. Westerveld ${ }^{1}$, Alan W. McKeown², Mary Ruth McDonald*3

${ }^{1}$ Univ. of Guelph, Plant Agriculture, Guelph, Ontario, N1G 2W1, Canada; ${ }^{2}$ Univ. of Guelph, Plant Agriculture, Guelph, Ontario, N1G2W1, Canada; ${ }^{3}$ Univ. of Guelph, Plant Agriculture, Guelph, Ontario, N1G 2W1, Canada

Residual nitrogen $(\mathrm{N})$ in agricultural soils is an environmental concern. Nitrogen requirements for carrots were examined over a two-year period in Ontario, Canada. Carrots, cvs. 'Idaho' and 'Fontana' were seeded into organic and mineral soil in 2002 and 2003 in the same plots. In $2002, \mathrm{~N}$ was applied at $0 \%, 50 \%, 100 \%, 150 \%$, and $200 \%$ of current Ontario recommendations. Each experimental unit was split in half in 2003 with one half getting the same $\mathrm{N}$ rate as in 2002, and the second half getting no applied N. At harvest, total and marketable yield, weight per root, and quality were assessed. Yield and quality were unaffected by $\mathrm{N}$ rate in both mineral soil in 2002 and organic soil in both years. On mineral soil in 2003 there was a linear increase in total and marketable yield and weight per root with increasing $\mathrm{N}$ rate, with total yield ranging between 36 and $55 \mathrm{t} / \mathrm{ha}$. However, in the treatments given no $\mathrm{N}$ in 2003, yield also increased from 36 to 47 t/ha between the 2002 no N and high $\mathrm{N}$ treatments. Consequently, a large portion of the increase in yield in 2003 on mineral soil was due to residual $\mathrm{N}$ from the previous season. Carrots are capable of taking up very high amounts of $\mathrm{N}$ from the soil over a growing season, but may only require additional $\mathrm{N}$ for maximum total yield if soil $\mathrm{N}$ content is low due to low mineralization rates or depletion by a previous crop. However, low $\mathrm{N}$ rates can reduce the ability to harvest the crop due to increased carrot leaf blight severity even when yield is unaffected.

\section{Nutrient Concentrations in Field-grown Lettuce Leaves and Roots}

Zhongchun Jiang*1

${ }^{1}$ SUNY Cobleskill, Dept. of Plant Science, Cobleskill, NY 12043

Nutrient concentrations in lettuce leaves are an important factor that affects lettuce quality, particularly the nutritional value of lettuce. When lettuce is grown hydroponically, tissue nutrient concentrations may be regulated through adjustments of the nutrients in the solution in which the lettuce is grown. However, when lettuce is grown in the field, the levels of tissue nutrients can be affected by many factors, such as soil conditions, fertilizer applications, and weather conditions. The objective of this study was to ascertain the variability of leaf and root tissue nutrients in loose-leaf lettuce grown in the field. An organic fertilizer that had an analysis of 4-6-6 as well as $3 \% \mathrm{Ca}, 0.5 \% \mathrm{Mg}$, and $5 \% \mathrm{~S}$ derived from dehydrated manure, crab meal, cocoa meal, and other materials was applied at the time of planting and also side dressed after planting. There were significant differences in the concentrations of some elements between leaf tissues and root tissues. Leaf $\mathrm{K}, \mathrm{Ca}$, and $\mathrm{Mg}$ concentrations were significantly higher than those in the roots while leaf $\mathrm{P}$ concentration was lower than that in the roots. Leaf $\mathrm{N}$ concentration was similar to root $\mathrm{N}$ concentration. Micronutrients, such as $\mathrm{Fe}, \mathrm{MN} \mathrm{Cu}, \mathrm{Zn}$, and $\mathrm{Mo}$, had lower concentrations in the leaves than in the roots. Leaf B concentration was similar to that in the roots. In addition, leaves accumulated lower concentrations of $\mathrm{Al}$ and $\mathrm{Na}$ than did the roots. No significant differences in the concentrations of these elements were observed between the fertilized plots and the unfertilized plots, which suggested that the field might have a sufficient fertility level and/or that the organic fertilizer might be slow in releasing its nutrients for the lettuce.

\section{Use Diluted Tomato Petiole Sap for K Measurement with the Cardy Meter}

Henry G. Taber*1, Vince Lawson ${ }^{2}$, Diane Shogren ${ }^{3}$

${ }^{1}$ Iowa State Univ., Horticulture, Ames, IA 50011; ${ }^{2}$ Iowa State Univ., Outlying Farms, Fruitland, IA 50011; ${ }^{3}$ Iowa State Univ., Horticulture, Ames, IA 50011

Undiluted tomato petiole sap from a variety by $\mathrm{K}$ rate experiment (48 treatment rep combinations) was used to measure K concentration via the battery operated portable Cardy meter and ICP laboratory instrumentation. Three sample 1998 dates, 16 July., 21 Aug., and 8 Sept., resulted in K sap readings by ICP of 3917, 2612, and 2297 ppm, respectively. At sap levels below $3000 \mathrm{ppm}$ the linear Cardy :ICP correlation was $r=0.04$, but above 3000 ppm only 0.53 . From 3500 to 5000 ppm K the Cardy meter under estimated actual sap K by 200 to 900 ppm. For the years 1999 and 2001, tomato petiole sap at each sample date (4) was diluted 1:1 with deionized water. The linear regression equation describing the relationship between ICP and Cardy meter measurements was: Cardy K ppm $=0.733 * \mathrm{ICP}+685(r=0.92, \mathrm{n}=190)$. The Cardy meter error over the 2000 to $5000 \mathrm{ppm} \mathrm{K}$ range was 8 to $12 \%$. Petiole sap K, measured by either Cardy or ICP, was highly correlated to whole leaf $\mathrm{K}$ concentration both years. But even though the slope of the regression lines was similar the intercepts were significantly different $(\mathrm{P} \leq .01)$. The significant $0.32 \% \mathrm{~K}$ difference in whole leaf between years precluded the development of a common regression line to predict whole leaf $\mathrm{K}$ from Cardy petiole sap determinations. The Cardy meter can be reliably used for tomato petiole $\mathrm{K}$ determination provided the sap is diluted and the usual handling precautions are taken to prevent petiole moisture loss.

\section{Lettuce Response to Phosphorus Fertilization in High P soils} P.R. Johnstone ${ }^{1}$, T.K. Hartz ${ }^{2} 2$

${ }^{1}$ Univ. of California, Dept. of Vegetable Crops, Davis, CA 95616; ${ }^{2}$ Univ. of California, Dept. of Vegetable Crops, Davis, CA 95616

Heavy Pfertilization of vegetable crops in the Salinas Valley of California have increased soil Plevels, with $>50 \mathrm{mg} \cdot \mathrm{kg}^{-1}$ bicarbonate-extractable $\mathrm{P}$ $\left(\mathrm{P}_{\mathrm{bc}}\right)$ now common. To evaluate the response of lettuce (Lactuca sativa L.) to $\mathrm{P}$ fertilization in fields with elevated soil $\mathrm{P}$ levels, 12 trials were conducted in commercial fields during 2002-2003. $\mathrm{P}_{\mathrm{bc}}$ at the trial sites varied from 53-171 $\mathrm{mg} \cdot \mathrm{kg}^{-1}$. In each trial four replicate plots receiving the growers' $P$ application were compared with paired plots in which no $\mathrm{P}$ was applied. Leaf $\mathrm{P}$ was monitored at cupping stage and at harvest. At harvest mean whole plant mass and $\%$ of marketable plants were recorded. The correlation of $\mathrm{P}_{b c}$ to bioavailable $\mathrm{P}\left(\mathrm{P}_{\mathrm{ba}}\right)$ was evaluated using 30 representative Salinas Valley soils; $\mathrm{P}_{\mathrm{bc}}$ varied among these soils from $15-177 \mathrm{mg} \cdot \mathrm{kg}^{-1} \cdot \mathrm{P}_{\text {ba }}$ was estimated by $\stackrel{\mathrm{P}}{\mathrm{P}}$ adsorption on an anion resin membrane during a $16 \mathrm{~h}$ incubation. The effect of temperature on P bioavailability in 6 of these soils was estimated by conducting the 
$\mathrm{P}_{\text {ba }}$ incubation at 5,15 and $25^{\circ} \mathrm{C}$. A significant increase in lettuce yield with $\mathrm{P}$ fertilization was achieved at only one trial site, a spring planting where $\mathrm{P}_{\text {bc }}$ was $54 \mathrm{mg} \mathrm{kg}^{-1}$; at all other sites, including 3 with $\mathrm{P}_{\mathrm{bc}}<60$ $\mathrm{mg} \mathrm{kg}{ }^{-1}, \stackrel{\mathrm{bc}}{\mathrm{P}}$ application resulted in no agronomic benefit. $\mathrm{P}$ application resulted in only a marginal increase in plant $\mathrm{P}$ uptake. $\mathrm{P}_{\text {ba }}$ was highly correlated with $\mathrm{P}_{\text {bc }}(r=0.89)$. $\mathrm{P}_{\text {aa }}$ increased approximately $40 \%$ across soils with each $10^{\circ} \mathrm{C}$ increase in soil temperature.

\section{Effects of the Fall Foliar Urea Application on N Reserves and Fruiting Performance of Gala/M26 Apple Trees in Pot-in-Pot System}

\section{Pinghai Ding*1, Minggang Cui ${ }^{2}$, Leslie H. Fuchigami ${ }^{3}$}

${ }^{1}$ Oregon State Univ., Dept. of Horticulture, Corvallis, OR 97331; ${ }^{2}$ Oregon State Univ., Dept. of Horticulture, Corvallis, OR 98331; ${ }^{3}$ Oregon State Univ., Dept. of Horticulture, Corvallis, OR 97331

Reserve nitrogen is an important factor for plant growth and fruiting performance in tree fruit crops. The fall foliar urea application appears to be an efficient method for increasing $\mathrm{N}$ reserves. The effect of fall foliar urea application on $\mathrm{N}$ reserves and fruiting performance were studied with four year old 'Gala'/M26 trees grown in 20 gallon containers in a pot-in-pot system from 2001 to 2003 at the Lewis-Brown Horticulture Farm of Oregon State Univ.. The trees were either sprayed with 0 or 2 times $3 \%$ urea after harvest in October. Shoot and spur samples were taken at the dormant season for reserve $\mathrm{N}$ analysis. Fruit performance was recorded in the following growing season. The fall foliar application significantly increased spur $\mathrm{N}$ reserve and had the trend to increase shoot $\mathrm{N}$ reserve but not significantly. The fall foliar application significantly increased tree fruit set and cluster fruit set. With normal fruit thinning, fall foliar urea application has the trend to increase both tree yield and average fruit size; without fruit thinning, fall foliar urea application has the trend to increase tree yield. These results indicate that fall foliar urea application an effective method to increase reserve $\mathrm{N}$ for maintaining tree yield.

\section{Boron Fertilization and Sour Cherry (Prunus cerasus) Fruit Quality}

Yufei Xu*1, Eric Hanson ${ }^{2}$, James Flore ${ }^{3}$, Wayne Loescher ${ }^{4}$

${ }^{1}$ Michigan State Univ., Horticulture, East Lansing, MI 48824; ${ }^{2}$ Michigan State Univ., Horticulture, East Lansing, MI 48824; ${ }^{3}$ Michigan State Univ., Horticulture, East Lansing, MI 48824; ${ }^{4}$ Michigan State Univ., Horticulture, East Lansing, MI 48824

In Michigan boron (B) deficiencies in sour cherry have resulted in routine use of B sprays to enhance fruit set and increase fruit yield. However, field observations indicate that high B levels are associated with premature softening, making fruit unacceptable for processing. Our fertilization studies show that fruit B levels are higher, but B generally has little or no effect on fruit size, maturity, color, or pull force. However, at some locations, B applications increase the number of soft fruit, especially when harvest is delayed well after the optimum maturity date (as indicated by pull force). B-induced yield increases can be achieved without inducing excessive fruit softening by careful monitoring of fruit maturation and prompt harvest. Leaf and fruit $\mathrm{B}$ levels will be presented.

\section{Nitrogen Storage and Its Interaction with Carbohydrates of Young Almond Trees in Response to Nitrogen Supply}

Guihong Bi*1, Carolyn Scagel ${ }^{2}$, Lailiang Cheng ${ }^{3}$, Leslie Fuchigami ${ }^{4}$

${ }^{1}$ Oregon State Univ., Horticulture, Corvallis, OR 97331; ${ }^{2}$ USDA-ARS, Horticultural Crops Research Laboratory; ${ }^{3}$ Cornell Univ., Horticulture; ${ }^{4}$ Oregon State Univ., Horticulture

June-budded 'Nonpareil/Nemaguard' almond (Prunus dulcis (Mill)D.A. Webb) trees were fertigated with one of five nitrogen $(\mathrm{N})$ concentrations $(0,5,10,15$, or $20 \mathrm{~mm})$ in a modified Hoagland's solution from July to September. In October, the trees were sprayed twice with either water or $3 \%$ urea, then harvested after natural leaf fall and stored at $2^{\circ} \mathrm{C}$. Trees were destructively sampled during winter storage to determine their concentrations of amino acids, protein, and non-structural carbohydrates (TNC). Increasing $\mathrm{N}$ supply either via $\mathrm{N}$ fertigation during the growing season or with foliar urea applications in the fall increased the concentrations of both free and total amino acids, whereas decreased their $\mathrm{C} / \mathrm{N}$ ratios. Moreover, as the $\mathrm{N}$ supply increased, the proportion of nitrogen stored as free amino acids also increased. However, protein was still the main form of $\mathrm{N}$ used for storage. The predominant amino acid in both the free and total amino-acid pools was arginine. Arginin $\mathrm{N}$ accounted for an increasing proportion of the total $\mathrm{N}$ in both the free and total amino acids as the $\mathrm{N}$ supply was increased. However, the proportion of arginine $\mathrm{N}$ was higher in the free amino acids than in the total amino acids. A negative relationship was found between total amino acid and non-structural carbohydrate concentrations, suggesting that TNC is increasingly used for $\mathrm{N}$ assimilation as the supply of $\mathrm{N}$ increases. Urea applications decreased the concentrations of glucose, fructose, and sucrose, but had little influence on concentrations of sorbitol and starch. We conclude that protein is the primary form of storage N, and that arginine is the predominant amino acid. Furthermore, the synthesis of amino acids and proteins comes at the expense of non-structural carbohydrates.

\section{Fertilization Strategies for Silene vulgaris (Caryophyllaceae)} Production, a Wild Species with Alimentary Use

Jesús Arreola ${ }^{1}$, José Antonio Franco ${ }^{* 2}$, Juan José Martínez-Sánchez ${ }^{3}$

'Universidad Politécnica de Cartagena, Producción Vegetal; ${ }^{2}$ Universidad Politécnica de Cartagena, Producción Vegetal, Cartagena, Murcia, 30203, Spain; ${ }^{3}$ Universidad Politécnica de Cartagena, Producción Vegetal

The wild native vegetable cultivation in Spain is very interesting due to the potential value as leafy vegetable. In order to preserve the minor crop diversity we investigate several wild species as Silene vulgaris. This is a perennial herbs, widespread in Europe and North of Africa, very appreciated by leaf in the Iberian Peninsula. In this work, six fertilization treatments with different Base Fertilizer : Top Fertilizer were evaluated in the field on Mediterranean coast of Spain: T0 (without fertilization), T1 (5000 and 0), T2 (2500 and 725), T3 (2500 and 363), T4 (1250 and 725),T5 (1250 and 363), T6 (625 and 181) kg·ha ${ }^{-1}$, Base fertilized, and Top fertilizer respectively. Silene vulgaris seedlings 30 days old were transplanted to $1 \mathrm{~m}^{2}$ experimental plots under drip irrigation. and previously Base fertilized with Guano of fish (4\% N, 8\% $\mathrm{P}, 4 \% \mathrm{~K}$ ). Thirty days later a Top fertilization were applied with $\mathrm{KNO}_{3}$ $(13,8 \% \mathrm{~N}$ and $44 \% \mathrm{~K})$. Two harvests were carried out 55 and 110 days after plantation and the parameters measured were the fresh mass and the dry mass. In the first harvest, both fresh and dry mass were significantly greater in T3 (8541 and $1522 \mathrm{~kg} \cdot \mathrm{ha}^{-1}$, respectively), while T0 produced the smallest yield (3765 and $625 \mathrm{~kg} / \mathrm{ha}$, respectively). In the second harvest, $\mathrm{T} 4$ produced the greatest values of fresh and dry mass (9995 and $903 \mathrm{~kg} \cdot \mathrm{ha}^{-1}$, respectively), while, again, T0 threw the smallest values (4846 and $464 \mathrm{~kg} \cdot \mathrm{ha}^{-1}$, respectively). This work was supported by the CICYT of Spain (Project AGL2000-0521) and by the Fundación Séneca of the Region of Murcia (project PI-27/00753/FS/01).

\section{Studies on the Nitrogen Absorption Rule}

\section{Kun Xu*1, Xiufeng Wang ${ }^{2}$, Fang Wang ${ }^{3}$}

${ }^{1}$ Shandong Agricultural Univ., Horticultural College, Tai'an, Shandong, 271018, China; ${ }^{2}$ Shandong Agricultural Univ., Horticultural College, Tai'an, Shandong, 271018, China; ${ }^{3}$ Shandong Agricultural Dept., Shandong Agricultural Dept.

The rate of fertilizer-N utilization by ginger was quite different in different applying stages. The results indicated that the rate of fertilizer-N utilization increased with the delay of application. The highest utilization rate was the fertilizer dressed at middle period of vigorous growth, which was $45.24 \%$; while the basal manure utilization rate was only $27.67 \%$. It was also shown that the nitrogen uptake from basal manure was distributed in highest level in main shoots and leaves, the nitrogen derived from fertilizer dressed at middle period of vigorous growth was mostly distributed into rhizomes, and nitrogen absorbed from fertilizer dressed at early period of vigorous growth was distributed evenly into all organs. The reclamation rate from fertilizer dressed at middle period of growth was the highest and lowest reclamation rate was the basal manure. The content of fertilizer-N and soil-N in ginger plant was determined, it was shown $56.57 \%$ plant-N was derived from soil-N, the remaining $43.43 \%$ was from fertilizer-N. The nitrogen from soil played 
a very important role in ginger production, therefore the problem of how to maintain high soil fertilizer must be paid more attention.

\section{Nutrient Release Characteristics From Four Types of Con-} trolled-release Fertilizers

Donald J. Merhaut*1, Joseph Albano ${ }^{2}$, Eugene K. Blythe ${ }^{3}$, Julie Newman ${ }^{4}$ ${ }^{1}$ Univ. of California, Botany and Plant Sciences, Riverside, CA 92521; ${ }^{2}$ USDA-ARS USDA-ARS, Fort Pierce, FL 34945; ${ }^{3}$ Auburn Univ., Horticulture, Auburn Univ., AL 36849; ${ }^{4}$ Univ. of California, Cooperative Extension, Ventura, CA 93003

Release patterns of ammonium, nitrate, phosphorus, potassium, calcium, magnesium, iron, manganese and zinc were measured during an eleven month period for four types of Controlled Release Fertilizers (CRF): Apex 17-5-11, Multicote 17-5-11, Nutricote 18-6-8 and Osmocote 24-4-9. Rate of fertilizer incorporation was $2.3 \mathrm{~kg} / \mathrm{m}^{3}$ of nitrogen. Media consisted of $50 \%$ composted forest products, $35 \% 1 / 4 \%-3 / 4 \%$ pine bark and $15 \%$ washed Builder's sand. The media was also amended with $0.60 \mathrm{~kg} / \mathrm{m}^{3}$ of dolomite. Fertilizer was incorporated into the media with a cement mixer and placed into 2.6-L black polyethylene containers. Containers were placed on benches outside. Air and media temperature were monitored throughout the 11-month period. Containers were irrigated through a ring-dripper system. Leachate was collected twice weekly. Leachate electrical conductivity, $\mathrm{pH}$, and nutrient content were measured weekly. Significant differences in the nutrient release patterns were observed between fertilizer types throughout much of the experimental period. Release rates were significantly greater during the first 20 weeks of the study compared to the last 20 weeks of the study, regardless of the fertilizer type.

\section{Soil Phosphorus Status and Environmental Risk}

P.R. Johnstone ${ }^{1}$, T.K. Hartz*2

${ }^{1}$ Univ. of California, Dept. of Vegetable Crops, Davis, CA 95616; ${ }^{2}$ Univ. of California, Dept. of Vegetable Crops

Heavy P fertilization in the Salinas Valley of California has increased soil Pconcentration to levels of environmental concern. To determine the correlation of various soil test procedures with P pollution potential from agricultural land in this region, soil was collected from 30 fields, most in long-term vegetable rotations. Soils were analyzed for bicarbonateextractable $\mathrm{P}\left(\mathrm{P}_{\mathrm{bc}}\right)$, calcium chloride-extractable $\mathrm{P}\left(\mathrm{P}_{c}\right)$, bio-available $\mathrm{P}$ $\left(\mathrm{P}_{\text {ba }}\right.$, by an anion-resin membrane technique), and \% Paturation $\left(\mathrm{P}_{\text {sat }}\right.$, by an enrichment technique). The soils were then exposed to a simulated irrigation event, and soluble $\mathrm{P}$ concentration in runoff determined. In a separate experiment the effect of cover cropping on sediment and soluble $\mathrm{P}$ concentration in runoff was investigated; containers of six soils were planted with oats (Horteum vulgare L.), and then compared to containers of fallow soil. $\mathrm{P}_{\mathrm{cc}}, \mathrm{P}_{\mathrm{ba}}$ and $\mathrm{P}_{\text {sat }}$ were all highly correlated $(r$ $=0.86,0.89$ and 0.90 , respectively) with $\mathrm{P}_{\mathrm{bc}}$, which ranged from 15-177 $\mathrm{mg} \cdot \mathrm{kg}^{-1}$. Soluble $\mathrm{P}$ concentration in runoff was highly correlated with all measures of $\mathrm{P}$ status $\left(r=0.98,0.93,0.85\right.$ and 0.83 for $\mathrm{P}_{\mathrm{cc}}, \mathrm{P}_{\mathrm{ba}}, \mathrm{P}_{\mathrm{sa}}$ and $\mathrm{P}_{b c}$, respectively). These results suggest that while $\mathrm{P}_{b c}$, the standard agronomic measure of soil $\mathrm{P}$ status, is a useful indicator of $\mathrm{P}$ pollution potential, $\mathrm{P}_{c c}$ (a simple laboratory procedure that could be adapted as an on-farm 'quick test' technique) may be superior for that purpose. Across soils, cover cropping reduced soluble P concentration in run-off by $41 \%$, and sediment in the runoff by $85 \%$.

\section{Response of 'Nocellara del Belice' Olive Trees to Organic Foliar Fertilization}

Michelangelo Policarpo ${ }^{1}$, Riccardo Lo Bianco*2

${ }^{1}$ Università degli Studi di Palermo, Dipartimento di Colture Arboree, Palermo, Italy; ${ }^{2}$ Università degli Studi di Palermo, Dipartimento di Colture Arboree, Palermo, Italy

Five different types/combinations of foliar fertilizers were tested on eight-year-old trees of 'Nocellara del Belice' olive grown in central Sicily. Trees were sprayed four times during Summer and Fall 2002 with Floral 20-20-20 (mineral N, P, K, and microelements; FLO) in combination with Alga Cifo (extract of brown algae; ALG), Floral 20-20-20 alone, Alga Cifo alone, Azomin (organic N, amino acids and peptides; $\mathrm{AZO}$ ), Supernat93 (organic $\mathrm{N}$ and $\mathrm{K}$, distillation residue;
SUP), and water (control). Yield and trunk circumference were measured during Fall 2002, whereas other vegetative and reproductive parameters were measured during Spring-Fall 2003. AZO and SUP trees produced more than control and ALG trees, whereas only AZO trees showed higher yield efficiency than control. The number of inflorescences per shoot was greatest in FLO and ALG trees and smallest in control trees. Percentage of ovary abortion and June drop were lowest in AZO trees and highest in FLO+ALG and ALG trees, whereas ALG was the only fertilizer that caused a greater fruit drop at harvest. Shoot growth was significantly reduced in ALG and FLO trees, and AZO trees presented leaves with reduced specific weight. Organic foliar fertilization with AZO and SUP generally improved yield and growth of 'Nocellara del Belice' olive trees by reducing ovary abortion and June drop and increasing shoot growth.

\section{Poster Session 27-Pomology 2 \\ July 18, 2004, 5:30-6:30 PM Rio Grande Exhibit Hall}

145 The Study of Pollination and Fruit Set and Determination Suitable Pollinizers for Two Iranian Commercial Apple Cultivars Golab Kohanz and Shafiabadi

\section{Alireza Talaie*1, Ahmad Ershadi ${ }^{2}$, Ali Vezvaei ${ }^{3}$}

${ }^{1}$ Univ. of Tehran, Horticulture, Karaj, Tehran, Iran; ${ }^{2}$ Univ. of Tehran, Hortiulture, Karaj, Tehran, Iran; ${ }^{3}$ Univ. of Tehran, Horticulture, Karaj, Tehran, Iran

In order to study pollination and fruit set and determine the best pollinizers for two Iranian apple cultivars, Golab Kohanz and Shafiabadi, experiments were conducted during two years. Different pollen sources including pollen of cultivars Golab Isfahan, Golab Kohanz, Mashhad Nouri, Shafiabadi and also open pollination were used. Pollen sources had significant effects on fruit set, fruit weight, diameter, shape, dry weight, total soluble solids (TSS), sugar and seed contents in cv. Golab Kohanz. Trees pollinated by pollen of Shafiabadi had highest fruit set, fruit weight, diameter, shape, dry weight, TSS., sugar, and seed content. Pollen sources significantly affected fruit set, fruit weight, diameter, shape, and seed content in cv. Shafiabadi. The highest fruit set, fruit weight, diameter, and seed content was resulted from flowers pollinated by Golab Kohanz. Golab Kohanz and Shafiabadi had 3.3\% and $0.5 \%$ fruit set from self pollination, respectively, and seemed to be completely incompatible. Fruit resulted from self pollination were generally small and of low quality. Regardless to fruits obtained from pollination, different pollen sources had small effects on fruit quality. The results indicated that cvs. Shafiabadi and Mashad Nouri are the best pollinizers for Golab Kohanz and Golab Kohanz was superior pollinizers for Shafiabadi.

146 A Comparison Study of the Effects of M.9 and Seedling Rootstocks on Two Iranian Cultivars, Golab Kohanz and Shafiabadi

Alireza Talaie*1 ${ }^{*}$, Alireza Esmaili Falak ${ }^{2}$, Mohammad Ali Asgari ${ }^{3}$

${ }^{1}$ Univ. of Tehran, Horticulture, Karaj, Tehran, Iran; ${ }^{2}$ Univ. of Tehran, Horticulture, Karaj, Tehran, Iran; ${ }^{3}$ Univ. of Tehran, Horticulture, Karaj, Tehran, Iran

The main aim of this study was to investigate the effects of two apple rootstocks (M9 and Seedling) on the growth, total yield, fruit quality and mineral composition in leaves and fruits of two Iranian cultivars Golab Kohanz and Shafiabadi. The 10-year-old experimented trees were on stage of commercial cropping. The experiment was conducted in a randomized complete-block design in split plot tests with two factors and four replications. The effects of rootstocks on trunk diameter, current seasonal shoot length, primary fruit set percentage, total yield/ha and individual fruit weight were significant $(P<0.01)$ in first year, but not significant on total yield and individual fruit weight in the second year. The effect of cultivar was only significant at current seasonal shoot length in the first year and total yield and individual fruit weight in both years. Fruit characters were also affected by rootstock, so fruit on M9 rootstock had more flesh firmness, most PH, TSS, and dry matter, but the effect of cultivars was not significant on fruit quality charac- 
ters in both years. Cultivar Shafiabadi on M9 rootstock produced the highest yield/ha in all treatment combinations. The results of mineral analysis relieved the effects of rootstock on $\mathrm{N}$ and $\mathrm{Zn}$ concentration in leaves. Golab Kohanz/M9 rootstock showed the highest K content in leaves while the highest $\mathrm{Zn}$ amount was Golab Kohanz/Seedling rootstock. Other nutrient contents were affected neither by rootstocks nor cultivars. In fruit, rootstock effect on $\mathrm{Mg}$ and $\mathrm{P}$ concentration was significant; and the highest $\mathrm{K}$ content was found in fruit of Golab Kohanz/M9 and the highest $\mathrm{Mg}$ and $\mathrm{Ca}$ amount was also recorded in Golab Kohamz/Seedling rootstock.

147 The Effects of Four Clonal Rootstocks on Growth Indices, Yield, Fruit Quality, and Quantity of 'Golden Smoothee' Apple in Iran's Climate Conditions

Alireza Talaie*1, Ali Gharaghani ${ }^{2}$, Mohammad Ali Asgari ${ }^{3}$

${ }^{1}$ Univ. of Tehran, Horticulrue, Karaj, Tehran, Iran; ${ }^{2}$ Univ. of Tehran, Horiculture, Karaj, Tehran, Iran; ${ }^{3}$ Univ. of Tehran, Horticulture, Karaj, Tehran, Iran

In this research the effect of four clonal rootstocks (B9, M9, M26, and MM106) on growth characteristics, flowering and fruiting, and fruit quality and quantity of 'Golden Smoothee' apple (Malus $\times$ domestica Borkh.) were studied during 2001 and 2003. Trees were 8 years old at the beginning of study. Experiments were planned in randomized complete-block design with four treatments (four rootstocks) and four replications. Rootstocks had significant effects on all growth characteristics. The highest tree height, shoot growth, and tree crosssectional area were found on MM106; with B9 was the least and M9 and M26 were intermediate. The effect of year, and interaction of year on rootstocks were nonsignificant. Rootstock has highly affected flowering and fruiting characteristics. The highest flowering efficiency related to M9 and B9. The highest primary and secondary fruit set and fruit set efficiency found with M9 and M26. The highest preharvest fruit abscission observed with M26. The M9 had the least preharvest fruit abscission. Yield of M9 was the highest and B9 was the least. The M9 has the most yield efficiency and MM106 had the least. Effect of year was significant in many characteristics related to flowering and fruiting. Generally, trees had better conditions in first year. Among fruit quantitative treatments, rootstock only affected fruit weight significantly. Fruit harvested from B9 had the least weight and other rootstocks had similar fruit weight. Generally rootstock had no noticeable effect on fruit quantity and quality.

148 Utilizing Aboveground Rhizotrons to Study Root Growth and Pathogen Movement in Simulated Orchard Conditions

Wesley T. Watson*1, David N. Appel², Michael A. Arnold³, Charles M. Kenerley ${ }^{4}$, James L. Starr

${ }^{1}$ Texas A\&M Univ., Forest Science, College Station, TX 77843-2135; ${ }^{2}$ Texas A\&M Univ., Plant Pathology and Microbiology, College Station, TX 77843-2132; ${ }^{3}$ Texas A\&M Univ., Horticultural Sciences, College Station, TX 77843-2133; ${ }^{4}$ Texas A\&M Univ., Plant Pathology and Microbiology, College Station, TX 77843-2132; ${ }^{5}$ Texas A\&M Univ., Plant Pathology and Microbiology, College Station, TX 77843-2132

Several techniques have been used to study root growth and pathogen movement along roots between trees, including profile walls, microrhizotrons, and soil cores. These assessments can be very time consuming, cost prohibitive, and ineffective when studying soilborne pathogen movement across overlapping roots between adjacent trees in an orchard. Three aboveground rhizotrons were designed and constructed to study the movement of Phymatotrichopsis omnivora (Duggar) Hennebert (syn. Phymatotrichum omnivorum Duggar) along overlapping apple roots [Malus sylvestris (L.) Mill. var. domestica (Borkh.) Mansf. (syn. M. domestica Borkh. non Poir.)] in simulated orchard conditions. Two experiments involved boxes using either observation windows or microrhizotron observation tubes between trees. A third experiment utilized 45-gallon containers $\left(171,457 \mathrm{~cm}^{3}\right)$ joined by innovative observation windows. The container rhizotrons reduced labor and material costs, were more effective at monitoring roots, were more convenient than field measurements, and more closely simulated orchard growing conditions. This method provides several advantages to better study and manipulate the rooting environment of orchard-grown trees.

\section{Antioxidant Content of Peach and Plum Genotypes}

David Byrne*1, Marcia Vizzotto ${ }^{2}$, Luis Cisneros-Zevallos ${ }^{3}$, David Ramming ${ }^{4}$, W. Okie ${ }^{5}$

${ }^{1}$ Texas A\&M Univ., Horticulture Science, College Station, TX 77843-2133; ${ }^{2}$ Texas A\&M Univ., Horticulture Science, College Station, TX 77843-2133; ${ }^{3}$ Texas A\&M Univ., Horticulture Science, College Station, TX 77843-2133; ${ }^{4}$ USDA-ARS, USDA-ARS, Parlier, California, 93648; 5 USDA-ARS, Southeastern Fruit \& Nut Research Lab, Byron, GA 31008-7066

Stone fruits contain a range of phenolic compounds and carotenoids which have been implicated in improving human health. The objective of this study was to characterize the phytochemicals and antioxidant activity (AOA) exhibited in peaches and plums. Twenty-two peach varieties and fifty-three plum varieties with different flesh and skin color collected from fields in California, Georgia, and Texas were analyzed for their antioxidant content and AOA. Total phenolics, anthocyanins, carotenoids were analyzed spectrophotometrically. AOA was evaluated by DPPH. Anthocyanin and phenolic contents were higher in red-flesh than in white/yellow-flesh peaches. Carotenoid content was higher in yellow-flesh [2-3 mg $\beta$-carotene $/ 100 \mathrm{~g}$ fw (fresh weight)] than in white or red-flesh peaches $(0.01-1.8 \mathrm{mg} \beta$-carotene $/ 100 \mathrm{~g} \mathrm{fw})$. AOA was about 2-fold higher in red-flesh varieties than in white/yellow-flesh varieties. Among the peaches, the AOA was well correlated with both phenolic and anthocyanin content. Among the plums, the anthocyanin content increased with the red color intensity. Although the plums varied widely in phenolic content, the red/purple-flesh plums generally had higher phenolic content (400-500 mg chlorogenic acid/100 g fw) than the other plums. Carotenoid content in plums was similar for all varieties $(0.2-2$ $\mathrm{mg} \beta$-carotene $/ 100 \mathrm{~g}$ fw). AOA was higher in red/purple-flesh varieties; however, it was well correlated only with the phenolic content in light colored flesh plums. These results suggest that red-flesh peach varieties have a greater potential health benefit based on antioxidant content and AOA as compared to the white/yellow-flesh varieties. Although this trend is not clear over all the plum varieties; the red/purple-flesh plums usually have higher antioxidant content and AOA.

150 Solution Characteristics Affect Pollen Germination and Growth, and Pistil Viability: Implications for Developing Chemical Blossom Thinners for Apple

Curt R. Rom*1, Zimian Niu², Vikramjit Bajwa ${ }^{3}$

${ }^{1}$ Univ. of Arkansas, Horticulture, Fayetteville, AR 72701; ${ }^{2}$ Univ. of Arkansas, Horticulture, Fayetteville, AR 72701; ${ }^{3}$ Univ. of Arkansas, Horticulture, Fayetteville, AR 72701

A strategy of chemical crop load control has been to use chemical desiccants to prevent fertilization and cause fruitlet drop. However, little is known of the solution characteristics that reduce pollen viability, inhibit pollen germination and growth, and cause pistil damage. This project was established to determine the solution characteristics effecting those results. Apple pollen was dispersed on germination media mixed with PEG (MW 10,000) to attain osmotic tensions from 0 to $-5.0 \mathrm{MPa}$ to evaluate effect on pollen germination and growth. Similarly, apple pollen was dispersed on germination adjusted to a range of $\mathrm{pH}$ from 2.3 to 12.0 with acids and $\mathrm{NaOH}$. Excised apple pistils were place on filter paper supports saturated with solutions with osmotic tension adjusted by PEG in the range of 0 to $-5.0 \mathrm{M} \mathrm{Pa}$, and $\mathrm{pH}$ from 3.0 to 12.0. Solutions of osmotic tension in the range of 0 to $-5.0 \mathrm{M} \mathrm{Pa}$ were applied by brush to intact pistils on apple flowers in a greenhouse and under field conditions. Pollen germination decreased with increasing osmotic tension and no pollen germinated at tensions greater than 4.0. Pistils, either excised or intact, had significant desiccation and death when treated with solution osmotic tensions greater than 4.0. Fruit set of individual spurs of the cvs Jonagold, Gala, and Arkansas Black were highly related to pistil survival $48 \mathrm{~h}$ after treatment with PEG. When solution osmotic potential exceeded 4.0, fruit set was reduced by more than $80 \%$. Pollen germination was reduced by more than $50 \%$ at solution $\mathrm{pH}$ below or equal to 4.0 and greater than 10.0 and completely inhibited at solution $\mathrm{pH}$ below or equal to 3.0 and greater than 11.0. Similar results were observed for excised pistil and intact viability. 
151 Ten Year Performance of 'Gala' on 18 Dwarf Apple Rootstocks in Michigan

Ronald L Perry*1, Dario Stefanelli², Gail Byler ${ }^{3}$

${ }^{1}$ Michigan State Univ., Horticulture, East Lansing, MI 48824; ${ }^{2}$ Michigan State Univ., Horticulture, East Lansing, MI 48824; ${ }^{3}$ Michigan State Univ., Clarksville Horticulture Exper. Station, Clarksville, MI 48815

Trees of Gala were planted in 1994 on 18 rootstocks at the Clarksville Horticulture Experiment Station as one cooperating site of 26 North American sites organized by the NC-140 Regional Pome and Stone fruit rootstock committee. One tree each of seven rootstock treatments and two on B.9 and B.491 have died since establishment. Death has been caused by wind (brittle union) on most of the trees in replication one, on the western exterior of the plot which is exposed to strong wind. The most vigorous trees in this planting are those on V.1 and M.26 and least vigorous on M.27 and P.22. Cropping in 2003 was highest on Pajam 2, Ottawa 3 and M.9 NAKB 337, yielding an average of between 60 to $70 \mathrm{~kg}$ per tree. Cropping over the years has been highest on PJ.2, M.9 EMLA, and O.3. Cumulative yield efficiency in this plot is highest on P.16, followed by P.22 and B.491. Trees on M.26 are the least efficient over the years. Average fruit weight was highest in 2003 on V.1 and PJ.2. M.9 NAKB 337, the dominant international an national standard M.9 clonal rootstock is not as productive and as precocious as many other M.9 clonal stocks in this trial. After 10 years of evaluation, there appears to be no significant difference in cropping, cumulative yield, for 'Gala' among the top eight rootstocks led by M.9 Pajam 2. M.9 NAKB 337 is not among the top eight rootstocks at this site. Pajam 2 is impressive from the view that while it is the top cropping stock, it is the rootstock in 2003 which also averaged the largest fruit. Among the M.9 clonal rootstocks, PJ 2 is also the most vigorous which for North American commercial apple orchards, has excellent commercial potential to withstand field and production stresses.

\section{Growing Olives in Texas}

Nasir S.A. Malik*1, Joe M. Bradford ${ }^{2}$, Jim Brockington ${ }^{3}$

${ }^{1}$ USDA-ARS, Integrated Farming and Natural Resources Research Unit, Weslaco, TX 78596; ${ }^{2}$ USDA-ARS, Integrated Farming and Natural Resources Research Unit, Weslaco, TX 78596; ${ }^{3}$ USDA-ARS, Integrated Farming and Natural Resources Research Unit, Weslaco, TX 78596

Olives have not been commercially grown in Texas because earlier investigators considered Texas climate inappropriate for olive cultivation. No experimental investigations were conducted in Texas. Olives, however, grow in very diverse climatic conditions throughout the world. More than 2000 varieties of olives have been reported worldwide. Olive accessions have also shown adaptability to local climates. United States imports thousands of tons of olive oil each year. Some of these requirements could be fulfilled internally if vast lands available for cultivation in Texas could be utilized for olive production. We have started experimental research growing olives in Texas. Our initial surveys of olives groves established during the last 4-6 years have revealed the existence of at least two trees with remarkable adaptability to Texas conditions. One of these trees had flowered and fruited in the Rio Grande Valley where earlier workers had predicted that flowering in olives will not occur. Thus, there appears enough genetic diversity and clonal variations even among existing olive trees in Texas that there is a hope for viable cultivations of olives in Texas. Clones from these trees have now been produced for testing at various locations within the Texas Valley. Grafting experiments have shown that scions from flowering shoots could produce flowers even on juvenile rootstocks thus providing quicker methods for propagating and evaluating selected clones. Relatively inexpensive chilling chambers were developed to study chilling requirements for flower induction in selected olive varieties. Out initial data shows that Arbequina could flower under mild chilling conditions.

153 Effects of Fruits Loading, Thinning Time, and Water Stress on Medium-size and Regular Shaped Fruit of 'Niitaka' Pear

Wol-Soo Kim*1, Xiu-Yu We ${ }^{2}$

${ }^{1}$ Chonnam National Univ., Dept. of Horticulture, Gwangju, 500-757, South Korea; ${ }^{2}$ Chon- nam National Univ., Dept. of Horticulture, Gwangju, 500-757, South Korea

Consumers in the United States. and the European Union prefer to purchase medium-sized and symmetrical pears, while most Koreans prefer fruit that is as large as possible. This study was carried out to determine the effect of fruit loading, thinning time, and water management at full bloom stage on the number of seed and size and shape of fruit. As fruit loading increased and the time of fruit thinning was delayed, there was a decrease in fruit weight. The rate of fruit weight under $450 \mathrm{~g}$ was $41.7 \%$ in the treatment of $30 \%$ increase of fruit loading compared to control. There was an increasing tendency of symmetry fruits as the increase of fruit loading. By water stress treatment for 30 days after full bloom, a lot of medium sized fruit were harvested. The rate of symmetrical fruits was increased from the fruit, which held nine to ten seeds per fruit as well as uniformed seed development. Therefore, these results suggested that the number of seed s per fruit showed a close relationship to fruit shape, but water stress and fruit thinning time did not affect the fruit shape.

\section{Early Performance of 'McIntosh' Apple Trees on Several Semidwarf Rootstocks in the 1999 NC-140 Rootstock Trial}

Wesley Autio*1, John Cline ${ }^{2}$, Robert Crassweller ${ }^{3}$, Charles Embree ${ }^{4}$, Elena Garcia ${ }^{5}$, Emily Hoover ${ }^{6}$, Kevin Kosola ${ }^{7}$, Ronald Perry ${ }^{8}$,

Terence Robinson ${ }^{9}$

${ }^{1}$ Univ. of Massachusetts, Plant \& Soil Sciences, Amherst, MA 01003-9294; ${ }^{2}$ Univ. of Guelph, Plant Agriculture, Simcoe, ON N3Y 4N5, Canada; ${ }^{3}$ Pennsylvania State Univ., Horticulture, Univ. Park, PA 16802; ${ }^{4}$ Agriculture \& Agri-Food Canada, Atlantic Food and Horticulture Research Centre, Kentville, NS B4N 1J5, Canada; ${ }^{5}$ Univ. of Vermont, Plant and Soil Science, Burlington, VT 05405; ${ }^{6}$ Univ. of Minnesota, Horticultural Science, St. Paul, MN 55108; ${ }^{7}$ Univ. of Wisconsin, Horticulture, Madison, WI 53706; ${ }^{8}$ Michigan State Univ., Horticulture, East Lansing, MI 48824; ${ }^{9}$ Cornell Univ., Horticultural Science, Geneva, NY 14456

'McIntosh' apple trees [Malus ×sylvestris (L.) Mill. Var domestica (Borkh.)] on five semidwarfing rootstocks (CG.4814, CG.7707, G.30N, M.7 EMLA, and Supporter 4) were planted at 10 locations (MA, MI MN NS 2 in NY ON PA VT and WI) under the direction of the NC140 Multistate Research Project. After four growing seasons (through 2002), trees on CG.7707, G.30N, Supporter 4, and M.7 EMLA were significantly larger than those on CG.4814. Cumulative root suckering was most from trees on M.7 EMLA, and least from trees on CG.7707, G.30N, and Supporter 4. Yield per tree in 2002 and cumulatively was greatest from trees on G.30N and least from trees on CG.7707 and M.7 EMLA. In 2002 and cumulatively, CG.4814 resulted in the greatest yield efficiency, and M.7 EMLA resulted in the lowest. In 2002, fruit from trees on M.7 EMLA were largest, and those from trees on CG.4814 were smallest. On average, M.7 EMLA resulted in the largest fruit, and G.30N resulted in the smallest. Limited data will be presented on CG.6210, CG.8, G.30T, and M.26 EMLA, which are planted only at some locations. Data for the fifth season (2003) will be presented.

\section{Early Performance of 'Fuji'Apple Trees on Several Semidwarf Rootstocks in the 1999 NC-140 Rootstock Trial}

Wesley Autio*1, LaMar Anderson ${ }^{2}$, Bruce Barritt ${ }^{3}$, Robert Crassweller $^{4}$, David Ferree ${ }^{5}$, George Greene ${ }^{6}$, Scott Johnson ${ }^{7}$, Joseph Masabni ${ }^{8}$, Michael Parker ${ }^{9}$, Gregory Reighard ${ }^{10}$

${ }^{1}$ Univ. of Massachusetts, Plant \& Soil Sciences, Amherst, MA01003-9294; ${ }^{2}$ Utah State Univ., Plants, Soils, \& Biometrics, Logan, UT 84322-4820; ${ }^{3}$ Washington State Univ., Tree Frui Research \& Extension Center, Wenatchee, WA 98801; ${ }^{4}$ Pennsylvania State Univ., Horticulture, Univ. Park, PA $16802 ;{ }^{5}$ Ohio State Univ., Horticultural \& Crop Science, Wooster, OH 44691; ${ }^{6}$ Pennsylvania State Univ., Horticulture, Wiscasset, ME 04578; ${ }^{7}$ Univ. of California, Kearney Agricultural Center, Parlier, CA 93648; ${ }^{8}$ Univ. of Kentucky, UK Research \& Extension Center, Princeton, KY 42445; ${ }^{~ N o r t h ~ C a r o l i n a ~ S t a t e ~ U n i v ., ~ H o r t i c u l t u r e, ~ R a l e i g h t, ~}$ NC 27694-7609; ${ }^{10}$ Clemson Univ., Horticulture, Clemson, SC 29634-0375

'Fuji' apple trees [Malus $\times$ sylvestris (L.) Mill. Vardomestica. (Borkh.)] on five semidwarfing rootstocks (CG.4814, CG.7707, G.30N, M.26 EMLA, and M.7 EMLA) were planted at nine locations (CA, KY MO NC OH PA SC UT and WA) under the direction of the NC-140 Multistate Research Project. After four growing seasons (through 2002), trees on CG.7707 and M.7 EMLA were the largest, and those on M.26 EMLA were the smallest. M.7 EMLA resulted in more cumulative root suckering per tree than did any other rootstock. Yield per tree in 2002 
and cumulatively was greatest from trees on CG.4814, CG.7707, and G.30N and least from trees on M.26 EMLA and M.7 EMLA. The most yield efficient trees in 2002 and cumulatively were on CG.4814, and the least efficient trees were on M.26 EMLA and M.7 EMLA. Rootstock did not affect fruit weight in 2002; however, on average, CG.7707 resulted in the largest fruit, and CG.4814 resulted in the smallest. Limited data will be presented on CG.6210, G.30T, and Supporter 4 , which are planted only at some locations. Data for the fifth season (2003) will be presented.

\section{Early Performance of 'Fuji' Apple Trees on Several Dwarf Rootstocks in the 1999 NC-140 Rootstock Trial}

Wesley Autio*1, LaMar Anderson ${ }^{2}$, Bruce Barritt ${ }^{3}$, Robert Crassweller $^{4}$, David Ferree ${ }^{5}$, George Greene ${ }^{6}$, Scott Johnson ${ }^{7}$, Joseph Masabni $^{8}$, Michael Parker ${ }^{9}$, Gregory Reighard ${ }^{10}$

${ }^{1}$ Univ. of Massachusetts, Plant \& Soil Sciences, Amherst, MA 01003-9294; ${ }^{2}$ Utah State Univ., Plants, Soils, \& Biometrics, Logan, UT 84322-4820; ${ }^{3}$ Washington State Univ., Tree Fruit Research \& Extension Center, Wenatchee, WA 98801; ${ }^{4}$ Pennsylvania State Univ., Horticulure, Univ. Park, PA 16802; ' Ohio State Univ., Horticulture \& Crop Science, Wooster, OH 44691; ${ }^{6}$ Pennsylvania State Univ., Horticulture, Wiscasset, ME 04578; ${ }^{7}$ Univ. of California, Kearney Agricultural Center, Parlier, CA 93648; ${ }^{8}$ Univ. of Kentucky, Univ. of Kentucky Research \& Education Center, Princeton, KY 42445; ${ }^{9}$ North Carolina State Univ., Horticulture, Raleigh, NC 27695-7609; ${ }^{10}$ Clemson Univ., Horticulture, Clemson, SC 29634-0375

'Fuji' apple trees [Malus $\times$ sylvestris (L.) Mill. Var domestica (Borkh.)] on nine dwarfing rootstocks (CG.4013, CG.5179, G.16N, G.16T, M.9 NAKBT337, M.26 EMLA, Supporter 1, Supporter 2, and Supporter 3) were planted at 10 locations (CA, KY MO NC OH 2 in PA SC UT and WA) under the direction of the NC-140 Multistate Research Project. After four growing seasons (through 2002), largest trees were on CG.4013. Smallest trees were on M.9 NAKBT337, Supporter 1, Supporter 2, and Supporter 3. Trees on CG.5179, G.16 N, G.16T, and M.26 EMLA were intermediate. Cumulative root suckering was greatest from trees on CG.4013 and similar from the other rootstocks. CG.4013, CG.5179, and G.16T resulted in the greatest yields per tree in 2002, and M.26 EMLA, M.9 NAKBT337, Supporter 2, and Supporter 1 resulted in the lowest. Cumulatively, CG.4013 resulted in the greatest yields per tree, and M.26 EMLA resulted in the lowest. Rootstock did not affect yield efficiency in 2002, but cumulatively, Supporter 1, Supporter 2, and Supporter 3 resulted in the most efficient trees, and M.26 EMLA the least. Fruit weight in 2002 or on average was not affected by rootstock. Limited data will be presented on CG.3041, CG.5202, and CG.5935, which are planted only at some locations. Data for the fifth season (2003) will be presented.

\section{Early Performance of 'McIntosh'Apple Trees on Several Dwarf Rootstocks in the 1999 NC-140 Rootstock Trial}

Wesley Autio*1, John Cline ${ }^{2}$, Robert Crassweller ${ }^{3}$, Charles Embree ${ }^{4}$, Elena Garcia ${ }^{5}$, Emily Hoover ${ }^{6}$, Kevin Kosola ${ }^{7}$, Ronald Perry ${ }^{8}$,

Terence Robinson ${ }^{9}$

${ }^{1}$ Univ. of Massachusetts, Plant \& Soil Sciences, Amherst, MA 01003-9294; ${ }^{2}$ Univ. of Guelph, Plant Agriculture, Simcoe, ON LOR 2E0, Canada; ${ }^{3}$ Pennsylvania State Univ., Horticulture, Univ. Park, PA 16802; ${ }^{4}$ Agriculture \& Agri-Food Canada, Atlantic Food and Horticulture Research Centre, Kentville, NS B4N 1J5, Canada; ${ }^{5}$ Univ. of Vermont, Plant \& Soil Science, Burlington, VT 05405; ${ }^{6}$ Univ. of Minnesota, Horticultural Science, St. Paul, MN 55108; ${ }^{7}$ Univ. of Wisconsin, Horticulture, Madison, WI 53706; ${ }^{8}$ Michigan State Univ., Horticulture, East Lansing, MI 48824; ${ }^{9}$ Cornell Univ., Horticultural Science, Geneva, NY 14456

'McIntosh' apple trees [Malus × sylvestris (L.) Mill. Var domestica (Borkh.)] on 10 dwarfing rootstocks (CG.3041, CG.4013, CG.5179, CG.5202, G.16N, G.16T, M.9 NAKBT337, Supporter 1, Supporter 2, and Supporter 3) were planted at 10 locations (MA, MI MN NS 2 in NY ON PA VT and WI) under the direction of the NC-140 Multistate Research Project. After four growing seasons (through 2002), trees on CG.5202 and CG.4013 were significantly larger than those on all other rootstocks. Smallest trees were on M.9 NAKBT337. Trees on other rootstocks were intermediate. Rootstock did not influence cumulative root suckering. Yield per tree in 2002 was greatest from trees on CG.4013 and lowest from trees on M.9 NAKBT337; however, cumulatively, trees on M.9 NAKBT337 and CG.4013 yielded the most. Yield efficiency in 2002 was not affected by rootstock. Cumulatively, rootstock had very little effect, but trees on CG.5202 were the least efficient. In 2002, M.9 NAKBT337, CG.3041, and Supporter 2 resulted in the largest fruit, and CG.5179 resulted in the smallest. On average, M.9 NAKBT337 resulted in the largest fruit, and G.16T resulted in the smallest. Limited data will be presented on CG.5935 and M.26 EMLA, which are planted only at some locations. Data for the fifth season (2003) will be presented.

\section{Peach Evaluation Website}

Desmond R. Layne*1, W.R. "Dick” Okie², Eric J. Hitzler ${ }^{3}$

${ }^{1}$ Clemson Univ., Horticulture, Clemson, SC 29634-0375; ${ }^{2}$ SE Fruit \& Tree Nut Res Lab, USDA-ARS, Byron, GA 31008; ${ }^{3}$ Clemson Univ., Horticulture, Seneca, SC 29678

The evaluation of peach and nectarine cultivars and advanced selections for suitability of production in the southeastern U.S. has been conducted at Clemson Univ. since 2000. Currently, there are 240+ cultivars and advanced selections being tested at the university's Musser Fruit Farm in Seneca, S.C. The harvest season begins in early May and ends in the middle of September. Additionally, two on-farm grower trials were planted in the primary peach growing regions of the Piedmont (Cowpens, S.C.) and the Ridge (Monetta, S.C.). At the grower locations, advanced selections are compared with industry standard cultivars. Evaluation data collected includes bloom and ripe date, fruit set, shape, color, size, firmness, taste and disease susceptibility. Digital photos are taken to scale at commercial maturity. Evaluation information, photos, plus chill hours, variety descriptions and other valuable information are on the website. In 2004, substantial improvements were made to the site utilizing a database, search and compare tools. The website has been well received by the southeastern commercial peach growers and is utilized to assist them in cultivar selection and to learn more about peach culture in general.

\section{Poster Session 28-Vegetable Crops Management 2 \\ July 19, 2004, 12:30-1:30 PM Rio Grande Exhibit Hall}

\section{Plant Arrangement and Cultivar Effects on Yield and Fruit Quality of Bell Pepper}

Brian A. Kahn*1, Daniel I. Leskovar ${ }^{2}$

${ }^{1}$ Oklahoma State Univ., Dept. of Horticulture and Landscape Architecture, Stillwater, OK 74078-6027; ${ }^{2}$ Texas A\&M Universisty, Texas Agricultural Experiment Station, Uvalde, TX 78801

Single- and double-row arrangements of a fixed population (one plant every $0.285 \mathrm{~m}^{2}$ ) were compared in factorial combination with two (2002) or five (2003) cultivars for effects on yield and fruit quality of bell pepper (Capsicum annuum L.). Arrangements for 2002 were: (1) $1.9 \mathrm{~m}$ between centers of double-row beds, rows on beds $30 \mathrm{~cm}$ apart, plants within rows $30 \mathrm{~cm}$ apart; (2) single rows $0.95 \mathrm{~m}$ apart, plants within rows $30 \mathrm{~cm}$ apart; (3) $1.52 \mathrm{~m}$ between centers of double-row beds, rows on beds $24 \mathrm{~cm}$ apart, plants within rows $37.5 \mathrm{~cm}$ apart; and (4) single rows $0.76 \mathrm{~m}$ apart, plants within rows $37.5 \mathrm{~cm}$ apart. Only arrangements (1) and (2) were used in 2003. Row arrangement did not affect marketable fruit production in Oklahoma in 2002, but single rows resulted in a greater weight of fruit with blossom-end rot than double rows. Arrangement (2) resulted in both a greater weight of U.S. No. 1 fruit and a greater weight of sunburned fruit than arrangement (1) in Texas in 2002. 'King Arthur' produced more marketable fruit than 'X3R Wizard' in Oklahoma in 2002, but the opposite occurred in Texas. Arrangement (2) resulted in a greater weight of U.S. No. 1 fruit than arrangement (1) in both locations in 2003. Arrangement (2) also resulted in greater weights of sunburned (Oklahoma) or total cull (Texas) fruit than arrangement (1) in 2003. 'Lafayette' and 'X3R Wizard' produced a greater weight of marketable fruit than 'Boynton Bell', 'Karma', and 'King Arthur' in Texas in 2003, but not in Oklahoma. Plant arrangement $\times$ cultivar interactions were not evident in Oklahoma and minimal in Texas. Given the tested population, a single row arrangement is likely to result in higher U.S. No. 1 fruit yields than 
a double-row arrangement, despite an increased potential for cull fruit production with single rows.

39 Evaluation of Adaptation and Yield of Commercial Tomato (Lycopersicon esculentum Mill.) Hybrids under Mulching and Technified Fertilization and Irrigation

Francisco Radillo-Juárez ${ }^{* 1}$

${ }^{1}$ Universidad de Colima, Facultad de Ciencias Biológicas y Agropecuarias, Colima, Colima, 28070, Colima, Mexico

In the world horticultural production, the tomato (Lycopersicon esculentum Mill.) contributes with the $47 \%$ of the destined area. In Mexico, $10 \%$ of the area is cultivated under intensive systems, where is used one or more technologies for obtaining higher productivity and quality; however, the environmental conditions are determinant factors to produce red tomato in the dry tropic, influencing the adaptation and persistence in the market. The aim of this research was to evaluate the adaptation and yield performance of tomato hybrids in fresh production under mulching, fertilization and irrigation. The tomato cultivars used were: 'Access', 'Centurion', 'Bishop', 'Dean', and 'Yaqui' (control). They were distributed under a Completely randomized blocks design with four replications. The experiment was carried out in Villa de Alvarez, Colima, México. 'Yaqui' exhibited the highest plant height $98.8 \mathrm{~cm}$, as web as the highest fruit diameter with $4.61 \mathrm{~cm}$; 'Bishop' produced the highest number with 154.5 fruits per plant, followed by 'Yaqui', and 'Centurion', with 91 fresh fruits. In the variable fruit weight , 'Yaqui' showed $93.44 \mathrm{~g}$. In total fresh fruit yield per plant, 'Yaqui' produced the highest yield with $8.46 \mathrm{~kg}$, followed by 'Bishop' with 4.91 $\mathrm{kg}$; and total yield of 117.5 , and $68.2 \mathrm{t} \cdot \mathrm{ha}^{-1}$, respectively. Yaqui' was the genotype with best adaptation and agronomic characteristics. We speculate that environment conditions in field are determinant factors in the introduction of new tomato introductions.

\section{Carrot Cultivar Trials in Oklahoma}

\section{Lynn P. Brandenberger*1, Lynda K. Wells ${ }^{2}$, Bruce B. Bostian ${ }^{3}$}

${ }^{1}$ Oklahoma State Univ., Horticulture, Stillwater, OK 74078-6027; ${ }^{2}$ Oklahoma State Univ., Horticulture, Stillwater, OK 74078-6027; ${ }^{3}$ Oklahoma State Univ., Horticulture

The objectives of this trial were to collect yield and quality data on a fall planted carrot trial. Fifteen different carrot varieties were included in the trial. Plots were 20 feet by 2.5 feet and consisted of two rows of carrots with 15 -inch row centers. Plots were replicated 4 times in a RBD. Carrots were direct seeded on 8 Aug. 2003 at 20 seeds per foot. Plots were fertilized with $90 \mathrm{lbs} /$ acre of nitrogen and received overhead water as needed. Yield and quality data were recorded on 5 Dec. 2003. Data included exterior root color, interior root color, percentage of split and forked roots, overall yield, average root length and weight. Exterior root color did not vary significantly for any of the cultivars in the trial, but interior root color varied significantly for several cultivars. 'First Class', 'Bolero', and 'C 7105' had the most distinct differences between the pith and out ring colors as indicated by the interior root color ratings and 'Ingot' had the lowest. Interior root color ratings for these four cultivars were 3.8, 3.6, 3.1, and 1.4, respectively. Crispness did not vary for either the initial or second ratings that were recorded. Of potential defects only the percentage of forked roots varied significantly and of these four cultivars had less than $10 \%$ forked roots. 'Florida', 'Kamaran', 'Pipeline', and 'C 7105' had 5\%, 7\%, 9\%, and $9 \%$ forked roots, respectively. 'Samantha' had $31 \%$ forked roots, the highest percentage recorded in the trial. No differences were recorded for root weight, diameter or length. The three highest yielding cultivars in the trial were 'Ingot', 'Heritage', and 'Neptune' that had overall yields of 24.9, 20.6, and 20.6 tons/acre. 'Bremen' recorded the lowest yield in the trial with 13.7 tons/acre.

\section{Chemical Control in the Soil Fungus (Pyrenochaeta terrestris) in Onion Production}

Ruben Macias-Duarte ${ }^{1}$, Raul Leonel Grijalva-Contreras*2, Manuel de Jesus Valenzuela-Ruiz ${ }^{3}$, Fabian Robles-Contreras ${ }^{4}$
'INIFAP-Caborca, Soil \& Horticultural, Caborca, Sonora, 83600, Mexico; ${ }^{2}$ INIFAP-Caborca, Protected Horticulture, Caborca, Sonora, 83600, Mexico; ${ }^{3}$ INIFAP-Caborca, Viticulture, Caborca, Sonora, 83600, Mexico; ${ }^{4}$ INIFAP-Caborca, Agroclimatology, Caborca, Sonora, 83600, Mexico

The producers areas of onion in Mexico, are affected by the existence and increment of pathogens organisms of the soil like the fungus Pyrenochaeta terrestris, This problem increased its presence and damages due to the consecutive establishment of this vegetable year with year on the same soils. The fungus is activated and this disease developed when the soil temperature is increased. The disease infection of the plants causes rot and death of roots and small bulbs whit no commercial value, and low yields. According that the objective of the present research was to evaluate three treatments for the control of this organism pathogen: The experiment was carried out on INIFAP-CIRNO Experimental Station on a severally infested soil whit this fungus. The sow date was on 6 Jan. 2002, in this trial we used "local" variety. The treatments evaluated were Trichoderma $\left(30 \mathrm{~L}^{\cdot} \mathrm{ha}^{-1}\right)$, Humega $8 \%$ $\left(180 \mathrm{~L} \cdot \mathrm{ha}^{-1}\right)$, Isofert $25\left(400 \mathrm{~L} \cdot \mathrm{ha}^{-1}\right)$ and a control (without treatment). The products were applied using the drip irrigation system. The results indicate that the treatments with Trichoderma and Humega $8 \%$ presented the lower percent of disease roots with $33 \%$ and those of more incidence were the control and Isofert 25 with $46 \%$ and $47 \%$ of disease roots, respectively. The results show $13 \%$ efficiency with the use of Trichoderma with respect to control; however this treatment did not affect the bulb weight and yield, control treatment obtained the greatest bulb weight and yield with $212 \mathrm{~g}$ for bulb and $80.9 \mathrm{t} \cdot \mathrm{ha}^{-1}$ against $196 \mathrm{~g}$ and $71.9 \mathrm{t} \cdot \mathrm{ha}^{-1}$, respectively, of the Trichoderma, which was seemingly a secondary negative effect in decrement the yield.

\section{Yield and Quality of Onion Varieties Under Direct Seed and Transplant Seedling}

Ruben Macias-Duarte ${ }^{1}$, Raul Leonel Grijalva-Contreras*2, Manuel de Jesus Valenzuela-Ruiz ${ }^{3}$, Fabian Robles-Contreras ${ }^{4}$

${ }^{1}$ INIFAP-Caborca, Soil \& Horticultural, Caborca, Sonora, 83600, Mexico; 2 INIFAP-Caborca, Protected Horticulture, Caborca, Sonora, 83600, Mexico; ${ }^{3}$ INIFAP-Caborca, Viticulture, Caborca, Sonora, 83600, Mexico: ${ }^{4}$ INIFAP-Caborca, INIFAP-Caborca, Caborca, Sonora, 83600, Mexico

The onion bulb production In Mexico is about 39,000 ha annually. Yield is variable according to the technological capacity and economic condition of the grower. However, The technology adoption (new varieties, efficient irrigation system and establishment methods) is increased during the last years. Traditionally in Mexico the grower use the manual transplant of seedling, that which increases the cost and time of this labor. The objective of the present Experiment was to evaluate Two establishment methods (direct seed and transplant seedling) and the effect on 24 bulb varieties. The evaluation was carried out in INIFAPCIRNO Experimental Station in furrows with $1.00 \mathrm{~m}$ of separation among them, with double row of plants, the amount of nitrogen and phosphorus used were 180 and $80 \mathrm{~kg} \cdot \mathrm{ha}^{-1}$ respectively, we used the drip irrigation system. In this experiment we observed that the system of direct seed obtained better yield (18\%), bulb weight $(21 \%)$ and precocity (11 days) in comparing to the transplant methods, however in the first treatment the floral stem emission was greater $(6.7 \%$ vs $1.1 \%$ ) of the transplant methods. The white varieties with high yield were: White onion 214 and Cal 128 with 71.4 and 65.7 ton/ha. The purple varieties was $\mathrm{F}_{1} \mathrm{Cal} 192$ with $68.3 \mathrm{t} \cdot \mathrm{ha}^{-1}$ and the yellow varieties was Ringer Cal 160 with $63.2 \mathrm{t} \cdot \mathrm{ha}^{-1}$.

\section{Influence of Plant Density on Yield and Quality in Tomatoes Under Greenhouse Conditions in the Northwest on Mexico}

Raul Leonel Grijalva-Contreras*1, Ruben Macias-Duarte ${ }^{2}$, Manuel de Jesus Valenzuela-Ruiz ${ }^{3}$, Fabian Robles-Contreras ${ }^{4}$

${ }^{1}$ INIFAP-Caborca, Protected Horticulture, Caborca, Sonora, 83600, Mexico; ${ }^{2}$ INIFAPCaborca, Soil \& Horticultural, Caborca, Sonora, 83600, Mexico; ${ }^{3}$ INIFAP-Caborca, Viticulture, Caborca, Sonora, 83600, Mexico; ${ }^{4}$ INIFAP-Caborca, Agroclimatology, Caborca, Sonora, 83600, Mexico

Production of high value crops in greenhouse in the Northwest of Mexico is an efficient way to achieve high yield, and high quality and 
the some time vegetables with less pesticide residue. The objective of this experiment was to evaluate the effects of three different plant densities $\left(1.89,2.50\right.$, and 3.78 plants $\left./ \mathrm{m}^{2}\right)$ on yield and fruit quality on tomatoes. This experiment was carried out in the Experimental Station (INIFAP-CIRNO) inside polyethylene greenhouse. In this Trial we used soil medium and the variety used was 'Matrix'. The date seedling establishment was on 26 Jan. 2003. Plant density did have an effect on yield, but did not affect the fruit size. Yield per square meter had a linear response a plant density. The yield obtained were 21.8, 16.1 and 14.7 $\mathrm{kg} / \mathrm{m}^{2}$ using 3.78, 2.50 and 1.89 plants $/ \mathrm{m}^{2}$, respectively. Weight fruit varied from 200.4 to $247.6 \mathrm{~g} /$ fruit for all densities. Also the density not affected the fruit color. None of the treatments evaluated had problems of insect pest and disease.

\section{Influence of Colored Plastic Mulches on Soil Temperature and Muskmelon Root Respiration}

John Jifon*1

${ }^{1}$ Texas A\&M Univ., Horticulture, Weslaco, 78596

Use of plastic mulch to increase rhizosphere temperatures is a common practice in spring production of vegetable crops. However, supraoptimal soil temperatures during the fruit maturation period in early summer can impair root function and reduce produce quality. The effects of colored plastic mulch on rhizosphere temperature and 'Primo' muskmelon root respiration were investigated in the field during Fall (Aug.-Nov. 2002) and Spring (Mar.-May 2003) seasons. Rhizosphere temperatures (measured at $0.1 \mathrm{~m}$ below the soil surface with thermocouples) and respiration under four plastic mulches (black, silver, white, and clear), and a bare ground control were studied. The soil warming properties of the different mulches differed between Spring and Fall. Bare ground rhizosphere temperatures declined from $\approx 33$ to $21^{\circ} \mathrm{C}$ in the Fall and increased from 14 to $26^{\circ} \mathrm{C}$ in Spring. In both studies, black and clear plastic mulches had the highest rhizosphere warming effects $\left(3-8{ }^{\circ} \mathrm{C}\right)$ compared to bare ground. In the Fall, average midday soil temperatures under the white and silver mulches were $2-3{ }^{\circ} \mathrm{C}$ cooler than the bare ground treatment. Canopy establishment was accelerated by plastic mulches in Spring but not in Fall. Root + soil respiration was positively correlated with measured rhizosphere temperatures $(r=0.69)$, with the highest respiration rates recorded under the clear and black plastic mulches. More than $80 \%$ of fruits from the clear plastic treatment were deformed and unmarketable. The number of marketable fruit was similar among the black, white and silver mulch treatments and significantly greater (32\% in Spring \& 12\% in Fall) than in the bare ground treatments.

\section{Crop Diversification In Ontario: Adaptation of Annual Globe Artichokes}

Mary Ruth McDonald*1, Kevin Vander Kooi², Cathy Bakker ${ }^{3}$, Alan McKeown $^{4}$

${ }^{1}$ Univ. of Guelph, Plant Agriculture, Guelph, Ontario, N1G 2W1, Canada; ${ }^{2}$ Univ. of Guelph, Plant Agriculture, Kettleby, Ontario, L0G 2W1, Canada; ${ }^{3}$ Univ. of Guelph, Plant Agriculture, Simcoe, Ontario, N3Y 4N5, Canada; ${ }^{4}$ Univ. of Guelph, Plant Agriculture, Simcoe, Ontario, N3Y 4N5, Canada

Globe artichoke (Cynara scolymus L.) is a high value cool season crop which requires vernalization to induce flower formation. The climate in Ontario does not allow for survival of perennial cultivars or for consistent natural vernalization of annuals. Three methods of vernalization were tested : a controlled environment chamber, a lighted cold storage, or $\mathrm{GA}_{3}$ application in the field. Plants, cv. Green Globe Improved, were grown in a greenhouse set at $25^{\circ} \mathrm{C}$ day temperature in 72 -cell Styrofoam trays in a peat mix. At 4 weeks, plants receiving vernalization were transferred to growth chambers, or lighted coolers (four standard 8 foot cool white fluorescent lamps) at $10^{\circ} \mathrm{C}$ for two weeks. The others stayed in the greenhouse. GA treatments (PROGIB, $15 \mathrm{~g}$ ai/ha) were applied at 2, 4 and 6 weeks after transplanting. Cultivars Green Globe Improved, Imperial Star, Emerald, and Large Green Globe were evaluated in separate trials. Trials were conducted at Simcoe, on coarse sand in a high heat area, and Kettleby, on organic soils in a cooler area of
Ontario. Shortly after planting at Simcoe several $30^{\circ} \mathrm{C}$ days occurred which devernalized and injured the crop. Artichokes grew well at the Kettleby site. Vernalization in the growth chamber was most effective and resulted in the earliest bud formation and highest total yield (1503 cases/ha). Large Green Globe was not well adapted to Ontario conditions. Imperial Star and Emerald produced the highest yields, 2180 and 1779 cases/ha, respectively. Globe artichokes can be grown successfully as an annual crop in cool production areas of Ontario.

\section{Plant Density Affects Yield and Quality of Confectionery Pumpkin Seeds}

Sung Eun Lee*1, Sang Gyu Lee ${ }^{2}$, Chiwon W. Lee ${ }^{3}$

${ }^{1}$ North Dakota State Univ., Dept. of Plant Sciences, Fargo, ND 58105; ${ }^{2}$ North Dakota State Univ., Dept. of Plant Sciences, Fargo, ND 58105; ${ }^{3}$ North Dakota State Univ., Dept. of Plant Sciences, Fargo, ND 58105

The influence of plant density on yield of three confectionery seed pumpkin accessions was investigated under non-irrigated field conditions. Seeds of Golden Delicious (GD), open-pollinated Chinese snow-white seed (CS), and a selection from Austrian hull-less (HL) pumpkin were planted 30, 60, and $90 \mathrm{~cm}$ apart in rows that were $127 \mathrm{~cm}$ apart with seedlings thinned to one plant per hill. Plants were grown from 23 May to 18 Sept. One fruit per plant was harvested from five plants for each of the three replications. The number of seeds (and dry weight of seed) per fruit were 242 (59 g), 304 (87 g), and 334 (106 g), respectively, at 30,60 , and $90 \mathrm{~cm}$ spacing for GD. The number of seeds (and dry weight of seed) per fruit were 219 (108 g), 266 (108 g), and 258 (106 $\mathrm{g})$, respectively, at 30,60 , and $90 \mathrm{~cm}$ spacing for CS. The number of seeds (and dry weight of seed) per fruit were 376 (76 g), 404 (94 g), and 304 (82 g), respectively, at 30, 60, and $90 \mathrm{~cm}$ spacing for HL. Highest seed yield was at $60 \mathrm{~cm}$ plant spacing for CS and HL, whereas GD produced highest seed yield at $90 \mathrm{~cm}$ plant spacing. The differences in total seed yield, seed size, and confectionery seed quality, as influenced by plant density and seed source, were also characterized.

\section{High-density Planting System with Nursery Plants by Cutting of Tomato}

Seung-Ku Yang ${ }^{1}$, Kyong-Ju Choi ${ }^{2}$, Soon-Ju Chung ${ }^{3}$, Wol-Soo Kim*4

${ }^{1}$ Jeollanamdo Agricultural Research-Extension Services, Dept. of Horticulture, Naju, Jeonnam, 542-715, South Korea; ${ }^{2}$ Jeollanamdo Agricultural Research-Extension Services, Dept. of Horticulture, Naju, Jeonnam, 542-175, South Korea; ${ }^{3}$ Chonnam National Univ., Dept. of Horticulture, Gwangju, 500-757, South Korea, ${ }^{4}$ Chonnam National Univ., Dept. of Horticulture, Gwangju, 500-757, South Korea

In order to cultivate tomato of the first fruit cluster harvest a lot of nursery plants were required as much as 75,000 to 100,000 plants per hectare in green house in Korea. Therefore, it needs too many expenses to buy tomato seeds. This study was carried out to confirm the possibility of alternative use of the tomato cuttings instead of tomato seedlings of two varieties. The cutting materials of each node were taken from the suitable transplanting tomato seedling nursery plants in commercial green house. Four to five nodes of seedling nursery plants were cut into plug tray with 50 to 128 cells, 23 to $80 \mathrm{~mL} /$ cell in cell capacity. At 5 days after cutting rooting was initiated and the rooted plants could be transplanted as cutting nursery plants. The cutting nursery plants of Rockusanmaru and Momotarou-yoku varieties were planted to the perlite media in hydroponics bench in green house with 111,110 plants/ha (90 $\mathrm{cm} \times 10 \mathrm{~cm}$ ) in planting density at 8 May 2002 . The matured fruits were harvested from 9 July through 26 July 2002 . The number of harvested fruits was 2.9 to 3.3 for the two varieties. The fruit weight was 138 to $153 \mathrm{~g}$ for 'Rockusanmaru', and 127 to $146 \mathrm{~g}$ for 'Momotarou-yoku'. The cutting nursery plants of 'Rockusanmaru' showed higher fruit yields as much as 51.5 tons/ha than that of seedlings as 40.3 tons/ha. There was a similar result in 'Momotarou-yoku'. The duration from cutting to harvest of first fruit cluster was required 89 to 105 days, as well as 63 to 79 days from field planting to harvest. In conclusion the cultivation with tomato cutting nursery plants was considered as better effects in shorter periods in nursery raising and higher yields in comparison to conventional cultivation with seedlings. 
48 The Economical Management of Recirculation Solution and Development of Automatic Controlling Program for Hydroponics

\section{Jae-Woo Soh*1, Yong-Beom Lee ${ }^{2}$}

${ }^{1}$ Univ. of Seoul, Environmental Horticulture, Seoul, 130-743, Republic of Korea; ${ }^{2}$ Univ. of Seoul, Environmental Horticulture, Seoul, 130-743, Republic of Korea

Experiments were carried out to determine nutrient management system for butterhead lettuce 'Omega' and leaf lettuce 'Grand Rapids' in nutrient film technique (NFT), and to develop a rapid and reliable program for recirculation solution. The effects of controlling solutions with UOSL (Leaf Lettuce solution of the Univ. of Seoul, Korea; $\mathrm{NO}_{3}-\mathrm{N} \mathrm{10.55,}$ $\mathrm{NH}_{4}-\mathrm{N} 1.02, \mathrm{P} 2.0, \mathrm{~K} 6.7, \mathrm{Ca} 3.5, \mathrm{Mg} 2.0, \mathrm{SO}_{4}-\mathrm{S} 2.0 \mathrm{me} \cdot \mathrm{L}^{-1} ; \mathrm{Fe} 2.0, \mathrm{Cu}$ 0.1 , B $0.5, \mathrm{Mn} 0.3, \mathrm{Zn} 0.3$, Mo $0.05 \mathrm{ppm}$ ) were studied by greenhouse with managing by distilled water (DW), managing $\mathrm{pH}$ and $\mathrm{EC}(\mathrm{CM})$, managing by nutrient solution analysis $(\mathrm{MN})$, managing by nutrient solution with leaf analysis (ML). The $\mathrm{CO}_{2}$ assimilation, transpiration rate, relative chlorophyll contents, leaf color, fresh weight and dry weight were highest in MN control in the butterhead 'Omega' and in $\mathrm{MN}$ and ML control in the leaf lettuces 'Grand Rapids'. The highes relative growth rate (RGR) was in MN ML in the butterhead 'Omega' but those wasn't in the leaf lettuce 'Grand Rapids'. Calculation program of adjustable solution was based on the main works by Visual Basic 5.0 The developed program could select an automatic and passive process considering the type of fertilizers, run-off rate, nutrient concentration, and water volume, for calculation. All of them were done successfully by the fast and precise calculation program.

\section{Effect of Different Heat Periods on Fusarium oxysporum f. sp. melonis Survival and Viability}

Roney Ballinas-Cano ${ }^{1}$, Javie Farias-Larios², Mario Orozco-Santos ${ }^{3}$, J. Gerardo López-Aguirre*4, Emilio Sánchez-Arevalo ${ }^{5}$

${ }^{1}$ Universidad de Colima, Facultad de Ciencias Biológicas y Agropecuarias, Tecomán, Colima, 28100, México; ${ }^{2}$ Universidad de Colima, Facultad de Ciencias Biológicas y Agropecuarias, Tecomán, Colima, 28100, México; ${ }^{3}$ INIFAP, Campo Experimental Tecomán, Tecomán, Colima, 21800, México; ${ }^{4}$ Universidad de Colima, Facultad de Ciencias Biológicas y Agropecuarias, Tecomán, Colima, 28100, México; ${ }^{5}$ Universidad de Colima, Facultad de Ciencias Biológicas y Agropecuarias, Tecomán, Colima, 28100, México

Soil solarization is used for soil born pathogens control, as a result of temperature increase in soil, around $10^{\circ} \mathrm{C}$ higher than in not solarized soils. In Mexico, is mostly used to decrease cost to control of different diseases that affect to melon crop, one of them is caused by Fusarium oxysporum f. sp. melonis (L \& C) Snyder \& Hansen, which is characterized by wilt and yellowing in melon plants. The objective of this assay was to evaluate the effect of heat on infective capacity of $F$. oxysporum f. sp. melonis in melon plants and its reproduction capacity after to be under different periods of heat under laboratory conditions. Isolated was taken from melon plants from Carmelitas Ranch in the Colima Municipality. Inoculation was $1 \times 10^{-6}$ conidia concentration. Cloth bags, with $20 \mathrm{~g}$ of inoculated soil, were introduced at $9 \mathrm{~cm}$ depth in metallic pots (16 cm diameter and $18 \mathrm{~cm}$ depth) containing $4 \mathrm{~kg}$ of not inoculated soil during 24,48,72,96, and $120 \mathrm{~h}$, with 6 replications. After each period, $1 \mathrm{~g}$ was taken from the cloth bags used in heat treatments, later was diluted in $50 \mathrm{~mL}$ of distillated water, and petri dishes containing PDA, were inoculated with $1 \mathrm{~mL}$ from that dilution and inoculum viability was registered at $96 \mathrm{~h}$ after incubation. Parameters evaluated were: mycelium growth, propagule number, and conidia number. Results showed a positive effect to control of Fusarium oxysporum $\mathrm{f}$ sp. melonis, in treatments with a higher heat period, respecting to the control. Is necessary to evaluate this technique under field conditions during summer season.

\section{Effect of Soil Solarization on Wilt by Fusarium in Muskmelon (Cucumis melo L.) in Western Mexico}

Mario Orozco-Santos ${ }^{1}$, Javier Farias-Larios², J. Gerardo López-Agu-

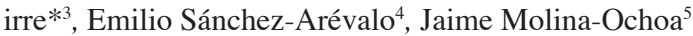

${ }^{1}$ INIFAP, Campo Experimental Tecomán, Tecomán, Colima, 28100, México; ${ }^{2}$ Universidad de Colima, Facultad de Ciencias Biológicas y Agropecuarias, Tecomán, Colima, 28100 México; ${ }^{3}$ Universidad de Colima, Facultad de Ciencias Biológicas y Agropecuarias, Tecomán, Colima, 28100, México; ${ }^{4}$ Universidad de Colima, Facultad de Ciencias Biológicas y Agropecuarias, Tecomán, Colima, 28100, México; ${ }^{5}$ Universidad de Colima, Facultad de Ciencias Biológicas y Agropecuarias, Tecomán, Colima, 28100, México

In Central Pacific region, Mexico, are cultivated around 17,000 ha of cucurbitaceous. This crops are affected by wilt, this disease is caused by Fusarium oxysporum (F.o.) Schlechtend. Some farmers are using resistant varieties to this disease, but resistance is different to each cultivar. Soil fumigation is other way to control this pathogen. Soil solarization is a new alternative for Fusarium oxysporum control. The objective of this research was to evaluate the effect of soil solarization on Fusarium oxysporum for wilt control in muskmelon crop in Colima State. The experiment was carried out under field conditions, using Cantaloupe melon (Cucumis melo L.) Cv. Ovation, in Ixtlahuacán municipality during November-December. Clear plastic was used (thickness 110). Evaluation of solarization periods were 0, 10, 20, and 30 days. Experimental design was full random blocks, with four replications. Evaluated variables were: soil temperature at 5-,10-, and 20-cm soil depth, propagule number of Fusarium oxysporum in soil, wilt incidence and yield. For determine Fusarium oxysporum survival, a strain isolated from infected plants was used. Fungi was introduced in cloth bags, containing 10 gr of sterile sand with $10 \mathrm{~mL}$ of a suspension of 19,000 conidia/mL. Later were introduced four cloth bags per treatment at 5-,10-, and $20-\mathrm{cm}$ soil depth. When plants were harvested, was taken the sick plants percentage. Results shown that soil solarization periods had not an effect on the propagule number at the soil depth for the solarization periods. Also soil solarization had not and effect on plant yield. Is necessary to do the same experiment during different season, as June-July or September- October, to have a higher soil temperature and humidity.

\section{Carotenoids and Quality of Watermelon as Affected by Deficit Irrigation and Growing Season}

\section{Haejeen Bang*1, Daniel I. Leskovar², Kilsun $\mathrm{Yoo}^{3}$}

${ }^{1}$ Texas A\&M Univ., Vegetable and Fruit Improvement Center, Dept. Hort. Sciences; ${ }^{2}$ Texas A\&M Univ., Texas Agr. Exp. Station, Dept. Hort. Sciences; ${ }^{3}$ Texas A\&M Univ., Vegetable and Fruit Improvement Center, Dept. Hort. Sciences

This experiment was conducted to determine the effects of deficit irrigation and growing season on fruit quality, carotenoid content and yield of red-, orange-, and yellow-fleshed diploid and triploid watermelon. Irrigation rates were 1.0 evapotranspiration (ET) and 0.5 ET. Diploid cultivars were Summer Flavor 710 (red), Tendersweet (orange), and Summer Gold (yellow). Triploid cultivars were Summer Sweet 5244 (red), Sunshine (orange), and Amarillo (yellow). Four-week old containerized transplants were planted in the field at TAES-Uvalde on 27 Mar. and 21 May 2003. Deficit irrigation imposed after plants were fully established reduced the individual fruit weight and size in the early planting. Soluble solids content (SSC) and firmness was not affected by irrigation rate in both plantings. SSC varied across cultivars and increased with maturity, particularly for the triploid cultivar Amarillo. In general, triploids were firmer than diploid cultivars. Total carotenoid content was not affected by irrigation during early planting. Diploid and triploid red-fleshed watermelon cultivars had significantly higher carotenoid content than orange- and yellow-fleshed cultivars. The major carotenoid was lycopene (more than $65 \%$ ), followed by prolycopene $(20 \%)$ and B-carotene $(7 \%)$.

\section{Interactive Effects of $\mathrm{K}$ and $\mathrm{B}$ on Tomato Shoulder Check, a Quality Defect in Fresh Market Tomato}

Jinsheng Huang*1, Sieglinde Snapp ${ }^{2}$

${ }^{1}$ Michigan State Univ., Horticultural Science, East Lansing, MI 48823; ${ }^{2}$ Michigan State Univ., Horticultural Science, East Lansing, MI 48824

Potassium (K) and boron (B) nutrition play an important role in control of tomato quality. To evaluate the interactive effects of $\mathrm{K}$ and $\mathrm{B}$ on yield and fruit quality in fresh market tomatoes, two-year field experiments were conducted in 2002 and 2003 in Southwest Michigan, using the industry standard cultivar 'Mountain Spring' and recommended practices for irrigated, staked fresh market production. Six treatments evaluated three fertilizer regimes applied during fruit development $(1 \mathrm{~N}: 1 \mathrm{~K}, 1 \mathrm{~N}: 2 \mathrm{~K}$ and $1 \mathrm{~N}: 3 \mathrm{~K}$ ) and two weekly $\mathrm{B}$ foliar sprays (none and $300 \mathrm{mg} \cdot \mathrm{L}^{-1} \mathrm{~B}$ ) 
at fruit set stage. Increasing $\mathrm{K}$ concentration in the fertilizer increased $\mathrm{K}$ content in both leaf and fruit tissue, but reduced calcium content in leaf tissue. $1 \mathrm{~N}: 3 \mathrm{~K}$ fertilizer treatment increased tomato shoulder check incidence. The overall total percent shoulder check defect was $32.7 \%, 33.5 \%$ and $38.2 \%$ for $1 \mathrm{~N}: 1 \mathrm{~K}, 1 \mathrm{~N}: 2 \mathrm{~K}$ and $1 \mathrm{~N}: 3 \mathrm{~K}$ fertilizers, respectively. Weekly $\mathrm{B}$ foliar spray increased both tomato marketable yield and fruit quality. Less shoulder check incidence was obtained with a foliar B spray. Boron foliar spray also increased $\mathrm{K}$ content in fruit tissue for $1 \mathrm{~N}: 1 \mathrm{~K}$ and $1 \mathrm{~N}: 2 \mathrm{~K}$ treatments. The $1 \mathrm{~N}: 2 \mathrm{~K}$ plus $\mathrm{B}$ foliar spray is recommended for improving tomato yield and quality.

\section{Productivity and Fruit Quality in Tomatoes Varieties Under Greenhouse Conditions in the Northwest of Mexico}

Raul Leonel Grijalva-Contreras*1, Ruben Macias-Duarte ${ }^{2}$, Manuel de Jesus Valenzuela-Ruiz ${ }^{3}$, Fabian Robles-Contreras ${ }^{4}$

${ }^{1}$ INIFAP-Caborca, Protected Horticulture, Caborca, Sonora, 83600, Mexico; ${ }^{2}$ INIFAPCaborca, Soil \& Horticultural, Caborca, Sonora, 83600, Mexico; ${ }^{3}$ INIFAP-Caborca, Viticulture, Caborca, Sonora, 83600, Mexico; ${ }^{4}$ INIFAP-Caborca, Agroclimatology, Caborca, Sonora, 83600, Mexico

The production of vegetables in Mexico under greenhouse conditions has been increased notably during the last years. Actually the area is about 1,250 ha. Tomatoes is the vegetables more important with $70 \%$. The objective of this experiment was to evaluate ten beef tomatoes varieties growing on soil medium and to choice those with high yield, fruit quality and disease resistant. The experiment was carried out on the Experimental Station (INIFAP-CIRNO) inside Polyethylene greenhouse. The soil characteristics are clay loam texture, electrical conductivity $\left(1.22 \mathrm{ds} \cdot \mathrm{m}^{-1}\right.$ and $\left.\mathrm{Ph} 7.96\right)$. The date seedling establishment on 25 Oct. 2003 (28 days after sow seed). The plant density used was of 3.78 plants per square meter. The harvest period occurred from 20 feb. Feb. 20 to 27 May and they were carried out an average of sixteen cutting. There were nonsignificant differences in yield and weight fruit among varieties. Yield varied from 26.2 and $19.2 \mathrm{~kg} \cdot \mathrm{m}^{-2}$. The varieties with more yield were Clarion, GC-29125, Attention, Thomas and Charleston with 26.2, 24.7, 24.4, 24.2 and $21.5 \mathrm{~kg} \cdot \mathrm{m}^{-2}$, respectively. Fruit weight varied from 96.5 to 174.0 grams per fruit. The important insect pests in this year were Leaf Miner (Lyriomyza sp.); Army worm (Heliothis op.) and white fly (Bemissia sp.) however, we have not recorded any important disease during this trial.

\section{Poster Session 29-Fruit Breeding}

July 19, 2004, 12:30-1:30 PM Rio Grande Exhibit Hall

\section{4 'Native Blue', a New Southern Ornamental (Vaccinium darowii) Blueberry Cultivar}

Stephen J. Stringer*1, Arlen Draper ${ }^{2}$, James M. Spiers ${ }^{3}$

${ }^{1}$ USDA ARS, Small Fruit Research Station, Poplarville, MS 39470; ${ }^{2}$ USDA ARS, Small Fruit Research Station, Poplarville, MS 39470; ${ }^{3}$ USDA ARS, Small Fruit Research Station, Poplarville, MS 39470

Ornamental blueberries are increasing in popularity in southern landscaping due to their attractive foliage and also since they provide food and serve as attractants to birds and other wildlife. 'Native Blue', tested as MS611, resulted from a cross of two native diploid Vaccinium darowii clones, Florida 4B X US 799. US 799 was selected from seedlings grown from open-pollinated seed collected by Dr. Paul Lyrene in Ocala National Forest, Florida. The Cross was made by Dr. Arlen Draper and selected in the greenhouse in 1987. Plants of 'Native Blue' are low growing, compact, and finely branched with small, glaucous leaves and are quite typical of V.darowii. In test plots in Mississippi, the plants set many small berries and after four years have have grown to a height of approximately 18 inches. Desireable characteristics include beautiful pastel foliage, hardy and vigorous plants producing much fruit that are attractive to native birds.
445 Segregation of Resistance to Root-knot Nematodes in a Vitis Nesbittiana Hybrid Population

Laurie E. Boyden*1, Peter Cousins ${ }^{2}$

${ }^{1}$ Cornell Univ., Plant Genetic Resources Unit, Geneva, New York, 14456; ${ }^{2}$ USDA-ARS, Cornell Univ., Plant Genetic Resources Unit, Geneva, New York, 14456

Development of rootstocks resistant to root-knot nematodes (Meloidogyne spp.) is a priority in grape breeding. The $N$ allele, present in Harmony and Freedom rootstocks, confers resistance to $N$-avirulent strains of Meloidogyne. Extensive planting of rootstocks containing $N$ has led to the development of $N$-virulent nematode strains, prompting a search for new resistance alleles. A seedling population derived from Vitis nesbittiana Comeaux was evaluated to investigate the genetic control of nematode resistance in this species. Hybridization with easily propagated rootstock selections will be required to utilize nematode resistance found in $V$. nesbittiana, a native of Mexico. The female parent of the population was $161-49 \mathrm{C}$, a $V$. riparia $\times$ V . berlandieri hybrid rootstock. 161-49C does not contribute nematode resistance to its progeny. The male parent was V. nesbittiana DVIT 2236.12, an accession held in the U.S. National Plant Germplasm system. Nematode resistance of the 161-49C $\times$ V . nesbittiana DVIT 2236.12 population was assessed in greenhouse pot culture. Seedling roots were stained in an eosin-Y solution six weeks after inoculation with $1500 \mathrm{~N}$-virulent $M$. arenaria juveniles. Resistance classes of seedlings were determined by assessing the degree of galling and number of egg masses per root system. Segregation in the seedling population was consistent with a $1: 1$ ratio of resistance to susceptibility, indicating that the $V$. nesbittiana accession is heterozygous for a dominant allele conferring resistance to $N$-virulent root-knot nematodes. The genetic relationship between this allele and the $N$ allele has yet to be determined.

\section{Correlation of Basal Node and Cluster Numbers in Grapevines} Peter Cousins*1

${ }^{1}$ USDA-ARS, Plant Genetic Resources Unit, Geneva, NY 14456

The grapevine shoot consists of nodes without clusters (inflorescences) basal to a zone in which leaf-opposed clusters are found at the nodes. Beyond the cluster zone leaf-opposed tendrils are borne at the nodes. The numbers and possible relationship of basal nodes and clusters are important in grapevine breeding and improvement. Basal node number influences cluster placement within the canopy, which relates to light penetration to the fruit and fruit maturation and to application of cultural practices, including harvest and cluster treatments. Cluster number is a primary yield component. Basal node and clusters numbers were counted on ten primary shoots each of forty grapevine (Vitis) accessions. The accessions analyzed are cultivars and wild species collections held in the United States National Plant Germplasm System. The correlation coefficient of the number of basal nodes and number of clusters was calculated using the means of the ten observations per accession. Basal node and clusters numbers were negatively correlated; the correlation coefficient was -0.763 , which is significant $(P<0.001)$. The negative correlation of basal node and cluster number has implications for grapevine improvement.

\section{Characterization of Apple Hybrids (Malus $\times$ domestica Bork.)}

Aroldo Isudro Rumayor Flores*1, Jose Antonio Vázquez Ramos², Martínez Cano Andres ${ }^{3}$, Borrego Escalante Fernando ${ }^{4}$

${ }^{1}$ Saltillo, Coahuila, 25230, Mexico; ${ }^{2}$ U.A.A.A.N., Horticultura, Saltillo, Coahuila, 25000, Mexico; ${ }^{3}$ U.A.A.A.N., Horticultura, Saltillo, Coahuila, 25315, Mexico; ${ }^{4}$ U.A.A.A.N., Fitomejoramiento, Saltillo, Coahuila, 25000, Mexico

In hybrids of apple (Malus $\times$ domestica Bork.) subjected to study phenological in Aguanueva, Coahuila, Mexico, their requirements of chill hours $(\mathrm{CH})$, heat units (HU), bud breaking flower and vegetative \% (BB) for good adaptation to warm milder climate, bloom period (BP), and vegetative period (VP), were determined using the Methodology of Identification of New Cultivars of Fruit Breeding (Ploudiv 1983). They were material with requirements of cold from 200 up to 650 $(\mathrm{CH})$ when they underwent a test of controlled conditions of $(\mathrm{CH})$. These materials are; AR-109 (200 CH), AR-106 (300 CH), AR-108 
(300 CH), AR- $147(300 \mathrm{CH}), \mathrm{AR}-144(550 \mathrm{CH})$, and AR-a60 (650 $\mathrm{CH})$, while the control Mutant Aguanueva II $(500 \mathrm{CH})$. Under winter conditions of the year 2000 with so slone $168.76(\mathrm{CH})$, some materials showed a bud break superior to the control. The bud break dates understand between 30 days before the witness Aguanueva II, as the hybrid AR-147 and 34 days later in the case of the hybrid AR-151, location this way to the materials as: Early with regard to the control; AR-16-S (24 days), AR-130 (14 days) and AR-147 (30 days). Similar to the control; AR-144, AR-103 and AR-127. Later than the control; AR-111 and AR-103-B. since they don't require spray bud breaking res compounds for their bud break and they have bloom period (BP) of 8 to 21 days. And when presenting low chill requirements they will be set fruit in a microclimate frost-free and growing and have their cultivation in a mild winter climate.

\section{8 'Shenandoah': A New Fire Blight-resistant Pear Cultivar}

Richard L. Bell*1, Tom van der Zwet ${ }^{2}$, Diane D. Miller ${ }^{3}$

${ }^{1}$ USDA, ARS, Appalachian Fruit Research Station, Kearneysville, WV 25430; ${ }^{2}$ USDA, ARS, Appalachian Fruit Research Station, Kearneysville, WV 25430; ${ }^{3}$ Ohio Agricultural Research and Development Center, The Ohio State Univ., Horticulture and Crop Science, Wooster, OH 44691

'Shenandoah' is a new European pear (Pyrus communis L.) cultivar which combines resistance to fire blight with fruit of excellent quality. The original seedling tree was selected in 1985 from a cross of 'Max Red Bartlett'x US 56112-146, and was tested under the original seedling number, US 78304-057. The fruit of 'Shenandoah' is pyriform in shape, and moderately large in size, averaging $72 \mathrm{~mm}$ in diameter and $92 \mathrm{~mm}$ in height. Skin color at harvest is light green, turning yellow-green when ripe. The skin finish is glossy, and $10 \%$ to $20 \%$ of the fruit surface is blushed red. There is light tan russet at the calyx. Lenticles are slightly conspicuous, and are surrounded by small, light brown russet. The stem is medium to long $(\approx 25 \mathrm{~mm})$, of medium thickness, and slightly curved. Harvest maturity occurs about four weeks after 'Bartlett', and the fruit will store in refrigerated $\left(-1^{\circ} \mathrm{C}\right)$ air storage for at least four monthswithout core breakdown or superficial scald. The flesh texture is moderately fine, juicy, and buttery. Grit cells are moderately small and occur primarily around the core and in a thin layer under the skin. The flavor is aromatic, similar to 'Bartlett', and is moderately acidic during the first two months of storage, becoming subacid after longer storage. The tree is moderate in vigor on 'Bartlett' seedling and ' $\mathrm{OHxF}$ 97' rootstocks, and upright-spreading in habit. Shenandoah' blooms in mid-season, similar to 'Bartlett'. Yield has been moderately high and precocious, and with no pronounced biennial pattern. Fire blight resistance is similar to 'Seckel', with infections extending no further than 1-year-old branches. Artificial blossom inoculations indicate a moderate degree of blossom resistance to fire blight infection.

\section{Poster Session 30-Postharvest}

\section{July 19, 2004, 12:30-1:30 PM Rio Grande Exhibit Hall}

\section{Qualitative and Quantitative Measures of Onion Bulb Firmness}

Troy A. Larsen*1, Christopher S. Cramer ${ }^{2}$

${ }^{1}$ New Mexico State Univ., Dept. of Agronomy \& Horticulture, Las Cruces, NM 88003; ${ }^{2}$ New Mexico State Univ., Dept. of Agronomy \& Horticulture, Las Cruces, NM 88003

Current onion varieties that are grown in New Mexico were developed for hand harvesting and not for mechanical harvesting. In order for onion production in New Mexico to remain a viable commodity, firmer onion varieties need to be developed for mechanical harvesting. In this study, bulb firmness of onions was examined in short and intermediate-day onion entries comparing a qualitative 'finger pressure' method with a digital FFF-series durometer. After harvesting and curing of the onion bulbs, dry outer scales were removed before durometer measurements were taken at two perpendicular points on the vertical center axis of the bulb. Following the durometer measurements, bulb firmness was rated by 'finger pressure' applied to multiple points on the vertical center axis.
For intermediate and late-maturing entries, durometer measurements and firmness rating were positively correlated in a strong fashion $(r=0.77$ to 0.87 ). Early maturing entries, NMSU 02-25 and NMSU 02-03 both had high durometer averages and firmness ratings. 'NuMex Crimson' and 'NuMex Crispy' had the highest durometer averages and firmness ratings among intermediate maturing entries while 'NuMex Solano' and NMSU 01-06 had the highest among late maturing entries. From our results, the durometer can be useful in providing a quantifiable measure of bulb firmness.

\section{Effects of Storage Conditions on Postharvest Qualities in Garlic Bulbs (Allium sativum L.)}

Sun-Tay Choi ${ }^{1}$, Ro-Na Bae*2, Dae-Sung Chung ${ }^{3}$, Seung-Koo Lee ${ }^{4}$

${ }^{1}$ National Horticultural Research Institute, Postharvest Technology Research Team, Suwon, Korea; ${ }^{2}$ College of Agriculture and Life Science, Seoul National Univ., National Instrumentation Center for Environmental Management, Suwon, Korea: ${ }^{3}$ National Horticultural Research Institute, Postharvest Technology Research Team, Suwon, Korea; ${ }^{4}$ College of Agriculture and Life Science, Seoul National Univ., Dept. of Plant Science, Seoul, Korea

To investigate quality changes of garlic associated with cultivars and storage conditions, northern type 'Seosan' and sub-tropical type 'Daeseo' garlics were stored at controlled atmosphere $\left(\mathrm{O}_{2} 3 \%, \mathrm{CO}_{2} 5 \%,-1\right.$ $\pm 1^{\circ} \mathrm{C}$ ) condition, low temperature $\left(-1 \pm 1^{\circ} \mathrm{C}\right)$, and room temperature $\left(20 \pm 5^{\circ} \mathrm{C}\right)$. The rate of sprouting, weight loss, enzymatic pyruvic acid content, and degree of greening in crushed garlic were determined during storage. The rate of sprouting was higher in 'Daeseo' than in 'Seosan' garlic in all storage conditions. Sprouting was effectively suppressed in low temperature and controlled atmosphere storage. Weight loss in 'Daeseo' garlic was higher than in 'Seosan' garlic. Enzymatic pyruvic acid (EP) contents increased for 3 months storage period, and then decreased gradually as the storage period was prolonged at room or low temperatures. However, EP content decreased dramatically during storage under CA condition in both cultivars. When garlic bulbs were crushed, greening appeared in the garlic stored at low temperature for more than one month. However, greening did not occur in the crushed garlic bulbs stored in CA condition.

\section{Physiological and Microbiological Characteristics of Fresh- cut Cucumber Stored in CA/MAP in Relation to High CO Atmosphere}

Hidemi Izumi ${ }^{* 1}$, Moritoshi Tachibana ${ }^{2}$, Chika Yamamoto ${ }^{3}$, Mio Nagano

${ }^{1}$ Kinki Univ., School of Biology-Oriented Science and Technolgy, Naga, Wakayama, 649-6493, Japan; ${ }^{2}$ Kinki Univ., School of Biology-Oriented Science and Technolgy, Naga, Wakayama, 649-6493, Japan; ${ }^{3}$ Kinki Univ., School of Biology-Oriented Science and Technolgy, Naga, Wakayama, 649-6493, Japan; ${ }^{4}$ Kinki Univ., School of Biology-Oriented Science and Technolgy, Naga, Wakayama, 649-6493, Japan

Fresh-cut cucumber slices were stored at 10 and $20{ }^{\circ} \mathrm{C}$ in high $\mathrm{CO}_{2}$ controlled atmospheres $(5 \%, 10 \%$, and $20 \%)$ or in MAP of OPP nonperforated and perforated with 50 micro $\mathrm{m}$ pores (P-plus) films. In CA storage, respiration rates and surface yellowing of slices were reduced by high $\mathrm{CO}_{2}$ atmospheres at $10^{\circ} \mathrm{C}$, but increased with increasing $\mathrm{CO}_{2}$ levels at $20^{\circ} \mathrm{C}$. Counts of mesophiles, psychrotrophs and coliform group on slices stored at $10{ }^{\circ} \mathrm{C}$ were not affected by high $\mathrm{CO}_{2}$, except lactic acid bacteria, which the counts increased when stored in $20 \%$ $\mathrm{CO}_{2}$. At $20^{\circ} \mathrm{C}$, all bacterial counts were higher with slices in $10 \%$ or $20 \% \mathrm{CO}_{2}$ than those in air or $5 \% \mathrm{CO}_{2}$. For MAP study, the used films were non-perforated OPP films $\left(1170 \mathrm{~mL} / \mathrm{m}^{2} /\right.$ day $/$ atm, $\mathrm{O}_{2}$ permeability $)$ and P-plus films having high $\left(51000\right.$ and $74000 \mathrm{~mL} / \mathrm{m}^{2} /$ day $/$ atm for storage at 10 and $20^{\circ} \mathrm{C}$, respectively) and low $(17000$ and $51000 \mathrm{~mL} /$ $\mathrm{m}^{2} /$ day/atm for storage at 10 and $20^{\circ} \mathrm{C}$, respectively) $\mathrm{O}_{2}$ permeability. Cucumber slices were stored in MAP for 7 days at $10{ }^{\circ} \mathrm{C}$ and 2 days at $20{ }^{\circ} \mathrm{C}$. The $\mathrm{CO}_{2}$ accumulated to $17.5 \%$ and $30 \%$ and $\mathrm{O}_{2}$ depleted to 2.5 and $3 \%$ at 10 and $20^{\circ} \mathrm{C}$, respectively, in the non-perforated OPP film packages. Ethylene accumulated only in non-perforated OPP films at both temperatures. Growth of coliform group at $20{ }^{\circ} \mathrm{C}$ and lactic acid bacteria at 10 and $20^{\circ} \mathrm{C}$ was greater in slices packaged in non-perforated OPP films than in P-plus films, while growth of mesophiles and psychrotrophs was similar in any packaging films. At the end of storage period, the bacteria isolated frequently from cucumber slices were Enterobacteriaceae and plant pathogenic bacteria. Lactic 
acid bacteria such as Leuconostoc citreum were detected on slices in non-perforated OPP films.

260 Storage of Zapote Mamey Fruit under Controlled Atmosphere Arturo Martínez-Morales ${ }^{1}$, Iran Alia-Tejacal*2, María-Teresa Colinas-León ${ }^{3}$, María-Teresa Martínez-Damián ${ }^{4}$

${ }^{1}$ Instituto Tecnológico de Villahermosa, Instituto Tecnológico de Villahermosa, Villahermosa, Tabasco, 86010, México; ${ }^{2}$ Universidad Autónoma del Estado de Morelos, Facultad de Ciecias Agropecuarias, Cuernavaca, Morelos, 62210, México; ${ }^{3}$ Universidad Autónoma Chapingo, Depratamento de Fitotecnia, Texcoco, Estado de México, 56230 México; ${ }^{4}$ Universidad Autónoma Chapingo, Departamento de Fitotecnia, Texcoco, Estado de México, 56230, México

Zapote mamey fruit (Pouteria sapota) has a great potential for exportation, due to its organoleptic characteristics, however, very little is known about harvest technologies to increase its shelf life. So in this research, zapote mamey fruit from two harvest dates in the same year, were stored at $12{ }^{\circ} \mathrm{C}[95 \%$ relative humidity $(\mathrm{RH})]$ for 14,21 , and 28 days under controlled atmospheres $\left(10 \%\right.$ or $5 \% \mathrm{CO}_{2}+5 \% \mathrm{O}_{2}$ with balance of nitrogen), in addition, two groups of fruit were stored at the same temperature and time intervals, but with no controlled atmosphere (CA). Variables considered were: $\mathrm{CO}$ and ethylene production inmediately after transfer to ambient conditions $\left(29^{\circ} \mathrm{C} \pm 2{ }^{\circ} \mathrm{C} ; 85 \% \mathrm{RH}\right)$. Control fruit from both harvest dates had a typical climacteric behaviour, ripening 2 to 3 days after transfer to ambient temperature. Fruit from the first harvest date, stored for 14 and 21 days under CA had a ripening process similar to the control, however fruit stored for 28 days fail to ripen even after 6 days at ambient temperature. Fruit from the second harvest date did not show this ripening problem.

261 Sensory and Analytical Analyses of Fruit Quality Constituents of Fresh-cut Orange- and Green-fleshed Honeydews and Orangefleshed Cantaloupe

Robert A. Saftner*1, Judith A. Abbott ${ }^{2}$, Gene E. Lester ${ }^{3}$

${ }^{1}$ USDA, ARS, Produce Quality and Safety Laboratory, Beltsville, MD $20705 ;{ }^{2} \mathrm{USDA}, \mathrm{ARS}$, Produce Quality and Safety Laboratory, Beltsville, MD 20705; ${ }^{3}$ USDA, ARS, Subtropical Agricultural Research Center, Weslaco, TX 78596

New fresh-cut melon products prepared from orange-fleshed honeydews have recently become available in retail markets. We compared fresh-cut chunks of orange-fleshed honeydew ('Temptation' and four breeding lines), green-fleshed honeydew ('Honey Brew'), and cantaloupe ('Cruiser'). All genotypes had similar respiration and ethylene production rates and soluble solids contents: genotype means for soluble solids contents were between $9.4 \%$ and $10.1 \%$. Five hundred untrained consumers preferred the flavor, texture, and overall eating quality of the orange honeydews to the green cultivar, with 'Temptation' scoring highest. 'Temptation' chunks were less firm at the time of processing and after 12 days storage than chunks prepared from all other genotypes. The color of orange-fleshed honeydew chunks was intermediate between that of cantaloupe and green-fleshed honeydew and the color was maintained during 12 days storage. Total aromatic volatiles from juice extracts of orange-fleshed honeydew chunks was 1.2 to 4.7 times higher than that of green-fleshed honeydew extracts and volatiles from cantaloupe was $>4.8$ fold greater than extracts from 'Temptation' and $>9.3$ fold higher than that of other honeydew extracts. Many individual volatiles were identical in cantaloupe and honeydews; however, honeydew genotypes, particularly the orange-pigmented types, were distinctive from cantaloupe in having relatively high levels of various nonenyl and nonadienyl acetates of uncharacterized aromas. The results indicate that 'Temptation' and other orange-fleshed honeydews are a promising new melon type for fresh-cut processing.

262 Correlation of Increased Alternative Oxidase Gene Expression With Reduced Chilling Injury in Cold-stored Tomatoes (Lycopersicon esculentum)

Raymond Fung *1, Chien Wang ${ }^{2}$, David Smith ${ }^{3}$, Kenneth Gross ${ }^{4}$, Yang $\mathrm{TaO}^{5}$, Meisheng Tian ${ }^{6}$

${ }^{1}$ U.S. Dept. of Agriculture, Produce Quality and Safety Laboratory, Beltsville, MD 20705 2350; ${ }^{2}$ U.S. Dept. of Agriculture, Produce Quality and Safety Laboratory, Beltsville, MD
20705-2350; ${ }^{3}$ U.S. Dept. of Agriculture, Produce Quality and Safety Laboratory; ${ }^{4}$ U.S. Dept of Agriculture, Produce Quality and Safety Laboratory; ${ }^{5}$ Univ. of Maryland, Biological Resources Engineering Dept.; ${ }^{6} \mathrm{Mt}$. Albert Research Center, HortResearch

Methyl salicylate (MeSA) and Methyl jasmonate (MeJA) treatments increased chilling resistance of light red tomato (Lycopersicon esculentum cv. Beefsteak) and extended shelf life and fresh-cut quality. We previously showed induction of AOX expression by low temperature and that induction of AOX transcript by MeSA and MeJA is correlated with resistance against chilling injury in peppers. Here, we investigate tomato, which is genetically closely related to peppers and belongs to the same Solanaceae family. In particular, we used four EST tomato clones of AOX from the public database that belong to two distinctly related families, 1 and 2 defined in plants. Three clones designated as LeAOX1a, $1 \mathrm{~b}$ and $1 \mathrm{c}$ and the fourth clone as LeAOX2. Probes for these four genes were designed and Southern blotting done to confirm that they do not cross-hybridize. We will present data from Southern, Northern hybridization and RT-PCR to show: (1) gene copy number of each of these AOX members in the tomato genome; (2) gene-specific expression profiles in response to MeSA and MeJA in cold stored tomato; and (3) the relative transcript abundance of these four AOX genes.

\section{Supercritical Fluid Extraction of Limonoids from Grapefruit} Seeds

Jun Yu*1, Romeo Toledo², Rakesh Singh ${ }^{3}$, Leonard Pike ${ }^{4}$, Bhimanagouda Patil ${ }^{5}$

${ }^{1}$ Texas A\&M Univ., Horticulture; ${ }^{2}$ Univ. of Georgia, Food Science and Technology; ${ }^{3}$ Univ. of Georgia, Food Science and Technology; ${ }^{4}$ Texas A\&M Univ., Horticulture; ${ }^{5}$ Texas A\&M Univ.-Kingsville, Citrus Center

Grapefruit seeds were studied for the extraction of limonoids using supercritical $\mathrm{CO}_{2}$ extraction (SC-CO $)$ technique. Limonin aglycone was successfully extracted with $\mathrm{SC}-\mathrm{CO}$ directly from grapefruit seeds; and the limonin glycoside was extracted using $\mathrm{SC}-\mathrm{CO}_{2}$ and ethanol as co-solvent from the spent seeds after the extraction of limonin aglycone. In an effort to optimize the extraction conditions of limonin aglycone, pressure, temperature, time effects were investigated. Various times of extraction, $\mathrm{CO}_{2}$ flow rate and the feeding modes of $\mathrm{CO}_{2}$ were also employed to obtain the highest yield of limonin aglycone. Optimal conditions to achieve the highest limonin aglycone $(0.63 \mathrm{mg} / \mathrm{g}$ seeds $)$ were $48.3 \mathrm{MPa}, 50^{\circ} \mathrm{C}$ and $60 \mathrm{~min}$ with $\mathrm{CO}_{2}$ bottom feeding, flow rate about $5 \mathrm{~L} / \mathrm{min}$. The extraction conditions for limonin glycoside to achieve highest yield were further optimized. The highest extraction yield $(0.62$ $\mathrm{mg}$ limonin glycoside $/ \mathrm{g}$ seeds) were at $48.3 \mathrm{MPa}, 50^{\circ} \mathrm{C}, 30 \%$ molar fraction of ethanol $\left(\mathrm{X}_{\mathrm{Fth}}=0.30\right)$ and 40 min with $\mathrm{CO}_{2}$ top feeding, flow rate about $5 \mathrm{~L} / \mathrm{min}$. The results demonstrated that supercritical $\mathrm{CO}_{2}$ extraction of limonoids from grapefruit seeds, a citrus juice industry byproduct, has practical significance for commercial production.

\section{Postharvest Calcium Chloride Dips of Whole Tomato Fruit Reduce Postharvest Decay}

Mark A. Ritenour*1, Peter J. Stoffella ${ }^{2}$, Zhenli He ${ }^{3}$, Michael S. Burton ${ }^{4}$ ${ }^{1}$ Univ. of Florida, Indian River Res. \& Ed. Center, Horticultural Sciences Dept., Fort Pierce, FL 34945; ${ }^{2}$ Univ. of Florida, Indian River Res. \& Ed. Center, Horticultural Sciences Dept., Fort Pierce, FL 34945; ${ }^{3}$ Univ. of Florida, Indian River Res. \& Ed. Center, Fort Pierce, FL 34945; ${ }^{4}$ Univ. of Florida, Indian River Res. \& Ed. Center, Fort Pierce, FL 34945

Previous research suggests that treatment of sliced or vacuum-infiltrated tomato fruit with calcium chloride $\left(\mathrm{CaCl}_{2}\right)$ solutions may reduce decay, but no work on dipping whole tomatoes has been reported. In the present experiments, 'FL 47' tomato fruit were collected at the mature green or pink stage from a local packinghouse, held at 12.5 or $25.0^{\circ} \mathrm{C}$ overnight, and then dipped in solutions with $0.5 \%$ to $5 \% \mathrm{CaCl}_{2}$ with or without $150 \mathrm{ppm}$ sodium hypochlorite. Fruit were dipped for 1 to 4 minutes at temperatures ranging from 0 to $35^{\circ} \mathrm{C}$. Mature green fruit dipped in solutions with $0.5 \%$ and $1.0 \% \mathrm{CaCl}_{2}$ at $35^{\circ} \mathrm{C}$ had significantly lower rates of decay following storage at $12.5^{\circ} \mathrm{C}(90 \% \mathrm{RH})$ than the control ( $27 \%$ vs. $36 \%$ decay, respectively). These fruit were also significantly softer after 2 weeks of storage than control fruit $(0.85 \mathrm{~mm}$ vs. $0.74 \mathrm{~mm}$ deformation, respectively) and appeared to be slightly more ripe. Decay in fruit dipped in $2 \% \mathrm{CaCl}_{2}$ was not significantly different from the control, while fruit dipped in $3 \%$ to $5 \% \mathrm{CaCl}_{2}$ developed significantly 
more decay than control fruit. The $\mathrm{CaCl}_{2}$ treatments had no significant effect on decay of fruit treated at the pink stage and none of the treatments at $0{ }^{\circ} \mathrm{C}$ significantly affected postharvest decay. Dips in $2 \%$ to $5 \%$ $\mathrm{CaCl}_{2}$ significantly increased tomato peel calcium content after storage. Dipping time had no significant effect on peel calcium content.

265 Antioxidant and Ethylene-related Changes in 'Chandler' Strawberry Fruit as Influenced by Maturity

Floyd M. Woods*1, William A. Dozier, Jr. ${ }^{2}$, Robert C. Ebel ${ }^{3}$, David G. Himelrick ${ }^{4}$, Cecilia Mosjidis ${ }^{5}$, Raymond H. Thomas ${ }^{6}$, Bryan S. Wilkins ${ }^{7}$, James A. Pitts ${ }^{8}$

${ }^{1}$ Auburn Univ., Dept. of Horticulture, Auburn, AL 36849-5408; ${ }^{2}$ Auburn Univ., Horticulture, Auburn, AL 36849-5408; ${ }^{3}$ Auburn Univ., Horticulture, Auburn, AL 36849-5408; ${ }^{4}$ Louisiana State Univ., Horticulture, Baton Rouge, Louisiana, 70803-2120; ${ }^{5}$ Auburn Univ., Horticulture, Auburn, AL 36849-5408; ${ }^{6}$ Auburn Univ., Horticulture, Auburn, AL 36849$5408 ;{ }^{7}$ Auburn Univ., Horticulture, Auburn, AL $36849-5408 ;{ }^{8}$ Auburn Univ., Horticulture, Auburn, AL 36849-5408

The relationship between fruit maturation and accumulation of hydrogen peroxide $\left(\mathrm{H}_{2} \mathrm{O}_{2}\right)$, lipid peroxidation, ethylene $\left(\mathrm{C}_{2} \mathrm{H}_{4}\right)$ production, antioxidant activity (hydrophilic, lipophilic and total) and the antioxidant enzyme ascorbate peroxidase (APX, EC 1.11.1.11) in fruit pericarp tissue of 'Chandler' (Fragaria $\times$ ananassa Duch.) strawberry were measured. 'Chandler' fruit pericarp maturation and ripening were accompanied by a decline in $\mathrm{H}_{2} \mathrm{O}_{2}$ content early in fruit development followed by a rapid accumulation. An increase in membrane lipid peroxidation (thiobarbituric acid reactive substances, TBARS) coincided with accumulation of $\mathrm{H}_{2} \mathrm{O}_{2}$, which preceded a rise in $\mathrm{C}_{2} \mathrm{H}_{4}$ production. In general, antioxidant activity declined as fruit matured and ripened. APX enzyme activity increased by 2 -fold and peaked at the pink stage of development and then gradually declined with ripening. $\mathrm{H}_{2} \mathrm{O}_{2}$ may serve as a signal molecule to initiate the cascade of oxidative processes during maturation and ripening. APX enzyme activity during maturation and ripening was not substantial and thus, may not have a role in alleviating accumulation of $\mathrm{H}_{2} \mathrm{O}_{2}$ and subsequent events related to oxidative senescence in fruit pericarp. To our knowledge, this is the first study to present fractionated antioxidant activities (HAA, LAA and TAA) from strawberry pericarp as assessed by the ABTS + radical cation assay. A fundamental understanding of the mechanisms involved in the senescent related-oxidative changes during strawberry fruit ontogeny in relation to quality and nutrition is discussed.

\section{Glycoalkaloid and Chlorophyll Changes in Eight Potato Va- rieties Exposed to Light}

Francine Dickie ${ }^{1}$, Ron Voss ${ }^{* 2}$, Gyunghoon Hong ${ }^{3}$, Marita Cantwell ${ }^{4}$

${ }^{1}$ Univ. of California, Vegetable Crops, Davis, CA 95616; ${ }^{2}$ Univ. of California, Vegetable Crops, Davis, CA 95616; ${ }^{3}$ Univ. of California, Vegetable Crops, Davis, CA 95616; ${ }^{4}$ Univ. of California, Vegetable Crops, Davis, CA 95616

Red and white skin potatoes ('Cal Red', 'Cal White', 'Durango', VC1015, 'Yukon Gold', 'Latona',A94381, and 'Satina') were harvested from plots in commercial fields in Kern and San Joaquin Counties and at the Univ. California Research Center at Tulelake. After washing and sorting, potatoes were held in plastic trays in the dark (black plastic bags) or exposed to light ( $90 \mathrm{~cm}$ below cool-white fluorescent GE WattMiser $34 \mathrm{~W}$ bulbs, $\approx 1300 \mathrm{lux}$ ) at $20^{\circ} \mathrm{C}$. After $0,3,6$ and 9 days, potatoes were scored for appearance of greening ( 1 to 5 scale), evaluated for external color ( $\mathrm{L} * \mathrm{a} * \mathrm{~b} *$ color values), skin chlorophyll concentration, and glycoalkaloid concentrations. For the latter, freeze-dried slices of tuber were extracted and analyzed by colorimetry and HPLC for alpha-solanine and alpha-chaconine. Initial glycoalkaloid concentrations varied among cultivars, with ' $\mathrm{Cal}$ Red' consistently having the highest concentrations. Tubers stored in the dark had no or a slight increase in glycoalkaloid concentrations. Light exposure resulted in increased glycoalkaloid concentrations in all cultivars, but to varying degrees. Some varieties had negligible changes while others increased as much as eightfold. The average increase was $300 \%$. Generally, 'Cal White' had the largest light-induced increases in glycoalkaloids.
267 Physicochemical and Antioxidant Changes in Six Alabamagrown Blackberry Cultivars

Raymond H. Thomas ${ }^{1}$, Floyd M. Woods*2, William A. Dozier, Jr. ${ }^{3}$, Robert C. Ebel $^{4}$, Monte Nesbitt ${ }^{5}$, Brian S. Wilkins ${ }^{6}$, David G. Himelrick ${ }^{7}$

${ }^{1}$ Auburn Univ., Horticulture, Auburn, AL 36849-5408; ${ }^{2}$ Auburn Univ., Horticulture, Auburn, AL 36849-58408; ${ }^{3}$ Auburn Univ., Horticulture, Auburn, AL 36849-5408; ${ }^{4}$ Auburn Univ., Horticulture, Auburn, AL 36849-5408; ${ }^{5}$ Auburn Univ., Horticulture, Auburn, AL 36849-5408; ${ }^{6}$ Auburn Univ., Horticulture, Auburn, AL 36849-5408; ${ }^{7}$ Louisiana State Univ., Horticulture, Baton Rouge, LA 70803-2120

Blackberries are an excellent source of natural antioxidants. Fully ripened fruit of 'Apache', 'Arapaho', 'Chester', 'Loch Ness', 'Navaho', and 'Triple Crown' thornless blackberries were evaluated for their physicochemical and antioxidative activity. Differences in initial $\mathrm{pH}$, titratable acidity (TA), total soluble solids (TSS), TSS/TA ratio and soluble sugars (reducing sugar, sucrose, and total sugars) differed among cultivars. Differences among cultivars with respect to reduced ascorbic acid (AA) were established, but there were no differences in either oxidized ascorbic acid (DHA) or total ascorbic acid (TAA) content. Antioxidant activity was determined by ABTS radical cation procedure for fractionated crude fruit extracts and the cultivars varied in the parameters evaluated. Hydrophilic antioxidant activity (HAA) was not different among cultivars evaluated. In contrast, lipophilic antioxidant activity (LAA) and total antioxidant activity (TAA) differed. The results obtained in this study indicate that Alabama- grown blackberries vary in their quality indices and are an excellent source of natural antioxidants. Information compiled will assist in marketing, handling, postharvest storage of these fruit and serve as a guide to partial fulfillment of recommended daily dietary requirements.

\section{Postharvest Application of Riboflavin Enhances Red Color in Strawberry}

Adam Dale $^{1}$, Stoyan Prigozliev ${ }^{2}$, George Chu*3, Selim Kermasha ${ }^{4}$

${ }^{1}$ Dept. of Plant Agriculture, Univ. of Guelph, Simcoe, Ontario, N3Y 4N5, Canada; ${ }^{2}$ Univ. of Guelph, Dept. of Plant Agriculture, Simcoe, Ontario, N3Y 4N5, Canada; ${ }^{3}$ Univ. of Guelph, Dept. of Plant Agriculture, Guelph, Ontario, N1G 2W1, Canada; ${ }^{4}$ McGill Univ., Dept. of Food Science, Ste-Anne-de-Bellevue, Quebec, H9X 3V9, Canada

'Seascape' strawberries were harvested and treated with various concentrations of riboflavin and placed on a lab bench for $0,1,2,3$, or 4 days, respectively, in a cold room at $4{ }^{\circ} \mathrm{C}$. After each day, samples were taken and stored in a freezer at $-20{ }^{\circ} \mathrm{C}$ until they were evaluated for anthocyanins content. Both exogenously applied riboflavin and storage time increased cyaniding 3-glucoside and pelargonidin 3-glucoside in the strawberry fruits. This result indicates that riboflavin could be used to increase red color in strawberries destined for processing as well as be included as a vitamin supplement in the processed products.

\section{Poster Session 31-Ornamental Plant Breeding 2}

July 19, 2004, 12:30-1:30 PM

Rio Grande Exhibit Hall

\section{The Inheritance of Several Traits in Three Diploid Interspecific Rose Populations}

David Shupert*1, Natalie Anderson ${ }^{2}$, David Byrne ${ }^{3}$

${ }^{1}$ Texas A\&M Univ., Horticultural Sciences, College Station, TX 77843; ${ }^{2}$ Texas A\&M Univ., Horticultural Sciences; ${ }^{3}$ Texas A\&M Univ., Horticultural Sciences

Seedlings from three interspecific backcross rose populations derived from a $F_{1}$ population were used to study inheritance of several traits in roses. Three $\mathrm{F}_{1}$ plants (WOB13, WOB21, and WOB26) from the hybridization of the diploid parents Rosa wichuraiana and 'Old Blush' were backcrossed to 'Old Blush' to produced three populations to observe the segregation of several morphological and disease resistance traits. The segregating rose traits in the backcrosses are no prickles on stems, non-recurrent blooming habit, white single flowers, black spot resistance, and powdery mildew resistance present in the Rosa wichuraiana parent compared to prickles on stems, recurrent blooming habit, pink double flowers, black spot susceptible, and powdery 
mildew susceptible present in the 'Old Blush' parent. Visual data was collected for the segregating traits using color standards and rating scales as appropriate. The three populations expressed the segregating traits to varying degrees. Under the environmental conditions at College Station, Texas the population 'Old Blush' $x$ WOB26 had a greater expression of the traits for no prickles on stems, recurrent blooming habit, disease resistance to black spot, and disease resistance to powdery mildew, which are traits desired in breeding programs. The segregation of flower color (white/pink), and flower type (single, semi double, and double) were similar in all three populations.

\section{Pollen Viability of Clerodendrum}

Cary Hebert*1, Jeff Kuehny ${ }^{2}$, Charles Johnson ${ }^{3}$, Annina Delaune ${ }^{4}$

${ }^{1}$ Louisiana State Univ., Horticulture, Baton Rouge, LA 70803-2120; ${ }^{2}$ Louisiana State Univ., Horticulture, Baton Rouge, LA 70803; ${ }^{3}$ Louisiana State Univ., Horticulture, Baton Rouge, LA 70803; ${ }^{4}$ Louisiana State Univ., Horticulture, Baton Rouge, LA 70803

The genus Clerodendrum belongs to the family Verbenaceae of which there are over 400 tree, shrub, and vine species. Species of Clerodendrum vary in leaf size, shape and texture; inflorescence shape; and flower shape, size and color. There is commercial interest in developing hybrids with desirable floricultural attributes. Interspecific hybridization could be used to increase variability in flower color, inflorescence shape, plant vigor, leaf color and shape for selection. Pollen viability among species is in question because of absence of seed set on many selected plants. The need for assessing viability of pollen used is important in determining the strategies to be used in hybridization. Clerodendrum floribundum, C. speciosissimum, C. splendens, C. $\times$ speciosum $(C$. thompsonia $\times$. splendens) and $C$. quadriloculare grown in a greenhouse under natural daylight were used as pollen sources. Pollen was collected from recently opened anther, placed in a scintillation vial on ice, and brought into the laboratory. A peroxidase test, dehydrogenase test, and the fluorescein diacetate procedure were used to determine percent viability of pollen before, during and after anthesis for each Clerodendrumspecies.

\section{Stratification Methods for Rosa Germination}

\section{Natalie Anderson*1, David Byrne ${ }^{2}$}

${ }^{1}$ Texas A\&M Univ., Horticulture, College Station, TX 77843-2133; ${ }^{2}$ Texas A\&M Univ., Horticulture, College Station, TX 77843-2133

Poor germination in Rosa has been an obstacle to breeding programs for years. Rose breeders generally stratify rose seed under cool, moist conditions for 4-10 weeks by planting directly into the seedling flat/bed or in a small container followed by planting the germinating seed into the seedling flat/bed. This experiment used 9 genotypes and compared these two approaches combined with variations in the stratification media (sand, perlite, sphagnum moss and Sunshine Mix \#4). Over all stratification media and genotypes, germination was not influenced by whether the seed was stratified directly in the seedling flat/bed or in a small container. However, the process of transplantation of the delicate germinating seed from the small container to the flat/bed resulted in greater mortality of the germinating seedlings. he stratification media affected the germination of the rose seed. Sunshine Mix \#4 gave the best germination as compared to all other media types tested. As expected the germination of the genotypes varied greatly, ranging from $0.7 \%$ to $37.1 \%$.

\section{Comparison of Gamete Selection for Heat Stress and Cool Temperature Tolerance}

Leslie Blischak*1, Richard. E. Veilleux ${ }^{2}$

${ }^{1}$ Virginia Polytechnic Institute and State Univ., Horticulture ${ }^{2}$ Virginia Polytechnic Institute and State Univ., Horticulture

Gamete selection was examined as a breeding tool in developing Phalaenopsis hybrids that are more cool or warm temperature tolerant. Four pairs of hybrid cultivars of Phalaenopsis were cross-pollinated, and then exposed to two temperature extremes, $30^{\circ} \mathrm{C} / 25^{\circ} \mathrm{C}$ and $14{ }^{\circ} \mathrm{C} / 9$ ${ }^{\circ} \mathrm{C}$, during pollen tube development and subsequent fertilization. One of each pollinated orchid cultivar was placed in either of two growth chambers and exposed to an 11-h photoperiod with an irradiance of $180 \mu \mathrm{mol} \cdot \mathrm{m}^{-2} \cdot \mathrm{s}^{-1}$ and a relative humidity of $70 \%$ during the day and $50 \%$ at night for 3-7 days depending on the temperature treatment. The plants were returned to the greenhouse after the initiation of fruit set and the pods were collected after 150 days. Seeds collected from these treatments were surface-sterilized, placed on Phytamax medium and evaluated for protocorm development after 73 days on a thermogradient table ranging from 10 to $30^{\circ} \mathrm{C}$. For the first family for which reciprocal crosses were available, the number of protocorms per plate ranged from 0 in the coldest treatments to 290 at $28^{\circ} \mathrm{C}$. For cold pollinated seeds, protocorm development was optimum at 22 and $28{ }^{\circ} \mathrm{C}$ (means of 290 and 250 protocorms per plate, respectively) whereas the greatest protocorm development for warm pollinated seeds occurred at 20 ${ }^{\circ} \mathrm{C}$ (103 protocorms per plate). Of the 1471 total protocorms scored, 1095 were from cold pollinations, whereas 376 were from the warm pollinations. Additional replication is required to confirm the greater germinability of cold-pollinated seed at higher temperatures.

\section{Somaclonal Variation in Coreopsis grandiflora 'Domino'}

Brian W. Trader*1, Hope A. Gruszewski², Norman I. Barclift ${ }^{3}$, Richard E. Veilleux ${ }^{4}$, Holly L. Scoggins ${ }^{5}$

${ }^{1}$ Virginia Tech, Horticulture, Blacksburg, VA 24060; ${ }^{2}$ Virginia Tech, Bioinformatics; 3 _ ; Virginia Tech, Horticulture, Blacksburg, VA 24060; ${ }^{5}$ Virginia Tech, Horticulture, Blacksburg, VA 24060

Coreopsis grandiflora (tickseed) regenerates readily from leaf segments allowing the possibility to exploit somaclonal variation as a means to develop novel phenotypes. We used true leaves from in vitro seedlings of Coreopsis grandiflora 'Domino' grown on MS basal medium as explants in a series of experiments to evaluate the effect of media, leaf explant orientation, and genotype on shoot regeneration. Genotype accounted for most of the variation with two particular seedlings regenerating freely and eight others generally recalcitrant. From these two seedlings, designated $\mathrm{E} 2$ and $\mathrm{H} 2$, shoots were regenerated and acclimated to the greenhouse over a period of weeks. Once the plants had established $(\approx 6$ weeks after acclimatization) they were vernalized by moving them to a lighted bench (12-h photoperiod) in a walk-in cooler at $4{ }^{\circ} \mathrm{C}$. On transfer back into the greenhouse, the plants flowered within a few weeks; 15 of 175 somaclones were selected based on distinct differences in flower orientation and appearance. The selected somaclones were propagated by division and transplanted to the field in May 2002 in a randomized complete-block design with three-plant plots and three replications, to determine if the novel characteristics persisted through an additional propagation cycle. In the field, plant height, leaf dimension, flowering, and flower dimensions were scored in June-July 2003. Significant differences were found between somaclones and the original E2 and H2 similarly propagated seedlings for desirable (more petals per flower, greater flowering, shorter plants), undesirable (less flowering, smaller flowers), and neutral (narrower leaves, taller plants) traits.

\section{Poster Session 32-Teaching Methods}

July 19, 2004, 12:30-1:30 PM Rio Grande Exhibit Hall

\section{OASIS: Organic Vegetable Production Teaching Endeavor and Community Supported Agriculture Venture}

\section{Constance L. Falk ${ }^{1}$, Pauline $\mathrm{Pao}^{2}$, Christopher S. Cramer*3}

${ }^{1}$ New Mexico State Univ., Agricultural Economics and Agricultural Business, Las Cruces, NM 88003-0003; ${ }^{2}$ New Mexico State Univ., Agricultural Economics and Agricultural Business, Las Cruces, NM 88003-0003; ${ }^{3}$ New Mexico State Univ., Agronomy and Horticulture, Las Cruces, NM 88003-0003

In January 2002, an organic vegetable garden on the New Mexico State Univ. (NMSU) main campus was initiated to expose students to organic production practices and agricultural business management. The project named, OASIS (Organic Agriculture Students Inspiring Sustainability), is funded by a USDA Hispanic Serving Institution Grant and operated as a Community Supported Agriculture (CSA) venture. 
Students enroll in an organic vegetable production class during spring and fall semesters to help manage and work on the project. The CSA model of farming involves the sale of shares to members who receive weekly allotments of the farm's output. The objectives of the project are to provide students with a multi-disciplinary experiential educational opportunity, to investigate the feasibility of small scale organic drip irrigated farming in the Chihuahuan desert, to demonstrate the CSA model to the local community, to trial vegetable varieties, and to provide a site where faculty can conduct research or student laboratory exercises. This is the first organic vegetable garden on the NMSU main campus, the first organic vegetable production class, and the first CSA venture in southern New Mexico. The project has grown about 230 varieties of vegetables, herbs, and flowers in the first two years of production, and has grossed at total of $\$ 32,000$ in revenues from both years on $2 / 3$ of an acre of land. In the first year, 32 members purchased 18.5 full share equivalents, and in 2003, 69 members purchased 39.5 full share equivalents.

\section{Can a Floral Design Lab Course Be Taught Effectively Using} Web-Based Delivery?

Sharon Henss*1, Jayne Zajicek ${ }^{2}$, R. Daniel Lineberger ${ }^{3}$

${ }^{1}$ Texas A\&M Univ., Horticulture, College Station, TX 77843-2133; ${ }^{2}$ Texas A\&M Univ., Horticulture, College Station, TX 77843-2133; ${ }^{3}$ Texas A\&M Univ., Horticulture, College Station, TX 77843-2133

The performance and satisfaction of students enrolled in a traditionally structured lecture/lab floral design course and a Web-based version of the same course were compared. Students were assigned randomly to course sections by available seating. Data collected included a demographic survey, design and course evaluations, and test grades. Significant differences were noted in class grades, with students in the traditionally taught course outperforming the Web-based students in both lecture and lab grades. Results from a survey instrument designed to determine whether students were suited to the distance learning environment (given only to the Web-based students) indicated a direct correlation between distance preparedness and course grades. A higher level of distance course preparedness correlated with a higher grade in the course. There was also a direct correlation between grades and whether the student was in the course with the delivery method they preferred. Students who were assigned to the course they preferred had significantly higher grades than students who did not. These results indicate that overall, a course such as floral design may be more effectively taught through traditional teaching techniques. However, certain students with adequate computer skills and a preference for Web-based courses may be successful in courses such as floral design.

\section{Using Digital Imaging to Enhance Learning in Undergraduate Plant Biology Courses}

Alice S. Waegel*1

${ }^{1}$ Neumann College, Biology, Aston, PA 19014

With grant funds for upgrading technology in undergraduate science laboratories, digital cameras and microscopes were acquired for use in undergraduate biology laboratories. The digital imaging equipment has been used to enhance student learning in both Bio 244 Plant Biology and Bio 480 Biology Independent Study. In the student research oriented independent study course, digital photo-microscopy with a Nikon Digital Still camera (DXM 1200) mounted on a Nikon Stereoscopic Zoom microscope (SMZ800) was used to illustrate a research project involving the effect of mycorrhizae fungi on root development of the shining club moss Huperzia lucidula. Digital photomicrographs of fungi isolated from the roots of H. lucidula collected in the wild were included in the student researcher's final PowerPoint report on the experiment. In Bio 244 Plant Biology the digital imaging equipment was used in a tree identification project. Students took Nikon Coolpix 995 cameras to a local arboretum (Tyler Arboretum, Media, $\mathrm{Pa}$.) where, after minimal instruction in camera operation, they took photographs of 10 trees for inclusion in a tree identification PowerPoint presentation. Each pair of students selected different trees from their peers, taking shots of overall habit, leaves, bark, and flowers/fruit if present. Photos were downloaded onto lab computers at the conclusion of the field trip. The students were then responsible for incorporating descriptive text and digital images into PowerPoint presentations shown to the class later in the semester. Students and professor participated in the grading process, using a rubric which students helped design. In the end of course evaluations, digital imaging projects were highly rated by students.

\section{Enhancing Students' Learning of High Technology in Hor- ticulture}

Kent D. Kobayashi*1

${ }^{1}$ Univ. of Hawaii at Manoa, Tropical Plant \& Soil Sciences Dept., Honolulu, HI 96822

How do we enhance students' learning experience and help them be aware of current and emerging technology used in horticulture? An undergraduate course on "Computer Applications, High Technology, and Robotics in Agriculture" was developed to address these needs. Its objectives were to familiarize students with the ways computers, high technology, and robotics are used in agriculture and to teach students how to design, build, and run a robot. The diverse topics included computer models and simulation, biosensors and instrumentation, graphical tracking and computer scheduling, new methods in plant ecology, automation and robotics, Web-based distance diagnostic and recommendation system, GIS and geospatial analysis, and greenhouse environmental control. An individual speaker presented one topic each week with students also visiting some speaker's labs. The students did active, hands on learning through assignments on computer simulations (STELLA simulation language) and graphical tracking (UNHFloraTrack software). They also built, programmed, and ran robots using Lego Mindstorms robotic kits. The course was evaluated using the Univ.'s CAFE system. There were also open-ended questions for student input. On a scale of 1 (strongly disagree) to 5 (strongly agree), mean scores of the 20 CAFE questions ranged from 3.71 to 4.75 with an overall mean of 4.22. When comparisons to other TPSS courses were possible, this course had a higher mean score for four out of seven questions. Course evaluations indicated this special topics course was important and valuable in helping enhance the students' learning experience.

\section{Multimedia Instrument for Greenhouse Education: Establish- ing Potential Clientele}

Milton E. Tignor*1, Gene A. Giacomelli², Tracy A. Irani ${ }^{3}$, Chieri Kubota $^{4}$, Margaret J. McMahon ${ }^{5}$, Sandra B. Wilson ${ }^{6}$, David A. Heleba

${ }^{1}$ Univ. of Vermont, Plant and Soil Science, Burlingtion, VT 05405-0082; ${ }^{2}$ The Univ. of Arizona, Dept. of Agriculture and Biosystems Engineering, Tucson, AZ 85719; ${ }^{3}$ Univ. of Florida, Dept. of Agricultural Education \& Communication, Gainesville, FL 32611-0540; ${ }^{4}$ The Univ. of Arizona, Dept. of Agriculture and Biosystems Engineering, Tucson, AZ 85719; ${ }^{5}$ Ohio State Univ., Dept. of Horticulture and Crop Science, Columbus, OH 43210 ${ }^{6}$ Univ. of Florida, Dept. of Environmental Horticulture, Fort Pierce, FL 34945-3138; ${ }^{7}$ Univ. of Vermont, Dept. of Plant and Soil Science, Burlington, VT 05405-0082

Currently, in the United States, the greenhouse industry covers more than 15,000 acres and is supported by a diverse number of firms with employee expertise that includes greenhouse manufacturing, engineering, irrigation, horticulture, IPM, sales, marketing, and business management. The growing greenhouse industry continues to be in need of highly trained undergraduates that have mastered an amalgam of scientific and business concepts necessary to be competitive in today's agricultural marketplace. Using a multidisciplinary approach we are creating a multimedia instrument for utilization in a variety of greenhouse related courses. This instrument ultimately will be available on the web for anyone to access. To ensure that our vision matches need, we have reviewed the courses offered throughout the United States at 1862, 1890, and 1994 land grant institutions. Course information collected includes; college, Dept., title, level, description, website (if available) and instructor e-mail (if available). Interestingly, there are at least 84 courses offering some aspect of greenhouse science in the U.S. Most are offered in Colleges of Agriculture or Engineering, but are housed in 17 diverse Dept.s. Examples include Dept.s of Horticulture Agronomy and Horticulture; Agricultural Biosystems and Engineering, Plant, Soil, and Entomological Science; and Horticulture, Forestry, Landscape \& Parks. This information will be utilized to focus the 
instructional design phase of the multimedia instrument, to contact current course instructors for feedback, and to frame future development of the resource.

\section{Integrating Horticulture into Middle School Science Curricu- lums to Satisfy Educational Standards}

Kathryn L. Karsh*1, Edward W. Bush ${ }^{2}$, Dianne M. Lindstedt ${ }^{3}$, Pam

\section{B. Blanchard ${ }^{4}$}

${ }^{1}$ Louisiana State Univ., Horticulture, Baton Rouge, LA 70803; ${ }^{2}$ Louisiana State Univ., Horticulture, Baton Rouge, LA 70803; ${ }^{3}$ louisiana State Univ., Louisiana Sea Grant College Program, Baton Rouge, LA 70803; ${ }^{4}$ Louisiana State Univ., Curriculum and Instruction, Baton Rouge, LA 70803

Louisiana requires schools to address designated educational standards at specific grade levels. Science is a challenging subject at the middle school level. A hands-on approach has been proven more effective than traditional classroom teaching. A program was developed by a cooperative effort between Louisiana Sea Grant and the LSU AgCenter Dept. of Horticulture within the Coastal Roots Nursery Program. Eight lesson plans were designed to meet 16 standards and 275 students in four schools. Pre- and post-test were given to each grade in addition to the Children's Attitude Toward Environment Scale (CATES). Additional pre- and post-test were given to classes not participating in the program. The evaluations tested both short and long term memory on material contained in the lesson plans. The data was analyzed by school, sex, and grade level.

\section{Development of an Air Quality Learning and Demonstration} Center at the Arboretum at Penn State

\section{John M. Skelly ${ }^{1}$, Don D. Davis² ${ }^{2}$ Dennis R. Decoteau*3}

${ }^{1}$ Penn State Univ., Dept. of Plant Pathology, Univ. Park, PA 16802; ${ }^{2}$ Penn State Univ., Dept. of Plant Pathology, Univ. Park, PA 16802; ${ }^{3}$ Penn State Univ., Dept of Horticulture, Univ. Park, PA 16802

An Air Quality Learning and Demonstration Center has been developed within the Arboretum at Penn State Univ.. The Center provides opportunities where students (of all ages) and teachers (grade-school through to classes within the Univ.) can learn about air quality as one of our most important natural resources. A seasonally interactive display of air quality monitoring instrumentation, self guided walkways through gardens of air pollution sensitive plant species, innovative techniques for demonstrating the effects of air pollutants on plants, displays of recent research findings, industry supported displays of pollution abatement technologies, and a teaching pavilion are within the Center. A Pennsylvania Dept. of Environmental Protection air quality monitoring station with ozone, sulfur dioxide, nitrogen oxides, carbon dioxide, $\mathrm{PM}<2.5 \mathrm{u}$ mass and speciation samplers, and a complete meteorological station provide data on the immediate environmental parameters. These data are relayed to an LCD crystal display board that has been mounted on the outside of the monitoring building; visitors are able to see the various measures of the air quality on a real time basis. Pannier type fiberglass display panels provide understandings of the various facets of air pollution formation and transport phenomena, air quality monitoring methods, the functions of open-top chambers, foliar symptoms expressed by pollution sensitive plants within the bioindicator gardens, and the impacts of pollution on agricultural and forested ecosystems. Handicapped accessible walkways lead visitors throughout the Center to the Teaching Pavilion that easily accommodates 80 persons. The pavilion is equipped with drop down curtains, electric power, and internet connections.

\section{Using Dreamweaver and WebCT to Support an Online Hor- ticulture Course}

Dennis J. Osborne ${ }^{* 1}$, Douglas C. Sanders², Leigh Jay Hicks³ ${ }^{3}$ Donna Petherbridge ${ }^{4}$

${ }^{1}$ NC State Univ., Horticultural Science, Raleigh, NC 27695-7609; ${ }^{2}$ NC State Univ., Horticultural Science, Raleigh, NC 27695-7609; ${ }^{3}$ Duke Univ., Divinity School, Durham, NC 27708; ${ }^{4}$ NC State Univ., Learning Technology Service/DELTA, Raleigh, NC 27695

The software package Macromedia Dreamweaver ${ }^{\mathrm{TM}}$ and learning management system $\mathrm{WebCT}^{\mathrm{TM}}$ are becoming de facto standards used to develop university distance education courses. NC State Univ. adopted these tools as part of its extensive support program for creating new distance courses, transforming existing classroom presentations into distance courses or upgrading existing distance courses. While production tools are becoming standardized, a "standard" course framework does not exist because most faculty believe that "no other course is like mine". However, initial course placement online and course maintenance thereafter would be facilitated if a standardized course framework could be adopted and widely implemented. We developed such a framework, readily adaptable to many courses, by using the Libraries feature in Dreamweaver $^{\mathrm{TM}}$ to create a model for easy navigation and standard course formatting for distance courses. Library items can be easily changed for use in different courses, and the entire framework can then be uploaded into WebCT ${ }^{\mathrm{TM}}$ for delivery to students . The model is used for several graduate level horticulture courses at NC State Univ.. Using this framework will allow any faculty member to easily fit his or her course into a replicable framework.

\section{University of Florida's Plant Medicine Program}

Robert J. McGovern*1

${ }^{1}$ Univ. of Florida-IFAS, Plant Medicine Program, Gainesville, FL 32611-0680

The Univ. of Florida's College of Agricultural and Life Sciences and Institute of Food and Agricultural Sciences have taken a bold step in teaching crop health management with the creation of the Plant Medicine Program. This innovative program offers students a multidisciplinary approach to solving the challenges of crop production that leads to the Doctor of Plant Medicine (DPM) degree. Extensive coursework in the Plant and Soil Sciences, Entomology, Plant Pathology, and Nematology provides students with the fundamental knowledge needed to be successful problem solvers and decision makers. Students apply their expertise to practical situations during multiple internships with a wide array of professionals. Interns have worked nationally and internationally on a wide variety of crops with private corporations, public institutions, and government and non-government agencies, in research, regulatory, and extension capacities. Students have the opportunity to tailor their program to reflect specific interests while maintaining a strong foundation in the discipline of Plant Medicine through the core courses. Since its inception in 1999, enrollment in the Plant Medicine Program has grown to over 40 students, and beginning in 2003, graduates have become valued members of the global agricultural community.

\section{Designing a Children's Garden for Experiential Learning in the South Carolina Botanical Garden}

Robert F. Polomski*1, Carri Carver Wallace ${ }^{2}$, Mary Taylor Haque ${ }^{3}$, Lisa K. Wagner ${ }^{4}$, James E. Arnold ${ }^{5}$, Amy D. Craddock ${ }^{6}$, Christian Maloney Cicimurri ${ }^{7}$, Lisa D. Chancellor ${ }^{8}$

${ }^{1}$ Clemson Univ., Horticulture, Clemson, SC 29634-0375; ${ }^{2}$ Clemson Univ., Horticulture, Clemson, SC 29634-0375; ${ }^{3}$ Clemson Univ., Horticulture, Clemson, SC 29634-0375; ${ }^{4} \mathrm{Clem}-$ son Univ., SC Botanical Garden, Clemson, SC 29634-0174; ${ }^{5}$ Clemson Univ., SC Botanical Garden, Clemson, SC 29634-0174; ${ }^{6}$ Clemson Univ., SC Botanical Garden, Clemson, SC 29634-0174; ${ }^{7}$ Clemson Univ., Bob Campbell Geology Museum, Clemson, SC 29634-0130; ${ }^{8}$ Clemson Univ., SC Botanical Garden, Clemson, SC 29634-0174

An interdisciplinary team of Clemson Univ. faculty, graduate students, and undergraduate students partnered with the South Carolina Botanical Garden staff and children from the "Sprouting Wings" after-school garden program to plan and design a 2.5-acre Children's Garden. Imaginative and educational, the plans call for a series of outdoor theme gardens. Proposals for 13 theme gardens include a "Dinosaur Dig", a "Food for Thought Garden", a "Hide-and-Seek Garden", a "Terraced Sitting Garden", an "Ethnobotany Garden", a "Wonders of Water Garden", a "Learning from Nature Outdoor Classroom", a "Carolina Fence Garden", a "Cottage Garden”, a "Bold View Butterfly Garden", a "Woodland Wonderland", a "Playful Plaza Garden," and an "Arbored Entrance and Exit Garden." Project methodology included research, case studies, site analysis, program development, preliminary plans, master plan, and individual garden designs with plan views, elevation drawings, detail drawings, and plant lists. Using an experiential learning 
pedagogy, a design class of 15 students contributed an estimated 2,000 hours of work while learning about landscape design. Results included 30 drawing boards depicting research, analysis, and design proposals, which were presented to the South Carolina Botanical Garden Staff for approval in Fall 2003. Note: This material is based upon work supported by the cooperative State Research, Education, and Extension service, U.S. Dept. of Agriculture, under Agreement No. 2002-38411-122122. Any opinions, findings, conclusions, or recommendations expressed in this publication are those of the authors and do not necessarily reflect the view of the U.S. Dept. of Agriculture.

\section{Poster Session 33-Vegetable Breeding 2}

\section{July 19, 2004, 12:30-1:30 PM Rio Grande Exhibit Hall}

\section{Cultivars Suitable for Watermelon Rind Pickles}

Gabriele Gusmini*1, Jonathan Schultheis ${ }^{2}$, Todd Wehner ${ }^{3}$

${ }^{1}$ North Carolina State Univ., Horticultural Science, Raleigh, NC 27695-7609; ${ }^{2}$ North Carolina State Univ., Horticultural Science, Raleigh, NC 27695-7609; ${ }^{3}$ North Carolina State Univ., Horticultural Science, Raleigh, NC 27695-7609

Salted or sweet pickles made from the rind of watermelon (Citrullus lanatus) fruit are commonly produced in North America, Europe, and Asia. Among growers and food processors, there is an increasing interest in identifying cultivars suitable for industrial production of watermelon rind pickles. Cultivars for pickling should have a thick, white rind (mesocarp). The objective of our study was to evaluate adapted watermelon cultivars for use in pickling. We measured rind thickness of cultivars in eight North Carolina trials conducted in 1995 to 2002. The top three cultivars for rind thickness ( 22 to $24 \mathrm{~mm}$ ) were Jubilee, Arriba and Charleston Gray (seeded), and Fantastik, Sweetheart and Triple Crown (seedless). Cultivars with the thinnest rind ( 7 to $8 \mathrm{~mm}$ ) were Emperor, Scarlet Trio, Tri-X-464 and Carnival.

\section{Evaluation of Altered Cucumber Plant Architecture as a Means to Reduce Phytophthora Fruit Rot}

\section{Kaori Ando*1, Rebecca Grumet ${ }^{2}$}

${ }^{1}$ Michigan State Univ., Horticulture, East Lansing, MI 48824; ${ }^{2}$ Michigan State Univ., Horticulture, East Lansing, MI 48824

Phytophthora capsici fruit rot is an increasingly serious disease affecting cucumber production throughout the Eastern U.S. The absence of genetically resistant cultivars and rapid development of fungicide resistance makes it imperative to develop integrated disease management strategies. Cucumber fruits which come in direct contact with the soil-borne pathogen are usually located under the canopy where moist, warm conditions favor disease development. We sought to examine whether variations in plant architecture traits that influence canopy structure or fruit contact with the soil make conditions less favorable for disease development. As a 'proof of concept' to test whether an altered canopy could facilitate $P$. capsici control, we tested the effect of increased row spacing and trellis culture on disease occurrence in the pickling cucumber 'Vlaspik.' Trellis plots indicated that removal of fruit contact from soil reduced disease occurrence. Currently available variation in plant architecture was tested using nearly-isogenic genotypes varying for indeterminate $(D e)$, determinate $(d e)$, standard leaf $(L L)$, and little leaf $(l l)$ traits. Although differences were observed in peak mid-day temperatures under the different canopies, there were not differences in disease occurrence among the genotypes. A collection of 150 diverse cucumber accessions identified to serve as a representative sample of the germplasm, was observed for possible variation in plant architecture. Variation was observed for an array of traits including main stem length, internode length, leaf length and width, and number of branches. Interesting types that may allow for more open canopies include reduced branching habit and compact/ bushy growth.
64 Inheritance of Resistance to the Watermelon Strain of Papaya Ringspot Virus in Watermelon

Nihat Guner*1, Zvezdana Pesic-VanEsbroeck ${ }^{2}$, Todd Wehner ${ }^{3}$

${ }^{1}$ North Carolina State Univ., Horticultural Science, Raleigh, NC 27695-7609; ${ }^{2}$ North Carolina State Univ., Plant Pathology, Raleigh, NC 27695-7616; ${ }^{3}$ North Carolina State Univ., Horticultural Science, Raleigh, NC 27695-7609

Sources of resistance to the watermelon strain of papaya ringspot virus (PRSV-W) have been identified within the watermelon (Citrullus lanatus) germplasm collection. Inheritance of resistance to papaya ringspot virus-watermelon strain was studied in three $C$. lanatus var. citroides accessions: PI 244017, PI 244019, and PI 485583. The susceptible parent lines 'Allsweet', 'Calhoun Gray', and 'New Hampshire Midget' were crossed with resistant accessions to develop $\mathrm{F}_{1}, \mathrm{~F}_{2}$, and $\mathrm{BC}_{1}$ generations for six families. A single recessive gene was found to control resistance to PRSV-W. The gene symbol 'prv' is proposed for PRSV-W resistance in watermelon. Additional work is needed to determine whether the genes in PI 244017, PI 244019, and PI 485583 are allelic for resistance to PRSV-W.

65 Even Though Applying SSD or Bulk Method in Breeding, Selection is Necessary With a Little Increasing Population

Zhoo-Hyeon Kim*1

${ }^{1}$ Gyeongsang Natl' Univ., Dept. of Horticulture, Jinju, 660-701, South Korea

On the process of plant breeding, SSD(single seed descendant) method and bulk method are sometimes considered as they need no selections till being done active selection. It should be tested it was right or not. One $\mathrm{F}_{2}$ population was used for 8 years - selection based on two ways of selection: one was selected only on fruit characteristics without considering any other characters, the other was selected with considering several for agricultural aspects, even though on only visual observations. Nineteen lines were selected: fifteen lines from the latter, four lines from the former; and grown under four different environments for evaluation, which method is better, and which line is best. The characters related to plant status (plant height, leaf) and fruit characteristics were recorded. For the selection of the best lines, three methods were applied: Anderson's Metroglyph Analysis method (1957), Finlay and Wilkinson's Adaptation Analysis method (1963), Grafius's Geometrical Interpretation method (1956). Different three groups of best lines were formed by the three methods, independently. But the best few lines were always included in the three best groups . Among the best few lines, all of four lines from all round selection were always included, but only very few lines from selecting based on only fruit characters. It means that all round selection is more successful Therefore, even though the selection method is SSD or Bulk method, it seems to be more reasonable to be selected lines based on observation on as many characters as possible, at same times with more lines, even if without any measuring, only with visual observation. If wanting only to progress generations without any selection, while hope to get available population, one should bred much more lines.

\section{Bulb Firmness of Hybrid Onions}

\section{Troy A. Larsen*1, Christopher S. Cramer ${ }^{2}$}

${ }^{1}$ New Mexico State Univ., Agronomy and Horticulture, Las Cruces, NM 88003; ${ }^{2} \mathrm{New}$ Mexico State Univ., Agronomy and Horticulture, Las Cruces, NM 88003

New Mexico onion production will begin using mechanical harvesters in the near future in order to stay competitive in today's market. Past onion breeding objectives have focused on improving onions for hand harvesting instead of mechanical harvesting. Our breeding program is starting to evaluate germplasm for bulb firmness. The objectives of this study were to evaluate hybrid lines for their bulb firmness, to compare two methods of measuring bulb firmness, and to compare bulb firmness using two different production schemes. Bulb firmness of spring-transplanted and spring-seeded intermediate-day hybrid breeding lines was measured using a digital FFF-series durometer and a subjective rating of firmness achieved by squeezing bulbs. Bulbs were rated on a scale of 1 (soft) to 9 (hard). In general, these hybrid lines produced very firm 
to hard onions whether the lines were transplanted or direct-seeded. Bulb firmness of these lines measured with the durometer was greater when the lines were direct-seeded (74.9) than when transplanted (73.5). Conversely, when firmness was measured with our subjective rating, transplanted onions exhibited slightly greater firmness (8.9) than directseeded onions (8.8). For both transplanted and direct-seeded onions, durometer readings were weakly correlated in a positive fashion with our subjective rating. In general, durometer readings gave a greater spread in firmness measurements with a range of 69.6 to 77.8 in firmness values. Subjective ratings of bulb firmness ranged from 8.5 to 9.0. Depending on the firmness of evaluated breeding lines, our subjective rating system should be adjusted to better distinguish firmness differences between bulbs.

\section{Trait Heritability Estimates of an Open-pollinated Onion Population}

Christopher S. Cramer*1

${ }^{1}$ New Mexico State Univ., Agronomy and Horticulture, Las Cruces, NM 88003-0003

Heritability estimates of bolting percentage (BP), pink root (PR) and Fusarium basal rot (FBR) incidences, and percentage of single centered (PSC) bulbs were calculated for an intermediate-day, open-pollinated onion population using selection response and half-sib (HS) family analyses. BP was determined by counting the number of seedstalks per plot when the population was seeded at an earlier planting date to induce bolting. PR and FBR incidences were determined by rating 30 bulbs/plot for the severity of PR and FBR, and calculated an incidence rate from the number of infected bulbs out of 30 rated. The PSC bulbs was determined by cutting transversely 30 bulbs at the vertical center of the bulb and looking for the presence of a single growing point or multiple growing points within $1.3 \mathrm{~cm}$ from the center of the bulb. Families were also evaluated for bulb quality that consisted of shape, size, maturity, firmness, number of scale layers, and dry outer scale thickness, adherence, retention, and color. Families were selected based upon an index that equally weighted BP, PR and FBR incidences, PSC bulbs, and bulb quality. No progress was made for BP even though the narrow sense heritability $\left(\mathrm{h}^{2}\right)$ estimate was 0.51. PR and FBR incidence was reduced by $18 \%$ and $12 \%$, respectively, and realized heritability $(\mathrm{RH})$ estimates of 0.65 and 0.60 , respectively, were calculated. $\mathrm{h}^{2}$ estimates calculated through HS family analysis was 0.46 and 0.37 , respectively, for these two traits. Very little progress was made for the PSC bulbs and this was reflected in a RH estimate of 0.17 . However, the $\mathrm{h}^{2}$ estimate was 0.71 , suggesting that progress should be possible.

\section{Heritability Patterns of Elastic and Viscoelastic Components of Tomato Firmness Derived from Intra- and Interspecific Genetic Backgrounds}

John R. Stommel ${ }^{1}$, Judith A. Abbott*2, David Francis ${ }^{3}$, Mary J. Camp ${ }^{4}$ ${ }^{1}$ USDA-ARS, Vegetable Laboratory, Beltsville, MD 20705-2350; ${ }^{2}$ USDA-ARS, Produce Quality and Safety Laboratory, Beltsville, MD 20705-2350; ${ }^{3}$ The Ohio State Univ., Dept. of Horticulture and Crop Science, Wooster, OH 44691; ${ }^{4}$ USDA-ARS, Biometrical Consulting Service, Beltsville, MD 20705-2350

Tomato fruit firmness is a key quality component of tomatoes produced for processing applications. Fruit firmness is generally considered a quantitatively inherited trait. Pericarp firmness of modern tomato cultivars is believed to be derived from a fairly narrow genetic background and is the result of the cumulative effort of numerous breeders over many years. Despite inferior phenotypes, wild species contain loci that can substantially increase tomato fruit quality. In the current study, inheritance of fruit firmness in firm and ultra-firm processing tomato germplasm developed from transgressive segregants of interspecific Lycopersicon esculentum $\times$ L. hirsutum and intraspecific L. esculentum crosses was characterized. Large-fruited breeding lines that varied in fruit firmness from soft to firm were identified for genetic analyses. A six-parent diallel of these advanced breeding lines was developed for field trials over multiple locations. Fruit firmness in the resulting 36 lines was determined by measuring fruit elastic properties during fruit puncture and compression. Following loading for compression, stress relaxation was recorded for $15 \mathrm{~s}$. A three-parameter model was used to fit the relaxation curves. There was little correlation between firmness (maximum force) and the three relaxation parameters, i.e., firmness measured the elastic component and the relaxation parameters measured the viscous portions of the texture. General and specific combining ability for firmness derived from the respective genetic backgrounds was determined. Genetic variance components for fruit firmness were estimated using a diallel analysis and narrow sense heritability was measured using parent-offspring regression.

\section{Identification of Specialty Potato Selections with High Anti- oxidant Activity}

Lavanya Reddivari*1, Anna L. Hale ${ }^{2}$, Douglas C. Scheuring ${ }^{3}$, J. Creighton Miller, Jr. ${ }^{4}$

${ }^{1}$ Texas A\&M Univ., Dept. of Horticultural Sciences, College Station,, TX 77843-2133; ${ }^{2}$ Texas A\&M Univ., Dept. of Horticultural Sciences, College Station, TX 77843-2133; ${ }^{3}$ Texas A\&M Univ., Dept. of Horticultural Sciences, College Station, TX 77843-2133; ${ }^{4}$ Texas A\&M Univ., Dept. of Horticultural Sciences, College Station, TX 77843-2133

In recent years, much emphasis has been placed on functional/antioxidant properties of various fruits and vegetables and their contribution to human health. Since average per capita consumption of potatoes in the United States is about 137 pounds, even moderate levels of antioxidants could be viewed as an important human health benefit. Variation in antioxidant activity has not been extensively investigated for colored potatoes (specialty selections). Therefore, the objective of this study was to evaluate antioxidant activity of specialty selections from the Texas Potato Variety Development Program and identify elite lines to use in breeding for improvement of this trait. Potato tubers were also assessed for their outer appearance, skin color, flesh color, spoilage and yield characteristics. Specialty potato selections (320 lines) were screened for total antioxidant activity using the 2,2-Diphenyl-1-picrylhydrazyl (DPPH) assay. After an initial screening, the top $10 \%$ of selections were reevaluated in the following year. Significant $(P \leq 0.01)$ differences were found among selections and, for some selections, differences were found between seasons. Total antioxidant activity ranged from $27 \mu \mathrm{g} / \mathrm{gfw}$ to $832 \mu \mathrm{g} / \mathrm{gfw}$. The specialty selection CO112F2-2 (purple flesh) had the highest antioxidant activity ( $832 \mu \mathrm{g} / \mathrm{gfw})$ irrespective of season. In most cases, purple flesh selections produced the highest antioxidant activity, probably due to the presence of anthocyanins, followed by yellow selections.

\section{Poster Session 34-Floriculture 2}

\section{July 19, 2004, 12:30-1:30 PM Rio Grande Exhibit Hall}

\section{Assessing Genetic Variability of Pelargonium Species Using PCR-based TRAP Markers}

Wai-Foong Hong ${ }^{1}$, Chang-Qing Bai $^{2}$, Michael Broe ${ }^{3}$, Jinguo $\mathrm{Hu}^{4}$, Charles Krause ${ }^{5}$, David Tay*6, Guo-Liang Wang ${ }^{7}$

${ }^{1}$ The Ohio State Univ., Dept. of Plant Pathology, Columbus, OH 43210; ${ }^{2}$ The Ohio State Univ., Ornamental Plant Germplasm Center, Columbus, OH 43210; ${ }^{3}$ The Ohio State Univ., Ornamental Plant Germplasm Center, Columbus, OH 43210; ${ }^{4}$ USDA-ARS Northern Crop Science Laboratory, Sunflower Research Unit, Fargo, ND 58105; ${ }^{5}$ USDA-ARS, Application Technology Research Unit, Wooster, OH 44691; ${ }^{6}$ The Ohio State Univ., Ornamental Plant Germplasm Center, Columbus, $\mathrm{OH} 43210 ;{ }^{7}$ The Ohio State Univ., Dept. of Plant Pathology, Columbus, OH 43210

Pelargonium is one of the important flower crops in USA. It is a priority genus for conservation at the USDA Ornamental Plant Germplasm Center (OPGC). It belongs to Geraniaceae family and comprises of about 280 species. To understand the genetic variation of the $\mathrm{Pel}$ argonium collection at OPGC, the PCR-based TRAP (target region amplified polymorphism) marker system which was newly developed in sunflower was used in this study. Twelve sets of primers were used to fingerprint 46 accessions representing 21 commercial $P$. hortorum, 17 scented geraniums and 8 other unidentified Pelargonium taxa. About 150 DNA bands could be detected in each primer and accession combination. Cluster analysis showed that molecular data was highly correlated with the phenotypes. Cultivars with similar morphological 
traits were clustered together. These results demonstrated that the TRAP system is a useful technique for the characterization and classification of Pelargonium collections.

\section{Plant Regeneration from Leaf of Streptocarpus $\times$ hybridus Voss. Cultured In Vitro}

Maria Cantor*1, Rodica Pop ${ }^{2}$, Ioana Pop ${ }^{3}$

${ }^{1}$ Univ. of Agricultural Sciences and Medicine Veterinary Cluj-Napoca, Horticulture/Floriculture, Cluj-Napoca, Cluj, 400372, Romania; ${ }^{2}$ Univ. of Agricultural Sciences and Medicine Veterinary Cluj-Napoca, Horticulture/ Biotechnology, Cluj-Napoca, Cluj, 400372, Romania; ${ }^{3}$ Univ. of Agricultural Sciences and Medicine Veterinary Cluj-Napoca, Horticulture/Informatics, Cluj-Napoca, Cluj, 400372, Romania

The Streptocarpus is propagated ease vegetatively from leaf cuttings all year round, but is grown on a very limited scale commercially in Romania. Successful protocol for direct shoot regeneration from in vitro Cape primrose (Streptocarpus $\times$ hybridus Voss.) leaf explants has been developed. The ease of tissue culture propagation can promote Streptocarpus production and facilitated the rapid introduction of this new species. Adventitious shoot regeneration was inducted in vitro on MS basal medium, using different concentration of NAA (1, $\left.1.5,2 \mathrm{mg} \cdot \mathrm{L}^{-1}\right)$ and cyokinin $\mathrm{TDZ}\left(0.1,0.5,1 \mathrm{mg} \cdot \mathrm{L}^{-1}\right)$. High frequency regeneration was obtained from leaves when cultured in the media supplemented with $1 \mathrm{mg} \cdot \mathrm{L}^{-1} \mathrm{NAA}$ plus $0.5 \mathrm{mg} \cdot \mathrm{L}^{-1} \mathrm{TDZ}$ and the percent of regeneration resulted is between $70 \%$ to $100 \%$. Complete plantlets were acclimatized and successfully transplanted to glasshouse conditions. The total duration of the cycle from leaf explants through complete plantlets was 10 weeks.

\section{Morphogenetic Response of Lilium michiganense to Four Auxins In Vitro}

Jim Ault ${ }^{* 1}$, Sandy Siqueira ${ }^{2}$

${ }^{1}$ Chicago Botanic Garden, Ornamental Plant Research, Glencoe, IL 60022; ${ }^{2}$ Chicago Botanic Garden, Ornamental Plant Research, Glencoe, IL 60022

Shoot, root, and callus induction were examined in the North American lily, Lilium michiganense, in response to treatment with four auxins. Seed from controlled crosses were aseptically excised from slightly immature capsules and cultured in vitro on Murashige and Skoog basal medium and vitamins with $30 \mathrm{~g} / \mathrm{l}$ sucrose, $7.0 \mathrm{~g} / \mathrm{l}$ agar, and a $\mathrm{pH}$ $=5.7$. Seed were maintained at $20^{\circ} \mathrm{C}$ with a 14 -h photoperiod. After 5.0-5.5 months, leaves and roots were removed from seedlings, the bulbs transversely sectioned, then the bulb sections cultured cut-surface down on the identical medium supplemented with 0.0, 1.0, 2.0, 4.0, or $8.0 \mu \mathrm{M}$ dicamba, picloram, K-NAA, or 2,4-D. PGRs were added to medium prior to autoclaving except dicamba which was dissolved in $50 \%$ ethanol and added after medium autoclaving. 16 explants were utilized for each treatment. The experiment was conducted three times. Morphogenetic response (\# of shoots produced, \% of explants forming roots, and \% of explants forming callus) was tabulated 4 months after treatment. Shoot formation was promoted by treatment with dicamba, picloram, and K-NAA in comparison to the control ( 2.5 shoots/explant). Shoot formation varied significantly in response to individual dicamba, picloram, and 2,4-D concentrations. Amaximum of 7.9 shoots per explant was promoted by $4.0 \mu \mathrm{M}$ K-NAA and $1.0 \mu \mathrm{M}$ dicamba, respectively. Root and callus formation also varied significantly between auxin treatments. Root formation was inhibited by dicamba, picloram, and $2,4-\mathrm{D}$ treatments in comparison with the control (100\% rooting); callus formation was promoted by dicamba, picloram, and K-NAA treatments in comparison with the control (15\% callusing).

\section{Developmental Anatomy of Adventitious Shoot Formation on Antirrhinum majus L. Hypocotyls In Vitro}

James S. Busse1, Monica Figueroa-Cabanas², Dennis P. Stimart*3

${ }^{1}$ Univ. of Wisconsin-Madison, Horticulture, Madison, WI 53706; ${ }^{2}$ Univ. of WisconsinMadison, Horticulture; ${ }^{3}$ Univ. of Wisconsin-Madison, Horticulture

Adventitious shoot formation in vitro from Antirrhinum majus L. hypocotyls was investigated using two inbred lines, the most and least regenerative lines selected from screening. Time course analysis indicated cell division in the most regenerative line occurred first in one or a small number of epidermal cells with periclinal and anticlinal divisions. Subsequently, cortical then vascular cells were recruited beneath the dividing epidermal cells. Once shoots formed, their vascular system was continuous with the original hypocotyl explant. The least regenerative line had no cell division directed toward organogenesis. Shoot formation on hypocotyls of A. majus was adventitious in origin, by direct organogenesis and genotype dependent.

Poster Session 35-Pomology/Temperate Tree Nut Crops

July 19, 2004, 5:00-6:00 PM Rio Grande Exhibit Hall

159 The Effect of IBA on Rooting of Semi-hardwood Cutting of Three Selected Local Olive Genotypes of Kermanshah Province, Iran

Alireza Talaie* ${ }^{*}$, Majid Zohouri ${ }^{2}$

${ }^{1}$ Univ. of Tehran, Horticulture, Karaj, Tehran, Iran; ${ }^{2}$ Univ. of Tehran, Horticulture, Karaj, Tehran, Iran

The experiment was carried out to study the effect of IBA hormones on rooting systems of selected local olive genotypes in Kermanshah province, Iran. This work was designed as a factorial experiment in a complete randomized block with three replications and 10 cuttings in each treatment. The effects of IBA hormone concentrations i.e.: 4000, 3000, 2000 and 1000 PPM in three selected local genotypes of bn42, dd9, D1, and Zard genotype as controlled were studied and compared. The results showed that the ultimate root length was obtained in genotypes bn42, D1, and Zard with application of 3000 PPM concentration and average numbers of roots in genotypes of bn42, dd9, and D1 with 4000 PPM concentration were observed. The average of the longest roots was found in genotype bn42, dd9, D1 and Zard with 3000 PPM concentration, and the average of the highest root number in bn 42 and Zard with the concentration of 3000 PPM in genotype dd9, and D1 with 4000 PPM concentration. The highest percentage of rhyzogenesis was observed genotypes of bn42 and dd9 with 2000 PPM concentration and in the genotypes D1 and Zard with 4000 PPM concentration. The average root length was increased consequently in genotypes bn42, D1, Zard, and dd9. The sequence of rhyzogenesis percentage was obtained in bn42, Zard, D1, and dd9. Dry weight percentage was also obtained in genotypes bn42, Zard, D1, and dd9, respectively.

160 Study of Some Morphological and Quantitative Properties in Native Olive Genotypes of Kermanshah Province, Iran, Using Cluster Analysis and Determining Their Seed Germination Percentage Alireza Talaie*1, Rasoul Akrami ${ }^{2}$

${ }^{1}$ Univ. of Tehran, Horticulture, Karaj, Tehran, Iran; ${ }^{2}$ Kermanshah Research Center, Horticutural Division

The objective of this study was the identification of existing olive trees in eight regions of Kermanshah province and investigation of their fruit, seed, and leaf characteristics in order to be used in the olive production industry of Iran. The germination ability of olive seed in field and nursery were also studied. In this research, 61 genotypes were identified and their characteristics were studied. It was found out that the present genotypes of Kermanshah showed different vegetative and reproductive growth based on the climatic and topographic conditions. This was verified by cluster analysis of the genotypes of different regions, which showed clearly their far and close relations. It was found out that some of the genotypes in the region spite of their appearance differences have same origin and most probably should be considered as the same genotype. The results also showed that favorable seed bed, planting depth and scarification of the seeds have positive effects on their germination while scarification of the seeds without other treatments had no significant effect on the seed germination. 
161 Crop Load and Shoot Type Affect Return Bloom of Pecans

Charles T. Rohla*1, Michael W. Smith², Niels O. Maness ${ }^{3}$, William R. Reid ${ }^{4}$

${ }^{1}$ Oklahoma State Univ., Horticulture \& Landscape Architecture, Stillwater, OK $74075 ;{ }^{2}$ Oklahoma State Univ., Horticulture \& Landscape Architecture, Stillwater, OK 74078; ${ }^{3}$ Oklahoma State Univ., Horticulture \& Landscape Architecture, Stillwater, OK 74078; ${ }^{4}$ Kansas State Univ., Horticulture, Forestry, \& Recreation Resources, Chetopa, KS 67336

Trees with about the same crop load were hand thinned to $1,<2$, or $<3$ fruit per cluster or not thinned while the ovule was about one-half expanded. Treatments were replicated three times. Vegetative, and bearing terminal, lateral and shoots with secondary growth were tagged in October, and flowering was determined the following year. Shoots and roots were sampled during dormancy and analyzed for organically bound N, and K. Results indicated that branches with secondary growth produced substantially more shoots and flowers than other branch types. The unthinned trees produced fewer total flowers per branch, had a lower percentage of branches with flowering shoots, and smaller flower clusters than thinned trees. Organically bound $\mathrm{N}$ in the roots and shoots was not affected by crop load. Crop load appeared to be negatively related to $\mathrm{K}$ concentration in roots $<1 \mathrm{~cm}$ in diameter, but not in roots $>1 \mathrm{~cm}$ in diameter. The data suggest that neither $\mathrm{N}$ nor $\mathrm{K}$ were limiting in trees with large crops.

\section{Effects of Fruit Cluster Size and Shoot Type on Selected Pecan Characteristics}

Charles T. Rohla*1, Michael W. Smith², Niels O. Maness³, William R. Reid ${ }^{4}$

${ }^{1}$ Oklahoma State Univ.,Horticulture \& Landscape Architecture, Stillwater, OK $74075 ;{ }^{2} \mathrm{Okla}$ homa State Univ., Horticulture \& Landscape Architecture, Stillwater, OK 74078; ${ }^{3}$ Oklahoma State Univ., Horticulture \& Landscape Architecture, Stillwater, OK 74078; ${ }^{4}$ Kansas State Univ., Horticulture, Forestry, \& Recreation Resources, Chetopa, KS 67336

Whole fruit clusters were collected from three shoot types: terminal and lateral shoots without secondary growth, and shoots with secondary growth. Fruit per cluster was counted and nuts were individually weighed, shelled and graded. Return bloom of the same shoots was measured. Results indicated that cluster size of lateral bearing shoots was negatively related to next year's average kernel weight, nut weight, and kernel percentage. However, only kernel percentage was related to cluster size on terminal bearing shoots, and none of these parameters were related to cluster size on shoots with secondary growth. Cluster size and total kernel weight per shoot were positively related for the three shoot types. Return bloom of terminal shoots was negatively related to cluster size, but cluster size did not affect return bloom of the other shoot types.

\section{Effects of Three Levels of Midday Stem Water Potential on Chandler Walnut Growth and Yield in California}

Richard P. Buchner*1, Allan Fulton², Bruce Lampinen ${ }^{3}$, Ken Shackel ${ }^{4}$, Terry Prichard ${ }^{5}$, Larry Schwankl ${ }^{6}$, Sam Metcalf ${ }^{7}$, Cayle Little ${ }^{8}$

${ }^{1}$ Univ. of California, Cooperative Extension, Red Bluff, CA 96080; ${ }^{2}$ Univ. of California, Cooperative Extension, Red Bluff, CA 96080; ${ }^{3}$ Univ. of California Davis, Pomology, Davis, CA 95616; ${ }^{4}$ Univ. of California Davis, Pomology, Davis, CA 95616; ${ }^{5}$ Univ. of California, Cooperative Extension, Stockton, CA 95205; 'Univ. of California Davis, LAWR, Davis, CA 95616; ${ }^{7}$ Univ. of California Davis, Pomology, Davis, CA 95616; ${ }^{8}$ Univ. of California Davis, Pomology, Davis, CA 95616

Ninth leaf California Chandler Walnuts (Juglans regia) on Northern California Black (Juglans hindsii) or Paradox (English/black hybrid) rootstock were irrigated to achieve three levels of Midday Stem Water Potential (MSWP). Target potentials were: 1) low water stress (average MSWP of -3.2 bars); 2) mild water stress (average MSWP of -6.2 bars); and 3) moderate water stress (average MSWP of -7.3 bars). Stem Water Potential was measured midday $(12-4 \mathrm{pm})$ by placing leaves inside water impervious, light blocking foil bags. Leaves remained bagged for at least ten minutes to achieve equilibrium. Bagged leaves were removed, placed inside a pressure chamber and stem water potential was measured at endpoint. Data are presented for the 2002 and 2003 seasons. Withholding irrigation water had a significant impact on 'Chandler' growth, productivity, and profitability particularly on young, vigorously growing trees. Chandler/Black appears to be more tolerant to water stress compared to Chandler/Paradox For Chandler on Paradox, water stress significantly reduced growth, yield, price per pound, percent edible kernel, and resulted in darker kernels. In addition, water stress significantly increased the total percent offgrade. Withholding irrigation does not appear to be a good strategy in young, vigorously growing 'Chandler' orchards. Mature trees and trees grafted onto Northern California black rootstock may be more tolerant of moisture stress.

\section{Manual and Chemical Inducement of Sylleptic Shoots in Apple} in the Fruit-tree Nursery

Stanislav Tojnko ${ }^{1}$, Zlatko Cmelik*2, Frane Strikic ${ }^{3}$

${ }^{1}$ Faculty of Agriculture Univ. of Maribor, Fruit growing, Maribor, 2000, Slovenia; ${ }^{2}$ Faculty of Agriculture Univ. of Zagreb, Pomology, Zagreb, 10000, Croatia; ${ }^{3}$ Institute for Adriatic Crops and Karst Reclamation Split, Fruit growing, Split, 21000, Croatia

The ability of various treatments to induce sylleptic shoot development of nursery trees of the apple 'Jonagold' and 'Golden Delicious' on rootstock M.9 was investigated. The leader management techniques were: removal of sub-terminal leaves, removal of sub-terminal leaves with application of $0.25 \%$ Paturyl $10 \mathrm{WSC}$ (6-benzyladenine), and treatment with $0.25 \%$ Paturyl 10 WSC (two times at 24 days interval); application of $20 \%$ Promalin (GA4+7) two times in 9 days interval; and control; starting when scion length was $75 \mathrm{~cm}$. Removal of sub-terminal leaves increased total branch length, but not stimulated the lateral branching. Treatments with Paturyl resulted in the lower tree height, in the higher number of branches, and in the greater branch length. Removal of sub-terminal leaves in combination with Paturyl increased the lateral shoot number even more than treatment only with Paturyl. Promalin increased branching, but had little influence on the total branch length. In addition, Promalin decreased branch crotch angles.

165 Effect of Rhodopseudomonas p. on Tree Growth and Fruit Quality of 'Niitaka' Pear

Yang-Key $\mathrm{Na}^{1}$, Kwang-Chul $\mathrm{Na}^{2}$, Byeong-Sam Kim³ ${ }^{3}$, Kyong-Ju $\mathrm{Choi}^{4}$, Gil-Ho Shin ${ }^{5}$, Wol-Soo Kim*6

${ }^{1}$ Jeollanamdo Agricultural Research and Extension Service, Dept. of Horticulture, Naju, Jeonnam, 542-175, South Korea; ${ }^{2}$ Chonnam National Univ., Dept. of Horticulture, Gwangju, 500-757, South Korea; ${ }^{3}$ Jeollanamdo Agricultural Research and Extension Service, Dept. of Horticulture, Naju, Jeonnam, 542-175, South Korea; ${ }^{4}$ Jeollanamdo Agricultural Research and Extension Service, Dept. of Horticulture, Naju, Jeonnam, 542-175, South Korea; ${ }^{5}$ Jeollanamdo Agricultural Research and Extension Service, Dept. of Horticulture, Naju, Jeonnam, 542-175, South Korea; ${ }^{6}$ Chonnam National Univ., Dept. of Horticulture, Gwangju, 500-757, South Korea

The objective of this study was to determine the effect of Rhodopseudomonas $p$., which isolated from domestic soil on the density of microorganism in soil, leaf and SSC in pear (Pyrus pyrifolia) fruit. The solution of Rhodopseudomonas $\mathrm{p}$. was sprayed over canopy and fertigated around trunk in 12-year-old 'Niitaka' pear with Y-training system. The spray and fertigation were performed 11 times at 15-day intervals from 22 Apr. to 22 Sept. with 200 times diluted solution (v/v). The width and length of treated leaf was increased by $1.4 \mathrm{~mm}$ and 0.9 mm compared to them of control. There was no difference in chlorophyll a content between treatments. The treatment increased SSC relatively to control by $0.7 \%$ and fruit firmness by 0.29 higher but there was no difference fruit weight. Hinter ' $L$ ' value was higher by 3.5 and Hunter 'a' lower by 0.2 compared to control so fruit color was more clean than control. In fertigation treatment, the density of microorganism and fluorescent bacteria in soil showed increasing tendency compared to control but the opposite in bacteria. These results suggested that the spray and fertigation of Rhodopseudomonas $p$. solution improve SSC and color of pear fruit.

166 Effect of Soluble Calcium and IBA Treatments on Fruit Characteristics and Browning of Blossom End Part in 'Fuyu' Sweet Persimmon

Wol-Soo Kim*1, Young Kim²

${ }^{1}$ Chonnam National Univ., Dept. of Horticulture, Gwangju, 500-757, South Korea; ${ }^{2}$ Chon- 
nam National Univ., Dept. of Horticulture, Gwangju, 500-757, South Korea

Sweet persimmon, 'Fuyu', is the major cultivar for MA storage, but browning of blossom end part (BBEP) and darkening are occurring during storage and decrease fruit qualities in fresh fruit markets in Korea. The symptom of BBEP of fruit started to occur on the blossom end part and spread to the middle and stem end part. These fruits lose their marketable values. Calcium has very important role in cell membrane in physical and physiological. This study was conducted to investigate the effect of soluble Ca treatments of fertigation (FG) and foliar application (FA) on soil properties, tree growth and fruit quality and on the occurrence of BBEP. Ca content was high in Ca FA and $\mathrm{Ca}$ + IBA FG compared to other treatments. This increase might affect the soil $\mathrm{pH}$, and so $\mathrm{pH}$ followed the same pattern of Ca content in soil. In leaves and fruits, $\mathrm{Ca}$ content was much higher in $\mathrm{Ca} \mathrm{Ca} F A$ and $\mathrm{Ca}+$ IBA, Ca FG, respectively. Ca content in fruit parts showed stem end part "middle part" blossom end part. In fruit quality, fruit firmness, soluble solid content and fruit weight did not show any tendency in treatments. The occurrence rate of BBEP was very low $14 \%$ in Ca FA and $20 \%$ in $\mathrm{Ca} F \mathrm{FG}$ than $50 \%$ in control. These results showed that $\mathrm{Ca}$ content in soil, leaves and fruits was increased by soil FG and FA and the increased $\mathrm{Ca}$ content in blossom end part have a negative relationship with BBEP in sweet persimmon.

\section{Performance of Pillar and Upright Form Peach Trees Grown in a Central Leader or Multiple Leader Orchard System at Vari- ous Planting Densities}

Stephen Miller*1, Ralph Scorza ${ }^{2}$

${ }^{1}$ Agricultural Research Service, Appalachian Fruit Research Station, U.S. Dept. of Agriculture, Kearneysville, WV 25430; ${ }^{2}$ Agricultural Research Service, Appalachian Fruit Research Station, U.S. Dept. of Agriculture, Kearneysville, WV 25430

Peach trees with a pillar (P) (columnar) or upright (UP) growth habit were planted at four in-row spacings $(1.5,2.0,4.0$, and $6.0 \mathrm{~m})$ in 1999 and trained to a central leader or multiple leader system to evaluate their performance in an orchard environment. A standard (S) form peach cultivar ('Harrow Beauty') was included for comparison. In this replicated study using a split-split-split plot design, one-half of the trees were summer pruned (SP) 6 weeks before harvest in each growing season from 2001 to 2003. Growth habit, tree spacing, and SP had a significant effect on tree growth and time necessary for dormant pruning. Growth habit and spacing also affected time required to summer prune. Total pruning time for all growth habits was significantly greater for SP trees compared to non-SP trees. Cumulative yields per tree were greater for UP and S habit trees than P trees over the first four seasons. Per tree yields increased as the in-row spacing increased but were decreased slightly by SP. UP trees consistently produced larger size fruit than P or $\mathrm{S}$ trees. Potential yields per ha and pruning times based on projected best tree spacings will be presented. UP form trees provide a good transition for growers going from low-density to high-density peach systems, with significant advantages in yield and fruit quality.

\section{Proper Management for Alternate Fan System in Asian Pear (Pyrus pyrifolia cv. Niitaka) Trees}

\section{Jae-Young Lee*1, Yong-Koo Kim², Hee-Seung Park}

${ }^{1}$ Bio Impact Co., Ltd., Research and Development, Seoul, 137-875, Korea Republic; ${ }^{2}$ Kyung Hee Univ., Dept. of Horticulture, Yongin, 449-701, Korea Republic; ${ }^{3}$ Chung Ang Univ., Dept. of Horticultural Science, Anseong, 456-756, Korea Republic

To maintain appropriate tree shapes for Asian pear trees, multi-leader system would be more suitable, which could be obtained from the proper training systems. Controlling apical dominance should be the major factor for tree shape management and this might be modified by branch bending or pruning methods. When the tree shape was managed with Alternate Fan System, too narrower branch angle depressed flower bud formation because of the vigorous shoot growth but too wider angle also decreased that formation because of the numerous water sprouts. The tree with 75 degrees of internally deviated angle performed superior result in fruiting process. Additionally, heading-back pruning could be another for water sprout emerging. For that reason, the severer headingback pruning stimulated the more water sprout emerging. The proper pruning method could be obtained by considering the relation between main stem width and sum of remained branch width.

\section{Renewal Method of Lateral Branches Using Water Sprouts in Japanese Apricot}

Yang-Key $\mathrm{Na}^{1}$, Byeong-Sam Kim², Kyong-Ju Choi ${ }^{3}$, Young Kim${ }^{4}$, Wol-Soo Kim*5

${ }^{1}$ Jeollanamdo Agricultural Research and Extension Service, Dept. of Horticulture, Naju, Jeonnam, 542-175, South Korea; ${ }^{2}$ Jeollanamdo Agricultural Research and Extension Service, Dept. of Horticulture, Naju, Jeonnam, 542-175, South Korea; ${ }^{3}$ Jeollanamdo Agricultural Research and Extension Service, Dept. of Horticulture, Naju, Jeonnam, 542-175, South Korea; ${ }^{4}$ Chonnam National Univ., Dept. of Horticulture, Gwangju, 500-757, South Korea; ${ }^{5}$ Chonnam National Univ., Dept. of Horticulture, Gwangju, 500-757, South Korea

Recently, the acreages Japanese apricot have been increased for being known of the medical functions. However, the increase of tree height, overgrowing trees and light deficiency at the bottom of canopy induced the poor fruit quality and higher labor charges. This study was conducted to assess the effects of training time, angle and length of water sprout on tree growth, the shoot-curbing, and the occurrence of new shoot for 2 years. Water sprouts were trained on 5 , and 25 June, and 15 July with three varying angles of $30^{\circ}, 45^{\circ}$ and $60^{\circ}$, and cut at three lengths $(50$, $80,110 \_$) after harvest. Compared to control, the treatment on June 25 showed the highest values of $76 \%, 82 \%$ of internode and shoot length respectiely. In the treatment of training angle, shoot length was $71 \%$ in both $30^{\circ}$ and $45^{\circ}$ but heavily limited to $36 \%$ in $60^{\circ}$ with comparing to control. The occurrence of shoots showed 18.1, 24.6, and 36.3 in treatment of 50,80 and $110 \mathrm{~cm}$, respectively, and in $80 \mathrm{~cm}$, the number of shoot with diameter more than $0.5 \mathrm{~mm}$, which is suitable for bearing mother branch, was higher. The best result was obtained in method of branch training with $45^{\circ}$ and heading-back $80 \mathrm{~cm}$ at height on 15 June for the renewal of lateral branch.

\section{Malformed Fruits in 'Niitaka' Pear Influenced by Pruning Strength, GA and Mepiquat Treatment}

Wol-Soo Kim*1, Jung-An $\mathrm{Jo}^{2}$

${ }^{1}$ Chonnam National Univ., Dept. of Horticulture, Gwangju, 500-757, South Korea; ${ }^{2}$ Chonnam National Univ., Dept. of Horticulture, Gwangju, 500-757, South Korea

This study was carried out to observe the effects of the pruning strength and the growth regulator on shoot growth and fruit shape in Pyrus pyrifolia $\mathrm{cv}$. Niitaka. GA paste (GA) was known as a promoter of malformed fruits, but Mepiquat as an inhibitor. Light pruning treatment, of which removed the half of lateral shoots, decreased leaf area, weight, thickness, and the length of shoots and internodes in comparison to severe pruning. The occurrence of calyx perpetual fruit (CPF) in fruitlet stage was higher about $45 \%$ in severe pruning than in light pruning. Light pruning decreased malformed fruit by $10 \%$ compared to severe pruning at harvest stage, but there was no difference in soluble solid content of fruits between two treatments. Also light pruning decreased fruit weight. GA paste treatment on 50 days after full bloom significantly increased fruit weight, but Mepiquat decreased. In treatment of Mepiquat and GA the occurrence of malformed fruit was $31.3 \%$ and $35 \%$, respectively and the index of symmetry was higher than control. Therefore, these results suggested that the light pruning has a positive effect on the production of symmetry fruit.

\section{Morphological Characteristics of Stone Cells in Fruit of Asian, European, and Chinese Pears}

\section{Wol-Soo Kim*1, Jin-Ho Choi ${ }^{2}$}

${ }^{1}$ Chonnam National Univ., Dept. of Horticulture, Gwangju, 500-757, South Korea; ${ }^{2}$ Chonnam National Univ., Dept. of Horticulture, Gwangju, 500-757, South Korea

The stone cells are observed in the process of lignifications of tissues in flesh of pear as a depressing factor of fruit quality. These studies were carried out to search the effect of stone cells on fruit quality, to investigate the anatomical characteristics, such as formative period and distribution of stone cell, to seek forming causes. During the growing seasons of 2002 and 2003, samples for anatomical investigations were taken periodically in Pyrus pyriforia cv. Niitaka, P. communis cv. 
Bartlett and P. ussiriansis cv. Yari. The morphology of stone cell in the fruit flesh was observed by using optical microscope, scanning electron microscope (SEM) and transmission electron microscope (TEM). By optical microscope, stone cell observed first from 14 days after full bloom. The adjacent cells to stone cell was first showed spherical type on initial forming stage but showed radial form at 90 days after full bloom. The shape of stone cell inspected by SEM was like a cluster and its size was various. By using TEM, components of stone cell, such as nucleus and vacuole, and secondary cell wall thickening were observed, so it could consider that the stone cell is living thing. The largest amount of stone cell clusters existed beneath fruit skin.

\section{Poster Session 36-Postharvest}

July 19, 2004, 5:00-6:00 PM

Rio Grande Exhibit Hall

269 1-Methylcyclopropene (1-MCP) for Extending Postharvest Quality of Chinese Winter Jujube

Lin Shen*1, Jiping Sheng ${ }^{2}$

${ }^{1}$ China Agricultural Univ., Food Biotechnology Dept., Beijing, 100083, China; ${ }^{2}$ China Agricultural Univ., Food Biotechnology Dept., Beijing, 100083, China

Chinese Winter Jujube (Zizyphus jujuba Mill.) is a kind of new fresh consumed jujube fruit with high quality originated in China, but its postharvest shelf-life is short at room temperature (often 7 days). A study was conducted to determine the effect on 1-methylcyclopropene (1-MCP) on changes in ethylene production, respiration rate, firmness, electrolyte leakage and vitamin C. Chinese Winter Jujube fruits harvested at half-red stage, were randomized into rigid, vented containers $\left(0.5 \mathrm{~m}^{3}\right.$; $\mathrm{n}=5)$, treated with $1 \mu \mathrm{L} \cdot \mathrm{L}^{-1}$ for $12 \mathrm{~h}$ at room temperature $\left(20 \pm 2{ }^{\circ} \mathrm{C}\right)$, then stored at $20^{\circ} \mathrm{C}$. Fruits treated with $1-\mathrm{MCP}$ had significant lower ethylene production, it showed $21 \%$ lower $\left(0.128 \mu \mathrm{L} \cdot \mathrm{kg}^{-1}\right.$ per hour $)$ at 8 th day. Respiration rate had no significant difference between treated and control during the $12 \mathrm{~d}$ storage. Firmness of treated fruits was from $15.4 \%$ to $26.3 \%$ higher than that of control, while the electrolyte leakage was from $12.2 \%$ to $27.4 \%$ lower than that of control. The content of vitamin $\mathrm{C}$ by $1-\mathrm{MCP}$ treatment was $11.2 \%$ higher than control at the last day of storage $(368 \mathrm{mg} / 100 \mathrm{~g})$. The results indicated that $1-\mathrm{MCP}$ had positive results on maintaining postharvest shelf-life of half-red stage of Chinese Winter Jujube fruit.

270 1-Methylcyclopropene (1-MCP) Application Influences Citrus Juice Color and Vitamin C Concentration in Postharvest Storage Huating Dou*1, Gary A. Coates ${ }^{2}$

${ }^{1}$ CREC, Florida Dept. of Citrus, Lake Alfred, FL 33850; ${ }^{2}$ CREC, Florida Dept. of Citrus, Lake Alfred, FL 33850

Influence of 1-MCP application in citrus fruit juice color and vitamin C concentration was determined for 'Fallglo' tangerines, 'Valencia' oranges, and white 'Marsh' grapefruit. MCP was applied at $500 \mu \mathrm{L} \cdot \mathrm{L}^{-1}$ for 'Fallglo', and $1000 \mu \mathrm{L} \cdot \mathrm{L}^{-1}$ for 'Valencia' oranges and 'Marsh' grapefruit at $75^{\circ} \mathrm{F}$ for 7 hours in a container of $3^{\prime} \times 3^{\prime} \times 3.5^{\prime}$ dimension. After three months storage at $40{ }^{\circ} \mathrm{F}$ and $93 \%$ relative humidity, vitamin $\mathrm{C}$ concentration in juice $(\mathrm{mg} / 100 \mathrm{~mL})$ was higher in MCP treated than non-treated 'Valencia' oranges (37.1 vs. 30.6) and 'Fallglo' tangerines (26.9 vs. 24.0). No difference was found in vitamin C concentration from 'Marsh' grapefruit juice either treated (27.9) or non-treated (28.7) with MCP. Forty percent of vitamin C concentration was lost from one month after packing to the third month in storage for white 'Marsh' grapefruit. Vitamin C loss was much slower for tangerines in comparison to grapefruit in postharvest. Juice color was not influenced by the MCP application for 'Valencia' oranges while Hue and Chroma were improved in treated fruits for 'Fallglo' tangerines and 'Marsh' grapefruit compared to non-treated fruits. Applying MCP before degreening reduced vitamin $\mathrm{C}$ degradation 6 weeks after packing but not at 12 weeks for 'Fallglo' tangerines. However, fruit color was improved at 6 and 12 weeks of storage. These results are important for postharvest quality management of citrus fruit and juice.

271 Influence of 1-Methylcyclopropene (1-MCP) on the Shelf Life and Deterioration of Fresh-cut Cantaloupe

Jiwon Jeong*1, Jeffrey Brecht ${ }^{2}$, Donald Huber ${ }^{3}$, Steve Sargent ${ }^{4}$

${ }^{1}$ Univ. of Florida, Horticultural Science, Gainesville, FL 32611; ${ }^{2}$ Univ. of Florida, Horticultural Sciences Dept., Gainesville, FL 32611 ; ${ }^{3}$ Univ. of Florida, Horticultural Sciences, Gainesville, FL 32611; ${ }^{4}$ Univ. of Florida, Horticultural Sciences, Gainesville, FL 32611

A study was conducted to determine the influence of the ethylene action inhibitor, 1-methylcyclopropene (1-MCP) on the shelf life and deterioration of fresh-cut cantaloupe (Cucumis melo var. reticulatus) during storage at $5{ }^{\circ} \mathrm{C}$. Intact cantaloupe fruit, cv. Durango (3/4 to full-slip stage) were treated with $1-\mathrm{MCP}\left(1 \mu \mathrm{L} \cdot \mathrm{L}^{-1}\right)$ for $24 \mathrm{~h}$ at $20^{\circ} \mathrm{C}$. Following cooling to $5^{\circ} \mathrm{C}$, the fruit were processed into $\approx 2.5$-cm cubes and subsequently dipped in $1.34 \mathrm{~mm}$ sodium hypochlorite solution for $20 \mathrm{~s}$. Fresh-cut cubes were stored in 1.7-L vented plastic containers for $12 \mathrm{~d}$ at $5{ }^{\circ} \mathrm{C}(85 \% \mathrm{RH})$. Intact fruit treated and stored under identical conditions were also examined. While 1-MCP-treated cantaloupe cubes were about $35 \%$ firmer than control cubes after the $24-\mathrm{h}$ at $20^{\circ} \mathrm{C}$ 1-MCP treatment, little softening occurred in either treatment during the subsequent $12-\mathrm{d}$ at $5{ }^{\circ} \mathrm{C}$ storage period. In contrast, control and 1-MCP-treated intact fruit softened nearly $40 \%$ and $15 \%$, respectively. 1-MCP did not significantly influence flesh color and soluble solid contents of either intact cantaloupe or fresh-cut cubes during storage at $5{ }^{\circ} \mathrm{C}$. Increased decay incidence was observed in 1-MCP-treated fresh-cut cantaloupe cubes.

272 A Summary of Physiological Processes or Disorders in Fruits, Vegetables and Ornamental Products that are Delayed or Decreased, Increased, or Unaffected by Application of 1-Methylcyclopropene (1-MCP)

Chris Watkins*1, William B. Miller ${ }^{2}$

${ }^{1}$ Cornell Univ., Hort., Ithaca, NY 14853; ${ }^{2}$ Cornell Univ., Hort., Ithaca, NY 14853

The discovery and subsequent commercialization of 1-MCPhas resulted in intense research interest around the world. A web site (http://www. hort.cornell.edu/mcp/) has been developed which provides a summary of the effects of 1-MCP on climacteric (18 species) and non-climacteric (6) fruits, vegetables (13), fresh cut produce (5), cut flowers and pot plants (more than 50 species has been created. The site is updated on a regular basis. For edible crops, most citations are available for apple (32 citations) and banana (21 citations). The ornamental literature is much less concentrated, and most crops are represented by a single citation. For all commodities, the majority of research has been focused on quality responses of the various products to $1-\mathrm{MCP}$, although increasingly 1 MCP is being used to investigate physiological and biochemical events associated with development, ripening and/or senescence.

273 Large-scale Application of 1-Methylcyclopropene Results in Extended Marketable Shelf Life and Persistence of the Full-ripe Condition of Commercially Handled Banana Fruit

Daniel Stanley*1, Donald Huber ${ }^{2}$

${ }^{1}$ Univ. of Florida, Horticultural Sciences, Gainesville, FL 32611; ${ }^{2}$ Univ. of Florida, Horticultural Sciences, Gainesville, FL 32611

Banana production is geographically isolated from consumer markets in temperate regions. This disparity has prompted study of ethylene antagonists such as 1-methylcyclopropene (1-MCP) to extend marketable shelf life. Banana fruit (Musa acuminata v. Cavendish) were treated with ethylene $(100 \mathrm{ppm})$ in sea containers $\left(24 \mathrm{~h}, 14.4{ }^{\circ} \mathrm{C}, 90 \%\right.$ $\mathrm{RH})$. After venting, one container was provided with $300 \mathrm{ppb} 1-\mathrm{MCP}$ $\left(12 \mathrm{~h}, 15^{\circ} \mathrm{C}\right)$. Controls were maintained in similar containers without 1-MCP. After treatments, ripening was monitored at $18{ }^{\circ} \mathrm{C}$. Color was graded from values of 2 (green) to 7 (yellow, with sugar spots). During storage at $18{ }^{\circ} \mathrm{C}$, control fruit remained within the color range of 4 to 6 (considered the most marketable) for $3 \mathrm{~d}$ compared with $6 \mathrm{~d}$ for 1-MCP-treated fruit. The time to reach stage 7 occurred at 8 and $13 \mathrm{~d}$, respectively, in control and 1-MCP treated fruit. Sugar spots occurred 
after 6 to $7 \mathrm{~d}$ for both control and 1-MCP-treated fruit. Thereafter, incidence diverged significantly, with 1-MCP-treated fruit remaining below $10 \%$ for $11 \mathrm{~d}$ and control fruit exceeding $30 \%$ by $10 \mathrm{~d}$. Through the first $5 \mathrm{~d}$, firmness (initially $75 \mathrm{~N}$ ) declined at comparable rates in both treatments, with control fruit declining to $20 \mathrm{~N}$ after $15 \mathrm{~d}$. 1-MCP-treated fruit remained near $40 \mathrm{~N}$ throughout storage. Ripening variability did not differ within the treatments. Informal sensory analysis showed that some participants preferred the taste and firmness properties of 1-MCP-treated fruit while others preferred the lower firmness of traditionally ripened fruit. The sweetness of treated fruit was only slightly lower than that of control fruit, yet was still considered acceptable. Work in progress is addressing sugar transformations in 1-MCP-treated banana fruit.

\section{Impact of 1-Methycyclopropene and Controlled Atmosphere Storage on Volatile Production in 'Gala' Apples}

Harmander Pal Singh*1, Dennis P. Murr², Gopi Paliyath³ Jennifer R. DeEll ${ }^{4}$

${ }^{1}$ Univ. of Guelph, Dept. of Plant Agriculture, Guelph, Ontario, N1G 2W1, Canada; ${ }^{2}$ Univ. of Guelph, Dept. of Plant Agriculture, Guelph, Ontario, N1G 2W1, Canada; ${ }^{3}$ Univ. of Guelph, Dept. of Plant Agriculture, Guelph, Ontario, N1G 2W1, Canada; ${ }^{4}$ Ontario Ministry of Agriculture and Food, Ontario Ministry of Agriculture and Food, Simcoe, Ontario, N3Y 4N5, Canada

'Gala' apples (Malus $\times$ domestica Borkh) were harvested at optimum maturity for long-term storage, precooled overnight at $0{ }^{\circ} \mathrm{C}$, treated with $1 \mu \mathrm{L} \cdot \mathrm{L}^{-1} ; 1$-methylcyclopropene $(1-\mathrm{MCP})$ for 24 hours at $0{ }^{\circ} \mathrm{C}$ and then placed in controlled atmosphere (CA) to determine the storage regime that would have the least negative impact on post-storage aroma volatile production. Fruit were stored at $0^{\circ}$ and $2.5^{\circ} \mathrm{C}$ in ultra low oxygen $\left(0.6 \% \mathrm{O}_{2}-0.6 \% \mathrm{CO}_{2}\right.$; ULOCA), low oxygen $\left(1.2 \% \mathrm{O}_{2}-1.2 \%\right.$ $\mathrm{CO}$; LOCA $)$ and standard $\left(2.5 \% \mathrm{O}_{2}-2.5 \% \mathrm{CO}_{2}\right.$; SCA $) \mathrm{CA}$ for 120 and 240 days, and in ambient air for 60, 90, 120 and 150 days. Post-storage fruit volatiles were quantified by headspace analysis using a solid-phase micro-extraction (SPME) probe and FID-GC, and key volatiles were identified by GC-MS. Fruit volatile production was greatest at harvest, and decreased thereafter for fruit held in air and CA for up to 150 or 240 days, respectively. 1-MCP treatment resulted in reduced rates of respiration, ethylene and volatile production, regardless of storage regime, and resulted in a reduced production rate of all the major volatile compounds, including esters, alcohols, acids, aldehydes and ketones. Post-storage volatile production was the least in fruits removed from $0{ }^{\circ} \mathrm{C}$ in ULO, followed by LO, SCA, and then air. 1-MCP treatment inhibited post-storage volatile production in CA- and air-stored fruit by as much as 95 percent. However, recovery of aroma was delayed significantly in fruit which had been held at $0{ }^{\circ} \mathrm{C}$ vs. $2.5^{\circ} \mathrm{C}$, suggesting aroma volatile synthesis in 'Gala' is chilling sensitive.

\section{Suppression of Ethylene Responsiveness Prolongs Cucumber Fruit Shelf Life in the Presence and Absence of Exogenously Applied Ethylene}

Luiz Lima ${ }^{1}$, Brandon Hurr*2, Donald Huber ${ }^{3}$

${ }^{1}$ Univ. of Florida, Horticultural Sciences, Gainesville, FL 32611; ${ }^{2}$ Univ. of Florida, Horticultural Sciences, Gainesville, FL $32611 ;{ }^{3}$ Univ. of Florida, Horticultural Sciences, Gainesville, FL 32611

Ethylene induces postharvest problems in many fruits, including members of the Cucurbitaceae. The effects of ethylene and its antagonist 1-methylcyclopropene (1-MCP) were studied on cucumber fruit, a cucurbit harvested immature. Beit Alpha cucumbers (cv. Manar) were harvested and exposed to 0.5 or $1.0 \mu \mathrm{L} \cdot \mathrm{L}^{-1} 1$-MCP prior to exposure to ethylene at $10 \mu \mathrm{L} \cdot \mathrm{L}^{-1}$ at $15^{\circ} \mathrm{C}$. Fruit exposed to ethylene exhibited significant quality loss upon exposure to ethylene, including epidermal yellowing, a $40 \%$ reduction in firmness and, following longer exposure $(6 \mathrm{~d})$, epidermal sloughing and placental watersoaking. After $8 \mathrm{~d}$ cucumbers exhibited a $75 \%$ reduction in firmness and acute pathogen incidence. Control fruit (no ethylene, no $1-\mathrm{MCP}$ ) were visually acceptable but firmness had declined $30 \%$ compared with initial values Fruit exposed to 1-MCP were resistant to applied ethylene, with firmness declining $10\left(1.0 \mu \mathrm{L} \cdot \mathrm{L}^{-1} 1-\mathrm{MCP}\right)$ to $20 \%\left(0.5 \mu \mathrm{L} \cdot \mathrm{L}^{-1}\right)$ during storage for $14 \mathrm{~d}$ at $15^{\circ} \mathrm{C}$. Firmness of fruit treated with $1-\mathrm{MCP}$ at 1.0 $\mu \mathrm{L} \cdot \mathrm{L}^{-1}$ was $28 \%$ higher than controls receiving only air, suggesting that ethylene production contributes to softening of cucumber during storage. The softening and watersoaking of fruit treated with ethylene was accompanied by downshifts in pectin mol mass. Fruit exposed to 1-MCP showed significantly reduced mol mass downshifts. The data indicate that cucumber show a PCD response to ethylene that is largely prevented by suppression of ethylene perception. The response of cucumber to ethylene parallels that for other cucurbits, and provides additional information that the benefits of 1-MCP extend beyond application to climacteric fruits.

\section{Quality of Tomato Slices Freshly Cut from Fruit Treated with Methyl Jasmonate}

Chien Wang*1

${ }^{1}$ U.S. Dept. of Agriculture, Produce Quality and Safety Laboratory, Beltsville, MD 2075-2350

The objective of this study was to determine if treatment with methyl jasmonate (MJ), a naturally occurring substance, would extend the shelf life of tomato slices, specifically when slices were cut from fruit previously treated with this natural product. Tomatoes were harvested at breaker stage. The fruit were divided into four lots. The first three lots were treated with $\mathrm{MJ}$ right after harvest at the breaker stage. Fruit from the first lot were sliced immediately after MJ treatment. Fruit from the second lot were placed at $20^{\circ} \mathrm{C}$ and allowed to ripen to red stage before slicing. Fruit from the third lot were treated the same way as those in the second lot except they received an additional MJ treatment just before slicing. Fruit from the fourth lot were placed at $20^{\circ} \mathrm{C}$ and allowed to ripen to red stage before $\mathrm{MJ}$ treatment and slicing. Each lot also included an untreated control. MJ treatments were carried out in 200-Lairtight containers. MJ was spotted onto filter paper at final vapor concentration of 10-5 M. Fruit were cut with a meat slicer to obtain slices with 5-mm thickness. Slices were placed in 1-L clear plastic trays with lids and stored at $5{ }^{\circ} \mathrm{C}$. Samples were transferred daily from 5 to $20{ }^{\circ} \mathrm{C}$ for evaluation. Fresh-cut tomatoes treated with $\mathrm{MJ}$ and sliced at breaker stage (lot 1) had less decay, better quality, and longer shelf life than the untreated slices. However, no differences were found between the control slices and treated slices at the red stage regardless the time of MJ treatment and whether or not additional MJ treatments were applied (lots 2, $3 \& 4$ ). The results indicate that the effectiveness of MJ in reducing decay and maintaining quality is affected by the stages of ripeness of tomatoes and the types of decay.

\section{Evaluation of Methanethiol and Dimethyl Disulfide in the Homogenate Fractions of Fresh and Frozen Broccoli Tissues}

Artemio Z. Tulio, Jr.*1, Yoshinori Ueda², Hiroyuki Yamanaka ${ }^{3}$, Yoshihiro Imahori ${ }^{4}$, Kazuo Chachin ${ }^{5}$, Artemio Z. Tulio, Jr. *6

${ }^{1}$ Osaka Prefecture Univ., Laboratory of Postharvest Physiology, Graduate School of Agriculture and Biological Sciences, Sakai, Osaka, 599-8531, Japan; ${ }^{2}$ Osaka Prefecture Univ. Laboratory of Postharvest Physiology, Graduate School of Agriculture and Biological Sciences, Sakai, Osaka, 599-8531, Japan; ${ }^{3} 2$ Hagoromo-Gakuen Junior College, Laboratory of Nutrition and Food Science, Sakai, Osaka, 592-8344, Japan; ${ }^{4}$ Osaka Prefecture Univ. Laboratory of Postharvest Physiology, Graduate School of Agriculture and Biological Sciences, Sakai, Osaka, 599-8531, Japan; ${ }^{5}$ Osaka Joshigakuen Junior College, Division of Food and Nutrition, Osaka, 543-0073, Japan; ${ }^{6}$ The Ohio State Univ., Dept. of Horticulture and Crop Science, Wooster, OH 44691

The emission of methanethiol (MT) and dimethyl disulfide (DMDS) from homogenate fractions of fresh and frozen broccoli tissues was analyzed using gas chromatography coupled with flame photometric detector after incubating for $2 \mathrm{~h}$ at $30^{\circ} \mathrm{C}$ in a water bath. Both sulfur compounds were detected in the headspace of the residue fraction of fresh broccoli but not frozen tissues. Only DMDS was formed in the filtrate and supernatant fractions of fresh tissues but their emission was also suppressed in frozen tissues. Phosphate buffer treatment reduced the amount of MT formed on the residue of fresh tissues, whereas treatment of enzyme co-factor, pyridoxal phosphate, and its substrate, S-methyl-L-cysteine sulfoxide, in the residue fraction of frozen broccoli did not induce the formation of MT except for DMDS Both compounds were also inhibited in the residue fraction of the fresh tissues by aminooxyacetic acid, a potential inhibitor of pyridoxal 
phosphate-dependent enzymes, indicating that these objectionable odors were produced upon the action of cysteine sulfoxide lyase. This enzyme, which yielded strong activity in the residue upon extraction with buffer containing Triton X-100, is highly likely to be a bound enzyme. Inhibition of MT and DMDS in frozen broccoli tissues is likely attributed to the retardation of the enzyme action due in part to the loss of the co-factor and its substrate, and owing to the solubility of MT and its affinity to gaseous condition.

\section{Poster Session 37-Nursery Crops}

July 19, 2004, 5:00-6:00 PM

Rio Grande Exhibit Hall

\section{Raw and Composted Paper Mill Sludges and Municipal Com- post in Nursery Substrates}

Calvin Chong*1, Peter Purvis ${ }^{2}$

${ }^{1}$ Univ. of Guelph, Dept. of Plant Agriculture, Guelph, Ontario, N1G 2W1, Canada; ${ }^{2}$ Univ. of Guelph, Dept. of Plant Agriculture, Guelph, Ontario, N1G 2W1, Canada

Silverleaf dogwood (Cornus alba L. 'Argenteo-marginata'), forsythia (Forsythia $\times$ intermedia Zab. 'Lynwood Gold'), and weigela (Weigela florida Bunge A.DC. 'Red Prince') were grown in \#2 (6-L) containers filled with $100 \%$ bark or bark mixed with $20 \%, 40 \%$, or $60 \%$ (by vol.) each of raw paper mill sludge (RB group), composted paper mill sludge (CB group), a proprietory paper mill sludge-derived compost (PB group), and municipal compost (MB group). A fifth substrate group (MH) consisted of $100 \%$ hemp chips or hemp chips mixed with the same rates of municipal compost. The containers were trickle-irrigated and fertilized with a controlled-release fertilizer. Among the bark-amended groups, growth was highest for dogwood and forsythia with $\mathrm{PB}$, increasing dramatically and peaking at ca. $40 \%$ rate (68 and $94 \mathrm{~g} /$ plant top dry weight, respectively). Growth of these species was intermediate with $\mathrm{MB}$ and $\mathrm{CB}$ and least with $\mathrm{RB}$, increasing to rates $\geq$ $50 \%$ in these groups, except for a nonsignificant response of dogwood to RB. Growth of weigela increased equally with $\mathrm{PB}$ and MB substrates up to ca. $40 \%$ (117 g/plant), but was unresponsive to rates of RB and $\mathrm{CB}$. With the hemp-amended MH group, growth of all three species increased to rates $\geq 50 \%$ (62,93, and $116 \mathrm{~g}$ /plant for dogwood, forsythia, and weigela, respectively). Growth of the three species over most rates of all substrate groups was similar to, or exceeded, that in $80 \%$ bark: $15 \%$ peat: $5 \%$ topsoil, a proven nursery mix. Top dry weight of all three species was positively correlated with soluble salts concentrations in the substrates at planting after first irrigation $\left(0.23-1.72 \mathrm{dS} \cdot \mathrm{m}^{-1}\right.$, range over all substrates) and at various intervals during the season.

\section{Nitrogen Requirement of Prosopis velutina Seedlings}

Kathryn S. Hahne ${ }^{1}$, Ursula K. Schuch*2

${ }^{1}$ Univ. of Arizona, Plant Sciences, Tucson, AZ 85721; ${ }^{2}$ Univ. of Arizona, Plant Sciences, Tucson, AZ 85721

The objective of this study was to determine whether mesquite (Prosopis velutina ) seedlings have a preference for the ammonia or nitrate form of nitrogen $(\mathrm{N})$, and to determine the optimum rate of $\mathrm{N}$ to maximize growth and minimize $\mathrm{N}$ leaching when seedlings are grown in different substrates. Mesquite seedlings were fertigated with different ratios of $\mathrm{NH}_{4}^{+}: \mathrm{NO}_{3}{ }_{3}^{-}$to determine effects on shoot and root growth and $\mathrm{N}$-uptake efficiency. Nutrient solution containing $67 \% \mathrm{NH}_{4}^{+}: 33 \% \mathrm{NO}_{3}{ }^{-}$resulted in greatest biomass after 120 days of fertigation. N leachate remained stable until 12 weeks after the onset of treatment, but increased significantly by week 16 . Subsequently, mesquite seedlings were grown in sand or soilless media and were fertigated with a solution of $67 \% \mathrm{NH}_{4}^{+}: 33 \%$ $\mathrm{NO}_{3}{ }^{-}$at a rate of $25,50,100$, or $200 \mathrm{mg} \cdot \mathrm{L}^{-1}$ of $\mathrm{N}$. After 60 days, plants in media produced $41 \%$ more leaves and total biomass compared to those in sand. Leaf number was greatest for plants grown at $200 \mathrm{mg} \cdot \mathrm{L}^{-1}$ of $\mathrm{N}$ in both substrates. Root biomass of plants in media showed no response to increasing $\mathrm{N}$ concentrations while root biomass of seedlings in sand were similar for the three lower $\mathrm{N}$ concentrations and nearly doubled for the highest one. Shoot biomass of seedlings receiving 25, 50 , or $100 \mathrm{mg} \cdot \mathrm{L}^{-1}$ of $\mathrm{N}$ was similar, but more than doubled for plants fertigated with $200 \mathrm{mg} \cdot \mathrm{L}^{-1}$ of $\mathrm{N}$. N leachate losses were highest from seedlings growing in sand and receiving the two higher $\mathrm{N}$ fertigations, those in media had greatest $\mathrm{N}$ leachate loss when fertigated at 200 $\mathrm{mg} \cdot \mathrm{L}^{-1}$ of $\mathrm{N}$. For balanced mesquite seedling growth and minimum $\mathrm{N}$ leaching losses, concentrations between 50 to $100 \mathrm{mg} \cdot \mathrm{L}^{-1}$ of $\mathrm{N}$ are recommended. Implications of using a sand culture system vs. soilless growing substrate for nutrition studies will be discussed.

\section{Spacing and Fertilizer Application Method Influence Container Plant Growth and Runoff}

Jeff B. Million*1, Thomas H. Yeager ${ }^{2}$, Joseph P. Albano ${ }^{3}$

${ }^{1}$ Univ. of Florida, Environmental Horticulture, Gainesville, FL 32611; ${ }^{2}$ Univ. of Florida, Environmental Horticulture, Gainesville, FL 32611; ${ }^{3}$ U.S. Dept. of Agriculture, U.S. Horticultural Research Laboratory, Ft. Pierce, FL 34945

The influence of production practices on runoff from container nurseries was investigated in Spring 2003 (March to July) and Fall 2003 (August to January). Viburnum odoratissimum (Ker-Gawl.) liners were planted in 3.8-L containers with a 2 pine bark : 1 sand : 1 Canadian peat substrate and placed on $1.5 \mathrm{~m}^{2}$-platforms at one of two plant spacing densities: 16 or 32 plants $/ \mathrm{m}^{2}$ [spaced to 16 plants $/ \mathrm{m}^{2}$ after 13 weeks (spring) or 14 weeks (fall)]. Overhead sprinkler irrigation was applied daily $(1 \mathrm{~cm})$ and runoff collected weekly. Osmocote $18 \mathrm{~N}-2.6$ $\mathrm{P}-10 \mathrm{~K}$ was surface-applied to each container $(15 \mathrm{~g})$ in the spring and surface-applied or incorporated in the fall. Cumulative runoff averaged $1240 \mathrm{~L} \cdot \mathrm{m}^{-1}$; in spring (19 weeks) and $1050 \mathrm{~L} \cdot \mathrm{m}^{-1}$; in fall (20 weeks), which represented $72 \%$ and $66 \%$ of applied irrigation plus rainfall, respectively. The lower density spacing resulted in a $19 \%$ increase in cumulative runoff in spring (1340 vs. $\left.1130 \mathrm{~L} \cdot \mathrm{m}^{-1}\right)$ but had no effect in fall $\left(970\right.$ vs. $\left.890 \mathrm{~L} \cdot \mathrm{m}^{-1}\right)$. Weighted average $\mathrm{EC}_{\mathrm{wa}}$ of runoff decreased $10 \%\left(0.436\right.$ vs. $\left.0.485 \mathrm{dS} \cdot \mathrm{m}^{-1}\right)$ and $12 \%\left(0.420 \mathrm{vs} .0 .476 \mathrm{dS} \cdot \mathrm{m}^{-1}\right)$ with the lower density spacing in spring and fall, respectively. $\mathrm{EC}_{\mathrm{wa}}$ in fall was not affected by fertilizer method. Plant size index [(height + width)/2] was reduced $22 \%$ in both spring ( $38.7 \mathrm{vs} .49 .7 \mathrm{~cm}$ ) and fall $(26.9 \mathrm{vs} .34 .4 \mathrm{~cm})$ when plants were grown at the lower density spacing throughout production. This reduction in plant size was attributed to container heat stress. Plant size was unaffected by fertilizer application method (fall) but fertilizer incorporation resulted in greener plants than surface-applied fertilizer (60 vs. 53 SPAD readings).

\section{Differential Growth, Quality and Nutrient Responses of Azalea Hybrids to Salinity}

Raul I. Cabrera*1

${ }^{1}$ Texas A\&M Univ., Horticultural Sciences, Dallas, TX 75252

The azalea hybrids 'Delaware Valley White' ('DVW') and 'Hershey Red' ('HR') were grown in 7-L containers filled with a 4 sphagnum peat : 2 pine bark : 1 sand medium (v/v) and fertigated for 15 weeks with a complete nutrient solution supplemented with 0,6 and $12 \mathrm{~mm}$ $\mathrm{NaCl}-\mathrm{CaCl}_{2}$ (2:1 molar ratio). Regardless of salinity stress, ' $\mathrm{DVW}$ ' plants had dry weights and leaf areas significantly higher (by $24.7 \%$ and $10.2 \%$, respectively) than in 'HR' plants. Salinity, however, caused differential growth and quality responses between the hybrids. Growth in 'DVW' plants decreased with salinity increases, with $22.6 \%$ and $32.4 \%$ reductions in total dry weight and leaf area, respectively, observed at $12 \mathrm{~mm}$ salt compared to controls. Conversely, 'HR' plants exposed to $12 \mathrm{~mm}$ salt showed no differences in yield parameters with respect to the controls, whereas plants receiving $6 \mathrm{~mm}$ salt showed increases of $14.0 \%$ and $7.1 \%$ in total dry weight and leaf area, respectively, with respect to the controls. Plant quality, as assessed by visual symptoms of salt injury ("salt burn"), was significantly reduced by salinity increases in 'DVW' plants, but was not affected in 'HR' plants. While unaffected by salinity, leaf $\mathrm{K}$ status in 'HR' plants was significantly lower than in 'DVW', which showed increases in $\mathrm{K}$ concentration with salinity increases. Leaf $\mathrm{Ca}, \mathrm{Cl}$ and $\mathrm{Na}$ concentrations increased with added salinity in both hybrids. The 'DVW' plants, however, accumulated exceedingly higher $\mathrm{Cl}$ and $\mathrm{Na}$ concentrations (up to $3.33 \%$ and $5,650 \mathrm{mg} \cdot \mathrm{L}^{-1}$ respectively) than in 'HR' plants (up to $1.31 \%$ and 
$463 \mathrm{mg} \cdot \mathrm{L}^{-1}$, respectively). Only the yield and quality of 'DVW' plants were negatively and significantly correlated to increases in leaf $\mathrm{Cl}$ and Na concentrations.

\section{Examining Nutrient Treatments Used on Balled and Burlapped Colorado Spruce Trees to Maintain Postharvest Quality}

Robert R. Tripepi*1, Mary W. George ${ }^{2}$, K. Amanda Permann³ ${ }^{3}$ John E. Lloyd ${ }^{4}$

${ }^{1}$ Univ. of Idaho, Horticultural Sciences Division, PSES, Moscow, ID 83844-2339; ${ }^{2}$ Univ. of Idaho, Horticultural Sciences Division, PSES; ${ }^{3}$ Univ. of Idaho, Horticultural Sciences Division, PSES; ${ }^{4}$ Univ. of Idaho, Horticultural Sciences Division, PSES

The goal of this study was to examine the effectiveness of several nutrient treatments to maintain or enhance the growth and foliar nutrition of Colorado spruce (Picea pungens Engelm.) trees while they were in a mulch holding bed. Sixty 1.5 to $1.8 \mathrm{~m}$ tall Colorado spruce trees with $61 \mathrm{~cm}$ (24 inch) diameter root balls were heeled into a holding bed of fresh pine bark mulch. The treatments applied to the root balls were a control (pine bark without fertilizer), Osmocote 15-9-12 distributed over the top of the ball at $114.2 \mathrm{~g}$ (label rate) per root ball, one Ross Gro-Stake 10-10-10 Evergreen fertilizer spike per ball, one-half cartridge of Ross Root Feeder 10-12-12 evergreen fertilizer injected into the root ball at four points, or a 50:50 mixture (by volume) of Eko Compost mixed with pine bark. Trunk diameters and tree heights were measured and foliar samples for nutrient analyses were collected before applying these treatments and at the end of the growing season 17 weeks later. Overall, the Colorado spruce trees appeared quite normal throughout the study. Changes in tree height and trunk diameter by the end of the growing season were unaffected by the nutrient treatments. By fall, needles from trees treated with the mixture of 50:50 compost:bark had the highest levels of foliar $\mathrm{N}, \mathrm{Mg}$, $\mathrm{Ca}, \mathrm{S}, \mathrm{MN}$ and $\mathrm{B}$. Trees treated with one fertilizer spike had the second highest levels of foliar $\mathrm{N}$ and $\mathrm{S}$, and these levels were significantly higher than those of trees receiving the other fertilizer treatments. Even though all nutrient treatments failed to influence increases in tree heights and trunk diameters during the first growing season after digging, the compost:bark mixture and to some extent the fertilizer spike improved foliar nutrition during this time.

\section{Flowering of Containerized Field-grown Garden Roses is Affected by Dig Date, Chill Hours, and Forcing Location}

\section{H. Brent Pemberton*1, Ursula K. Schuch ${ }^{2}$}

${ }^{1}$ Texas A\&M Univ. Agricultural Research and Extension Center, Dept. of Horticultural Sciences, Overton, TX 75684; ${ }^{2}$ Univ. of Arizona, Plant Sciences Dept., Tucson, AZ 85721

Rose (Rosa sp.) cultivars Blue Girl and Mister Lincoln were harvested bare-root on 1 Nov. 2001 and 22 Nov. 2002 from a commercial nursery in Arizona. Grade 1 plants were then potted and forced to flowering in either Tucson, Ariz., or Tyler, Texas. Total chilling hours were calculated as the number of hours that the plants were exposed to a temperature below $7{ }^{\circ} \mathrm{C}$ in the field and during shipping and cold storage. Data were recorded when the petals on the first flower beg an to reflex. Overall, the number of flowering shoots and plant performance was positively correlated to digging date, weeks of cold and total chilling hours received. Days from potting to flower were negatively correlated to weeks of cold storage and chilling hours. However, when the data were separated by location, the number of flowering shoots, the percentage flowering shoots, and plant performance was positively correlated to weeks of cold and chilling hours in Arizona, but was positively correlated to digging date in Texas. Days from potting to first leaf unfolding were recorded in Arizona only and were negatively correlated to weeks of cold storage and chilling hours. Days from potting to flower were negatively correlated to chilling hours at both locations and also to weeks of cold storage in Texas. The increase in chilling from two or four weeks of cold storage increased the number of flowering shoots and performance rating of plants forced in Arizona during both seasons, but only for the 2001 season in Texas. During the 2002 season in Texas, these responses were not influenced by cold storage, but were greater than those seen during the 2001 season. In Arizona, days from potting to flower were greater in 2001 than 2002, and decreased in response to cold storage in 2001 , but not in 2002 .

\section{BMP Development and Implementation Process for the Nursery Industry}

\author{
Thomas H. Yeager*1, Kenneth A. Kuhl ${ }^{2}$
}

${ }^{1}$ Univ. of Florida, Environmental Horticulture, Gainesville, FL $32611 ;{ }^{2}$ Florida Dept. of Agriculture and Consumer Services, Office of Agricultural Water Policy, Tallahassee, FL 32301

Nursery operations have strategically positioned themselves close to markets and many are now an agricultural entity surrounded by urban encroachment. The environmental pressures of society have mounted at unprecedented rates, resulting in additional regulations for nurseries. Development and implementation of Best Management Practices (BMPs) for the nursery industry allows nurseries to be proactive and not wait for regulations that might harm the industry. Univ. extension personnel with BMP subject matter expertise can play a pivotal role in assisting the industry with development and implementation of proactive BMPs. Important steps that have served as a model for BMP development and implementation include the following. Establish need - the industry leadership must explain to nursery personnel the reasons why BMPs are needed and elicit assistance with BMP development from university personnel. Committee guidance-the industry leadership establishes a steering committee of nursery personnel representing various interests of the industry to work with university and regulatory personnel to conceptualize BMPs and develop objectives. Consensus development-steering committee communicates their objectives to the nursery industry, explains the impacts, and provides a mechanism for feedback to achieve broad-based stakeholder participation. BMPs drafted - steering committee writes a draft BMP manual that is available for industry review. Industry-wide input-steering committee aggressively seeks input from the industry, implements as many suggestions as possible, and informs industry of BMP manual revisions. Educational programs - university extension personnel conduct training for nursery operators implementing BMPs and track the impact of BMPs on nurseries.

\section{Development of an Ohio Liner Production System Using Retractable Roof Greenhouses}

Alison A. Stoven*1, Hannah M. Mathers ${ }^{2}$, Daniel K. Struve ${ }^{3}$

${ }^{1}$ Ohio State Univ., Horticulture and Crop Science, Columbus, OH 43210-1096; ${ }^{2}$ Ohio State Univ., Horticulture and Crop Science, Columbus, OH 43210-1096; ${ }^{3}$ Ohio State Univ., Horticulture and Crop Science, Columbus, OH 43210-1096

A study was conducted to determine if similar quality shade tree liners could be produced using a retractable-roof greenhouse structure versus an outdoor environment. All plants were started in a heated greenhouse on campus in $250 \mathrm{XL}$-sized containers. The species included Eastern redbud, red oak (both grown from seed) and Autumn Blaze maple and Prairifire crabapple (both grown from rooted cuttings). On 15 Mar. 2003, half the plants remained in the heated greenhouse and the other half were moved to a Cravo retractable-roof structure and placed on heating mats set at $22{ }^{\circ} \mathrm{C}$. In May, all of the plants (retractable and greenhouse) were upshifted into 3-gallon Spin-out ${ }^{\circledR}$ treated containers. Trees in each environment were fertilized with either Osmocote ${ }^{\circledR}$ $(20 \mathrm{~N}, 2.2 \mathrm{P}, 6.6 \mathrm{~K})$, nine month release, applied broadcast at $45 \mathrm{~g} / \mathrm{pot}$, or with a 100 ppm-N water-soluable fertilizer $(21 \mathrm{~N}, 3.1 \mathrm{P}, 5.9 \mathrm{~K})$, applied at $0.1 \mathrm{~g} \mathrm{~N} /$ day. All trees received the same irrigation volume (1 L/day). All trees were grown according to nursery standards including bamboo staking, taping and regular pruning. Plants were arranged in a completely randomized design in each environment. The Cravo structure provided a more uniform environment with reduced air and soil temperature fluctuations versus the outdoor environment. Liners produced in the Cravo structure were taller, had greater caliper and root and shoot mass. Slow release fertilizer produced larger plants. Root dry weight for trees inside the Cravo environment increased nearly five times over the harvest dates of July to October with the maples having the largest root weight. 
440 Defoliating Lilac Seedlings in Field Production

Bert Cregg*1

${ }^{1}$ Michigan State Univ., Dept. of Horticulture and Dept. of Forestry, East Lansing, MI 48824

Lilac (Syringa vulgaris L) seedlings are commonly grown in many seedling nurseries in Michigan. Typically seedlings are lifted in the fall and stored prior to shipment or stored by the customer. A major problem in field production of lilacs is that seedlings often retain their leaves late in the fall. If the leaves are not removed prior to storage or shipment, the seedlings will mold and deteriorate. Therefore, growers must spend additional labor to remove the leaves, often by hand. The goal of this research was to evaluate chemical alternatives to defoliate lilac seedlings in field nurseries. Two on-farm research trials were conducted in 2001 and 2003 in cooperation with a seedling grower in Saugatuck, MI. In Experiment 1, Florel (1/2 and 1/4 dilution) and chelated copper $(0.5 \%$ and $1 \%$ solution) were sprayed by and onto lilac in the seedling bed. Florel and chelated copper effectively reduced leaf area of lilac seedlings. Less than $20 \%$ of the initial leaf area remained on the $1 \%$ copper and $1 / 2$ Florel-treated seedlings. The $1 / 2$ Florel and $1 \%$ chelated copper completely defoliated $67 \%$ and $40 \%$ of the seedlings, respectively, whereas only $17 \%$ on the control seedlings lost all their leaves prior to lifting. Both levels of Florel and the $1 \%$ copper treatment reduced growth of seedlings after planting. In experiment 2 , we applied chelated copper treatments at varying rates $(0.25 \%$ and $0.5 \%)$ and times ( 1 application and 2 applications) using the cooperators' spray equipment. Repeated applications of chelated copper were more effective in reducing seedling leaf area than a single application at both concentrations tested.

\section{The Use of Leaf Removal and Prohexadione-Ca to Modify 'Camarosa' Strawberry Nursery Plant Morphology for Plasticul- ture Fruit Production}

Julia Reekie*1, Peter Hicklenton², John Duval ${ }^{3}$, Craig Chandler ${ }^{4}$, Paul Struik ${ }^{5}$

${ }^{1}$ Agriculture and Agri-Food Canada, Berry Crops Research, Kentville, Nova Scotia, B4N 1J5, Canada; ${ }^{2}$ Agriculture and Agri-Food Canada, Berry Crops, Kentville, Nova Scotia, B4N 1J5, Canada; ${ }^{3}$ Univ. of Florida, Horticultural Science, Dover, FL 33527-9664; ${ }^{4}$ Univ. of Florida, Horticultural Science, Dover, FL 33527-9664; ${ }^{5}$ Wageningen Univ., Dept. of Plant Sciences, Wageningen, 6709 RZ, the Netherlands

Our previous work on modifying strawberry plant morphology used either mowing to remove the leaf laminas and part of the petioles on 'Camarosa', or a new reduced-risk gibberellin synthesis inhibitor, Prohexadione-Ca(ProCa), to restrict cell elongation in 'Sweet Charlie'. These early studies showed promising results in acheiving desirable plant size and increasing fruit yield in annual hill plasticulture. Therefore, in the growing seasons of 2001 and 2002, we used 'Camarosa' to explore the possibility of combining mowing and ProCa as a means of modifying strawberry transplant morphology in the nurseries, and studied its effect on fruit production in annual hill plasticulture. Plants were mowed and treated with $62.5 \mu \mathrm{L} \cdot \mathrm{L}^{-1}$ of ProCa in a nursery field in Nova Scotia $\left(45^{\circ} 26^{\prime} \mathrm{N}, 63^{\circ} 27^{\prime} \mathrm{W}\right)$. Treatments consisted of either mowing, the application of ProCa, or a combination of mowing and ProCa on one of two dates, 5 or 19 Sept. ProCa application early in the growing season had increased the production of daughter plants in the nursery. All plants were harvested in early October, and immediately transplanted in Dover, Fla. $\left(28^{\circ} 00^{\prime} \mathrm{N}, 82^{\circ} 22^{\prime} \mathrm{W}\right)$. Fruits were collected twice weekly from late November to February or March. At time of harvest, both mowing and ProCa reduced plant height and total leaf area; plants which were treated with ProCa and mowed were the shortest. On average, treated plants had higher fruit yield as compared to untreated plants. In 2001, early fruit production in December was increased significantly in treated plants.

442 Investigating Water Requirements of Select, Field-grown Tree Species in a Semi-arid Climate

Thayne Montague*1, Lindsey Fox ${ }^{2}$

${ }^{1}$ Texas Tech Univ., Dept. of Plant and Soil Science,Lubbock, TX 79409-2122; ${ }^{2}$ Texas Tech Univ., Dept. of Plant and Soil Science, Lubbock, TX 79409-2122

Recent droughts and depleted water tables across many regions have elevated the necessity to irrigate field-grown (FG) nursery trees. At the same time, ordinances restricting nursery irrigation volume have been implemented, often without regard to plant water requirements. This research investigated growth of seven FG tree species (Acer buergeranum, A. campestre, A. $\times$ freemanii 'Autumn Blaze', A. truncatum, Quecus muehlenbergii, $Q$. polymorpha, and $Q$. robur) subjected to three reference evapotranspiration (ETo) irrigation regimes (100\%, 60\%, and 30\% ETo) in a semi-arid climate. During Spring 2002, nine containerized $(11.3 \mathrm{~L})$ trees of each species were field planted in a randomized block design. Each year trees were irrigated through a drip irrigation system. During the first growing season, all trees were irrigated at $100 \%$ ETo. Irrigation treatments began Spring 2003. Growth data (shoot elongation and caliper increase) were collected at the end of the 2003 growing season. Species growth data were subjected to analysis of variance. If treatment differences were found, means were separated by Fisher's least significant difference. Shoot growth was influenced by irrigation regime for each species except $A$. campestre and $Q$. robur. For each of the five remaining species, the greatest shoot growth increase was generally not associated with the greatest irrigation regime. In a similar manner, caliper increase was influenced by irrigation regime for each species. The $100 \%$ ETo irrigation regime produced the greatest caliper increase for A. buergeranum, A. truncatum, $Q$. polymorpha, and $Q$. robur. For remaining species, the greatest caliper increase was generally not associated with the greatest irrigation regime.

\section{Hydrogel Amendments Do Not Decrease the Time Interval Be- tween Waterings for Container-grown Geranium and Ninebark}

Jeffrey H. Gillman*1

${ }^{1}$ Univ. of Minnesota, Dept. of Horticultural Science, St. Paul, MN 55108

Hydrogels are crystals that can suck up 600 or more times their weight in water. These gels are sold as additives for soils and container media for the purpose of reducing the frequency of watering. Five different hydrogels and a control were tested on geranium and 3 different hydrogels and a control were tested on ninebark to see how long plants could be kept healthy without watering. Growth was roughly similar among the control and the different hydrogels tested with the exception of Hydrosorb ${ }^{\mathrm{TM}}$, which stunted the growth of the ninebark. After plants reached a size that was considered saleable watering was stopped and the plants were allowed to dry out. None of the hydrogels kept the plants supplied with water for any longer than the controls. Hydrosorb ${ }^{\mathrm{TM}} \mathrm{did}$ appear to keep ninebarks at a healthy water potential for longer than the other hydrogels and the control, however, this is almost certainly because of the smaller size of the plants.

\section{Poster Session 38-Plant Biotechnology 2 \\ July 19, 2004, 5:00-6:00 PM Rio Grande Exhibit Hall}

93 Evaluation of Resistance to Gummy Stem Blight (Didymella bryoniae) Disease in ipt (Isopentenyl Transferase) Transformed Watermelon Plants

Fahrettin Goktepe ${ }^{1}$, Harrison Hughes ${ }^{* 2}$

${ }^{1}$ Colorado State Univ., Horticulture \& Landscape Architecture, Fort Collins, CO 80523-1173, ${ }^{2}$ Colorado State Univ., Horticulture \& Landscape Architecture, Fort Collins, CO 80523-1173

Watermelon plants are susceptible to Gummy stem blight disease that considerably reduces yields worldwide. In order to develop nonspecific resistance, watermelon cv. Crimson Sweet was transformed with copper inducible isopentenyl transferase (ipt), the rate-limiting step in cytokinin biosynthesis, gene via Agrobacterium tumafaciences (LBA4404). Transformed (ipt) and nontransformed plants were grown at approximately $28-30{ }^{\circ} \mathrm{C}$ day, $20-22^{\circ} \mathrm{C}$ night and 16 hours daylight under greenhouse conditions. Once the plants initiated new growth both transgenic plants and wild type plants were sprayed with one of three different concentrations $(0,10 \& 50 \mu \mathrm{M})$ of $\mathrm{CuSO}_{4}$. Plants were sprayed twice to run-off in a twenty-four hour time period before inoculation with the pathogen. Cultures of the pathogen Didymela bryonia(W353) 
were grown for about 3 weeks and an inoculum containing $10^{5}$ conidia per $\mathrm{mL}$ was sprayed with the prepared suspension until initial run-off in a humidified chamber. The disease symptoms were evaluated after one week with resistance demonstrated in all treated transgenic plants. All nonsprayed transgenic and wild type plants showed similar disease symptoms. Infected leaf samples were surface sterilized and re-cultured on V8 medium. The characteristics of the recovered pathogen confirmed that it was identical to the stock culture of W353. The same experiment has been conducted on seedlings from transgenic ( $T_{1}$ generations) and non-transformed plants. The non-transformed seedlings showed the first disease symptoms on their cotyledons and lower leaves. Disease resistance was observed in seedlings of the treated transformed plants as compared to nontransformed ones.

\section{Activation of Isopentenyl Transfarese (ipt) Gene in Transformed Watermelon Influences Seed Number and Other Characteristics}

\section{Fahrettin Goktepe ${ }^{1}$, Harrison Hughes*2}

${ }^{1}$ Colorado State Univ., Horticulture \& Landscape Architecture, Fort Collins, CO 80523-1173; ${ }^{2}$ Colorado State Univ., Horticulture \& Landscape Architecture, Fort Collins, CO 80523-1173

The watermelon cv. Crimson Sweet was transformed with the copper inducible isopentenyl transferase, the rate-limiting step in cytokinin biosynthesis, gene via Agrobacterium tumafaciences (LBA4404). Transformed (ipt) and nontransformed plants were regenerated from tissue culture and clonally propagated by the rooting of leaf node cuttings. Twelve plants of each were grown in 1-gal. pots. Once the plants initiated new growth both transgenic plants and wild type plants were sprayed with one of four different concentrations $(0,5,10, \& 50 \mu \mathrm{M})$ of $\mathrm{CuSO}_{4}$. The experimental unit was a single plant with three replicates. The growth rate, number of leaves, flowers, lateral shoots, and chlorophyll content were measured weekly for five weeks. Treated transgenic plants had greater numbers of leaves, flowers and lateral branches as well as higher chlorophyll levels. Pollen viability was examined in all treatments with no differences among treatments. Plants of both types were self pollinated to generate seeds. Female flowers were bagged before opening and then selfed. Selfed flowers were bagged for at least two days. The fruits were grown for eight to ten weeks with support. Once they reached maturity, fruits were harvested and fruit shape, flesh color, brix, number of normal seeds, number of colored but empty seeds and number of white seeds were recorded. Significant differences were observed only in seed number between wild type and transgenic (both treated and nontreated,) watermelon fruits. The number of seeds in transgenic watermelon plants treated with $\mathrm{CuSO}_{4}$ was reduced to about $5 \%$ to $7 \%$ of wild type plants. Transgenic plants which received no $\mathrm{CuSO}_{4}$ had approximately $33 \%$ to $50 \%$ of the seed of wild type.

\section{Ethylene-inducible Expression of ipt Gene Produces a Dramatic Increase in Fower Bud Count in Transgenic Plants}

Richard J. McAvoy*1, Mariya V. Khodakovskaya ${ }^{2}$, Hong Liu ${ }^{3}, \mathrm{Yi} \mathrm{Li}^{4}$

${ }^{1}$ Univ. of Connecticut, Dept. of Plant Science, Storrs, CT 06269-4163; ${ }^{2}$ Univ. of Connecticut, Dept. of Plant Science, Storrs, CT 06269-4163; ${ }^{3}$ Univ. of Connecticut, Dept. of Plant Science; ${ }^{4}$ Univ. of Connecticut, Dept. of Plant Science

Cytokinins play an important role in regulating plant growth and development. The cytokinin gene, isopentenyl transferase (ipt), was placed under the control of the ACC oxidase promoter from the $L E A C O 1$ gene from Lycopersicon esculentum and introduced into Nicotiana tabacum (cv. Havana) and chrysanthemum (Dendranthema $\times$ grandiflorum 'Iridon'). Transformants were confirmed by PCR reaction and Southern blot and analyzed for phenotypical changes under both greenhouse and growth chamber conditions. With both species, LEACO1-ipt transgenic plants displayed a wide range of vegetative and generative phenotypes. With plants growing in the vegetative state, some LEACO1-ipt transgenic lines appeared similar to the non-transgenic wild-type cultivars while other lines showed excessive lateral branch development and short internodes. With plants grown under generative conditions, several LEACO1-ipt transgenic lines showed a 2 to 10-fold increase in the number of flower buds relative to the wild-type cultivars. With chrysanthemum, dramatic increases in bud count were observed on transgenic lines that otherwise displayed a morphology similar to the non-transgenic lines. Analysis of ipt expression indicated a marked change in gene expression between the most extreme phenotypes observed in this study. LEACO1-ipt lines that express normal vegetative development but increased flower bud counts appear to have great potential for ornamental crop improvement.

\section{Increased Tolerance to Cold Storage in Transgenic Petunia Plants expressing the $F A D 7$ Gene}

Mariya V. Khodakovskaya ${ }^{1}$, Richard J. McAvoy*2, Hao Wu', $\mathrm{Yi} \mathrm{Li}^{4}$

${ }^{1}$ Univ. of Connecticut, Dept. of Plant Science, Storrs, CT 06269-4163; ${ }^{2}$ Univ. of Connecticut, Dept. of Plant Science, Storrs, CT 06269-4163; ${ }^{3}$ Univ. of Connecticut, Dept. of Plant Science; ${ }^{4}$ Univ. of Connecticut, Dept. of Plant Science, Storrs, CT 06269

It has been reported that constitutive expression of the fatty acid desaturase enzyme increased the trienoic fatty acid content of thylakoid membranes in transgenic tobacco, allowing the membranes to remain fluid under cold conditions. While increased cold tolerance resulted from this genetic modification, plants with a constitutively expressed desaturase enzyme would not be particularly well suited for growth under warm temperatures. To increase the ability of plants to tolerate prolonged cold-storage and still perform under greenhouse production conditions $\left(25^{\circ} \mathrm{C}\right)$, a unique cold-inducible genetic construct was cloned and tested. The FAD7 gene, which encodes an omega-3-fatty acid desaturase enzyme, was put under the control of a cold-inducible promoter (cor15a) from Arabidopsis thaliana. Transgenic petunia plants (cv, Marco Polo Odyssey) harboring cor15a:FAD7 were established and conformed by PCR and Southern analysis. Therefore in our study, $F A D 7$ gene expression was induced by exposure to cold temperatures and down regulated under normal growing conditions. RT-PCR indicated a marked increase in FAD7 expression between transgenic plants exposed to a short (3 days) cold treatment prior to long-term cold storage and those that did not receive a cold induction treatment. Transgenic and wild-type plants were induced in cold $\left(3^{\circ} \mathrm{C}\right)$ for 3 days, returned for normal greenhouse conditions for 5 days and then subjected 3 weeks of continuous cold storage. It was observed that two out of eight transgenic lines showed superior cold tolerance relative to wild-type petunia plants. Additionally, plants that showed cold tolerance completely recovered; growing and flowering normally when returned to the $25^{\circ} \mathrm{C}$ greenhouse conditions.

\section{Wound-inducible Expression of the ipt GeneStimulates Enhanced Lateral Shoot Development in Tobacco}

Mariya V. Khodakovskaya ${ }^{1}$, Richard J. McAvoy*2, ${ }^{2}$ eming Luo ${ }^{3}, \mathrm{YiLi}^{4}$

${ }^{1}$ Univ. of Connecticut, Dept. of Plant Science, Storrs, CT 06269-4163; ${ }^{2}$ Univ. of Connecticut, Dept. of Plant Science, Storrs, CT 06269-4163; ${ }^{3}$ Univ. of Connecticut, Dept. of Plant Science; ${ }^{4}$ Univ. of connecticut, Dept. of Plant Science, Storrs, CT 06269

The bacterial isopentenyl transferase (ipt) gene involved in cytokinin biosynthesis was fused with a promoter from the serine proteinase inhibiter (win3.12) gene of Populus x generosa and introduced into Nicotiana tabacum (cv. Havana). Transformants were confirmed by PCR reaction and Southern blot analysis, and then analyzed for phenotypic characteristics. RT-PCR analysis detected transcripts of the ipt gene following the wounding of win3.12:ipt transgenic plants. In win3.12: ipt transgenic plants, lateral shoot number and the diameter of lateral branches that developed following apical shoot removal increased relative to wild-type plants. However, the increase in cytokinin production following wounding appeared to be short lived. The potential utility of this construct in enhancing lateral branching in ornamental crops will be discussed.

\section{Agrobacterium-mediated Transformation of Cotyledon Explants of Bottle Gourd (Lagenaria siceraria $\mathrm{S}$.)}

\section{Jeung-Sul Han*1, Chang Kil Kim²}

${ }^{1}$ Rural Development Administration, National Horticultural Research Institute, Suwon, Kyonggi-Do, 441-440, Republic of Korea; ${ }^{2}$ Sangju National Univ., Horticulture, Sangju, Kyongsangbuk-Do, 742-711, Republic of Korea

A procedure for producing transgenic bottle gourd plants by inoculating cotyledon explants with Agrobacterium tumefaciens strain AGL1 
carrying a binary vector pCAMBIA3301, which contains glufosinate ammonium-resistant (bar) and the reporter $(g u s)$ genes, is describe. Infection was the most effective (highest infection frequency and index) when explants were co-cultivated with Agrobacterium for 6-8 days on co-cultivation medium supplemented with 0.001-0.1 mg/L L-a-(2aminoethoxyvinyl) glycine (AVG). Transgenic plants were obtained with frequencies of about $0.2 \%$ when the explants were cultured on selection medium (MS medium supplemented with $3.0 \mathrm{mg} / \mathrm{LBAP}, 0.5$ $\mathrm{mg} / \mathrm{L} \mathrm{AgNO}$, $500 \mathrm{mg} / \mathrm{L}$ cefotaxime, $2.0 \mathrm{mg} / \mathrm{L} \mathrm{DL}$-phosphinothricin, $0.3 \%$ sucrose and $0.8 \%$ Plant Agar. A histochemical gus assay, PCR and Southern blot analyses confirmed that transformation had occurred. Genetic analysis of $\mathrm{T}_{1}$ progenies showed that the transgenes were inherited in a Mendelian fashion. To our knowlege, this study represents the first report for Agrobacterium-mediated transformation in bottle gourd, rootstock for watermelon and other cucurbit crops in many countries.

99 Effect of $\mathrm{CdCl}_{2}$ on the Growth and Antioxidases Activities in Transgenic Metallothionein and Wild Type Tobacco Leaves

Jiping Sheng*1, Lin Shen ${ }^{2}$, Binggen $\mathrm{Ru}^{3}$

${ }^{1}$ China Agricultural Univ.; Peking Univ., College of Food Science, Beijing, 100083; 1000871, China; ${ }^{2}$ China Agricultural Univ., College of Food Science, Beijing, 100083 China; ${ }^{3}$ Peking Univ., College of Life Science, Beijing, 1000871, China

Metallothioneins (MTs) has selective capability to bind heavy metals such as $\mathrm{Cd}$ and $\mathrm{Pb}$. Former study in our lab showed that MT gene from mouse was transferred into tobacco to absorb more heavy metals from soil. This study was conducted to plant transgenic tobacco and wild type tobacco on MS media with $20 \mu \mathrm{mol} \cdot \mathrm{L}^{-1} \mathrm{CdCl}_{2}$. Transgenic tobacco grew strong, whereas the growth of wild type tobacco was severely prohibited. At 21st day, an average single transgenic plant weight was 1.5 times higher than that of wild type, and its height was also 1.33 higher. The activities of antioxidases, such as POD, CAT, PPO in transgenic tobacco leaves showed significant lower than that of wild type, which was $32.3 \%, 43.3 \%, 187.5 \%$ lower respectively. The results indicated that the transgenic MT tobacco had higher Cd tolerance, and a promising future in the application of environmental cleaning.

\section{Increased Flower Longevity in Petunia with Male Sterility}

Alan G. Smith*1, Nicole Gardner ${ }^{2}$, Elizabeth Zimmermann ${ }^{3}$

${ }^{1}$ Univ. of Minnesota, Horticultural Science, St. Paul, MN; ${ }^{2}$ Univ. of Minnesota, Horticultural Science; ${ }^{3}$ Univ. of Minnesota, Horticultural Science

Flower longevity is an important character in many ornamental crops. The processes of pollination and fertilization can cause senescence of the petals through the action of ethylene or its precursors. Preventing the production of pollen and therefore pollination could delay the senescence of petals. We tested whether male-sterility would increase flower longevity in petunia. The gene consisted of a stamen-specific promoter isolated from a Lycopersicon esculentum gene driving the expression of a barnase. Barnase is a RNase that is cytotoxic. The gene was introduced into 'Lavender Storm' and 'Purple Wave' petunia by Agrobacterium-mediated gene transfer. Five independent transgenic lines of both cultivars were regenerated, rooted, and grown in a greenhouse. All lines showed complete male-sterility as measured by the lack of detectable pollen. Two transgenic lines and a non-transformed control of each cultivar were propagated vegetatively and the flower longevity of each genotype was determined in a greenhouse experiment. There were two treatments: no pollination or pollination with cross-compatible pollen. All sterile genotypes that were not pollinated had increased flower longevity relative to pollinated sterile flowers or either treatment of male fertile (non-transformed) genotypes. These results indicate an application for sterility in the production of petunia flowers with increased longevity. Male and female sterility may be applicable in other ornamental crops where pollination or fertilization is a trigger to petal senescence.
92 Construction of a BAC Library Covering a Common Region between Two Sugar Beet Translocation Lines with Two Cyst Nematode Resistance Genes

Suren Samuelian*1

${ }^{1}$ Cornell Univ., Horticulture, Geneva, NY 14456

Resistance against the beet cyst nematode $(\mathrm{BCN})$ has been introduced into cultivated sugar beet from wild beet by conventional breeding. The first gene effective against the BCN, Hs 1pro-1, was isolated from the sugar beet translocation line A906001. It is assumed that a second nematode resistance gene, Hs 1pro-1, is present in the translocation line PRO3, which does not carry Hs 1 pro- 1 but still imparts complete resistance against the nematode and resides in the overlapping region between the two lines. The overall goal of this study was to construct a bacterial artificial chromosome (BAC) library to facilitate the cloning of Hslpro-1. A BAC library from PRO3 was constructed containing 45,041 clones with an average insert size of $108.36 \mathrm{~kb}$. Screening of the library with organelle specific probes indicated less than $1 \%$ mitochondrial and $4 \%$ chloroplast DNA content. The library covers 6.17 genome equivalents which provides a $99.76 \%$ probability of recovering any specific sequence present in the genome.

\section{Poster Session 39-Floriculture 3}

July 19, 2004, 5:00-6:00 PM Rio Grande Exhibit Hall

310 Effects of GA $\mathrm{G}_{3}$ on Poinsettia Over-retarded with Paclobutrazol Amy D. McDaniel*1, Yin-Tung Wang ${ }^{2}$

${ }^{1}$ Weslaco ISD, Weslaco High School, Weslaco, TX 78596; ${ }^{2}$ Texas A\&MUniv., Horticultural Sciences, Weslaco, TX 78596

Astudy was initiated to determine the effect of $\mathrm{GA}_{3}$ as a counter measure to restore the growth of over-retarded poinsettia. Euphorbia pulcherrima 'Sonora Red' plants were treated once foliarly with paclobutrazol at 40 or $80 \mathrm{mg} \cdot \mathrm{L}^{-1}$ one week following pinching. Four weeks later, plants receiving the $80 \mathrm{mg} \cdot \mathrm{L}^{-1}$ rate were treated once foliarly with $\mathrm{GA}_{3}$ at 0 , $10,20,30$ or $40 \mathrm{mg} \cdot \mathrm{L}^{-1}$. The effect of $\mathrm{GA}_{3}$ was visible within 3 days of application. $\mathrm{GA}_{3}$ between 10 and $40 \mathrm{mg} \cdot \mathrm{L}^{-1}$ caused long internodes, excessive stem elongation, as well as small leaves and bracts, resulting in unmarketable plants. Plants receiving $10 \mathrm{mg} \cdot \mathrm{L}^{-1} \mathrm{GA}_{3}$ were nearly twice the height of the over-retarded plants $(31 \mathrm{vs} .17 \mathrm{~cm})$, with increasingly taller plants at higher concentrations, up to $30 \mathrm{mg} \cdot \mathrm{L}^{-1}$. In a second experiment, single-stemed plants were treated with one foliar spray of 50 or $150 \mathrm{mg} \cdot \mathrm{L}^{-1}$ paclobutrazol two weeks following the beginning of short days. After another 3 weeks, the overdosed plants were then foliarly treated once with $0,3,5,10$, or $15 \mathrm{mg} \cdot \mathrm{L}^{-1} \mathrm{GA}_{3}$. $\mathrm{GA}_{3}$ at all rates promoted stem elongation and resulted in large bracts and much increased inflorescence diameter. The $15 \mathrm{mg} \cdot \mathrm{L}^{-1} \mathrm{GA}_{3}$ rate resulted in undesirable long internodes on the upper stem. Plants that received 3,5 , or $10 \mathrm{mg} \cdot \mathrm{L}^{-1} \mathrm{GA}_{3}$ were of excellent quality, with their heights and inflorescence sizes similar to those of plants receiving 50 $\mathrm{mg} \cdot \mathrm{L}^{-1}$ paclobutrazol $(26 \mathrm{~cm})$. Parallel experiments using 'Burgundy Cortez' had similar results.

\section{Effect of Antivirals on the Elimination of Lily Symptomless} Virus in Lilium Oriental Hybrid 'Casa Blanca'

Jin Ha Woo*1, Hyo Hoon Nam², Hyun Suk Lee ${ }^{3}$, Kyeong Bae Choi ${ }^{4}$, Jea Tak Yoon ${ }^{5}$, Kiu Weon Kim ${ }^{6}$

${ }^{1}$ Gyeongbuk Agricultural Extension Services, Horticultural research, Daegu, 702-320, South Korea; ${ }^{2}$ Gyeongbuk Agricultural Extension Services, Horticultural Research, Daegu, 702 320, South Korea; ${ }^{3}$ Gyeongbuk Agricultural Extension Services, Horticultural Research, Daegu, 702-320, South Korea: ${ }^{4}$ Gyeongbuk Agricultural Extension Services, Horticultural Research, Daegu, 702-320, South Korea; ${ }^{5}$ Gyeongbuk Agricultural Extension Services, Horticultural Research, Daegu, 702-320, South Korea; ${ }^{6}$ Yeungnam Univ., Horticultural Science, South Korea

This study was conducted to find out the effect of antivirals during tissue culture for lily symptomless virus (LSV) free stock production of Oriental lily. Scales and bulblets of LSV-infected Lilium Oriental 
hybrids 'Casa Blanca' were used as plant materials. Scales and bulblets were cultured in Murashige and Skoog (MS, 1962) medium added 20 $\mu \mathrm{M}$ of virazole, and $0,20,40$, and $80 \mu \mathrm{M}$ of azauracil or thiouracil for 12 weeks prior to LSV detection to examine the effect of antivirals. The survival rate in scaling was observed to be lower than bulblet culture in vitro and higher concentration of azauracil and thiouracil also effected on lower survival rate. The enlargement of bulblet tended to be promoted in low concentration without regard to kinds of antivirals, and especially most effective in $20 \mu \mathrm{M}$ of azauracil. Elimenation rate of LSV was $0 \%$ in control, on the contrary, antivirals treatment which resulted in complete elimination of LSV.

\section{Effect of Pre-treatment Solution on Iris hollandica Flower:} Vase life, Anthocyanin Content, and Peroxidase Activity

\section{Su-Jeong Kim*1, Chun-Woo Nam², Dong-Lim Yoo ${ }^{3}$, Seung-Yeol} $\mathrm{Ryu}^{4}$, Ki-Sun $\mathrm{Kim}^{5}$

${ }^{1}$ National Institute of Alpine Agriculture, Horticulture Dept., Pyeongchang-gun, Gang won-do, 232-955, S. Korea; ${ }^{2}$ National Institute of Alpine Agriculture, Horticulture Dept. Pyeongchang-gun, Gangwon-do, 232-955, S. Korea; ${ }^{3}$ National Institute of Alpine Agriculture Horticulture Dept.,Pyeongchang-gun, Gangwon-do, 232-955, S.Korea: ${ }^{4}$ National Institute of Alpine Agriculture, Horticulture Dept., Pyeongchang-gun, Gangwon-do, 232-955, S.Korea; ${ }^{5}$ Seoul National Univ., Horticulture Dept., Seoul, Seoul, 151-742, S. Korea

Iris hollandica 'Blue Magic' was treated with deionazed water as a control, $3 \%$ sucrose (Suc), $3 \%$ sucrose plus $0.4 \mathrm{~mm}$ silver thiosulphate (Suc+STS), $3 \%$ sucrose plus $200 \mathrm{mg} \cdot \mathrm{L}^{-1} 8$-hydroxyquinoline sulphate (Suc+HQS) and $3 \%$ sucrose plus $100 \mathrm{mg} \cdot \mathrm{L}^{-1}$ benzyl amino-purine (Suc+BA) for $4 \mathrm{hrs}$ and then transferred to tap water. The vase life treated with Suc+BA was extended 4 days longer than that of control. The treatment Suc+STS or Suc+HQS did not improve vase life. The amounts of water uptake and transpiration by all treatments decreased after harvest, but those values were higher in cut iris treated with Suc+BA than in those with control. Cut flowers treated with by Suc+BA markedly improved water balance, comparing with control which was quickly changed to minus value. Anthocyanin content in petals of cut flower treated with Suc+BA was 3.5 fold higher than that of control. The treatment by Suc+BA delayed discoloration in petals and senescence of cut Iris. Peroxidase (POD) activities of all treatments were reached maximum at 4 th day after treatment and decreased thereafter. POD activity was highest when the cut iris was treated with Suc+BA. These results show that the use of Suc+BA is most effective treatment for improving the vase life and quality of cut Iris flowers.

\section{Alleviation of Nitric Oxide-induced Flower Abscission and Leaf Toxicity in Phlox by Sucrose and 1-MCP}

Narendra Sankhla ${ }^{1}$, Wayne Mackay*2, Tim Davis ${ }^{3}$

${ }^{1}$ Texas A\&M Univ., TAES, Dallas, TX 75252-6599; ${ }^{2}$ Texas A\&M Univ., TAES, Dallas, TX 75252-6599; ${ }^{3}$ Texas A\&M Univ., Horticulture, Dallas, TX 75252-6599

Low concentration fumigation with nitric oxide ( $\mathrm{NO}^{*}$ ) has been shown to extend the postharvest life of a range of flowers, fruits and vegetables by down-regulating ethylene production. Since ethylene is involved in flower abscission and leaf senescence of 'John Fanick' phlox cut flower heads, a superior selection of perennial phlox (Phlox paniculata L.) bearing attractive long-lasting flowers, we have evaluated the effect of NO* delivered in vivo using sodium nitroprusside (SNP) as the source of NO* donor, on postharvest performance of 'John Fanick' phlox flower heads. Although the presence of SNP $\left(10-200 \mu \mathrm{mol} \cdot \mathrm{L}^{-1}\right)$ in the vase solution promoted the abscission of the open flowers, the young flower buds continued to open even in the presence of high SNP concentrations. On the other hand, at high SNP concentrations, the leaves became either yellow, or more frequently turned progressively black and senesced. Inclusion of sucrose in the vase solution, or pretreatment of flower heads with either 1-MCP or STS, significantly delayed the abscission of flowers and blackening of leaves. The pretreatment of flower heads with either 1-MCP or STS, or the presence of sucrose in the vase, together with SNP, greatly reduced the toxicity of the latter chemical resulting in improved postharvest display life. These results indicate that in 'John Fanick' the leaves are relatively more susceptible to $\mathrm{NO}^{*}$-induced toxicity than the flowers. However, both sucrose and ethylene perception inhibitors are able to minimize the toxicity of high concentrations of $\mathrm{NO}^{*}$ delivered in vivo via SNP.

\section{Sucrose and Ethylene Biosynthesis/Perception Inhibitors Additively Enhance Postharvest Display Life of Cut Racemes of Lupinus havardii Wats.}

Wayne Mackay*1, Narendra Sankhla ${ }^{2}$, Tim Davis ${ }^{3}$

${ }^{1}$ Texas A\&M Univ., TAES, Dallas, TX 75252-6599; ${ }^{2}$ Texas A\&M Univ., TAES, Dallas, TX 75252-6599; ${ }^{3}$ Texas A\&M Univ., Horticulture, Dallas, TX 75252-6599

Over the years, by recurrent phenotypic selection, breeding and evaluation, we have developed blue, white, and pink flowered lines of Big Bend bluebonnet (L. havardii Wats.). The racemes, which differ in their sensitivity to ethylene, hold promise as a new specialty cut flower crop. The key determinants of postharvest longevity and performance of cut racemes are flower abscission and senescence. Our studies indicated that the addition of sucrose in the holding solution greatly enhanced the vase life, although the optimum sucrose concentration varied considerably in different lines. In blue flowered lines (e.g., 'Texas Sapphire', Blue Select) sucrose concentration greater than $2 \%$ induced 'osmotic wilting' followed by senescence of the standard petal (banner spot petal), while the petals in white flowered lines (e.g., 'Texas Ice', White Select) did not show any wilting even in $4 \%$ to $6 \%$ sucrose. Ethylene perception inhibitors such as 1-MCP or STS completely suppressed the induction of flower abscission in racemes of all the bluebonnet lines. Ethylene biosynthesis inhibitors (e.g., ReTain, $\mathrm{CO}^{++}$), on the other hand, were relatively less effective than 1-MCP/STS. Both ethylene perception as well as biosynthesis inhibitors, in combination with sucrose, acted additively and further enhanced the postharvest performance by delaying flower abscission/senescence.

\section{Influence of Plant Growth Regulators on Growth, Flowering and Corm Yield of Gladiolus (Gladiolus grandiflorus L.) cv. Oscar}

Rajendra P. Maurya*1, Champa lal Nagda*2

${ }^{1}$ Central Arid Zone Research Institute, Jodhpur-342 003, India, Division Of Soil-water-plant-relationship, Jodhpur, Rajasthan, 342 003, India; ${ }^{2}$ Maharana Pratap Univ. of Agriculture and Technology, Udaipur-313 001, India, Dept. of Horticulture, Udaipur, Rajasthan, 313 001, India

In a field experiment, uniform sized corms of gladiolus (Gladiolus grandiflorus L. cv. Oscar) were planted in last week of October at a distance of $30 \mathrm{~cm}$. between rows and $20 \mathrm{~cm}$. between plants. The effect of GA $(50,100 \mathrm{ppm})$, Cycocel $(500,1000)$ and NAA $(50,100 \mathrm{ppm})$ on gladiolus plants. It was concluded that foliar application of 100 ppm $\mathrm{GA}_{3}$ at 45 days after corm planting has shown superiority in all vegetative, floral characters and corm \& cormel yield viz., plant height $(128.53 \mathrm{~cm})$, number of leaves $(8.57)$ per plant, spike length $(108.33$ $\mathrm{cm})$, spike weight $(128.87 \mathrm{~g})$, number of florets $(17.60)$ per spike, size of second florets $(15.07 \mathrm{~cm})$, number of spikes $(1.67)$ per plant, size of largest corm $(7.52 \mathrm{~cm})$, number of corms (1.80) per plant,number of cormels (11.53) per plant and weight of corms (79.33 g) per plant. Whereas, a highest longevity of florets opening or survival on spike (20.33 days) was recorded in 1000 ppm Cycocel.

\section{Effect of Vernalization and Growth Regulators on Flowering of Ornithogalum 'Chesapeake Snowflake'}

Jin Wang ${ }^{1}$, Virginia R. Walter*2

${ }^{1}$ Southwest Forestry College and Life Science college of Yunnan Univ., Horticulture Dept. Kunming, Yunnan, 650224, P.R China: ${ }^{2}$ California Polytechnic State Univ., Horticulture and Crop Science Dept., San Luis Obispo, CA 93407

The effect of vernalization and two growth regulators Fascination ${ }^{\mathrm{TM}}$ and Pro-Gibb ${ }^{\circledR}$ on the growth, inflorescence development and flowering of Ornithogalum 'Chesapeake Snowflake' was studied. Regardless of bulb size, chilling bulbs for 3 weeks at $10^{\circ} \mathrm{C}$ before planting accelerated flowering of the first inflorescence and shorten leaf length by $3-5 \mathrm{~cm}$ as compared to non-chilled bulbs. Fascination ${ }^{\mathrm{TM}} 10 \% 100 \mu \mathrm{L}^{\mathrm{T}}$ and Pro-Gibb ${ }^{\circledR}$ $200 \mathrm{ppm}$ accelerated flowering of first inflorescence by large bulbs (8- to 10 -cm circumference) as compared to controls. PGR treatments appear to have no effect on small bulbs (3-5-cm circumference). 
317 Carnation Vase Life as Affected by Gibberellic Acid and Benzyladenine Treatments

\section{Cesar A. Martinez-Mateo ${ }^{1}$, J. Pablo Morales-Payan*2}

${ }^{1}$ Universidad Nacional Pedro Henriquez Ureña, Plant Sciences, Santo Domingo, Dominican Republic, ${ }^{2}$ Universidad Nacional Pedro Henriquez Ureña, Plant Sciences, Santo Domingo, Dominican Republic

Experiments were conducted to determine the effect of dipping open 'Scania' carnation flowers in aqueous solutions of benzyl adenine (BA) $\left(0,13,26,39\right.$, and $\left.52 \mathrm{mg} \cdot \mathrm{L}^{-1}\right)$ and gibberellic acid $\left(\mathrm{GA}_{3}\right)(0,10$, 20,50 , and $\left.100 \mathrm{mg} \cdot \mathrm{L}^{-1}\right)$ on flower vase life. Flowers were dipped for two minutes in $\mathrm{BA}$ or $\mathrm{GA}_{3}$ solutions, and visual symptoms of flower senescence were periodically recorded based on distortion, discoloration, and permanent wilting of the petals. In general, visual symptoms of senescence progressed more slowly in BA-treated flowers than in $\mathrm{GA}_{3}$ treated and control flowers. One week after treatment, the only flowers with satisfactory appearance (slight or no petal distortion, wilting or discoloration) were those treated with BA at the rate of $13 \mathrm{mg} \cdot \mathrm{L}^{-1}$ and $\mathrm{GA}_{3}$ at the rate of $50 \mathrm{mg} \cdot \mathrm{L}^{-1}$.

\section{Effects of Silicon Additive to the Growth and Postharvest Life of Hydroponically Grown 'Kardinal' Roses}

Virginia R. Walter*1

${ }^{1}$ California Polytechnic State Univ., Horticulture and Crop Science Dept., San Luis Obispo, CA 93407

A 100 parts per million solution of potassium silicate was added to the nutrient solution of well established, hydroponically grown 'Kardinal' rose plants. No significant effects of silicon were determined on post harvest life of the rose flowers harvested over a 3-month period as compared to flowers harvested from control plants grown without the silicon additive. Silicon additive did have a significant positive effect on the length of harvested stems.

\section{Shipping and 1-Methylcyclopropene (1-MCP) Effects on Shelf Life of Diascia $\times$ hybrida}

Shannon E. Beach*1, Terri W. Starman ${ }^{2}$

${ }^{1}$ Texas A\&M Univ., Dept. of Horticultural Sciences, College Station, TX 77843-1223; ${ }^{2}$ Texas A\&M Univ., Dept. of Horticultural Sciences, College Station, TX 77843-2133

Diascia $\times$ hybrida (diascia) is a cool season vegetative annual produced in 6 weeks in an 11.4-cm pot under greenhouse production. Early experiments noted that during simulated shipping in a growth chamber at 26.7 $\pm 0.3{ }^{\circ} \mathrm{C}, 0 \mu \mathrm{mol} \cdot \mathrm{m}^{-2} \cdot \mathrm{s}^{-1} \mathrm{PPF}$ and $50 \% \mathrm{RH}$, diascia flowers abscised. To test the effect of 1-MCP on retention of flowers during shipping, three hundred diascia plants were grown under temperature set points of $24^{\circ} / 18^{\circ} \mathrm{C}$ day/night in a glass greenhouse. Three harvests of 42 plants each were made as plants became marketable i.e., open flowers on six racemes. The treatments were factorial with three shipping durations (0, 1, or 2 days) and two 1-MCP (1-Methylcyclopropene, Ethylboc, Floralife, Waterboro, S.C.) treatments $\left(0 \mathrm{mg} \cdot \mathrm{L}^{-1}\right.$ and the commercially recommended application rate) and seven plants per treatment. Plants were boxed and sealed under 4-mL clear plastic tarps with duct tape and then treated with 1-MCP gas or water for 4 hours before moving to the growth room $\left(19^{\circ} \mathrm{C}, 10 \mu \mathrm{mol} \cdot \mathrm{m}^{-2} \cdot \mathrm{s}^{-1} \mathrm{PPF}\right)$ for 2 weeks. They remained in the boxes for the duration of simulated shipping treatments. Flower number, racemes with open flowers and a quality rating were given when removed from the shipping boxes. For plants in the first and second harvests, 1-MCP significantly reduced flower and raceme abscission 1 week after shipping regardless of shipping duration; this was not seen in the third harvest. Two weeks post shipment there was no difference in flower numbers between 1-MCP treated and untreated plants. With two exceptions, no differences among measured variables occurred due to shipping duration.

320 Balancing Act: Effects of Fertilizer and Uniconazole on Growth of Herbaceous Perennials

Holly L. Scoggins ${ }^{* 1}$, Joyce G. Latimer ${ }^{2}$

${ }^{1}$ Virginia Tech, Dept. of Horticulture, Blacksburg, VA 24061; ${ }^{2}$ Virginia Tech, Dept. of
Horticulture, Blacksburg, VA 24061

Increasing fertilizer levels may reduce production time but can lead to excessive growth of herbaceous perennials, requiring the application of plant growth regulators (PGRs). This study investigated the effects of ascending fertilizer rates in conjunction with two rates of uniconazole and a control. Rooted liners of Artemisia arborescens L. 'Powis Castle', Artemisia vulgaris L. 'Oriental Limelight, Astilbe chinensis (Maxim.) Franch. 'Pumila', Filipendula rubra (Hill) Robinson 'Venusta' and Perovskia atriplicifolia Benth. were potted with controlled-release fertilizer $(15 \mathrm{~N}-3.9 \mathrm{P}-10 \mathrm{~K})$ incorporated at $2.4,4.72$, and $7.11 \mathrm{~kg} \cdot \mathrm{m}^{-3}$. A single foliar spray application of uniconazole was applied two weeks after transplanting at a volume of $210 \mathrm{~mL} \cdot \mathrm{m}^{-3}$ and two rates from 15 to 60 $\mathrm{mg} \cdot \mathrm{L}^{-1}$ plus a control (species-dependent). Plant height and width were measured at 2,4,6, and 8 weeks after treatment (WAT). No interactions between fertilizer rate and uniconazole were observed. Main effects varied by species. The application of uniconazole controlled height and width of Artemisia 'Oriental Limelight' and Astilbe for the duration of the experiment. Height, width, and dry weight of Artemisia 'Oriental Limelight' increased with ascending fertilizer rates while Astilbe was not affected. Growth of Filipendula and Artemisia 'Powis Castle' was unresponsive to uniconazole, though dry weight was reduced for both at the lowest fertilizer rate. Uniconazole provided height control of Perovskia, but the effect did not persist beyond 6 WAT. Ascending fertilizer rates increased Perovskia dry weight but not height.

\section{Poster Session 40-Viticulture and Small Fruits}

\section{July 20, 2004, 12:30-1:30 PM Rio Grande Exhibit Hall}

\section{Actigard Reduces Anthracnose on Field-grown Strawberry}

Joel L. Shuman*1, Anthony D. Bratsch ${ }^{2}$

${ }^{1}$ Virginia Polytechnic Institute \& State Univ., Virginia Bioinformatics Institute, Blacksburg, VA 24061-0477; ${ }^{2}$ Virginia Polytechnic Institute \& State Univ., Horticulture, Blacksburg, VA 24061-0327

Anthracnose fruit rot (AFR) and crown rot can cause severe economic losses on susceptible 'Chandler' and 'Camarosa' strawberry in Virginia: 'Sweet Charlie' and 'Bish' are moderately resistant to resistant. Actigard (acibenzolar-S-methyl), an inducer of systemic acquired resistance, has been effective at reducing black spot and speck on tomato, blue mold on tobacco, and fire blight on apple. The objective of this study was to determine if Actigard, when spray-applied to field-grown strawberry, can reduce AFR better than or equal to several registered fungicides. Four varieties (VAR) (Chandler, Camarosa, Sweet Charlie, and Bish) were treated with four fungicides (FUNG) (water control, azoxystrobin, chlorothalonil, and actigard). Experimental design was a split plot with FUNG as the main plot and VAR as the split plot with four replicates. Standard annual hill system practices were used throughout. Plots were inoculated three times throughout the harvest season with a conidia : water solution of $1 \times 10^{6}$ conidia per $\mathrm{mL}$. Plots were treated with FUNG on a 14-day schedule from bloom to end of season. Plots were visually assessed for anthracnose and fruit were harvested $2 \times$ weekly and weighed into four categories: marketable, cull, fruit with anthracnose, and fruit with other diseases. Environmental conditions were conducive for anthracnose development: extended periods of rain and high relative humidity. Plots treated with water control had more AFR, other fruit rots, and higher overall disease ratings than those treated with a compound. Plots treated with actigard had the same level of AFR as did those treated with azoxystrobin. 'Chandler' and 'Camarosa' had considerably more AFR than 'Sweet Charlie' and 'Bish' had the least amount over all FUNG.

400 The Effects of Cultivar on the Arbuscular Mycorrhizal Fungi Symbiosis in Strawberries

Marjorie E. Ross*1, Emily E. Hoover ${ }^{2}$

${ }^{1}$ Univ. of Minnesota, Horticulture, St. Paul, MN 55108; ${ }^{2}$ Univ. of Minnesota, Horticulture, St. Paul, MN 55108

Cultivar may cause variation in arbuscular mycorrhizal fungi (AMF) 
colonization levels leading to differences in shoot growth and runner formation, and in pathogen control in strawberries. However, a clear consensus has not been reached regarding the degree to which cultivar affects the formation of the symbiosis or its functioning. The study was conducted on four commercial strawberry farms in Minnesota and Wisconsin to compare, within a farm, mycorrhizal colonization and plant response among three strawberry cultivars: 'Winona', 'Anapolis' and 'Jewel'. At each farm, two $6 \times 6$ meter plots of each cultivar were randomly selected. On each of three sampling dates, 4 whole plants and soil samples were collected from these plots in the 2003 field season. Roots were separated from shoots and leaves, and fresh and dry weights were taken. Leaves and soil were dried, weighed, and submitted for nutrient analysis. Soil nutrient analyses include phosphorus (Bray P), potassium, $\mathrm{pH}$, buffer $\mathrm{pH}$ and organic matter. Leaf tissue analyses include P, K, Ca, Mg, Na, AL Fe, MN Zn, Cu, B, Pb, Ni, Cr, and Cd. Roots were collected, frozen, and prepared for scoring using methods adapted from Koske and Gemma (1989). Presence of mycorrhizal colonization is being scored using the methods of McGongle et al. (1990). Levels of mycorrhizal colonization among different strawberry cultivars will be compared. We will also use biomass measurements, to determine mycorrhizal effects on plant growth among different cultivars. Soil and leaf analysis data will be used to determine effects of AMF on plant nutrition and compare effects among cultivars.

\section{The Effective Pollination Period in Rabbiteye Blueberry}

Patricio A. Brevis*1, D. Scott NeSmith ${ }^{2}$

${ }^{1}$ Univ. of Georgia, Horticulture, Griffin, GA 30223-1797; ${ }^{2}$ Univ. of Georgia, Horticulture, Griffin, GA 30223-1797

Rabbiteye blueberries (Vaccinium ashei Reade) often exhibit poor fruit set under commercial field conditions. Problems of low fruit set have been attributed to short periods of flower receptivity in different fruit crops. This study seeks to establish the effective pollination period(EPP, defined as the number of days during which pollination is effective to produce a fruit) in rabbiteye blueberry. The cultivars Brightwell and Tifblue were chosen due to their known difference in fruit set and field performance. Flowers were hand pollinated 0, 2, 4, 6, and 8 days after anthesis (DAA) using self- and cross-pollen. Fruit set, seeds per berry, berry weight and days to ripening were recorded. Fruit set showed a polynomial trend across flower ages. 'Brightwell' was highly receptive from the day of anthesis, whereas, 'Tifblue' receptivity was low until 2 DAA. 'Brightwell' and 'Tifblue' flowers produced adequate fruit set $(\geq 50 \%)$ over a period of 7 and 5 days, respectively. In 'Tifblue', fruit set was limited by the low receptivity of newly opened flowers. The difference in EPP helps to explain the performance of these cultivars in the field. The rate of ripening increased with flower age in both cultivars. The number of seeds per berry was affected by flower age only in 'Tifblue'. The effect of flower age on berry weight depended on the cultivar and the pollen source.

\section{Natural and Artificial Chilling of Southern Highbush Blueberry}

\section{Donna A. Marshall*1, Stephen J. Stringer ${ }^{2}$, James M. Spiers ${ }^{3}$}

${ }^{1}$ USDA-ARS, Small Fruits Research Station, Poplarville, MS 39470; ${ }^{2}$ USDA-ARS, Small Fruits Research Station, Poplarville, MS 39470; ${ }^{3}$ USDA-ARS, Small Fruits Research Station, Poplarville, MS 39470

A study was initiated in November, 2002 to determine the effects of exposing two Southern Highbush blueberries (Vaccinium corybosum L) to artificial chilling hours on initiation of bud break and advancement of floral and vegetative bud maturity. Plants of 'Jubilee' and 'Misty' were divided into 2 groups in which one was left outdoors, allowing chilling to occur and accumulate naturally, while the other group was placed in a growth chamber set at a constant artificial temperature of $4{ }^{\circ} \mathrm{C}$. Five plants of each cultivar were then placed into a heated greenhouse after $0,200,400,600$, or 800 hours of chilling (total hours of exposure to $<5{ }^{\circ} \mathrm{C}$ ) had accumulated for forcing of flower bud development. The progression of floral bud development of the terminal three buds on five tagged stems was observed at 7-10 day intervals for 30 days. At the end of the forcing period observations were also made on total percent vegetative and floral bud break. Prior to accumulating sufficient chilling requirements, chilling delivery method did not appear to influence the rate of floral bud development since none advanced past stage 3 regardless of chilling regime used. However after chilling requirements were met, flower buds of plants that were allowed to chill naturally developed more quickly than did those chilled by artificial means.

\section{Nitrate and Ammonium Uptake in Vaccinium Species Differing in Tolerance to High Soil pH}

Kevin R. Kosola*1, Rebecca L. Darnell ${ }^{2}$

${ }^{1}$ Univ. of Wisconsin, Madison, Horticulture, Madison, WI 53706; ${ }^{2}$ Univ. of Florida, Horticultural Sciences, Gainesville, FL 32611

Cultivated Vaccinium species (e.g. highbush blueberry, Vaccinium corymbosum, or cranberry, V. macrocarpon) commonly require acidic soil ( $\mathrm{pH} 4.5$ to 5.5) for optimum growth. Under these conditions, ammonium $\left(\mathrm{NH}_{4}^{+}\right)$is the dominant form of inorganic $\mathrm{N}$. In contrast, $V$. arboreum, the sparkleberry can tolerate higher-pH mineral soils, where nitrate $\left(\mathrm{NO}_{3}^{-}\right)$is typically the predominant inorganic $\mathrm{N}$ form. This tolerance may be related to increased ability to acquire and utilize $\mathrm{NO}_{3}-\mathrm{N}$. Measurements of ${ }^{15} \mathrm{NO}_{3}{ }^{-}$and ${ }^{15} \mathrm{NH}_{4}^{+}$influx kinetics in excised roots of $V$. arboreum, $V$. corymbosum, and $V$. macrocarpon did not support this hypothesis. $\mathrm{NO}_{3}^{-}$influx kinetics measured from 10 micromolar to 200 micromolar $\mathrm{NO}_{3}^{-}$were similar among all three species. $\mathrm{NO}_{3}{ }_{3}^{-}$ influx was consistently lower than $\mathrm{NH}_{4}^{+}$influx at all concentrations for all three species.

\section{Cutting Propagation Efficiency of Lowbush Blueberry (Vac- cinium angustifolium Ait.) Depending on the Conditions of Media and Cutting}

\section{Jun Gu Lee*1, Jong Nam Lee ${ }^{2}$, Eung Ho Lee ${ }^{3}$, Byoung Yil Lee ${ }^{4}$}

${ }^{1}$ National Institute of Alpine Agriculture, Alpine Crop Dept., Doammyun Pyeongchang, Gangwon, 232-955, Rep. of Korea; ${ }^{2}$ National Institute of Alpine Agriculture, Horticulture Dept., Doammyun Pyeongchang, Gangwon, 232-955, Rep. of Korea; ${ }^{3}$ National Institute of Alpine Agriculture, Horticulture Dept., Doammyun Pyeongchang, Gangwon, 232-955, Rep. of Korea; ${ }^{4}$ Seoul National Univ., Horticulture Dept., Seoul, Gangwon, 151-742, Rep. of Korea

Lowbush blueberry (Vaccinium angustifolium Ait.) have some potential agricultural benefits for soil covering and high nutritive antioxidant fruit production in highland of South Korea. As a preliminary research step to introduce and to rapidly propagate the lowbush blueberry in South Korea, we evaluated the cutting propagation efficiency under several cutting conditions. The $\mathrm{pH}$ of peatmoss media were adjusted to five target values of 4.5, 5.0, 5.5, 6.0, and control with air-slaked lime. Peatmoss were mixed with perlite at five levels of volume ratios in separate experimental design. The cuttings were also prepared with the three cutting regions from mother stock shoots and the number of nodes per cutting. The rooting of $V$. angustifolium cuttings initiated at 50 days after cutting in nursery bed, and at 70 days after cutting, shallow root ball were developed by $0.5 \mathrm{~cm}$ diameter. The rooting rate and root ball development were favorable in the $\mathrm{pH} 4.5$ and nonadjusted control $(\mathrm{pH}$ 4.15) while the mixed ratio of perlite did not affect on rooting efficiency ranging from $30 \%$ to $50 \%$ mixed treatment. Terminal and intermediate region from newly developed shoot performed higher cutting efficiency compared to the basal region, and four to six nodes per each cutting showed favorable shoot growth and root ball development compared to the 2-node cutting. Thus the cutting of upper shoot region having four to six nodes in acidic peatmoss nursery containing $30 \%$ to $50 \%$ perlite might be suitable preliminary screened conditions. The cutting propagation efficiency of the five lowbush blueberry clones were also evaluated depending on the summer and early spring cutting.

\section{Effects of Wood-chip Mulch on Growth and Productivity of 'Apache' Blackberry}

Curt R. Rom ${ }^{1}$, Jason McAfee*2

${ }^{1}$ Univ. of Arkansas, Horticulture, Fayetteville, AR 72701; ${ }^{2}$ Univ. of Arkansas, Horticulture, Fayetteville, AR 72701

'Apache' blackberry planted in 3-m plots spaced at $0.6 \mathrm{~m}$ between 
plants were maintained either with or without waste municipal wood chip mulch and grown for 5 years. Plots received similar weed control, pest management, and irrigation. All plots were annually hedged at $1.35-\mathrm{m}$ height twice during midsummer to encourage branching. Fruit were harvested beginning in the second season after a season of establishment. Annual yield in the mulched plots was $15 \%$ greater, average fruit size was $4 \%$ larger, and cumulative yield was $9 \%$ greater in the mulched plots compared to nonmulched control plots. In two seasons, average berry soluble solids content of fruit from mulched plots was slightly, but not significantly higher. Annual primocane number was $33 \%$ greater, floricane number $41 \%$ greater, floricane dry weight after harvest was $15 \%$ greater, and average plant height before summer pruning was $24 \%$ taller in mulched plots compared to nonmulched plots. Mulch significantly reduced weeds within the plots.

\section{Impact of Modified Atmosphere Storage on Eastern Thornless Blackberry Quality and Antioxidant Levels}

\section{J. Matt Fulkerson ${ }^{1}$, Douglas D. Archbold*2}

${ }^{1}$ Univ. of Kentucky, Horticulture, Lexington, KY 40546-0091; ${ }^{2}$ Univ. of Kentucky, Horticulture, Lexington, KY 40546-0091

Modified atmosphere (MA) storage of blackberries may maintain quality and increase storage life, but there is limited information about how eastern thornless cultivars respond to MA's. Because there is also a growing interest in the health benefits of antioxidants in blackberries, it would be useful to know how those levels might change during MA storage. In 2002, the eastern thornless blackberry variety Chester was stored in MA; treatments included a control, or initial levels of $20 \%$ $\mathrm{CO}_{2}$ or $5 \% \mathrm{O}_{2}$. Color, $\mathrm{pH}$, firmness, fresh weight, soluble sugars, titratable acidity, total antioxidant capacity, and the levels of major classes of compounds with antioxidant activity of the fruit were measured at harvest, after 1 week of MA storage at $4{ }^{\circ} \mathrm{C}$, and after 3 additional days at room temperature to simulate common industry practices and grocery display. Total antioxidant capacity was measured using the FRAP (ferric reducing/antioxidant power) assay, and total phenolics and anthocyanins were measured spectrophotometrically. In 2002, soluble sugar levels, fresh weight, titratable acidity, and all classes of antioxidants decreased from day 0 to day 7 to day 10 while the $\mathrm{pH}$ increased. Color values did not change. The only trait that differed among treatments was berry firmness; from day 0 to day 7 control fruit was the most firm, and those from the high $\mathrm{CO}_{2}$ treatment were the least firm. Studies were continued in 2003 with the addition of two more eastern thornless blackberry cultivars, Hull Thornless and Triple Crown, and these results will also be presented.

\section{Appearance of Xylella Fastidiosa in Pierce's Disease resistant and Susceptible Grapevines}

Xia Xu*1, Zhongbo Ren², Jiang $\mathrm{Lu}^{3}$

${ }^{1}$ Florida A\&M Univ., Center for Viticulture and Small Fruit Research, Tallahassee, FL 32317; ${ }^{2}$ Florida A\&M Univ., Center for Viticulture and Small Fruit Research, Tallahassee, FL 32317; ${ }^{3}$ Florida A\&M Univ., Center for Viticulture and Small Fruit Research, Tallahassee, FL 32317

Pierce's Disease (PD) is a major factor limiting grape production in the southeast United State. This disease is caused by a bacterium, Xylella fastidiosa Wells et al., which is transmitted to the xylem system of the grapevines primarily by glassy-winged sharpshooters (Homalodisca coagulata Say). Once it is in the xylem, the $X$. fastidiosa will use the xylem sap as a nutrient source to multiply, colonize, and eventually plug the xylem vessels and cause the PD in susceptible cultivars. On the other hand, symptoms of PD in tolerant cultivars do not appear until fruit maturation, and symptoms are rarely observed in PD resistant cultivars. In order to understand the correlation between $X$. fastidiosa and PD symptom development, a study was initialed to monitor $X$. fastidiosa in xylem of resistant, tolerant, and susceptible vines on a monthly basis. Presence of $X$. fastidiosa was detected directly from xylem sap of field-grown vines by medium culture and confirmed by polymerase chain reaction (PCR). Xylella fastidiosa was detectable throughout the growing season in PD susceptible cultivar 'Chardonnay', PD tolerant Florida hybrid grape 'Blanc du Bois', and muscadine cultivar 'Carlos'.
The bacteria were also appeared in the dormant vines with high density in cultivars 'Chardonnay' and 'Blanc du Bios'. Although X. fastidiosa was also found in dormant canes of 'Carlos', the density decreased throughout the late fall and winter months, and they were hardly found before June. The results indicated that $X$. fastidiosa were carried over from previous season in cultivars 'Chardonnay' and 'Blanc du Bois', while in PD tolerant cultivar 'Carlos', they were newly acquired from the sharpshooter feedings during the growing season.

\section{Vine Vigor and Fruit Characteristics of Muscadine Grapes} Zhongbo Ren*1, Jiang Lu*2, Xia Xu*3

${ }^{1}$ Florida A\&M Univ., Center for Viticulture and Small Fruit Research, Tallahassee, FL 32317; ${ }^{2}$ Florida A\&M Univ., Center for Viticulture and Small Fruit Research, Tallahassee, FL 32317; ${ }^{3}$ Florida A\&M Univ., Center for Viticulture and Samll Fruit Research, Tallahassee, FL 32317

Muscadine grape industry in the southeastern United Sates is expanding in recent years. To provide necessary information for the growing industry, 50 muscadine grape cultivars were evaluated for vigor and fruit characteristics at Florida A\&M Univ., Tallahassee, Fla. Vine vigor was measured by winter pruning weight and varied from 5.4 lb/vine to $35.7 \mathrm{lb} /$ vine. Among these cultivars, Triumph, Summit, and Tara were the least vigorous, while 'Carlos', 'Fry Seedless', and 'Gold Isle' produced the most pruning weight. Dry scar ranged from $60.6 \%$ (Darlene) to $97.7 \%$ (Dixie Red). Among the most important table grapes, 'Nesbitt', 'Alachua', 'Jumbo', 'Fry', 'Triumph', and 'Scarlete' showed more than $70 \%$ of dry scars. Fruit rot ranged from $0.3 \%$ (Gold Isle) to $31.8 \%$ (Dixie Land). 'Noble', 'Scarlet', 'Nesbitt', and 'Carlos' were the important cultivars with less than $5 \%$ rotted fruits. Commercial fruit index were different significantly among the cultivars, ranged from $45.5 \%$ to $96.4 \%$. Higher commercial fruit index of table grapes were found with 'Magnolia', 'Rosa', 'Scarlet', and 'Tara', while 'Dixie Land' (45.5\%) was the least. Seeds per fruit varied among the cultivars, ranging from 2.4 to 4.9. Fewer fruit seeds were found in 'Fry' and 'Nesbitt', while 'Granny Val', 'Senoria', 'Darlene' and 'Triumph' had more seeds per fruit than the others. Seed size also differed among the cultivars. 'Sugar Pop' had the largest seeds $(0.144$ $\mathrm{g} / \mathrm{seed}$ ), which was twice as the size of the smallest seeds of 'Welder' $(0.056 \mathrm{~g} / \mathrm{seed})$. Fruit soluble solids content (SSC) ranged from $11.7 \%$ to $16.9 \%$ among the cvs. evaluated. Higher SSCs were found in 'Welder', 'Fry Seedless', 'Scarlet', and 'Cowart', while 'Senoria' and 'Jumbo' had relatively low SSC.

\section{$409 \mathrm{CO}_{2}$ Assimilation, Photosynthetic Enzymes, and Carbohydrates of Grape Leaves (Vitis labrusca L. cv. Concord) in Response to Iron Supply}

\section{Brandon R. Smith*1, Li-Song Chen ${ }^{2}$, Lailiang Cheng ${ }^{3}$}

${ }^{1}$ Cornell Univ., Horticulture, Ithaca, NY $14853 ;{ }^{2}$ Fujian Agriculture and Forestry Univ., Horticulture, Fuzhou, 350002, P.R. China; ${ }^{3}$ Cornell Univ., Horticulture, Ithaca, NY 14853

Own-rooted one-year-old 'Concord' grapevines were fertigated twice weekly for 11 weeks with $1,10,20,50$, OR $100 \mu \mathrm{mol}$ iron (Fe) from ferric ethylenediamine di (o-hydroxyphenylacetic) acid in a complete nutrient solution. As Fe supply increased, leaf total Fe content did not change, whereas active Fe (extracted by 2, 2'-dipyridyl) and total chlorophyll content increased curvilinearly. $\mathrm{CO}_{2}$ assimilation and stomatal conductance increased curvilinearly with increasing active $\mathrm{Fe}$, whereas intercellular $\mathrm{CO}_{2}$ concentrations decreased linearly. Activities of key Calvin cycle enzymes, Rubisco, NADP-glyceraldehyde-3-phosphate dehydrogenase, phosphoribulokinase, stromal fructose-1,6-bisphosphatase (FBPase), and a key enzyme in sucrose synthesis, cytosolic FBPase, all increased linearly with increasing active Fe. No difference was found in the activities of ADP-glucose pyrophosphorylase and sucrose phosphate synthase of leaves between the lowest and the highest treatments, whereas slightly lower activities were observed in the middle Fe treatments. Content of 3-phosphoglycerate increased curvilinearly with increased active Fe, whereas glucose-6-phosphate and fructose-6-phosphate did not change. Glucose, fructose, sucrose, starch, and total non-structural carbohydrates at both dusk and predawn increased with increasing active Fe. Carbon export from starch 
breakdown during the night, calculated as the difference between dusk and predawn levels, increased as active Fe increased. In conclusion, $\mathrm{Fe}$ limitation reduces the activities of Rubisco and other photosynthetic enzymes, and hence $\mathrm{CO}_{2}$ assimilation capacity. Fe-deficient grapevines have lower concentrations of non-structural carbohydrates in source leaves, and therefore, are source limited.

\section{Application of Spectroscopy for Measuring Leaf Nitrogen, Chlorophyll and the Other Pigments in Pinot Noir Grape}

Pinghai Ding*1, Jessica M. Cortell ${ }^{2}$, Leslie H. Fuchigami ${ }^{3}$

${ }^{1}$ Oregon State Univ., Dept. of Horticulture, Corvallis, OR 97331; ${ }^{2}$ Oregon State Univ., Dept. of Food Science and Technology, Corvallis, OR 97331; ${ }^{3}$ Oregon State Univ., Dept. of Horticulture, Corvallis, OR 97331

Nitrogen is one of the most important nutrition factors affecting grapevine growth performance and berry quality. Leaf pigments contents and leaf areas are the important indicators of grapevine nitrogen status and plant performance. In order to find a efficient way to nondestructively measure leaf nitrogen and pigments status, the SPAD meter, CCM-200 and CM-1000 chlorophyll meter in comparisons with FOSS NIR system were used in measuring leaf nitrogen, leaf chlorophyll, carotenoids, flavonoids and anthocyanins in 7-year-old Pinot Noir grape with different rate of $\mathrm{N}$ treatments. The results indicate that the reading of all these meters have a good relationship with leaf $\mathrm{N}$, leaf chlorophyll and leaf area. But the accuracy among these meters was different, in which the accuracy of FOSS NIR is better than that of the SPAD meter, CCM-200 and CM-1000. There is the good relationship between leaf nitrogen contents, leaf area, leaf chlorophyll and carotenoids contents. Flavonoids and anthocyanins have the inverse relationship with leaf $\mathrm{N}$ contents and leaf area. FOSS NIR system can be use for nondestructive assessing nitrogen, leaf chlorophyll, carotenoids, flavonoids and anthocyanins whereas the other meters can only used for nondestructive assessing leaf nitrogen and leaf chlorophyll. These results indicate it is possible to use nondestructive spectral methods as the precision viticulture tools to manage vineyards nitrogen fertilization and grapevine performance.

\section{Soil pH Affects Growth and Nutrient Content of Grapes}

\section{Maru K. Kering ${ }^{1}$, Martin L. Kaps*2}

${ }^{1}$ Southwest Missouri State Univ., Fruit Science, Mountain Grove, MO 65711; ${ }^{2}$ Southwest Missouri State Univ., Fruit Science, Mountain Grove, MO 65711

The grape cultivars Vidal blanc, a French-American hybrid, and Norton, primarily Vitis aestivalis, were transplanted to 19-L pots with soil amended to $\mathrm{pH} 4.5,5.9,7.2$, and 8.5. The soil was a mixture of coarse sand and a silty clay loam in the proportion 2 to 1 . The experiment was a randomized complete block with two treatments (cultivar, soil $\mathrm{pH}$ ) and six replications. The objectives of the experiment were to determine vegetative growth and nutrient content of the two cultivars at varying soil $\mathrm{pH}$, and the soil $\mathrm{pH}$ within those tested that optimized growth. Vidal blanc was superior to Norton in all growth measurements after 94 days. At pH 7.2 and 8.5, significant reductions in shoot length; leaf area; and leaf, shoot and root dry weights occurred for Norton but not for Vidal blanc. Trends toward lower $\mathrm{P}, \mathrm{Mg}, \mathrm{Fe}$, and $\mathrm{MN}$ and higher $\mathrm{B}$ occurred at $\mathrm{pH}$ 8.5. Foliar symptoms of $\mathrm{Mg}$ and Fe deficiency were noticed for Norton at this elevated $\mathrm{pH}$ but not for Vidal blanc. The $\mathrm{pH}$ range 5.9 to 7.2 for Norton and 7.2 to 8.5 for Vidal blanc appeared to optimize growth for these two cultivars.

\section{Effects of Sunlight Exposure on Cluster Monoterpene Levels of 'Traminette' Grapes}

Patricia A. Sobieck*11, Bruce P. Bordelon ${ }^{2}$

${ }^{1}$ Purdue Univ., Horticulture and Landscape Architecture, West Lafayette, IN 47907; ${ }^{2}$ Purdue Univ., Horticulture and Landscape Architecture, West Lafayette, IN 47907

Monoterpenes are organic compounds found in high quantities in certain wine grape varieties, such as Riesling, Gewürztraminer, and muscatflavored varieties. These compounds exist in free and glycosidic form, and produce the characteristic aromas of such varieties. Traminette, released in 1996 as NY65.0533.13, is a cross between Joannes Seyve 23.416 and Gewürztraminer. This variety may be an alternative to Gewürztraminer in areas where cold temperatures prevent cultivation of such cold-tender varieties. The objective of this study is to determine the extent of which sunlight exposure influences monoterpene production in 'Traminette'. Various exposure levels were obtained through synthetic coverings and ambient shading. Fully exposed clusters on a vertically shoot positioned canopy received $55 \%$ of ambient light whereas clusters with 50 and $70 \%$ shade cloth received 14.7 and $5.3 \%$, respectively. Heavily shaded clusters (3+ leaf layers) received $2 \%$ of ambient light, and fully covered clusters received no light from véraison to harvest. Despite large differences in exposure level, cluster temperatures did not differ significantly between treatments. Results of monoterpene quantification show potentially volatile terpene (PVT) levels were 10-fold greater than free volatile terpene (FVT) levels in all treatments. PVT levels differ significantly between exposure groups in all locations at harvest, with exposed fruit having the highest concentration (6.5-7.5 $\left.\mathrm{mg} \mathrm{L}^{-1}\right)$. Heavy and moderate shade fruit had $25 \%$ lower PVT levels compared to exposed fruit. Fully covered clusters had $34 \%$ less PVT, whereas 50 and 70 shade cloth clusters were $20 \%$ lower than exposed. Subsequent years of research will further validate preliminary findings of this study.

\section{Effects of Harvest Pruning on 'Thompson Seedless' Grapevines} Matthew Fidelibus*1, David Smart ${ }^{2}$

${ }^{1}$ Univ. of California, Viticulture and Enology, Parlier, CA 93648; ${ }^{2}$ Univ. of California, Davis, Viticulture and Enology, Davis, CA 95616

In response to diminishing returns, the California raisin industry is rapidly adopting mechanical raisin harvesting practices to reduce cost. Whether the fruit will dry on the vine, or be laid on continuous trays to dry, the first step of mechanical raisin harvest generally involves severing the canes of vines with ripe fruit, a practice known as harvest pruning (HP). The potential physiological implications of HP are uncertain, so an experiment was established to assess the effects of HP on 40year-old 'Thompson Seedless' grapevines (Vitis vinifera L.) that were on their own roots, head-trained and cane pruned, and supported by a single wire trellis. Fruit achieved $20^{\circ}$ Brix by 2 Sept., at which time vines had a leaf area of about $21.6 \mathrm{~m}^{2}$. About $60 \%$ of the canopy leaf area was from canes, and thus removed by HP. The net $\mathrm{CO}_{2}$ assimilation rate $(\mathrm{A})$ of mature leaves on renewal shoots began to decline after about 8 Aug., but they maintained a positive $A$ until at least 31 Oct. Reduced A was due, in part, to chlorophyll degradation as evidenced by a decline in SPAD units occurring over the period that A declined. Harvest pruning generally did not affect A of mature leaves retained on renewal shoots, but those leaves maintained a positive A for at least $60 \mathrm{~d}$ after HP indicating that HP reduced the vines' photosynthetic capacity. Soil respiration also declined between summer and winter, probably in response to decreasing soil temperatures. Soil respiration was similar among HP and non-HP vines, except about $30 \mathrm{~d}$ after HP, when HP vines had about $30 \%$ lower soil respiration values than non-HP vines. Root growth was observed in summer and fall regardless of whether vines were subjected to HP.

\section{Foliar Urea Application in the Fall Affects Both Nitrogen and Carbon Storage in Young 'Concord' Grapevines Grown Under a Wide Range of Nitrogen Supply}

Guohai Xia*1, Lailiang Cheng ${ }^{2}$

${ }^{1}$ Cornell Univ., Hort., Ithaca, NY 14853; ${ }^{2}$ Cornell Univ., Hort., Ithaca, NY 14853

One-year-old 'Concord' vines were fertigated with $0,5,10,15$, or 20 $\mathrm{mm} \mathrm{N}$ in a modified Hoagland's solution for 8 weeks during summer. Half of the vines fertigated at each $\mathrm{N}$ concentration were sprayed with $3 \%$ foliar urea twice in late September while the rest served as controls. Four vines from each treatment combination were destructively sampled during dormancy to determine the levels and forms of $\mathrm{N}$ and carbohydrates. Nitrogen fertigation during the summer only slightly increased vine $\mathrm{N}$ concentration whereas foliar urea application in the fall significantly increased vine $\mathrm{N}$ concentration. In response to foliar 
urea application, concentrations of both free amino acid-N and protein- $\mathrm{N}$ increased, but the ratio of protein $\mathrm{N}$ to amino acid $\mathrm{N}$ decreased. Arginine was the most abundant amino acid in free amino acids and proteins, and its concentration was linearly correlated with vine $\mathrm{N}$ concentration. Concentrations of total non-structural carbohydrates (TNC) decreased slightly in response to $\mathrm{N}$ supply from fertigation. Foliar urea application in the fall significantly decreased TNC concentration at each $\mathrm{N}$ fertigation level. Starch, glucose and fructose decreased in response to foliar urea applications, but sucrose concentration remained unaffected. Approximately $60 \%$ of the carbon decrease in TNC caused by foliar urea application was recovered in proteins and free amino acids. We conclude that free amino acids account for a larger proportion of the $\mathrm{N}$ in vines sprayed with foliar urea, but proteins remain as the main form of $\mathrm{N}$ storage. In response to foliar urea application, part of the carbon from TNC is incorporated into proteins and free amino acids, leading to a decrease in the carbon stored in TNC and an increase in the carbon stored in proteins and free amino acids.

\section{Evaluation of Grapevine 'Cabernet Sauvignon' Response to Two Deficit Irrigation Strategies}

Ashley Basinger ${ }^{1}$, Edward Hellman*2, Steven Shelby ${ }^{3}$

${ }^{1}$ Texas Tech Univ., Plant \& Soil Science; ${ }^{2}$ Texas A\&M Univ., Horticultural Sciences, Lubbock, Texas, 79403; ${ }^{3}$ Texas A\&M Univ., Horticultural Sciences

Partial rootzone drying (PRD) and regulated deficit irrigation (RDI) were evaluated separately over two years on Vitis vinifera $\mathrm{L}$. variety 'Cabernet Sauvignon' for their applicability to commercial vineyards in Texas and to investigate their potential for enhancing grapevine acclimation and cold hardiness. PRD treatments compared the alternating-half-rootzone water application strategy of PRD to an equal volume of water applied to the entire rootzone and a $2 \times$ volume of water applied to the entire rootzone. RDI treatments compared the effects of deficit irrigation at different developmental stages of grapevine: post-fruit set to veraison; veraison to harvest; post-harvest; and a no-deficit control. The PRD treatment plots performed similarly to the equal volume treatment plots for yield and fruit composition. The double-volume treatment had a trend to higher yield in 2002 and statistically significant higher yields in 2003, and slightly lower soluble solids content of fruit in 2002. Thus, the two deficit treatments, PRD and Equal, experienced only a small reduction in performance while enabling reduced water usage. The PRD alternating-half-rootzone strategy demonstrated no advantage over a standard deficit irrigation strategy. Grapevines irrigated with the RDI strategy responded to this treatment most during the post-fruit set to veraison stage of development, which had lower yields and higher fruit soluble solids compared to the no-deficit treatment in 2002. Both PRD and RDI deficit irrigation strategies significantly increased the earliness and rate of periderm development on shoots in both years, but did not result in consistently greater cold hardiness compared to no-deficit treatments.

\section{Effect of the Accumulated Effective Chilling Hours at the Prun- ing Time on Budbreak Table Grape on Dessertic Condition}

Fabian Robles-Contreras ${ }^{1}$, Manuel de Jesus Valenzuela-Ruiz ${ }^{2}$, Raul Leonel Grijalva-Contreras*3, Ruben Macias-Duarte ${ }^{4}$

${ }^{1}$ INIFAP-Caborca, Agroclimatology, Caborca, Sonora, 83600, Mexico; ${ }^{2}$ INIFAP-Caborca, Viticulture, Caborca, Sonora, 83600, Mexico; ${ }^{3}$ INIFAP-Caborca, Protected Horticulture, Caborca, Sonora, 83600, Mexico; ${ }^{4}$ INIFAP-Caborca, Soil \& Horticultural, Caborca, Sonora, 83600 , Mexico

The grape crop is important in Sonora State, Mexico, even though the grape growers have some problems that put in risk its continuity. To decide the moment of pruning time is one of the important decisions that the grower must done, because that depends partly the moment and the magnitude the budbreak appeared. The objective of this study was to determine the pruning time using the Effective Chilling Hours $(\mathrm{ECH})$ obtained from the climatologic station. In a commercial lot of the Superior Seedless variety, we studied the effects of pruning at different times depending on the accumulation of ECH $(150,200,250$, 350 , and 400). The ECH was calculated by adding the hours that the temperature stayed in following rank $0{ }^{\circ} \mathrm{C}<\mathrm{X}<10^{\circ} \mathrm{C}$, reducing the hours when the temperature was greater or equal to $25^{\circ} \mathrm{C}$. The data used to calculate this were obtained from the two climatologic stations near the lot in study. The effect in the budbreak was studied in canes and spurs. The results obtained in this study show that the final budbreak in canes as in spurs were not affected by the treatments in study and it was $76.5 \%$ and $81.8 \%$ for canes and spurs respectively. There is a direct relation $\left(R^{2}=0.94\right)$ between the $\mathrm{ECH}$ at pruning time and the percentage of early budbreak in the canes - from $5.6 \%(150 \mathrm{ECH})$ to $54.1 \%(400 \mathrm{ECH})$. Whereas in spurs, the early budbreak was favored when pruning is done after at least $200 \mathrm{ECH}$.

\section{Disecantes Product Use in the Raisin Grape Production}

Manuel de Jesus Valenzuela-Ruiz', Raul Leonel Grijalva-Contreras $^{* 2}$, Fabian Robles-Contreras ${ }^{3}$, Ruben Macias-Duarte ${ }^{4}$

${ }^{1}$ INIFAP-Caborca, Viticulture, Caborca, Sonora, 83600, Mexico; ${ }^{2}$ INIFAP-Caborca, Protected Horticultural, Caborca, Sonora, 83600, Mexico; ${ }^{3}$ INIFAP-Caborca, Agroclimatology, Caborca, Sonora, 83600, Mexico; ${ }^{4}$ INIFAP-Caborca, Soil \& Horticultural, Caborca, Sonora, 83600, Mexico

The Caborca, Sonora, region, is the main producing zone of raisins grape in Mexico, with a surface of 5000 ha. Nevertheless although that produce raisins of excellent quality, it is frequent that during the drying time, some rain ocurre and cause loses in yield up to a $30 \%$ and the quality is affected. The objective of this study was the evaluation of several chemical disecantes agents to reduce the drying time of the raisins grape. This study was carry in the INIFAPCaborca. We evaluate eleven treatments containing diferent concentrations of Metil Oleate, Potassium Carbonate, Potassium Sorbate and combinations of these products, a mesh and the control were included, these applications were made immediately after cut the grape, once it was tended on the bed. The results indicate that the best treatment were the mixture made from Metil Oleate plus Potassium Carbonate at $4 \%$ both products followed by the same mixture at $2 \%$, those treatments reduced the drying time in a $50 \%$ and $35 \%$ respecively. When using the mesh the drying time was extend, it need 4 days more than the control, since its total time of drying was 21 days. It is important to note that the treatments that contain the mixture of metil oleate and potassium carbonate and the mesh not presented rotting problems, during the drying stage.

\section{Effect of the Harmony Rootstock on Yield and Qualiy 'Flame Seedless' Table Grape}

Manuel de Jesus Valenzuela-Ruiz', Fabian Robles-Contreras², Raul Leonel Grijalva-Contreras*33, Ruben Macias-Duarte ${ }^{4}$

${ }^{1}$ INIFAP-Caborca, Viticulture, Caborca, Sonora, 83600, Mexico; ${ }^{2}$ INIFAP-Caborca, Agroclimatology, Caborca, Sonora, 83600, Mexico; ${ }^{3}$ INIFAP-Caborca, Protected Horticulture, Caborca, Sonora, 83600, Mexico; ${ }^{4}$ INIFAP-Caborca, Soil \& Horticultural, Caborca, Sonora, 83600, Mexico

In the Northwest of Mexico, grape is one of the main crops, specially for table grape $(18,000$ ha), the 'Flame seedless' is one of the important cultivars. Some of the main problems present in this region is the shortage and high cost of the water, nematode and salinity. The objective of this investigation was to evaluate the effect of 'Harmony' rootstock on 'Flame seedless' for table grape. This study was caried in the INIFAP Caborca during 2001 cycle and consisted of ten plants of 'Flame Seedless' on 'Harmony' rootstock and ten control plants under the drip irrigation system, the statistical design used was completely randomized. The results obtained observe not negative effect for the 'Harmony' rootstock on the phenology of 'Flame seedless' (budbreak, flowering and color develpment). The effect was positive since harvest date advanced in 4 days (4 June), where as the control harvest was in 8 June, as far as color were no differences, because both treatments colored well, as far as quality this was better on rootstock than that was not grafted (greather berry size and cluster uniformity). The yield was 1,200 boxes/ha when we used rootstock, 335 boxes more than control and obtaining a saving cost of $100 \%$ in the nematode control and $30 \%$ in water consumption. 
233 Plugging Date and Cold Storage Affect Strawberry Transplant Production and Performance in Annual Plasticulture

Fumiomi Takeda Takeda ${ }^{1}$, Stan Hokanson*2, John Enns ${ }^{3}$, Penelope Perkins-Veazie ${ }^{4}$, Harry Swartz ${ }^{5}$

${ }^{1}$ USDA-ARS, Appalachian Fruit Research Station, Kearneysville, WV 25430; ${ }^{2}$ Univ. of Minnesota, Dept. of Horticural Science; ${ }^{3}$ USDA-ARS, Beltsville Agricultural Research Center, Fruit Laboratory; ${ }^{4}$ USDA-ARS, South Central Agricultural Research Laboratory; ${ }^{5}$ Univ. of Maryland, Dept. of Horticulture

'Chandler' strawberry plants were propagated in tissue culture and grown from April to August in a protected environment to produce stolons. July-harvested daughter plants were stuck in cell packs with rooting media and placed under mist sprinklers, or cold stored at 2 ${ }^{\circ} \mathrm{C}$ for 42 days. Among the July transplants, some were kept in the greenhouse until field planting (14 Sept.) and others were moved into a cold room on 14 August. Daughter plant size and position on the stolon affected rooting and quality of transplants. July-harvested daughter plants that were plugged and misted after being cold stored for 42 days developed fewer roots than daughter plants plugged immediately after detaching from mother plants in July or August. In the field, transplants produced from daughter plants harvested in July and cold stored for 42 days developed more stolons than transplants from July- and Augustharvested daughters that were not exposed to cold storage treatments. Larger daughter plants produced more branch crowns than did smaller daughter plants during the fall. All transplants from daughter plants harvested in July and propagated without cold treatment bloomed by November. Fruit production ranged from 521 to $703 \mathrm{~g}$ per plant. 'Chandler' plants from daughter plants that weighed $10 \mathrm{~g}$ produced $10 \%$ greater yield than those that weighed $<1.0 \mathrm{~g}$. Plants generated from daughter plants plugged in July produced $26 \%$ more fruit than those plants plugged in August. Greenhouse soilless systems can be used to grow 'Chandler' mother plants for generating runner tips and transplants for the annual plasticulture in colder climates. 'Chandler' plants produced in July can yield a late fall crop under high tunnels and more fruit in the spring than August-plugged transplants

\section{Poster Session 41-Produce, Quality, Safety and Properties} July 20, 2004, 12:30-1:30 PM Rio Grande Exhibit Hall

\section{Preharvest Application of Methyl Jasmonate Increases Content of Antioxidant Compounds and Oxygen Absorbing Capacities in Raspberries}

\section{Shiow Wang*1, Wei Zheng ${ }^{2}$}

${ }^{1}$ U.S. Dept. of Agriculture, Fruit Laboratory, Beltsville, MD 20705-2350; ${ }^{2}$ U.S. Dept. of Agriculture, Fruit Laboratory

The effects of preharvest methyl jasmonate (MJ) application on fruit quality, flavonoid content and antioxidant capacity (ORAC) in black raspberry cv. Jewel (Rubus occidentalis L) were studied under field conditions. Raspberries treated with $0.1 \mathrm{~mm}$ methyl jasmonate had $20 \%$ higher soluble solids content, $20 \%$ higher total sugars, $16 \%$ higher fructose, $34 \%$ higher glucose and $30 \%$ lower titratable acids, $31 \%$ lower malic acid and $17 \%$ lower citric acid than untreated fruit. Ellagic acid, quercetin 3-glucoside, kaempferol 3-glucoside, kaempferol 3-glucuronide, cyanidin 3-glucoside and cyaniding 3-rutinoside were found in raspberry fruit extract. Cyanidin 3-rutinoside was the most dominant anthocyanin and was the major contributor to antioxidant activity in Jewel raspberries. MJ treatments significantly enhanced the content of anthocyanins by $92 \%$, total phenolics by $53 \%$, flavonoids by $98 \%$ and the antioxidant capacities by $74 \%$ in the fruit. The ORAC value was positively correlated with anthocyanins and total phenolics. In this study, the correlation coefficient for ORAC (y) vs anthocyanins (x) was $0.977(y=0.056 x+27.874)$, and that for ORAC (y) vs. total phenolics (x) was 0.988 .
197 Effect of 1-MCP and NatureSeal ${ }^{\mathrm{TM}}$ on Fresh-cut Apple

H.P. Vasantha Rupasinghe*1, Dennis P. Murr², Jennifer R. DeEll², Joseph Odumeru ${ }^{4}$

${ }^{1}$ Nova Scotia Agricultural College, Environmental Sciences, Truro, Nova Scotia, B2N 5E3, Canada; ${ }^{2}$ Univ. of Guelph, Plant Agriculture, Guelph, Ontario, N1G 2W1, Canada; ${ }^{3}$ Ontario Ministry of Agriculture and Food, Fresh Market Quality, Simcoe, Ontario, N3Y 4N5, Canada; ${ }^{4}$ Univ. of Guelph, Laboratory Services, Guelph, Ontario, N1H 8J7, Canada

Wounding during processing triggers physiological reactions that limits shelf-life of fresh-cut apples. Exposure of 'Empire' and 'Crispin' apples at harvest to the ethylene antagonist 1-methylcyclopropene $\left(1-\mathrm{MCP}, \mathrm{SmartFresh}^{\mathrm{TM}}\right)$ on the maintenance of fresh-cut apple quality was evaluated in combination with post-cut dipping of NatureSeal ${ }^{\mathrm{TM}}$. Efficacy of 1-MCP on fresh-cut physiology and quality depended on the storage duration and apple cultivar. Ethylene production and respiration of apple slices were inhibited by 1-MCP but not by NatureSeal. Total volatiles produced by fresh-cut apples was not affected by the treatments. 1-MCP influenced the quality attributes of fresh-cut apple slices prepared from apples stored either 4 months in cold storage or 6 months in controlled atmosphere. Enzymatic browning and softening of the cut-surface, total soluble solids, and total microbial growth were suppressed by 1-MCP in 'Empire' apples. Overall, the influence of 1-MCP on quality attributes in 'Crispin' apple slices was marginal. NatureSeal consistently maintained the firmness of fresh-cut apple slices held at $4{ }^{\circ} \mathrm{C}$ for up to 21 days. The additive effect of $1-\mathrm{MCP}$ in the maintenance of apple quality is an advantage for processing and marketing of fresh-cut apples.

\section{Bioflavonoids of Apples: Effects of Genetic Variability, Fruit Parts and Processing}

Vicky W. Lee ${ }^{1}$, H.P. Vasantha Rupasinghe*2, Chung-Ja Jackson ${ }^{3}$

${ }^{1}$ Univ. of Guelph, 1Dept. of Human Biology and Nutritional Sciences, Guelph, Ontario, N1G 2W1, Canada; ${ }^{2}$ Nova Scotia Agricultural College, Environmental Sciences, Truro, Nova Scotia, B2N 5E3, Canada; ${ }^{3}$ Univ. of Guelph, Laboratory Services, Guelph, Ontario, $\mathrm{N} 1 \mathrm{H} 8 \mathrm{~J} 7$, Canada

Apples are excellent sources of dietary phenolics, in particular flavonoids and chlorogenic acid, which are potent antioxidants that may play important roles in the prevention of chronic diseases. This study investigated the major phenolics profiles of apple fruit in relation to (1) the distribution among 8 Ontario-grown cultivars, (2) the different fruit parts, and (3) the effect of processing of fresh-cuts. In addition, total antioxidant capacity (TAC) and total phenols content (TPC) were measured in apples by spectrophotometric assays. Flavonoids and chlorogenic acid were quantified using HPLC/PDA. Vitamin C was quantified using HPLC/Fluorescence. TAC, TPC and flavonoids levels were the highest in Honey Crisp and Delicious, moderate in Idared, Spartan, Granny Smith, and Cortland, and the lowest in Crispin and Empire. Apple peel contained 2 to 10 -fold higher TAC, TPC and total of 10 major phenolics than that of core and flesh indicating peeling of apples during processing could reduced significantly the nutritional quality of fresh-cut apples. Dihydrochalcone (phloridzin) and chlorogenic acid levels were 2 to 21-fold higher in apple core than skin and flesh. TAC levels and vitamin $\mathrm{C}$ contents could be increased up to 3-fold and 14 to 20 -fold, respectively by the post-cut dipping treatment with an ascorbic acid-based antioxidant formula. The phenolic profiles of sliced apples were stable up to 21 days at $4^{\circ} \mathrm{C}$.

\section{Morphological Characteristics of Stone Cells in Fruit of Pears} Wol-Soo Kim*1, Jin-Ho Choi ${ }^{2}$

${ }^{1}$ Chonnam National Univ., Dept. of Horticulture, Gwangju, 500-757, South Korea; ${ }^{2}$ Chonnam National Univ., Dept. of Horticulture, Gwangju, 500-757, South Korea

The stone cells events in the process of lignifications of plant tissues in flesh of Asian pear have been growing as a depressing factor of fruit quality. Therefore, these studies were carried out to search the effect of stone cells on fruit quality, to investigate the anatomical characteristics, such as formative period and distribution of stone cell, to seek forming causes, and to determine the effects of drought stress and calcium foliar application on the formation of stone cell. Fruit quality as contents of 
the stone cells, such as texture profile, reducing sugars, firmness, and fruit size, were determined. During the growing season of 2002 and 2003, samples for anatomical investigations were taken periodically in Pyrus pyriforia cv. Niitaka, Pyrus communis cv. Bartlett and Pyrus ussiriansis cv. Yari. The morphology of stone cell in the fruit flesh was observed by using optical microscope, scanning electron microscope (SEM) and transmission electron microscope (TEM).

\section{Screening Carotenoid Content in Seeded and Seedless Watermelon Fruit}

Penelope Perkins-Veazie ${ }^{* 1}$, J.K. Collins ${ }^{2}$, Warren Roberts ${ }^{3}$

${ }^{1}$ USDA-ARS, Scarl, Lane, OK 74555; ${ }^{2}$ USDA, Scarl, Lane, OK 74555; ${ }^{3}$ Oklahoma State Univ., Horticulture, Lane, OK 74555

Watermelons contain the carotenoids b-carotene, phytofluene, lycopene, and lutein. These carotenoids play an important role in plant oxidative protection and may serve to protect humans against oxidative assaults. Of the carotenoids, lycopene is the predominant pigment in red-fleshed melons $\left(30-130 \mu \mathrm{g} \cdot \mathrm{g}^{-1}\right)$, b-carotene is present in small amounts $\left(1-14 \mu \mathrm{g} \cdot \mathrm{g}^{-1}\right)$, and other carotenoids are present in minute amounts $\left(1-3 \mu \mathrm{g} \cdot \mathrm{g}^{-1}\right)$. Seventy varieties were screened for lycopene content using scanning colorimetry, spectrophotometry, and HPLC techniques, and grouped as low, medium, high, or very high in lycopene. Pink-fleshed heirloom varieties such as Sweet Princess and Black Diamond contained low amounts of lycopene $\left(<40 \mu \mathrm{g} \cdot \mathrm{g}^{-1}\right)$. A number of seeded and seedless varieties had medium amounts of lycopene $\left(40-60 \mu \mathrm{g} \cdot \mathrm{g}^{-1}\right)$. Varieties in the high category $\left(60-80 \mu \mathrm{g} \cdot \mathrm{g}^{-1}\right)$ were primarily seedless types, although 'Dixie Lee', an open-pollinated, seeded variety had $69 \mu \mathrm{g} \cdot \mathrm{g}^{-1}$, indicating that high lycopene content is not restricted to hybrid or seedless melon germplasm. Six selections were found to be very high in lycopene $\left(>80 \mu \mathrm{g} \cdot \mathrm{g}^{-1}\right)$, including the minimelon Hazera 6008 (Extazy). Total carotenoids and carotenoid profiles were determined by HPLC for 23 varieties in 2003. Both seeded and seedless type melons had varieties high in b- carotene, lycopene, and total carotenoids. These results indicate that commercial watermelon varieties have a wide range in lycopene and b-carotene content, and that most commercially important varieties are high in lycopene and total carotenoids, providing important sources of phytonutrients to the human diet.

\section{Antioxidant Detection in Berry Samples from Alaska}

Roseann Leiner ${ }^{1}$, Abraham Smyth ${ }^{2}$, Rudy Candler ${ }^{3}$, Patricia S. Holloway*4

${ }^{1}$ Univ. of Alaska Fairbanks, Palmer Research and Extension Center, Plant Animal and Soil Sciences, Palmer, AK 99645; ${ }^{2}$ Univ. of Alaska Fairbanks, Palmer Research and Extension Center, Plant Animal and Soil Sciences, Palmer, AK 99645; ${ }^{3}$ Univ. of Alaska Fairbanks, Palmer Research and Extension Center, Plant Animal and Soil Sciences, Palmer, AK 99645 ; ${ }^{4}$ Univ. of Alaska Fairbanks, School of Natural Resources and Agricultural Sciences, Plant Animal and Soil Sciences, Fairbanks, AK 99645

Berries and vegetables can be sources of beneficial phytochemicals that may have antioxidant activity in the human diet. Information on type and quantity of phytochemicals may open new crop opportunities for berries and vegetables harvested in Alaska. A method was developed for detecting ascorbic acid and eight phenolic acids on an HPLC instrument using a reverse phase Merck Chromolith C18 column. The method used UV absorbance detection at $280 \mathrm{~nm}$ to separate a standard solution of the following nine phytochemicals: ascorbic acid, gallic acid, protocatechuic acid, p-hydroxybenzoic acid, p-hydroxyphenylacetic acid, caffeic acid, syringic acid, p-coumaric acid and ferulic acid. The mobile phase was a mixture $(3.5 \%$ to $14 \%$ gradient) of organic solvent (5 parts acetonitrile : 2 parts methanol) and aqueous solvent ( $2 \mathrm{mmol}$ aqueous trifluoroacetic acid - TFA) at a flow rate of $2 \mathrm{~mL} / \mathrm{min}$. In 2003, over 60 samples of berries and 60 samples of baby greens were extracted and analyzed. Plant samples were extracted by blending $10-20 \mathrm{~g}$ of frozen plant tissue with 5 parts TFA. The extracts were centrifuged, diluted $4: 1$ and filtered $(0.2 \mu \mathrm{m})$. Chromatograms from HPLC analysis for all samples were complex in peak size and number. Chromatograms for six extracts of high bush cranberries, Viburnum edule, exhibited intense peaks that indicate the presence of caffeic acid, based on retention times. Chromatograms for seven extracts of rose hips, Rosa acicularis, exhibited peaks that indicate the presence of ascorbic acid, based on retention times. Gallic acid and p-hydroxybenzoic acid are apparent minor components in the leaves of some baby greens. This research will continue in 2004 with more plant samples and further method development for detection of other phytochemicals.

\section{Sensory and Instrumental Measurement of Texture of Fruits and Vegetables}

Judith A. Abbott*1

${ }^{1}$ USDA-ARS, Produce Quality and Safety Laboratory, Beltsville, MD 20705-2350

Demand for fresh fruits and vegetables is increasing worldwide in response to health concerns, wealth, and the desire for variety in the diet. However, consumption of produce is contingent on the ability of the industry to provide high quality fresh produce and on its convenience, as well as on consumer education and economics. Texture measurement is accepted by horticultural industries as a critical indicator of quality of fruits and vegetables. The fresh produce industry and, indirectly, consumers need methods for measuring produce texture to ensure the quality within a grade, and scientists need measurements to quantify the results of their treatments, whether treatments are genetic, chemical, or physical. The variety of attributes required to fully describe textural properties can only be fully measured by sensory evaluation by a panel of trained assessors. However, instrumental measurements are preferred over sensory evaluations for both commercial and research applications because instruments are more convenient, less expensive, and tend to provide consistent values when used by different people. Thus, instrumental measurements need to be developed that predict sensory evaluations of texture. Such instrumental measurements can then provide a common language among researchers, producers, packers, regulatory agencies, and customers. We compare sensory evaluations of specific critical textural attributes to instrumental force/deformation measurements on a wide variety of fruits and vegetables with relatively uniform bulk tissues, such as apples, bananas, carrots, jicama, melons, pears, potatoes, rutabagas, and several others.

\section{Fresh Produce Food Safety Training Program and Curriculum Development for the Southeast}

Dennis Osborne*1, Douglas C. Sanders ${ }^{2}$, Donn R. Ward ${ }^{3}$

${ }^{1}$ NC State Univ., Horticultural Science, Raleigh, NC 27695-7609; ${ }^{2}$ NC State Univ., Horticultural Science, Raleigh, NC 27685-7609; ${ }^{3}$ NC State Univ., Food Science, Raleigh, NC 27895-7624

This project directly addresses national food safety "priority issues". Project design incorporates food safety and food chain security as focal points of educational efforts, then initiates practical, producerlevel research, teaching, and extension whereby food handling and safety issues are addressed in a systems context. The overall Project goals are (1) to deliver information about Fresh Produce Food Safety ("FPFS") programs and principles defined in the FDA Guide to fresh fruit and vegetable handlers in the Southeastern United States, (2) to provide hands-on individual state assistance with FPFS program implementation, and (3) to determine the influence of packing line procedures on the survival of foodborne pathogens. Part of the education envisioned under the new grant is introducing the concepts of recall and traceback. These concepts, proposed for incorporation into a new Country of Origin Labeling (COOL) act being discussed for adoption, possibly in 2006, essentially allows for the traceback of food to its point of origin. Osborne and others published a new protocol last month as "Model Recall Program for the Fresh Produce Industry" and want to help growers stay ahead of the curve on these issues. As a consequence of this project, the region's commercial fresh fruit and vegetable handlers will acquire the knowledge and skills necessary to establish effective GAPs programs. Developing new GAPs programs to fit the specific needs of the packing and chain store operations in the Southeastern United States can significantly reduce the possibility of illness originating from Southeastern fresh fruit and vegetables. 
Delivering such programs will serve as a valuable training tool for fresh produce industries nationwide.

\section{Poster Session 42-Organic Horticulture}

\section{July 20, 2004, 12:30-1:30 PM Rio Grande Exhibit Hall}

\section{Comparison to Polyphenol Contents and Anti-oxident Activity} of Apple Fruits by Organic Cultivation

Wol-Soo Kim*1, Jung-An Jo ${ }^{2}$

${ }^{1}$ Chonnam National Univ., Dept. of Horticulture, Gwangju 500-757, 500-757, South Korea; ${ }^{2}$ Chonnam National Univ., Dept. of Horticulture, Gwangju, 500-757, South Korea

Although fruits obtained by organic cultivation (OC) have been believed to be healthier than those by conventional cultivation (CC), but clear experimental evidences supporting the assumption are still lacking. Therefore this study was carried out to investigate the effects of OC on total polyphenol content and anti-oxidant activity in 'Hongro' apples (Malus domestica). Anthocyanin content of fruit skin was increased in apples from OC. Soluble solid content and $\mathrm{pH}$ of apple juice was higher in the $\mathrm{OC}$ than in the $\mathrm{CC}$, but total acidity in fruit juice showed reversed result. Also, chlorophyll content showed no difference between OC and CC. Total polyphenol compounds extracted with methanol, were higher in the $\mathrm{OC}$ than in the $\mathrm{CC}$, and also higher in peel than in flesh. Also, anti-oxidant activity estimated by free radical scavenging effect showed significantly stronger under the OC than the CC.

\section{Control of the Foliar Disease, Septoria lycopersici, in Organic Tomato Production}

Karen Joslin*1, Henry Taber ${ }^{2}$, Sara Helland ${ }^{3}$, Mark Gleason ${ }^{4}$

${ }^{1}$ Iowa State Univ., Horticulture, Ames, IA 50011; ${ }^{2}$ Iowa State Univ., Horticulture, Ames, IA 50011; ${ }^{3}$ Iowa State Univ., Plant Pathology, Ames, IA 50011; ${ }^{4}$ Iowa State Univ., Plant Pathology, Ames, IA 50011

Disease management in organic tomato production poses one of the greatest challenges for organic producers in humid climates. Both organic and conventional tomato growers have relied on copper $(\mathrm{Cu})$ fungicides to control many diseases, including Septoria lycopersici common in tomato production. Concerns have been raised regarding the use of $\mathrm{Cu}$ fungicides, because of their potential to cause plant damage and toxicity to beneficial organisms. The objectives of this research were to: 1) investigate the efficacy of compost tea made from either windrow composted cattle manure (WCCM) or vermicomposted cattle manure (VCM), and 2) compare the efficacy of organic fungicides with conventional fungicides to control $S$. lycopersici in organic tomatoes. Treatments included 1) a control, 2) a conventional treatment in which fungicide applications of Bravo plus $\mathrm{Cu}$ and Quadris plus $\mathrm{Cu}$ were alternated, 3) copper fungicide (Champion), 4) Serenade ${ }^{\mathrm{TM}}$ Fungicide (Bacillus subtilis), 5) WCCM compost tea, and 6) VCM compost tea. Disease pressure was mostly from the bacteria speck/spot complex. Disease severity was significantly $(P<0.05)$ reduced and marketable yield was $60 \%$ higher with the two Cu treatments (No. 2 and 3), compared to other treatments. A follow-up greenhouse experiment is in progress and will be presented with the field data.

\section{University of Arkansas Agriculture Professionals' Perceptions toward Sustainable Agriculture}

Heather Friedrich*1, Curt R. Rom² ${ }^{2}$ Jennie Popp ${ }^{3}$, Barbara Bellows ${ }^{4}$, Donn Johnson ${ }^{5}$

${ }^{1}$ Univ. of Arkansas, Horticulture, Fayetteville, AR 72701; ${ }^{2}$ Univ. of Arkansas, Horticulture, Fayetteville, AR 72701; ${ }^{3}$ Univ. of Arkansas, Ag Econ, Fayetteville, AR 72701; ${ }^{4}$ NCAT-ATTRA, Soil and Water Quality, Fayetteville, AR 72702; ${ }^{5}$ Univ. of Arkansas, Entomology, Fayetteville, AR 72701

Interest IN and conversion to sustainable agriculture practices, such as organic agriculture, integrated pest management or increasing biodiversity, has been increasing for a number of years among farmers and ranchers across the United States In order to meet the needs of producers, university researchers and educators must adapt their program areas to reflect this change toward sustainable agriculture practices. Although consumers, producers, and extension workers have been surveyed regarding their attitudes and interests in sustainable agricultural practices, few surveys have examined sustainable agriculture perceptions among university agriculture professionals. The object of this study was to survey 200 agriculture professionals, including research scientists, classroom educators of the Land-Grant agricultural college and the Cooperative Extension service of a southern state with a traditional agricultural economy in order to determine their perceptions and attitudes toward sustainable agriculture and to gather information on current research and education activities relevant to sustainable agriculture. Seventy-eight questions were asked concerning professional incentives, personal and professional importance of topics under the sustainable agriculture rubric, current research and educational activities, and demographics. By conducting this research we hope to identify factors that are an impedance or assistance to future research and education to support sustainable agriculture. The survey findings will provide a foundation for directing and developing agriculture research and education programs for row crops, fruit, vegetable and livestock production.

\section{Suppression of Septoria Leaf Spot Disease of Tomato Using Aerated Compost Tea}

\section{Chandrappa Gangaiah*1, Edward E. Carey ${ }^{2}$, Ned A. Tisserat ${ }^{3}$}

${ }^{1}$ Kansas State Univ., Dept. of Horticulture, Forestry and Recreation Resources, Manhattan, KS 66506-5506; ${ }^{2}$ Kansas State Univ., Dept. of Horticulture, Forestry and Recreation Resources, Manhattan, KS 66506-5506; ${ }^{3}$ Kansas State Univ., Dept. of Plant Pathology, Manhattan, KS 66506-5505

Compost teas, made using an aerated brewing process, have been reported to have potential for controlling a range of plant diseases and improving crop health. Septoria leaf spot of tomato, caused by the fungus Septoria lycopersici, is a common and destructive disease of tomato in Kansas. A field trial was conducted at Wichita, Kansas during Summer 2003 to evaluate the potential of pre-plant compost, and compost tea applied as a foliar spray or through drip fertigation, to control Septoria leaf spot of tomato. The experimental design included three factors: Pre-plant application of $13 \mathrm{~N}-13 \mathrm{P}-13 \mathrm{~K}$ or vermicompost; fertigation with $\mathrm{CaNO}_{3}$ or compost tea; and foliar spray with compost tea, fungicide (Dithane) or water. A split plot design was used with fertigation treatments as main plots and the other two factors as sub-plots. There were 3 replications. Tomato cultivar Merced was used and individual plots consisted of 5 plants grown on beds covered with red plastic mulch and supported by stake and weave system. Aerated compost tea was brewed weekly using a vermicompost-based recipe including alfalfa pellets, molasses, humic acid, fish emulsion and yucca extract and applied to plots starting 2 weeks after transplanting. Disease incidence and severity were recorded weekly for 3 weeks following the appearance of disease. Plots were harvested twice weekly and counts of No. 1, No 2 and cull grade tomatoes were recorded. There were no effects of pre-plant or fertigation treatments on Septoria leaf spot disease, but there was a significant effect due to foliar sprays, with mean severity of compost-tea-sprayed plots $(26.3 \%)$ and fungicide-sprayed plots (31.9\%) significantly lower than water-sprayed plots $(45.9 \%)$ at trial termination.

\section{Organic Options for Managing Weeds in Highbush Blueberries} William J. Sciarappa*1, Gary C. Pavllis ${ }^{2}$

${ }^{1}$ Rutgers Univ., Agriculture \& Resource Management Agents, Freehold, NJ 07728; ${ }^{2}$ Rutgers Univ., Agriculture \& Resource Management Agents, Mays Landing, NJ 08330

Weeds are especially problematic in highbush blueberry which has a long establishment period, shallow-fibrous roots, and poor competitive ability in obtaining water, nutrients and sunlight. Commercial approaches in certified organic blueberry fields compared horticultural management methods in two New Jersey sites. The trials utilized both new and established blueberry blocks having trickle or overhead irrigation. Commercial methods investigated included rotary cultivation, mowing, propane flaming, cover crops, landscape fabric, and various mulches. Mulch comparisons included pine bark mulch, hardwood mulch, coffee 
grinds, cocoa grinds, municipal leaf mulch, and composted tea leaves. 3 ' $\times 12$ ' plots were replicated 4 times in 4 adjoining rows. Applications of 3-4 inches of these mulches within the crop row to a new planting of Duke highbush blueberry have provided a combined weed control level of ca. $95 \%$ without landscape fabric and $\approx 98 \%$ with landscape fabric during 2003. Walkway weed suppression in new plantings was achieved with the establishment of two types of fine leafed turf fescues and monthly mowings. Bare ground percentage decreased from $80 \%$ to $<2 \%$ within one year's time as these fine fescues gradually out-competed annual weeds for space. These fescue cover crops increased ground coverage from $8 \%$ to $>95 \%$ over the seven month growing season. Such varieties were selected because they have good germination, require little water, use limited nitrogen and can squeeze out weeds through allelopathy. Applied research studies indicate that several suitable methods can be utilized for effective weed management in organic highbush blueberry production systems.

\section{Virulence of Native and Exotic Entomopathogenic Nematodes (Rhabditida: Steinerematidae, Heterorhabditidae) Against Larvae of the Agave Weevil, Scyphophorus acupunctatus (Coleoptera: Curculionidae)}

Jaime Molina-Ochoa*1, Eva Judith Hueso-Guerrero ${ }^{2}$, Roberto Lezama-Gutiérrez ${ }^{3}$, Javier Farías-Larios ${ }^{4}$, Francisco Radillo-Juárez ${ }^{5}$, Abraham García-Berbe ${ }^{6}$, Jalil Fallad-Chávez ${ }^{7}$

${ }^{1}$ Universidad de Colima, Facultad de Ciencias Biológicas y Agropecuarias, Tecomán, Colima, 28100, México; ${ }^{2}$ Universidad de Colima, Facultad de Ciencias Biológicas y Agropecuarias, Tecomán, Colima, 28100, México ${ }^{3}$ Universidad de Colima, Facultad de Ciencias Biológicas y Agropecuarias, Tecomán, Colima, 28100, México; ${ }^{4}$ Universidad de Colima, Facultad de Ciencias Biológicas y Agropecuarias, Tecomán, Colima, 28100, México; ${ }^{5}$ Universidad de Colima, Facultad de Ciencias Biológicas y Agropecuarias, Tecomán, Colima, 28100, México; ${ }^{6}$ Sagarpa, Instituto Nacional de Investigaciones Forestales, Agrícolas y Pecuarias, La huerta, Jalisco, 48850, México; ${ }^{7}$ Universidad de Guadalajara, Centro Universitario de la Costa Sur, Autlán, Jalisco, 48900, México

The agave weevil (Scyphophorus acupunctatus Gyllenhal) (AW) is widely distributed and is severe pest of plants in the Order Liliales, Familiy Agavaceae, such as Agave tequilana, A.fourcroydes, A. sisalana, A. sp., Polianthes tuberosa, and Yucca sp. Some of these species have importance as ornamental, medicinal, fragrant essence, and raw fiber. AW is controlled with insecticides, but insecticides are unable to reach the larvae in the galleries where the larvae borrows the agave crowns. Galleries are cryptic habitats where the entomopathogenic nematodes are able to infect instars of the AW. Recently, Hueso-Guerrero, and Molina-Ochoa (2004) reported the occurrence of native steinernematid nematodes naturally infecting the AW larvae. Virulence of isolates and strains of steinernematid and heterorhabditid nematodes against AW larvae was determined under laboratory conditions. Three native steinernematid isolates obtained from naturally infected AW larvae (A1, A2, and A3) were bioassayed a concentration of 100 nematodes/ $\mathrm{mL}$ and petri dish $(60 \times 10 \mathrm{~mm})$ arenas. Native isolates were isolated from AW larvae attacking agave crowns. Other strains evaluated were: S. carpocapsae All and Mexican, S. riobrave, and Heterorhabditis bacteriophora NC2. Native steinernematid isolates caused $100 \%$ mortality, however exotic strains caused mortality ranges between $90 \%$, and $40 \%$. Steinernema carpocapsae All strain, S. riobrave, $H$. bacteriophora NC2, and S. carpocapsae Mexican strains caused 90\%, $60 \%, 50 \%$, and $40 \%$ mortality, respectively. Results suggest that native steinernematid isolates, and $S$. carpocapsae All strain have potential as biological control agents against the AW weevil.

\section{Sweet Corn Production by Using Poultry Manure}

Muddappa Rangappa*1, Harbans L. Bhardwaj², H.O. Dalton ${ }^{3}$

${ }^{1}$ Virginia State Univ., Agricultural Research Station, Petersburg, VA 23806; ${ }^{2}$ Virginia State Univ., Agricultural Research Station, Petersburg, VA 23806; ${ }^{3}$ Virginia State Univ., Agricultural Research Station, Petersburg, VA 23806

Alternative to the use of synthetic nitrogen fertilizers can be the utilization of a natural organic source of on-farm animal manure nutrients for the growth, development and production of agricultural crops. The main objective of this research was to compost the poultry manure with organic amendments and utilize for sweet corn production. The composition of composted and uncomposted poultry manure was compared and field experiments were conducted during 2002 and 2004 at Randolph farm of Virginia State Univ. located near Petersburg, Virginia.The field experiments included seven treatments: control with un-composted manure, four treatments with manure (composted with wheat straw turned weekly, composted with wheat straw turned bi-weekly, composted with clover hay turned weekly, and composted with clover hay turned bi-weekly), recommended rate of $\mathrm{N}$ fertilizer, and a control without any treatment. Results indicated that composting of poultry manure with an organic amendment such as wheat straw or clover hay helps poultry manure's transformation into a usable fertilizer material for supporting crop production. However, use of clover hay was observed to be desirable than wheat straw for sweet corn production. Addition of clover hay resulted in significantly increased ear fresh and dry weight and also resulted in taller plants. The affects of biweekly vs. weekly turning compost on performance of sweet corn were not significant.

\section{Mustard Cover Crops for Control Soilborne Disease and Weeds, and Nitrogen Cycling in Cool Season Vegetable Production in the Salinas Valley}

Richard Smith*1, Krishna Subbarao², Steve Koike ${ }^{3}$, Steve Fennimore ${ }^{4}$, Adelia Barber ${ }^{5}$

'Univ. of California, Univ. of California Cooperative Extension, Monterey County, Salinas, CA 93901; ${ }^{2}$ Univ. of California, Davis, Dept of Plant Pathology, Salinas, CA 93905; ${ }^{3}$ Univ. of California, Univ. of California Cooperative Extension, Monterey County; ${ }^{4}$ Univ. of California, Davis, Dept of Vegetable Crops; ${ }^{5}$ Univ. of California, Univ. of California Cooperative Extension, Monterey County

Growers in the Salinas Valley are not able to rotate away from lettuce to other crops such as broccoli, as often as would be desirable due to economic pressures such as high land rents and lower economic returns for rotational crops. This aggravates problems with key soilborne diseases such as Sclerotinia minor, Lettuce Drop. Mustard cover crops (Brassica juncea and Sinapis alba) are short-season alternative rotational crops that are being examined in the Salinas Valley for the potential that they have to reduce soilborne disease and weeds. Mustard cover crops have been have been shown to suppress various soilborne diseases and there are also indications that they can provide limited control of some weed species. However, no studies have shown the impact of mustard cover crops under field conditions on $S$. minor. In 2003 we conducted preliminary studies on the incidence of $S$. minor and weeds following mustard cover crops in comparison with a bare control or an area cover cropped to Merced Rye (Secale cereale). There was a slight, but significant reduction of $S$. minor infection in one of three trials following mustard cover crops. Mustard cover crops also reduced emergence of Shepherd's Purse (Capsella bursa-pastoris) and Common Purslane (Portulaca oleracea) these studies. Mustard cover crops have distinct nitrogen cycling characteristics. They were shown to reach a peak of release of nitrogen in 30 to 50 days following incorporation into the soil. The levels of nitrogen that are released by mustard cover crops were substantial and could be useful in nitrogen fertilizer programs for subsequent vegetable crops.

\section{Hormonal Concentration and Growth in Chili Plants Inoculated with Several Mycorrhizal Fungus, Evaluated in Different Steps}

Francisco Roman-García ${ }^{1}$, María Patricia Yahuaca-Mendoza², Javier Farias-Larios ${ }^{3}$, J. Gerardo López -Aguirre**4, Sergio Aguilar-Espinosa $^{5}$, María del Rocío Flores-Bello ${ }^{6}$

${ }^{1}$ Universidad de Zacatecas, Unidad Académica de Agronomía, Zacatecas, Zacatecas, Mexico; ${ }^{2}$ Universidad Autónoma de Zacatecas, Facultad de Medician Humana y Ciencias de la Salud, Zacatecas, Zacatecas, México; ${ }^{3}$ Universidad de Colima, Facultad de Ciencias Biológicas y Agropecuarias, Tecomán, Colima, 28100, México; ${ }^{4}$ Universidad de Colima, Facultad de Ciencias Biológicas y Agropecuarias, Tecomán, Colima, 28100, México; ${ }^{5}$ Universidad de Colima, Facultad de Ciencias Biológicas y Agrpecuaraias, Tecomán, Colima, 28100, México; ${ }^{6}$ Universidad de Colima, Facultad de Ciencias Biológicas y Agropecuarias, Tecomán, Colima, 28100, México

The contribution of arbuscular endomycorrhizal fungus (AMF) on hormonal levels increase in chili plants, at different steps is currently unknown. In this experiment was evaluated the effect of Glomus sp. 
Zac-19, G. etunicatum and G. intraradices, inoculation mirasol and ancho cultivars, under greenhouse conditions. Plants were growing in pots containing $1 \mathrm{~kg}$ of substrate ( 3 sand : 1 soil ratio). The effect was measured on fresh fruit production and indolacetic acid, giberellin $\mathrm{GA}_{3}$ and 6-aminopurine concentration. Also plant parameters measured were: plant height, foliar area, stem diameter, root length, aerial fresh weight, total fresh weight, fruit weight and mycorrhizal colonization. All treatments were imposed using 16 replications in a full random design. Results shown that mycorrhizal colonization average of the three fungus was $44 \%$ in mirasol cultivar y $42 \%$ in ancho cultivar. Mycorrhizal colonization had an effect on growth and development in both cultivars, expressed in a greater height, leaf number, foliar area, total fresh weigh and fruit mass. Was registered an increase of $80 \%$ in the yield in inoculated plants respecting to control. Indolacetic acid and gibberellins concentration in shoots, were bigger in plants colonized by arbuscular mycorrhizal fungus (AMF) than in control. The 6-aminopurine levels in roots of colonized plants by AMF shown higher values. These results suggest that AM fungi modify the hormonal concentration and some growth factors in chili plants.

\section{Poster Session 43-Floriculture 4}

\section{July 20, 2004, 12:30-1:30 PM Rio Grande Exhibit Hall}

\section{Influence of Different Crown Manipulation Treatments on} Shoot Production of Four Cultivars of Daylily

Johnny Carter*1, Johnson Clarence ${ }^{2}$

${ }^{1}$ Fort Valley State Univ., Agricultural Research, Fort Valley, GA 31030; ${ }^{2}$ Fort Valley State Univ., Agricultural Research Station

During Fall 2003, a study similar to that of Fall 2002 was conducted to determine the effect of crown manipulation on shoot production in four cultivars of daylily. Three crown manipulation treatments: (1) the shoot cut back two centimeters from crown, (2) the shoot cut back to the crown, and (3) shoot cut back to the crown and scooped out were compared to a control. Four daylily cultivars, 'Bull Durham', 'Amber Lamp', 'Angus McLeod', and 'Alvatine Taylor' were used in this study. After eight weeks of observations, the results showed that the cut back to crown treatment caused a significant increase in the number of shoots when compared to the control and other two treatments. Shoot production for the cultivar 'Angus McLeod' was significantly better than the other cultivars. Results obtained for Fall 2003 study were similar to that of Fall 2002. These results imply that cutting the shoots back to the crown in some daylily cultivars could possibly be used to enhance multiplication of daylilies during propagation.

341 Flowering and Inflorescence Development of Lachenalia aloides 'Pearsonii' as Influenced by Bulb Storage and Forcing Temperature

Mark Roh*1

${ }^{1}$ Floral and Nursery Plants Research Unit, USDA, ARS, National Arboretum, Beltsville, MD 20705

The effect of bulb storage and forcing temperatures on growth, flowering, and inflorescence development and the death of inflorescence (blast) of Lachenalia aloides Engl., 'Pearsonii' was investigated. Following development of about 5 florets, bulbs were stored at $10,12.5,15,20$, and $25^{\circ} \mathrm{C}$ for 15,30 , or 45 days and forced in greenhouses at $17 / 15^{\circ} \mathrm{C}$ and $21 / 19^{\circ} \mathrm{C}$. Flowering was accelerated, and leaf length and floret number were reduced, when bulbs were stored at $10,12.5$, or $15^{\circ} \mathrm{C}$ for 45 days compared to storing at 20 or $25^{\circ} \mathrm{C}$. Flowering was further accelerated by forcing at $17 / 15^{\circ} \mathrm{C}$ compared to $21 / 19^{\circ} \mathrm{C}$. When bulbs were stored at $10,15,20$, or $25^{\circ} \mathrm{C}$ for 4 weeks and grown in greenhouses at $17 / 15$ ${ }^{\circ} \mathrm{C}, 21 / 19{ }^{\circ} \mathrm{C}, 25 / 23{ }^{\circ} \mathrm{C}$, and $29 / 27^{\circ} \mathrm{C}$, the incidence of inflorescence blast was increased when bulbs were stored at 10 and $15{ }^{\circ} \mathrm{C}$ and forced at $25 / 23^{\circ} \mathrm{C}$ compared to low temperatures. Bulbs were forced in greenhouses maintained at $18 / 16{ }^{\circ} \mathrm{C}, 22 / 20^{\circ} \mathrm{C}$, or $26 / 24{ }^{\circ} \mathrm{C}$ for 12 weeks. During forcing, plants were subjected to constant or alternating forcing temperatures at 4-week intervals. Inflorescence blast occurred when the temperature was $26 / 24^{\circ} \mathrm{C}$ during the first 4 weeks after potting. Storing Lachenalia bulbs at $10 \& \# 176$ to $15^{\circ} \mathrm{C}$ before potting then forcing at $17 / 15^{\circ} \mathrm{C}$ accelerated flowering and produced quality plants with short leaves and floral stems. Inflorescence development during bulb $10{ }^{\circ} \mathrm{C}$ treatment and inflorescence blast that occurred after only 3 days of $35^{\circ} \mathrm{C}$ was demonstrated using scanning electron microscopy and magnetic resonance imaging techniques.

\section{Bleeding Hearts Turn Yellow: A Case Study to Determine the} Cause of Chlorosis in a Crop of Cut Dicentra spectabilis

Marci Spaw ${ }^{1}$, Kimberly A. Williams*2, Ingrid L. Mallberg ${ }^{3}$, Laurie Hodges $^{4}$, Ellen T. Paparozzi ${ }^{5}$

${ }^{1}$ Kansas State Univ., Horticulture, Forestry, and Rec. Res., Manhattan, KS 66506-5506; ${ }^{2}$ Kansas State Univ, Horticulture, Forestry, and Rec. Res., Manhattan, KS 66506-5506; ${ }^{3}$ Univ. of Nebraska, Agronomy and Horticulture, Lincoln, NE 68583-0915; ${ }^{4}$ Univ. of Nebraska, Agronomy and Horticulture, Lincoln, NE 68583-0915; ${ }^{5}$ Univ. of Nebraska, Agronomy and Horticulture, Lincoln, NE 68583-0915

Case studies promote the development of problem-solving skills, but few have been created for horticulture and related curricula. This webbased decision case presents the challenge of determining the cause of symptoms of foliar chlorosis in a crop of cut Dicentra spectabilis while forcing it for Valentine's Day sales. It provides a tool to promote the development of diagnostic skills for production dilemmas, including nutritional disorders, disease and insect problems, and evaluation of the appropriateness of cultural practices. Cut Dicentra is a minor crop and standard production practices are not well established. Therefore, solving this case requires that students research production protocol as well as nutritional and pest problems to develop a solution. In this case study, which is supported by an image-rich web-based version at www.hightunnels.org/cutflowercasestudy.htm, a grower at Flint's Flower Farm must determine the cause of foliar chlorosis that is slowly appearing on about half of the plants of her cut Dicentra crop. The condition could be related to a number of possible problems including a nutritional disorder, insect attack, disease infection, or production practices. Some resources are provided to aid students in gathering background information. Data accumulated by the grower is presented to allow students to logically eliminate unlikely solutions and predict (a) probable cause(s). The solution, which is rather unique to this crop, is provided. This case study is intended for use in upper-level undergraduate courses of floriculture production, nutrient management, plant pathology, and entomology.

343 Summary Lecture vs. Asynchronous Web-based Method for Instruction of Site Planning for Protected Environment Structures Marci Spaw*1, Kimberly A. Williams ${ }^{2}$, Laura A. Brannon ${ }^{3}$

${ }^{1}$ Kansas State Univ., Horticulture, Forestry, and Rec. Res., Manhattan, KS 66506-5506; ${ }^{2}$ Kansas State Univ., Horticulture, Forestry, and Rec. Res., Manhattan, KS 66506-5506; ${ }^{3}$ Kansas State Univ., Psychology, Manhattan, KS 66506-5302

This study compared student learning outcomes of two teaching methodologies: a summary lecture and an asynchronous web-based method that included a case study (www.hightunnels.org/planningcasestudy. $\mathrm{htm}$ ) followed by an all-class discussion. Twenty-one students taking an upper-level undergraduate course in greenhouse management were randomly split into two groups. Each group experienced both methodologies with presentations designed to provide complimentary information about site planning for protected environment structures; however, the order in which the groups received the methods was reversed. After each presentation, the participants were given an identical quiz (Time 1 and Time 2) comprised of questions that assessed knowledge gained, higher-order learning, and their perception of how confident they would be in solving actual site planning scenarios. Though quiz scores were not different between the two groups after Time 1 or 2 , overall quiz scores improved after Time 2 for both groups combined $(P=0.03)$. When questions were categorized as lower-order vs. higher-order learning, a greater increase in scores was observed in higher-order learning ( $P=0.12$ vs. $P=0.04$, respectively). Although students' perceived confidence was not influenced by which method 
was received first $(P=0.23)$, their confidence increased after Time 2 compared to Time $1(P=0.07)$. Rather than one teaching method being superior to the other, this study suggests that it is beneficial to use both. Interestingly, while students overwhelmingly preferred to receive the summary lecture before the web-based method, there was no significant difference in test scores between the two orders, suggesting that neither order offered any advantage.

\section{Production Systems for Winter Cut Flowers in a Tobacco Transplant Greenhouse}

Carl E. Niedziela, Jr.*1, Guochen Yang ${ }^{2}$

${ }^{1}$ North Carolina A\&T State Univ., Natural Resources and Environmental Design, Greensboro, NC 27411; ${ }^{2}$ North Carolina A\&T State Univ., Natural Resources and Environmental Design, Greensboro, NC 27411

Plug seedlings of lisianthus [Eustoma grandiflorum (Raf.) Shinn. 'Mariachi'] and stock [Matthiola incana (L.) R.Br. 'Cheerful White'] were planted on 20 Nov. 2003 followed by plug seedlings of snapdragon (Antirrhinum majus L. 'Maryland') and seeds of sunflower(Helianthus annuus L. 'Sunbrite') the next day. Each species was planted in four production systems (harvest lugs, lay-flat bags, pots, and polystyrene trays). Production systems were randomized in a Latin-square design with four replications of each system. Each treatment plot was $0.7 \mathrm{~m} \times$ $1.1 \mathrm{~m}$. Planting densities was 62 plants $/ \mathrm{m}^{2}$ for stock and 31 plants $/ \mathrm{m}^{2}$ for lisianthus, snapdragon, and sunflower. The harvest lugs were $55 \mathrm{~cm}$ $\times 37 \mathrm{~cm} \times 16 \mathrm{~cm}$. The lay-flat bags were $114 \mathrm{~cm} \times 30 \mathrm{~cm} \times 3 \mathrm{~cm}$. The pots were $25 \mathrm{~cm}$ bulb pans. The polystyrene trays were $67 \mathrm{~cm} \times 34 \mathrm{~cm}$ $\times 5 \mathrm{~cm}$ and contained 32 square cells. All of the containers were filled with the same tobacco germination media. The plants in the harvest lugs, lay-flat bags and pots were irrigated daily with $150 \mathrm{mg} \cdot \mathrm{kg}^{-1}$ of $\mathrm{N}$ from $20 \mathrm{~N}-4.4 \mathrm{P}-16.6 \mathrm{~K}$. The plants in the polystyrene trays were floated on a solution of $150 \mathrm{mg} \cdot \mathrm{kg}^{-1}$ of $\mathrm{N}$ from $20 \mathrm{~N}-4.4 \mathrm{P}-16.6 \mathrm{~K}$. Float solutions were monitored and adjusted weekly for volume and fertilizer concentration. Individual stems were harvested from each species at the appropriate stage of development for market. The weight and length of individual stems were recorded. Rate of growth and maturation differed between production systems and locations in the greenhouse. Detailed results will be presented.

\section{Growth and Flowering Responses of Cyclamen persicum to Temperature and Photosynthetic Photon Flux}

\section{Wook Oh*1, In Hye Cheon², Ki Sun Kim ${ }^{3}$}

${ }^{1}$ Seoul National Univ., Horticultural Science, Seoul, Seoul, 151-742, Republic of Korea; ${ }^{2}$ Seoul National Univ., Horticultural Science, Seoul, Seoul, 151-742, Republic of Korea; ${ }^{3}$ Seoul National Univ., Horticultual Science, Seoul, Seoul, 151-742, Republic of Korea

This research was conducted to investigate the growth and flowering responses of Cyclamen persicum Mill. 'Piccolo' to temperature and photosynthetic photon fluxes (PPF), and to obtain fundamental data for production of good quality pot plant. Cyclamen plants with 10 fully unfolded leaves were grown in growth chambers maintained at three day/night temperatures [20/10 (LT), 25/15 (MT), and $30 / 20{ }^{\circ} \mathrm{C}$ (HT)] combined with three PPF [250 (LF), 350 (MF), and 650 (HF) $\mu \mathrm{mol} \cdot \mathrm{m}^{-2} \cdot \mathrm{s}^{-1}$ ] under $14 \mathrm{~h}$-photoperiod. After 3 months, the higher the temperature was, the greater plant width was. It was the greatest under MT/MF and HT/MF. The number of leaves was greater with increasing temperature and PPF. Petiole length, leaf size, and fresh weight were higher with increase in temperature but decrease in PPF. Days to flowering were lower in MT/MF and MT/HF, but higher under LT regardless of PPF. The number of flowers was the highest under $\mathrm{MT} / \mathrm{MF}$ and $\mathrm{MT} / \mathrm{HF}$, and higher under $\mathrm{MF}$ in each temperature treatment. Flowering period was longer in LT and MT compared with HT. Most leaves of plants grown under HT curled upward because of boron deficiency induced by higher temperature and lower humidity. Chlorophyll content was higher in medium and low temperature, except LT/HF. The lower side of leaf in low temperature was more reddish compared to that in higher temperature due to some pigments considered as anthocyanin. Photosynthesis was the highest in MT/MF, but low in MT/HF and LT/HF in accordance with the chlorophyll fluorescence $(\mathrm{Fv} / \mathrm{Fm})$ which was lower under the same environment.
These results indicate that $25 / 15^{\circ} \mathrm{C}$ and $350 \mu \mathrm{mol} \cdot \mathrm{m}^{-2} \cdot \mathrm{s}^{-1}$ yielded the best pot cyclamen in this study.

\section{Effects of Reversed Day/Night Temperatures on a Doritaenopsis Hybrid Orchid}

Yin-Tung Wang*1

${ }^{1}$ Texas A\&M Univ., Horticultural Sciences, Weslaco, TX 78596

It not clear how a prolonged period of cool days and warm nights affect Phalaenopsis hybrids which take up $\mathrm{CO}_{2}$ mainly at night. The 'Lava Glow' clone of the hybrid Doritaenopsis (Phal . Buddha's Treasure $\mathrm{x}$ Doritis pulcherrima ) $15 \mathrm{~cm}$ in leaf span were subjected to day/night (12 h each daily) temperatures of 30/25, 25/30,25/20, or $20 / 25^{\circ} \mathrm{C}$ at 170 umol.m ${ }^{-2} .{ }^{-}-{ }^{1} P P F$. After nine months, plants under the higher average daily temperature (ADT) produced more leaves. Those grown at $30 / 25^{\circ} \mathrm{C}$ had the largest leaf span and total length of the new leaves. Plants under $30 / 25,25 / 30,25 / 20$, or $20 / 25^{\circ} \mathrm{C}$ had $5.0,4.7,3.6$, and 2.8 new leaves and $72,61,42$, and $28 \mathrm{~cm}$ in total new leaf length, respectively. Cool days and warm nights resulted in smaller leaf span and reduced leaf growth, particularly at 20/25 than at $25 / 30^{\circ} \mathrm{C}$. Within a given ADT, cooler days resulted in shorter leaves. Leaves produced by plants at the lower ADT had a smaller length to width ratio and the more desirable oval shape. The most striking effect of $20 / 25^{\circ} \mathrm{C}$ was that 14 out of 15 plants bloomed, whereas only 5 plants under $25 / 20{ }^{\circ} \mathrm{C}$ and none in the $30 / 25$ or $25 / 30{ }^{\circ} \mathrm{C}$ treatment flowered. In a second experiment, $18-22 \mathrm{~cm}$ plants were subjected to $30 / 20,20 / 30,25 / 15$, or $15 / 25^{\circ} \mathrm{C}$. After 29 weeks, similar results were obtained. All plants under $15 / 25^{\circ} \mathrm{C}$ bloomed, whereas none in the other treatments produced flowers. Long-term exposure to $15 / 25^{\circ} \mathrm{C}$ resulted in slow leaf production and undesirable small leaves. These results suggest that, with day temperatures in the $20-15^{\circ} \mathrm{C}$ range, nights $10-5^{\circ} \mathrm{C}$ warmer are not desirable for rapid vegetative growth. However, cool days and warm nights may be used to effectively induce the flowering process.

\section{Enhanched Development and Flowering of Rudbeckia hirta in Far-red Amended Environments}

Meriam Karlsson*1, Jeffrey Werner ${ }^{2}$

${ }^{1}$ Univ. of Alaska, Dept. of Plant, Animal and Soil Sciences, Fairbanks, AK 99775-7200; ${ }^{2}$ Univ. of Alaska, Dept. of Plant, Animal and Soil Sciences, Fairbanks, AK 99775-7200

The importance of far-red in the spectral energy distribution was evaluated for the development of Rudbeckia hirta. In a high pressure sodium production system of $8 \mathrm{~mol} \cdot \mathrm{m}^{-2}$ per day during 16 hours, a limited number of incandescent lamps were added to provide 15 to $20 \mu \mathrm{mol} \cdot \mathrm{m}^{-2} \mathrm{~s}^{-1}$. The red to far-red ratio decreased through the addition of incandescent lighting from 2.2 of high pressure sodium to 1.2. The dwarf $R$. hirta cultivars Toto Gold, Toto Lemon and Toto Rustic, suitable as container or bedding plants, were transplanted into $10-\mathrm{cm}$ containers 1 month after seeding and the experiment was initiated 3 weeks later. At this time, the plants had 7 to 8 leaves and were 3 to $4 \mathrm{~cm}$ in height. Flowering time decreased with 10 to 14 days for the $R$. hirta cultivars in the incandescent amended environment compared to exclusively high pressure sodium irradiance. Overall plant height averaged $24 \mathrm{~cm}$ for 'Toto Lemon', $26 \mathrm{~cm}$ for 'Toto Rustic' and $28 \mathrm{~cm}$ for 'Toto Gold'. All three cultivars grew ' $4 \mathrm{~cm}$ taller by adding incandescent light. Main branches of each plant averaged 4 with 14 developed flowers and flower buds independent of cultivar and light quality. Average flower diameter increased $0.5 \mathrm{~cm}$ in incandescent amended environments to $7.1 \mathrm{~cm}$ for 'Toto Gold' and 'Rustic' and $6.4 \mathrm{~cm}$ for 'Toto Lemon'.

\section{Storage Temperature and Duration Effects on Growth and Development of Ornamental Gingers}

Maria P. Paz ${ }^{* 1}$, Jeff S. Kuehny ${ }^{2}$, Gloria B. McClure ${ }^{3}$, Richard Criley ${ }^{4}$, Charles J. Graham ${ }^{5}$

${ }^{1}$ Univ. of Florida, Dept. of Environmental Horticulture, Gainesville, FL 32611-0670; ${ }^{2}$ Louisiana State Univ., Dept. of Horticulture, Baton Rouge, LA 70803; ${ }^{3}$ Louisiana State Univ., Dept. of Horticulture, Baton Rouge, LA 70803; ${ }^{4}$ Univ. of Hawaii at Manoa, Dept. 
of Tropical Plants and Soil Sciences, Honolulu, HI 96822; ${ }^{5}$ Louisiana State Univ., Dept. of Horticulture, Baton Rouge, LA 70803

Ornamental gingers are popular cut flowers and have been promoted as a promising potted flower crop because of unique foliage, long-lasting colorful bracts, and few pest problems. Rhizomes are the primary means of propagation in late spring followed by shoot growth and flowering, and plants enter dormancy under short days in the fall. Termination of dormancy is important for greenhouse forcing and extending the growing season. Manipulation of rhizome storage to satisfy dormancy requires investigation into the storage environment. It appears that controlling growth, development and flowering in geophytic plants is dependent on reserve accumulation, mobilization, and redistribution. Rhizomes of four ginger species (Curcuma alismatifolia Gagnep., C. roscoeana Wallich, Globba winittii C.H. Wright, and Kaempferia galanga L.) were stored for 0 to 16 weeks at 15,20 , or $25{ }^{\circ} \mathrm{C}$ to determine the effect on growth, flowering, respiration rates, and carbohydrate content. Upon completion of treatment application, rhizomes were planted in a peat moss:bark:perlite mix and placed in a greenhouse with $25{ }^{\circ} \mathrm{C}$ day $/ 21^{\circ} \mathrm{C}$ night temperatures with $40 \%$ shade. The production time, days to emergence (DTE) and days to flower (DTF), was reduced with an increase in storage temperature and duration for all species. DTE and DTF for Globba and Kaempferia were hastened when rhizomes were stored for 16 weeks at $25^{\circ} \mathrm{C}$. For C. alismatifolia, DTE and DTF were hastened when rhizomes were stored at $25^{\circ} \mathrm{C}$ for at least 10 weeks. For C. roscoeana, storage at $25^{\circ} \mathrm{C}$ for 14 or 16 weeks was found to hasten emergence. The response of respiration and carbohydrate concentration was not consistent with rhizome and plant growth responses.

\section{Performance of Poinsettia Cultivars Evaluated in 2003}

Christopher Catanzaro*1, Haval Kamake ${ }^{2}$, Sarabjit Bhatti ${ }^{3}$

${ }^{1}$ Tennessee State Univ., Institute of Agricultural and Environmental Research, Nashville, TN 37209-1561; ${ }^{2}$ Tennessee State Univ., Institute of Agricultural and Environmental Research, Nashville, TN 37209-1561; ${ }^{3}$ Tennessee State Univ., Institute of Agricultural and Environmental Research, Nashville, TN 37209-1561

Twenty-one commercially introduced or trial cultivars of poinsettia (Euphorbia pulcherrima Willd. ex Klotzsch) supplied by Dummen USA or Ecke were grown at the TSU main campus farm during Autumn 2003. Ten plants of each cultivar were potted in 6-inch standard containers and grown from rooted cuttings to finished plants according to industry cultural practices in a glass greenhouse. Plant heights were recorded weekly. The date on which anthers began to shed pollen (flowering date) was recorded to calculate response time after initiation of short days. Also recorded on the flowering date were final plant height and two measurements of plant width and inflorescence width. Most cultivars finished within two weeks of the predicted response time of 7.5-9 weeks. However, flowers of 'Infinity Red', 'Merlot', 'Mirage', and 'Premium Marble' shed pollen especially late. Flower structures aborted on 'Prestige', 'Elegance Hot Pink' and 'Premium Hot Pink'. Most cultivars were relatively compact at finish date. 'Twister', 'EuroGlory', and 'Coco 2000 White' were particularly small, with average heights of 28-30 cm and average widths of $17 \mathrm{~cm}$ or less. 'Spotlight Dark Red' was tallest $(37 \mathrm{~cm})$ and widest $(41 \mathrm{~cm})$, and also had the widest inflorescences $(26 \mathrm{~cm})$. Quality issues observed on some cultivars included low inflorescence number, excessive bract overlap, bract burn, bract reversion, high height to width ratio, and low plant vigor. Cultivars with overall high quality performance included 'Premium Red', 'Infinity Red', 'Spotlight Dark Red', 'Coco 2000 Red', and 'Freedom', which all scored highly in the consumer preference survey conducted at the end of the study.

\section{Plasticity in Leaf and Photosynthetic Characteristics of Ficus benjamina Ggrown under Different Lght Regimes}

Qibing Wang ${ }^{1}$, Jianjun Chen ${ }^{2}$

${ }^{1}$ Univ. of Florida, Mid-Florida Research and Education Center, Apopka, FL 32703; ${ }^{2}$ Univ. of Florida, Mid-Florida Research and Education Center, Apopka, FL 32703

Ficus benjamina is considered to have a high degree of morphological and physiological plasticity in response to light levels. In this study, leaf area and thickness, specific leaf area (SLA), chlorophyll content, and photosynthetic characteristics of Ficus benjamina 'Common'; grown in a shaded greenhouse under four maximum photosynthetic photon flux densities (PPFDs) of $150,250,450$, or $650 \mu \mathrm{mol} \cdot \mathrm{m}^{-2} \cdot \mathrm{s}^{-1}$ were investigated. Results showed that plants grown under 450 and 650 PPFDs had higher SLA and leaf thickness but smaller leaf areas than those grown under 150 and 250 PPFDs. Total chlorophyll content per unit leaf area decreased as PPFDs increased. Net photosynthetic rates $(P n)$ increased from $2.7 \mu \mathrm{mol} \cdot \mathrm{m}^{-2} \cdot \mathrm{s}^{-1}$ under 150 PPFD to $5.7 \mu \mathrm{mol} \cdot \mathrm{m}^{-2} \cdot \mathrm{s}^{-1}$ under 450 PPFD, then slightly decreased to $5.5 \mu \mathrm{mol} \cdot \mathrm{m}^{-2} \cdot \mathrm{s}^{-1}$ under 650 PPFD. The highest net photosynthetic rate was not associated with higher intercellular $\mathrm{CO}_{2}$ concentrations $(\mathrm{Ci})$ and stomatal conductance $(g s)$ as plants grown under 250 PPFD had the highest $(\mathrm{Ci})(259 \mathrm{ppm})$ and $g s$ $\left(0.1 \mathrm{~mol} \cdot \mathrm{m}^{-2} \cdot \mathrm{s}^{-1}\right)$, which suggests that photosynthetic enzymes could play a increasing role under 450 PPFD. Plant quality, however, was not necessarily correlated with the $P n$ because only those grown under 250 PPFD had appropriate heights, large and dark green leaves, and well-spread branches, and thus were graded higher than plants grown under the other PPFDs. This study shows that fine-tuning production light level is important for high quality Ficus benjamina production.

\section{Types and Location of Calcium Oxalate Crystals in Dieffen- bachia Cultivars}

Hui $\mathrm{Cao}^{1}$, Hui $\mathrm{Cao}^{2}$, Dennis B. McConnell ${ }^{3}$, Jianjun Chen*4

${ }^{1}$ Univ. of Florida, Environmental Horticulture, Gainesville, FL 32611-0670; ${ }^{2}$ Univ. of Florida, Environmental Horticulture, Gainesville, FL 32611-0670; ${ }^{3}$ Univ. of Florida, Environmental Horticulture, Gainesville, FL 32611-0675; ${ }^{4}$ Univ. of Florida, Mid-Florid Research \& Education Center, Apopka, FL 32703-8504

The irritant effect of Dieffenbachia sap is attributed to protelytic enxymes but calcium oxalate crystals are considered to puncture cells and allow enzyme entrance. To date, no detailed study of the location, type, or frequency of calcium oxalate crystals in Dieffenbachia species or cultivars has been undertaken. To do so, three uniform tissue culture plantlets of Dieffenbachia 'Carina','Rebecca' or 'Star Bright' were transpanted into $15 \mathrm{~cm}$ pots, grown in a shaded greenhouse under $385 \mu \mathrm{mol} \cdot \mathrm{m}^{-2} \cdot \mathrm{s}^{-1}$ and fertigated with $20 \mathrm{~N}-8.7 \mathrm{P}-16.6 \mathrm{~K}$ water-soluble fertilizer at $\mathrm{N}$ concentrations of $200 \mathrm{mg} \cdot \mathrm{L}^{-1}$ twice weekly. Ten weeks later, samples of stem, root, and leaves were taken from 4 pots of each cultivar to determine the distribution and type of calcuium oxalate crystals in each plant organ via polarized light microscopy. Two types of calcium oxlate crystals, raphides and druses, were found in the stem, leaves and roots. Druse density increased as leaves andd stems matured while the number of raphide idioblasts remained relatively constant. Crystal density was highest at lateral initation sites of buds and roots. Significant differences were found in crystal density among cultivars even though 'Carina' and 'Star Bright' are sports selected from 'Camille'. This suggests that reduction of calcium oxalate density of Dieffenbachia cultivars is possible through breeding.

\section{Characterization of Postharvest Disorders and the Effect of Shipping on Shelf Life of 22 Vegetative Annual Cultivars}

Shannon E. Beach*1, Terri W. Starman ${ }^{2}$

${ }^{1}$ Texas A\&M Univ., Horticultural Sciences, College Station, TX 77843-2133; ${ }^{2}$ Texas A\&M Univ., Horticultural Sciences, College Station, TX 77843

Vegetative annuals are increasing in popularity among greenhouse growers and consumers but little is known about their postharvest shelf life. Twenty-two cultivars from ten species of vegetative annuals were grown to marketability with optimum greenhouse culture. Plants were then subjected to one of three shipping durations $(0,1$, or 2 days) in simulated shipping i.e., a growth chamber at $26.7 \pm 0.3^{\circ} \mathrm{C}, 0$ $\mu \mathrm{mol} \cdot \mathrm{m}^{-2} \cdot \mathrm{s}^{-1}$, and $50 \%$ relative humidity. The plants were then moved to simulated postharvest environment i.e., growth room at $21.1 \pm 1.3{ }^{\circ} \mathrm{C}$ and $6 \mu \mathrm{mol} \cdot \mathrm{m}^{-2} \cdot \mathrm{s}^{-1}$ to evaluate shelf life. Flower number and plant quality rating were measured weekly in addition to observations of plant appearances. Some of the postharvest disorders noted on several species and cultivars were stem die back, leaf chlorosis, stem elongation, bud abortion, flower drop, and flower fading. The majority of the cultivars maintained their quality one-week postharvest although flower drop 
was common. After the first week of shelf life, decline in vegetative and reproductive tissues were noted in most plants. Cultivars from nine species: Argyranthemum frutescens (L.) Sch. Bip, Bracteantha bracteata (Vent.) Anderb. \& Haegi, Calibrachoa hybrid Lave Lex, Diascia $\times$ hybrida, Lantana camara L., Nemesia $\times$ hybrida, Petunia $\times$ hybrida, Sutera hybrida, and Sutera cordata showed decreased flower number and/or quality rating due to shipping duration, with increased shipping duration causing accelerated postharvest disorders. The only species unaffected by shipping duration was Angelonia angustifolia Benth.

\section{Assessing Color Change in Woody Floral Stems}

Christine Meyer ${ }^{1}$, Ellen T. Paparozzi*2, Scott J. Josiah³ ${ }^{3}$ Erin M. Blankenship ${ }^{4}$

${ }^{1}$ Univ. of Nebraska, Agronomy and Horticulture, Liincoln, NE 68583-0724; ${ }^{2}$ Univ. of Nebraska, Agronomy and Horticulture, Lincoln, NE 68583-0724; ${ }^{3}$ Univ. of Nebraska, School of Natural Resources; ${ }^{4}$ Univ. of Nebraska, Statistics

Woody floral stems are an emerging specialty crop within the floral industry, and stem color is a key to marketability. This study was conducted to assess stem color change over time in order to determine the optimum window for stem harvest. Plants of 'Scarlet curls', 'Flame' willow, 'Bailey', 'Cardinal' and 'Yellow twig' dogwood were planted in a randomized complete block design in rows parallel to a windbreak.. Each experimental unit consisted of a group of five plants, each of the same cultivar. Plants were initially tagged at a set height and stem diameter and measured for color. Each stem was also tagged with one of three colored tapes, according to initial color: green for green colored stems, red for stems already showing color change, and pink for intermediate colored stems. Color was assessed initially and on a weekly basis for 10 weeks, starting at the end of September, using the Royal Horticultural Society color chart. Data were analyzed using a repeated measures procedure. 'Scarlet curls' and 'Flame' stems, already displaying color, attained the darkest color value for their cultivar at an early stage and were at the point of harvest in early November, while stems that were initially green never attained a similar dark color value. 'Yellow twig' dogwood stems already displaying color and those beginning to color attained the darkest color value in late November. 'Cardinal' stems attained a darker color value more quickly than other dogwood stems. In most cases, stems of 'Cardinal' dogwood could be harvested from early October until early December, while early November was the optimum time to harvest 'Bailey' dogwood stems. Woody florals planted closest to the windbreak were more variable in color development and, in some cases, appeared to be more vigorous.

\section{Effect of Temperature and Salinity on the Germination of Lagurus ovatus $\mathbf{L}$.}

Santiago Carreño ${ }^{1}$, Encarnación Conesa ${ }^{2}$, José Antonio Franco*3, Juan José Martínez-Sánchez ${ }^{4}$

${ }^{1}$ Universidad Politécnica de Cartagena, Producción Vegetal, Cartagena, Murcia, 30203, Spain; ${ }^{2}$ Universidad Politécnica de Cartagena, Producción Vegetal; ${ }^{3}$ Universidad Politécnica de Cartagena, Producción Vegetal, Cartagena, Murcia, 30203, Spain; ${ }^{4}$ Universidad Politécnica de Cartagena, Producción Vegetal

Lagurus ovatus is an annual grass typical of sandy coastal soils, widespread in southern Europe. The color and texture of the inflorescence have such features that give good qualities as dry flower. In this work we have studied the germination capacity of Lagurus ovatus in different conditions of temperature, light and salinity. Seeds harvested in of the province of Murcia (Southeast of Spain) were tested in germination chambers with constant temperatures $\left(5,10,15,20,25\right.$ and $\left.30{ }^{\circ} \mathrm{C}\right)$ and combined temperatures $\left(20 / 30,15 / 25,10 / 20\right.$ and $\left.5 / 15^{\circ} \mathrm{C}\right)$. For each treatment, the photoperiod was 12 hours and total darkness. The results showed that total darkness was required to germination and the highest germination were obtained with constant temperatures of $10^{\circ} \mathrm{C}(90 \%)$ and $15^{\circ} \mathrm{C}(66 \%)$. Temperatures above or below reduced significantly the final germination. With alternate temperatures, the highest values were recorded when at least for 12 hours the temperature was $10{ }^{\circ} \mathrm{C}$ or $15^{\circ} \mathrm{C}\left(5 / 15,10 / 20\right.$ and $\left.15 / 25^{\circ} \mathrm{C}\right) 87 \%, 93 \%$, and $88 \%$ respectively. Once calculated the optimum temperature a salinity experiment was carried out to determine how this parameter affected germination. The assay was carried out at $10 / 20^{\circ} \mathrm{C}$. The seeds were watered with a $\mathrm{NaCl}_{2}$ solution of: $0,2.5,5,7.5,10,12.5,15$ and $17.5 \mathrm{dS} \cdot \mathrm{m}^{-1}$. The greatest germination was obtained in non-saline control ( $88 \%)$ and its was linearly reduced with increases in salinity to $10 \mathrm{dS} \cdot \mathrm{m}^{-1}(4 \%)$. No germination was registered from 12.5 to $17.5 \mathrm{dS} \cdot \mathrm{m}^{-1}$. When non-germinated seeds were transferred to distilled water after the exposure to salinity, rates of germination were very high in all cases. This work was supported by the CICyT of Spain (project AGL2000-0521).

\section{Characterizing the Vernalization Response of Campanula} 'Birch Hybrid' to Temperatures Between -2.5 to $20{ }^{\circ} \mathrm{C}$

Sonali Padhye*1, Arthur Cameron ${ }^{2}$

${ }^{1}$ Michigan State Univ., Dept. of Horticulture, East Lansing, MI 48824; ${ }^{2}$ Michigan State Univ., Dept. of Horticulture, East Lansing, MI 48824

Campanula 'Birch Hybrid' has an obligate vernalization requirement, though little is known about the vernalization response as a function of temperature and duration. The objective of this study was to characterize the qualitative and quantitative effects of exposure to -2.5 to $20^{\circ} \mathrm{C}$ on $C$. 'Birch Hybrid' flowering. Plugs were bulked at $20^{\circ} \mathrm{C}$ for 4 weeks and then transferred to $-2.5,0,2.5,5,7.5,10,12.5,15,17.5$ or $20{ }^{\circ} \mathrm{C}$ for $0,3,5,7,9$, or 12 weeks. Plugs were then potted and grown at $20^{\circ} \mathrm{C}$ under $16-\mathrm{h}$ photoperiod. Nine plants were used per treatment. Date of first open flower and the number of open flowers and flowering nodes $7 \mathrm{~d}$ later were recorded. No plants flowered after 0 or 3-week treatments. One plant held at $20{ }^{\circ} \mathrm{C}$ flowered and no plants flowered after exposure to $17.5^{\circ} \mathrm{C}$. After 5 weeks at 0 to $7.5^{\circ} \mathrm{C}, 100 \%$ of plants flowered with the fastest flowering after 2.5 to $7.5^{\circ} \mathrm{C}$. The number of flowering nodes and open flowers were similar for plants held at -2.5 to $10^{\circ} \mathrm{C}$ for 5 weeks. All plants flowered following 7 weeks at -2.5 to $12.5^{\circ} \mathrm{C}$, though flowering was quickest after exposure to 2.5 to $7.5^{\circ} \mathrm{C}$. After 7 weeks, plants held at -2.5 to $10{ }^{\circ} \mathrm{C}$ produced similar number of flowering nodes and open flowers. Following 9 weeks, all plants at -2.5 to $12.5^{\circ} \mathrm{C}$ flowered and 2.5 to $7.5^{\circ} \mathrm{C}$ treated plants flowered first. The number of flowering nodes was uniform across -2.5 to $12.5^{\circ} \mathrm{C}$ and the highest number of flowers was produced at $12.5^{\circ} \mathrm{C}$. All plants held at $-2.5^{\circ} \mathrm{C}$ died after 12 weeks. After 12 weeks, all plants flowered following 0 to $15^{\circ} \mathrm{C}$. However, following $15{ }^{\circ} \mathrm{C}$, plants produced fewer flowers and flowering nodes. Overall, the optimal vernalization response was between 0 to $7.5^{\circ} \mathrm{C}$.

\section{Photosynthesis and Growth of Single-node Cutting Rose 'Red Velvet' and 'Vital' by Nutritional Control in a Plant Factory}

\section{Kyung-Hwan Yeo*1, Jung-Min Son ${ }^{2}$, Yong-Beom Lee ${ }^{3}$}

${ }^{1}$ The Univ. of Seoul, Environmental Horticulture, Seoul, Korea; ${ }^{2}$ The Univ. of Seoul, Environmental Horticulture, Seoul, Korea; ${ }^{3}$ The Univ. of Seoul, Environmental Horticulture

Plant factory is a new plant production system that enables high quality, year-round, and planned production by controlling the environment. However, the recirculation of the nutrient solution leads to several problems because of unstable condition by nutrient uptake. The concentrations of nutrients in the recirculating solution should be kept at the required levels, since an optimum nutrition is determined by the specific concentrations of an element and mutual ratio to other nutrients in the root zone. Consequently, the nutrient solution is required adjustments based on regular analysis of the drain water and relationships among nutrient uptake, growth stage, and environmental factors for plant quality. This study was conducted to examine the effect of mineral nutritional control by five different methods on growth and photosynthesis of single-stemmed rose 'Red velvet' and 'Vital' in a plant factory. The nutritional control of nutrient solution was as following: the control of electrical conductivity (EC), N, P, and K elements (NPK), macro elements $(\mathrm{M})$, macro and micro elements $(\mathrm{MM})$ to target ranges in root environment, and the supplement of nutrient solution (S). The growth of single-node cutting rose 'Vital' and 'Red velvet' was higher in the $\mathrm{M}$ and $\mathrm{MM}$ than that of other control systems. Although $\mathrm{M}$ and MM system showed no significant difference, the photosynthetic rate, stomatal conductance, and transpiration rate were higher than those with other systems. The maximal efficiency of photochemistry (Fv/Fm) was higher in the M and MM control system, which showed the high- 
est root activity. These results could be attributable for modelling the mineral nutritional control system, which reduces the use of fertilizers and increases the productivity of single-stemmed rose.

\section{Growth and Pigmentation in Three Poinsettia Cultivars}

Alejandro Garcia ${ }^{1}$, María Teresa Colinas-León², Iran Alia-Tejacal*3, Jaime Sahagún-Castellanos ${ }^{4}$

${ }^{1}$ Universidad Autonoma Chapingo, Instituto de Horticultura, Texcoco, Estado de México, 56230, México; ${ }^{2}$ Universidad Autonóma Chapingo, Departamento de Fitotecnia, Texcoco, Estado de México, 56230, México; ${ }^{3}$ Universidad Autonoma del Estado de Morelos, Facultad de Ciencias Agropecuarias, Cuernavaca, Morelos, 62210, México; ${ }^{4}$ Universidad Autonama Chapingo, Departamento de Fitotecnia, Texcoco, Estado de México, 56230, México

Marmol, Subjibi, and V-17 Angelika cultivars were evaluated under two different growing conditions; Cuautla (average temperature of $24.6^{\circ} \mathrm{C}$, $70 \%$ to $80 \%$ relative humidity $(\mathrm{RH})$, latitude $18^{\circ} 49^{\prime}$, altitude 1,300 $\mathrm{msl}$ ) and Texcoco (average temperature of $18{ }^{\circ} \mathrm{C}, 40 \%$ to $50 \% \mathrm{RH}$, latitude $19^{\circ} 23^{\prime} 40^{\prime \prime}$, altitude $2,250 \mathrm{msl}$ ), under greenhouse conditions in 6 " pots. Variables considered were: total anthocyanins, carotenoids and chlorophyll content, chlorophyll a, b, and a/b, specific weight and leaf area, to evaluate differences between growing conditions. There were significative differences in total anthocyanin content for 'Subjibi' and V-17 'Angelika', being higher in plants grown in Texcoco. In relation to carotenoids and chlorophylls there were differences for plants from the two growing regions, being Cuautla (highest temperature) where these pigments were higher independent of the cultivar. Specific leaf weight was higher for plants grown in Texcoco with significant differences for 'Subjibi' and V-17 'Angelika'. Leaf area was higher for the three cultivars in Cuautla throughout the growing period.

\section{Tolerance to Low Temperature of Wild, Semi-cultivated, and Cultivated Poinsettia Genotypes}

Erik Navarro-López ${ }^{1}$, María Teresa Colinas-León², Jaime SahagúnCastellanos $^{3}$, Emmanuel Cruz-San Pedro ${ }^{4}$, Iran Alia-Tejacal*5

${ }^{1}$ Universidad Autonóma Chapingo, Instituto de Horticultura, Texcoco, Estado de México, 56230, México; ${ }^{2}$ Universdidad Autonóma Chapingo, Depratamento de Fitotecnia, Texcoco, México, 56230, México; ${ }^{3}$ Iniversidad Autonóma Chapingo, Departamento de Fitotecnia, Texcoco, México, 56230, México; ${ }^{4}$ Universidad Autónoma Chapingo, Departamento de Fitotecnia, Texcoco, Estado de México, 56230, México; ${ }^{5}$ Universidad Autónoma del Estado de Morelos, Facultad de Ciencias Agropecuarias, Cuernavaca, Morelos, 62210, México

Commercial red cultivars (Freedom and Subjibi), semicultivated (Xochimilco and Chapingo) and a wild genotype (Puebla) were stored at $2,7{ }^{\circ} \mathrm{C}$ [96\% relative humidity $\left.(\mathrm{RH})\right]$, and $18{ }^{\circ} \mathrm{C}(50 \% \mathrm{RH})$ for 24 and 48 hours. Variables considered were: $\mathrm{CO}_{2}$ and ethylene production, color, chlorophyll content and appearance, evaluating cut leaves and potted plants. $\mathrm{CO}_{2}$ and ethylene production were higher in the wild and semi-cultivated genotypes (cut leaves). The $2{ }^{\circ} \mathrm{C}$ temperature had an influence in $\mathrm{CO}_{2}$ production, but it did not affect ethylene. In potted plants, bracts did not show changes in color components (brightness, chroma and hue) in relation to low temperatures or storage time. There were no differences in leaf chlorophyll (Spad) with the exception of one of the semi-cultivated genotypes (Xochimilco) where the $2{ }^{\circ} \mathrm{C}$ treatment reduced the spad units. Leaves and bracts showed a slightly wilted appearance after storage at 2 and $7{ }^{\circ} \mathrm{C}$, but they recovered afterwards at ambient temperature of $18{ }^{\circ} \mathrm{C}$.

\section{Effect of Photoselective Shadecloth and Plastic Film on Growth of Chrysanthemums under Supplemental Lighting}

Kent D. Kobayashi*1

${ }^{1}$ Univ. of Hawaii at Manoa, Tropical Plant \& Soil Sciences, Honolulu, HI 96822

Controlling plant height is an important practice in the ornamental plant industry. With high cost of growth regulators and concern about their environmental aspects and health of workers, alternative ways of controlling growth may be advantageous. Objective was to determine effect of photoselective shadecloth and plastic film on growth of 'Barbara', 'Shasta', and 'Chesapeake' mums under supplemental lighting. In experiment 1, 'Barbara' plants (two and four weeks old) were placed under either wide spectrum fluorescent lamps and incandescent light bulbs (control) or lights covered with photoselective shadecloth. In experiment 2,3-week-old 'Shasta' and 'Chesapeake' plants were placed under lights or lights covered with photoselective plastic film. Effect of shadecloth differed with age of 'Barbara' plants. For 1-month-old plants placed under lights, stem diameter, stem dry weight, and root dry weight were reduced under shadecloth compared to control. No differences were observed for plant height, pot height, leaf number, leaf area/plant, and leaf dry weight. For 2-week-old plants, leaf number, leaf area/plant, leaf dry weight, and stem dry weight were less under shadecloth than control. No effects on plant height, pot height, stem diameter, and root dry weight were observed. Plastic film reduced plant height and pot height for 'Shasta' and 'Chesapeake' plants and reduced stem dry weight and total plant dry weight for 'Shasta'. No differences were seen for other growth measurements. This study indicated photoselective shadecloth did not control height of 'Barbara' and its effect on growth was influenced by plant age. Photoselective plastic film controlled height of 'Shasta' and 'Chesapeake' and offers an alternative method for growth control of mum plants.

\section{Poster Session 44-Human Issues in Horticulture/ \\ Consumer Horticulture and Master Gardners \\ July 20, 2004, 12:30-1:30 PM Rio Grande Exhibit Hall}

225 Horticultural Therapy Improves Vocational Skills, Self-esteem, and Environmental Awareness of Criminal Offenders in a Community Corrections Setting

Richard H. Mattson*1, Eunhee Kim², Gary E. Marlowe³, Jimmy D. Nicholson 4

${ }^{1}$ Kansas State Univ., Dept. of Horticulture, Forestry and Recreation Resources, Manhattan, KS 66506-5506; ${ }^{2}$ Kansas State Univ., Dept. of Horticulture, Forestry and Recreation Resources, Manhattan, KS 66506-5506; ${ }^{3}$ Adult Probation, 6th Judicial District, Community Supervision and Corrections Dept., Powderly, Texas $;{ }^{4}$ Adult Probation, 6th Judicial District, Community Supervision and Corrections Dept., Paris, TX 75461-0977

At the Lamar County Adult Probation Program in Paris, Texas, a three-year study (Spring 2001-Fall 2003) involving 376 probationers was conducted to investigate the rehabilitative effects on probationers of a horticulture vocational training program. Data were collected on 189 adults who were randomly assigned to a horticulture group doing greenhouse plant production and vegetable gardening activities. The horticulture group was compared with 187 adults who were in a non-horticulture community service group doing trash clean-up and janitorial work. Within the horticulture group, significant improvement occurred in horticultural knowledge (KSU General and Specific Horticulture Exams), self-esteem (Rosenberg Self-Esteem Scale), and environmental awareness (Environmental Response Inventory). These changes did not occur within the non-horticulture community service group. Future research will examine recidivism rates and vocational placements of probationers from both groups.

\section{Integrating ISO 14000 Environmental Management Standards} into Intensive Ornamental Plant Production Systems

John D. Lea-Cox *1

${ }^{1}$ Univ. of Maryland, Dept. of Natural Resource Sciences and Landscape Architecture, College Park, MD 20742

Environmental and human safety regulations are now an inevitable part of horticultural crop production. For most businesses, worker training and the subsequent collection and administration of data required for reporting purposes is often regarded as an economic burden. There are few systematic models that firstly provide an ecompassing approach to this business requirement, but more importantly which provide resources that simplify and perhaps automate the reporting of data to any significant degree. A good environmental management system (EMS) should provide a framework to systematically plan, control, measure and improve an organization's environmental performance and assessment. Significant environmental improvements (and cost 
savings) can be achieved by assessing and improving management and production processes, but only if the data are collected and analyzed quickly and easily. Many times, growers do not realize the relationship between their improved environmental performance and other key EMS benefits, such as reduced liability, better credit ratings, enhanced employee performance, improved customer relations, marketing advantages together with improved regulatory compliance. The International organization for Standardization (ISO) 14001 series is the most widely accepted international standard for EMS. Growers in most states in the US are required to document their use of pesticides and other agrochemicals that can impact human health, and in some states are also required to to document and monitor their applications of water and nutrients, in an effort to environmental pollution. This paper will illustrate the key elements of environmental management systems and how this can be integrated into production management using process management software.

227 Preliminary Study of the Impact of an After School Gardening and Nutrition Program on Children's Nutrition Knowledge, Fruit and Vegetable Preference, and Self-efficacy of Gardening and Eating Fruits and Vegetables

\section{Suzanne A. Poston*1, Candice A. Shoemaker ${ }^{2}$}

${ }^{1}$ Kansas State Univ., Horticulture, Forestry, and Recreational Resources, Manhattan, KS 66506; ${ }^{2}$ Kansas State Univ., Horticulture, Forestry, and Recreational Resources

Two age appropriate curricula for third through fifth graders, Professor Popcorn (PP) and Junior Master Gardener: Health and Nutrition from the Garden (JMG), were compared for their effectiveness in teaching nutrition knowledge, improving fruit and vegetable preference, and improving self-efficacy in gardening and eating fruits and vegetables as part of an after school learning program. Eighteen third through fifth graders participated in an eight lesson summer program (11 in PP, 7 in JMG), and eleven fourth graders participated in JMG during the fall. Knowledge, preference and self-efficacy measures were obtained at baseline and at the end of the program. There were no significant differences in these variables between the participants in PP and JMG at end-program. One interesting finding, however, was the change in gardening self-efficacy of the summer JMG group compared to the fall JMG group. Gardening self-efficacy of the summer JMG group increased $(P=0.063)$ while that of the fall JMG group decreased $(P=0.012)$ from baseline to end-program. Further investigations examining the role seasons have in the outcome of a garden-enhanced nutrition program and the activities of gardening occurring at different times throughout the growing season are suggested. In addition, further research should examine the amount of classroom time versus gardening time that is needed to make a garden-enhanced nutrition program more effective in an after school learning program.

\section{Deltiological Analysis of Early Developments in Florida Horticulture}

\section{George Fitzpatrick*1, Mary Lamberts ${ }^{2}$, Eva Worden ${ }^{3}$}

${ }^{1}$ Univ. of Florida, Environmental Horticulture, Homestead, FL 33030; ${ }^{2}$ Univ. of Florida, Horticultural Sciences, Homestead, FL 33030; ${ }^{3}$ Univ. of Florida, Environmental Horticulture, Ft. Lauderdale, FL 33314

Horticultural activities in Florida have been chronicled in many sources, including the technical literature and the popular press. One oftenoverlooked source is the visual images on postcards that were sold in Florida in the early years of the 20th century. Many such cards have images featuring scenes of landscape horticulture, olericulture and pomology. While dates of postmarks may not be accurate reflections of publication dates, deltiology, the study of postcards, can involve the analysis of pigments, rag content of card stock, and other measurable parameters to determine the age of particular images. The introduction, development, ascendancy and sometimes decline of certain horticultural crops in Florida are reflected in postcard images taken between the years 1908-1950. Representative images are shown of past and present plants that have been important in Florida horticulture.
229 Educational Programs for Hispanics in the New Jersey Landscape Industry

Pedro Perdomo*1, Kenneth Karamichael ${ }^{2}$

${ }^{1}$ Rutgers Cooperative Extension, Agriculture and Resource Management Agents, Morristown, NJ 07963-0900; ${ }^{2}$ Cook College - Rutgers Univ., Office of Continuing Professional Education, New Brunswick, NJ 08901-8519

Industry statistics indicate that there are approximately 150,000 people working in the green industry in New Jersey. About $50 \%$ to $60 \%$ are Hispanic. Nationally, $43 \%$ of Hispanics are not proficient in English. The education of Hispanic workers in their own language increases job skills, improves efficiency, and on the job safety. Spanish language horticultural courses were offered to educate members of the landscape community in New Jersey. Spanish language courses included general turf management, pruning of trees and shrubs, plant identification, hazardous tree identification, and basic pesticide training. The landscape classes began with a slide presentation that covered basic concepts, materials, and techniques that the landscaper should be aware of. Whenever possible, the courses were taught in a bilingual (Spanish/English) format to help participants familiarize themselves with English terms. Along with the in-class training, outdoor demonstrations were incorporated into all courses and participants were given the opportunity to practice what they had learned in the classroom. Over one hundred fifty employees registered for the classes between Jan. and Dec. 2003. Certificates of attendance were issued to all participants and were considered as a positive component of the courses. About $24 \%$ of the participants attended more than one of the courses and $100 \%$ would recommend the courses to their friends and co-workers. Seventy five percent of landscape business owners stated that they would consider sending other employees to future courses. Fifty percent of the participants were interested in attending courses that covered technical information, such as those offered to the English speaking landscape community.

\section{Rapid Response Educational Efforts: Keeping Cooperative Extension Ahead of the Curve}

William T. Hlubik ${ }^{1}$, Nicholas Polanin*2, Madeline Flahive DiNardo ${ }^{3}$, Richard Weidman ${ }^{4}$, David Smela ${ }^{5}$, James Marko ${ }^{6}$, Sean Convery ${ }^{7}$

${ }^{1}$ Rutgers Univ., Agriculture and Resource Management, New Brunswick, NJ 08901; ${ }^{2}$ Rutgers Univ., Agriculture and Resource Management, New brunswick, NJ 08901; ${ }^{3}$ Rutgers Univ., Agriculture and Resource Management, New Brunswick, NJ 08901; ${ }^{4}$ Rutgers Univ., Agriculture and Resource Management, New Brunswick, NJ 08901; ${ }^{5}$ Rutgers Univ., Agriculture and Resource Management, New Brunswick, NJ 08901; ${ }^{6}$ Rutgers Univ., Agriculture and Resource Management, New Brunswick, NJ 08901; ${ }^{7}$ Rutgers Univ., Agriculture and Resource Management, New Brunswick, NJ 08901

Today's fast paced and technology-enriched lifestyles require that many traditional educational seminars and workshops be transformed into "sound bites" of "edu-tainment" if Extension is to keep pace with clientele needs for specific and timely information that's useful and straight to the point. To remain a viable source of timely research-based information, Extension can stay ahead of this curve by utilizing today's technology to inform and educate the public on current issues or outbreaks. This presentation will highlight two such cases where technology delivery systems were utilized to maximize audience size and create an informed public in as short amount of time as possible. Public Service Announcements (PSA's) televised over New Jersey's Public Broadcasting Service (PBS), New Jersey Network (NJN), addressed water conservation and landscape issues during the recent northeastern drought. The potential viewing audience is over eight million people, including all of New Jersey and parts of Pennsylvania, Delaware, New York, and Connecticut. The second case study will highlight a fully interactive CD-ROM on the Asian Long Horned Beetle (ALB) that was created within 12 months of the pest's discovery in Jersey City, N.J. This CD-ROM, containing curricula, PowerPoint presentations and evaluative tools, is currently being used throughout the northeast and in Canada for the most recent infestation of ALB. Filming for both Rapid Response efforts was done with a Sony DSR-500 DV Cam Camcorder and a Canon XL-1 Camcorder. Digital editing was completed on an Apple G4 running OS X with Avid Express Meridian Non-Linear Editing Software version 4.5 with 3D effects, Apple Final Cut Pro 3.0, Adobe After Effects 5.5, 
and PhotoShop 7.0. Stills were taken with a Sony Mavica and Nikon CoolPix digital cameras.

\section{Landscape Retrofit: Redesigning Desert Landscapes}

Robert L. Morris ${ }^{1}$, Angela O'Callaghan*2

${ }^{1}$ Univ. of Nevada Reno, Cooperative Extension, Las Vegas, NV 89146-3160; ${ }^{2}$ Univ. of Nevada Reno, Cooperative Extension, Las Vegas, NV 89146-3160

The Las Vegas Valley receives most of its water from the Colorado River due to a static federal water allocation the remainder from pumping groundwater. The increased water demand due to the population rise in the Las Vegas Valley is expected to overtake its current water allocation in the next few years. Over $60 \%$ of the potable water used in the Las Vegas valley is used to irrigate urban landscapes. Poorly designed desert landscapes can ultimately use more water than traditional landscapes and increase residential energy costs. Most of the desert landscaping currently installed by homeowners either ignores principles that conserve water or conserve energy. The program was designed to be used with homeowner associations and commercial landscapers. The residential homeowner proved to be the most responsive to this type of program. The overall goal of this program is to teach residents how to convert a high water use landscape to lower water use and reduce dependence on potable water for irrigation and still maintain high quality landscapes. In 1995, a 7-week, hands-on, landscape design curriculum was developed and used to teach homeowners how to create desert landscape designs that conserve water and energy and compared its water use to traditional, turfgrass landscapes. Participants leave the course with a finished design of their making with information on how to install the landscape themselves or how to hire a professional to do the installation. In 1996-97 a Master Gardener was taught and mentored how to teach the class in Las Vegas using the existing curriculum. Since 1995, over 500 residents have been trained and water use savings documented by the existing water purveyors. This program is self-funded through class fees.

\section{Tracking Horticultural Impact of Master Gardeners}

William J. Sciarappa*1, Diane C. Zahorsky², Richard G. Obal ${ }^{3}$, Vivian A. Quinn ${ }^{4}$

${ }^{1}$ Rutgers Univ., Agriculture \& Resource Management Agents, Freehold, NJ, 07728; ${ }^{2}$ Rutgers Univ., Rutgers Cooperative Extension, Freehold, NJ 07728; ${ }^{3}$ Rutgers Univ., Agriculture \& Resource Management Agents, Freehold, NJ 07728; ${ }^{4}$ Rutgers Univ., Rutgers Cooperative Extension, Freehold, NJ 07728

The Master Gardener program in Monmouth County began in 1999. In order to justify the initiation of such a time and resource intensive program for Rutgers Univ., detailed records of participant activities throughout the county were compiled. The educational program consists of several components related to horticultural science. These classroom topics are basic horticulture, environmental factors for plant growth, soils and fertilizers, plant propagation, vegetable gardening, integrated pest management, turfgrass systems and practical horticultural techniques. Since 1999, 145 graduates have passed through the program and contributed a total of 35,274 volunteer hours. The key horticultural program segments that result in direct return on this substantial investment include: 1) horticultural helpline-answering home gardening questions; 2) horticultural help - promoting gardening programs in schools, parks, etc; 3 ) Community outreach - lectures and demonstrations, hort therapy; 4) horticultural research at university extension and education farms; and 5) laboratory assistance - plant and pest identification, test measurements. The calculated value of such volunteer help at $\$ 15.43$ per hour leads to a horticultural contribution of $\$ 544,277$ over 5 years. It is important to realize that many key programs would not have even been initiated without the ability to quickly assemble large numbers of skilled volunteers on a part-time basis. The training program and handson experience made these Master Gardeners capable of detailed data collection from ornamental and agricultural plant studies. This impact expands and synergizes the plant science programs of the professional staff on both a county and statewide basis.

\section{Clinic Outreach Impact Survey}

\section{Kerrie B. Badertscher*1, Carol A. O’Meara ${ }^{2}$}

${ }^{1}$ Colorado State Univ., Cooperative Extension, Longmont, CO 80501; ${ }^{2}$ Colorado State Univ., Cooperative Extension, Longmont, CO 80501

Since the 1970's, the Colorado Master Gardener ${ }^{\mathrm{sm}}$ (MG) program in Boulder County has had volunteer opportunities external to the extension office site. Collaboration occurs with various green industry locations via "clinics". Volunteers are on location Friday through Sunday, April through mid-July to answer questions for the public at large. Due to the length of time this program had been in place, the staff time and resources committed to it, and budget cutbacks, need for a study of impact and effectiveness of this program was identified. A three-year study was conducted to determine efficacy, pertinence and should this system remain status quo. In year 1, a sampling of the general public was conducted to determine: behavioral change as a result of receiving information (such as a diagnosis); was the information delivered in a timely fashion; satisfaction level; pesticide usage trends; continuance of this program and other data points. In year 2, active MG's in Boulder County were surveyed about participation at various facilities, information about clientele activity, and success rate with clients. Additionally, their comfort level on ability to assist clients plus their perception of the value of clinics to the community were surveyed. Data on diagnostics was correlated with weekly statistics. In year 3, partnering Green Industry collaborators were surveyed to gauge satisfaction with clinic service, timeliness of clinic schedule, and value of clinic service to business, and overall benefits to their staff resources.Reports on each survey will be delivered.

\section{Evaluation of Master Gardeners of Greater Kansas City}

\section{Lala A. Kumar*1, Jan Schwarz ${ }^{2}$}

${ }^{1}$ Univ. of Missouri, Outreach \& Extension, Independence, MO 64055; ${ }^{2}$ Univ. of Missouri Kansas City, Institute of Human Development, Kansas City, MO 64108

The Master Gardener Program sponsored by the Univ. of Missouri provides the metropolitan Kansas City area with information, demonstrations and programs designed to educate the general public about gardening topics and suggests solutions to current or anticipated problems. The main objectives of this evaluation were to identify the satisfaction level of clients (public) and the Master Gardeners from the program, demographics of Master Gardeners, how the program has changed the quality of life of the Master Gardeners and to identify any constraints. An evaluation committee consisting a social scientist, horticulturist and Master Gardeners were formed to develop the process and tools necessary for a comprehensive evaluation. It was decided that each facet of the program should have its own separate evaluation. The committee met several times to develop evaluation tools (survey questionnaires), to gather information from clients and the Master Gardeners. The results indicate a high level of satisfaction from clients and the Master Gardeners. The program had made positive changes in lives of Master Gardeners. The results provide guidance in decision making for further implementation such as it was found that the program should give a strong emphasis on providing new or advance horticultural information to Master Gardeners through continuing education.

\section{The Master Gardeners of Southern Nevada}

\section{Angela O'Callaghan*1}

${ }^{1}$ Univ. of Nevada, Cooperative Extension, Las Vegas, NV 89146

Gardening in the Mojave requires different skills from those needed elsewhere. Southern Nevada's population explosion greatly increased requests for appropriate horticultural information. This placed a large demand on Cooperative Extension. To meet the need, volunteers receive extensive training on topics of interest to residents. Those who complete training and meet other requirements are titled "Master Gardeners". Two hundred volunteers staff a help-line 5 days per week and participate in 20 community projects designed and led by Master Gardeners under UNCE supervision. About 50 people annually attend a 70 hour session (daytime or evening). The evening session was added 
to give people with day jobs the chance to learn gardening information in order to contribute to the community. Extension faculty and other professionals teach the classes. Topics include horticulture and plant nutrition, soils, irrigation, pruning, plant diseases and insects, and desert ecology. Students evaluate each class. Attendees come to the program through mass media and word of mouth. Most Master Gardeners are white, but active recruitment has increased the number of participants of color. For certification, one must complete training, pass a compre- hensive final exam, and give a minimum of 50 hours -15 hours at the help desk and another 35 hours either at the help desk or a project. Volunteers are recertified each year if they contribute at least 35 hours at projects or the help desk and spend 15 hours in continuing education. Those who cannot meet the requirements are placed on inactive status. Adding an orientation session introducing Cooperative Extension, the MG program and its volunteer requirement has improved the ratio of attendees to those who later become certified. 